Sous la direction de

Alicia Fernandez Garcia

Mathieu Petithomme

\title{
CONTESTER EN ESPAGNE
}

CRISE DÉMOCRATIQUE ET MOUVEMENTS SOCIAUX
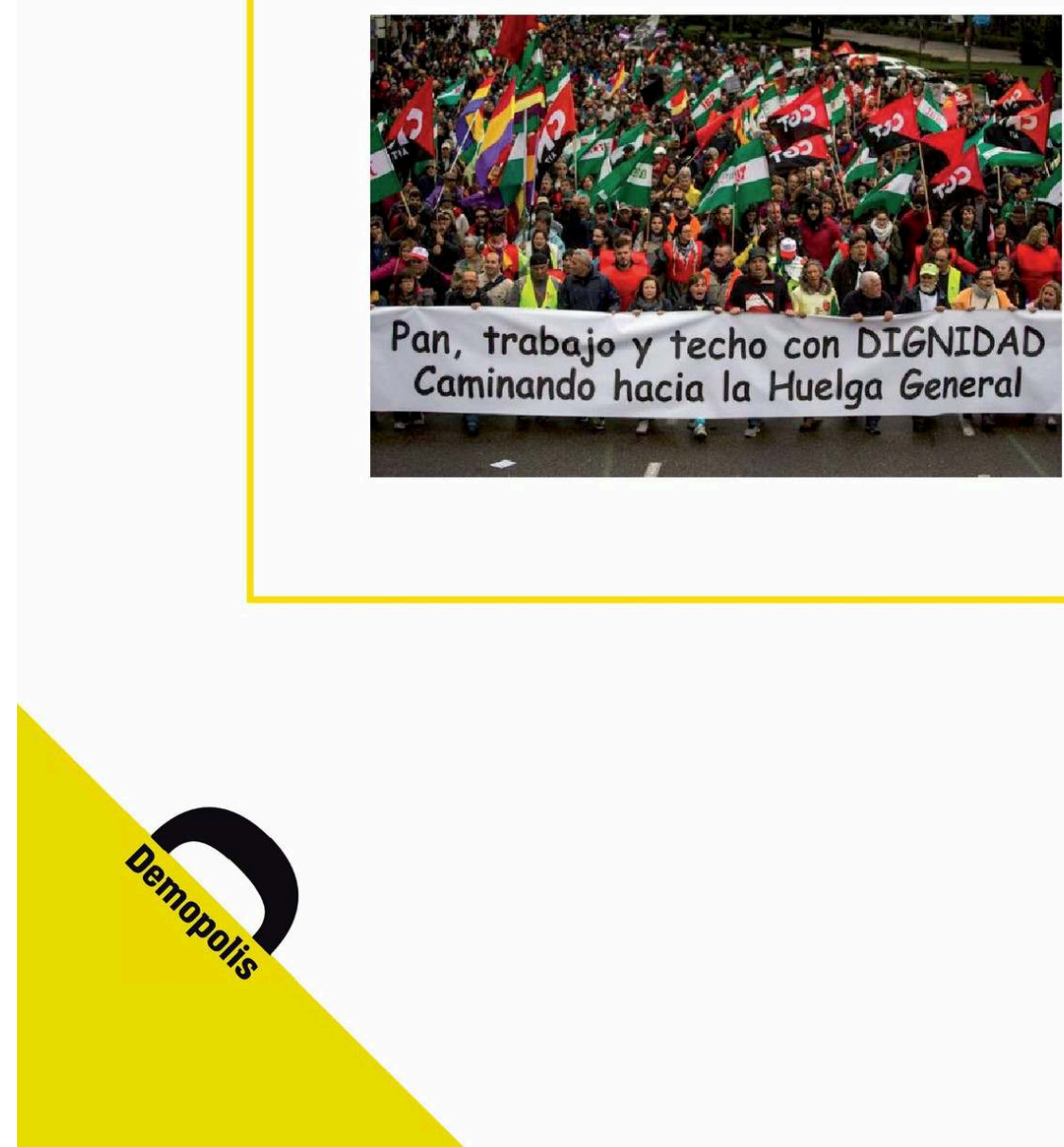


\section{Contester en Espagne}

Crise démocratique et mouvements sociaux

\section{Alicia Garcia Fernandez et Mathieu Petithomme (dir.)}

DOI : 10.4000/books.demopolis. 1862

Éditeur : Demopolis

Année d'édition : 2016

Date de mise en ligne : 26 octobre 2020

Collection : Quaero

ISBN électronique : 9782354571528

\section{Drentation}

http://books.openedition.org

Édition imprimée

ISBN : 9782354570903

Nombre de pages : 332

\section{Référence électronique}

GARCIA FERNANDEZ, Alicia (dir.) ; PETITHOMME, Mathieu (dir.). Contester en Espagne : Crise

démocratique et mouvements sociaux. Nouvelle édition [en ligne]. Paris : Demopolis, 2016 (généré le 28 octobre 2020). Disponible sur Internet : <http://books.openedition.org/demopolis/1862>. ISBN : 9782354571528. DOI : https://doi.org/10.4000/books.demopolis.1862.

(C) Demopolis, 2016

Conditions d'utilisation:

http://www.openedition.org/6540 
Sous la direction de

Alicia Fernandez Garcia

Mathieu Petithomme

\section{CONTESTER

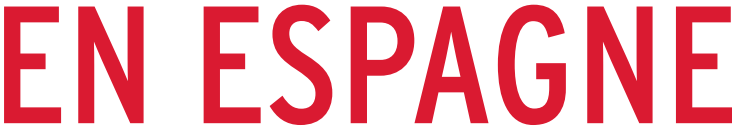

CRISE DÉMOCRATIQUE ET MOUVEMENTS SOCIAUX

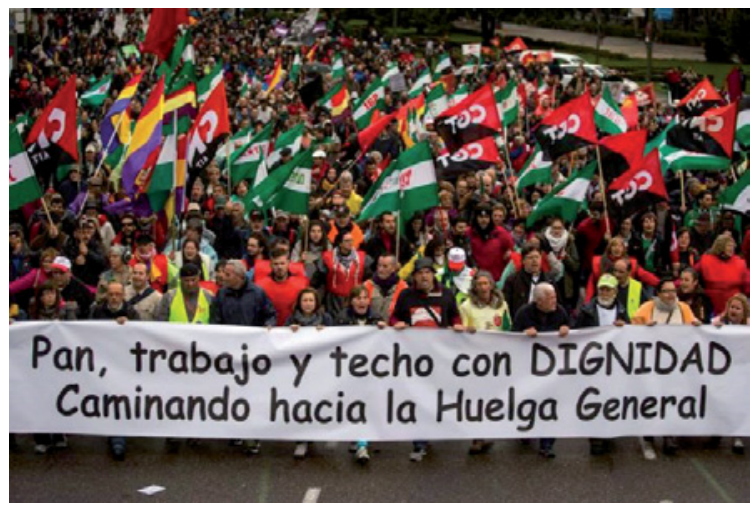



Cet ouvrage a été publié avec le soutien du Centre de recherches juridiques de Franche-Comté (EA 3225), de l'école doctorale Lettres, Langues et Spectacle, du Centre de recherches ibériques et ibéro-américaines (CRIIA/EA 369) et du Conseil Scientifique de l'université de Nanterre. 
CONTESTER EN ESPAGNE 


\section{«QUAERO »}

\section{Collection dirigée par Jean-Christophe Tamisier}

Dernières parutions :

Emmanuel Ethis,

Le cinéma près de la vie. Prises de vue sociologique sur le spectateur du $\mathrm{XXI} I^{e}$ siècle.

Alexandre Fontaine, Aux heures suisses de l'école républicaine.

Prix Louis Cros 2015 de l'Académie des sciences morales et politiques

Christian Ghasarian,

Rapa. Île du bout du monde, île dans le monde.

Émilie Oléron Evans,

Nikolaus Pevsner, arpenteur des arts.

Pascale Rabault-Feuerhahn (dir.),

Théories intercontinentales. Voyages du comparatisme postcolonial.

Michèle-H. Salamagne et Patrick Thominet (dir.),

Accompagner. Trente ans de soins palliatifs en France.

Illustration de couverture:

Marches de la dignité pour " le pain, un travail et un toit ",

Madrid, 22 mars 2014 (LD).

(C) Éditions Demopolis, 2015

$$
\begin{aligned}
& \text { 4, rue Scipion } \\
& 75005 \text { Paris }
\end{aligned}
$$

www.demopolis.fr

ISBN : 978-2-35457-090-3 
Sous la direction de

ALICIA FERNÁNDEZ GARCÍA

et MATHIEU PETITHOMME

\title{
CONTESTER EN ESPAGNE
}

\author{
CRISE DÉMOCRATIQUE \\ ET MOUVEMENTS SOCIAUX
}





\section{Les auteurs}

Matilde Alonso Pérez est docteure en sciences économiques et professeure des universités en économie à l'université de Lyon 2.

Karine Bergès est maîtresse de conférences en civilisation espagnole à l'université de Cergy-Pontoise (UFR LEI) et chargée de mission " égalité femmes-hommes ".

Christel Birabent Camarasa est maîtresse de conférences associée à l'université de Lyon 3 et traductrice-interprète professionnelle.

Alicia Fernández García est professeure certifiée d'espagnol, doctorante à l'université Paris Ouest Nanterre La Défense et ATER en civilisation hispanique à l'université de Paris-Est Marne-la-Vallée.

Elíes Furió Blasco est professeure des universités en civilisation espagnole à l'université de Lyon 3 et spécialiste en sciences économiques.

Sylvie Koller est maîtresse de conférences en études ibériques et ibéro-américaines à l'université de Rennes 2, membre du laboratoire interdisciplinaire de recherches sur les Amériques.

Benoît Pellistrandi est historien, spécialiste de la vie politique et culturelle de l'Espagne des $\mathrm{XIX}^{\mathrm{e}}$ et $\mathrm{XX}^{\mathrm{e}}$ siècles, ancien directeur des études (époques moderne et contemporaine) de la Casa Velázquez (Madrid), et membre correspondant de la Real Academia de la Historia (Madrid).

Mathieu Petithomme est maître de conférences en science politique à l'IUT de Besançon et chercheur au Centre de recherches juridiques de Franche-Comté.

Mercè Pujol Berché est professeure des universités en espagnol à l'université de Paris Ouest Nanterre La Défense et co-directrice du Centre de recherches ibériques et ibéro-américaines (EA 369 Etudes Romanes). 



\section{AVANT-PROPOS}

Contester dans l'Espagne d'aujourd'hui. Le titre même de cet ouvrage est une invitation à l'analyse des causes et des effets des nombreuses mobilisations sociales et politiques qui ont bousculé le pays depuis 2008. Violence de la crise après l'éclatement de la bulle immobilière marquée par l'appauvrissement des classes populaires, la hausse des inégalités et les expulsions locatives, plans d'austérité drastiques et chômage avoisinant les $25 \%$, renouveau de l'émigration des jeunes entraînant un vieillissement et un déclin démographique, multiplication des affaires de corruption touchant jusqu'à la famille royale, radicalisation de l'indépendantisme en Catalogne, crise du bipartisme, les éléments "dramatiques" ne manquent pas dans le tableau de l'Espagne d'aujourd'hui. La crise économique, sociale et politique enclenchée depuis 2008 marquera toute une génération. Les années 2007-2015 seront présentées comme une " décennie perdue » dans les manuels d'histoire, puisque le niveau de vie des Espagnols est revenu à ce qu'il était au début des années 2000. Les frais d'inscription à l'université ont augmenté, les prestations sociales aux familles ont été réduites et les frais de santé seront désormais moins remboursés. Les sans-papiers ne peuvent plus avoir accès aux soins suite à la remise en cause de la couverture maladie universelle. Les exigences européennes et le soutien au dogme des plans d'austérité par les gouvernements du socialiste José Luis Rodríguez Zapatero (2004-2011) et du conservateur Mariano Rajoy (2011-2015), ont frappé l'État-providence espagnol de lourds coups de butoir.

Mais au-delà du pessimisme, des drames humains et de la résignation, ce livre montre que cette période troublée a aussi été marquée par le renouveau de l'action citoyenne et par l'essor de nouveaux mouvements sociaux: luttes contre les expulsions; mouvement des indignés mobilisés à Madrid en 2011 pour dénoncer les limites de la démocratie représentative; résistance syndicale aux plans d'austérité à travers trois grèves générales en quelques années, du jamais vu depuis la transition; " marées " citoyennes contre les coupes budgétaires pratiquées 
dans l'éducation et la santé; mobilisations féministes contre le projet de loi anti-avortement, et républicaines en faveur de l'abdication de Juan Carlos I ${ }^{\mathrm{er}}$ et d'un référendum sur la monarchie; renouveau des groupes anarchistes et d'extrême gauche qui furent jusqu'à " faire le siège » du Congrès des députés; regain d'intérêt pour le théâtre social, le cinéma engagé, le flamenco militant et les pratiques artistiques critiques. La crise démocratique et l'indignation citoyenne ont peu à peu laissé place à une politisation nouvelle de la société espagnole pour la défense de ses droits fondamentaux (logement, éducation, santé), qui s'exprime aussi par la critique de la corruption politique et du fonctionnement d'institutions issues de la constitution de 1978 et qui ont très peu évolué depuis lors.

Il est d'ailleurs frappant de noter l'inscription résolument " progressiste " de la contestation dans un pays qui, pour une raison historique liée à l'héritage dictatorial franquiste, demeure imperméable à la poussée de l'extrême droite observée ailleurs en Europe. Les enquêtes d'opinion montrent aussi que malgré la crise, les Espagnols demeurent assez pro-européens.

En réunissant les travaux de neuf spécialistes issus de différentes disciplines des sciences sociales (économistes, hispanistes, politologue et historien), ce livre offre des analyses de l'intérieur sur les principaux mouvements sociaux qui ont fait l'actualité espagnole des dernières années. Rédigé en 2014 et en 2015, il éclaire ainsi le lecteur sur l'ensemble des phénomènes sociaux et politiques de l'histoire du temps présent: il explique les causes et les principaux effets postérieurs de la crise de 2008, présente le contexte de crise de légitimité des partis dominants et de l'institution royale, et montre en parallèle le caractère historiquement minoritaire du mouvement républicain en Espagne. Le livre permet aussi de comprendre le rôle et les revendications des féministes espagnoles, l'impact durable dans le débat d'idées du mouvement des indignés, la "transition démocratique " du nationalisme basque radical par la sortie de la violence, ou encore la radicalisation de l'indépendantisme en Catalogne, un sujet d'actualité brûlant. Cet ouvrage collectif de référence montre enfin la transformation de l'indignation citoyenne par l'essor de nouvelles pratiques sociales et la prise de pouvoir progressive en politique d'une nouvelle génération, où les femmes occupent un rôle majeur. L'émergence de nouvelles alternatives telles que Citoyens au centre droit et que Podemos, qui propose un discours plus critique et transversal, illustre ainsi ce désir de "régénération " démocratique. Les élections européennes de 2014 puis les municipales 
et régionales de 2015, qui ont permis à des listes citoyennes établies autour de Podemos de conquérir Madrid, Barcelone, Valence mais aussi Saragosse et Cadix, ont donné une illustration de plus de la volonté de changement des Espagnols à la faveur du nouveau cycle politique et social qui s'annonce.

Alicia FERnÁndez García et Mathieu Petithomme

Marne la Vallée/Besançon,

5 novembre 2015. 



\title{
1 \\ La crise démocratique espagnole et le renouveau de la contestation sociale
}

\author{
Alicia FERnÁndez GARCía et Mathieu Petithomme \\ Ceci n'est pas une crise, c'est un changement dans les \\ règles du jeu, qui emmène le monde vers plus d'inégali- \\ tés et un appauvrissement global. \\ (Josep Fontana)
}

Pétri de l'expérience de ses 83 ans, l'historien Josep Fontana, professeur émérite à l'université Pompeu Fabra de Barcelone, n'a pas la langue dans sa poche. Né en 1931, année de la proclamation de la Seconde République, disciple de Jaume Vicens i Vives, expulsé de l'université de Barcelone avec Miquel Roca Junyent pour leur opposition au régime franquiste en 1966, il a dédié l'ensemble de sa vie à l'histoire contemporaine dans une perspective critique. Pour lui, la crise espagnole est avant tout « une crise démocratique, marquée par le manque de contrôle des citoyens sur les décisions irresponsables des entités financières et des responsables politiques ${ }^{1}$ ». Les dernières années ont en effet été caractérisées en Espagne par des débats publics intenses concernant les responsabilités du personnel politique, des banques et de la spéculation financière dans l'émergence de la crise. Peu à peu, le discours dominant sur le "développement infini " que devaient connaître les générations espagnoles futures s'est effondré. Les ruines immobilières, l'émigration des jeunes et le retour de nombreux quadragénaires chez leurs parents à la retraite faute de revenus suffisants, ont substitué à l'imaginaire collectif du progrès futur l'amertume d'un quotidien marqué par le déclassement social.

1. Entretien avec Josep FonTANA, dans José Miguel Monzón (connu comme «El Gran Wyoming »), No estamos solos. Un retrato de gente que está cambiando este país, Madrid, Planeta, 2014, p. 77. 
Loin des promesses électorales, d'autres images ont fait la une de la presse écrite et des journaux télévisés: celles des drames humains, des expulsions locatives et des queues interminables de chômeurs devant les agences pour l'emploi; celles aussi d'une classe politique volontiers donneuse de leçons relatives aux " efforts nécessaires " à fournir par les citoyens, euphémismes commodes pour imposer des coupes budgétaires massives dans l'éducation et la santé. Mais les Espagnols ont aussi pris conscience, scandale après scandale, de la face cachée de nombre de leurs représentants politiques, grands adeptes de l'évasion fiscale, de la surfacturation des marchés publics et de pratiques d'enrichissement illicite. Cette perception largement partagée, entre dégradation sans précédent des conditions de vie et hausse des inégalités, parallèlement aux révélations hebdomadaires des fraudes massives commises par les élites dirigeantes, a débouché sur un renouveau de la contestation sociale.

Comment expliquer la crise économique, sociale et politique que traverse l'Espagne d'aujourd'hui? Comment les mouvements sociaux ont-ils contribué à la politisation de nouveaux enjeux, au changement social et à l'évolution des mentalités? Ce chapitre d'introduction récapitule et analyse de façon critique les principales étapes de la crise économique, sociale et politique espagnole depuis 2008. Il synthétise d'abord les aspects essentiels de l'éclatement de la " bulle immobilière " et de l'appauvrissement des classes moyennes et populaires. Il revient ensuite sur les politiques d'austérité menées tant par le PSOE que par le $\mathrm{PP}$, sur leur perception par les citoyens ainsi que sur la crise de la représentation politique. Puis il présente le renouveau de la contestation, en évoquant l'émergence d'une multiplicité de mouvements sociaux, de résistances et de revendications citoyennes au cours des dernières années. La dernière section présente le plan et précise l'approche de l'ouvrage, qui offre au lecteur une vision synthétique mais détaillée, à partir d'analyses de spécialistes, des principaux bouleversements sociopolitiques de l'Espagne d'aujourd'hui.

\section{DE LA RÉCESSION ÉCONOMIQUE À LA CRISE SOCIALE}

\section{L'éclatement de la « bulle immobilière "}

Les effets du développement de la crise économique au sein des principaux pays industrialisés à partir de 2007, suite à la faillite de Lehman Brothers et à la crise des subprimes aux États-Unis, furent renforcés en Espagne par l'éclatement de la bulle immobilière en 2008 puis par la 
crise bancaire de 2010, qui ont engendré une augmentation du chômage et une dégradation des conditions de vie des classes moyennes et populaires ${ }^{2}$. Certains analystes avaient pourtant critiqué depuis des années le caractère superficiel du " miracle économique espagnol ", un " modèle " de développement soutenu de façon consensuelle par le Parti populaire (PP) et le Parti socialiste (PSOE), fondé sur les secteurs du bâtiment, du tourisme, les dépenses des ménages et la consommation intérieure grâce à l'accès facile au crédit ${ }^{3}$. Les déficits des administrations de l'État et des communautés autonomes, la restriction des crédits bancaires aux entreprises et la hausse des prêts immobiliers impayés ont transformé la récession économique et la crise immobilière en un appauvrissement sans précédent de nombreux secteurs de la société.

La crise immobilière s'explique par une hausse continue des mises en chantier durant les années 1990-2000, alors même que la démographie espagnole est déclinante et vieillissante et que de nombreux appartements et maisons, transmis le plus souvent par héritage et conservés au sein de la famille, sont vides et en mauvais état. La hausse de l'immigration au début des années 2000 puis lors du premier mandat de José Luis Rodríguez Zapatero, a entretenu le fantasme du dynamisme économique illimité. Mais le principal problème historique de l'Espagne est lié à ce que Samir Amin appelait en son temps «le développement inégal ", à savoir le fait que les fruits de la croissance restent très mal répartis, et que l'accès à l'éducation et à la formation est très inégal selon les classes sociales. Les classes populaires, peu formées, sont touchées de plein fouet en temps de crise ${ }^{4}$. Au tournant des années 2000, l'Espagne était arrivée à une situation où l'appât du gain à court terme de promoteurs immobiliers a conduit à la multiplication de "villes nouvelles " et à la construction de quartiers parfois très éloignés des transports et des infrastructures publiques, à travers la "vente " aux classes populaires de l'idéal d’un ascenseur social fondé sur l'accès à la propriété et le crédit facile.

\footnotetext{
2. La crise des «subprimes » trouve son origine dans les prêts immobiliers faciles et à risque concédés par des banques américaines aux particuliers et aux entreprises, sans respecter les garanties traditionnelles nécessaires. Ces prêts ont été surnommés «prêts Ninja » pour «No Income, No Jobs and Assets », sachant qu'ils furent parfois consentis à des gens sans revenus, sans travail et sans aucun type de propriétés ou de ressources. Cette spéculation financière déclencha des impayés en chaîne, des expulsions et des saisies immobilières, puis la chute des principales banques américaines et le tarissement du crédit. Cf. Paul JoRION, La crise. Des subprimes au séisme financier planétaire, Paris, Fayard, 2008.

3. Vicenç NAVARRo, «El desastre économico actual era predecible », Público, 29 avril 2013.

4. Samir AMIN, Le développement inégal: Essai sur les formations sociales du capitalisme périphérique, Paris, Éditions de Minuit, 1973.
} 
Les banques ont ainsi multiplié les prêts immobiliers sur 25 ou 30 ans, mais aussi sur 35 voire même 40 ans, donnant à des particuliers l'illusion de l'enrichissement et du progrès social grâce à l'accès à la propriété... Mais la vérité est que des dizaines de milliers de citoyens ordinaires, abusés par le langage commercial, se sont retrouvés engagés à vie envers leur banque. D’où une réduction de leur capacité de mobilité géographique pour trouver un travail en cas de chômage. Un facteur culturel, bien mis en avant par Sandra Gaviria dans ses travaux, a aussi renforcé ce processus : influencées par le discours politique dominant et la pression sociale, les familles espagnoles ont toujours perçu négativement la location, comme "de l'argent dépensé bêtement ", et ont donc incité leurs enfants à accéder à la propriété dès leur obtention d'un travail $^{5}$. Mais avec la stagnation de la démographie et l'émergence d'une génération " ni ni ", sans travail ni études, la demande de logements est devenue beaucoup plus faible que l'offre florissante. Les prix de l'immobilier ont très fortement chuté (-20\% en moyenne) dans la veine de la déflation enregistrée en mars 2009. Beaucoup d'Espagnols qui avaient acheté leur bien lorsque l'inflation des prix était à son comble, avant la crise de 2008, doivent désormais payer des crédits immobiliers très souvent à taux variables, et qui sont surtout très largement supérieurs au prix de vente estimé de leur maison ou appartement. Les crédits immobiliers impayés ont explosé, passant de $1 \%$ à $13 \%$ depuis 2007 , d'où la multiplication des expulsions de propriétaires, mais aussi de locataires: l'éclatement de la bulle immobilière a notamment mis au chômage une part importante des ouvriers du bâtiment. Les ouvriers de plus de 40 ans, ayant souvent travaillé toute leur vie dans ce secteur, éprouvent aujourd'hui de très grandes difficultés à se reconvertir, handicapés par leur manque de formation initiale, leur âge et la concurrence des ouvriers venus d'Amérique latine et des pays d'Europe de l'Est; ils sont donc les premiers à être exposés au chômage de longue durée.

$\mathrm{Au}$ niveau local, durant les années 1990-2000, les élites politiques ont été largement complices des risques pris par le secteur bancaire, en soutenant elles-mêmes des projets immobiliers peu viables dans leurs villes et leurs régions. La liste est très longue, mais citons quelques exemples emblématiques. L’aéroport de Castellón de la Plana, inauguré le 25 mars 2011 par Carlos Fabra, ancien président de la députation provinciale de Castellón de 1995 à 2011, largement impliqué dans le réseau

5. Sandra GAVIRIA, Juventud y familia en Francia y en España, Madrid, Centro de Investigaciones Sociológicas, Centro de investigaciones sociológicas, 2007. 
de corruption "Gürtel ", n’a par exemple jamais été mis en service ${ }^{6}$. La sculpture de Juan Ripollés, "l'homme-avion ", installée à l'entrée de l'aéroport, symbolise la démesure de ces investissements publics. Ironie de l'histoire, nombreux sont ceux qui associent désormais l'« hommeavion " à Carlos Fabra, présenté en 2008 comme " un citoyen et un homme politique exemplaire " par Mariano Rajoy, alors chef de l'opposition, même si l'artiste nie officiellement avoir voulu le représenter ${ }^{7}$. Le circuit de formule 1 de Valence, construit sur une ancienne zone industrielle à la périphérie de la ville derrière le port, n'a jamais servi et tombe en ruines. La bibliothèque municipale de Leganés (Madrid), qui a coûté 12 millions d'euros à la ville, n'a jamais été ouverte au public. Le tramway de Jaén, dont les rames et les wagons sont en place, n’a jamais fonctionné en raison d'un coût financier impossible à assumer pour la municipalité andalouse.

Photo 1.1 « L'homme-avion », sculpture de Juan Ripollés, aéroport de Castellón de la Plana ${ }^{8}$

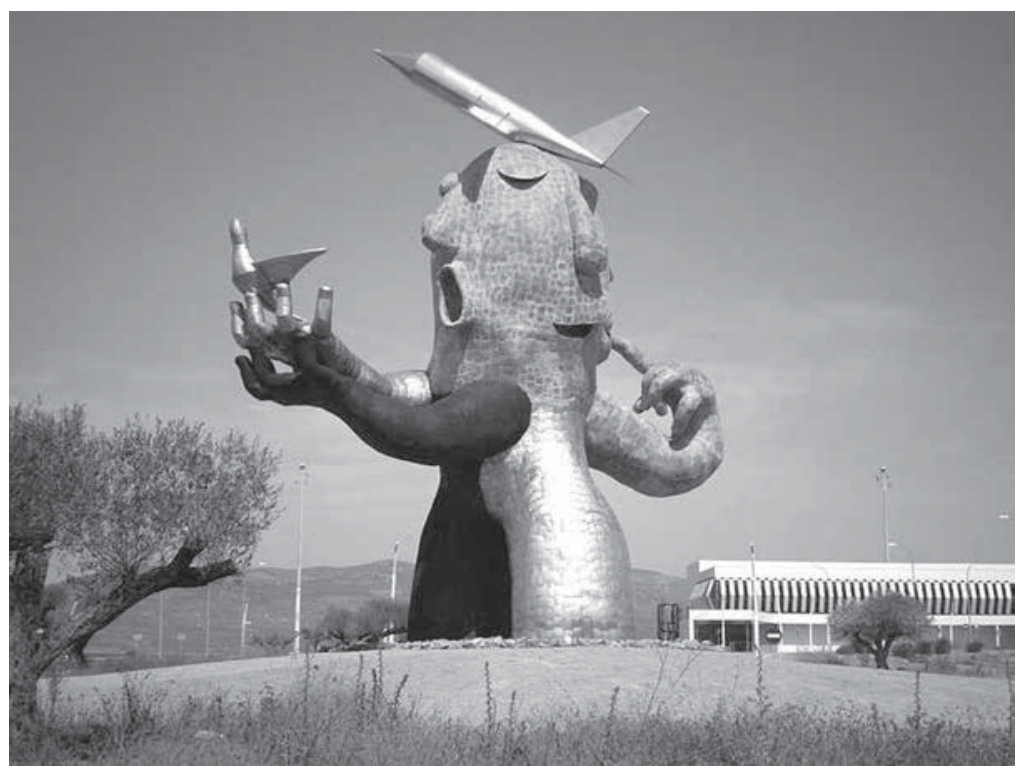

6. Carlos Fabra fut condamné en 2013 à quatre années de prison pour plusieurs délits et une fraude de 700000 euros à l'administration fiscale. Cf. « Los Fabra: 150 años de caciquismo en Castellón », La Vanguardia, 15 juillet 2012.

7. "Rajoy: "Fabra es un ciudadano y un político ejemplar para el PP" », El País, 11 juillet 2008. 8. Image libre de droits d'auteur, [http://commons.wikimedia.org/wiki/File:El_hombre_avi\%C3 \%B3n.JPG]. 
D’autres exemples emblématiques peuvent encore être évoqués: l'aéroport abandonné de Ciudad Real; la Cité de la Lumière, qui a coûté 265 millions d'euros à la communauté valencienne et devait devenir un haut lieu de la production cinématographique espagnole; le Centre culturel international Oscar Niemeyer à Avilés, ou encore la Cité des sciences de Valence, deux véritables gouffres financiers. La multiplication des lignes de train à grande vitesse sans rentabilité suffisante représente une illustration supplémentaire ${ }^{9}$. Cette "folie des grandeurs » des élites locales durant les années du boom économique (19932007) a engendré le surendettement de nombreuses communautés autonomes. Parmi les plus mauvais élèves, on trouve les communautés de Valence, de Murcie, de Castille-La Manche et des Baléares gouvernées par le PP, mais aussi l'Andalousie dirigée par le PSOE, ou des communautés autonomes gouvernées pendant longtemps par des partis nationalistes, comme la Catalogne (Convergència i Unió de 1980 à 2003) ou les îles Canaries (Coalition Canaries). La presse a de même révélé en 2012 que les communautés autonomes de Madrid et de Valence avaient enregistré des déficits publics plus importants que prévus, de 2090 et 900 millions d'euros respectivement, en raison de "déficits occultes ", ce qui contraignit à réviser à la hausse le déficit total de l’État, de 8,5\% à $8,9 \%{ }^{10}$.

La crise économique mondiale s'est donc conjuguée en Espagne avec des dépenses publiques et des projets d'investissement parfois très contestables qui ont aggravé l'état des finances publiques. Après avoir " sauvé » les banques malgré le caractère très répréhensible de certaines de leurs pratiques de spéculation sur les marchés financiers et d'octroi de prêts sans garanties suffisantes, l'État s'est endetté à nouveau pour éviter la faillite de certaines communautés autonomes. Ainsi, de 2008 au début 2014, hormis deux trimestres en 2010, l'Espagne n'a connu qu'une récession continue et de forte ampleur. $\mathrm{Si}$, comme on vient de le rappeler, la crise résulte largement de la spéculation immobilière et financière des établissements bancaires, l'aggravation de la récession s'explique aussi, comme en Grèce, par des facteurs externes liés à la financiarisation de l'économie: la "perte de confiance " des marchés envers l'Espagne a contribué au triplement de la dette publique (de 36,1\% du PIB en 2007 à $93,4 \%$ en 2013), et à une augmentation de $50 \%$ de sa prime de risque.

9. «El AVE no alcanza el umbral de rentabilidad por viajeros en ninguna línea », La Vanguardia, 26 avril 2012.

10. "Los déficits ocultos de las comunidades de Madrid y de Valencia: un escándalo más », El País, 15 septembre 2012. 


\section{Une dégradation sans précédent des conditions de vie}

La crise économique a engendré un appauvrissement des classes moyennes et populaires. De 2007 à 2011, les $10 \%$ les plus pauvres de la population ont vu leurs revenus diminuer de $42,4 \%$, le salaire moyen et le PIB par habitant ont baissé, alors que les salaires les plus élevés ont continué à augmenter ${ }^{11}$. Le chômage a littéralement explosé: touchant 1,7 million de personnes, soit 7,95 \% de la population active au printemps 2007, il a atteint le maximum historique de 6,2 millions de personnes, à savoir $27,16 \%$ de la population active début $2013^{12}$. De nombreuses familles ont réduit leur consommation alimentaire et des carences nutritives disparues sont réapparues chez de jeunes enfants issus de familles défavorisées. L’Espagne est ainsi devenue le deuxième pays le plus inégalitaire de l'Union européenne derrière la Grande-Bretagne ${ }^{13}$. En novembre 2014, le salaire minimum était de 645,30 euros net par mois; le nombre de chômeurs atteignait 5,6 millions de personnes, soit $24,47 \%$ de la population active et $53,1 \%$ des jeunes; 2,9 millions de chômeurs de longue durée se trouvaient dans cette situation depuis plus d'un an et 1,8 million de familles avaient l'ensemble de leurs membres au chômage ${ }^{14}$. L'administration estimait que 32,9\% des salariés touchaient un revenu inférieur ou équivalent au salaire minimum, fait illustrant une forte précarisation de larges secteurs de la société ${ }^{15}$. Enfin, sur 14,3 millions de salariés, 23,9\% (2,8 millions) étaient employés à temps partiel, un phénomène qui s'est renforcé suite aux deux réformes du marché du travail de 2010 et $2012^{16}$.

Conséquence de la crise, la population a même diminué de 310000 individus depuis 2012 (pour atteindre les 46,5 millions en 2014), en raison d'un ralentissement très net du taux de fécondité et d'une augmentation de l'émigration, qui a touché près de 547000 personnes pour la seule année 2013, principalement des migrants latino-américains qui ont préféré retourner dans leur pays d'origine, mais aussi des

\footnotetext{
11. José OTERO, «España sufre la crisis más desigual », El País, 19 juin 2014.

12. Enquête de population active (EPA), Institut national de statistiques (INE), premier trimestre 2013.

13. Luis DONCEL, «Parálisis en la economía española », El País, 15 août 2008.

14. Service public d'État de l'emploi, novembre 2014.

15. Agence d'État d'administration des impôts, novembre 2014. Voir aussi « Cobrar lo mínimo de lo mínimo », Alternativas Económicas, n 17, septembre 2014, p. 25.

16. EPA, INE, Madrid, deuxième trimestre 2014
} 
nationaux des pays d'Europe de l'Est ${ }^{17}$. Plus grave encore, une partie de cette nouvelle émigration concerne de jeunes Espagnols diplômés au chômage, partis pour l'Allemagne, le Royaume-Uni et la France principalement, mais aussi pour des pays émergents d'Amérique latine comme le Brésil et l'Argentine ${ }^{18}$. L'émigration a augmenté de 5,5\% de 2008 à 2012, même si le chiffre officiel de 400000 départs est largement sous-estimé en raison de la très grande quantité d'Espagnols qui ne s'enregistre pas auprès de leur consulat à l'étranger ${ }^{19}$. Enfin, $91 \%$ des emplois détruits entre 2008 et 2013 ont touché des jeunes de moins de 35 ans, un chiffre qui parle de lui-même ${ }^{20}$. Avec un taux de chômage de plus de $50 \%$ chez les moins de 25 ans, la crise a donc engendré une radicalisation de la jeunesse ${ }^{21}$.

Mais la crise espagnole n'est pas uniquement économique et sociale. C'est aussi une crise du politique, face à l'incapacité des dirigeants à limiter les effets de la récession sur la population et à trouver des solutions pour y remédier, comme aussi en raison de l'ampleur de la corruption des élites et de pratiques clientélistes qui affaiblissent les fondements du système représentatif, basé en théorie sur la confiance et la délégation du pouvoir ${ }^{22}$. La crise a mis en évidence l'écart immense entre, d'une part, les coupes budgétaires et les mesures d'austérité imposées aux citoyens et, d'autre part, l'enrichissement et les pratiques illégales et immorales de nombreux dirigeants politiques et financiers. En 2008, la plus grande part des élites politiques estimait que l'on allait assister à un scénario similaire à celui de 1993: la récession serait limitée dans le temps. Pas besoin donc de s'affoler. Ni même de mener des politiques de traitement social du chômage afin de limiter l'amplification de la crise, par exemple à travers des programmes et des formations de reconversion pour les salariés, ou le soutien aux familles

17. «Evolución de la población en España : 2001-2014 », INE, 2014.

18. « La salida de inmigrantes reduce la población en España por segundo año », El País, 30 juin 2014.

19. «Emigración en España », INE, 2012. Voir aussi Soledad GIMÉNEZ, « Casi 400000 españoles emigraron en busca de trabajo desde 2008 », [http://www.publico.es], 12 janvier 2013.

20. « Destrucción de empleo en España », EPA, 2013.

21. Sur les trajectoires de cette génération, voir par exemple le livre de Benjamín Serra, originaire de Valence, titulaire de deux masters et qui raconte comment il a été amené à s'expatrier à Londres et à travailler comme agent d'entretien. Cf. Benjamín SERRA, Sobradamente preparado para limpiar váteres en Londres: La voz esperanzada de una juventud dispuesta a ganar la batalla del futuro, Madrid, Península, 2014.

22. Pour des réflexions classiques sur le socle de la légitimité populaire dans les régimes représentatifs, cf. Bernard MANIN, Principes du gouvernement représentatif, Paris, Flammarion, 2012; Pierre RosANVALLON, La légitimité démocratique. Impartialité, réflexivité, proximité, Paris, Points, 2010. 
en voie de paupérisation. Une cure drastique d'austérité suffirait pour conjurer les « excès » du passé, pensèrent-elles.

Après tout, les Espagnols avaient vécu quinze années de croissance économique, de 1993 à 2008. Ils s'étaient enrichis et embourgeoisés, choisissant d'acheter des voitures et des appartements à leurs enfants grâce aux crédits immobiliers et à la consommation. Ils avaient incité ces derniers à vite trouver de l'« argent facile " et un travail dans le bâtiment plutôt qu'ils ne les avaient encouragés à étudier. Ils avaient mobilisé leurs relations personnelles, actionné les "enchufes " (pistons), pour leur trouver " une bonne place " sur le marché du travail. Bref, les Espagnols avaient vécu au-dessus de leurs moyens et ils pouvaient bien faire quelques efforts. Si on leur enlevait quelques avantages, ce ne serait pas la fin du monde. Et tout repartirait comme avant. Ce discours, même ainsi résumé jusqu'à sa caricature, n’est pourtant pas très éloigné de ceux que les élites des partis dominants, PP et PSOE en tête, purent tenir à partir de 2008. Il constitua la trame de fond justificative de la volte-face libérale et des politiques d'austérité menées par José Luis Rodriguez Zapatero qui touchèrent d'abord les catégories populaires, alors même qu'il avait été élu sur un programme de réduction des inégalités. Mais l'amplification des scandales de corruption et d'enrichissement des responsables publics, la révélation de pratiques clientélistes et d'échanges de faveurs entre les élites politiques et financières, alors même que les classes populaires et moyennes ressentaient - et continuent de ressentir - très fortement les effets de la crise dans leur vie quotidienne, ont débouché sur une crise très forte de la représentation politique et une prise de conscience des limites du système institutionnel issu de la constitution de 1978.

\section{DE LA CRISE ÉCONOMIQUE À LA DÉFIANCE POLITIQUE}

\section{La perception de l'échec du néolibéralisme et des politiques d'austérité}

Après presque une décennie de crise économique et sociale écoulée depuis les prémices de la récession en 2007, le jugement très négatif et critique des Espagnols à l'égard de leurs élites politiques est d'inspiration avant tout rétrospective: tant le PSOE, qui a gouverné de 2004 à 2011 sous la direction de José Luis Rodríguez Zapatero, que le 
gouvernement du PP de Mariano Rajoy au pouvoir depuis lors ont été incapables de modifier leurs pratiques politiques et les orientations traditionnelles de leurs politiques publiques pour enrayer la progression du chômage et combattre la hausse des inégalités. Il convient donc de revenir brièvement sur les principales orientations des politiques publiques menées par le PSOE et par le PP au cours de la dernière décennie (depuis 2004) pour comprendre le fondement de la défiance croissante des citoyens à leur égard. Jordi Sevilla a bien montré comment le PSOE a peu à peu affirmé, au début des années 2000, une synthèse idéologique entre socialisme et libéralisme, s'inspirant de la " troisième voie " sociale-démocrate théorisée par Anthony Giddens et mise en pratique par le travailliste Tony Blair (1997-2007) ${ }^{23}$. Le PSOE est progressivement devenu un parti "social-libéral " ne cherchant plus véritablement à remettre en cause les excès de la financiarisation de l'économie. Sa cure d'opposition durant les gouvernements conservateurs de José María Aznar de 1996 à 2004 et la croissance économique du pays durant ces années, réelle mais fondée sur des bases très fragiles et largement artificielles, favorisèrent le ralliement de ses élites à la doxa néolibérale ${ }^{24}$.

Cette évolution idéologique permet d'expliquer le fait que le bilan du PSOE sous les gouvernements de José Luis Rodríguez Zapatero est très axé sur les évolutions "sociétales", plus que sur la réduction des inégalités sociales et l'émancipation des classes moyennes et populaires, des objectifs politiques pourtant traditionnels des partis socialistes européens. Les principales lois approuvées par le PSOE ont porté sur la violence domestique et l'égalité hommes-femmes (2004), le mariage pour les couples homosexuels et la "mémoire historique " de la guerre civile (2005) ${ }^{25}$. Le PSOE a adopté une ligne plus conciliante à l'égard des revendications nationalistes, en reconnaissant le pluralisme identitaire et culturel de l'Espagne et en soutenant le nouveau statut d'autonomie de la Catalogne en 2005. Le journaliste Fernando Jáuregui put publier dès 2008 un livre intitulé La déception, anticipant l'amertume de l'électorat populaire vis-à-vis d'un gouvernement plus centriste et libéral, axé sur les questions de droits et de libertés, que fondamentalement de gauche et voulant modifier les structures

23. Anthony GIDDENS, La tercera vía. La renovación de la socialdemocracia, Madrid, Taurus, 2003. 24. Jordi SEVILLA, De nuevo socialismo, Barcelona, Crítica, 2002, p. 8.

25. Antonio PAPELL, Zapatero 2004-2008. La legislatura de la crispación, Madrid, Foca Ediciones, 2008 , p. 347-358. 
économiques et limiter les inégalités ${ }^{26}$. Le politologue Carlos Taibo parla même dès 2007 d'une "illusion d'optique " pour évaluer le bilan du gouvernement socialiste: pour lui, son augmentation très faible et purement symbolique du salaire minimum (2004), sa décision de libéraliser le marché hypothécaire en facilitant l'accès au "crédit facile " pour les particuliers (en 2007), sa myopie face à la « bulle de la brique ", et son refus de mener une véritable réforme fiscale en faveur des classes populaires, étaient autant d'illustrations de son orthodoxie économique libérale et de son renoncement à défendre un véritable projet d'émancipation sociale ${ }^{27}$.

Pourtant, dans son programme électoral de 2008, le PSOE promit un "saut définitif " vers le plein emploi et l'approfondissement de l'État-providence, une déduction d'impôt de 400 euros pour l'ensemble des citoyens à approuver par le premier Conseil des ministres, une augmentation du salaire minimum à 800 euros et la construction de 1,5 million de logements sociaux sur dix ans pour permettre aux jeunes de s'émanciper en échange d'un loyer modeste de 210 euros $^{28}$. Mais la campagne électorale de 2008 fut surtout marquée par une " lutte politique " médiatisée et personnalisée entre José Luis Rodríguez Zapatero et Mariano Rajoy selon le sociologue Enrique Gil Calvo, et par «l'absence absolue d'idées politiques » pour le journaliste Josep Ramoneda ${ }^{29}$. Malgré les premiers signes évidents de dégradation économique enregistrés depuis la fin de l'année 2007, José Luis Rodríguez Zapatero

26. Fernando JAUREGUI, La decepción. Crónica amarga y secreta de cuatro años de crispación, Barcelona, Debate, 2008. Cf. de même Félix OVEJERO, " ¿Es de izquierdas la política del PSOE? », El noticiero de las ideas, $n^{\circ} 31,2007$, p. 15-23. Les positions de Fernando Vallespin, professeur de science politique de l'Université autonome de Madrid et ancien directeur du Centre de recherches sociologiques (CIS), furent très écoutées et influencèrent la campagne électorale du PSOE de 2004. Il critiqua la « troisième voie » et soutint qu'un socialisme rénové doit maintenir le rôle central de l'État et se focaliser principalement sur l'investissement en capital humain par l'éducation, la formation des chômeurs et la réduction des inégalités. Avec le recul, force est de constater que le PSOE a surtout utilisé stratégiquement ses idées pour jouer son rôle d'opposition et accéder au pouvoir, mais n'a pas développé de politiques publiques novatrices qui puissent favoriser l'égalité sociale et la redistribution des richesses. Cf. Fernando VALLESPIN, El futuro de la política, Madrid, Taurus, notamment p. 142-158. Voir aussi ses articles «Socialismo post-idéologico » et « La izquierda posible » paru dans El País le 28 mai et le 13 juillet 2000.

27. Carlos TAIBO, «Zapatero, ¿en la izquierda? », La Vanguardia, 18 juin 2007.

28. Jesús Caldera, le coordinateur du programme électoral du PSOE, soutint ainsi qu'«il est essentiel d'avoir une vision optimiste du futur du pays, parce que ceux qui pronostiquent la catastrophe développent une attitude contraire au plein emploi », cf. Jesús CALDERA, déclaration lors de la réunion du bureau exécutif du PSOE le 16 janvier 2007, cité dans Antonio PAPEL, op. cit., 2008, p. 314

29. Enrique GIL CALvo, La lucha política a la española. Tragicomedia de la crispación, Madrid, Taurus, 2007 ; Josep RAmonedA, « Sin ideas políticas », El País, 6 mars 2008. 
stigmatisa comme " antipatriotes " ceux qui selon lui " exagéraient la crise économique ", promettant que l'Espagne serait prochainement "dans la Champions League de l'économie mondiale " ${ }^{30}$. Le programme électoral du PSOE fut d'ailleurs intitulé: « Pour le plein emploi: Raisons pour grandir ${ }^{31}$. José Luis Rodríguez Zapatero nia pendant longtemps la crise, préférant parler des "faiblesses " ou d'un "ralentissement " de l'économie, et ce, jusqu'au 8 juillet 2008, lorsqu'il reconnut son existence et utilisa pour la première fois le terme de "crise " lors d'un entretien à la chaîne Antena $3^{32}$. La semaine suivante, Martinsa-Fadesa, la première entreprise immobilière du pays, fit faillite, laissant des centaines de chantiers à l'abandon et plusieurs milliers d'ouvriers au chômage.

L'histoire donna donc raison à Carlos Taibo, d'autant plus que suite à l'éclatement de la bulle immobilière et à la faillite des principales banques espagnoles, le PSOE appliqua sans broncher les mesures d'austérité prônées par la "Troïka " (Commission européenne, Banque centrale européenne et Fonds monétaire international), s'aliénant durablement le soutien des classes populaires les plus touchées par la crise. En août 2008, le gouvernement socialiste entreprit d'appliquer un plan d'austérité drastique de 24 mesures en contradiction totale avec ses promesses électorales: réduction de $70 \%$ des ouvertures de poste et de $5 \%$ des salaires dans la fonction publique; hausse de la TVA; gel des pensions de retraite et augmentation de l'âge de départ à 67 ans (avec l'appui du PP à travers le "pacte de Tolède "); remise en cause des principales avancées sociales de la législature antérieure (" chèque bébé » de 2500 euros, approuvé en juillet 2007 pour soutenir la natalité, et déduction de 400 euros sur l'impôt sur le revenu); de même qu'une réforme du travail en septembre 2010 qui réduisit les primes de licenciement de 33 à 25 jours d'indemnisation par année travaillée et déboucha sur une grève générale ${ }^{33}$.

Le PSOE renonça à augmenter à 800 euros le salaire minimum, qui resta donc de 641 euros net par mois jusqu'à la fin de son second mandat en novembre 2011. Les dépenses publiques furent réduites de 15000 millions en 2010, les investissements publics diminuèrent et les

\footnotetext{
30. José LoBo, «Zapatero vuelve a tachar de "antipatriotas'a quienes "exageran" la crisis económica », [Elconfidencial. com], 30 avril 2008, consulté le 14 janvier 2015.

31. «El PSOE presenta los motivos para crecer », Público, 3 mars 2008.

32. José LoBO, «Ni crisis, ni desaceleración: Zapatero habla ahora de "debilidades" económicas », [Elconfidencial. com], 14 mai 2008, consulté le 15 janvier 2015.

33. Natalia JUNQUeRA, « Las 10 grandes rectificaciones de Zapatero », El País, 24 août 2011.
} 
communautés autonomes se livrèrent à des licenciements et des réductions de salaire sous la pression de l'État central, lui-même soumis aux conditions et pressions de la Troïka et des créanciers européens de l'Espagne. En juin 2009, les prix de l'essence et du tabac augmentèrent pour la première fois depuis 1996. En janvier 2010, ce fut le tour des prix de l'électricité $(+2,6 \%)$ et des billets de trains $(+6 \%)$. Au $1^{\text {er }}$ janvier 2011 , les prix de l'électricité $(+9,8 \%)$, des billets de train et des autoroutes augmentèrent de nouveau et les pensions de retraite furent gelées. Le taux de chômage atteignait alors 29,7 \% en Andalousie, 28,5 \% dans les îles Canaries et $26,1 \%$ à Murcie $^{34}$. Malgré ses critiques sur ce point à l'encontre des gouvernements de José María Aznar, José Luis Rodríguez Zapatero n'hésita pas à privatiser Aena, l'entreprise nationale qui gérait jusqu'alors les aéroports et la navigation aérienne, de même qu'une partie de la loterie nationale. L'approbation d'une réforme constitutionnelle avec l'appui du PP, qui instaura une « règle d'or " limitant le déficit public en août 2011, montra bien la priorité donnée au remboursement de la dette et à la réduction des dépenses publiques.

Certes, le gouvernement socialiste chercha à relancer l'investissement public à travers le " plan $\mathrm{E}$ " qui mobilisa 11000 millions d'euros et permit de financer des projets au sein des municipalités. Alors que le gouvernement américain laissa les banques qui avaient trop de risques financiers faire faillite, appliquant ainsi à la lettre la doctrine libérale, ce qui devait d'ailleurs se révéler bénéfique sur le long terme, les États européens vinrent au chevet des banques, ce qui transforma les dettes bancaires en dettes publiques. Ces politiques néolibérales où l'État a sauvé des banques pourtant responsables de la spéculation financière, ont non seulement été menées sans contreparties quant à une plus ferme régulation des activités bancaires et des marchés financiers, mais ont aussi déresponsabilisé les principaux acteurs à l'origine de la crise. En Espagne, de nombreuses banques ont ainsi été « sauvées » par l'État (Caja Castilla-la-Mancha en mars 2009; CajaSur en mai 2010 par exemple), le gouvernement socialiste ayant déboursé 30000 millions d'euros pour l'achat d'actifs financiers par le Trésor public. Mais la faillite des banques et l'intervention de l'État ont fait exploser la dette publique et les déficits. Peu à peu, les conditions de vie des Espagnols se sont largement dégradées. Le renoncement idéologique du PSOE et son choix de l'austérité débouchèrent sur sa plus large défaite depuis la transition lors des élections législatives du 29 novembre 2011: Alfredo

34. Alejandro BoLAÑOS, "Una crisis de 4,9 millones de parados », El País, 30 avril 2011. 
Pérez Rubalcaba obtint alors seulement 28,7 \% des voix (contre 43,8 \% en 2008), le PP raflant au contraire la majorité absolue avec $44,6 \%$ des suffrages exprimés.

Cette politique néolibérale et complaisante à l'égard des principaux responsables de la crise bancaire fut toutefois poursuivie par le gouvernement conservateur de Mariano Rajoy. Ainsi, fin 2011, la Banque d'Espagne intervint pour sauver la Caisse d'épargne de la Méditerranée, puis nationalisa les banques CatalunyaCaixa, Novacaixa Galicia et Banco de Valencia pour un montant total de 7500 millions d'euros, ce qui fit augmenter d'autant la dette publique - qui atteignit alors les $8 \%$ du produit intérieur brut (PIB). Puis en 2012, le gouvernement du PP prit le contrôle de Bankia, entité financière contrôlant de nombreuses banques et caisses d'épargne (Caja Madrid, Bancaja, Caja Canarias, Caixa Laietana, Caja Rioja, Casa Ávila et Caja Segovia) et dont le président, Rodrigo Rato, responsable d'une gestion désastreuse, était un membre influent du $\mathrm{PP}^{35}$. Face à des pertes financières énormes, on injecta 19000 millions d'euros d'argent public pour sauver cet établissement, dans ce qui devait devenir le plus important plan de sauvetage de l'histoire de l'Espagne et l'un des principaux en Europe. Mais ce plan ne fut pas suffisant. Le 7 mai 2012, un apport de 23500 millions d'euros supplémentaires apparut nécessaire pour derechef « sauver» Bankia.

Devant l'ampleur des pertes, le gouvernement sollicita le soutien de l'Union européenne à hauteur de cent milliards d'euros; il l'obtint le 9 juin 2012, officiellement pour " assainir le système financier espagnol » en prêtant aux banques ${ }^{36}$. Les pertes des banques, responsables de la spéculation financière et immobilière par l'octroi massif de crédits à des personnes et à des entreprises sans garanties suffisantes lors des années du " boom ", furent donc transformées en dette publique, dont le remboursement et les intérêts, payés par le contribuable espagnol, ne devaient plus être rendus à l'État mais aux créanciers extérieurs. Les actions des gouvernements du PSOE et du PP furent dès lors très critiquées par l'opinion publique, désormais très consciente du mécanisme pervers de la dette. Les banques ont été déresponsabilisées malgré leurs excès spéculatifs et l'ampleur de leur évasion fiscale, et l'État, donc l'ensemble des citoyens, dut et devra longtemps payer le prix d'une dette dont ces derniers ne sont que partiellement responsables. En

35. Iñigo DE BARRóN, « Rato dimite como presidente de Bankia », El País, 7 mai 2012. 36. Iñigo DE BARRón, « El Estado nacionaliza el grupo de Bankia », El País, 10 mai 2012. 
échange des emprunts contractés par l'État pour assainir les finances des banques, les créanciers extérieurs ont en effet exigé une réduction des déficits publics, qui se sont creusés de façon mécanique par les faillites bancaires et la hausse des taux d'intérêt sur les marchés financiers. Pour répondre aux conditions européennes, le paiement de la dette et la réduction des dépenses publiques sont devenus l'alpha et l'oméga de l'ensemble des politiques gouvernementales depuis 2008, à l'exclusion de tout autre projet économique alternatif. De nombreux Espagnols ont ainsi perdu tout espoir face aux discours de partis dominants n'offrant que l'austérité comme horizon politique.

Dès sa prise de pouvoir et avec l'appui de CiU, Mariano Rajoy décida, pour compenser ces énormes pertes financières, d'augmenter l'impôt sur le revenu, de réduire le déficit public de 13,4 milliards d'euros (la plus importante coupe budgétaire depuis 1978) à travers des privatisations, des licenciements, la poursuite du gel du salaire des fonctionnaires et une diminution de $40 \%$ des investissements publics en 2012. Puis des coupes budgétaires à hauteur de 18 milliards d'euros furent imposées aux communautés autonomes. Comme le PSOE avant lui, le PP renia ses promesses électorales en menant une politique d'austérité: privatisation des entreprises publiques; coupes budgétaires dans le secteur de la santé et de l'éducation; nouvelle augmentation de la TVA de $18 \%$ à $21 \%$ en juillet 2012 ; suppression des paies extra de Noël des fonctionnaires et réduction du nombre de congés, etc. Qui plus est, ces politiques n'eurent pas d'effets à court terme, puisque l'Espagne entra à nouveau en récession fin 2011 et y resta jusqu'à la fin 2013. Pendant cette période, 374000 emplois publics furent supprimés. En 2012 puis en 2013, de nouvelles augmentations du prix de l'électricité furent décidées ( $+5 \%$ en deux ans), et le salaire minimum demeura gelé à 645,30 euros par mois. Mais la dette extérieure espagnole n'en aura pas moins triplé en moins d'une décennie, atteignant les $160 \%$ du PIB en 2014. Fin 2013, l'Eurostat estima même le revenu par habitant à $96 \%$ de la moyenne européenne, ce qui signifiait une régression du pays à la situation qui était la sienne quinze ans plus tôt, en 1998.

Malgré le retour d'une - faible - croissance économique en 20142015, le discours officiel sur la "sortie de crise " peine à convaincre les Espagnols des classes moyennes et populaires, pour qui les dernières années et le temps présent demeurent associés à la récession économique, à la hausse des inégalités et à la remise en cause de nombreux droits sociaux. Les fruits de cette croissance ne bénéficient en effet pas 
à tous, loin de là. Les inégalités se sont d'ailleurs largement renforcées depuis 2008. Une situation perçue avec un sentiment partagé d'injustice, d'autant plus qu'elle coïncide avec la multiplication des affaires de corruption.

\section{L'impact de la corruption sur la crise de la représentation politique}

Dans l'Espagne d'aujourd'hui, la multiplication des affaires de corruption politique est telle que cet enjeu constitue désormais la seconde préoccupation majeure des citoyens, derrière la question du chômage ${ }^{37}$. L'«affaire Gürtel " révélée le 6 février 2009 par l'enquête du juge Baltasar Garzón sur le financement illégal du PP de la communauté valencienne est la plus emblématique. Ses membres ont détourné les fonds publics dédiés à la Feria de Valence et à la visite fastueuse du Pape Benoît XVI en 2006, surfacturé des contrats de travaux publics avec des entreprises travaillant avec la Generalitat, et développé un réseau de financement occulte des campagnes électorales de 2007 et de $2008^{38}$. Mais bien d'autres cas de corruption ont éclaboussé les fédérations régionales du PP depuis 2008. Les PP de la Rioja et de Biscaye sont soupçonnés d'avoir acheté leur siège (pour le premier), ou payé l'hypothèque et effectué des travaux au sein de celui-ci (pour le second), grâce à de l'argent issu de la " double comptabilité » du PP national. Le PP de Cantabrie est quant à lui accusé d'avoir bénéficié de donations illégales. Des municipalités qui ont été ou qui sont encore gouvernées par le PP sont aussi mises en cause: Valence, Pontevedra, Tolède, Boadilla del Monte ou Arganda del Rey, pour n'en citer que quelques-unes. María Dolores de Cospedal, secrétaire général du PP depuis 2008 et présidente de la Junte des communautés de Castille-La Manche depuis 2011, a ainsi été indirectement mise en cause après la découverte du détournement de 200000 euros octroyés à la compagnie Sacyr à Tolède pour le traitement des déchets, une somme qui aurait permis de financer sa campagne électorale régionale de $2007^{39}$.

En mars 2015, de nombreuses affaires menacent encore le PP au pouvoir et plusieurs de ses fédérations. Le parti est soupçonné, suivant les «papiers de Bárcenas » révélés durant l’enquête sur le réseau

\footnotetext{
37. Sondage El País/Metroscopia, 2 novembre 2014.

38. José Manuel Romero, "Gürtel, la corrupción que colonizó el Partido Popular », El País, 16 janvier 2015.

39. José MARÍA IRUJo, « Un contrato de basuras bajo sospecha », El País, 20 juillet 2013.
} 
Gürtel, d'avoir payé en liquide et sans déclarations fiscales les travaux de son siège pour un montant de 1,7 million d'euros, et d'avoir acheté des actions du groupe Libertad Digital avec de l'argent illicite issu de sa "double comptabilité " (connue comme " la caisse b " du parti). Le 18 janvier 2010, le quotidien El Mundo fit état de déclarations de Luis Bárcenas, confiant avoir distribué chaque mois à des dirigeants du PP, pendant de nombreuses années, des enveloppes contenant de 5000 à 15000 euros procédant d'entreprises de sécurité, du bâtiment ou de donations non déclarées ${ }^{40}$. Dans le cadre de l'" affaire Bárcenas ", dont le principal inculpé est l'ancien trésorier du PP, le parti est soupçonné d'avoir mis en place un système de financement occulte de 1990 à 2007, qui lui aurait notamment permis de tirer profit de huit millions d'euros de donations illégales ${ }^{41}$. Malgré la gravité des faits reprochés aux personnes soupçonnées de corruption, le sentiment largement partagé par les Espagnols est que les peines sont très légères et que la justice n'est pas la même pour tous.

Il suffit par exemple de constater le grand écart entre les peines requises par les juges anticorruption et les durées effectives de détention des deux principaux "boucs émissaires " de l'affaire Gürtel, Francisco Correa et Luis Bárcenas. Les juges réclament cent vingtcinq années de prison et une amende de 15,5 millions d'euros pour Francisco Correa, accusé de corruption, trafic d'influence, blanchiment de capitaux, fraude fiscale, association illicite et falsification de documents ${ }^{42}$. Ils réclament aussi quarante-deux années de prison pour Luis Bárcenas, qui s'est enrichi grâce à des commissions pour son travail d'intermédiaire entre des entreprises obtenant des contrats publics et des dirigeants du PP obtenant des rétrocommissions, occultant 42,8 millions d'euros à l'administration fiscale sur des comptes bancaires en Suisse $^{43}$. L'un n'a effectué que trois années de prison de 2009 à 2012 en détention préventive, obtenant sa mise en liberté grâce au paiement de 200000 euros; l'autre est resté dix-neuf mois en détention à la prison madrilène de Soto del Real pour les mêmes délits. Même s'il est possible qu'ils retournent en prison à l'issu de leur procès, il est peu probable que cela soit le cas en raison des aménagements de peines, ce qui donne à la société l'image d'une impunité « des politiques » et « des

40. «Las revelaciones de Bárcenas », El Mundo, 18 janvier 2010.

41. «Los escándalos que amenazan el PP », El País, 16 janvier 2015.

42. María FABRA, « Bárcenas ya está en la carcel », El País, 28 juin 2013.

43. José Manuel Romero et Fernando PÉREZ, «El fiscal detalla la financiación ilegal del PP durante 15 años », El País, 16 janvier 2015. 
puissants ${ }^{44} »$. Quarante et un autres prévenus doivent d'ailleurs être jugés, dont l'ancienne ministre de la Santé Ana Mato pour «participation à titre lucratif » à l'appropriation de biens publics, ou encore Pablo Crespo, ancien secrétaire général du PP de Galice et ami personnel de l'actuel chef du gouvernement Mariano Rajoy. Mais la prescription très rapide des délits financiers, après seulement trois ou quatre ans dans la plupart des cas et, à l'inverse, les délais très longs des procédures judiciaires, permettent le plus souvent aux prévenus d'échapper à des condamnations.

La corruption politique mine le socle du lien représentatif et l'impunité renforce l'indignation citoyenne et la montée de l'antiparlementarisme. La fraude fiscale fut ainsi estimée à 42 milliards d'euros en 2012 par le ministère des finances ${ }^{45}$. Mais les contrôles fiscaux ciblent principalement les professions libérales, les autoentrepreneurs, les artisans et les petits commerçants, même si leurs fraudes ne représentent que $8 \%$ du total. Les entreprises multinationales et les grandes fortunes sont les principaux responsables de la fraude fiscale en Espagne mais sont rarement condamnées, ce qui renforce le sentiment que la loi et la justice ne s'appliquent pas de la même manière pour les "citoyens ordinaires " et pour les "puissants ${ }^{46}$ ". L'amnistie fiscale décidée par le PP en mars 2012 a donné une image déplorable. En outre, elle n’a débouché que sur une régularisation de $5 \%$ des sommes estimées de l'évasion fiscale. D'autres artifices légaux provoquent aussi l'indignation des citoyens: par exemple, la possibilité du gouvernement d'accorder un " pardon " (indulto) en dépit d'un verdict judiciaire à certaines personnes condamnées; ou encore, le fait que 17621 personnes bénéficient d'une "immunité » liée à leurs responsabilités publiques ou politiques, principalement les juges, mais aussi plus de deux mille politiciens ${ }^{47}$.

Le plus grave est que ces scandales touchent l'ensemble de la classe politique. En 2009, le procureur général de l’État (" fiscal general»),

44. Lorsque Luis Bárcenas sortit de prison en janvier 2015, il déclara: " J'ai été fort. Le PP n'a rien à craindre ", un euphémisme pour dire que des condamnations de hauts dirigeants semblent improbables. Son avocat eut même le culot de déclarer : « Mon client a payé pour les autres. Avoir 40 millions en Suisse, ce n'est pas un délit », cf. Fernando PÉREZ, «Bárcenas sale de prisión : " He sido fuerte. El PP no tiene nada que temer », El País, 23 janvier 2015.

45. «El fraude fiscal alcanza en España el $6 \%$ del PIB », [http ://www.publico.es], 26 février 2013.

46. "Un estudio concluye que hay hasta 26 billones de euros ocultos en paraísos fiscales », [http://www.europapress.

com], 17 juillet 2012.

47. «Quiénes son los aforados en España y quién los juzga », El País, 2 septembre 2014. 
Cándido Conde-Pumpido, révéla que 730 enquêtes pour corruption étaient en cours et concernaient l'ensemble des partis, donnant une image lamentable d'impunité généralisée: 464 affaires concernaient des membres du PSOE et du PP (respectivement 264 et 200), soit $63 \%$ du total, mais de nombreuses autres procédures ${ }^{48}$ impliquaient des membres de la Coalition Canaries (43 procédures), de CiU (30), du parti andalouciste (24), d'Izquierda Unida (20), du groupe indépendant libéral à Ceuta, Melilla et Marbella (17), de l'Union de Majorque (7), d'Esquerra Republicana de Catalunya (5), du Bloc nationaliste galicien (BNG, 3) et du Parti nationaliste basque (PNV, 3). Lors des élections municipales du 22 mai 2011, plus de cent responsables politiques impliqués dans des affaires de corruption n'hésitèrent pas à se présenter sur les listes électorales, leur réélection étant d'ailleurs souvent leur seul moyen d'éviter des condamnations et de maintenir leur « immunité ", désormais synonyme d'impunité pour de nombreux citoyens ${ }^{49}$. En 2015, environ trois cents hommes et femmes politiques sont encore mis en cause, dont une trentaine de maires et une centaine d'anciens maires. Aucune institution n'est épargnée, même la monarchie, à travers l'affaire Nóos qui implique l'infante Christine de Bourbon, fille de Juan Carlos I ${ }^{\mathrm{er}}$, mariée à Iñaki Urdangarín, le principal prévenu. Les citoyens ont ainsi l'impression que tous les partis sont corrompus et que le système politique régi par la constitution de 1978 est à bout de souffle, ne permettant plus de lutter efficacement contre ces dérives.

Le 25 juillet 2014, Jordi Pujol, l'ancien "président tout-puissant " de la Generalitat de Catalogne de 1980 à 2003 a même avoué publiquement avoir caché pendant trente-quatre ans, depuis 1980, sur des comptes en Suisse et en Andorre, une fortune de plusieurs dizaines de millions d'euros supposée correspondre à l'héritage de son père ${ }^{50}$. De nombreux soupçons pèsent aussi sur le financement illégal de son parti, Convergència Democràtica de Catalunya ("Convergence démocratique de Catalogne ", $C D C$ ), et sur des pratiques de corruption et de blanchiment d'argent dans son entourage, ses fils Jordi, Oleguer et Oriol étant eux-mêmes notamment soupçonnés de fraudes massives. Ce scandale a

48. Quelques cas peuvent être cités parmi les plus emblématiques. Pour le PP: les affaires Bárcenas; Brugal et Fabra mettant en cause les anciens maires d'Alicante et de Valence; les cas Faycán; Gürtel ; Palma Arena etc. Pour le PSOE : affaire des ERE d'Andalousie correspondant à des détournements ou à de fausses primes de licenciement; affaire Filesa; Flick; Mercasevilla etc. Pour CiU : affaire Palau; Pallerols; Banca Catalana etc. 
particulièrement choqué les opinions publiques espagnole et catalane, tant il illustre le cynisme et les pratiques quasi mafieuses répandues parmi les élites des partis dominants, et même parmi les nationalistes catalans, dont le discours politique a pourtant toujours été axé sur leur " exemplarité ", leur modernisme et leur " différence " par rapport aux autres élites espagnoles ${ }^{51}$.

Le cas des « cartes opaques » révélé par la presse en septembre 2014, qui permirent à de nombreux dirigeants politiques d'utiliser pour leur bénéfice personnel des comptes non déclarés à la Caja Madrid et chez Bankia (à hauteur de 15 millions d'euros), illustra une fois encore les liens douteux des représentants politiques avec les banques, et les pratiques illégales de nombreuses élites politiques et financières ${ }^{52}$. Le fait que les directeurs et les conseillers des principales banques et des caisses d'épargne espagnoles soient souvent issus des partis politiques est un problème majeur qui favorise l'opacité et les échanges de faveur entre des acteurs qui jouent un "double jeu ", et dont les trajectoires illustrent l'utilisation des positions de pouvoir dans le champ politique comme moteur de l'accumulation de richesses économiques ${ }^{53}$. En 2012, 48 des 487 postes des conseils d'administration de l'IBEX 35, qui regroupe les principales multinationales espagnoles (Banco Santander, Endesa, Iberdrola, Telefónica, Bankia etc.), étaient occupés par des membres du PSOE et du PP (mais aussi six par des membres de CiU et un respectivement pour Izquierda Unida et le PNV), qui avaient exercé ou qui exerçaient encore des responsabilités politiques en parallèle ${ }^{54}$.

L'indice de perception de la corruption de l'ONG Transparency International classa ainsi l'Espagne en treizième position parmi les pays de l'UE et à la trentième dans le monde en 2012, derrière l'Ouganda, en notant que le pays régresse d'année en année et qu'il s'agit du seul pays de l'UE qui ne s'est pas encore doté d'une véritable loi sur la transparence en politique. Ce classement a suscité un tel débat que le chef du

51. Sur ce point, voir les déclarations du maire de Barcelone, Xavier TRIAS, "La sombra del pujolismo se ha acabado y se abre una nueva etapa », La Vanguardia, 29 juillet 2014.

52. «Las tarjetas opacas de Caja Madrid al detalle », El País, 31 janvier 2015.

53. Sur la notion de « double-jeu » politico-économique des acteurs entre différentes sphères et/ou arènes, voir les travaux d'Yves DEZALAY et notamment avec Antonin COHEN et Dominique MARCHETTI, «Esprits d'État, Entrepreneurs d'Europe », Actes de la recherche en sciences sociales, $n^{\circ} 166-167,2007$, p. 4-13. De même, cf. Yves DEZALAY, « The legal construction of a politics of notables. The double game of the patricians of the Indian bar on the market of civic virtue » Retfaerd, vol. 3, n 114, 2006, p. 42-63.

54. «Transparencia International Ilama a frenar la corrupción para salir de la crisis », El País, 5 décembre 2013 Voir de même « España no es Uganda, ¿o sí ? », El Mundo, 13 juin 2012. 
gouvernement Mariano Rajoy a dû lui-même se justifier en déclarant que « l'Espagne, ce n'est pas l'Ouganda ", dans un exercice de défense de sa politique anti-corruption qui a plus fait rire que convaincu ${ }^{55}$. L'indignation citoyenne est d'autant plus forte que de nombreux commentateurs ont souligné à juste titre la médiocrité de la classe politique espagnole, dont le recrutement dépend amplement de réseaux familiaux de patronage et de cooptation, et qui se caractérise par le manque d'expérience professionnelle et une faible maîtrise des langues étrangères et des nouvelles technologies ${ }^{56}$.

\section{Au-delà des affaires, les limites du système institutionnel issu de la constitution de 1978}

La crise espagnole est aussi une crise institutionnelle, dans la mesure où il existe un soutien de plus en plus large au sein de la société à l'idée d'une réforme de la constitution de 1978, notamment en ce qui concerne l'indépendance de la justice, la loi électorale et la question territoriale. Tout d'abord, il subsiste un problème hérité de la période franquiste lié à la séparation encore imparfaite des pouvoirs exécutif et judiciaire. En effet, les principaux dirigeants du pouvoir judiciaire, les membres du ministère fiscal d'Espagne, du Conseil général du pouvoir judiciaire et du Tribunal constitutionnel, sont nommés par les pouvoirs exécutif et législatif. Le système électoral majoritaire permet ainsi au gouvernement, qui s’appuie sur une majorité relative ou absolue, de nommer des juges dont la philosophie est réputée proche de sa tendance politique. Cela peut avoir des effets déterminants, s'agissant par exemple des décisions du Tribunal constitutionnel sur les recours des partis de l'opposition à l'égard d'une loi. La question de l'impartialité des juges, notamment dans la prise en compte de la corruption qui touche les élites, mais aussi plus généralement, est ainsi mise en cause. On a particulièrement pu l'observer lorsque le juge constitutionnel Francisco Pérez de los Cobos, qui a milité de longues années au sein du PP, a rejeté en 2011 les demandes catalanes liées au statut d'autonomie de 2005, ou encore, lorsque le magistrat Pedro González-Trevijano, nommé par le PP, s'est prononcé contre le référendum catalan du 9 novembre 2014. Dans les affaires anticorruption, le fait que le mandat

55. « Comparar España con Uganda le sale caro a Rajoy », [http://www.elplural.com], 14 juin 2012, consulté le 1er février 2015.

56. «Los políticos españoles : sin idiomas, sin experiencia laboral y lejos de las nuevas tecnologías », [http://www.20

minutos. com], 15 juin 2014, consulté le 10 février 2015. 
du juge instructeur expire au bout de deux ou trois ans permet souvent au gouvernement de le remplacer par un magistrat moins zélé, ce qui constitue une façon indirecte « d'enterrer » une affaire par la procrastination et l'absence de volonté politique.

Les citoyens sont, de même, de plus en plus conscients des limites du système électoral et de la loi sur les partis hérités de la transition. Le système électoral majoritaire favorise un bipartisme figé et les deux partis dominants, comme ailleurs en Europe, sont critiqués pour le manque de renouvellement de leur idéologie et de leur personnel politique. Le système de listes fermées, qui ne permet pas aux citoyens de choisir directement leurs candidats préférés et les oblige à voter pour les candidats choisis par les partis est directement mis en cause par une nouvelle formation comme Podemos, qui veut inciter les citoyens à choisir eux-mêmes leurs candidats par des votes électroniques et des listes ouvertes. Mais la critique majeure de la loi électorale est surtout liée à la grande opacité du financement des partis, dans un contexte où les citoyens demandent plus de transparence pour lutter plus effectivement contre la corruption. Seuls Unión Progreso y Democracia (UPyD), la formation de Rosa Diez, et le nouveau parti Podemos de Pablo Iglesias publient leurs comptes sur internet.

Légalement, les partis doivent présenter un rapport annuel sur l'état de leurs finances au Tribunal de las Cuentas, l'équivalent espagnol de la Cour des comptes. L’organisme doit se prononcer sur la validité des comptes dans une période de six mois, mais ce délai n’est jamais respecté. Pire, le dernier rapport comptable date de 2007 et la loi établit une prescription judiciaire après quatre ans pour le délit de financement illégal. Autrement dit, le manque de moyens du système judiciaire, sa faible indépendance par rapport au pouvoir exécutif et l'intérêt partagé des partis dominants au maintien d'un système opaque, permettent aux acteurs de maintenir des pratiques illégales, notamment dans le financement des campagnes et la passation des marchés publics, sans trop de crainte des conséquences judiciaires ${ }^{57}$. De plus, hormis dans le cas où une procédure judiciaire ouverte affecte directement un parti, seul un accord consensuel entre les membres de la Cour des comptes,

57. Sur une discussion des limites du rôle du Tribunal de las Cuentas en Espagne sur la transparence du financement des partis, cf. Mathieu PetithommE, Dépolitiser l'Europe. Comment les partis dominants évitent le conflit sur l'intégration européenne, Paris, L'Harmattan, 2015, notamment le chapitre VII, p. 291-311. Voir aussi du meme auteur «Second order elections but also «low-cost» campaigns? National parties and campaign spending in European elections: A comparative analysis », Perspectives on European Politics and Society, vol. 13, $n^{\circ} 2,2012$, p. 149168. 
qui sont nommés par les responsables politiques, permet d'entamer des procédures et d'imposer des peines, accord hautement improbable. D'autres privilèges des membres de la classe politiques sont difficilement justifiables aujourd'hui: les parlementaires espagnols peuvent ainsi bénéficier d'une retraite à taux plein après avoir siégé seulement sept années au Congrès des députés ${ }^{58}$.

Une réforme constitutionnelle est aussi plébiscitée par les partis de gauche et régionalistes, celle qui établirait définitivement un État fédéral en dépassant les limites du " fédéralisme asymétrique " propre à l'État des autonomies et en réévaluant le rôle du Sénat ${ }^{59}$. Le financement des autonomies (qui accorde un statut particulier à la Catalogne, la Galice et au Pays basque) pose problème dans la mesure où il est le sujet de perpétuelles négociations entre les communautés autonomes et l'État central, entre demandes d'autonomie accrue et projets de recentralisation. Il alimente aussi des luttes de pouvoirs entre les communautés pour faire prévaloir leurs intérêts à la solidarité interrégionale et la fédéralisation, ou à l'autonomie fiscale et politique. Enfin, une réforme du statut de la monarchie est souvent mise en avant, notamment suite à l'affaire de corruption mettant en cause le gendre de Juan Carlos $\mathrm{I}^{\mathrm{er}}$, afin de restreindre l'immunité à la seule personne du roi et à sa famille immédiate, et non à l'ensemble de la famille royale, cousins et neveux inclus. Mais sur l'ensemble de ces questions, audelà de ses déclarations d'intention, le PSOE n'a pas fait preuve d'une grande volonté politique durant ses gouvernements de 2004 à 2011. Le PP cherche aujourd'hui à maintenir le statu quo, alors même que les sondages d'opinion montrent une forte attente des Espagnols à l'égard d'éventuelles réformes institutionnelles. Ils sont très critiques envers la passivité et l'immobilisme des partis dominants sur ces questions. Et ce d'autant plus que ces derniers ont collaboré pour réformer la constitution en 2011, et instaurer une obligation légale de ne pas dépasser un déficit public annuel de plus de $3 \%$ du PIB. Une preuve de plus que réformer la constitution est possible.

\footnotetext{
58. Cette mesure fut mise en œuvre lors de la transition pour permettre aux élites politiques exilées durant la dictature franquiste d'avoir droit à une pension de retraite lors de leur retour en Espagne, mais elle a été maintenue jusqu'à nos jours, même s'il n'y a désormais plus aucune justification à un tel traitement de faveur, hormis celle de maintenir ce qui est perçu comme un « privilège » injuste par la société.

59. Alicia FERnÁndez García et Mathieu Petithomme, «Structuration et trajectoires idéologiques des partis nationalistes catalans depuis la transition : ERC, CiU et le PSC en perspective comparée », Cahiers de civilisation espagnole contemporaine, n 11, 2014.
} 


\section{LE RENOUVEAU DE LA CONTESTATION DANS L'ESPAGNE CONTEMPORAINE}

\section{Une multiplicité de manifestations anti-austérité}

Comme au Portugal, en Grèce, en Italie et ailleurs en Europe, les Espagnols se sont activement mobilisés depuis 2008 pour contester les effets de la crise économique, et pour dénoncer les responsables politiques et financiers de la récession. La manifestation de rue, entendue comme toute " occupation momentanée par plusieurs personnes d'un lieu ouvert public ou privé et qui comporte directement ou indirectement l'expression d'opinions politiques ", est revenue avec force sur le devant de la scène médiatique à travers de nombreuses mobilisations collectives $^{60}$. Les Espagnols sont descendus en masse dans la rue afin de s’opposer aux plans d'austérité imposés par le PSOE puis par le PP, dans le contexte des pressions plus globales de la Troïka. Les principaux syndicats, Comisiones Obreras (CC. OO) et Union générale des travailleurs (UGT), s’opposèrent ainsi dès le 27 décembre 2007 à la " loi Omnibus ", qui appliquait la directive Bolkestein ${ }^{61}$ à l'Espagne et engendra une privatisation du secteur des services. Les chauffeurs routiers le 8 juin 2008, puis les chômeurs, les étudiants, les personnels de l'éducation, de la santé et les membres des fonctions publiques des communautés autonomes, touchés de plein fouet par les politiques d'austérité et les licenciements, se mobilisèrent ensuite lors de nombreuses manifestations et " marées ${ }^{62}$ ".

Le refus par les citoyens des deux « réformes du travail " proposées par le PSOE le 9 septembre 2010 puis par le PP en mars 2012, et leur opposition plus générale aux politiques d'austérité, ont débouché sur quatre grèves générales en trois ans, le plus souvent convoquées par CC. OO et l'UGT, alors que sept grèves générales seulement avaient été enregistrées depuis l'approbation de la constitution en $1978^{63}$. Ces grèves eurent lieu le 29 septembre 2010 puis le 27 janvier 2011 (principalement

\footnotetext{
60. Olivier FILLIEULE, Stratégies de la rue, Paris, Presses de Sciences-Po, 1997, p. 44.

61. Sur les résistances à la directive Bolkestein, cf. Amandine CRESPY, Qui a peur de Bolkestein? Conflit, résistances et démocratie dans I'Union européenne, Paris, Economica, 2012.

62. Les «marées » correspondent au terme utilisé en Espagne depuis 2008 pour qualifier la convergence de collectifs, d'associations et de syndicats divers vers un même mouvement social, en jouant sur l'image d'une déferlante de revendications citoyennes. Les « marées » ont d'ailleurs habilement incité les manifestants à se vêtir suivant un code couleur : marée « verte » dans l'éducation, « blanche » dans la santé, « violette » pour les féministes etc.

63. « Las huelgas generales de la democracia », El País, 14 juin 2010.
} 
en Catalogne, en Galice, au Pays Basque et en Navarre sous la direction des syndicats ELA-STV, LAB, CIG, CGT et CNT), de même que le 29 mars et le 14 novembre $2012^{64}$. La fréquence de ces manifestations montra la mobilisation très forte des salariés pour la défense du secteur public, mais aussi contre le chômage, les licenciements et le recours accru aux contrats précaires et à durée déterminée. Le 15 septembre 2012, en aboutissement des mouvements de protestation enregistrés dans l'ensemble de l'Espagne, la " marche sur Madrid " ou " marche de la dignité ", culmina sur la Plaza de Colón, en opposition aux politiques d'austérité et aux coupes budgétaires ${ }^{65}$. Cette manifestation qui réunit

Photo 1.2 Tract de convocation de la grève générale du 29 septembre 2010

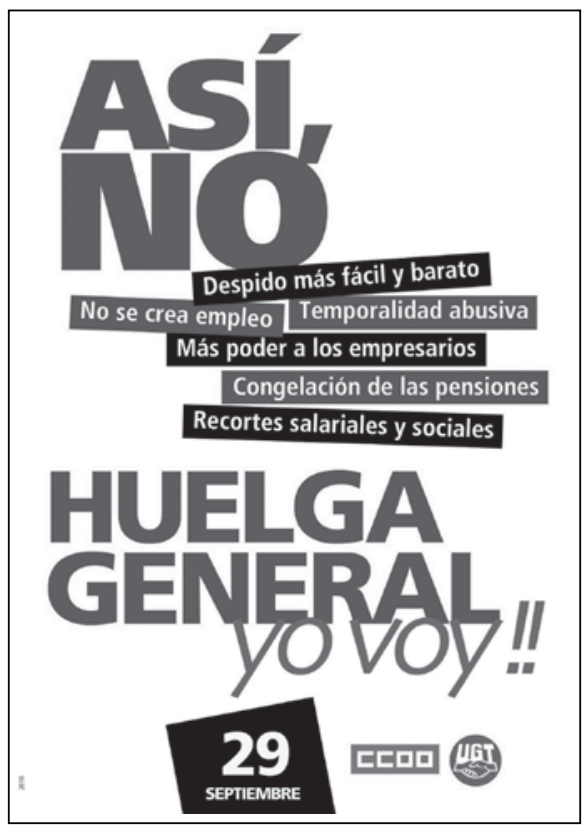

64. ELA-STV: Eusko Langileen Alkartasuna, Solidarité des travailleurs basques; LAB: Langile Abertzaleen Batzordeak, Commissions des ouvriers abertzales ; CIG : Confédération intersyndicale galicienne ; CGT : Confédération générale du travail ; CNT : Confédération nationale du travail.

65. Ces manifestations contre l'austérité se traduisirent aussi par des mobilisations autour du scandale des "preferentes», des placements sur des participations, présentés comme sans risques aux petits épargnants dans le cadre de pratiques commerciales agressives des banques, qui débouchèrent sur la ruine de ces particuliers et l'évaporation de leur épargne dans des actifs toxiques. Le 23 mars 2013, le gouvernement conservateur décida pourtant de convertir ces participations en actions des banques, ce qui supposa une réduction de leur valeur qui oscilla entre $10 \%$ et $70 \%$, suscitant une large indignation citoyenne. 
plus de 500000 personnes se fit à l'appel du Sommet social dirigé par les deux syndicats majoritaires, mais regroupa aussi 217 collectifs distincts. Les manifestants réclamèrent " du pain, du travail et de la dignité ", et exigèrent un référendum sur les politiques d'austérité.

Les manifestations anti-austérité touchèrent particulièrement les secteurs de la santé et de l'éducation. En 2011, le projet de privatisation de nombreux hôpitaux de la communauté de Madrid déclencha une "marée blanche" d'infirmier (ère) $s$ et de médecins grévistes, suivant une forme protestataire ensuite reprise par d'autres secteurs. En avril 2012, de nombreux citoyens se mobilisèrent de même contre l'instauration du "co-paiement pharmaceutique ", aux termes duquel les usagers payeront désormais une franchise de $10 \%$ sur le prix des médicaments, une mesure qui touche proportionnellement davantage les classes populaires puisqu'elle ne tient pas compte du revenu du patient. Enfin, le choix du gouvernement conservateur de mettre fin à l'assistance sanitaire gratuite aux 910000 immigrants illégaux ou qui ne cotisent pas à la Sécurité sociale, déclencha une campagne "Moi Oui, Santé universelle " ("Yo Si, Sanidad Universal »), qui donna lieu à de nouvelles manifestations et à une campagne de désobéissance civile de médecins et de personnels de la santé. Certains d'entre eux, comme le docteur Juan Luis Ruiz-Giménez, très connu en Espagne, refusent d'appliquer la loi qu'ils jugent contraire aux principes éthiques de leur profession, l'«obligation de soin envers les malades " étant un principe cardinal ${ }^{66}$. D'autres manifestations eurent lieu en septembre 2012 contre la décision de la ministre de la Santé Ana Mato de ne plus faire rembourser 417 médicaments par la Sécurité sociale selon un processus connu comme le "medicamentazo ». Enfin, comme le montre bien Karine Bergès dans le présent ouvrage, les Espagnoles se sont activement mobilisées contre le projet de réforme de la loi sur l'avortement, forçant le ministre de la Justice, Alberto Ruiz-Gallardón, à démissionner.

Dans le secteur de l'éducation, des manifestations massives d'étudiants, de personnels et d'associations de parents d'élèves se sont déroulées à partir de la fin de l'année 2012 contre la « loi organique pour l'amélioration de la qualité éducative " (LOMCE), connue comme la " loi Wert ", du nom de son promoteur et promulguée le 10 octobre $2013^{67}$. Cette loi a modifié profondément le système éducatif espagnol.

66. Juan Luis RUIz-GIMÉNEZ, "La insumisión en favor de la asistencia », dans José Miguel MonZón, op. cit., 2014, p. 77.

67. «El Congreso aprueba la reforma educativa Wert con los únicos votos del Partido Popular », El Mundo, 10 octobre 2013. 
Elle a imposé d'augmenter le nombre d'heures de cours des professeurs à tous les niveaux ainsi que le nombre d'élèves par classe. Elle a limité les possibilités de redoublement, instauré une sélection plus précoce des élèves dotés de problèmes d'apprentissage en cherchant à les orienter vers l'enseignement professionnel, lui-même dégradé puisqu'il faudra désormais une année supplémentaire pour pouvoir entrer à l'université par cette voie. Cette loi a octroyé la possibilité aux centres scolaires " concertés" (semi-privés) d'effectuer une ségrégation des sexes ${ }^{68}$. Les directeurs des centres scolaires devront être élus à travers un concours sous le contrôle de l'administration centrale, où la communauté professorale du centre éducatif aura moins de $50 \%$ des voix, actant une recentralisation de la compétence éducative. La possibilité a été donnée aux chefs d'établissements d'avoir recours à des sociétés privées pour assurer la sécurité de leur école. Alors que les langues régionales ont été reléguées au rang de matières de "spécialité ", les élèves auront désormais deux possibilités (et non une seule) de choix s'agissant de la matière " religion ». L'enseignement de l'économie a été aussi renforcé et une matière d'« initiation à l'entreprenariat » a été créée.

Au niveau universitaire, la loi a instauré une diminution drastique des bourses, une quasi-disparition des subventions accordées au programme d'échange Erasmus et une augmentation des frais d'inscription, déjà très élevés par rapport à d'autres pays européens ${ }^{69}$. La radio Cadena Ser estima ainsi que le coût des études en Espagne s'avérait cinq fois plus élevé qu'en France ${ }^{70}$. La plupart des dispositions de la loi firent l'objet de fortes oppositions. Les manifestants dénoncèrent une " privatisation " de l'enseignement supérieur, réservé aux seuls élèves dont les parents pourraient payer des frais d'inscription. Le fait que la loi introduise une difficulté supplémentaire d'accès à l'université pour les élèves issus de l'enseignement professionnel donna l'impression de l'instauration d'un système à deux vitesses, qui pénalisera encore plus les enfants des classes moyennes et populaires. La recentralisation de la compétence éducative au détriment des communautés autonomes,

68. "Las cuatro mayores críticas a la polémica ley Wert », El País, 5 octobre 2013.

69. En Espagne, il faut compter par exemple entre 1500 et 3000 euros de frais d'inscription par an pour des études de médecine, soit entre 9500 et 12000 euros jusqu'à l'obtention du droit d'exercer en tant que stagiaire médecin interne, auxquels il faut ajouter près de 500 et 700 euros annuels de frais pour l'achat de manuels spécialisés. Les frais d'inscription sont très variables suivant les filières et les universités, mais rarement inférieurs à 1000 euros par année universitaire.

70. Cf. «Estudiar la carrera en Francia es cinco veces más barato que en España », Cadena Ser, 9 janvier 2013. 
l'accès mis sur la religion et l'économie et la relégation du statut des langues régionales provoquèrent un tollé. La « loi Wert " déboucha le 24 octobre 2013 sur une grève générale de tous les niveaux éducatifs publics, de la maternelle à l'université, dans l'ensemble des communautés autonomes: ce fut la première grève unitaire de l'enseignement public de l'histoire de la démocratie espagnole.

\section{L'émergence du mouvement des indignés}

Les manifestations syndicales et citoyennes anti-austérité, les critiques grandissantes à l'égard de la classe politique et des banques et la remise en cause de l'avenir de toute une génération, débouchèrent sur la création de collectifs tels que Juventud Sin Futuro ("Jeunes sans futur ") et Democracia Real Ya ("Démocratie réelle maintenant »), qui appelèrent à manifester dans l'ensemble de l'Espagne le 15 mai 2011 pour dénoncer les responsables de la crise et demander l'instauration d'une "démocratie réelle", plus participative et horizontale, et qui mettrait réellement en œuvre les principes de justice et d'égalité. Ces manifestations massives furent suivies par des occupations de plusieurs places, dont les plus médiatisées furent celles de la Plaça Catalunya à Barcelone et de la Puerta del Sol à Madrid. Ces protestations débouchèrent sur la création du mouvement des indignés, dénommé " $15-\mathrm{M}$ " dans le contexte espagnol, en référence à son action collective initiale.

En occupant ces lieux publics par des campements permanents et en organisant des actions collectives à travers des manifestations, des assemblées et par un fonctionnement dépersonnalisé, les indignés créèrent une nouvelle "structure d'opportunités politiques ". Charles Tilly a bien montré qu'il existe dans toute société des acteurs qui disposent d'un accès privilégié aux arènes institutionnelles, et d'autres acteurs plus ou moins dominés ("challengers"), qui sont contraints d'avoir recours à la mobilisation et à la protestation afin de défendre leurs droits, en mobilisant les personnes directement concernées et en faisant plus largement appel au soutien de l'opinion publique ${ }^{71}$. En ce sens, par la création de campements permanents à Madrid et à Barcelone notamment, les indignés provoquèrent dans la société espa-

\footnotetext{
71. Charles TILLY, "Social movements and national politics », dans Charles BRIGHT et Susan HARDING (dir.), Statemaking and social movements: Essays in history and theory, Ann Arbor, University of Michigan Press, 1984, p. 306. Pour une critique de cette notion, cf. Olivier FILLIEULE, «Requiem pour un concept. Vie et mort de la notion de "structure des identités politiques" », dans Gilles DORRONSORO (dir.), La Turquie conteste, Paris, Éditions du CNRS, 2006, p. 201-218.
} 
gnole un "choc moral ", largement relayé par la presse écrite et les télévisions, qui créa un effet d'entraînement et favorisa la mobilisation de secteurs sociaux dépourvus de tradition militante ${ }^{72}$. Par l'envahissement, le blocage et l'occupation de nombreux espaces publics, des milliers d'Espagnols ont cherché à créer des espaces de débat qui puissent donner corps aux revendications des " sans voix".

D’autres indignés reprirent ensuite cette forme d'occupation médiatisée: sur la place Syntagma à Athènes, le boulevard Rothschild à Tel Aviv à l'été 2011 ou à travers le mouvement Occupy Wall Street qui occupa le parc Zuccotti à New York. Cette forme d'occupation de lieux publics n'est toutefois pas entièrement nouvelle, et se situe dans la lignée des campements et des villages alternatifs réunis par les mouvements altermondialistes dans les années $2000^{73}$. L'idée sous-jacente est d'inscrire un mouvement social dans la durée et dans un espace social donné, en cherchant à agir "ici et maintenant ", et en manifestant par la non-violence une opposition au système néolibéral et au dévoiement de la démocratie représentative. Par l'occupation collective de la Puerta del Sol, les manifestants ont généré une forme d'expressivité en affirmant la visibilité d'un groupe social, tout en mettant sur le devant de la scène publique des demandes sociales et politiques précises: dénonciation de la corruption des élites, de la responsabilité des banques et des entités financières dans la crise; opposition à la financiarisation de l'économie; lutte contre les expulsions locatives, les politiques d'austérité et les coupes budgétaires dans l'éducation et la santé; critique des organisations partisanes traditionnelles, de la loi sur les partis et du système politique issu de la constitution de $1978^{74}$.

L'impact du 15-M va bien au-delà des occupations et doit être compris à un niveau plus global, celui de la remise en cause des discours politiques dominants et de la prise de conscience de l'opinion publique espagnole. Les indignés ont contribué à questionner des "cadres d'interprétation " qui faisaient jusqu'alors consensus et ont proposé

72. James JASPER, The art of moral protest, Chicago, The University of Chicago Press, 1997; Youssef El CHAZLI, "Sur les sentiers de la Révolution. Comment des Égyptiens "dépolitisés" sont-ils devenus révolutionnaires? », Revue Française de Science Politique, vol. 62, n 5-6, 2012, p. 843-866.

73. Sur ce point, voir par exemple Éric AgRikoliansky, Olivier FILlieule et Nonna Mayer, L'altermondialisme en France. Genèse et dynamique d'un mouvement social, Paris, Flammarion, 2005.

74. Pour une revue de la littérature sur les mouvements des «indignés » et "Occupy », cf. Héloïse NEZ, «Indignados and Occupiers », dans Guya Accornero et Olivier FILLIEULE (dir.), Social movements studies in Europe: The state of the art, New York, Berghan Books, 2013, p. 115135. 
des idéaux politiques alternatifs ${ }^{75}$. Ils se sont attachés à rompre le cercle vicieux de la crise, du désespoir et de la lassitude, en redonnant de l'espoir aux citoyens par l'action collective et en promouvant l'idée que « Oui, c'est possible! ( (iSi se puede!) de changer les choses. La sociologie des mobilisations a bien montré qu'en période de routine politique, lorsqu'un domaine de politique publique fait l'objet d'un consensus, une coalition dominante d'acteurs impose son monopole sur l'interprétation de la réalité politique et sociale. La presse, les campagnes électorales, les médias (notamment télévisuels) sont autant de lieux et de moments où certains cadres d'interprétation dominent le traitement des problèmes publics ${ }^{76}$. Par l'action protestataire, les indignés ont promu de nouveaux slogans et arguments dans leurs manifestations et prises de position dans les médias, qui ont forgé ce que William Gamson dénomme des " contre-cadrages" de la réalité sociale et politique ${ }^{77}$. De nouvelles questions ont aussi été " mises sur l'agenda " (agenda setting) politique, par exemple l'idée d'une réforme de la constitution, la dénonciation des inégalités, du clientélisme et du manque d'indépendance de la justice ${ }^{78}$.

\section{Le développement de nouveaux répertoires d'action}

La crise économique et sociale a, de même, déterminé l'essor de nouvelles luttes, par exemple autour du droit au logement et de la résistance aux expulsions, qui ont débouché sur l'utilisation de répertoires d'actions collectives traditionnellement peu employés dans la société espagnole. En novembre 2010, à La Bisbal del Penèdes en Catalogne, des militants et de simples citoyens se réunirent ainsi devant le logement de Luis, un mécanicien au chômage, dont la banque CatalunyaCaixa voulait l'expulser. En alertant les journalistes, en manifestant devant son domicile, en dénonçant le comportement de la banque et en portant atteinte à son "image de marque ", ils réussirent à empêcher

75. La théorie des "cadres d'interprétation » a été formulée par David Snow et ses collègues, cf. David SNOw, Burke ROCHFORD, Steven WORDEN et Robert BENFORD, "Frame alignment processes, micromobilization and movement participation ". American Sociological Review, $n^{\circ}$ 51, 1986, p. 464-481; David SNow et Robert BENFORD, « Ideology, frame resonance and participant mobilization », dans Bert KLANDERMANS, Hanspeter KRIESI et Sidney TARROW (dir.), From structure to action: Comparing social movement research accross cultures, Greenwich, JAI Press, 1988, p. 197-218.

76. Daniel CEFAï, «La construction des problèmes publics. Définitions de situations dans des arènes publiques », Réseaux, vol. 14, n 75, 1996, p. 43-66.

77. William Gamson, Talking Politics, Cambridge, Cambridge University Press, 1992.

78. Philippe Blanchard, «Agenda », dans Olivier FILlieule, Lilian MATHIEU et Cécile PÈchu (dir.), Dictionnaire des mouvements sociaux, Paris, Presses de Sciences Po, 2009, p. 24. 
l'expulsion de Luis. À Madrid, le 15 juin 2011, cinq cents personnes se regroupèrent suivant le même procédé devant le domicile d'une famille bulgaro-libanaise dans le quartier de Tetuán, s'opposèrent physiquement à la police et empêchèrent son expulsion. L’usage réfléchi de la désobéissance civile et la médiatisation de ces actions eurent des effets immédiats, ce qui engendra peu à peu la structuration de la "Plateforme des affectés par l'hypothèque " (Plataforma de Afectados por la Hipoteca, PAH), d'abord à Barcelone et en Catalogne sous la direction d'Ada Colau et Adrià Alemany, puis dans le reste de l'Espagne. Sa campagne "Stop Desahucios ", en protestant par des sifflets et des regroupements et en cherchant à s'interposer face aux forces de police pour empêcher les expulsions a eu des répercussions importantes.

Photo 1.3 Action du collectif Flo6x8 ("Flamenco et Activisme »), devant une banque BBVA, Séville, 2011.

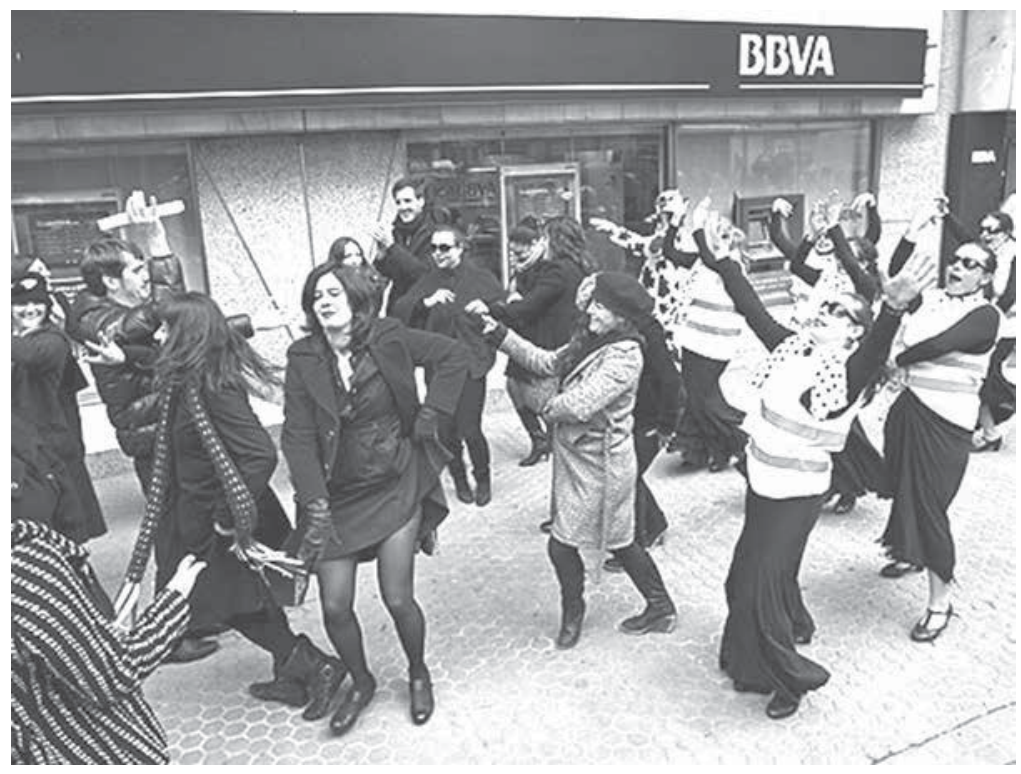

Les mobilisations collectives sous la forme d'attroupements et de protestations qui se sont déployées sur le lieu même de l'injustice dénoncée, selon un répertoire d'action qui rappelle les protestations paysannes, villageoises et les "charivaris " du milieu du XIX siècle étudiés par Charles Tilly, illustrent le renouveau de modes d'action 
anticonventionnels et de la désobéissance civile ${ }^{79}$. Cette tendance à la radicalisation des mouvements protestataires a été palpable lors des affrontements violents, le 23 mai 2012, entre les forces de police et les mineurs des Asturies et de Castille-et-León luttant contre le projet de fermeture de plusieurs mines et de réduction des aides au charbon. Mais il existe aussi beaucoup d'autres exemples illustrant l'essor de ces nouveaux répertoires d'action: ainsi, on peut citer les cris d'intimidation (" escraches") sous les fenêtres d'hommes politiques corrompus, les affrontements violents avec les forces de police (35 mises en détention, 64 blessés dont 28 hospitalisations) lors du mouvement "Occupe le Congrès " du 25 septembre 2012; ou encore, l'invasion du Parlement andalou en juillet 2014 par le collectif Flo 6x8, un groupe d'artistes qui danse, chante et repolitise le flamenco lors de performances exécutées dans des banques ou des lieux publics, en dénonçant en chansons les responsables de la crise ${ }^{80}$.

Comme l'analyse fort bien le sociologue Jésus Casquete, les rassemblements de masse comme les "marées ", les manifestations des indignés et les appels à l'occupation de lieux publics n'ont pas simplement eu pour fonction de résister à des programmes d'austérité ou de privatisations gouvernementaux ou locaux, mais ont aussi fonctionné comme « des opportunités de cimenter un groupe social " ${ }^{81}$. En faisant partager une cause commune aux participants, ces mobilisations ont créé un sentiment d'" effervescence collective " comme le disait Durkheim, chez de nombreux citoyens ${ }^{82}$. La fréquence des manifestations des dernières années a "renforcé la solidarité entre les groupes protestataires ", forgeant des rituels d'action collective et engendrant " un effet socialisateur permettant l'identification et l'adhésion " du plus grand nombre à des luttes communes ${ }^{83}$. De plus, les actions pro-

\footnotetext{
79. Charles TILLY, La France conteste de 1600 à nos jours, Paris, Fayard, 1986, p. 15-20.

80. Le mouvement «Occupe le Congrès » fut renommé « Entoure le Congrès » suite aux polémiques qu'il suscita, certains conservateurs parlant même d'un « mouvement terroriste ». Suite aux violences policières du 25 septembre, de nouvelles concentrations eurent lieu sur la Plaza de Neptuno près du Congrès dans les jours qui suivirent. Cet épisode déclencha une réaction du gouvernement, et inspira d'ailleurs le vote d'une nouvelle loi sur "les libertés publiques », qui criminalise les mouvements sociaux spontanés et facilite notamment la détention de personnes filmant les forces de police. Quant à lui, le collectif Flo6x8 regroupe des activistes de Séville. Pour avoir une idée de leurs performances, voir les vidéos disponibles sur leur site internet [http://www.flo6x8.com].

81. Jésus CASQuete, "The power of demonstrations », Social movement studies, vol. 5, $n^{\circ} 1$, 2006, p. 48.

82. Émile DURKHeIm, Les formes élémentaires de la vie religieuse, Paris, Alcan, 1912, p. 299-300.

83. Olivier FILLIEULE et Danielle TARTAKOWSKY, La manifestation, Paris, Presses de Sciences-Po, 2013, p. 106-107.
} 
testataires de nombreux secteurs de la société ont permis, à travers la sensibilisation et la mobilisation de l'opinion publique, de forcer les arènes institutionnelles et d'obliger les acteurs politiques à s'ouvrir à la discussion. En revendiquant de représenter la " majorité silencieuse ", les « $99 \%$ contre $1 \%$ ", les manifestants ont donné une représentation symbolique aux " citoyens d'en bas ", au " peuple » et à ses intérêts présentés comme mis à mal par une coalition d'élites politico-financières ${ }^{84}$. On peut donc parler d'une institutionnalisation de l'indignation dans l'Espagne contemporaine: d'un comportement minoritaire, porté essentiellement par les syndicats et les mouvements de chômeurs à partir de 2008, puis par les jeunes indignés en 2011, l'indignation s'est peu à peu diffusée au sein de la société espagnole, pour devenir majoritaire au sein des classes moyennes et populaires. Ces mouvements sociaux ont non seulement repolitisé la société espagnole, mais ils ont aussi ouvert la voie à l'émergence de nouvelles forces politiques et à une recomposition des équilibres électoraux dans les années à venir.

\section{COMPRENDRE LA CRISE DÉMOCRATIQUE ESPAGNOLE}

Dans le contexte de l'Espagne d'aujourd'hui, l'objectif de cet ouvrage collectif est donc de mieux comprendre les ressorts de la crise économique, sociale et politique du pays, en s'appuyant dans une perspective pluridisciplinaire, sur les regards croisés d'économistes, de politologues, d'historiens et d'hispanistes français et espagnols. Il s'agit à la fois d'étudier dans le détail les mécanismes et les effets de la crise sur la société et les institutions espagnoles, mais aussi de déceler les résistances et les mouvements sociaux qui ont émergé au cours des dernières années. Un accent particulier est ainsi mis sur leurs origines, leurs structures, leurs revendications et leurs contributions respectives au changement social et à l'évolution des discours politiques et des mentalités.

La première partie de l'ouvrage replace d'abord la problématique dans le contexte de la crise économique et du renouveau parallèle de la contestation. À partir de leur regard d'économistes, Elíes Furió Blasco, Matilde Alonso Pérez et Christel Birabent Camarasa étudient, chiffres à l'appui, le défi de la montée du chômage en s’intéressant à ses facteurs explicatifs, conjoncturels et structurels. Analysant avec précision la

84. Sur cette question du travail symbolique de représentation politique, cf. Pierre BouRDIEU, « La représentation politique. Éléments pour une théorie du champ politique », Actes de la recherche en sciences sociales, $\mathrm{n}^{\circ} 36-37,1981$, p. 3-24. 
réforme du marché du travail entreprise par le gouvernement conservateur, principale réponse à la crise des politiques publiques gouvernementales, ils montrent aussi que ses effets sont beaucoup plus limités que les conservateurs veulent bien le reconnaître. Alicia Fernández García s'intéresse ensuite au renouveau du mouvement républicain dans le contexte de l'abdication de Juan Carlos $\mathrm{I}^{\text {er }}$, en montrant à la fois le caractère rassembleur de la revendication de l'instauration d'une "Troisième République ", mais aussi la faiblesse du républicanisme en Espagne, et le lien des mobilisations récentes avec la défiance croissante à l'égard des élites politiques. Au moment même où les Espagnols étaient touchés de plein fouet par la montée du chômage et les programmes d'austérité, la crise de légitimité de la monarchie a débouché sur un renouveau des débats sociaux et politiques quant à l'apport potentiel du républicanisme au changement social. Déplaçant notre regard des questions économiques aux rapports de genre et aux enjeux sociétaux, Karine Bergès offre enfin une synthèse érudite de l'évolution des revendications et de l'éventail très large des mouvements féministes dans l'Espagne d'aujourd'hui.

La seconde partie du livre se focalise sur la radicalisation des revendications identitaires et l'essor de nouveaux mouvements sociaux. Mercè Pujol Berché s'intéresse à la trajectoire des mouvements indépendantistes catalans depuis la Diada de 2011, mais aussi dans le contexte historique plus large d'une croissance des demandes d'autonomie, et d'un retour de la question identitaire depuis le rejet des principales mesures de reconnaissance de la "nation " et de l'identité catalanes dans la ligne du statut d'autonomie de 2005. Mathieu Petithomme revient sur l'actualité du nationalisme basque radical dans le contexte de sortie de la lutte armée ouvert par le cessez-le-feu unilatéral de l'ETA en 2011. Il montre que ce secteur de la société basque s'articule autour d'un mouvement social très ancré et dispose de nombreux relais, et expose la structuration progressive d'un indépendantisme démocratique, qui s'appuie sur des partis politiques et des collectifs qui s'insèrent de plus en plus dans le jeu politique institutionnel. Sylvie Koller revient quant à elle sur le mouvement le plus emblématique des dernières années, celui des indignés et du 15-M, en précisant les logiques de sa structuration, ses principales revendications et son impact plus général sur le débat d'idées dans la société espagnole.

La dernière partie du livre déplace la focale des enjeux économiques et sociaux vers les questions politiques, institutionnelles et démocratiques. Mathieu Petithomme dépeint la structuration de la 
Plateforme des affectés par l'hypothèque (PAH) autour de la lutte contre les expulsions, un phénomène tout à fait nouveau dans l'histoire de l'Espagne contemporaine, et pleinement lié à l'éclatement de la " bulle " immobilière. Benoît Pellistrandi porte un regard d'historien sur la crise de légitimité de la monarchie espagnole, en se demandant dans quelle mesure l'accession au trône de Philippe VI pourrait permettre à la monarchie de redorer son blason auprès de l'opinion publique. Enfin, le dernier chapitre empirique revient sur l'émergence d'une nouvelle alternative politique, Podemos, une formation très critiquée par certains, qui prétend offrir un débouché politique à l'indignation citoyenne et à la crise des partis traditionnels. La conclusion de l'ouvrage propose un regard d'ensemble sur la crise économique et politique espagnole: au-delà de la récession et des drames sociaux et humains des dernières années, l'Espagne n'est-elle pas à un tournant historique, marqué par l'essor de nouvelles pratiques et alternatives politiques et par un renouveau de l'engagement citoyen? 

PREMIÈRE PARTIE

\section{DE LA CRISE ÉCONOMIQUE \\ AU RENOUVEAU DE LA \\ CONTESTATION SOCIALE}





\title{
2 \\ Le défi de la montée du chômage et la réforme du marché du travail
}

\author{
Elíes Furió BLASCO, Matilde ALONSO PÉREZ \\ et Christel BIRABENT CAMARASA
}

Lorsqu'il est fait référence aux causes du très fort taux de chômage espagnol, deux motifs sont habituellement mis en avant: tout d'abord la forte croissance des salaires, bien supérieure à celle compatible avec le pleinemploi du facteur travail dans un moment de crise [...] et également la " rigidité " excessive institutionnelle de notre marché du travail ${ }^{1}$.

La citation ci-dessus reflète la double réalité actuelle du marché du travail espagnol: une forte croissance du chômage qui touche, en valeur absolue, six millions de personnes. Sans conteste le pire problème socioéconomique du pays. Le diagnostic officiel considère les rigidités du marché du travail espagnol comme les causes principales du chômage. Ces rigidités empêcheraient une adéquation de l'emploi à la conjoncture économique. Cependant, la citation mise ici en exergue n'est pas tirée d'un ouvrage traitant de la situation actuelle du marché du travail espagnol et du diagnostic qui en est fait. Il s'agit du premier paragraphe de l'introduction du livre de Lluís Fina et Luis Toharia Cortés, Les causes du chômage en Espagne. Un point de vue structurel, publié en 1987. L'état du marché du travail et le diagnostic sont toujours les mêmes. Nous apportons ici quelques éléments complémentaires en ce sens.

En effet, depuis 2008, la "Grande Récession " a de nouveau démontré le caractère chronique du déséquilibre qui touche le marché du travail espagnol. Le taux de chômage, extrêmement élevé, est également beaucoup plus volatil que celui d'autres pays européens. Or, notre regard d'économistes nous mènera à démontrer ci-après que le taux de chômage élevé en Espagne n’est pas uniquement la conséquence de

1. Lluís FinA et Luis TOHARIA CORTÉs, Las causas del paro en España. Un punto de vista estructural, Madrid, Fundación IESA, 1987, p. 5. 
la crise économique. Sans minimiser l'ampleur de cette dernière, sa spécificité et sa large incidence sur le marché de l'emploi, il est important de rappeler que le chômage était certes moindre, mais déjà conséquent même en phase de croissance $^{2}$ (1993-2007). De plus, la situation aurait été la même dans les années 1960 si les presque deux millions d'Espagnols partis de chez eux en quête d'un emploi dans un autre pays européen avaient été comptabilisés. La croissance de l'emploi dans les années 1960 a été fort modeste eu égard à la croissance assez soutenue de l'économie, et l'émigration a diminué de façon mécanique les chiffres du chômage. La persistance du chômage en Espagne n'est donc pas conjoncturelle et ses causes non plus.

Le chômage est la préoccupation majeure des Espagnols; il a un impact décisif eu égard à l'élaboration d'un projet de vie. Selon un sondage du Centre de recherches sociologiques (CIS) de Madrid réalisé en octobre 2014, il représente le plus grave problème de la société espagnole pour $76 \%$ des gens, avant la corruption $(42,3 \%)^{3}$. L'évolution de l'emploi et du chômage, tout comme leur répartition, ont d'énormes répercussions économiques, sociales et politiques. Ainsi, la dégradation du marché du travail pousse les électeurs à sanctionner le parti au pouvoir. Sur le plan socio-économique, l'augmentation du chômage avec la crise a mis un frein aux changements qui étaient en train de se produire dans la sphère familiale. Il y avait une plus grande émancipation des jeunes, les liens familiaux s'étaient affaiblis, et le nombre de divorces et de séparations avait augmenté. Toutes ces transformations ont été paralysées suite à la crise économique, à la montée en flèche du chômage, à la diminution du pouvoir d'achat et l'augmentation de la pauvreté. L’augmentation des inégalités en Espagne fait partie des évolutions soulignées par Thomas Piketty dans ses études ${ }^{4}$. L'Espagne est redevenue un pays d'émigration nette pour motifs économiques, après de nombreuses années de croissance de l'immigration économique ${ }^{5}$.

2. Par exemple, lors de la crise de 1993, le chômage atteignait déjà 24,8 \%. De 1994 à 2007, il a ensuite diminué continuellement, mais hormis de 2005 à 2007, il n'a jamais été inférieur à $10 \%$. Cf. graphique 2.1 ci-dessous.

3. Sondage réalisé du $1^{\text {er }}$ au 13 octobre sur un échantillon de 2480 personnes représentatives de la population espagnole à travers des entretiens en face-à-face au domicile des enquêtés, CIS, Madrid, 2014.

4. Thomas PIKETty, Le capital au xxie siècle, Paris, Éditions du Seuil, 2013.

5. Matilde Alonso, Elíes Blasco et Christel BiRABent, Panorama de l'Espagne contemporaine, Ellipses, Paris, 2008, chapitre VIII. 
Dans ce chapitre, nous analyserons également le contenu de la réforme du marché du travail mise en œuvre en 2012 par le gouvernement de Mariano Rajoy, du Parti populaire. Selon le texte de la réforme, les causes du chômage résideraient dans le manque de flexibilité à l'embauche et au licenciement ainsi que dans le manque de correspondance entre les salaires, les conditions et la situation de l'entreprise. Il est bien entendu trop tôt pour évaluer l'efficacité de la réforme, mais certains éléments démontrent ses limites. La réforme cherche à augmenter la flexibilité interne des entreprises pour permettre une meilleure adéquation aux fluctuations économiques. Elle présente cependant des carences importantes à la fois en matière de lutte contre la dualité du marché du travail, de politiques actives d'emploi, d'amélioration de la productivité et de garanties sociales.

Nous présenterons d'abord l'ampleur du chômage et certaines de ses caractéristiques, puis nous analyserons ses causes en profondeur. Nous comparerons ensuite la situation espagnole à celle des autres pays européens, puis le contenu de la réforme du travail sera présenté en troisième section. Le chapitre se terminera enfin par une discussion sur les apports et les limites de cette réforme pour combattre le problème du chômage en Espagne.

\section{LE PROBLÈME DU CHÔMAGE EN ESPAGNE ET SES EXPLICATIONS}

\section{Un enjeu ancien, revenu sur le devant de la scène depuis 2008}

Le grand déséquilibre qui caractérise le marché du travail est l'un des problèmes les plus graves de l'Espagne. C'est le pays de l'Union européenne dont le taux de chômage est le plus élevé. Au second trimestre 2013, selon l'Enquête de population active publiée par l'institut national de statistiques (INE), on dénombrait 5977500 personnes en situation de chômage, c'est-à-dire 26,26 \% de la population active. Il est évident que la gravité du chômage est intimement liée à la crise économique nationale et internationale actuelle. Cependant, deux éléments doivent être pris en compte lors de l'examen du chômage en Espagne. Tout d'abord, le problème du chômage est structurel et systématique. Ensuite, il convient de noter que d'autres pays dans la même situation obtiennent actuellement de meilleurs résultats dans la lutte contre le chômage. 
Rappelons quelques chiffres en lien avec le premier motif afin de mettre en évidence le caractère structurel du déséquilibre du marché du travail espagnol. Pendant les années 1950-1960, un grand nombre d'Espagnols ont émigré vers d'autres pays européens (France, Allemagne et Suisse notamment) à la recherche d'un emploi ${ }^{6}$. Cette émigration (plus d'un million et demi de personnes selon certaines estimations) a permis à l'Espagne, lors du "boom économique " de la fin des années 1960 et du début des années 1970, de connaître une situation de quasi plein emploi ${ }^{7}$. Sans cette émigration l'augmentation des postes de travail grâce à l'industrialisation et à l'essor du tertiaire n'eût pas suffi. Ajoutons que pendant toutes ces années, la croissance démographique était importante, mais la " nouvelle population » était encore trop jeune et ne faisait donc pas encore pression pour entrer sur le marché du travail.

Le deuxième élément à prendre en compte pour démontrer le caractère structurel du chômage en Espagne est la situation de ce dernier pendant la récente période d'expansion économique. Entre le deuxième trimestre de 1993 et le deuxième trimestre de 2008, l'Espagne a vécu 60 trimestres (15 ans) de croissance économique ininterrompue alors que le chômage n'est pas descendu sous le seuil de 7,95 \% (premier trimestre 1997). Le deuxième trimestre de 1993 correspond au début de la reprise après la récession de fin 1992-début 1993. La récession actuelle a débuté en Espagne au troisième trimestre de 2008. Pendant cette longue période de croissance économique (1993-2008), le meilleur résultat relatif au marché du travail espagnol a été bien plus mauvais que celui de certains pays européens au plus fort de la "Grande Récession ". Par exemple, selon l'office européen de statistiques Eurostat, en avril 2013, le chômage en Allemagne ou en Slovaquie était inférieur à 6,4\%. En comparaison, comme le montre le graphique 2.1, du premier trimestre de 1980 au premier trimestre de 2005, le taux de chômage espagnol a été supérieur à $10 \%{ }^{8}$. Pendant les douze trimestres

6. On estime qu'environ deux millions d'Espagnols sont partis travailler en Europe. Cf. Carmen GonZÁLEZ ENRíaueZ, ¿Emigran los españoles?, ARI, Real Instituto Elcano, n 39, 18 septembre 2013.

7. Rappelons que pendant toute la décennie des années 1960, l'emploi a modestement augmenté de $0,6 \%$ par an, alors que la croissance réelle moyenne du PIB était supérieure à 7,5\% et le taux d'accroissement naturel de la population de l'ordre de 1,2 \%. Cf. Lluís FINA, « El paro en España: sus causas y la respuesta de la política económica », dans Lluís FINA et Luis ToHARIA CORTÉS, op. cit., Madrid, Fundación IESA, 1987, p. 23.

8. Pour une réflexion sur les causes générales du chômage en période de croissance voir Alice MougLIN, "Comment expliquer la persistance du chômage en période de relance? », Regards croisés sur l'économie, n 13, 2013/1, p 128-132. 
consécutifs postérieurs à cette dernière date, il a été inférieur à $10 \%$, avec un minimum de 7,95 \%. À partir du deuxième trimestre de 2008, il a de nouveau dépassé le seuil de $10 \%$ pour s'envoler jusqu'à $27,16 \%$ au premier trimestre de 2013 et diminuer légèrement début 2014. Si l'on considère que le taux de chômage frictionnel ${ }^{9}$, motivé par la rotation et la recherche d'emploi est d'environ $5 \%$, on peut enfin noter que depuis le premier trimestre de 1978, le marché du travail espagnol est toujours au-dessus de ce taux. Il s'agit donc d'un chômage structurel aux causes multiples.

Graphique 2.1. L'évolution du chômage en Espagne, 1976-2013 (\%)

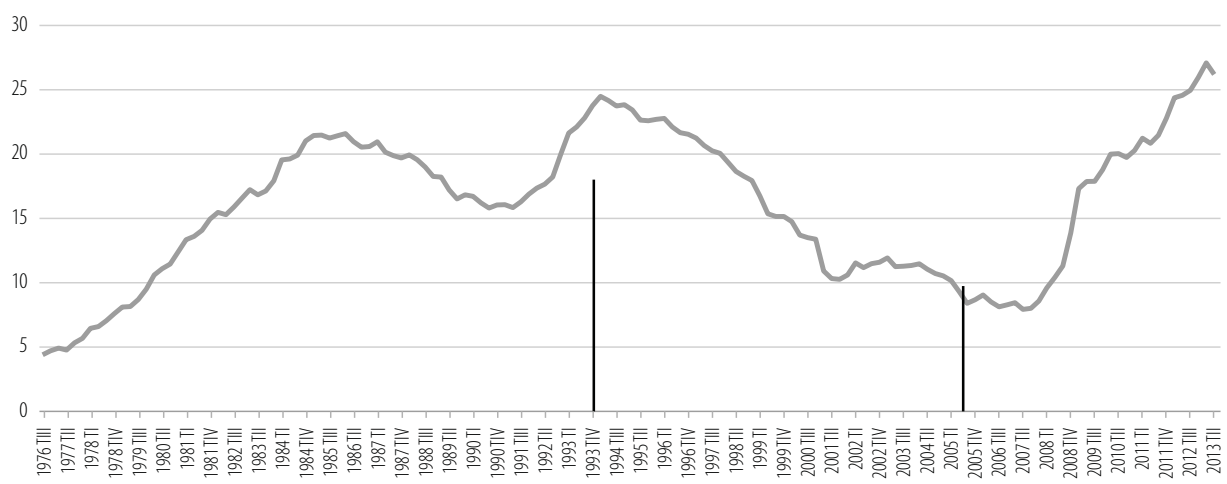

Élaboration personnelle des auteurs à partir de l'enquête de population active, INE, Madrid, [www.ine.es].

Le tableau 2.2 ci-dessous montre le lien étroit qui existe entre l'âge et le chômage en Espagne. Le taux de chômage des personnes âgées de 16 à 34 ans dépasse largement la moyenne nationale. La situation est tout particulièrement préoccupante pour la population de 16 à 19 ans, qui voit plus des deux tiers de sa tranche d'âge au chômage. Chez les jeunes de 20 à 24 ans, une personne sur deux est également au chômage. On notera que, parmi la jeunesse espagnole, la situation est un peu plus favorable aux femmes qu'aux hommes. Le niveau moyen de formation des jeunes femmes est supérieur à celui des jeunes hommes,

9. Le chômage frictionnel indique un chômage provoqué par le délai nécessaire à une personne pour trouver un autre emploi. Sont également causes de ce chômage les imperfections du marché du travail (absence de transparence, mauvaise diffusion de l'information, etc.). II est souvent présenté comme inévitable et peu compressible. 
ce qui explique en partie cette situation plus positive des femmes. En revanche, au fur et à mesure de l'avancement dans les groupes d'âge, le taux de chômage général diminue et la situation des hommes devient meilleure que celle des femmes. Cependant, nous verrons par la suite que, dans la période de crise actuelle, contrairement aux crises passées, la situation des femmes s'est proportionnellement moins dégradée que celle des hommes.

Tableau 2.2. Taux de chômage en Espagne par âge et par genre, 2006 et 2012 (\%)

\begin{tabular}{lcccccc}
\hline & \multicolumn{2}{c}{ Général } & \multicolumn{2}{c}{ Hommes } & \multicolumn{2}{c}{ Femmes } \\
\hline & 2006 & 2012 & 2006 & 2012 & 2006 & 2012 \\
\hline 16 à 19 ans & 29,0 & 72,6 & 23,7 & 72,0 & 36,5 & 73,5 \\
20 à 24 ans & 14,8 & 49,1 & 12,3 & 50,5 & 17,8 & 47,6 \\
25 à 29 ans & 10,2 & 32,2 & 8,0 & 33,9 & 12,9 & 30,3 \\
30 à 34 ans & 8,0 & 25,3 & 5,8 & 25,9 & 10,9 & 24,6 \\
35 à 39 ans & 7,1 & 22,0 & 4,9 & 21,0 & 10,2 & 23,3 \\
40 à 44 ans & 6,9 & 22,0 & 4,6 & 20,6 & 9,9 & 23,6 \\
45 à 49 ans & 5,8 & 21,2 & 4,0 & 20,2 & 8,3 & 22,2 \\
50 à 54 ans & 6,1 & 19,8 & 4,0 & 19,5 & 9,5 & 20,0 \\
55 à 59 ans & 6,1 & 18,8 & 5,0 & 18,7 & 8,3 & 19,0 \\
60 à 64 ans & 4,9 & 16,0 & 4,5 & 16,3 & 5,5 & 15,5 \\
65 à 69 ans & 2,0 & 4,8 & 2,0 & 5,3 & 2,0 & 4,3 \\
70 ans et plus & 0,7 & 1,2 & 0,2 & 0,2 & 1,8 & 2,6 \\
\hline Total & 8,5 & 25,0 & 6,3 & 24,7 & 11,5 & 25,4 \\
\hline
\end{tabular}

Élaboration personnelle des auteurs à partir de l'enquête de population active, INE, Madrid, [http://www.ine.es], 2012. Pour une meilleure lisibilité du tableau, les chiffres ont été arrondis à la décimale..

De plus, il existe un lien très clair entre le niveau de formation et le taux de chômage. Le chômage est plus élevé parmi les catégories dont le niveau de formation est le plus bas, et il diminue pour les personnes dont le niveau de formation est plus élevé. En 2012, le taux de chômage des personnes ayant achevé le cycle d'enseignement primaire - on parle ici des personnes qui n'ont pas réussi à terminer leur éducation secondaire obligatoire (13-14 ans en Espagne, 11 ans en France) - était de $37,54 \%$, en moyenne annuelle. En revanche, cette même année, pour la catégorie de personnes disposant d'une formation supérieure (sans doctorat) le taux de chômage était de 15,22 \%, bien inférieur à la 
moyenne nationale. Pour les personnes titulaires d'un doctorat, le taux de chômage était même inférieur à $5 \%{ }^{10}$.

Signalons cependant qu'en Espagne, deux problèmes opposés coexistent: l'échec scolaire et la surqualification. Le premier est principalement dû à l'abandon prématuré du système éducatif par des jeunes attirés par la forte demande de main-d'œuvre et les niveaux de salaires élevés du secteur du bâtiment pendant la phase d'expansion. Le problème de la surqualification tient quant à lui à deux raisons: l'offre et la demande de travail. En matière d'offre, il s'agit de l'arrivée sur le marché du travail de jeunes diplômés dans des domaines où l'emploi n'est pas systématiquement au rendez-vous. C'est le cas de nombreux diplômés universitaires en sciences sociales et humaines ainsi que de certaines formations d'ingénieurs. La demande est, quant à elle, liée à la structure productive, qui n'utilise pas certaines activités technologiquement avancées, ce qui ne permet pas à certains jeunes diplômés de trouver un emploi en Espagne. Il convient finalement de préciser que pendant la période d'expansion, le pays a connu une forte croissance économique, mais doublée d'une destruction d'emplois dans certains secteurs particuliers. La sous-partie suivante revient sur ces questions.

\section{Offre et demande de travail}

Tout d'abord, le schéma 2.3 ci-après montre les variables déterminantes de la croissance démographique. Pendant la période de croissance qui a précédé la "Grande Récession ", la population espagnole est passée d'une situation de quasi-stagnation à une forte croissance démographique due à un solde migratoire très favorable. En 1976, le taux d'accroissement naturel, à savoir la différence entre les naissances et les décès, était de 10,48 pour 1000 habitants. C'est à partir de ce moment-là que s'amorça une diminution drastique de ce taux, qui chutera à $0,16 \%$ on 1998 . Cette très forte diminution est la preuve d'une stagnation de l'accroissement due à la forte chute de la fécondité et de la natalité. En 1976, l'âge moyen de la maternité des femmes était de 28,51 ans, alors qu'en 2012 il était passé à 31,55 ans. L’augmentation de l'âge des femmes lors de la naissance de leur premier enfant réduit les possibilités de naissance d'un deuxième et d'un troisième enfant, et va en conséquence de pair avec une diminution de la fécondité et de la taille de la cellule familiale. En 1976, le taux de fécondité d'une

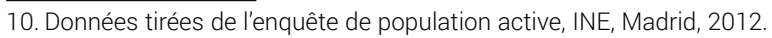


Schéma 2.3. Les facteurs de la croissance démographique

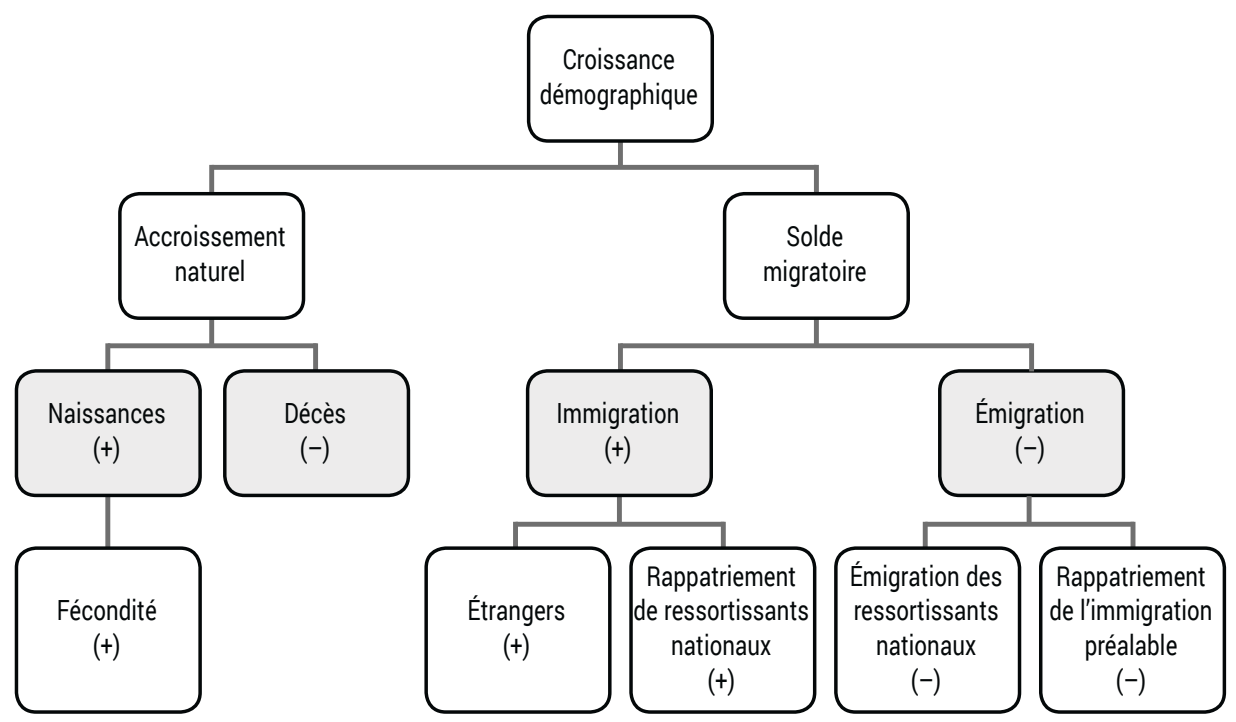

Élaboration personnelle des auteurs.

Espagnole de 28 ans était de 183,82 \% ${ }^{11}$. En 2012, la fécondité d'une femme espagnole de 28 ans était de 62,49\%o.

Cette tendance à la diminution des naissances s'est accompagnée d'une diminution significative de la mortalité. De fait, pendant de nombreuses années, le maintien de l'accroissement naturel a été dû à la diminution des décès plus qu'à l'augmentation des naissances. Une telle tendance démographique ne favorise donc pas l'arrivée sur le marché de l'emploi d'une plus importante "force de travail ", mais engendre plutôt une augmentation des populations dépendantes, notamment celle des plus de 65 ans, comme l'illustre le schéma 2.4 ci-après.

La situation de croissance naturelle presque nulle et de stagnation de la force de travail a été compensée par une forte augmentation

11. Le taux de fécondité est le nombre d'enfants nés vivants pour 1000 femmes de 15 à 49 ans (Enfants nés vivants/Femmes de 15 à 49 ans) x 1000 . Il est également calculé par groupes d'âge. 
Schéma 2.4. Population et offre de travail

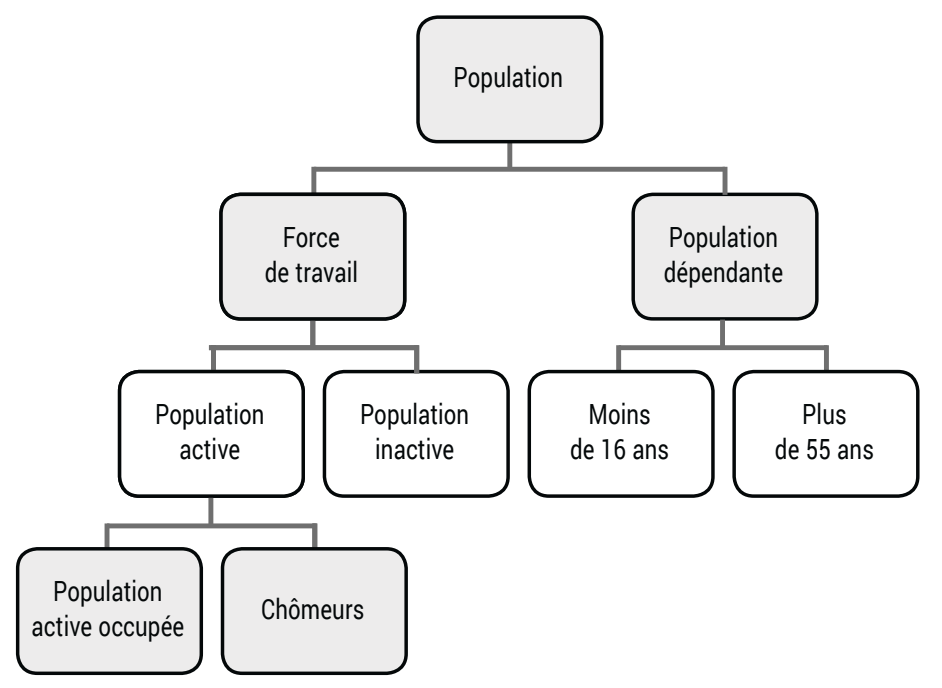

Source : élaboration personnelle.

du solde migratoire. Pendant la période de croissance économique, l'Espagne est devenue pour la première fois un pays récepteur d'immigration. En 1998, cette population représentait 1,6 \% de la population totale. Un pourcentage relativement bas par rapport aux $9 \%$ de l'Allemagne ou aux 5,4\% de la France en 1999. À cette époque, une proportion importante des immigrants était des Européens retraités qui s'étaient installés de manière permanente sur le littoral ou dans les îles espagnoles. En revanche, le début du $\mathrm{XxI}^{\mathrm{e}}$ siècle a vu une arrivée massive d'immigrants en Espagne pour des raisons économiques. Ils représentent désormais plus de $11 \%$ de la population espagnole. L'importance quantitative de ces immigrants est bien supérieure à celle d'autres pays européens ayant une grande tradition d'accueil pour motifs économiques, comme peuvent l'être l'Allemagne, la France ou le Royaume Uni (tableau 2.5). 
Tableau 2.5. Immigration en Europe (\% de population immigrée par rapport à la population totale) -

\begin{tabular}{rrrrrrr}
\hline & Allemagne & Irlande & Espagne & France & Italie & Royaume Uni \\
\hline 1998 & 9,0 & 3,0 & 1,5 & - & 1,7 & 3,6 \\
1999 & 8,9 & 3,0 & 1,6 & 5,6 & 2,0 & 3,9 \\
2000 & 8,9 & 3,2 & 2,0 & - & 2,2 & - \\
2001 & 8,8 & 3,9 & 2,9 & - & - & 4,5 \\
2002 & 8,9 & 7,1 & 3,8 & - & - & - \\
2003 & 8,9 & 6,1 & 5,3 & 5,6 & 2,7 & 4,7 \\
2004 & 8,9 & 5,3 & 6,5 & - & 3,4 & 5,0 \\
2005 & 8,8 & 6,0 & 7,8 & 5,8 & 4,1 & 5,2 \\
2006 & 8,8 & 10,9 & 9,1 & 5,6 & 4,5 & 5,7 \\
2007 & 8,8 & 10,5 & 10,4 & 5,8 & 5,0 & 6,0 \\
2008 & 8,8 & 12,6 & 11,6 & 5,8 & 5,8 & 6,6 \\
2009 & 8,8 & 9,9 & 11,6 & 5,9 & 6,5 & 6,8 \\
2010 & 8,7 & 8,6 & 11,6 & 5,8 & 7,0 & 7,0 \\
2011 & 8,8 & 8,1 & 11,4 & 5,9 & 7,5 & 7,2 \\
2012 & 9,1 & 10,6 & 11,2 & 5,9 & 7,9 & 7,6 \\
\hline
\end{tabular}

Source : élaboration personnelle à partir de

[http://appsso.eurostat.ec.europa.eu/nui/setupDownloads.do] (12/13)

Il s'agissait, nous l'avons dit, d'une immigration économique qui allait favoriser non seulement une croissance démographique, mais également une forte augmentation de la population active et de la population active occupée (schéma 2.4). C'était une population jeune, en âge de travailler, qui a augmenté la force de travail espagnole et qui recherchait activement un emploi, permettant par là-même à la population active de croître. Tout comme l'indique le tableau 2.6, en 1991, en Espagne, on dénombrait 23,4 millions de personnes en âge de travailler, et 30,4 millions en 2007. En proportion de la population totale, l'augmentation a été d'un peu plus de deux pour cent, mais la population active de 2007 comptait sept millions de personnes de plus (plus d'un tiers) qu'en 1991. Ceci suppose une forte hausse de l'offre potentielle de travail sur le marché du travail espagnol. " Potentielle " car seule une partie de cette offre cherche activement un emploi.

La recherche d'emploi a crû pendant cette période, tout comme le démontre le taux d'emploi, qui est passé d'un peu plus de $50 \%$ en 1991 à $59 \%$ en 2007. C'est cette augmentation sensible de la population active 
qui nous permet d'expliquer l'ampleur de la croissance économique et la non-diminution du niveau de chômage. Notons que le taux d'emploi a été particulièrement élevé pour les femmes, tout comme pour la population immigrante. Le tableau 2.6 nous permet d'observer que la crise n'a pas entraîné une diminution importante du taux d'emploi, contrairement aux crises précédentes. En pratique, l'ensemble de l'augmentation de la force de travail est passé à la population active occupée. En 1991, on dénombrait 13 millions d'actifs occupés en Espagne; en 2007, ils étaient plus de 20 millions, une hausse de plus de $50 \%$. En d'autres termes, alors que la force de travail a augmenté d'un tiers, l'emploi a augmenté de moins de deux tiers. La différence entre les deux a signifié une diminution du chômage de 700000 personnes. Pendant la période allant de 1991 à 2007, huit millions d'emplois ont été créés en Espagne. Mais pendant les cinq années suivantes, entre 2007 et 2012, plus de trois millions d'emplois ont été détruits.

Tableau 2.6. Force de travail, activité, population active occupée et chômage en Espagne

\begin{tabular}{|c|c|c|c|c|c|}
\hline & & 1991 & 1999 & 2007 & 2012 \\
\hline \multirow{2}{*}{ Force de travail } & 106 & 23,4 & 26,8 & 30,4 & 30,40 \\
\hline & $\%$ (population) & 65,2 & 67,1 & 67,8 & 66,40 \\
\hline \multirow{4}{*}{ Taux d'activité } & Total & 50,8 & 52,5 & 58,9 & 59,98 \\
\hline & Femmes & 34,7 & & 48,9 & 53,39 \\
\hline & Hommes & 68,0 & & 69,3 & 66,93 \\
\hline & Immigrants & & & 76,0 & 75,10 \\
\hline \multicolumn{3}{|r|}{1991} & 1994 & 2007 & 2012 \\
\hline \multicolumn{2}{|c|}{ Population active occupée (106) } & 13,0 & & 20,3 & 17,282 \\
\hline \multicolumn{2}{|r|}{ Chômeurs (106) } & 2,5 & 3,8 & 1,8 & 5,769 \\
\hline \multicolumn{2}{|c|}{ Taux de chômage (\%) } & 16,3 & 24,1 & 8,3 & 25,030 \\
\hline
\end{tabular}

Source : élaboration propre des auteurs à partir de l'INE, [www.ine.es].

Cette augmentation importante de la force de travail et de l'emploi pendant la période de croissance économique est allée de pair avec la transformation de la structure productive et active de l'économie espagnole. Le graphique 2.7 ci-dessous reprend la transformation de la structure de l'emploi en Espagne pendant la dernière étape de croissance et la Grande Récession. Trois séries de données sont représentées de 2001 à 2013 dans l'industrie manufacturière, le secteur du bâtiment et dans 
l'ensemble des secteurs économiques. La destruction des emplois qui a accompagné l'entrée dans la crise est clairement visible. Pour l'ensemble de l'économie, la destruction de l'emploi débute au troisième trimestre 2008. Dans le secteur du bâtiment, celui qui a généré le plus d'emplois et, a posteriori, le plus de chômage, la destruction commence au premier trimestre 2008. Le graphique 2.7 permet également d'observer que, y compris pendant les années de forte croissance économique et de création d'emplois, dans l'ensemble de l'économie espagnole et le secteur du bâtiment en particulier, le secteur industriel perdait des emplois. De fait, pendant la période de 28 trimestres qui vont du premier trimestre 2001 au premier trimestre 2008 (au cours duquel le secteur de la construction commence à perdre des emplois), l'activité industrielle n'a connu que cinq trimestres de création d'emploi, deux avec une variation nulle et 21 trimestres de pertes. La différence entre la valeur maximale et la valeur minimale de l'emploi industriel est de 281700 emplois perdus. Si on leur ajoute les 220800 emplois perdus par le secteur de l'agriculture, nous parvenons à 504200 emplois qui, s'ils avaient été conservés, auraient permis de situer le taux de chômage aux alentours de $5 \%$. Ainsi, sans la destruction de l'emploi industriel et agricole, le chômage espagnol aurait eu un caractère conjoncturel et non pas structurel.

Graphique 2.7. L'emploi en Espagne

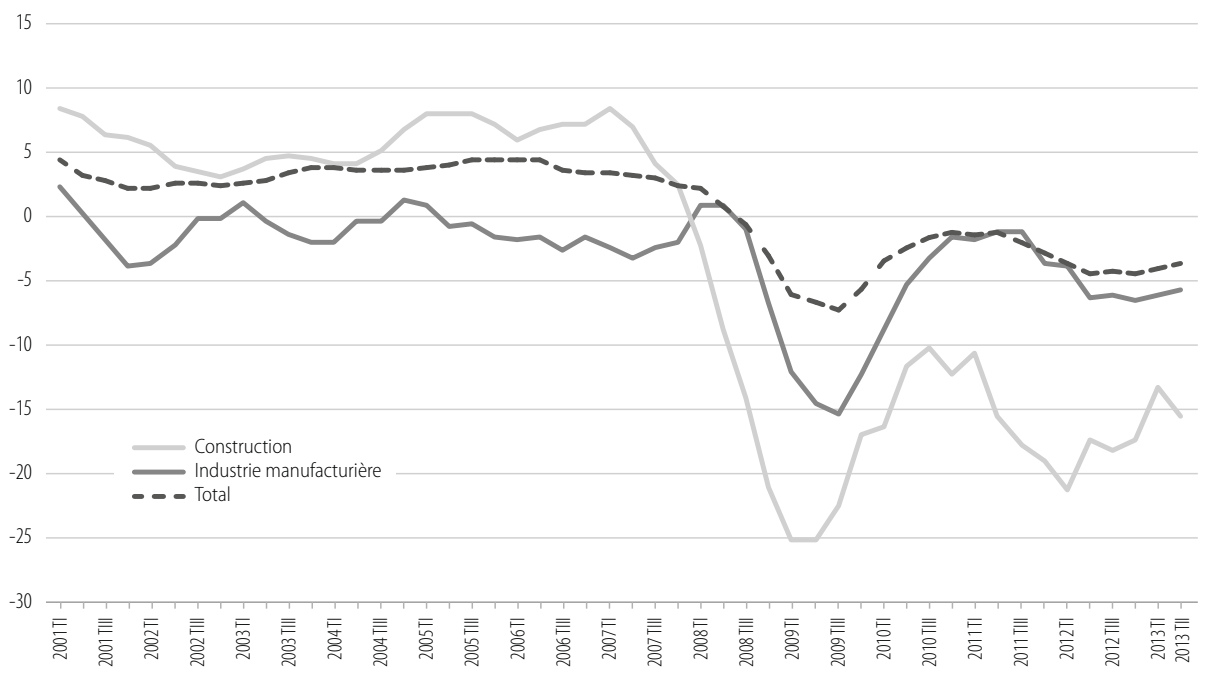


Cependant, le marché du travail espagnol est caractérisé par une proportion significative de chômage structurel. Le chômage est élevé, tant dans les périodes de crise grave (la phase actuelle) que dans celles d'expansion intense et continue (phase précédente). La période de croissance récente a été fondée sur l'expansion du secteur du bâtiment et le marché domestique. Ce dernier, nous l'avons vu dans les années 1960 et 1970, est trop réduit pour fournir suffisamment de croissance de l'emploi au bénéfice de toute la population espagnole. S'il est vrai que l'économie et les entreprises se sont internationalisées, notamment à partir des années 1990, ce phénomène n'a pas permis, pour différentes raisons, de créer des emplois. En revanche, d'autres pays plus petits que l'Espagne ont su combiner le marché national et l'extérieur pour développer une structure de production suffisant à répondre aux besoins de l'emploi national. Le marché du travail espagnol est atypique parmi les pays européens. Notons cependant que le marché du travail est fortement hétérogène en Europe et que les différents pays partagent peu de points communs. Avant d'étudier la réforme proposée par le gouvernement de Mariano Rajoy en 2012, penchons-nous d'abord sur les traits qui définissent l'hétérogénéité du marché du travail européen.

\section{L'HÉTÉROGÉNÉITÉ DU MARCHÉ DU TRAVAIL EUROPÉEN FACE À LA CRISE}

\section{Les points communs de l'Espagne avec le chômage en Europe}

$\mathrm{Au}$ plan européen, malgré certains points communs, le marché du travail a réagi à la crise économique de façon très hétérogène selon les pays. Les points communs sont dus aux traits démographiques du chômage. Le chômage est plus élevé chez les travailleurs au faible niveau de qualification, chez les jeunes et les personnes dépendant d'un contrat de travail temporaire. L'influence des contrats à durée déterminée sur l'augmentation du chômage est un mécanisme d'adaptation au cycle et à la saisonnalité des emplois. En conséquence, c'est la première catégorie touchée par le chômage lors d'un changement de phase de comportement de l'économie. Cependant, le degré de précarité du marché du travail dû à l'ampleur de ce type de contrat n'est pas le même dans toute l'Europe. Son impact quantitatif est donc différent selon les pays, même s'il convient de reconnaître qu'il s'agit d'un secteur très vulnérable. 
La situation des jeunes est très similaire. Malgré l'existence de grandes différences nationales, le taux de chômage dans cette catégorie est supérieur à la moyenne nationale de chaque pays. En 2011, les pays européens pour lesquels le chômage des jeunes était fort différent de la moyenne générale étaient la Grèce, l'Espagne, la Croatie et l'Italie. Dans tous ces pays, la différence était supérieure à vingt points. Alors qu'en Allemagne la différence était de 2,7 points et aux Pays-Bas de 3,2. La différence moyenne européenne (UE-27) était de 11,7 points, 13,3 pour la France. Le taux de chômage des jeunes des quatre premiers pays était supérieur à $40 \%$ pour l'Espagne et la Grèce; il dépassait $36 \%$ en Croatie et avoisinait les $30 \%$ en Italie. À l'opposé, le chômage des jeunes en Allemagne était de 8,6 \% et de 7,6 \% aux Pays-Bas. En France, il représentait $22 \%$ et la moyenne européenne (UE-27) $21,4 \%$. Cependant, si l'on considère le ratio de chômage des jeunes plutôt que le taux de chômage des jeunes, les résultats sont de meilleure qualité, mais une forte disparité persiste entre les pays ${ }^{12}$.

Pour les chômeurs de longue durée (chômage supérieur à 12 mois), la tendance européenne a été celle d'une augmentation tout au long de la crise économique, y compris avant celle-ci. En général, tout comme l'illustre le graphique 2.8, il existe un lien direct entre le déséquilibre général du marché du travail et le taux de chômage de longue durée. La Slovénie est le pays européen dans lequel le taux de chômage de longue durée est le plus important, suivi de l'Espagne, la Grèce, la Lettonie et l'Irlande. Le taux espagnol de chômage de longue durée est de $9 \%$, alors que la moyenne de l'UE-27 est de 4,1 \% et le taux français de $4 \%$.

En Espagne, selon les données de l'Enquête sur la population active (EPA) de l'INE pour l'année 2011, le chômage de longue durée représente environ la moitié du chômage total, alors que les personnes qui cherchent leur premier emploi représentent 8,5 \% des chômeurs. Ainsi, l'essentiel du problème du chômage espagnol est le chômage de longue durée (environ $50 \%$ en 2013, selon l'EPA). Environ un tiers des hommes chômeurs de longue durée ont moins de 30 ans, pour un quart des femmes (graphique 2.9). Le problème du chômage de longue durée en Espagne ne peut être résolu avec des solutions telles que la retraite anticipée, car il s'agit de personnes qui ont encore une vie professionnelle

12. Le ratio de chômage des jeunes est calculé sur la population d'un groupe d'âge (16 à 24 ans) indépendamment de leur situation, alors que le taux de chômage des jeunes est calculé sur la population active dudit groupe d'âge. Par exemple, les étudiants sont comptabilisés dans le ratio du chômage des jeunes et ils ne le sont pas dans le taux de chômage des jeunes. C'est la raison pour laquelle le taux de chômage est supérieur au ratio. 
de plus de 22 ans devant elles: 62,7 \% des hommes chômeurs de longue durée ont moins de 45 ans, 61,8 \% s'agissant des femmes.

Graphique 2.8. Chômage de courte et de longue durée en Europe (\%), 2011

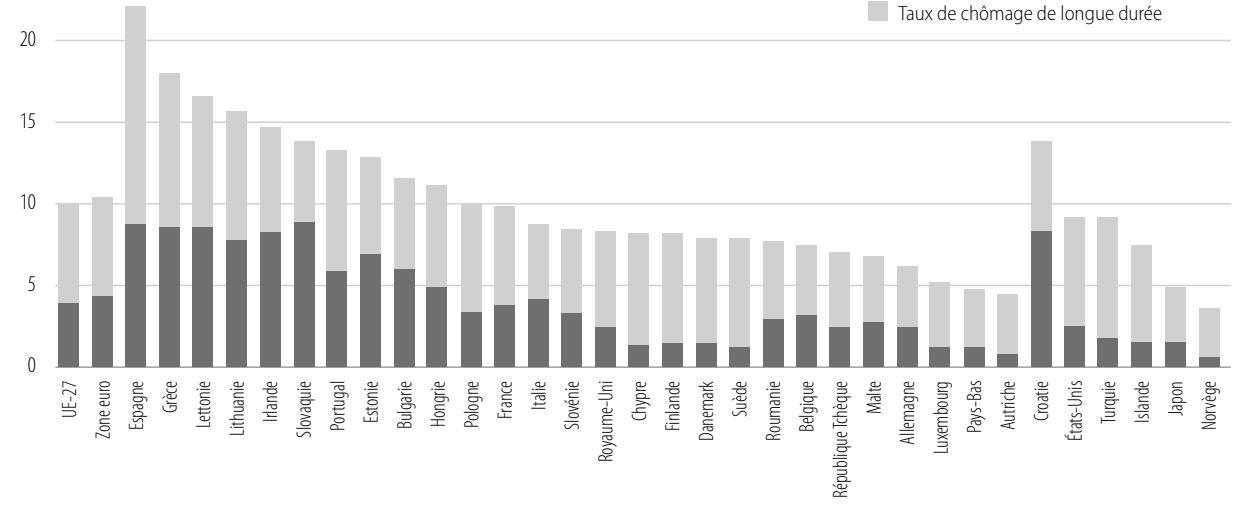

Source : élaboration à partir d'Eurostat, [http//epp.eurostat.ec.europa.eu] (18 octobre 2013).

Graphique 2.9. Le chômage de longue durée en Espagne, par âge et par genre (\%), 2010

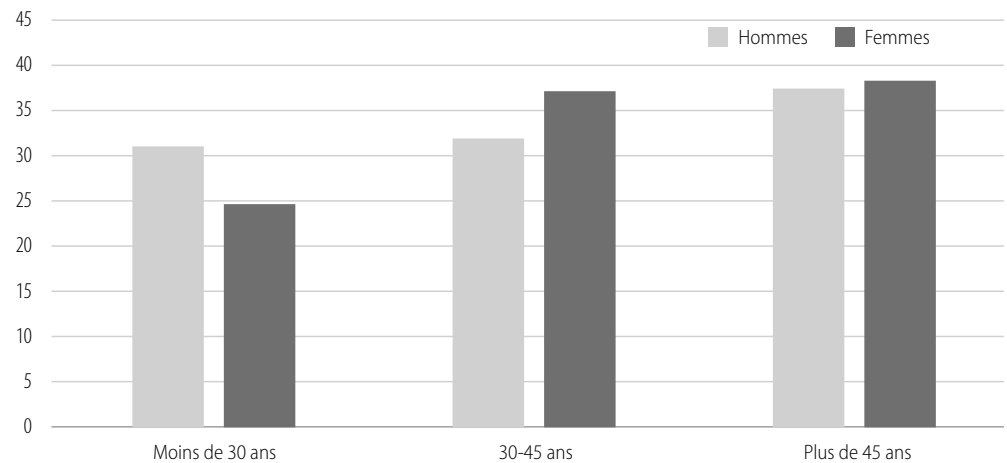

Source : Sara De La Rica, «Los desempleados de larga duración en España tras la crisis », [http://www.fedeablogs. net/economia/?p = 10248], 2011. 
Si le critère d'analyse est le niveau de formation, le chômage de longue durée touche des personnes occupant des postes de travail non manuels qualifiés (professionnels, techniciens, administratifs des groupes A-G): 45 \% de l'ensemble de ces chômeurs, selon les données de Sara de la Ric). L'autre catégorie importante est composée de chômeurs qui occupaient des postes de travail manuels non qualifiés (40\%). En moyenne, 40 \% du chômage de l'UE-27 correspond à un chômage de longue durée. Ce pourcentage prouve l'existence de causes structurelles, telles que les carences de formation et de compétences, la noncorrespondance entre la formation initiale et l'évolution des besoins des métiers, ainsi que le manque de formation continue et d'adaptation du capital humain aux besoins de l'économie. Le chômage de longue durée a un énorme coût social et économique pour un pays. Cependant, dans de nombreux pays tels que l'Espagne, l'action gouvernementale se concentre sur les conditions d'embauche et de licenciement, ainsi que sur la diminution des prestations chômage en tant qu'instruments de promotion de la réinsertion professionnelle de cette catégorie ainsi que pour inciter les chômeurs à chercher et à accepter les emplois qui leur sont proposés.

\section{Le chômage européen}

Le graphique 2.10 démontre que l'impact de la crise économique sur le marché du travail des pays européens a été très hétérogène: alors que dans la plupart des pays, le chômage a augmenté et à des rythmes différents, certains pays ont affiché des baisses. En 2007, le taux de chômage de la zone euro était de 7,6 \% et de 10,1 \% en 2011. Les pays européens dans lesquels le taux de chômage a augmenté le plus rapidement sont l'Irlande, l'Espagne et la Grèce, dont les taux ont été multipliés par 2,5, voire triplés dans le pire des cas. Entre 2007 et 2011, le taux de chômage en Irlande est passé de $4,6 \%$ à $14,4 \%$, de $8,3 \%$ à $21,7 \%$ en Espagne et de $8,3 \%$ à $17,7 \%$ en Grèce. En revanche, le chômage a diminué en Allemagne, il est resté stable en Autriche et aux Pays-Bas, et il a légèrement augmenté en France pendant la même période.

Cette disparité ne peut être totalement attribuée aux conséquences différentes de la crise dans les économies européennes. La crise économique ne peut être la cause unique d'augmentation du chômage en Espagne. Il existe d'autres facteurs, dont certains sont liés aux caractéristiques de la crise (et non à son ampleur) et d'autres à la réponse que les pays ont apportée à la diminution de la demande de travail. Cet ensemble de facteurs permet d'expliquer pourquoi un même niveau de 
contraction de l'économie entraîne plus de chômage en Espagne qu'en Allemagne, par exemple. Tout d'abord, depuis le début de la présente crise européenne, il s'avère que le chômage est plus important dans les pays qui ont fondé leur croissance sur la demande interne, ce qui est le cas de l'Espagne, que dans les pays dont le moteur de croissance est l'exportation, comme l'Allemagne. Les calculs permettent d'estimer une élasticité 3,6 fois supérieure dans les premiers pays à ce qu'elle est dans les seconds ${ }^{13}$.

Graphique 2.10. Impact de la crise sur le marché du travail européen (base 2007)

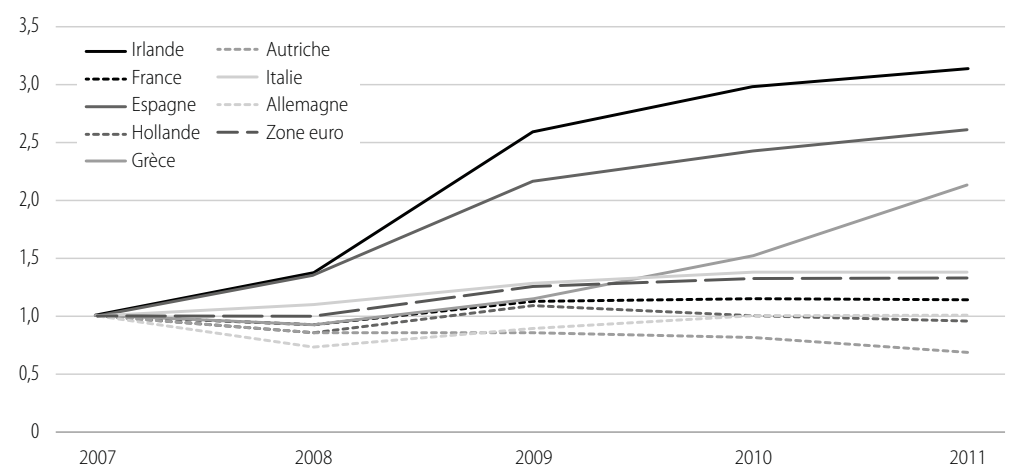

Source : élaboration propre des auteurs à partir d'Eurostat, [http://epp.eurostat.ec.europa.eu] (18 octobre 2013).

Dans un deuxième temps, selon les pays, l'adéquation de la demande de travail aux moindres niveaux de production suite à la crise économique a été faite en adaptant la force de travail ou en diminuant les heures de travail. Ainsi, en Allemagne et en Autriche, la diminution du temps de travail a permis d'ajuster l'emploi à la mauvaise conjoncture, alors qu'en Espagne c'est le nombre d'employés qui a été ajusté ${ }^{14}$. La conséquence est une plus grande augmentation du chômage dans le dernier cas. Malgré la portée globale de la crise, ses conséquences ont été différentes selon les activités et elles ont été particulièrement graves

13. Cristina FERNÁNDEZ et Mario IZQUIERDo, «El ajuste de los mercados laborales europeos desde el inicio de la crisis », Boletín Mensual del Banco de España, octobre 2013, p 45-55.

14. Le chômage a beaucoup augmenté aux États Unis et également en Suède pendant la crise. Cependant, cette augmentation est bien plus faible qu'en Espagne pendant la même période. Voir Christel GILLES et Jean-Paul NicoLAl, « L'ajustement de l'emploi durant la crise dans huit grands pays industrialisés », Regards croisés sur l'économie, n¹3, 2013/1, p 112-127. 
dans des secteurs tels que la construction et l'immobilier. Les secteurs touchés par la crise n’ont pas été les mêmes selon les pays européens, ce qui explique les conséquences différentes sur le chômage. En Espagne, le secteur de la construction était surdimensionné par rapport à sa taille dans les autres pays européens, ce qui explique l'impact majeur de la crise. Mais il sera également plus difficile de créer de nouveaux bassins d'emploi, car l'économie nécessite un changement de grande envergure.

En outre, dans les pays comme l'Espagne, où la population a perçu que la crise était particulièrement grave et qu'elle allait persister, l'augmentation du chômage a été plus importante. La perception d'une grave crise a transformé les habitudes de comportement social de la population. La consommation a eu tendance à se contracter et à provoquer une chute plus importante de l'activité et de la demande de travail. Si, à ces conditions défavorables, nous ajoutons un fort degré d'endettement des familles et des entreprises, la contraction de la consommation et des investissements à des fins préventives est encore plus compréhensible. Étant donné la réponse fortement distincte du marché du travail espagnol face à la crise et à la persistance d'un fort composant de chômage structurel, il convient à présent d'analyser la politique économique appliquée par le gouvernement de Mariano Rajoy pour faire face jusqu'à la fin de 2013.

\section{LA RÉFORME DU MARCHÉ DU TRAVAIL EN ESPAGNE: UNE POLITIQUE EFFICACE DE LUTTE CONTRE LE CHÔMAGE?}

\section{Politique économique générale et réforme du travail}

Dans un contexte de fortes coupes budgétaires, le gouvernement conservateur de Mariano Rajoy a envisagé la réforme du marché du travail comme la seule action possible afin de remédier au grave problème du chômage. Les restructurations budgétaires ont consisté en des diminutions des dépenses publiques et des augmentations d'impôts obérant le pouvoir d'achat des Espagnols. Ces derniers ont réduit leurs niveaux de consommation et d'investissement. Cette situation, unie à la diminution des dépenses publiques, a entraîné une forte contraction de la demande intérieure. Le tarissement des crédits à destination des entreprises et des familles a encore accentué ce phénomène. Dans le schéma de politique économique choisi par le gouvernement Rajoy, 
l'objectif prioritaire avoué est la diminution du déficit public. Cet objectif macroéconomique est prioritaire par rapport à toute autre considération de politique économique ou générale. Selon le raisonnement gouvernemental, la réduction du déficit public est une condition nécessaire pour que le pays puisse atteindre d'autres objectifs, tels que par exemple, la reprise de l'activité économique et des emplois. Dans le domaine de l'emploi et de la lutte contre le chômage, la réforme fiscale semble être une étape préalable et nécessaire mais pas une condition suffisante. Selon les projets du gouvernement, une réforme structurelle du marché du travail espagnol est nécessaire. Cette nécessité peut difficilement être mise en doute si nous tenons compte de la situation qui vient d'être décrite ci-dessus. En revanche, la nature même de la réforme est une question bien plus sujette à débat et à polémique, tant sur le plan technique que politique. Il ne s'agit pas ici de lancer un débat contrefactuel, mais il est nécessaire de décrire le contenu de la réforme du gouvernement Rajoy et d'évaluer ses conséquences sur le marché du travail pour établir dans quelle mesure elle est ou non une arme contre le chômage.

\section{Le contenu de la réforme du travail}

Le décret-loi $n^{\circ}$ 3/2012 du 10 février 2012 prenant des mesures urgentes pour la réforme du marché du travail, publié au Bulletin officiel de l'État (BOE) du samedi 11 février, reconnaît ouvertement que le marché du travail espagnol présente de graves déséquilibres, notamment concernant les jeunes et les chômeurs de longue durée ${ }^{15}$. Pour le gouvernement, la gravité de la situation du chômage en Espagne exigeait une réforme urgente du marché du travail ${ }^{16}$. Le contenu de la réforme peut être schématisé en trois parties: une première partie relative à la négociation collective, une deuxième portant sur les coûts et les procédures de licenciement, et une troisième relative aux modalités d'embauche (schéma 2.11).

\footnotetext{
15. Boletín Oficial del Estado, 11 février 2012, n 36, Sec. I. Pág. 12 485, [http://www.boe.es/ boe/días/2012/02/11/pdfs/BOE-A-2012-2076.pdf].

16. La forme juridique de la réforme est un décret-loi. Ce type de texte, conformément au cadre juridique espagnol, est une norme ayant force de loi qui peut être dictée par l'exécutif en cas de nécessité extraordinaire ou d'urgence. Les décrets-lois ont un caractère provisoire: une fois dictés, ils devront être soumis au vote du Congrès des députés; ce dernier pourra les valider, les abroger ou permettre leur examen en tant que loi ordinaire urgente. Le caractère d'urgence et de nécessité extraordinaire d'adoption de la réforme du travail ne provenait pas des difficultés du marché du travail, mais plutôt de la pression des marchés financiers et des autorités européennes, tels la Banque centrale européenne et le Fonds monétaire international.
} 
Schéma 2.11. La réforme du Travail de 2012

Négociation collective
- Décentralisation des conventions
- Mobilité géographique
- Mobilité interne
- Assouplissement de la négociation

Coûts et procédures de licenciement

- Motifs économiques de licenciement

- Indemnisations pour licenciement abusif

- Suppression de l'autorisation administrative

- Suppression de l'obligation de payement jusqu'à la décision judiciaire

Modalités d'embauche
• Embauche
• Contrat d'aide à l'emploi
- Contrat de formation et d'apprentissage
- Entrat à temps partiel
- Médiation
- Agencenen de placement de contrats temporaires
- Entreprises de travail temporaire

En matière de négociation collective, la réforme pousse à un grand changement et modifie le lien entre les forces en présence en diminuant la capacité d'intervention des syndicats. Sont concernées les questions relatives au niveau de négociation, à la flexibilité interne et à l'assouplissement des négociations. La réforme est favorable à une décentralisation des domaines de négociation collective pour les rapprocher davantage de la situation des entreprises. Les conventions d'entreprise seront plus à même d'intégrer la véritable situation de celles-ci, d'adapter les niveaux de salaire de base et les compléments, la rétribution des heures supplémentaires et le temps de travail. 
En matière de flexibilité interne, il est davantage loisible de ne pas appliquer les conditions adoptées dans les conventions. Les motifs pour lesquels l'entreprise peut imposer la mobilité géographique sont assouplis; l'intervention de l'autorité de travail n'est plus nécessaire; enfin, en accord avec les représentants syndicaux, il est possible d'établir des ordres de priorité pour certains collectifs (travailleurs ayant charge de famille, dépassant un certain âge, etc.). En matière de mobilité interne, la main-d'œuvre n'est plus inscrite dans une "catégorie professionnelle " mais dans un "groupe professionnel ", qui englobe les aptitudes professionnelles, les diplômes et le contenu général de la prestation, ce qui signifie un élargissement des possibilités de mobilité interne. L'assouplissement des conventions collectives tient à mettre fin à ce que l'on appelle «l'ultra-activité ». Il est mis fin au renouvellement automatique de la convention existante par manque d'accord lors des négociations d'une nouvelle convention. Après la réforme, c'est celle de niveau supérieur qui s'appliquera.

En matière de coûts et de simplification des procédures de licenciement, la réforme contient une redéfinition des motifs de licenciement économique, un nouveau traitement des indemnités de licenciement, ainsi que la suppression de l'autorisation administrative. En ce qui concerne la révision des causes objectives de licenciement, le texte du décret-loi entend par licenciement collectif la rupture des contrats de travail fondée sur des motifs économiques, techniques, organisationnels ou de production lorsque, sur une période de 90 jours, la rupture concerne au moins: a) dix salariés, dans les entreprises de moins de cent employés; b) $10 \%$ des employés de l'entreprise dans le cas de celles de cent à trois cents employés; et c) trente employés dans les entreprises de plus de trois cents employés. D’une part, on considère que divers motifs économiques sont réunis lorsqu'une situation économique négative ressort des résultats de l'entreprise, en cas d'existence de pertes actuelles ou prévues, ou de la diminution persistante de son niveau de revenus ou des ventes. En tout état de cause, on considère que la diminution est persistante si elle se poursuit pendant trois trimestres consécutifs.

D'autre part, des motifs techniques sont réunis lorsque des changements se produisent, entre autres, dans le domaine des moyens ou des outils de production; les motifs organisationnels sont réunis lorsque des changements se produisent, entre autres, dans le domaine des systèmes et des méthodes de travail du personnel ou dans le mode d'organisation de la production; les motifs productifs sont réunis lorsque des 
changements se produisent, entre autres, dans la demande de produits ou de services que l'entreprise prétend placer sur le marché. Enfin, on considère également comme licenciement collectif la rupture des contrats de travail qui touchent l'ensemble des effectifs de l'entreprise, lorsque le nombre de salariés est supérieur à cinq, si le licenciement se produit en conséquence de la cessation totale de l'activité de l'entreprise fondée sur les mêmes motifs que précédemment (art. 51.1) ${ }^{17}$. En outre, la possibilité de licencier pour motifs économiques, techniques, organisationnels et de production est étendue au personnel de service dépendant du secteur public.

S'agissant des indemnités pour licenciement abusif, elles passent de 45 jours par année travaillée avant la réforme à 33 jours après celleci. Le nombre maximum de mensualités passe de 42 à 24 . En outre, le besoin d'autorisation administrative pour les licenciements collectifs est supprimé, tout comme l'obligation de l'entreprise de payer le préavis entre le moment de notification du licenciement et celui de la résolution judiciaire. Cette suppression des salaires de préavis ne se fera pas si l'employé est réembauché ou s'il s'agit d'un représentant du personnel. Une nouvelle modalité de licenciement collectif est également créée.

En matière de nouvelle embauche, différents cas de figure sont envisagés. Le premier est celui du nouveau contrat indéfini de soutien d'aide à l'emploi. Cette solution peut être utilisée par les entreprises de moins de 50 employés; le contrat est de type indéfini, à temps complet et prévoit une période d'essai d'un an. Celle-ci bénéficie de nombreux avantages fiscaux. L'employé peut percevoir 25 \% des prestations chômage en plus de son salaire. Ce contrat doit être conservé pendant au moins trois ans. La deuxième solution est le contrat de formation et d'apprentissage, pour les moins de trente ans. À l'expiration du contrat, l'employé ne pourra être embauché sous cette forme par la même entreprise ou par une entreprise différente pour la même activité ou la même fonction objet de la qualification professionnelle associée au contrat. Il pourra en revanche être embauché dans les mêmes conditions pour une formation différente. Le temps de travail ne pourra être supérieur à $75 \%$ pendant la première année et à $85 \%$ les deuxième et troisième années. Ce type de

\footnotetext{
17. II est obligatoire de verser une somme au Trésor public lorsque le licenciement collectif touche plus de cinquante employés, que l'entreprise a plus de 500 employés, que des employés de plus de 50 ans sont touchés et que l'entreprise (ou groupe d'entreprises auquel elle appartient) a dégagé des bénéfices lors des deux exercices précédant celui du plan social, cf. BOE-A-2011-10286, Ministerio de Trabajo e Inmigración. [http://www.boe.es/diario_boe/txt. php?id=BOE-A-2011-10286].
} 
contrat bénéficie d'importantes réductions pouvant aller jusqu'à $100 \%$ des cotisations. La troisième modification du contrat de travail tient à la possibilité de réaliser des heures supplémentaires en cas de contrat à temps partiel. La quatrième modification concerne la possibilité d'enchaîner sans limite les contrats à durée déterminée. D’autres modifications à des contrats préexistants sont également prévues.

\section{LA RÉFORME DU TRAVAIL ET LE PROBLÈME DU CHÔMAGE: OBSERVATIONS FINALES}

Il est difficile, au moment où nous rédigeons ces lignes, d'évaluer la capacité de la réforme du travail à contribuer à la réduction du chômage, tout d'abord parce qu'il s'est écoulé peu de temps depuis sa mise en œuvre, et également parce que l'économie espagnole ne s'est pas encore remise de la récession. En outre, le décret-loi, comme nous l'avons dit, modifie le rapport de force entre les agents sociaux et, dans un domaine sujet à négociation, il est encore trop tôt pour voir comment les uns et les autres, entreprises et syndicats, vont redéfinir leurs stratégies de négociation. Notons également que certains aspects de la loi peuvent avoir des conséquences inattendues. Par exemple, la simplification et la diminution des coûts des procédures de licenciement peuvent conduire à une nouvelle ou une plus forte judiciarisation des licenciements. En effet, l'élimination des indemnités de préavis est dissuasive, mais la possibilité de recevoir 33 jours d'indemnités pour licenciement abusif plutôt que les 20 jours habituels, peut permettre de compenser la perte de ces indemnités et conduire à une augmentation des cas portés devant les tribunaux.

Il existe d'autres sources d'effets collatéraux. En effet, la situation actuelle de l'économie espagnole ne reflète pas de baisse du chômage, alors que les salaires, eux, ont diminué. La réforme du travail permet d'adapter les conditions de travail à la situation particulière des entreprises et favorise selon le patronat un ajustement équilibré entre les salaires, l'emploi et la journée de travail. La réforme va plus dans le sens des revendications du patronat que de celles des salariés. Mais il en a résulté une diminution des emplois tant dans le secteur privé que dans le public.

Les études empiriques en économie nous permettent de comprendre les limites de l'approche présentée par la réforme. Depuis la fin des années 1970, l'étude classique de S. Nickell a permis de montrer 
qu'il n'existe en fait pas de relation causale directe entre les coûts de licenciement et le taux de chômage moyen ${ }^{18}$. Lorsque les coûts sont réduits, les entreprises licencient aisément et, ainsi, le coût de l'embauche est également diminué puisque, en cas d'éventuelle restructuration des effectifs à l'avenir, le processus sera moins onéreux. Cette situation permet certes aux entreprises de commencer à réembaucher dès qu'elles considèrent que la reprise économique est entamée, mais aussi de licencier au premier symptôme de crise. En conséquence, la fréquence d'entrée et de sortie des salariés du marché du travail risque d'augmenter, mais il n'y a toutefois aucune garantie qu'à moyen terme le taux de chômage diminue. Le chômage de longue durée peut diminuer si et seulement si cette population n'a pas, entre-temps, perdu une partie de ses compétences.

Mais le même argument peut également agir dans le sens contraire. Lorsque les coûts de licenciement sont plus élevés, les entreprises sont généralement plus réticentes à embaucher. Elles n'embauchent pas tant qu'elles ne sont pas totalement convaincues que la croissance de leur portefeuille de commandes sera durable dans le temps. Cependant, elles ne licencient pas non plus dès la première manifestation d'un changement de cycle. Elles préfèrent souvent stabiliser leurs effectifs, puisque l'effet net sera un emploi plus stable. Dans ce cas, il est plus probable que les entreprises cherchent à faire face à la chute de leur activité en ajustant les heures et les journées de travail de leurs salariés plutôt que les emplois. Le chômage augmentera moins et, en règle générale, la masse salariale diminuera moins, tout comme la consommation des ménages. Ainsi, l'effet multiplicateur du chômage sur la demande intérieure et le niveau de production sera moins important. Dans ce cas, où les coûts de licenciement sont plus élevés, il est certain que les entreprises embaucheront moins même pendant les phases de croissance. Elles seront cependant plus enclines à tenter d'augmenter la production par la productivité et l'amélioration technico-organisationnelle.

Certains auteurs ont démontré que les effets des coûts de licenciement sur la création d'emploi dépendent de la technologie, des perturbations économiques et des négociations entre les syndicats et les entreprises $^{19}$. Il a également été démontré que les coûts de licenciement

18. S. NICKELL, "Fixed costs, employment and labour demand over the cycle », Economica, $n^{\circ} 45,1978$, p 329-345.

19. Samuel BentoliLA et Guiseppe BertolA, «Firing costs and labour demand: How bad is Eurosclerosis? ", Review of Economic Studies, vol. 57, n³ 3, 1990, p. 381-402 ; Lars LJUNGaviST, "How do lay-off costs affect employment », Economic Journal, n 112, 2002, p 829-853. 
discriminent certains employés par rapport à d'autres, qu'ils bénéficient à certains et portent préjudice à d'autres. La diminution des coûts de licenciement et la simplification de la procédure ne semblent donc pas la meilleure façon de gommer la dualité du marché du travail, avec son nombre élevé de contrats à durée déterminée. Mais la solution la plus rapide afin de limiter la temporalité est de réduire la possibilité d'enchaîner lesdits contrats. L'absence de restrictions en la matière génère une dualité sur le marché du travail espagnol. Ainsi, pendant la période d'expansion, un peu moins des deux tiers des contrats de travail étaient à durée indéterminée et un peu plus d'un tiers étaient à durée déterminée. Certains auteurs soutiennent, à propos de cette dualité, que la réduction des coûts de licenciement des contrats à durée indéterminée permettra de réduire la dualitée ${ }^{20}$.

Mais la cause de cette dualité n'est pas le contrat à durée indéterminée, c'est l'enchaînement de contrats à durée déterminée pour des postes de travail et des employés qui ne sont pas temporaires. Il conviendrait, en toute logique, d'agir sur la cause pour diminuer la dualité du marché du travail. Les contrats à durée déterminée sont et seront toujours le mécanisme le plus immédiat d'ajustement de l'entreprise à la conjoncture économique. Cependant, le renouvellement excessif des effectifs suppose un coût pour l'employé et pour l'entreprise, surtout lorsque le but recherché est, à moyen terme, l'augmentation de la productivité et de la qualité de production. Remplacer les CDI et les CDD par un contrat unique est l'option proposée par Jean Tirole, prix Nobel d'économie $2014^{21}$. Ce contrat s'accompagnerait de plus de droits pour les salariés licenciés. L'idée d'un contrat unique est partagée par des économistes espagnols ${ }^{22}$. Ainsi, pensent-ils, pourraient être conciliées la flexibilité pour les entreprises, qui veulent réagir aux fluctuations de la demande et aux changements de technologie, et la protection pour les salariés.

20. Samuel BentoliLA, Pierre CAHUc, Juan Dolado et Thomas Le BARBANCHON, « Paro y empleo temporal durante la crisis : Una comparación entre Francia y España », in : VV. AA., La Crisis de la Economía Española. Análisis Económico de la Gran Recesión Madrid, Fedea, 2010, p 311-350.

21. Olivier BLANCHARD et Jean TIROLE, Protection de l'emploi et procédures de licenciement, La Documentation française, Paris, 2003.

22. Propuesta para la reactivación laboral en España, 2009, [http://www.crisis09.es/ propuesta/?page_id $=75$

5]. Voir également Nadaesgratis. es: Luis GARICANO, ¿Es constitucional el contrato único? 10 février 2012 [http://nadaesgratis.es/?p=18492]; José Ignacio ConDE-RUIZ, La maraña contractual actual: ¿No sería todo más fácil con un contrato único ?, 15 mai 2013, [http://nadaesgratis.es/?p=30661]. 
Par ailleurs, il existe un consensus selon lequel la réforme du travail actuelle devrait s'appliquer dans un contexte de croissance et non pas de grave récession ${ }^{23}$. Ne pas tenir compte de ce consensus revient, pour Paul Krugman, à ignorer les fondements de la théorie économique ${ }^{24}$. L'immédiate conséquence de ce type de réforme en pleine récession est qu'elle entraîne, comme nous l'avons déjà mentionné, une croissance rapide du chômage. Si la réforme du travail s'accompagne d'un plan strict de restructuration macroéconomique caractérisé par de fortes coupes dans les dépenses publiques et des hausses d'impôts, la situation économique et sociale des familles et des individus ne pourra qu'empirer. Les conséquences malheureuses de la réforme aux plans économique et social restent associées à la conjoncture du moment de sa mise en œuvre.

Dans un contexte de récession, la réforme a favorisé les restructurations de personnel en diminuant les coûts, et a facilité une diminution des coûts du travail. Même s'il est difficile de savoir dans quelle mesure cette diminution est due à la réforme ou à la crise. Il est certain que, pendant la première année de crise économique, les salaires réels ont augmenté en conséquence de l'indexation automatique, ce qui n'a fait qu'empirer la situation de certaines entreprises. La réforme corrige cet effet, mais elle ouvre également la porte aux abus de la part des entreprises qui mettent en avant la recherche de compétitivité pour diminuer les salaires. Ceci peut faire dégénérer les relations sur le lieu de travail. De fait, le débat sur les salaires pourrait profiter de la création de mécanismes institutionnels à l'échelle nationale compatibles avec les conventions collectives principales de l'entreprise.

Par ailleurs, la réforme n'inclut pas de politiques d'emploi. Par exemple, il n'y a pas eu plus de mesures en faveur de l'accompagnement des chômeurs à la recherche d'emploi. La seule mesure a été celle d'associer une formation obligatoire afin que les chômeurs en fin de droits perçoivent une prestation compensatoire. Les actions en faveur de la recherche d'emploi sont absentes de la réforme, tout comme les mécanismes d'adaptation du profil professionnel des personnes sans emploi aux nouveaux besoins du marché du travail. Le problème de l'échec scolaire et de la surqualification des jeunes Espagnols n'a pas non plus été résolu. Les chiffres du chômage de certaines catégories

23. Samuel BENTOLILA, et Marcel JANSEN, «La reforma laboral de 2012: una primera evaluación ». Apuntes Fedea, 2012, 16.

24. Paul Krugman, Ignorar la teoría básica causa desastres, Blog Paul Krugman, El País, 20 mai 2013. 
de jeunes dépassent les 70 \% et plus d'un tiers des chômeurs de longue durée sont des jeunes. Certains d'entre eux ont abandonné prématurément le système éducatif et il est important de mettre en œuvre des mécanismes de retour à l'enseignement traditionnel ou des mesures de formation. Le contrat d'apprentissage ne semble pas la solution pertinente pour les jeunes sans formation, car ils sont en concurrence avec des jeunes qui sont déjà passés, et avec succès, par le marché du travail.

Enfin, dans le domaine de la surqualification, la politique du gouvernement ne corrige pas l'inadéquation d'une partie des formations et de certains diplômes, mais tend plutôt à restreindre la demande d'éducation. La politique d'éducation a consisté à diminuer les dépenses (y compris les bourses) et à augmenter de manière significative les frais d'inscription, ce qui a entraîné l'expulsion et l'éviction d'une partie des étudiants de l'enseignement non obligatoire (essentiellement les études universitaires). Certains ont dû abandonner les études qu'ils avaient entamées suite à l'effet combiné de la perte d'emploi et de revenus de leurs familles et de l'augmentation des frais d'inscription. Dans la réforme des enseignements, c'est une vision idéologique de l'éducation et non pas l'ambition de résoudre les problèmes du système éducatif et du pays qui a prévalu.

Hier comme aujourd'hui, pour expliquer l'augmentation du chômage en Espagne, il est donc nécessaire de réévaluer les causes de la perte des emplois et/ou du manque de création de ces derniers. Dans le contexte actuel, tout comme pendant les années 1970, l'essoufflement du modèle de croissance est la principale cause de perte des emplois. Ainsi, de nombreux facteurs peuvent expliquer la situation, tels que la prépondérance du secteur du bâtiment et du marché intérieur dans la croissance économique de la période 1993-2007, la faible compétitivité internationale d'une grande partie de l'industrie et sa moindre orientation à l'exportation. Le problème du chômage en Espagne a un caractère structurel et sa résolution exige des actions aux conséquences importantes sur la sphère productive du pays. 



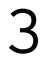

\title{
Le renouveau du mouvement républicain : de la nostalgie à la défiance citoyenne
}

\author{
Alicia FERNÁNDEZ GARCÍA
}

Marcheur, il n'y a pas de chemin. Le chemin se fait en marchant.

(Antonio Machado, 1912)

\begin{abstract}
A u cours des dernières années, les manifestations républicaines afin de célébrer la mémoire de la Seconde République ou de revendiquer l'instauration d'une "Troisième République " qui mettrait fin aux dérives du système politique actuel, ont connu un renouveau certain. Des voix de plus en plus nombreuses, issues principalement de la société civile et des milieux intellectuels, ont appelé à une "seconde transition " afin de dépasser les limites de la constitution de 1978. Mais l'histoire moderne et contemporaine du républicanisme en Espagne demeure non seulement limitée, mais aussi très controversée. Elle se concentre essentiellement sur deux épisodes, la Première République (11 février 1873-29 décembre 1874), très brève et marquée par l'instabilité politique, et la Seconde République (14 avril $1931-1^{\text {er }}$ avril 1939), qui gouverna en paix pendant seulement cinq ans jusqu'au coup d'État de juillet 1936, qui déclencha la guerre civile et obligea le gouvernement républicain de Largo Caballero et le président socialiste Manuel Azaña à se réfugier à Valence puis à Barcelone de 1937 à 1939¹ . Dans la mémoire collective des Espagnols, la Seconde République suscite le plus d'interprétations opposées: symbole d'une

1. Les travaux historiques sur ces deux périodes sont très nombreux et documentés. Citons seulement quelques travaux de référence réactualisés. Sur la Première République, cf. José María Jover Zamora, Realidad y mito de la Primera República, Pozuelo de Alarcón, EspasaCalpe, 1991 ; Josep FonTANA, La época del liberalismo. Vol. 6 de la collection Historia de España, dirigée par Josep FonTANA et Ramón VILLARES, Barcelone, Marcial Pons, 2007 ; Jorge VILCHES, Progreso y Libertad. El Partido Progresista en la Revolución Liberal Española, Madrid, Alianza Editorial, 2001.
\end{abstract}


tentative de modernisation inachevée pour certains face à la violence d'une partie de la classe dirigeante réactionnaire; régime honni par les autres, pour avoir exacerbé les divisions identitaires et les conflits idéologiques des années 1930 et conduit le pays à l'affrontement sanglant ${ }^{2}$.

On comprend donc aisément que la république comme régime politique et le républicanisme comme idéologie ne font pas consensus, loin de là. À l'inverse, il est associé à l'idéal politique de la gauche et demeure rejeté par la droite. Aujourd'hui, le républicanisme est même uniquement revendiqué par une certaine frange de la gauche, minoritaire au niveau des appareils politiques. Seuls deux partis, Izquierda Unida (IU) et Esquerra Republicana de Catalunya (ERC), se disent clairement " républicains ". L’ERC prône cependant la république avant tout dans le contexte catalan. Le soutien au républicanisme est quoi qu'il en soit plus largement partagé par les bases militantes du PSOE et les Espagnols de gauche. Ainsi, comment expliquer le renouveau du mouvement républicain dans l'Espagne d'aujourd'hui? La thèse de ce chapitre est que ce renouveau du républicanisme, qui demeure toutefois minoritaire, traduit une nostalgie idéalisée de la Seconde République, mais doit surtout être compris comme un symbole fort de défiance politique et de volonté de changement des citoyens.

En replaçant les mouvements sociaux récents dans le contexte de crise économique et sociale du pays depuis 2008, ce chapitre cherche à déceler les raisons du renouveau de la sympathie à l'égard du régime républicain, tout en évaluant la portée de ces mobilisations. Il s'agira de s'intéresser dans le détail aux principaux groupes et collectifs politiques et sociaux qui se sont mobilisés lors des dernières années autour de l'enjeu républicain. Par là même, nous chercherons à mettre en avant leurs principales revendications, et à réfléchir plus globalement sur la capacité d'influence de ce secteur d'opinion. En s'appuyant sur des travaux historiographiques, la première partie retrace brièvement les principales réalisations et les dilemmes de la Première et de la Seconde République, puis illustre à travers des exemples récents,

\footnotetext{
2. Sur la Seconde République, voir l'étude classique de Javier TUSELL, Las Constituyentes de 1931: unas elecciones de transición, Madrid, CIS, 1982. Pour une édition plus récente, voir Santos JULIA, La Constitución de 1937, Madrid, lustel, 2009. Voir de même les études classiques de Stanley PAYNE, La primera democracia española. La Segunda República, 1937-1936, Barcelona, Paidós, 1995, et El colapso de la República, Madrid, La Esfera de los Libros, 2005. Pour une vision synthétique d'ensemble, voir Julián CASANOVA, República y Guerra Civil. Vol. 8 de Historia de España, op. cit., 2007. Enfin, pour une étude plus récente sur la droite, voir Eduardo GonZÁLEZ CALLEJA, Contrarrevolucionarios. Radicalización violenta de las derechas durante la Segunda República, Alianza Editorial, Madrid, 2011.
} 
comment la mémoire républicaine demeure intimement liée à la question des victimes de la guerre civile. La seconde partie porte sur les mobilisations contemporaines, en montrant comment le mouvement républicain se situe à la confluence des mouvements sociaux, la "Troisième République " agissant comme un idéal rassembleur, et l'abdication du roi Juan Carlos $\mathrm{I}^{\mathrm{er}}$ ayant joué le rôle d'un événement déclencheur d'une repolitisation de la question du régime politique de l'Espagne. La troisième partie étudie le lien entre la revendication républicaine et les mouvements indépendantistes et régionalistes en Catalogne, au Pays basque et en Galice. Enfin, la conclusion propose une réflexion critique sur les mobilisations des dernières années, l'influence et les perspectives futures du républicanisme en Espagne.

\section{LA MÉMOIRE HISTORIQUE RÉPUBLICAINE EN ESPAGNE}

\section{La Première République: l’image négative de la " République de 1873 »}

La Première République fut le régime politique de l'Espagne du 11 février 1873 au 29 décembre 1874. Il s'inséra dans le cadre du sexennat démocratique enclenché par la révolution de 1868, qui déboucha sur le règne d'Amadeo Ier, puis sur la République suite à l'abdication le 11 février 1873 de ce dernier, acculé par la troisième guerre carliste, le conflit de Cuba, l'opposition des monarchistes partisans de la restauration d'Alfonse de Bourbon (fils d'Isabel II) et les insurrections républicaines ${ }^{3}$. La Première République prit fin suite au coup d'État du général Arsenio Martínez-Campos qui donna lieu à la restauration bourbonienne. Elle fut très brève et caractérisée par l'instabilité politique: durant ses onze premiers mois d'existence, elle enchaîna quatre présidents issus du Parti républicain fédéral. Le premier gouvernement d'Estanislao Figueras dut faire face à une situation de crise économique et sociale dans le contexte de la crise mondiale de 1873, marquée par l'augmentation du chômage et des grèves à répétition. En Andalousie, la république était associée symboliquement à la réforme agraire par les paysans sans terre des latifundios, des domaines agricoles immenses,

3. Stéphane MichONNEAU, «Le Sexenio démocratique 1868-1874 », dans Jordi CANAL (dir.), Histoire de l'Espagne contemporaine de 1808 à nos jours (2e édition), Paris, Armand Colin, 2014, chapitre IX. 
propriétés le plus souvent de nobles hidalgos issus de l'aristocratie madrilène: les paysans demandèrent ainsi la parcellisation immédiate des terres, entraînant de nombreux conflits locaux.

La Première République peina à faire respecter l'ordre public, notamment en raison de la présence de " juntes révolutionnaires " qui défièrent le pouvoir de l'administration centrale et des mairies. Les "Volontaires de la République ", une milice tolérée par le gouvernement, s'opposèrent ${ }^{4}$ aux " Volontaires de la Liberté ", la milice monarchiste fondée durant le règne d'Amadeo $\mathrm{I}^{\mathrm{er}}$. Les radicaux, qui défendaient la république unitaire, s'opposaient aux républicains fédéralistes, comme l'illustre la caricature du quotidien satirique La Flaca de 1873, eux-mêmes divisés entre les fédéralistes " modérés » et " intransigeants ${ }^{5}$ ». Plusieurs coups d'État déstabilisèrent le régime, notamment ceux du radical, président de l'Assemblée nationale Cristino Martos le 24 février puis le 8 mars, et à nouveau le 23 avril 1873, avec l'appui du général Pavia et du Parti constitutionnel, d'orientation conservatrice ${ }^{6}$. Les républicains fédéralistes " intransigeants ", qui dominaient la députation de Barcelone, proclamèrent de même l'État catalan en mars 1873.

Photo 3.1. Caricature de la I re République, revue satirique La Flaca, 3 mars 1873

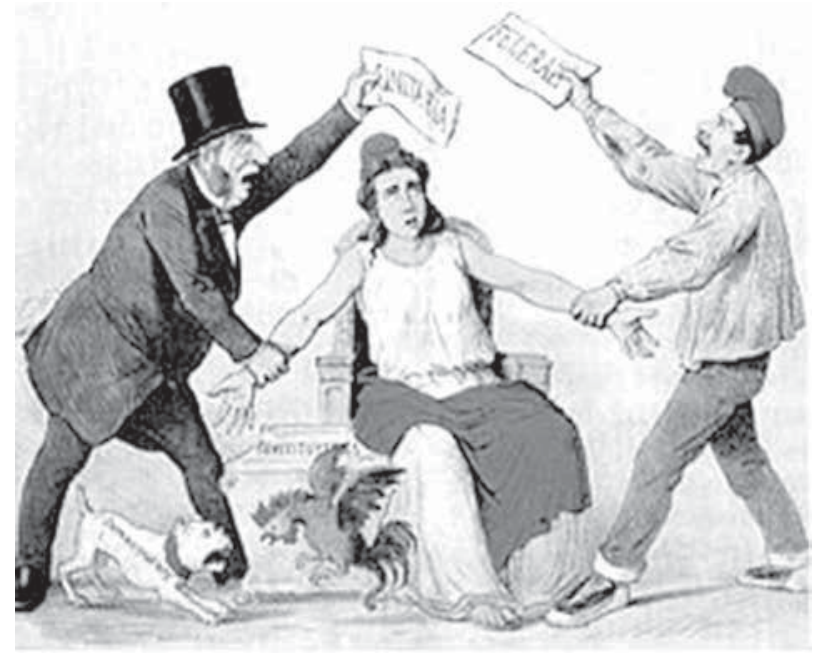

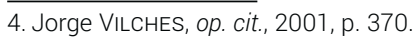

5. Josep FontANA, op. cit., 2007, p. 371-372.

6. Jorge VILCHES, op. cit., 2001, p. 372. 
Les élections du 10 au 13 mai 1873 illustrèrent bien le manque de légitimité du régime: non seulement les carlistes (en guerre depuis 1972) et les monarchistes partisans d'Alfonse de Bourbon dirigés par Cánovas del Castillo ne reconnaissaient pas la République, mais les radicaux, les membres du Parti constitutionnel et même les organisations ouvrières proches de l'Internationale socialiste boycottèrent le scrutin, de telle sorte qu'il n'y eut pas de véritable lutte électorale ${ }^{7}$. Avec $60 \%$ d'abstention, ces élections comptent parmi les moins mobilisatrices de l'histoire de l'Espagne: en Catalogne, seul $25 \%$ de l'électorat se rendit aux urnes et $28 \%$ à Madrid, et ce, malgré l'abaissement de l'âge du droit de vote de 25 à 21 ans $^{8}$. Les Espagnols doutaient beaucoup de la république. Le coup d’État du général Pavia, le 3 août 1874, remit en cause le fédéralisme et instaura une république unitaire, dirigée par le général Serrano, qui était d'ailleurs devenu le nouveau dirigeant du Parti constitutionnel. En parallèle avec l'instabilité gouvernementale et l'opposition entre partisans d'un régime fédéral ou unitaire et centralisé, la Première République dut faire face simultanément à trois conflits: la troisième guerre carliste (1872-1876) ${ }^{9}$, la révolution cantonale $^{10}$ et la guerre des Dix Ans, première guerre d'indépendance de Cuba (1868-1878).

7. Dans les quelques districts où une compétition électorale eut toutefois lieu, celle-ci s'organisa uniquement entre républicains fédéralistes « modérés » ou « intransigeants ».

8. Jorge VILCHES, op. cit., 2001, p. 381.

9. La troisième guerre carliste (21 avril 1872-28 février 1876), désigne l'affrontement qui opposa, d'une part, les partisans de Charles VII de Bourbon (1848-1909), prétendant carliste au trône d'Espagne (et aîné des capétiens et chef de la maison de France, considéré à ce titre par les légitimistes comme le roi de France « Charles XI »), et, d'autre part, les gouvernements

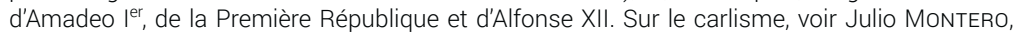
El Estado Carlista. Principios teóricos y práctica política (1872-1876), Madrid, Aportes XIX, 1992; Jordi CANAL, El Carlismo. Dos siglos de contrarrevolución en España, Madrid, Alianza Editorial, 2 000. Sur le lien de Charles VII à la maison de France, voir Jacques BERNOT, Les princes cachés: Histoire des prétendants légitimistes, Paris, Lanore, 2014, p. 13.

10. La révolution cantonale est un mouvement politique qui se fit jour en juillet 1873 par une grève révolutionnaire à Alcoy puis par l'insurrection de Carthagène le 12 juillet, et qui consista en une réorganisation d'une partie du territoire de l'Espagne en cantons, à savoir de fédérations de villes qui se regroupaient librement. II entraîna la démission de Pi y Margall, le ministre de I'Intérieur. Le mouvement s'étendit ensuite dans les régions de Valence, de Murcie, de l'Andalousie, en Estrémadure (à Coria, Hervás, Plasencia) où fut créé le journal El Canton Extremeño, et dans la province de Salamanque. La majorité des cantons, dotés de milices d'autodéfense, supprimèrent les monopoles et les impôts sur la consommation (droits d'octroi), tout en reconnaissant le droit au travail et en instaurant la journée de huit heures. Les cantons d'Almansa, Loja, Séville, Málaga, Cadix, Tarifa et surtout Carthagène, qui fut le dernier à résister (jusqu'au 13 janvier1874) furent les plus actifs. Ce mouvement était partisan d'un fédéralisme radical et eut une grande influence sur le mouvement ouvrier et surtout sur l'anarchisme en Espagne. Voir José BARÓn FERNÁNDEZ, El movimiento cantonal de 1873 ( $7^{a}$ República), La Corogne, Edicios do Castro, 1998, p. 214. 
Lors de son discours d'investiture à la Real Academia de la Historia en 1978, l’historien José María Jover Zamora dédia son exposé à la « réalité et aux mythes de la Première République ". Il montra combien la vision que l’on conserve de ce régime en Espagne reste stéréotypée et déformée. Il insista sur le caractère exagéré du parallèle parfois fait entre la révolution cantonale, très localisée et dont les effets furent limités, et la Commune de Paris, qui eut à l'inverse un impact mondial. S’il reconnut largement l'instabilité du régime et ses crises internes, Zamora mit en évidence la tendance de l'historiographie postérieure et d'importants historiens comme Manuel de la Revilla ou Marcelino Menéndez y Pelayo à promouvoir une " image de la République de 1873 » trop détachée de sa situation historique de référence et déformée par une vision conservatrice hostile stigmatisant le fédéralisme comme " absurde " et l'associant $\mathrm{au}$ " séparatisme " ${ }^{11}$. Ainsi, les déboires de la Première République, mais aussi les interprétations dominantes formulées dans les années et les décennies qui suivirent, décrédibilisèrent durablement le régime républicain en Espagne, en l'associant à l'« instabilité ", au "désordre ", à la " crise d'autorité ", à la " collectivisation ", au " socialisme " et à l'« utopie ${ }^{12}$. Autant de représentations sociales négatives qui contribuèrent à cimenter l'imaginaire collectif des Espagnols de la fin du XIX et du début du Xx ${ }^{\mathrm{e}}$ siècle. En 1979, malgré le rétablissement de la démocratie, le Dictionnaire de la langue espagnole de la Real Academia Española associait encore la république à un « lieu où règne le désordre pour excès de libertés ${ }^{13}$ ".

\section{La Seconde République: une image très clivée}

Suite à la démission du général Miguel Primo de Rivera en janvier 1930, le roi Alfonse XIII nomma le général Dámaso Berenguer chef du gouvernement dans le dessein de revenir à la "normalité constitutionnelle ». Mais l'expérience, qui ne dura que jusqu'en février 1931, connue comme la «Dictablanda» (la "dictature douce »), fut peu concluante. La monarchie et les anciens partis dynastiques étaient d'autant plus discrédités qu'ils avaient soutenu le régime de Primo de Rivera $^{14}$. Les élections municipales du 12 avril 1931 ne furent pas un

\footnotetext{
11. Ce discours fut revu et corrigé, publié puis réédité par la suite. Cf. José María JovER ZAMORA, op. cit., 1991, p. 80.

12. Ibid., p. 81.

13. Ibid., p. 82

14. Genoveva García QueIPo DE LLANO, El reinado de Alfonso XIII. La modernización fallida, Madrid, Historia 16, 1997, p. 130.
} 
triomphe pour les républicains, notamment dans les campagnes. Mais le fait que le vote rural ait été complètement déformé par l'influence et les pressions sociales des "caciques ", relais locaux des élites conservatrices et monarchistes, délégitima celui-ci, alors que les républicains remportèrent de larges victoires dans 41 capitales de province, dont Madrid et Barcelone, ce qui les incita à instaurer immédiatement la république ${ }^{15}$.

La Seconde République fut ainsi le régime politique démocratique sous lequel vécut l'Espagne entre le 14 avril 1931, date de sa proclamation, et le $1^{\text {er }}$ avril 1939, date du début de la guerre civile qui déboucha sur la dictature franquiste (1939-1975). Après la mise en place du gouvernement provisoire (avril-décembre 1931) qui approuva la constitution de 1931, la période durant laquelle la Seconde République gouverna " en paix " peut être divisée en trois phases. La première, de 1931 à 1933, permit à la coalition républicaine et socialiste dirigée par Manuel Azaña de mener à bien plusieurs réformes qui modernisèrent le pays. La seconde, de 1933 à 1935, considérée par la gauche comme une période réactionnaire, permit au gouvernement du parti républicain radical d'Alejandro Lerroux, avec l'appui de la droite catholique, la Confédération espagnole des droites autonomes (CEDA), de revenir sur une partie des réformes menées jusqu'alors. Durant cette période se produisit la révolution de 1934, une révolte populaire qui déboucha sur une véritable insurrection en Asturies et fut réprimée dans le sang par l'armée ${ }^{16}$. La troisième période fut marquée par la victoire du Front populaire, la coalition des gauches, lors des élections législatives de 1936: le Front ne put gouverner que cinq mois en raison du coup d’État des 17 et 18 juillet 1936 qui entraîna la guerre civile.

Durant la guerre, de 1936 à 1939, trois gouvernements républicains se succédèrent, dont aucun ne parvint à faire respecter le monopole de la violence de l'État central et la légalité républicaine sur son propre territoire. Le gouvernement républicain de José Giral dut ainsi composer avec des centaines de comités républicains d'autodéfense formés suite à la révolution sociale de 1936. Le gouvernement du socialiste Francisco Largo Caballero (septembre 1936-mai 1937), ex-dirigeant de l'Union générale des travailleurs (UGT), fut même obligé de composer avec la pression des anarchistes de la Confédération nationale du travail

\footnotetext{
15. Santos JULIA, op. cit., 2009, p. 20.

16. Sur ce point, voir Juan Pablo Fusı, « Nacionalismo y revolución : Octubre de 1934 en el País Vasco », dans Gabriel JACKSON et al. (dir.), Octubre 1934. Cincuenta años para la reflexión, Madrid, Siglo XXI, 1985, p. 110-123.
} 
(CNT), qui avaient joué un rôle central dans la révolution, organisèrent des grèves insurrectionnelles et des actions directes pour prendre le contrôle des usines, et formèrent de nombreuses milices d'autodéfense, notamment en Catalogne. Depuis Barcelone, le gouvernement du socialiste Juan Negrín (mars 1937-mars 1939) chercha à résister jusqu'au bout à l'avancée des troupes " nationales ", avant de prendre la route de l'exil, suite au coup d'État du général Casado.

La Seconde République eut à son actif des avancées sociales et politiques sans précédent. Dans ses principes fondamentaux, la constitution de 1931 proclama la séparation de l’Église et de l'État, le caractère laïc des institutions nationales et le principe de l'élection des responsables publics. Elle supprima aussi la seconde chambre trop aristocratique, reconnut le mariage civil et le divorce et imposa le suffrage universel, donnant ainsi aux femmes la possibilité de voter pour la première fois en $1933^{17}$. Une réforme agraire fut mise en place en 1932, de même que de nouveaux statuts d'autonomie en Catalogne, au Pays basque et en Galice. De nouveaux droits furent donnés aux travailleurs. Comme le souligne bien Mercedes Yusta, les importants progrès sociaux mais aussi les nombreux défis auxquels la Seconde République dut faire face ont donné corps à des interprétations opposées et très difficilement réconciliables sur les mérites ou au contraire les responsabilités de ce régime:

On trouvera difficilement dans l'histoire de l'Espagne une période aussi controversée que celle de la Seconde République. Pour les uns, elle représente une occasion unique de moderniser l'Espagne qui fut brutalement étouffée par ceux qui ne voulaient pas perdre leurs privilèges. Pour les autres, c'est la période qui exacerba les divisions et les conflits qui fracturaient la société espagnole, jusqu'à la faire éclater lors d’une sanglante guerre civile dont les politiciens républicains seraient partiellement, sinon totalement, responsables ${ }^{18}$.

C'est pourquoi, dans la mémoire collective espagnole, la Seconde République demeure davantage jugée à partir des événements historiques qui lui sont postérieurs, la guerre civile puis la dictature franquiste, plutôt qu'à partir d'une analyse du régime lui-même, de ses succès et de ses limites. La Seconde République demeure plus associée au traumatisme de la guerre civile qu'à ses nombreuses avancées sociales et politiques et à sa contribution à la modernisation de l'Espagne. Pour

17. Santos JULIA, op. cit., 2009, p. 30-35.

18. Mercedes YUSTA, « La Seconde République », dans Jordi CANAL (dir.), op. cit., 2014, p. 173. 
beaucoup, elle symbolise aussi le passé, une expérience certes novatrice pour l'époque, mais dont le prix à payer a été trop lourd dans le contexte espagnol. La propagande franquiste a d'ailleurs largement contribué à délégitimer ce régime, semant le doute dans les mémoires collectives en falsifiant allégrement l'histoire et en lui faisant porter la responsabilité de la guerre civile.

\section{Républicanisme et victimes de la guerre civile}

De nos jours, l'idée d'un retour à la république séduit d'abord les descendants des républicains et des victimes de la guerre civile, de même que les personnes qui ont personnellement vécu la répression franquiste. Pour cette frange de la société espagnole, la Seconde République se remémore avec nostalgie et symbolise l'idéal d'un régime démocratique et républicain, sans personnalisation excessive du pouvoir. La monarchie est perçue comme « illégitime ", sachant que Juan Carlos $\mathrm{I}^{\mathrm{er}}$ a été choisi et promu par Franco lui-même en 1969, et qu'elle aurait été imposée lors de la transition sans consultation des Espagnols. S'il est clair, comme le rappelle Paloma Aguilar Fernández dans son œuvre magistrale, que la restauration de la monarchie a constitué un élément clé du " compromis » de la transition, permettant de convaincre les élites de l'ancien régime franquiste et de la droite conservatrice d'accepter le nouveau système démocratique (ce qui semblerait confirmer l'argument d'une "imposition » de la monarchie), il ne faut toutefois pas oublier que les Espagnols se sont prononcés par référendum et ont massivement approuvé la constitution de $1978^{19}$. Il est vrai qu'un référendum qui aurait exclusivement porté sur la forme de l'État, proposant le choix entre république et monarchie, n'a pas été organisé. Une telle consultation aurait redonné corps au clivage issu de la guerre civile entre les républicains et les conservateurs que le pacte de la transition cherchait justement à effacer. Mais, en plébiscitant la constitution de 1978, qui précise bien dans son article 3 que la forme de l'État est une monarchie parlementaire, les Espagnols ont réinstauré la monarchie sur de nouvelles bases démocratiques, et lui ont donné la légitimité originelle qu'elle nécessitait.

\footnotetext{
19. Sur la question de la gestion de la «mémoire historique », l'ouvrage de Paloma Aguilar Fernández constitue sans aucun doute une référence par son détail, son érudition et sa perspective comparée. Cf. Paloma AguILAR FERnÁNDEZ, Políticas de la memoria y memorias de la política, Madrid, Alianza Editorial, 2008. Lors du référendum du 6 décembre 1978, sur 26,6 millions d'électeurs, 17,7 millions soit 67,1 \% ont voté. Parmi les suffrages exprimés, 87,8 \% des votants ont approuvé la nouvelle constitution démocratique.
} 
Ce rappel des circonstances historiques qui ont présidé à la restauration de la monarchie lors de la transition permet de bien comprendre pourquoi la nostalgie de la Seconde République subsiste encore en Espagne, mais demeure un phénomène social assez minoritaire. Elle touche surtout une génération de personnes plutôt âgées, issues des milieux communistes et républicains, pour qui la transition a été vécue comme une évolution incomplète: elle n'a pas débouché sur une restauration de la république, idéalisée comme le régime le plus démocratique possible, ni même permis de punir les crimes franquistes. Certes, la loi sur la mémoire historique approuvée par le Congrès des députés le 31 octobre 2007 durant le premier mandat du socialiste José Luis Rodriguez Zapatero, a reconnu symboliquement les souffrances de toutes les victimes de la guerre civile et de la dictature franquiste. Mais cette loi ne facilite pas l'ouverture des fosses communes, dans lesquelles se trouvent les restes de victimes et de disparus, qui est effectuée par des associations locales privées le plus souvent. La loi n’a pas non plus imposé une remise en cause totale de la présence des symboles franquistes dans les espaces publics: de nombreuses rues des villes et des villages d'Espagne arborent encore les noms de militaires responsables du coup d'État de 1936 et de dignitaires franquistes. Pour les descendants des personnes disparues, la transition symbolise donc toujours un « pacte de l'oubli » imposé au détriment des victimes et de la recherche de justice ${ }^{20}$.

Quelques exemples tirés de l'actualité récente permettent d'illustrer tant la nostalgie liée à la revendication républicaine, que son caractère minoritaire. À Madrid, le 6 décembre 2011, mille personnes se sont ainsi réunies pour manifester et rendre hommage au dirigeant communiste Julián Grimau, qui mourut en tombant d'une fenêtre en cherchant à échapper à la police franquiste ${ }^{21}$. De même, dans le cadre des protestations des indignés, le groupe des « Iaioflautas » a montré l'incorporation de la revendication républicaine au sein de ce nouveau mouvement social: en demandant "vérité, justice et réparation " pour les victimes de la guerre civile et du franquisme, ce collectif composé de personnes souvent âgées de plus de soixante-dix ans, a cherché à mettre en évidence le caractère actuel de ses revendications. La dénonciation des crimes de la guerre civile et de l'impunité est un élément central qui, aux yeux de

20. Pour Sandrine Lefranc, spécialiste de la « justice transitionnelle », toute transition démocratique se caractérise par ce dilemme moral lié à la conciliation d'objectifs distincts, d'une part, la réconciliation, la pacification et le pardon, et d'autre part, la nécessité de justice. VOIR Sandrine LEFRANC, Politiques du pardon, Paris, Presses universitaires de France, 2002.

21. Joaquín GIL, « Hay que luchar por la III República », El País, 6 décembre 2011. 
ce secteur de la société, illustrerait les limites du système politique actuel issu de la transition. Par exemple, en avril 2014, la plateforme Séville pour la République, en présence du coordinateur d'IU pour l'Andalousie, Antonio Maíllo, a organisé un hommage aux victimes du soulèvement militaire de juillet 1936 sur le lieu de la fosse commune du cimetière de San Fernando.

Dans plusieurs villes et villages d'Espagne, des drapeaux de la Seconde République sont hissés symboliquement par des maires républicains lors de la date anniversaire de sa proclamation, le 14 avril de chaque année. En 2010, lors du 79e anniversaire de la Seconde République, un drapeau de $79 \mathrm{~m}$ de long a été tiré par le PCE sur la Puerta del Sol à Madrid ${ }^{22}$. En 2012, ce fut aussi le cas à Palomares del Río dans la province de Séville, une petite ville dirigée par Juana Caballero à la tête d'une coalition entre IU et la Coalition andalouse. Les autorités de Villaverde del Río, une localité gouvernée par la même coalition, décidèrent aussi d’orner la mairie du drapeau républicain pendant une semaine à côté des autres drapeaux (de l'UE, de l'Espagne et de l'Andalousie), avant d'être condamnées à le retirer par le tribunal administratif de Séville.

Le 14 avril 2014, deux mille cinq cents personnes ont à nouveau défilé à Madrid de la Plaza de Cibeles jusqu'à la Puerta del Sol en empruntant la rue Alcalá, en mémoire de la proclamation de la Seconde République $^{23}$. Même si l'aversion de ces personnes à l'égard de la monarchie se comprend assez aisément pour les raisons historiques et familiales mentionnées précédemment, force est toutefois de constater que l'idéalisation de la Seconde République n’est pas partagée par la majorité des Espagnols, pour qui ce régime symbolise le passé et ses démons. La nostalgie de la Seconde République demeure minoritaire en ce qu'elle est associée symboliquement à un " retour en arrière ". Le propos d'un lecteur du quotidien El País de Majadahonda (Madrid) est parfaitement révélateur:

\footnotetext{
22. Jusqu'en 1931, les républicains espagnols célébraient l'anniversaire de la Première République le 11 février. Cette célébration a disparu par la suite, et fut remplacée par l'anniversaire de la proclamation de la Seconde République le 14 avril, qui fut d'ailleurs une " fête nationale » de 1932 à 1938 (même si dans les faits, seulement en territoire républicain à partir de 1936). Le 14 avril 1931, des milliers de personnes se sont réunies face à l'ancien ministère de l'intérieur, l'actuelle présidence du gouvernement de la communauté de Madrid, pour célébrer la fin du règne d'Alfonse XIII. Cf. "La bandera republicana regresa a la Puerta del Sol », El Mundo, 14 avril 2010. Sur l'utilisation symbolique par les municipalités du drapeau républicain ou des drapeaux catalan et basque, cf. Sebastian BALFOUR et Alejandro QUIROGA, España reinventada. Nación e identidad desde la Transición, Barcelona, Ediciones Península, 2007.

23. « Miles de personas claman en Madrid por la III República », El País, 14 avril 2014.
} 
Je ressens une grande sympathie pour le drapeau tricolore, mais plutôt que de mobiliser en faveur de la République du futur, je pense qu'elle implique un frein pour beaucoup de gens. Ce drapeau symbolise une idée de retour en arrière, avec une époque que nous cherchons tous à oublier. [...] Si nous avons évacué de nos vies les symboles fascistes et autoritaires du régime franquiste, il n’y a aucun sens à revendiquer le futur en enlevant la poussière sur des photos en noir et blanc. La République, comme système politique moderne fondé sur l'égalité devant la loi, le libre choix des représentants publics, la séparation et le contrôle des pouvoirs de l'État, et la pratique du respect et de la tolérance, est inévitablement notre futur. Mais nous avons besoin de nouveaux symboles, de toutes les couleurs, en haute définition et sans connotations négatives pour personne. Le drapeau tricolore ne fut pas celui de la première République de 1873, et il n’y a pas de raison pour qu'il soit celui de la République espagnole du futur ${ }^{24}$.

\section{LE MOUVEMENT RÉPUBLICAIN À LA CONFLUENCE DES MOUVEMENTS SOCIAUX}

\section{La « Troisième République », un concept rassembleur}

La revendication d'une "Troisième République " est un concept rassembleur pour l'ensemble des mouvements sociaux très divers qui se situent dans l'opposition au gouvernement conservateur de Mariano Rajoy. Les dérives du bipartisme figé issu de la transition, la corruption, de même que les politiques menées ces dernières années, guidées par l'austérité, les coupes budgétaires et la remise en cause de nombreux droits sociaux, sont très largement critiquées. Ces multiples griefs permettent de mieux idéaliser les alliances politiques, la reconnaissance des spécificités identitaires de certaines régions espagnoles et les avancées sociales de la Seconde République. D’une certaine manière, il est vrai que l'alternance figée entre le PP et le PSOE donne l'image d'un système à bout de souffle, ce qui suscite la comparaison avec le « turnismo " du système politique conservateur de la Restauration (1875-1923), lorsque le parti libéral de Práxedes Mateo Sagasta et le parti conservateur d'Antonio Cánovas del Castillo, deux organisations oligarchiques favorables à la monarchie, alternaient au pouvoir sans véritablement se

24. Carlos OtıvA, «La bandera de la República », Majadahonda, Cartas al lector, El País, 18 mai 2013. 
différencier ${ }^{25}$. Les critiques mettent en avant les nombreuses affaires de corruption qui ont éclaboussé les deux partis dominants ces dernières années, et leur manque de volonté commune de lutter contre "l'affairisme" de leurs élites politiques locales et nationales, des dérives qui constitueraient autant de réminiscences du clientélisme et des « caciques» des deux partis dynastiques de la Restauration ${ }^{26}$.

Mais la Seconde République est aussi largement idéalisée: on oublie vite l'instabilité, les sabotages, les attentats des groupes anarcho-syndicalistes et les affrontements politiques sans concession, à l'origine du climat néfaste de luttes idéologiques exacerbées qui a mené à la guerre civile. Il est d'ailleurs tout à fait significatif de noter que plus que " contre la monarchie ", les personnes qui se sont mobilisées au cours des dernières années en faveur d'une III $^{\mathrm{e}}$ République, ont avant tout manifesté " contre les élites " en général, et principalement contre le bilan passé du PSOE et la gestion actuelle du PP. Le propos de María, une jeune étudiante catalane de vingt-deux ans, rapporté par le quotidien El Mundo lors des manifestations de juin 2014, est ici assez révélateur:

Je pense que le système politique de 1978 ne marche plus. Chaque jour, nous voyons ses limites avec la multiplication des affaires de corruption qui touchent les élites. Mais les deux grands partis s'entendent pour ne rien changer, pour maintenir des lois qui favorisent l'impunité et ne permettent pas la transparence. C'est pour cela que je suis en faveur du référendum. Même si je suis contre la monarchie, je suis plus contre nos dirigeants. Je comprends que cela semble bizarre, mais c'est ainsi ${ }^{27}$.

On voit bien comment, même si certains se mobilisèrent très clairement contre l'institution monarchique elle-même, d'autres manifestèrent leur mécontentement plus général à l'égard du système politique dans son ensemble, et à l'encontre des partis dominants en particulier. Le mouvement républicain doit donc être analysé comme un catalyseur des revendications plurielles des mouvements sociaux.

En effet, il permet de réunir autour d'un concept et d'un horizon politique commun, des personnes qui se sont mobilisées autour d'enjeux

25. La principale différence était surtout liée au fait que le parti libéral soutenait un plus important développement des libertés constitutionnelles établies, dans le but de rapprocher la constitution conservatrice de 1876 de celle, plus démocratique, de 1869. Cf. Ignacio FERNÁNDEZ SARASOlA, Los partidos políticos en el pensamiento español. De la ilustración a nuestros días, Madrid, Marcial Pons, Ediciones de Historia, 2009, p. 179.

26. Sur le système politique de la Restauration, cf. Jordi CANAL (dir.), Histoire de l'Espagne contemporaine. De 1808 à nos jours, Paris, Armand Colin, 2009, p. 110-123.

27. El Mundo, 3 juin 2014, p. 3. 
sociaux pourtant distincts depuis la crise de 2008: "marée verte " contre les coupes budgétaires dans l'éducation; "marée blanche" contre les privatisations et la remise en cause de l'assistance universelle dans le secteur de la santé; syndicats contre la réforme du travail; collectifs féministes voyant dans la République un régime plus à même de favoriser l'égalité hommes-femmes, jeunes chômeurs et précaires pour qui le système politique de 1978 n'a pas tenu ses promesses, etc. Le concept de "Troisième République " permet de rassembler des personnes issues de mouvements sociaux distincts et aux revendications plurielles derrière une même matrice revendicative. Les mobilisations de juin 2014 illustrèrent d'une certaine manière l'essor de la « démocratie d'imputation " évoquée par Pierre Rosanvallon, caractérisée selon lui par la tendance avérée dans les sociétés contemporaines à se mobiliser « contre » tel ou tel projet de façon réactive, malgré la difficulté à mobiliser « en faveur » d'un projet de réforme ou d'une institution ${ }^{28}$. Le propos de Leandro Pullido, un délégué du syndicat Comisiones Obreras, illustre bien cette confluence des mouvements sociaux:

Nous sommes ici dans cette manifestation républicaine car nous allons nous rendre à l'ensemble des manifestations convoquées par des mouvements de gauche. Parce que nous sommes contre les expulsions, contre les coupes budgétaires, et bien sûr, contre la réforme du travail. Revendiquer la République, c'est revendiquer un autre modèle social et politique ${ }^{29}$.

Lors de ces mobilisations, les descendants des victimes républicaines de la guerre civile, les militants du Parti communiste d'Espagne et d'Izquierda Unida, de même que de nombreux jeunes, issus notamment du mouvement des indignés, ont constitué les principaux collectifs mobilisés. Le collectif Junta Estatal Republicana a joué un rôle central dans la convocation de ces manifestations, recueillant de même une pétition de 100000 signatures en faveur d'un référendum ${ }^{30}$. Lors de chaque manifestation républicaine à Madrid, des manifestations concomitantes ont eu lieu dans les grandes villes des provinces espagnoles, notamment en Andalousie où Izquierda Unida, le parti le plus nettement républicain,

28. Pierre Rosanvallon, La contre-démocratie. La politique à l'âge de la défiance, Paris, Le Seuil, 2014.

29. «Manifestaciones multitudinarias por la República », La Vanguardia, 5 juin 2014.

30. Pour Francisco Pérez Esteban, le porte-parole de la Junta Estatal Republicana, qui est d'ailleurs aussi le responsable fédéral des droits de l'homme d'IU, il faudrait « ouvrir un processus constituant pour définir le droit à décider entre la monarchie ou la République », cf. « La junta Republicana manifiesta por la República », El Mundo, 14 avril 2014. 
a le plus d'influence. Pour les jeunes et les étudiants qui sont nés après la transition, la figure du roi Juan Carlos n'est pas associée à son rôle de médiateur lors de la transition ou à sa défense des institutions démocratiques lors de la tentative de coup d'État du 23 février 1981. Il symbolise à l'inverse un régime vieillissant, monarchique et donc héréditaire, qui renvoie indirectement à l'endogamie et aux tendances oligarchiques qui prévalent dans la classe politique. Le propos de Nino Torre, le dirigeant des Jeunesses socialistes du PSOE, montre bien cela:

Les Jeunesses socialistes sont républicaines pour des raisons idéologiques, de mémoire et de principes éthiques. La défense de la République fait partie de son identité politique. Le régime monarchique est le résultat hérité d’une génération qui considère cette institution comme un élément unificateur et de stabilité, mais ce n’est plus vraiment le cas pour les jeunes d'aujourd'hui ${ }^{31}$.

Pendant longtemps, la position plus neutre et surplombante de la monarchie lui a permis d'éviter les critiques: le roi, personnage respecté dans le monde pour son rôle historique lors de la transition, représentait le prestige de l'Espagne et permettait d'appuyer la diplomatie du pays sur une figure d'autorité. Il jouait aussi un rôle de rassembleur du monde hispanophone, et de promotion des entreprises et des intérêts de l'Espagne à l'étranger. Mais les dernières années ont terni son image, notamment suite au scandale "Urdangarin ", et à son safari controversé à 30000 euros au Botswana en pleine crise économique ${ }^{32}$.

Izquierda Unida avec ses branches régionales est le seul parti qui milite très clairement pour l'instauration d'une Troisième République, et par défaut, pour l'organisation d'un référendum sur la forme de l'État. Le nouveau dirigeant d'IU, Alberto Garzón, propose ainsi un " référendum consultatif », sans forcément qu'il soit directement suivi d'effets juridiques, afin de pouvoir consulter les citoyens sur la forme de l'État espagnol: pour lui, "même si les citoyens choisissaient la monarchie, ce serait une grande avancée de les consulter ${ }^{33}$. Dans son récent ouvrage La Troisième République, il plaide pour " un changement des règles du jeu afin de se doter de mécanismes pour combattre la

\footnotetext{
31. «Las JSE llevamos la apuesta por la República », Público, 29 avril 2012.

32. « Malaise en Espagne après l'accident de chasse du roi au Botswana », Le Monde, 16 avril 2012.

33. Carmen MoRÁN, « Entrevista con Alberto Garzón : Aunque se eligiera Monarquía ya sería un gran avance el hecho de consultarlo », El País, 4 juin 2014.
} 
corruption et faciliter la transparence en politique ${ }^{34}$ ". La république constituerait selon lui le "symbole de cette nouvelle politique ${ }^{35}$ ". Il évoque le fait que "la modernisation des institutions est beaucoup plus lente et insuffisante par rapport aux demandes des citoyens, en raison des résistances et des intérêts des deux partis dominants à maintenir le système en place, notamment en ce qui concerne le flou autour du financement des partis et les entraves à l'indépendance de la justice ${ }^{36}$ ". Il note de même l'émergence d'une " jeunesse républicaine » beaucoup plus critique à l'égard de la monarchie que la génération antérieure, estimant ainsi que "les bases du PSOE sont républicaines, mais que l'appareil du parti parle pour elles dans un sens contraire ${ }^{37}$ ".

Même si certains des constats d'Alberto Garzón peuvent être justes, force est de constater que l'influence de IU est déclinante. Certes, le parti bénéficié d'un regain de sympathie entre 2009 et 2012, au plus fort de la crise, avec notamment une hausse des intentions de votes en sa faveur dans les sondages, mais l'ascension de Podemos et des partis de la " nouvelle politique " semble jouer très en défaveur d'une formation qui demeure associée à la " vieille politique $»^{38}$. Lors des manifestations républicaines des dernières années, bien peu furent ceux qui pouvaient nommer l'actuel secrétaire général du PCE, José Luis Centella. Lors d'une manifestation à Barcelone, un jeune manifestant demande d'ailleurs à un journaliste de La Vanguardia: «Il existe encore le parti des communistes? ", ce qui montre bien que pour les jeunes, la coalition est associée à une époque révolue ${ }^{39}$. Même si le concept de "Troisième République » rassemble une part importante des mouvements sociaux qui s'opposent aux politiques d'austérité, au gouvernement du PP et qui dénoncent la corruption, parmi les partis politiques, seuls IU et les partis régionalistes ou indépendantistes ( $E H$ Bildu, ERC et BNG) plaident pour un changement de régime. Mais comme nous le verrons, ces derniers défendent plus une évolution du statut de leur communauté autonome respective, qu'ils ne s'identifient à un changement de la forme de l'État central. Enfin, le PSOE demeure favorable à la monarchie et voit en Philippe VI le respect de la constitution et de la normalité

34. Alberto Garzón Espinosa, La Tercera República, Madrid, Madrid Ediciones Atalaya, 2014, p. 12. 35. Ibid., p. 15.

36. Ibid., p. 17

37. Ibid., p. 34.

38. Le parti citoyens d'Albert Rivera, symbole de la «nouvelle politique » avec Podemos dirigé par Pablo Iglesias, est en faveur du maintien de la monarchie, mais demande plus de transparence. 39. «Manifestaciones republicanas en Catalunya », La Vanguardia, 3 juin 2014. 
institutionnelle $\mathrm{e}^{40}$. Sa base militante est toutefois plus partagée et les jeunesses du parti sont ouvertement républicaines ${ }^{41}$.

\section{Les manifestations républicaines lors de l'abdication de Juan Carlos}

Les manifestations républicaines les plus importantes des dernières années eurent lieu lors de l'abdication de Juan Carlos $\mathrm{I}^{\mathrm{er}}$. Ces mobilisations citoyennes furent essentiellement spontanées, effectuées la plupart du temps sans convocation préalable ni demande d'autorisation, suite à la propagation de la nouvelle sur les réseaux sociaux ${ }^{42}$. Le 6 juin 2014, 4000 personnes se réunirent ainsi à Valence, et environ 1000 personnes respectivement à Castellón de la plana et à Alicante, reprenant le slogan " Pour la République, les processus constituants, le droit à décider et le référendum ${ }^{43}$ ». La revendication républicaine était ainsi mêlée à celle $\mathrm{du}$ "droit à décider », concernant tant la forme de l'État que l'indépendance ou non des "Pays catalans ", au sein desquels les indépendantistes incluent la communauté valencienne et son important groupe de locuteurs du catalan. Les mouvements de jeunesse Democracia Real Ya et Juventud Sin Futuro relayèrent activement l'appel à manifester. Quarante organisations de la communauté valencienne, des syndicats, des partis et des mouvements sociaux participèrent à ces manifestations ${ }^{44}$.

Parmi ces entités figuraient Compromís, Esquerra Unida del País Valencia (EUPV), Podemos, le PCE, les syndicats CC. OO et Intersindical Valenciana, de même que d'autres organisations comme Acció Cultural, les assemblées du 15-M, la PAH ou le collectif de la Marche pour la dignité $^{45}$. IU convoqua de même une grande manifestation à Madrid le samedi 7 juin $2014^{46}$. Dans l'ensemble, les manifestations furent importantes lors de l'abdication de Juan Carlos $\mathrm{I}^{\mathrm{er}}$, puis déclinèrent lors de la

40. L'ex dirigeant du PSOE, Alfredo Pérez Rubalcaba déclara ainsi que «la succession de Juan Carlos ler et sa succession par Philippe VI ouvre un temps nouveau pour l'Espagne. La monarchie incarne le compromis pour la coexistence et le consensus que représente notre loi fondamentale ». Cf. El Mundo, 15 juin 2014.

41. Lors des primaires du parti du 13 juillet 2014, José Antonio Pérez Tapias, représentant du courant «Gauche socialiste » demanda par exemple un référendum, le PSOE devant faire prévaloir sa « tradition républicaine » selon lui.

42. Àngels PIÑol et Jesús SERVulo GONZÁLEZ, « Miles de personas reclaman un referéndum sobre la Monarquía », El País, 2 juin 2014.

43. Le slogan exact en valencien était «Per la República, els processos constituents, el dret a decidir i per un referèndum ».

44. « Miles de personas piden en la calle un referéndum por la república », El Mundo, 7 juin 2014.

45. Cristina VÁZQUEZ, " 40 entidades se unen para reivindicar la república », El País, 6 juin 2014.

46. « IU comunica al Gobierno una manifestación para pedir un referéndum », El País, 4 juin 2014. 
proclamation du nouveau roi Philippe VI le 19 juin, preuve du caractère réactif et conjoncturel de ces mobilisations. Ainsi, le 19 juin, seuls 400 sympathisants républicains se mobilisèrent dans la rue à Valence. À Alicante, trois manifestations successives réunirent respectivement 3000, 2000 puis 1000 personnes environ. Lors de la proclamation du nouveau roi, il n'y eut pas de contestation massive, mais pas vraiment d'engouement non plus dans la plupart des villes espagnoles ${ }^{47}$. Comme le notèrent de nombreux journalistes et observateurs, hormis sur le trajet du convoi royal, peu de drapeaux de l'Espagne flottèrent aux balcons le jour de l'intronisation de Philippe VI: le sentiment le plus partagé fut une certaine forme de résignation.

L'étude des slogans les plus récurrents lors des manifestations permet d'illustrer le discours politique et les principales revendications des groupes mobilisés. Lors des actions collectives dans les villes moyennes de la communauté valencienne, à Gandia, Dénia, Alcoi et Elche, des lycéens et étudiants scandèrent des slogans en faveur d'un "référendum royal maintenant ", appelant "Les Bourbons aux élections", ou invoquant "La prochaine expulsion, à la Zarzuela ", comme le firent les jeunes d'Alicante ${ }^{48}$. Plutôt que de mettre en avant la légitimité " historique " de la monarchie, ils critiquaient son absence de «légitimité électorale ». Il est clair que dans la tradition monarchique, en GrandeBretagne, en Belgique ou ailleurs en Europe, l'institution royale ne se soumet pas au vote des citoyens lors d'élections régulières, puisqu'elle se fonde justement sur le type de "légitimité traditionnelle " évoquée par Max Weber, transmise de façon héréditaire et fondée sur les coutumes et la tradition ${ }^{49}$. Mais la "tradition" monarchique demeure contestée en Espagne, tant son histoire moderne et contemporaine a été liée à des épisodes répétés de dérives autoritaires et de gestion sulfureuse du pouvoir.

Les autres slogans principaux des manifestants faisaient référence à des questions d'ordre économique: "Non aux coupes budgétaires ", «Le gendre du Bourbon, en prison pour vol »; " Nous ne sommes pas des paysans, nous sommes des républicains "; "Pour le déficit, une réforme de la constitution est possible. Pour la monarchie aussi ». D'autres slogans appelaient à une "seconde transition" à travers une réforme des institutions et des pratiques politiques, afin de lutter

47. «Un día como cualquiera », El País, 19 juin 2014.

48. "Los republicanos exigen que los Borbones se sometan a una consulta », El País, 8 juin 2014.

49. Max WEBER, Économie et société, Paris, Flammarion, [1922] 2003, p. 219. 
Photo 3.2. Manifestation républicaine lors de l'abdication de Juan Carlos ${ }^{\text {er }}$, Puerta del Sol, Madrid, 2 juin 2014

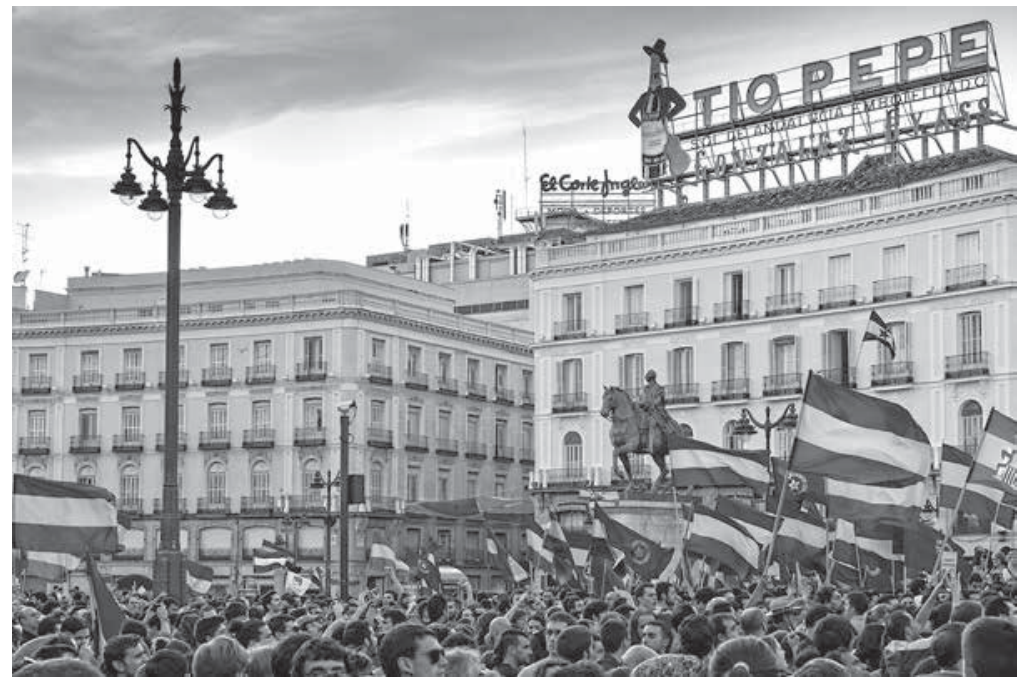

contre la corruption et d'introduire le respect de certains droits sociaux, comme celui au logement, dans une nouvelle loi fondamentale. En ce sens, on comprend bien que les manifestations républicaines lors de l'abdication de Juan Carlos doivent être analysées à partir du contexte social de l'Espagne d'aujourd'hui, marquée par un sentiment assez répandu d'injustice. Une perception fondée sur un manque d'équité dans l'imposition de politiques d'austérité aux classes populaires touchées de plein fouet par la crise, sur les inégalités de traitement face à la justice et l'impunité des "puissants ", ou encore sur la priorité donnée au paiement de la dette publique au détriment d'autres objectifs politiques et sociaux.

Lors de la succession, le 19 juin 2014, une cérémonie marquée par la sobriété, sans invitation de chefs d’État étrangers et sans la présence de Juan Carlos $\mathrm{I}^{\mathrm{er}}$, l'interdiction des drapeaux républicains durant le défilé suscita la polémique ${ }^{50}$. La police justifia cette mesure en invoquant la loi Corcuera de 1992 et une décision du tribunal supérieur de

50. Jesús DuVA, « La policía impedirá exhibir banderas republicanas durante el desfile », El País, 18 juin 2014. 
justice (TSJ) de Madrid motivée par le "risque d'affrontements ${ }^{51}$. Le " risque réel » et " certain " d'échauffourées selon le TSJ prévalut sur la liberté d'expression pour interdire la manifestation « Revendiquer la République face à la proclamation du nouveau roi ». La police interdit les drapeaux républicains sur le parcours de Philippe VI, même aux balcons, au motif qu'ils pouvaient constituer "des provocations pour les personnes qui suivent le défilé $»^{52}$. Les drapeaux des récalcitrants furent confisqués. Mais le TSJ reconnut qu'il n'était pas possible de mettre les personnes en détention, sauf dans le cas de désobéissance aux agents et d'altercations. La coordination républicaine de Madrid suspendit donc la manifestation prévue, appelant toutefois les citoyens à "exhiber pacifiquement " le drapeau républicain en symbole de "liberté inconditionnelle». La loi espagnole n'interdit pourtant pas l'usage d'un drapeau (quel qu'il soit) dans l'espace public. Il ne peut pas y avoir de sanctions. Le TSJ de Madrid annula d'ailleurs récemment un arrêté du maire de Torrelodones, qui cherchait à empêcher IU d'arborer un drapeau républicain durant les fêtes de la ville. Eduardo Madina, alors candidat au poste de secrétaire général du PSOE, déclara " ne pas voir de raison d'interdire les drapeaux républicains ». Pour autant, certains policiers distribuaient des drapeaux espagnols lors du défilé, sortant évidemment de leur rôle, selon une pratique dépourvue de neutralité. Même s'il est clair qu'il s'agissait avant tout de donner au reste du monde une bonne image d'unité et d'une succession monarchique réussie, il apparut aussi toutefois, de façon évidente, que l'argument de la sécurité fut utilisé politiquement par les juges madrilènes et par le gouvernement conservateur afin d'éviter une éventuelle politisation de la cérémonie de la succession.

\footnotetext{
51. Il est de notoriété publique que la « neutralité » du Tribunal supérieur de justice de la communauté autonome de Madrid peut parfois être mise en question, notamment sur les questions hautement politiques, telle que la succession par exemple. En effet, il faut tenir compte du fait qu'un tiers des sièges de la chambre civile et pénale sont réservés à des juristes reconnus, souvent anciens membres ou proches de partis politiques, nommés par le Conseil général du pouvoir judiciaire (CGPJ) sur proposition de l'assemblée législative de la communauté autonome de Madrid, dominée sans partage, faut-il le rappeler, par le parti populaire depuis 1995.

52. Les directives policières consistèrent à inciter les agents à prendre note des appartements ornant des drapeaux républicains sur le passage du cortège, et de chercher ensuite à savoir, par un contrôle au domicile des personnes concernées, si l'intention était de provoquer. On imagine le type de conversations surréalistes entre policiers et occupants pour savoir si ces derniers cherchaient à " provoquer » ou à simplement " exercer leur liberté d'expression ». Pour éviter les drapeaux républicains aux balcons, les policiers effectuèrent des visites dans les jours qui précédèrent le défilé.
} 


\section{RÉPUBLICANISME ET INDÉPENDANTISME}

Le renouveau de la revendication républicaine est aussi allé de pair avec l'essor des mouvements indépendantistes et régionalistes en Catalogne, au Pays basque et en Galice. En effet, ces communautés autonomes ont connu plusieurs manifestations où se sont mêlés républicains et indépendantistes, illustrant une certaine convergence entre les revendications de ces courants politiques pourtant très distincts.

\section{La demande d'un référendum dans le contexte de la consultation catalane}

En Catalogne, cinq mille personnes sont mobilisées sur la place Sant Jaume à Barcelone en réponse à l'abdication du roi Juan Carlos ${ }^{53}$. Dans le cas catalan, les partis politiques ERC, la Candidature d'unité populaire (CUP) et la petite formation Solidarité catalane utilisèrent la manifestation républicaine afin de remobiliser leurs sympathisants en faveur de l'indépendance. Le député régional et porte-parole adjoint d'ERC Oriol Amoròs, et les représentants du parti au Congrès des députés, Alfred Bosch et Joan Tardà, firent acte de présence. Au contraire, Convergència i Unió (CiU) ne se prononça pas sur l'abdication et ne se mobilisa pas non plus dans la rue, attitude montrant bien le conservatisme de la formation et son acceptation implicite de la monarchie. Une illustration par ailleurs de l'absence de consensus des indépendantistes catalans sur cette question, certains préférant le silence et l'évitement, d'autres la mobilisation et l'opposition. Comme ailleurs dans le reste de l'Espagne, les mobilisations furent plus nombreuses en réaction spontanée à l'abdication de Juan Carlos $\mathrm{I}^{\mathrm{er}}$ que lors de l'intronisation du nouveau roi Philippe VI: le 19 juin, seules six cents personnes se réunirent ainsi respectivement à Gérone et Lleida, et cinq cents personnes à Tarragone sur la Plaza de la Font.

L'Assemblée nationale catalane (ANC), à l'origine des plus importantes manifestations enregistrées depuis la transition démocratique en Catalogne, notamment le 5 septembre de chaque année depuis 2011 lors de la Diada, le "Jour de la Catalogne", se démarqua de même des mobilisations. L'ANC souligna que les revendications en faveur d'un changement de monarque ou d'un nouveau régime en Espagne doivent être séparées de celles portant sur la tenue d’un référendum

53. Maiol RogER, «El independentismo se moviliza a medio gas a favor de la República », El País, 3 juin 2014. 
sur l'indépendance de la Catalogne. Dans un communiqué ultérieur, l'ANC déclara de même qu'elle ne soutient pas la revendication d'une république espagnole, étant donné qu'elle se focalise uniquement sur la politique catalane, à travers la proclamation et la reconnaissance d'une république catalane indépendante ${ }^{54}$. Malgré cette position de la direction de l'ANC, des membres de son mouvement de jeunesse, l'Assemblée nationale des jeunes indépendantistes (ANJI-ANC), ont participé aux manifestations prorépublicaines, mais il est vrai en brandissant le plus souvent des drapeaux catalans. Le 2 juin à Barcelone, deux grandes estelades, le drapeau catalan, furent étendues sur le sol avec le slogan "nous voulons voter. 9N 2014 ", allusion très claire à la consultation souverainiste prévue pour le 9 novembre ${ }^{55}$. Dans une dynamique similaire à celle de l'ANJI-ANC, les Jeunesses socialistes du Partit dels Socialistes de Catalunya (PSC) et le député autonomique Ferran Pedret se démarquèrent des positions monarchistes du PSOE et du PSC, mettant en évidence l'existence d'un clivage générationnel dans la perception de la légitimité de la monarchie au sein du socialisme et de la gauche en Espagne.

Les souverainistes et les républicains ont protesté ainsi ensemble, unis par leur rejet commun de la monarchie plus que par un projet politique partagé. Certains ont brandi même deux drapeaux, l'un catalan, l'autre républicain, réclamant le changement de régime d'un État qu'ils désirent abandonner. Les slogans républicains tels que : "Espagne, demain sera républicain ", "Vers la Troisième République " ou "À bas la monarchie, à bas l'hypocrisie ", se sont partagé le terrain avec d'autres plus généraux comme : "En démocratie, le peuple décide ", "Le bipartisme PPSOE s'effondre, c'est notre moment ", ou d'autres encore, plus directement liés à la question catalane (« les Catalans nous n’avons pas de roi »; ou le traditionnel «I-Inde-Independencia », répété à de nombreuses reprises ces dernières années). Les revendications des manifestants ont mis en avant non seulement la crise de légitimité de la monarchie, mais aussi la paralysie du système politique, bloqué par l'alternance entre le PP et le PSOE, deux partis qui ont déçu les électeurs par leurs promesses non tenues. La crise de confiance des citoyens à l'égard de leurs élites politiques a ainsi dominé ces actions collectives. Des slogans tels que « les Bourbons sont des requins » ou « Urdangarín,

\footnotetext{
54. Rebeca CARANCO, « ¡A por la República catalana! », El País, 3 juin 2014. 55. «Miles de personas se concentran en Barcelona a favor de la República », El Mundo, 2 juin 2014.
} 
qu'il travaille au Burger King ", mirent en scène et dénoncèrent de façon imagée les affaires de corruption qui touchèrent l'entourage du roi Juan Carlos $\mathrm{I}^{\mathrm{er}}$. Certains protestataires se sont déguisés en clowns ou en animaux, avec des éléphants en carton, des têtes ou des combinaisons de lion, faisant allusion avec humour au malencontreux safari du roi au Botswana, qui révéla tant sa liaison adultère que son goût pour les activités de luxe, dans un contexte social et économique particulièrement difficile pour les Espagnols.

Au-delà des membres d'ERC et de la CUP, parmi les personnalités politiques qui se joignirent à ces manifestations, on nota surtout la présence des dirigeants d'Esquerra Unida i Alternativa (EUiA-ICV), Joan Herrera et Dolors Camats ${ }^{56}$. EUiA est le parti politique catalan au positionnement le plus cohérent sur la question, puisque des fédéralistes et des indépendantistes coexistent en son sein: il est favorable à l'instauration d'une "république espagnole " via l'instauration parallèle d'un État fédéral, appréhendé comme une fédération d'entités autonomes, qui inclurait donc potentiellement des éventuelles républiques catalane ou basque. Pour EUiA, comme pour Ada Colau, l'ex porte-parole de la $\mathrm{PAH}$, ou pour les "Iaioflautas ", la question démocratique à travers la demande de l'organisation de référendums, que ce soit dans le contexte du futur statut de la Catalogne ou sur le régime politique de l'État espagnol, joua un rôle central dans ces mobilisations. À titre d'illustration, on peut citer ici le propos de Ramón Barba, rapporté par El País, un Iaioflauta de Barcelone de 59 ans:

J'espère qu'il y aura un référendum. La Couronne a été imposée dans la Constitution sans débat. Là, c'est la même chose, l'abdication du roi a été une surprise pour tout le monde. Ils veulent aller vite pour introniser le nouveau roi sans débat. C'est un déni de démocratie. C'est la même chose pour le référendum catalan. Ils s'opposent au 9-N et ne veulent pas laisser le droit au peuple de décider de son propre futur.

Ce propos résume bien le grief principal des manifestants, à savoir l'idée du manque de consultation des citoyens et de l'imposition, tant de la forme de l'État espagnol que du statut de la Catalogne, à travers des pactes entre les élites dominantes ("ils») des deux principales forces politiques.

56. EUiA-ICV est une coalition de gauche alternative qui regroupe la branche catalane d'IU (EUiA), la formation Iniciativa per Catalunya, et le parti écologiste Els Verds (« les Verts »). 


\section{Au Pays basque: un enjeu mobilisateur pour les indépendantistes}

$\mathrm{Au}$ Pays basque, les militants de la gauche abertzale se sont joints aux manifestations des groupes républicains, des communistes et d'IU ${ }^{57}$. À Bilbao, les députés d'EH Bildu Oskar Matute et Maribi Ugarteburu et quelque 400 personnes seulement ont manifesté sur la place du théâtre Arriaga le 2 juin 2014, arborant de nombreuses ikurriñas en faveur de la "république basque libre " et de l'" indépendance ». Dès le départ, l'abdication du roi a été utilisée politiquement par les indépendantistes pour mettre en avant et remobiliser leurs sympathisants autour de l'enjeu de la création d'une "république basque " indépendante. $E H$ Bildu a ainsi incité d'autres formations politiques et collectifs de gauche, de même que certaines organisations syndicales (notamment Podemos, Ezker Anitza-IU, Equo, les jeunesses du PSE-EE, et l'UGT) ${ }^{58}$, à participer à une manifestation unitaire à Bilbao le 19 juin: mais alors que les manifestants " prorépublicains » demandaient un référendum sur le modèle d'État de l'Espagne (à travers le slogan "Monarkiari ez, hirtarrek erabaki ", "Non à la monarchie, les citoyens décident »), les indépendantistes prirent le soin de bien différencier leur cortège du reste des manifestants ${ }^{59}$. Ils appelaient à la création d'une " république basque indépendante ", en exigeant un processus démocratique qui permette " aux citoyens et aux peuples de l'État de décider de leur futur ${ }^{60}$.

Contrairement au reste de l'Espagne, où les actions collectives furent plus importantes lors de l'abdication de Juan Carlos ${ }^{\text {er }}$ puis s'essoufflèrent lors de l'intronisation du nouveau roi, le retrait du monarque suscita initialement peu de manifestations, avant que les indépendantistes se saisissent de l'occasion pour remettre leurs revendications sur le devant de la scène. Le 18 juin 2014, mille cinq cents personnes défilèrent à Vitoria-Gasteiz, puis deux mille personnes le jour suivant à Bilbao. Ce jour était aussi la date anniversaire de la prise de la ville par les troupes franquistes le 19 juin 1937, prétexte à la mobilisation de la Plateforme basque contre les crimes du franquisme. Contrairement au

\footnotetext{
57. "Cientos de personas se echan a la calle en contra de la Monarquía », El País, 2 juin 2014. 58. D'autres collectifs moins nombreux et représentatifs participèrent aussi à la manifestation, notamment Iratzarri-EKI, Alternativa Republicana, Antikapitalistak, Círculo Republicano, Colectivo Republicano de Euskal Herria, Gazte Komunistak, GKB, Goldatu, Ikasle Ekintza et URE Orduña.

59. «Concentraciones para reivindicar la república vasca o un referéndum », El País, 19 juin 2014.

60. «Manifestación contra la Monarquía », El País, 18 juin 2014.
} 
cas catalan, au Pays basque, les cortèges des différents collectifs mobilisés prirent toujours le soin de manifester séparément. EH Bildu revendiquait ainsi « la reconnaissance et le respect du droit à décider d'Euskal Herria ", alors qu'Ezker Anitza-IU axa ses slogans sur un changement de régime ("Jamais deux sans trois, République de nouveau "; " Les Bourbons aussi, à la queue de l'Inem ${ }^{61}$ »). À Saint-Sébastien, quatre cortèges distincts ont manifesté ${ }^{62}$.

\section{Des mobilisations minoritaires en Galice, symbole d'un régionalisme conservateur}

Enfin, en Galice, trois mille personnes se sont mobilisées à Vigo le 2 juin 2014 sur la rúa do Príncipe et devant le musée d’Art contemporain de la ville ${ }^{63}$. D'autres manifestations eurent lieu à La Corogne, à Ourense et à Lugo (où deux cents personnes à peine ont défilé). Les militants du Bloc nationaliste galicien («Bloque Nacionalista Galego, $\mathrm{BNG}$ ) et de l'Alternative galicienne de gauche (" Alternativa Galega de Esquerda, AGE), de même que les membres des Jeunesses socialistes de Galice, auront été les principaux initiateurs de ces actions collectives. Des représentants de Podemos se sont joints aussi aux cortèges qui entonnèrent des slogans comme "La Zarzuela, la prochaine expulsion ", "Référendum ", ou encore le désormais célèbre "Oui nous pouvons ». À Saint-Jacques de Compostelle, la revendication identitaire fut plus marquée: quatre cents personnes défilèrent en faveur de « l’indépendance » et d'une république de Galice. Comme en Catalogne, les groupes de jeunesse indépendantistes furent assez mobilisés, criant notamment « Dehors les Bourbons de notre nation " ( Fóra Borbóns da nosa nación »), " Notre ruine, c’est l’Espagne » ("A nosa ruina, España é »), ou encore "Avançons sans relâche vers la république galicienne " ( Avante sen tregua á república galega»). Lors de l'intronisation de Philippe VI, seuls quelques centaines de manifestants se mobilisèrent à nouveau dans ces villes, preuve du caractère très minoritaire, voire

61. L'Inem est I'Institut National de l'Emploi. À Bilbao, le groupe communiste appela à une "Troisième République» et entama le chant de l'internationale devant la mairie. À Pampelune, seule4 une centaine de personnes manifestèrent, et crièrent en basque « Dehors la monarchie! » et "République basque », illustrant bien la prédominance historique du conservatisme en Navarre et le caractère minoritaire des groupes républicains au sein de cette communauté autonome.

62. Depuis son élection en 2012 à Saint-Sébastien, le maire Juan Carlos Izagirre du parti indépendantiste basque Bildu, dresse symboliquement un drapeau républicain depuis le balcon de la mairie le 14 avril de chaque année.

63. « Miles de gallegos salen a la calle para pedir la República », El País, 2 juin 2014. 
résiduel de ce mouvement, dans une région où un conservatisme politique teinté de régionalisme domine ${ }^{64}$.

\section{RENOUVEAU ET DÉCLIN DU RÉPUBLICANISME DANS L'ESPAGNE D'AUJOURD'HUI}

Ainsi, au final, comment expliquer le renouveau du mouvement républicain dans l'Espagne d'aujourd'hui? En réponse à cette question, nous avons montré dans ce chapitre que la récurrence des manifestations républicaines ces dernières années est intimement liée au contexte de crise économique, sociale et politique qui caractérise l'Espagne depuis 2008. La crise a non seulement provoqué une paupérisation des classes moyennes et populaires et une augmentation des inégalités, mais s'est aussi traduite par une crise de légitimité des élites et du système politique issu de la transition et de la constitution de 1978. Cette situation de perte de confiance à l'égard du personnel politique et des principales institutions espagnoles a amené un nombre croissant de citoyens à réévaluer de façon critique le " pacte " de la transition. Pour les communistes et les descendants des républicains, victimes ou exilés pendant la guerre civile, la monarchie espagnole a été imposée d'en-haut par les élites de l'ancien régime franquiste, et constitue donc le dernier symbole d'une démocratisation inachevée. Pour ce secteur social qui demeure minoritaire dans l'Espagne d'aujourd'hui, la transition aura été incomplète et la république, idéalisée à partir du souvenir et d'une mémoire mythifiée et quelque peu déformée de la Seconde République, constituerait la solution.

Mais comme nous l'avons vu, l'histoire contemporaine du républicanisme en Espagne demeure très controversée et sujette à des interprétations opposées. Pour la majeure partie de la société espagnole, la « république " n'est pas instinctivement associée au futur, à la modernité, à la coexistence pacifique et au progrès social. Dans la mémoire collective, elle est plutôt accolée aux démons du passé, à la division et au conflit, et demeure très connotée idéologiquement en référence à l’idéal politique de la gauche, plus qu'elle ne symbolise un régime politique consensuel. C'est pourquoi la monarchie n’a pas échappé à la crise de légitimité qui touche l'ensemble des institutions espagnoles. Mais comme des témoignages de

64. Pour une étude synthétique de l'évolution des clivages politiques en Galice, voir Nieves LAGARES, José Manuel RIVERA et Ramón MAIZ, "Le nationalisme galicien: de l'accès au gouvernement à la crise électorale et organisationnelle », dans Alicia FERNÁNDEZ GARCíA et Mathieu Petithomme (dir.), Les nationalismes dans l'Espagne contemporaine (1975-2017). Compétition politique et identités nationales, Paris, Armand Colin, 2012, p. 135-166. 
manifestants ont permis de souligner, et comme le suggèrent les sondages d'opinion, ce sont d'abord les partis politiques traditionnels, leurs élites et le gouvernement qui sont mis en cause. Les Espagnols continuent de plébisciter majoritairement la monarchie et la figure du roi. Il est vrai toutefois que le cas Nóos, ayant mis en avant l'existence de pratiques de corruption dans l'entourage de Juan Carlos $\mathrm{I}^{\mathrm{er}}$, et son safari au Botswana en 2012 alors qu'il avait demandé aux Espagnols de " faire des efforts ", assurant que "la justice est la même pour tous " dans son discours de Noël du 24 décembre 2011, s'est révélé profondément en décalage avec le vécu quotidien des citoyens ordinaires. En seulement quelques semaines, Juan Carlos $\mathrm{I}^{\mathrm{er}}$ a perdu une bonne partie du crédit historique qui était le sien pour avoir joué un rôle majeur durant la transition, résisté à la tentative de coup d'État du 23 février 1981 et contribué à redonner à l'Espagne sa place dans le concert des nations européennes.

Pour autant, comme nous l'avons mis en avant, les manifestations survenues lors de son abdication ont été essentiellement spontanées, liées à l'effet de surprise et à l'euphorie du moment. Il ne s'est en rien agi d'un mouvement social massif d'opposition à la monarchie. Nous l'avons constaté, ces mobilisations ont surtout été importantes en Catalogne et au Pays basque, à savoir au sein de communautés autonomes où les manifestants ne se mobilisèrent pas tant contre la monarchie qu'en faveur d'un nouveau statut politique pour leur territoire. Il est d'ailleurs révélateur qu'en Galice, où coexistent régionalisme identitaire et conservatisme politique, les manifestations prorépublicaines furent très peu suivies. Dans l'ensemble de l'Espagne, l'intronisation du nouveau roi Philippe VI a sonné le glas de ces mobilisations et attesté une forme de résignation des citoyens. Le républicanisme demeure d'autant plus minoritaire aujourd'hui que le PSOE, qui reste à ce jour le principal parti de la gauche, est attaché au régime politique de la monarchie parlementaire, même si les opinions de sa base militante et de ses électeurs demeurent plus nuancées.

Conscient de la peur de l'inconnu et de l'image rassurante de stabilité que transmet la monarchie à beaucoup d'Espagnols, le nouveau parti Podemos a d'ailleurs fait évoluer sa position initiale, en évoquant la possibilité d'un référendum mais en ne mettant plus vraiment cette question au centre de ses préoccupations ${ }^{65}$. Le parti Citoyens d'Albert

65. Pour Pablo Iglesias, « l'abdication accélère la décomposition du régime de 1978 ». Podemos a dénoncé le pacte PSOE-PP pour la réforme de la loi organique qui a ouvert la succession Cf. Anabel DieZ, "Las fuerzas de izquierda piden un referéndum sobre la monarquía », El País, 2 juin 2014. 
Rivera, qui devrait concurrencer le PP en attirant une partie de son électorat libéral, ne demande pas non plus un changement de régime. Les manifestations républicaines de ces dernières années ont ainsi traduit l'indignation, la défiance politique généralisée et la volonté de changement des citoyens plus qu'un désir d'en finir avec la monarchie. L'abdication de Juan Carlos I ${ }^{\text {er }}$ et son remplacement par Philippe VI, qui s'appuie sur un couple royal doté d'une image moderne et glamour, furent en ce sens une décision sage et stratégique de Juan Carlos ${ }^{\mathrm{er}}$, afin de « sortir par le haut » de la crise de légitimité dans laquelle il avait fait entrer la monarchie du fait d'une succession d'épisodes polémiques. Seul l'avenir dira si le nouveau roi saura réaffirmer la légitimité de la monarchie ${ }^{66}$. Une institution dont le principal déterminant de légitimité populaire ne dépend pas tant de l'effet des mobilisations d'un mouvement social républicain qui demeure minoritaire que de sa propre capacité à incarner une autorité neutre, exemplaire et rassembleuse.

66. Conscient que la poussée du mouvement indépendantiste catalan constituera l'un des défis de son règne, le simple fait que Philippe VI propose le 26 juin 2014 à Gérone, lors de sa première visite en tant que chef de l'État en Catalogne, un discours d'apaisement, dont la moitié fut prononcé en catalan, illustre à cet égard une évolution qui peut paraître anecdotique, mais qui illustre bien une rupture avec le passé et avec la domination du castillan dans les discours de Juan Carlos ler. 


\title{
4
}

\section{Les féminismes dans l'Espagne d'aujourd'hui}

\begin{abstract}
Karine BERGÈS
Je m'obstine à penser que le féminisme n'est pas une politique que l'on peut appliquer sans les femmes, et à leur place, sans qu'elles-mêmes, collectivement et singulièrement, d'une génération à l'autre, s'y impliquent activement. Ce n'est pas une religion du salut, une nouvelle Écriture Sainte. Il n'y a pas de Terre Promise, pas de Moïse, pas de petite ou de grande mère des peuples. Mais il y a une marche collective et singulière, avec ses divisions et ses errances.

(Françoise Collin)
\end{abstract}

Après trente-six années de dictature, la mort du général Franco, le 20 novembre 1975, ferme la longue parenthèse d'un régime personnaliste, autoritaire et répressif reposant sur le seul pouvoir du Généralissime ${ }^{1}$. Si tous les citoyens furent privés des libertés fondamentales et contraints de se plier aux injonctions d'un régime national-catholique, les femmes endossèrent un double statut de victimes: on leur refusa la jouissance des droits civils et politiques à l'instar des hommes, mais également l'accès à la sphère publique, au nom d'un projet maternaliste et patriarcal consistant à " nationaliser " le corps des femmes au service des intérêts réputés fondamentaux du pays ${ }^{2}$. La propagande franquiste érigea l'image de la "gardienne du foyer " en archétype de la féminité hispanique, soumettant ainsi la moitié de la population à une domestication des corps et des esprits. Ce faisant, le

\footnotetext{
1. Pour faciliter la lecture du public français, la traduction de l'ensemble des textes en espagnol, ainsi que celle des noms des collectifs mentionnés, a été réalisée par les soins de l'auteure.

2. Karine BERGÈs, «La nacionalización del cuerpo femenino al servicio de la construcción de la identidad nacional en las culturas falangistas y franquistas ", dans Genre, sexe et nation: représentations et pratiques politiques en Espagne ( $X I X-X X^{e}$ siècles), Madrid, Mélanges de la Casa de Velázquez, 2012, p. 91-103.
} 
cantonnement des femmes dans la sphère intime s’accompagna d'une législation discriminante, d'une socialisation différenciée et d'une assignation sexuée des rôles. Il s'agissait, par l'imposition de politiques "domestiques", de gommer l'héritage de la Seconde République (1931-1936), au cours de laquelle un régime démocratique avait posé les premiers jalons de l'émancipation féminine. Non sans résistances, une législation favorable à l'amélioration de la condition juridique des femmes fut en effet portée par les idéaux républicains: inscription du droit de vote et de l'égalité des sexes dans la constitution du 9 décembre 1931, légalisation du divorce par la loi du 2 mars 1932, et du mariage civil par celle du 28 juin 1932. Si, comme le souligne Danièle BussyGenevois «La République, pour les Espagnoles, a signifié l'apprentissage de la lecture, de l'engagement politique et, avec difficulté, l'apprentissage du sens du vote ", ce lent processus de socialisation politique s'est vu interrompu par la victoire des forces nationalistes à la fin de la guerre civile $\left(1^{\mathrm{er}} \text { avril } 1939\right)^{3}$ : l'institutionnalisation du franquisme sonna le retour des femmes au foyer, le renoncement à leurs engagements militants et/ou professionnels dans la sphère publique et leur soumission à la politique nataliste du régime, sous la férule de l'Église et de la section féminine de la Phalange, appareil de contrôle hégémonique chargé de l'encadrement idéologique des femmes espagnoles tout au long de la dictature ${ }^{4}$.

En dépit de quelques initiatives isolées au cours des années $1960^{5}$, ce n’est qu'en 1975, lors de l'Année internationale de la femme décrétée

\footnotetext{
3. Danièle BusSY-GENEVoıs, "Citoyennes de la Seconde République », dans Marie-Aline BARRACHINA, Danièle Bussy-GenEVoIs et Mercedes Yusta (dir.), Femmes et démocratie: les Espagnoles dans l'espace public (1868-1978), Paris, Éditions du Temps, 2007, p. 145. Nous précisons, dans les notes à suivre, qu'il existe deux ouvrages du même nom mais dans deux maisons d'éditions différentes, l'un aux Éditions du Temps, l'autre chez Ellipse.

4. Sur la Section féminine de la Phalange, voir. les études francophones de Marie-Aline BARRACHINA; Femmes et démocratie: les Espagnoles dans l'espace public (1868-1978), Paris, Sedes-CNED, 2007 ; "La Section féminine et ses paradoxes », dans Marie-Aline BARRACHINA et. al. (dir.), op. cit., p. 147-176; Christine LAVAIL, "Les femmes de la Section féminine de la Phalange: entre espace privé et espace public », dans Florence BELMONTE (dir.), Femmes et démocratie: les Espagnoles dans l'espace public (1868-1978), Paris, Ellipses, 2007, p. 134-174; Karine BERGÈs, "Récits et expériences de la Guerre civile espagnole à travers les écrits des femmes phalangistes (1936-1940) », dans Florence BELMONTE, Karim BENMILOUD et Sylvie IMPARATO-PRIEUR (dir.), Guerres dans le monde ibérique et ibéro-américain, Berne, Peter Lang, 2014, p. 177-184.

5. On mentionnera la création de l'Association des femmes universitaires en 1953 et la fondation du Séminaire d'études sociologiques par María Laffite Campo Alange.
} 
par l'ONU, que le mouvement féministe se structure en tant que tel ${ }^{6}$. Convoquées dans la semi-clandestinité pour les 6 à 9 décembre 1975, les premières Journées de libération de la femme, à l'initiative de la plateforme des organisations de femmes et du Mouvement démocratique des femmes ${ }^{7}$, sont restées dans les annales comme l'acte fondateur du féminisme espagnol. Si cet événement traduisit la vitalité des revendications féministes, quelques semaines seulement après la mort du dictateur, il fut également le révélateur des controverses qui, tout au long de la transition démocratique (1975-1981), allaient fissurer le mouvement autour de deux tendances: le courant du " féminisme radical ", représenté par le Séminaire collectif féministe, soucieux de préserver son autonomie à l'égard des organisations politiques et syndicales, et celui $\mathrm{du}$ " féminisme-lutte des classes ", partisan d'inscrire les revendications féministes au sein de revendications plus générales, par le truchement des partis politiques, avec comme priorité absolue l'instauration d'un régime démocratique ${ }^{8}$. Les féministes de la double militance, bien que conscientes de la structure et du fonctionnement androcentrés des partis politiques, postulaient contre la double exploitation féminine: de classe (et contre celle-ci luttaient les partis politiques de gauche) et d'un

6. Le deuxième Congrès International de la Femme en juin 1970 avait dégagé un premier, bien que timide, espace de parole en faveur de l'émancipation des Espagnoles. Même si ce rassemblement, placé sous la tutelle de la Section féminine ne laissait que peu de place à de véritables changements idéologiques, il offrit une tribune à quelques voix réformatrices, à l'instar de María Telo Núñez, fondatrice de l'Association espagnole des femmes juristes (1971), à qui l'on doit la réforme visant à éliminer l'autorisation maritale obligatoire pour la femme mariée. Sur les réformes juridiques défendues par les avocates Mercedes Fórmica, en 1953, et María Telo Núnez, en 1974, voir Rosario RUIz FRANCo, ¿Eternas menores ? Las mujeres en el franquismo, Madrid, Biblioteca Nueva, 2007; Karine BERGĖS, « La Section féminine (1951-1975) : entre conservatisme et réformisme », dans Marie Claude CHAPUT, Christine LAVAIL (dir.), Sur le chemin de la citoyenneté, Femmes et Cultures Politiques. Espagne $X I X^{e}-X X^{e}$ siècles, Paris, université Paris Ouest Nanterre La Défense, 2009, p. 91-101.

7. Le Mouvement démocratique des femmes a été fondé en 1965 sous la tutelle du Parti communiste espagnol. Voir Mercedes ComABELLA, "Movimiento Democrático de Mujeres », dans Carmen Martínez TeN, Purificación GutiéRREZ LóPEZ, Pilar GonZÁlez RuIz (dir.), El movimiento feminista en España en los años 70, Madrid, Cátedra, 2009, p. 267-274.

8. Pour une étude détaillée du féminisme espagnol pendant la transition, voir María Ángeles LARUMBE, Una inmensa minoría. Influencia y feminismo en la Transición, Saragosse, Prensas universitarias de Zaragoza, 2002 ; Las que dijeron no. Palabra y acción del feminismo en la Transición, Saragosse, Prensas universitarias de Zaragoza, 2004 ; Españolas en la Transición : de excluidas a protagonistas (1973-1982), V. A, Madrid, Biblioteca Nueva, 2000 ; Isabel MorANT (dir.), Historia de las mujeres en España y América Latina. Del siglo XX a los umbrales del XXI, Vol. IV, Madrid, Cátedra, 2006; Pilar Folguera (dir.), El feminismo en España, dos siglos de Historia, Madrid, Ed Pablo Iglesias, 2007 ; Oliva María RUBıo et Isabel TEJEDA (dir.), 100 años en femenino. Una historia de las mujeres en España, Madrid, Acción Cultural Española, 2012. 
système d'oppression de sexe, le patriarcat ${ }^{9}$. Pour la tendance héritière du féminisme radical étasunien des années 1970 et du féminisme matérialiste français de Christine Delphy, il ne faisait nul doute que la double militance était un piège: dès 1975, l'avocate Lidia Falcón avait fondé les collectifs féministes, un espace de militance unique et de réflexion théorique, lesquels ont procédé à une réélaboration de l'héritage marxisteléniniste dans une perspective féministe, et ont formulé des postulats novateurs sur les mécanismes d'exploitation économique et sexuelle des femmes et sur les modes de "production domestique ". Ce courant n'a eu de cesse de défendre la constitution d'un mouvement autonome, exclusivement féminin, dont les principes idéologiques constitueront la clef de voûte du Parti féministe d'Espagne, légalisé en $1981^{10}$.

Entre 1976 et 1979, le mouvement féministe " croît en quantité et en qualité, les tendances se renforcent, les débats et les confrontations idéologiques, fortes et nombreuses, enrichissent le mouvement ${ }^{11}$ et, ses mobilisations fluctuent au gré de l'agenda politique de la transition: loi de réforme politique de 1976, premières élections libres du 15 juin 1977, rédaction de la constitution, majoritairement approuvée par le référendum du 6 décembre 1978, autant d'occasions de désaccord entre les féministes radicales et celles du " féminisme socialiste " ${ }^{12}$. Les Journées féministes de Grenade, qui mobilisèrent trois mille participantes en mai 1979, mirent à nu les lignes de fractures qui continuaient de diviser le mouvement autour de la double militance, mais de nouvelles divergences idéologiques vinrent se greffer aux clivages agissant depuis quatre ans. Contre les féministes radicales ou socialistes, par-

9. Celia Amorós, «Debates ideológicos en el movimiento feminista durante la transición española », dans Carmen MARTínEZ TEN et al. (dir.), op. cit., 2009, p. 196.

10. Sur les origines du Parti féministe en Espagne voir María ÁNGELES LARUMBE, Una inmensa minoría. Influencia y feminismo en la Transición, Zaragoza, Prensas Universitarias de Zaragoza, 2002.

11. Rosa PARDo, «El feminismo en España. Breve resumen, 1953-1985 », dans Pilar FolguERA (dir.), op. cit., 2007, p. 205.

12. Le texte final de la constitution, s'il levait les obstacles légaux à la participation politique des femmes et établissait dans son article 14 le principe de la «non-discrimination en fonction du sexe », n'incluait aucune revendication sur les droits sexuels ou la légalisation de l'avortement. Ce refus du droit au contrôle de la natalité et à la libre disposition de leur corps par les femmes, renforça les clivages entre les deux tendances du féminisme espagnol, les plus radicales rejetant d'un seul bloc le texte constitutionnel alors que les féministes de la double militance, tout en critiquant ses faiblesses, soutenaient que seul un cadre juridique était à même d'accompagner les réformes pour les droits des femmes. II en fut ainsi avec la loi du 22/1978 du 26 mai qui éliminait les articles 449 et 452 du Code pénal relatifs à l'adultère et avec la loi 45/1978 du 7 octobre qui dépénalisait la contraception. Pour la liste des lois réformistes à partir de 1978, voir Pilar FolgueRA, «Integrando el género en la agenda política. Feminismo, transición y democracia », dans Oliva María RuBIo et Isabel TEJEDA (dir.), op. cit., 2012, p. 105. 
tisanes d'une société dans laquelle les hommes et les femmes détiendraient les mêmes droits et obligations, les féministes différentialistes défendaient les visions essentialistes de la différence des sexes en attribuant des qualités ontologiques distinctes aux femmes et aux hommes. Si, comme le suggère María Ángeles Larumbe, "depuis son origine, notre féminisme s'est caractérisé par une fragmentation organisatrice accrue et des divergences théoriques marquées ", la dépénalisation de l'avortement et la légalisation du divorce demeuraient encore, à la fin des années 1970, des sujets de mobilisation collective et unitaire ${ }^{13}$. Pour le mouvement féministe dans son ensemble, l'obtention d'une loi sur le divorce (déjà accordée sous la Seconde République) devenait un enjeu crucial eu égard au texte constitutionnel qui établissait le principe de l'égalité de droit avec les hommes. À l'exception des secteurs les plus conservateurs et de l'Église catholique, cette demande était soutenue par la grande majorité des Espagnols, des responsables politiques, des professionnels du droit et des médias, et finit par être légalisée par la loi du 7 juillet $1981^{14}$. La bataille pour l'avortement, en revanche, se trouva être "la plus conflictuelle que le mouvement féministe eut à mener", en raison du manque de consensus dans la société civile ${ }^{15}$. Sous le slogan « contraception pour ne pas avorter, avortement pour ne pas mourir ", elle mobilisa les militantes tout en révélant la désunion des professionnels de santé ainsi que des clivages au sein même des partis progressistes. Preuve de ces résistances, la loi très restrictive du 5 juillet 1985 sur le droit à l'interruption volontaire de grossesse, approuvée sous la législature du socialiste Felipe González, limitait la dépénalisation de l'IVG à trois cas de figure seulement, comme nous le verrons plus en amont.

Pour clore cette mise en contexte du féminisme sous la transition démocratique, nous rappellerons que la contestation et l'activisme militants commencent à montrer des signes d'essoufflement à partir de 1982, date à laquelle on assiste à une dispersion du mouvement féministe revendicatif, devant la percée du féminisme dit

13. María Ángeles LARUMBE, «Feminismo y Transición democrática: logros y cuentas pendientes », dans Marie-Aline BARRACHINA, Danièle BussY-Genevols et Mercedes YUSTA (dir.), Femmes et démocratie : les Espagnoles dans l'espace public (1868-1978), Paris, Éditions du Temps, 2007, p. 217.

14. Les médias qui appuyèrent le plus la légalisation du divorce furent la revue Triunfo, Cambio 16, El País, et bien sûr la revue féministe radicale Vindicación Feminista qui, durant son existence, de 1976 à 1979, avait défendu dans ses colonnes le divorce et l'avortement sans aucune restriction.

15. María Ángeles LARUMBE, op. cit., 2007, p. 225. 
" académique » et " institutionnel ». Le développement du féminisme académique, à partir des années 1980, s'opéra à l'initiative d'intellectuelles qui, sous la transition, avaient concilié leurs activités académiques avec la militance dans les partis ou mouvements sociaux. Déçues par les organisations politiques, elles fondèrent des centres d'études sur les femmes dans les grandes universités espagnoles afin de récupérer l'héritage des demandes politiques et sociales des années antérieures. Le féminisme académique, entendu comme, " un instrument de changement social qui se doit d'être au service des agents et acteurs sociaux ${ }^{16}$ ", joua un rôle important dans les mobilisations féministes, notamment par le biais des groupes d'autoconscience et de l'Assemblée des femmes de la Complutense, lieu de socialisation féministe tout au long des années $1980^{17}$. Quant au " féminisme institutionnel ", il trouva son terrain d'expression dans la fondation de l'Institut de la femme, en octobre 1983, rattaché au ministère de la Culture $^{18}$ et dirigé par Carlota Bustelo, sous le premier gouvernement socialiste de la démocratie, avec comme mission de "promouvoir et d'encourager les conditions qui favorisent l'égalité entre les deux sexes et la participation des femmes à la vie politique, culturelle, économique et sociale ${ }^{19}$ ". Aussi absorba-t-il dans ses rangs des féministes actives au sein du PSOE, ce qui ne manqua pas de soulever de fortes controverses de la part du féminisme radical, qui critiquait l'atomisation de ses luttes au service des intérêts politiques et la dépolitisation des mouvements sociaux, vidés de leur radicalité et de leur potentialité transformatrice ${ }^{20}$. Cette institutionnalisation du féminisme s'est accompagnée d'une minoration du féminisme indépendant malgré les apports à son actif: s'il a "été décisif dans l'européisation de l'Espagne ${ }^{21}$ », en défendant des réformes qui ont modifié les droits

16. Pilar Folguera, « Voces del feminismo », dans Isabel MoRAnt (dir.), op. cit., 2006, p. 443.

17. Begoña MARUgán, María Jesús MiRAnda et Marta MAto, "El poder de los géneros y los géneros del poder. Relatos de un feminismo encarnado en tres generaciones", Encrucijadas. Revista Crítica de Ciencias Sociales, 2013, n 5, [http://e-archivo.uc3m.es/bitstream/ handle/10016/18940/marugan_poder_EN_2013.pdf?sequence=1], consulté en octobre 2014.

18. Pour un historique de l'Institut de la Femme, voir Celia VALIENTE Fernández, El feminismo de Estado en España. El Instituto de la Mujer (1983-2003), Valence, Institut Universitari d'Estudis de la Dona, 2006.

19. Site internet de I'Instituto de la Mujer, [http://www.inmujer.gob.es/home.htm], consulté en novembre 2014.

20. Pilar Folguera, « De la Transición política a la paridad », dans Pilar Folguera (dir.), op. cit, 2007, p. 179.

21. Mónica ThreLFALL, «El papel transformador del movimiento de mujeres en la transición política española », dans Carmen Martínez Telo et. al. (dir.), op. cit., 2009, p. 44. 
professionnels et juridiques des femmes, le mouvement féministe de la transition a également eu un impact sur l'évolution des mentalités. $\mathrm{Au}$ rythme de ses mobilisations, il est parvenu à instiller une véritable conscience politique aux Espagnoles et à impulser un changement social, qui s'est traduit par l'avènement d'une génération qui a fait sienne les combats historiques des années 1970: accès à l'éducation supérieure, indépendance économique et professionnelle, autonomie personnelle et liberté sexuelle.

Si ce rappel historique concernant le féminisme espagnol démontre sa portée transformatrice de la société espagnole, qu'en est-il de son cheminement au cours des trois dernières décennies? L'institutionnalisation du féminisme, à partir des années 1980, s'est-elle accompagnée d'une neutralisation des collectifs féministes les plus contestataires? En Espagne, le féminisme a-t-il réussi à survivre au « backlash » des années 1990, ce recul antiféministe occidental qui a délégitimé le féminisme en tant que mouvement social et politique ${ }^{22}$ ? Comment, en marge des campagnes portées par le féminisme institutionnel, les féministes des années 2000 sont-elles parvenues à reformuler d'anciennes questions ou à faire émerger des discours et des modes d'action novateurs? De quelle façon la culture de la contestation, refaçonnée par les mouvements citoyens contemporains, à l'instar du mouvement des indignés en 2011, a-t-elle impacté le féminisme espagnol? Dans quelle mesure les théories féministes sont-elles repensées sous l'influence d'un renouveau générationnel et d'une multiplicité de courants autonomes qui se sont positionnés en marge du féminisme mainstream? Autant de questionnements qu'il s'agira d'approfondir dans ce chapitre afin d'esquisser, en filigrane, une généalogie du féminisme espagnol, longtemps resté « un non-objet de l'histoire ${ }^{23}$ ", mais qui ne peut être compris sans l'analyse des espaces-temps dans lesquels il se déploie. Comme le fait remarquer Françoise Thébaud, « les féministes n’habitent pas des îlots de sonorités protégés ", c'est pourquoi nous interrogerons cette histoire des féminismes espagnols à l'aune des mutations politiques, économiques et sociales de la société espagnole contemporaine ${ }^{24}$.

22. Susan FALUDI, Backlash: la guerre froide contre les femmes, Paris, Editions des Femmes, 1993.

23. Brigitte STUDER et Françoise THÉBAUD, «Entre histoire et mémoire », dans Eliane GUBIN et. al. (dir.), Le siècle des Féminismes, Paris, Les éditions de l'Atelier, 2004, p. 28.

24. Françoise THÉBAUD, «Introduction au chapitre Féminismes et Politique », ibid., 2004, p. 223. 


\section{« NOSOTRAS, LAS MUJERES » : LES DÉBATS AUTOUR DE LA REDÉFINITION DU « SUJET DU FÉMINISME »}

Dans l'Espagne des années 1990, le féminisme le plus visible continue d'être porté par l'Institut de la femme et par les organisations proches du Parti socialiste qui inscrivent les politiques de genre au cœur de l'agenda politique: égalité professionnelle, législation sur la parité dans les sphères politiques, lutte contre les violences faites aux femmes ou encore réglementation de la prostitution ${ }^{25}$. Si ces problématiques méritent, sans nul doute, toute l'attention des institutions étatiques, la polarisation autour de thèmes consensuels et médiatiques a eu pour conséquence d'étouffer les revendications les plus radicales émanant des féminismes autonomes, très critiques à l'égard d'un féminisme mainstream accusé de tuer dans l'œuf le potentiel subversif du féminisme. Cette « décennie opaque $^{26}$ ", qui entérine la perte d'unité du mouvement, s'accompagne en miroir d'une féminisation croissante de la pauvreté, sous l'effet du tournant néolibéral des années 1990: chômage, massification de l'emploi précaire, accroissement du secteur informel, inégalités sociales et recrudescence des violences à l'encontre des femmes. Dans ce contexte de mondialisation néolibérale de nouveaux combats se font jour: la précarité, les migrations, le sida, la diversité sexuelle, le trafic prostitutionnel, la pornographie, l'écoféminisme ${ }^{27}$, à la faveur de nouveaux sujets aux profils hétérogènes, lesbiennes, transexuelles, queer, okupas ${ }^{28}$, migrantes, antimilitaristes, antifascistes. Ces féminismes dissidents composent « une nouvelle carte de groupes décentralisés qui élaborent, de manière critique et frontale des questionnements qui en général n'étaient pas abordés par le féminisme traditionnel ou étaient traités de façon

\footnotetext{
25. II faudra malgré tout attendre la première législature du socialiste José Luis Rodríguez Zapatero pour que ces problématiques deviennent un enjeu politique de premier plan avec l'approbation, le 28 décembre 2004, de la loi organique relative aux mesures de protection intégrale contre la violence de genre.

26. María MARTíNEZ GonZÁLEZ, «Les mobilisations féministes et les dynamiques identitaires: une étude du féminisme au Pays basque espagnol », Recherches féministes. Le féminisme: une question de valeur(s), $n^{\circ} 21,2008$.

27. La tradition écoféministe remonte aux années 1970 avec les théories de la penseuse libertaire française Françoise d'Eaubonne (1920-2005), mais ce courant a été réinvesti depuis les années 1990 jusqu'à aujourd'hui par les féministes. Pour une généalogie, cf. Alicia H. PULEO, Ecofeminismo. Para otro mundo posible, Madrid, Cátedra, 2011

28. Le mouvement Okupa, littéralement le mouvement des squats, puise ses racines dans les mouvements d'occupation allemand et italien des années 1970. En Espagne, il se consolide dans les années 1980 en réaction au desencanto de la fin de la transition démocratique, et rejette toutes les institutions au profit de l'action collective, de pratiques sociales, politiques et économiques alternatives, des utopies contestataires et de la contre-culture punk et rock.
} 
marginale ${ }^{29}$ ". Ils sont à l'origine de la formation d'une troisième vague féministe ${ }^{30}$, qui est née aux États-Unis au milieu des années 1990 avec la mobilisation des femmes de couleur (Black Feminism), des immigrées latino-américaines (Chicanas) et des lesbiennes politiques ${ }^{31}$, lesquelles ne s'identifient pas au féminisme radical étasunien de la deuxième vague, un féminisme intellectuel, blanc et hétérosexuel: pour ces catégories de femmes, "l'oppression ne vaut pour toutes les femmes en tout temps, en tout lieu et en toute situation ${ }^{32}$ » et n'est pas seulement le fait de l'oppression de sexe mais aussi de celle de classe et/ou de race, ce qui place le concept d'hybridité au cœur de la troisième vague.

Malgré les points de vue contrastés autour de ces questions, il semble acquis que le féminisme de la troisième vague travaille mieux l'approche intersectionnelle des luttes ${ }^{33}$, rejette plus systématiquement la bicatégorisation normative et s'efforce de dénaturaliser les identités en reprenant à son compte les théories queer, introduites par la philosophe américaine Judith Butler ${ }^{34}$. Ses réflexions ont incontestablement élargi l'horizon conceptuel des féminismes contemporains en

29. Silvia GIL, Nuevos feminismos. Sentidos comunes en la dispersión. Una historia de trayectorias y rupturas en el Estado español, Madrid, Traficantes de Sueño, 2011, p. 68.

30. L'historiographie distingue deux vagues féministes. La première vague renvoie au mouvement suffragiste, qui est apparu à la fin du xixe siècle aux États-Unis (1848) et en Grande Bretagne (1851), centré autour de la demande de l'égalité juridique, civile et politique entre les sexes. La deuxième vague (1970) a porté les revendications qui prônaient la libération des femmes des attaches et normes imposées par la société patriarcale. Ces revendications furent porteuses d'un renouveau du féminisme par le biais de mobilisations radicales (Mouvement de libération des femmes) qui ont pointé la dimension politique de questions traditionnellement considérées comme privées (les violences conjugales, la sexualité, etc.) et ont popularisé le slogan emblématique « le privé est politique ». Rappelons toutefois que ce découpage en vagues est loin de faire I'unanimité au sein de l'historiographie féministe, comme en témoignent, entre autres, les travaux de la philosophe française Geneviève FraISSE, Les excès du genre, Paris, Lignes, 2014.

31. Équivalent du «lesbianisme radical » qui se développe dans les années 1980 et pense l'hétérosexualité comme un « régime politique d'oppression » maintenant les femmes dans une position d'esclavagisme, d'où la nécessité de le renverser. Voir Monique WITTIG, La pensée Straight (2e éd.), Paris, Ballard, 2013 [2001] ; Christine BARD, « Le lesbianisme comme construction politique », dans Eliane GUBIN et. al. (dir.), op. cit, 2004, p. 111-126.

32. Mélissa BlAIS, Laurence ForTIN-PELLERIN, Ève Marie LAMPRON, Geneviève PAGÉ, "Pour éviter de se noyer dans la (troisième) vague : réflexions sur l'histoire et l'actualité du féminisme radical », Recherches Féministes, vol. 20, n², 2007, [http://id.erudit.org/iderudit/017609ar], consulté le 31 mars 2015.

33. L'intersectionnalité « dénonce la prétention à l'universalité d'un féminisme qui ignore son point de vue et appelle à une réflexion sur la coconstruction des différents rapports de domination », cf. Christine BARD, Le féminisme au-delà des idées reçues, Paris, Le cavalier bleu, 2012, p. 271.

34. Judith BUTLER, Gender Trouble: Feminism and the subversion of identity, London New York, Routledge, 1990. En Espagne, les études Queer doivent beaucoup à d'autres théoriciennes comme Donna Haraway, Teresa de Lauretis, Eve Kosofsky Sedgwick ou plus récemment Paul B. Preciado et Marie-Hélène Bourcier. 
formulant des critiques novatrices: critique de la contrainte de l'hétérosexualité, critique de la pensée dichotomique (bipartition de l'humanité en deux sexes), critique de la logique catégorielle comme mécanisme de pouvoir, remise en cause du fixisme identitaire (mutabilité des sujets) ${ }^{35}$.

À l'origine, le terme queer désignait en anglais ce qui est étrange, ce qui est inclassable et qui résiste aux normes de genre ${ }^{36}$. Utilisé depuis le XviII $^{\mathrm{e}}$ siècle comme un stigmate pour répertorier sous un même vocable l'abject et/ou le déviant, le terme a été resignifié au milieu des années 1980 par les communautés lesbiennes, gays, transsexuelles, pour revendiquer leur étrangeté et en signe de résistance politique aux normes hétérosexuelles: l'injure a alors "cessé d'être un instrument de répression sociale pour devenir un signe de résistance à la normalisation ", nous dit la philosophe espagnole et figure de proue de l'activisme queer, Paul B. Preciado ${ }^{37}$. Reprenant à son compte les travaux de Michel Foucault ${ }^{38}$ et les théories du déconstructionnisme derridien, ce mouvement prend la forme "d'un mouvement post-identitaire [...] qui n'est pas un mouvement d'homosexuels, ni de gays, mais de dissidents du genre, de résistance face aux normes qu'impose la société hétérosexuelle dominante ${ }^{39}$ ». La réflexion queer oppose à la pensée binaire "une théorie du continuum et de la mutabilitét0 ". Les positions sont vues comme interchangeables, et il n'y aurait plus à choisir entre telle ou telle catégorie, entre un registre sexuel ou un autre, entre l'homosexualité ou l'hétérosexualité, mais à s'identifier à partir d'une multiplicité de possibilités, en soumettant les corps à la performativité et en jouant sur " les genres ", qui sont envisagés de manière relationnelle dès lors que " la circulation de la masculinité et de la féminité ne dépend plus du sexe biologique ${ }^{41} »$.

35. Ces critiques ont été regroupées en quatre catégories par Diane LAMOUREUX, «La réflexion Queer: apports et limites », dans Maria NENGEH MENSAH (dir.), op. cit., 2005, p. 92.

36. Pour une histoire politique du terme queer, voir Paul B. PRECIADO, "Queer. Historia de una palabra », 2009, [http://paroledequeer.blogspot.fr/p/beatriz-preciado.html], consulté le 15 novembre 2014.

37. Paul B. PRECIADO (anciennement Beatriz Preciado) est l'auteure de Manifeste contra-sexuel, Paris, Balland, 2000 ; Testo Junkie : sexe, drogue et biopolitique, Paris, Grasset, 2008 ; Pornotopie, Paris, Climats, 2010.

38. Histoire de la Sexualité de Michel Foucault est parue en trois volumes entre 1976 et 1984 aux Éditions Gallimard. 1. La volonté de savoir 2. L'usage du plaisir 3. Le souci de soi.

39. Paul B. Preciado, op. cit., 2009.

40. Diane LAmoureuX, op. cit., 2005, p. 92.

41. Christelle TARAUD, Les féminismes en question. Éléments pour une cartographie, Paris, Éditions Amsterdam, 2005, p. 47. Entretien avec Marie-Hélène BOURCIER, théoricienne et activiste queer de référence en France. Elle a notamment publié la trilogie qui fait autorité sur la question : Queer Zones 1 (2001), Queer Zones 2 (2005), Queer Zones 3 (2011). 
Le questionnement sur le sujet même du féminisme se trouve au cœur du féminisme de la troisième génération. Dans les années 1970, "le mouvement des femmes se fondait sur une identité-femme très discutée mais qui cernait en quelque sorte une condition commune aux femmes $»^{42}$, nous dit Christine Bard pour le féminisme français. En Espagne, c'est au cours des Journées féministes de Madrid de 1993 que la crise du sujet du féminisme se fait jour. Lors de ces rencontres, l'identité-femme ou le sujet hégémonique du féminisme fut remise en question sous l'influence de jeunes collectifs, des féministes lesbiennes et de transsexuels rejetant "un sujet-femme unitaire pour dénoncer la situation de domination ${ }^{43}$. L'homogénéisation du sujet-femme, en partant du postulat de départ selon lequel toutes les femmes subissent une expérience commune de la domination exercée par le système patriarcal, est ainsi soumise à des débats virulents, qui sont à l'œuvre encore aujourd'hui au sein du mouvement féministe contemporain. Une partie des militantes, le plus souvent les féministes historiques des années 1970, expriment leurs réticences à abandonner « la fiction d'un sujet mythique et universalisant du féminisme ${ }^{44}$ ", comme substrat de leur identité collective alors que dans la pratique, la diversité des identités culturelles politiques au sein des féminismes relève d'une mutation incontestable. À l'heure actuelle, les crispations et les fractures se sont encore rigidifiées au sujet de l'intégration des trans au sein des espaces féministes, notamment lors de la célébration de la journée du 8 mars et d'autres commémorations féministes ${ }^{45}$, ce qui démontre que la politique des alliances qui est plébiscitée par les collectifs de la troisième génération ainsi que le souhait de voir converger les luttes demeurent l'un des défis majeurs du féminisme du XxI ${ }^{\mathrm{e}}$ siècle.

\footnotetext{
42. Christine BARD, Le féminisme au-delà des idées reçues, op. cit., p. 169.

43. María MARTínEZ GonZÁLEZ, Identidades feministas en proceso. Reiteraciones relacionales y activaciones emocionales en las movilizaciones feministas en el Estado español, Thèse de doctorat, Université du Pays-Basque, Bilbao, mars 2015, p. 341.

44. Elena CASADO APARICIO, " A vueltas con el sujeto del feminismo ", Política y sociedad, $n^{\circ} 30$, 2009, [http://revistas.ucm.es/index.php/POSO/article/viewFile/POSO9999130073A/24850], consulté le 31 mars 2015. De la même auteure, La construcción socio-cognitica de las identidades de género de las mujeres españolas (1975-1995), Thèse de doctorat, université Complutense, Madrid, 2002, [http://biblioteca.ucm.es/tesis/cps/ucm-t26344.pdf], consulté le 25 mars 2015. 45. Selon les témoignages des activistes transféministes madrilènes que j'ai pu recueillir, cette question a été l'objet de fortes dissensions dans la perspective du 8 mars 2014 où : un certain nombre de féministes historiques ou mainstream se sont opposées à la participation des collectifs trans à cette manifestation.
} 


\section{D'UNE VAGUE À L'AUTRE: L'ÉMERGENCE DE NOUVEAUX COURANTS FÉMINISTES}

Ces féminismes de la troisième génération trouvent leur matérialisation dans des répertoires d'action qui conjuguent la performance artistique (musique rock/punk, poésie, littérature), la sexualité (pornographie, sadomasochisme), les outils technologiques et la dimension politique pour déconstruire les contraintes imposées par un système normatif et hétéropatriarcal. Le "post-porn " est à ce titre l'une des manifestations artistiques du courant queer: il émerge aux États-Unis dans les années 1980, dans le Post Porn Modernist Manifiesto ${ }^{46}$, puis dans les performances d'Annie Sprinkle ${ }^{47}$ et se développe en Europe et, notamment en Espagne, au début des années 2000, dans les milieux activistes, pro-sexe ${ }^{48}$ et queer barcelonais ${ }^{49}$. Paul B. Preciado, qui a contribué à faire connaître ce courant en Espagne ${ }^{50}$, le définit comme « un espace d'action politique à travers lequel les femmes et les minorités sexuelles peuvent redéfinir leurs corps et inventer de nouvelles formes de production de plaisir qui résistent à la normalisation pornographique dominante ${ }^{51}$ ". Il s’agit d'une stratégie politique visant à se réapproprier les technologies de production et de représentation de la sexualité et du genre qui, loin

46. Sous l'impulsion de deux anciennes actrices pornographiques, Veronica Vera et Candida Royalle.

47. Ancienne prostituée et actrice pornographique américaine, Annie Sprinkle est aujourd'hui réalisatrice, éditrice, écrivaine et performeuse.

48. Féminisme pro-sexe: courant de pensée apparu dans les années 1980 en opposition aux féministes abolitionnistes. II pose comme principe que la liberté sexuelle est un élément essentiel de la liberté des femmes. Toute relation sexuelle consentante ne peut dès lors qu'être enrichissante, David Courbet, Féminismes et pornographie, Paris, La Musardine, 2012, p. 270.

49. Sur le "postporn", voir Marie-Hélène BOURCIER, Queer Zones. Politiques des identités sexuelles, des représentations et des savoirs, Paris, Balland, 2001 ; «Bildungs-Post-Porn : Notes sur la provenance du Post-Porn, un des futurs du féminisme de la désobéissance sexuelle », Rue Descartes, 2013/3, n 79, p. 42-60; Rachele BoRGHI, « Post-Porn », Rue Descartes, 2013/3, $n^{\circ} 79$, p. 29-41; Marie-Anne PAVEAU, Le discours pornographique, Paris, La Musardine, 2014. Voir également le documentaire, réalisé entre les États-Unis et l'Espagne par Virginie DESPENTES, Mutantes (Féminisme Porno Punk), 2009, commercialisé depuis 2010 en DVD sous le même nom, ainsi que l'essai de l'activiste et philosophe espagnole Marisol SALANOVA, Postpornografía, Murcie, Ed. Pictografía, 2012 et son blog, Filosofía del Postporno, [http://filosofiadelpostporno. blogspot.fr/], consulté le 12 novembre 2014. Pour les performances postporn et queer espagnoles, voir les collectifs comme Post Op, Quimera Rosa ou Oh-Kaña, 2010, [http://vimeo. com/12566813], consulté le 2 janvier 2015.

50. Paul B. Preciado et Marie-Hélène Bourcier sont à l'initiative du Maratón Postporno, un séminaire qui s'est tenu, les 6 et 7 juin 2003, au MACBA, musée d'Art contemporain de Barcelone et qui a proposé des conférences, discussions, tables rondes, performances autour des représentations politico-esthétiques de la postpornographie contemporaine.

51. Paul B. Preciado, «Postporno. Excitación disidente », [http://paroledequeer.blogspot.fr/p/ beatriz-preciado.html], consulté le 17 novembre 2014. 
de condamner la pornographie, à l'instar du courant abolitionniste, recherche l'empowerment des femmes: de " corps-objets " au service de la pornographie hétérosexuelle masculine mainstream, les porno-activistes deviennent des " corps-sujets ${ }^{52}$ ", engagées dans " un mouvement de résistance au modèle pornographique traditionnel visant à réinventer ses codes dans une logique de déconstruction et de dénaturalisation de la sexualité en produisant des contenus alternatifs ${ }^{53}$ ».

Cette approche de la pornographie, revendiquant un usage politique du corps et des sexualités, constitue le cœur de la militance artisticoféministe-queer de la performeuse madrilène Diana J. Torres qui a inventé un concept dissident, le "pornoterrorisme ${ }^{54}$ ", pensé comme une contre-offensive artistique, anticonformiste et radicale contre le poids des normes de genre et des dispositifs de contrôle de la sexualité. En réaction aux injonctions morales, sociales et légales de l'État, de l'Église et de la médecine, Diana J. Torres réinvestit l'espace pornographique afin d'élaborer une cartographie des sexualités dissidentes, et de libérer sa rage via le monstrueux revendiqué et la violence consentie ${ }^{55}$. La performance devient ainsi un espace laboratoire de la dissidence sexuelle, une " catharsis permettant d'évacuer par la production artistique une fureur désespérée ${ }^{56}$ » et le pornoterrorisme une action politique, « un acte de survisibilité ${ }^{57}$ " et de réappropriation des corps dans l'espace public.

Toutes ces formes de résistance aux normes de genre convergent au sein d'un autre courant, «le transféminisme», mouvement de

52. Comme le dit Annie SPRINKLE dans son ouvrage Hardcore from the Heart (2001), «La réponse au mauvais porno n'est pas d'interdire le porno, mais de faire de meilleurs pornos. », cité et traduit par Virginie Despentes, King Kong Théorie, Paris, Grasset, 2006, p. 87. À ce titre, voir les productions pornographiques féministes indépendantes de la réalisatrice et productrice suédoise Erika LUST, installée à Barcelone depuis 2000 : Handcuffs (2009), Cabaret Desire (2011), Room 33 (2011), X Confessions (2013-2014), [http://erikalust.com/fr/], consulté le 2 janvier 2015.

53. David Courbet, Féminismes et pornographie, op. cit., p. 270.

54. Diana J. ToRREs, Pornoterrorismo, Tafalla, Editorial Txalaparta, 2011. L'ouvrage a une version en français, Pornoterrorisme, Bayonne, Ed. Gatuzain, 2012.

55. L'espace pornographique est une «stratégie artistico-politique pour faire de nos corps la meilleure arme », Diana J. TORRES, Manifiesto pornoterrorista, 2012, [http://pornoterrorismo. com/lee/manifiesto-pornoterrorista/], consulté le 10 novembre 2014.

56. Claire LAGUIAN, «Fureur dé (CON) structrice et « viscéranimalité » du désir saphique dans la poésie du xxie siècle en Espagne », conférence lors de la Journée d'Études internationales, "Mi vagina clama una venganza ": fureur et désir féminins dans les littératures contemporaines de langues romanes, université de Paris Est Marne-La Vallée, 31 janvier 2014 (à paraître).

57. Arnaud AlessandRIN, « Notes de lecture. Diana J. Torres. Pornoterrorisme », Cahiers du Genre, 2013/2, n55, p. 227-251, [http://cahiers_du_genre.pouchet.cnrs.fr/pdf/NLCdG55.pdf], consulté en juin 2014. 
déconstruction du système sexe-genre, de l'hétéropatriarcat et résolument critique à l'égard des théories féministes classiques fondées sur une vision naturalisée du genre. Ce mouvement résulte de l'alliance entre les mouvements trans, queer et féministes, dans une approche intersectionnelle, afin de mener un combat sur plusieurs niveaux et de déployer des stratégies basées sur une politique de la coalition plutôt que sur un groupe social identitaire ${ }^{58}$. En Espagne, le transféminisme a commencé à gagner en visibilité à partir des Journées féministes de Grenade en 2009, mais il a surtout fait l'objet d'une tentative de théorisation lors des Journées transféministes de Barcelone en $2010^{59}$. C'est à Diana J. Torres que l'on doit l'initiative de la rédaction du " Manifeste pour la révolution transféministe ${ }^{60} "$, publié sur son blog le $1^{\mathrm{er}}$ janvier 2010, et signé à la fois par des collectifs, des artistes ou des activistes féministes, à l'instar de Paul B. Preciado, de la journaliste et féministe basque, Itziar Ziga ${ }^{61}$ ou encore de l'essayiste queer, Sayak Valencia. Rédigé selon une rhétorique guerrière, ce plaidoyer en faveur d'un renouvellement de la pensée féministe se veut résolument avantgardiste et dissident en proposant de "dynamiter le binôme genre et sexe comme pratique politique ${ }^{62}$ » et en appelant à "l'insurrection, à l'occupation des rues [...] à la désobéissance ${ }^{63}$ ", autant de pratiques

58. Voir la définition du transféminisme par l'association OUTrans fondée en 2009, [http:// outrans.org/infos/articles/transfeminisme], consulté le 24 novembre 2014. Précisons toutefois que le transféminisme diffère selon les contextes culturels dans lesquels il est appréhendé. Le transféminisme en France semble encore être plutôt le « féminisme des trans » alors que le transféminisme, dans les pays hispanophones, se fonde plus sur une approche intersectionnelle des luttes: par exemple alliance avec les femmes qui portent le voile et sont, à ce titre, discriminées et/ou les immigrées exploitées. Cf. Brigitte VASALLO, Pornoburka, Cardedeu, Associació Cultural Colectivo Cautivo, 2013. Pour une étude documentée sur ces questions, voir Karine ESPINEIRA, Transidentités. Ordre \& panique de genre, Paris, Éditions L'Harmattan, 2015.

59. Pour une conceptualisation récente de ce courant en Espagne, voir Miriam SoLÁ et Elena URKo (dir.), Transfeminismos. Epistemes, fricciones y flujos, Tafalla, Txalaparta, 2014.

60. «Nous sommes issues du féminisme radical, nous sommes les gouines, les putes, les trans, les immigrées, les noires, les hétérodissidents... nous sommes la rage de la révolution féministe et nous voulons montrer les crocs; sortir des officines du genre et des politiques correctes: que notre désir nous guide en étant politiquement incorrectes, en dérangeant, repensant et resignifiant nos mutations. Nous ne nous contentons plus d'être seulement des femmes. Le sujet politique du féminisme, "femmes", nous est étroit, il est excluant en soi, laissant dehors les gouines, les trans, les putes, celles qui portent le voile, celles qui gagnent peu et qui ne vont pas à la fac, celles qui crient, celles sans-papiers et les pédés », « Manifiesto para la Revolución transfeminista », 1er janvier 2010, [http://medeak.blogspot.com.es/2009/12/ manifiesto-para-la-insurreccion.html], consulté le 26 avril 2015.

61. Itziar ZIGA, Devenir perra, Barcelone, Melusina, 2009; Un zulo propio, Barcelone, Melusina, 2010; Sexual Herria, Tafalla, Txalaparta, 2011; Malditas. Una estirpe transfeminista, Tafalla, Txalaparta, 2014.

62. «Manifiesto para la Revolución transfeminista » op. cit.

63. Ibid. 
qui réactualisent la potentialité subversive du féminisme de la deuxième vague dans l'occupation de l'espace public et la politisation des questions sexuelles. Le transféminisme viendrait ainsi reformuler les thématiques chères au féminisme (violences, inégalités, sexualités, prostitution, pornographie), il serait même selon Diana J. Torres, « l'avenir du féminisme ${ }^{64}$ ", ce qui ne veut pas dire pour autant qu'il renie les apports et les combats des féministes historiques, même s'il prend ses distances vis-à-vis d'un mouvement social qu'il juge trop hétérocentré, trop blanc, trop intellectuel, incapable de repenser les nouvelles inégalités produites par l'économie néolibérale et le capitalisme gore ${ }^{65}$.

Le transféminisme, en tant que dépassement du féminisme, inclut les sujets des marges, les minorités sexuelles ou minorités ethniques et articule mieux les différents modes d'oppression (sexisme, homophobie, transphobie, racisme, capitalisme) tout en conservant le terme " féminisme ", qui à l'inverse du vocable queer, assume les connexions avec les discours et les pratiques politiques du féminisme historique. Espace transfrontière ${ }^{66}$ mais également caisse de résonance du local, de la "politique du vivant ${ }^{67}$ ", le transféminisme se recentre "sur la politisation du quotidien ${ }^{68}$ " et tisse des stratégies microsociologiques de résistance: il part des expériences des individus marginalisés pour questionner l'ordre économique néolibéral et les normes du système hérétopatriarcal, nouer de nouvelles coalitions et se réapproprier les luttes qui ont divisé et continuent de diviser les féminismes ${ }^{69}$. S'il est ardu d'élaborer une définition figée, tant ce courant résiste aux catégorisations rigides en raison de son hétérogénéité et des identités multiples qui le composent, le transféminisme peut, à l'instar des 100 antithèses

64. Diana J. ToRRES, op. cit, 2012, p. 180

65. Nous reprenons ici le titre de l'ouvrage de Sayak VALENCIA, Capitalismo gore, Barcelone, Melusina, 2010.

66. Silvia GIL; Amaia PÉREz ORozco, "Transfeminismo: ¿sujetos o vida en común?», Diagonalperiódico. net, 19 juillet 2010, [https ://www.diagonalperiodico.net/la-plaza/transfeminismo-sujetos-o-vida-comun.html], consulté le 17 novembre 2014.

67. Ce concept de «politique du vivant » est défini par Silvia GIL comme « la politique qui part de l'expérience et du quotidien, qui ne répond pas à un programme idéologique, ne représente pas un sujet identifiable, ni ne se base a priori sur aucune unité. C'est une politique du multiple, autonome, sans médiations ni représentations ». II s'oppose à la politique institutionnelle et à sa représentation verticale et élitiste, cf. Silvia GIL, op. cit, 2011, p. 70.

68. Amaia PÉREZ Orozco, Subversión feminista de la economía. Aportes para un debate sobre el conflicto capital-vida, Madrid, Traficantes de Sueño, 2014, p. 29.

69. Le transféminisme fait aussi débat au sein des féminismes latino-américains, cf. Florencia GoldsmaN, "Polémicas trans: nuevas categorías politicas en los encuentros feministas ", Pikara Magazine, 29 décembre 2014, [http://www.pikaramagazine.com/2014/12/polemicastrans-nuevas-categorias-politicas-en-los-encuentros-feministas/], consulté le 2 janvier 2015. 
du cyberféminisme, être défini par ce qu'il n'est pas ${ }^{70}$. C'est ainsi que Diana J. Torres propose une théorisation de ce courant à partir des alliances qu'il ne nouera jamais: le transféminisme, assure-t-elle, «ce ne sera pas avec celles qui censurent la pornographie; avec celles qui victimisent la prostitution et la confondent gravement avec l'esclavage; avec celles qui crient ni pute ni soumise; ni avec celles qui pensent que le sadomasochisme est aberrant et peu respectable; ni avec celles qui s'offusquent de l'exubérance et de l'effronterie ${ }^{71}$ ". Laboratoire expérimental et performatif, espace de discussions et de débats, le festival Octubre Trans, qui a lieu depuis quatre ans dans le quartier populaire de Lavapiés à Madrid, mais également à Barcelone et au Pays Basque, est emblématique de la vitalité de ce courant et de sa récente visibilité 72 . Il est organisé par plusieurs collectifs dont la Pandi Trans, un collectif de personnes trans fondé en octobre 2011, avec pour objectif de générer une réflexion-action autour des identités et des corps, "dans une perspective d'empowerment transféministe, autonome et anticapitaliste ${ }^{73}$ ".

La circulation de ces nouveaux courants a ouvert un horizon de possibilités mais, par ricochet, une nouvelle ligne de fracture au sein du féminisme espagnol contemporain: d'un côté, un féminisme hégémonique "pro-femme", héritier des postulats du féminisme de la deuxième vague, critiqué pour être un " féminisme autoréférentiel, qui s'adresse à elles-mêmes: femmes blanches, occidentales et de classe moyenne ${ }^{74} »$; de l'autre, le féminisme de la troisième vague, qui considère le sujet du féminisme comme multiple et entend croiser systématiquement les propositions féministes avec la race, la classe, le genre et la sexualité. La mobilité de ces courants alternatifs témoigne d'un renouvellement des théories et des pratiques féministes classiques depuis le milieu des années 1990 jusqu'à aujourd'hui: ils sont emblématiques d'un "féminisme au temps du post», nous dit la chercheuse María

70. Les 100 antithèses du cyberféminisme est un texte rédigé en 1997 par le collectif Old Boys Network lors de la première conférence internationale cyberféministe en Allemagne. II s'agissait de refuser une définition fermée du cyberféminisme mais de définir, en 100 antithèses, ce qu'il n'était pas.

71. Diana J. TORRES, op. cit., 2012, p. 182

72. Le festival en est à sa quatrième saison et, sous le slogan « Ce qui est incongru, ce n'est pas mon corps, mais ton regard » (La incongruencia no está en mi cuerpo, está en tu mirada), il propose, un mois durant, une programmation riche, hétéroclite, [http://octubretransmadrid2014. drupalgardens.com/content/otros-octubres], consulté le 17 novembre 2014.

73. [http://octubretransmadrid2014.drupalgardens.com/content/pandi-trans], consulté le 17 novembre 2014.

74. Beatriz GIMENO, "¿Qué feminismo?», Trasversales, 2009, n 16, [http://beatrizgimeno. es/2010/09/09/\%C2\%BFque-feminismo/], consulté le 24 novembre 2014. 
Martínez González, pour laquelle « il s'agit d'un féminisme qui ne renie pas ses origines [...] qui hérite des préoccupations de la deuxième vague mais les adaptent au temps présent ${ }^{75}$ ", un féminisme de la subversion capable de brouiller les catégories et les normes et de questionner les subjectivités et les corporalités socialement construites.

\section{« ¡LA REVOLUCIÓN SERÁ FEMINISTA O NO SERÁ! ": LA « MARÉE VIOLETTE » AU SEIN DU MOUVEMENT DES INDIGNÉS}

Si depuis la fin de la transition démocratique ce féminisme de la subversion semble s'être essoufflé, il n'a pourtant jamais cessé d'exister. Souvent repliée au cœur des quartiers, avec un champ d'action centré sur le local, la militance de ces groupes s'est opérée depuis les marges et les espaces underground. C'est un soulèvement de grande amplitude, la "révolution des indignés ", qui marque un tournant dans la reconfiguration de ce militantisme autonome, radical et contestataire ${ }^{76}$. Dès son occupation de la Puerta del Sol à Madrid, le 15 mai 2011 (15-M), le mouvement des indignés a été le catalyseur d'une insurrection citoyenne sans précédent contre le capitalisme, la spéculation financière et la corruption politique ${ }^{77}$. Encouragés par les événements du Printemps arabe, les manifestant(e)s s'insurgent contre les conséquences sociales de la crise morale et financière en proposant un modèle alternatif de démocratie, dite "réelle " ou " participative ». À ce titre, les acteurs et actrices du 15-M, aussi bien des représentant(e)s des mouvements sociaux alternatifs que des jeunes indigné(e)s sans passé militant, ont développé des formes de protestations citoyennes marquées par l'absence de leaders, l'autogestion, la politique participative, l'occupation et la politisation de l'espace public. Cette "insurrection des consciences ", que l'on a hâtivement présentée comme le fruit de la révolution d'une jeunesse précaire sans expérience militante antérieure, est en fait un mouvement hétérogène

\footnotetext{
75. María MARTínez GonzÁlEZ, « Jóvenes y feminismo: ¿hacia un feminismo de la « subversión »? », Revista vasca de sociología y ciencia política, 2007, n 43, p. 97-216.

76. Vocable repris de l'ouvrage de Stéphane HESSEL, Indignez-vous!, Montpellier, Indigène éditions, 2011.

77. Les indignés se sont rassemblés sous le slogan fédérateur « « Nous ne sommes pas des marchandises aux mains des politiciens et des banquiers ». Nous avons privilégié ici les expériences des indignés madrilènes en raison du cadre restreint de ce chapitre, mais la mobilisation a été tout aussi massive à Barcelone et dans d'autres grandes villes espagnoles (Valence, Málaga, etc.).
} 
traversé par des courants et des identités multiples ${ }^{78}$. Dans une perspective de genre, s'y côtoient une génération de jeunes féministes, proche de la mouvance anarchiste et anticapitaliste, des collectifs transféministes, que nous avons évoqués précédemment, mais également des féministes chevronnées, des " autonomes » des années 1980, qui prolongent ainsi des engagements militants de longue date.

Transformées en campements à ciel ouvert, les places et les rues ont accueilli le ferment de la contestation sociale et la Puerta del Sol, l'offensive des féministes rassemblées autour d'un espace militant: la Commission des féminismes de Sol, qui est devenue en quelques jours le centre névralgique des féminismes madrilènes. La valeur symbolique des lieux prend ici tout son sens: l'occupation de la place, autrement dit la subversion de l'espace, revient à signifier qu'un autre ordre social est possible, mettant à mal toute l'architecture du système politique représentatif au profit d'une démocratie directe. De fait, l'occupation de la place redonne sens à l'espace en tant que lieu ouvert, participatif, visible et de résistance, en syntonie avec l'idéologie même du mouvement du 15-M. Pour les féministes, la carpa de la Puerta del Sol ${ }^{79}$ s'est muée en lieu de résonance de tous les féminismes non étatiques dans une volonté de dépassement des clivages idéologiques et de mise en œuvre d'une politique des alliances: hétérosexuelles, bisexuelles, lesbiennes, transféministes, pro-sexe, queer, prostituées, travailleuses domestiques, migrantes, salariées, étudiantes, etc. Cette sororité dans la diversité ${ }^{80}$ a constitué un tournant indéniable dans la consolidation

\footnotetext{
78. Nous empruntons cette expression à l'ouvrage D'Athènes à Wall Sreet, Indignés!, échos d'une insurrection des consciences, Revue Contretemps (dir.), Paris, La Découverte, 2012. Pour une bibliographie sur le mouvement du 15.M cf., entre autres, Benjamín TEJERINA et Ignacia PERRUGORÍA, «Synchronizing identities: Crafting the space of mobilization in the spanish $15 \mathrm{M}$ »; Nicholas P. Petropoulos et George O. Tsobanoglou (ed.), The Debt Crisis in the Eurozone: Social Impacts, Cambridge Scholar Publishing, Newcastle, 2014, p. 282-304; Luis RuIz AJA, Florián Manuel PÉREZ, Teresa María GómEZ-PASTRANA, El descontento social y la generación IN, Madrid, Editorial Popular, 2013; Manuel CASTELLS, Redes de indignación y esperanza, Madrid, Alianza Editorial, 2012; Carlos TAIBO, El 15-M. Una brevísima introducción, Galice, Editorial Trifolium, 2014 ; El 15-M en sesenta preguntas, Madrid, Catarata, 2011; Que no se apague la luz. Un diario de campo del 15-M, Madrid, Catarata, 2012 ; La rebelión de los indignados, Carlos TAIBO, Josep Maria ANTENTAS y Esther VIVAS, Juan Pablo MATEO, Antoni DOMĖNECH, Iván GIMÉNEZ CHUECA, Juan Carlos Monedero (ed.), Madrid, Editorial Popular, 2011; Hablan los indignados, Juan ToRRES LóPEZ, Alberto GARzón, Aitor Romero OrTegA, Joel Serafín ALMENARA, Marcos RoITMAN, Gerardo TUDURI (ed.), Madrid, Editorial Popular, 2011; Cristina GARCíA-ROSALES et Manuel PENELLA HELLER, Palabras para indignados, Tarragona, Mandala Ediciones, 2011.

79. Il s'agit de la «tente féministe » installée sur la Puerta del Sol.

80. Le terme «sororité» est un héritage du féminisme de la deuxième vague, il est l'équivalent de la fraternité masculine et désigne le «lien politique et affectif établi entre femmes », Christine BARD, op. cit., 2012, p. 276.
} 
d'une "marée violette ${ }^{81}$ ", accueillant dans ses rangs des féminismes polymorphes mais soudés autour d'un projet commun: la subversion de l'ordre capitaliste, patriarcal et hétéronorméé ${ }^{82}$. Faisant la jonction avec le féminisme de la troisième vague, les féministes indignées revendiquent l'interrelation des multiples systèmes d'oppression et se sont efforcées d'intégrer toutes les commissions du 15-M pour rendre effective la transversalisation des propositions féministes. S'en est suivi un intense travail de pédagogie mais également de débat et de réflexion théorique qui a abouti à la rédaction de plusieurs textes et manifestes. Les treize propositions, publiées le 21 mai 2011, sont l'essence même des féminismes du 15-M en tant que mouvement pluriel, alternatif, horizontal, autonome, pacifique, progressiste, laïque et égalitaire ${ }^{83}$.

Photo 4.1. Pancarte féministe 15-M, Puerta del Sol, Madrid, mai 2011.

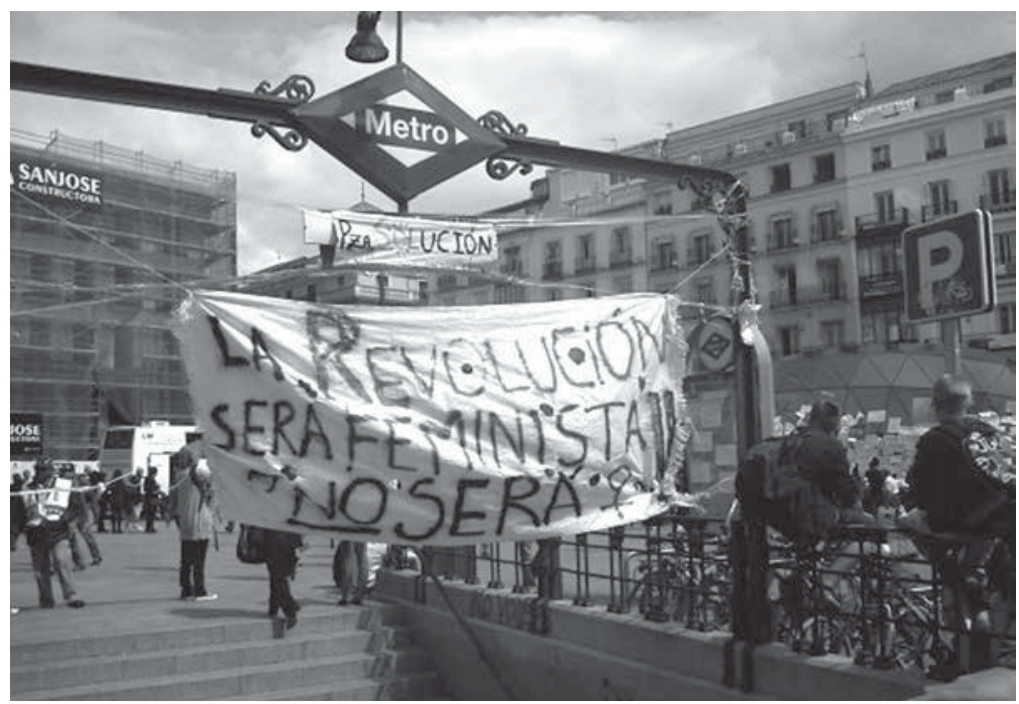

81. Ces marées (verte pour l'éducation, blanche pour la santé, violette pour le féminisme) sont « des mouvements ouverts qui cherchent à socialiser leurs revendications, qui en réalité, défendent des causes qui existaient déjà mais d'une façon radicalement nouvelle, qui sont complexes et sans possibilité d'être représentés de manière institutionnelle », cf. José Luis SÁNCHEZ, Las 10 mareas del cambio, Barcelone, Rocaeditorial, 2013, p. 14.

82. Le slogan fédérateur adopté lors des mobilisations était le suivant : "On se fait tous/toutes baiser par le système patriarcal » (El sistema patriarcal nos jode todxs)

83. Ces propositions sont consultables dans Dossier de la Comisión de Feminismos de Sol, 2011, [http://usteamujer.org/sites/default/files/Feminismos\%20Sol.pdf], consulté en octobre 2014. 
Les répertoires d'action de ces féminismes s'articulent autour " d'actions constructives et pédagogiques ${ }^{84}$ " et/ou " d'actions ludiques et artistiques ": " atelier de féminisme(s) pour débutants ", " journées ludiques des féminismes ", publication d'une littérature à caractère militant, d'une " liste d'attitudes micromachistes ", défense de l'avortement libre et gratuit ${ }^{85}$, guide de langage inclusif ${ }^{86}$ ou encore rédaction du manifeste Transmaricabollo ${ }^{87}$ pour défendre les droits des personnes LGBT et le travail sexuel. Enfin, à l'intérieur de la tente féministe de Sol une aide psychologique a été proposée à toutes les personnes victimes d'agressions sexistes, homophobes ou racistes en-dehors ou au sein même du campement. Rappelons que le mouvement du 15-M, guidé par des idéaux anticapitalistes, progressistes et libertaires, n'a pas été à l'abri de la reproduction des logiques de domination à l'œuvre dans la société civile: généralisation des insultes chargées de machisme et d'homophobie, refus d'incorporer les thèmes centraux du féminisme (avortement, violence sexiste, politiques du $\operatorname{car}^{88}$ ) dans le discours général du mouvement et résistances à la prise de parole féminine et féministe lors des assemblées générales ${ }^{89}$. Ces comportements ont été relevés dans la plupart des campements installés sur les places espagnoles et ont donné lieu à des contre-offensives originales. À Madrid, face à la banalisation dans les rangs des indignés du slogan, " politiciens, fils de putes ", des prostituées madrilènes ont confectionné des pancartes sur lesquelles on pouvait lire: " [Nous] les putes tenons à dire que les politiciens ne sont pas nos enfants ${ }^{90} "$, reprenant ainsi les slogans popularisés

84. Nous empruntons ces différentes catégorisations des répertoires d'action à Benjamín TEJERINA, La sociedad imaginada. Movimientos sociales y cambio cultural en España, Madrid, editorial Trotta, 2010, p. 89-90.

85. Voir le texte « Democracia Real y derecho de las mujeres a decidir », ibid., 25 mai 2011.

86. L'utilisation de la lettre « $x$ » fusionne le « $a$ », marque du féminin et le « 0 », marque du masculin pour neutraliser le genre. Cet emploi a été généralisé dans les écrits du 15-M.

87. L'équivalent français du « Manifeste transpédégouine ». Cf. " Manifiesto Transmaricabollo », Dossier de la Comisión de Feminismos de Sol, op. cit. Ce manifeste s'insurge contre les différentes oppressions dont sont victimes les trans, les femmes, les personnes homosexuelles et les migrant.e.s: racisme, sexisme, homophobie, capitalisme, religions, lobbys pharmaceutiques, médias et éducation véhiculant des principes sexistes ou homophobes.

88. Begoña MARUGÁn et. al., Op Cit, 2013, p. 26.

89. Sur cette question, voir Karine BERGĖS, «Quand les féminismes s'indignent. Le mouvement du 15-M entre revendications égalitaires et reproduction des logiques patriarcales », Erich FISBACH et Philippe RABATÉ (dir.), dans Actes choisis du colloque de Strasbourg "crise(s) dans le monde ibérique et ibéro-américain », HispanismeS, n 4, juillet 2014, [http://www.hispanistes. org/images/PDF/HispanismeS/Hispanismes_4/18shf\%20hispanismes\%204\%20berges\%20 karine. pdf], consulté le 20 novembre 2014.

90. Dossier de la Comisión de Feminismos de Sol, op. cit. 
par le mouvement global de la " Marche des salopes ${ }^{91}$ ». Le recours au dialogue et à l'humour, le retournement du stigmate en signe de protestation, la déconstruction des stéréotypes, autant de stratégies utilisées pour conjurer le machisme intériorisé... Selon la taille des campements, les résultats ont été inégaux. À Madrid ou Barcelone, en dépit des réticences initiales, les féministes sont parvenues à faire adopter un langage non sexiste, à produire des espaces féministes autonomes, à acquérir une légitimité et une visibilité inédites alors que dans d’autres villes, les résultats ont été moins probants.

À travers ces exemples, il est manifeste qu'en Espagne, depuis le début des années 2000, le féminisme est entré dans une phase de mutation et de reconfiguration, de l'aveu même de Justa Montero, activiste historique, qui évoque " un moment de déferlantes féministes, de mouvements tumultueux, vifs, critiques, radicaux et créatifs ${ }^{92}$ ". Preuve de la vitalité retrouvée des féminismes espagnols, l'extraordinaire mobilisation unitaire qu'a suscitée l'annonce du projet de réforme de la loi de l'avortement en décembre 2011, dont nous allons rendre compte dans le dernier volet de cette étude.

\section{« EN NUESTROS ÚTEROS, NO SE LEGISLA »: LA (RE)MOBILISATION UNITAIRE AUTOUR DE LA QUESTION DE L'AVORTEMENT}

Afin de comprendre la portée de cette mobilisation, il convient de retracer brièvement la généalogie des trois lois sur l'avortement qui ont prévalu depuis la fin de la dictature du général Franco, en novembre $1975^{93}$. C'est en 1985, sous la première législature socialiste de la démocratie, que la loi organique 9/1985 du 5 juillet a été adoptée.

\footnotetext{
91. Mouvement né au Canada en avril 2011 (Slut Walk) suite aux déclarations d'un policier de Toronto, Michael Sanguinetti, qui avait conseillé aux étudiantes de ne pas s'habiller « comme des traînées » si elles ne voulaient pas se faire agresser. Depuis lors, cette marche s'est étendue à toutes les grandes capitales du monde. Voir Nelly ANDRE, « Les nouvelles formes de protestation sociale: "la marche des salopes" en Amérique latine », Chronique des Amériques, vol. 14, $n^{\circ}$ 2, juin 2014, [http://www.ieim.uqam.ca/IMG/pdf/cda_volume_14_numero_2_juin_2014.pdf], consulté en septembre 2014.

92. Justa MONTERo, "Marejadas feministas», Diagonalperiodico. net, 1er avril 2014, [https://www.diagonalperiodico.net/la-plaza/22370-marejadas-feministas.htm], consulté le 10 novembre 2014.

93. Pour un historique complet, nous renvoyons à l'étude très documentée de Silvia BENAMú et Trinidad NogueRA, L'interruption volontaire de grossesse en Espagne, Fondation Jean-Jaurès, 4 mars 2014, [http://www.jean-jaures.org/Publications/Notes/L-interruption-volontaire-degrossesse-en-Espagne], consulté en juin 2014.
} 
Elle régularisait la dépénalisation de l'IVG dans trois cas de figure: viol, malformation du fotus, grave danger pour la santé physique ou mentale de la mère. Il s'agissait donc d'une loi restrictive qui ne serait modifiée qu'en 2010 sous la législature socialiste de José Luis Rodríguez Zapatero, soucieux de faire de l'Espagne une référence mondiale en matière de reconnaissance des droits des femmes. La loi organique du 3 mars procédait donc à la dépénalisation de l'IVG, sans conditions jusqu'à la quatorzième semaine de gestation et remplaçait le régime dit des " cas de figure " par un système régi par " les délais ", une mise en homogénéité avec les réglementations en vigueur de la plupart des démocraties européennes. Le changement de majorité, suite aux élections législatives anticipées de novembre 2011, qui ont porté au pouvoir la droite conservatrice de Mariano Rajoy, s'est accompagné d'un nouveau projet de loi sur l'avortement placé sous l'autorité du ministre de la Justice, Alberto Ruiz Gallardón. Cherchant sa légitimité dans des arguments d'ordre juridique, comme le respect à la " protection de la vie de l'enfant à naître " ou la " non-discrimination des personnes handicapées ${ }^{94}$ ", l'avant-projet de loi envisageait de circonscrire l'accès à l'avortement à deux cas de figure seulement: le viol et le grave danger pour la santé physique ou psychologique de la femme, la malformation du fœtus ne constituant plus à elle seule un motif légal. Pour la première fois en trente-cinq ans de démocratie, l'Espagne subissait un net recul en matière de droits des femmes et faisait face à la mise sous tutelle de leur corps, au service des intérêts politiques et idéologiques de l'État espagnol ${ }^{95}$.

De fait, la modification législative était destinée à séduire l'aile la plus conservatrice du parti au pouvoir, l'épiscopat espagnol et les groupes "pro-vie", très mobilisés contre la loi de 2010, alors que toutes les enquêtes d'opinion ont exprimé le rejet massif de la réforme soutenue par Alberto Ruiz Gallardón ${ }^{96}$. Ces enquêtes sont d'autant

94. Cf. Interview de Mercedes YustA, JOL Press, 23 janvier 2014, [http://www.jolpress.com/ espagne-avortement-ivg-mercedes-yusta-article-824094.html], consulté le 18 novembre 2014. 95. Cf. la tribune publiée par Paul B. PRECIADo dans Libération qui appelle toutes les femmes espagnoles à faire "la grève des utérus » en signe de résistance " matriotique », Libération, " Déclarer la grève des utérus », 17 janvier 2014, [http://www.liberation.fr/societe/2014/01/17/ declarer-la-greve-des-uterus_973661], consulté le 18 novembre 2014.

96. $73,3 \%$ de la population se déclare en faveur du maintien de la loi de $2010,86 \%$ des Espagnols considèrent que toute femme enceinte doit pouvoir décider librement de mener ou non sa grossesse à terme et $65 \%$ des électeurs du Parti populaire se déclarent à leur tour opposés à la loi Gallardón. [http://www.elmundo.es/espana/2014/01/03/52c659af268e3e382d8b 456b.html], [http://politica.elpais.com/politica/2012/07/28/actualidad/1343507067_583781. html], [http://elpais.com/elpais/2014/01/11/media/1389453933_455931.html], consultés le 18 novembre 2014. 
plus significatives qu'elles furent conduites dans un contexte de crise économique et de durcissement des politiques d'austérité dont la mise en œuvre fragilisait d'autant plus les femmes des classes moyennes et populaires. Aussi, n'est-il guère surprenant que l'annonce de ce projet de loi ait suscité une mobilisation sans précédent dans la société civile, confrontée à une précarisation généralisée et à la paupérisation croissante de la population féminine. Dans les cercles féministes, l'offensive a été orchestrée via la plateforme numérique Nosotras Decidimos, fondée en 2010, pour contrer les attaques à la suite de la dépénalisation de l'avortement par le gouvernement Zapatero ${ }^{97}$. Aujourd'hui intégrée par 355 organisations de femmes, elle fait office de porte-voix des revendications des Espagnoles pour l'accès à l'avortement libre et gratuit, et fédère la mobilisation au plan national et régional autour d'un large réseau de solidarité: preuve en est la convocation de grandes manifestations, comme celles du 28 septembre 2013, du $1^{\text {er }}$ février et du 8 mars $2014^{98}$.

Photo 4.2. Manifestation contre la loi de réforme de l'avortement, Madrid, 8 mars 2014.

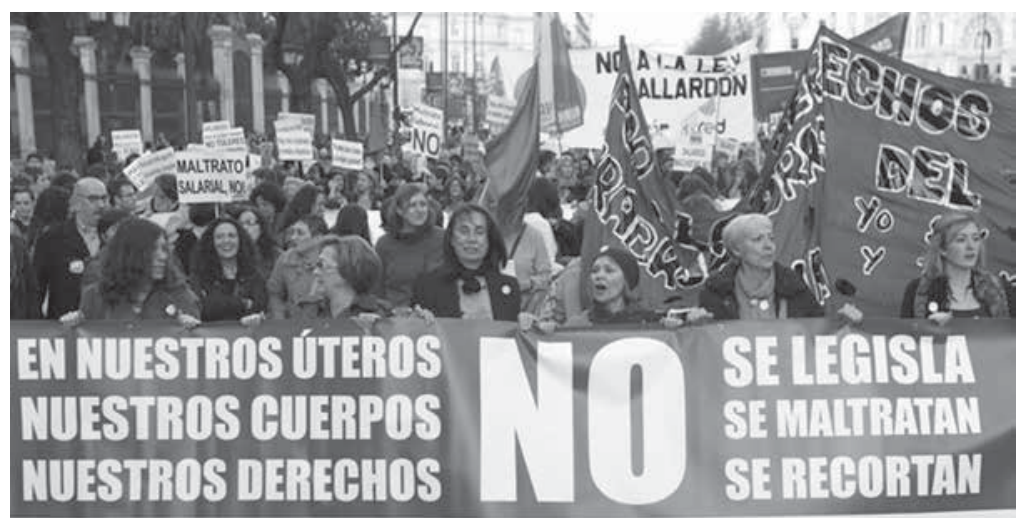

MOVIMIENTO FEMINISTA DE MADRID

Ces rassemblements citoyens et intergénérationnels ont constitué un front unitaire contre la loi Gallardón autour du slogan " On ne légifère pas dans nos utérus " et sont parvenus à faire circuler l'avant-projet de loi au-delà des frontières nationales, démontrant ainsi que les ressources informationnelles (réseaux sociaux, sites internet, etc.) s'imposent

97. [http://nosotrasdecidimos.org/], consulté le 18 novembre 2014.

98. 70000 personnes auraient défilé lors de la manifestation du 8 mars 2014. 
Photo 4.3. Manifestation en soutien aux femmes espagnoles, Paris, $1^{\text {er }}$ février 2014.

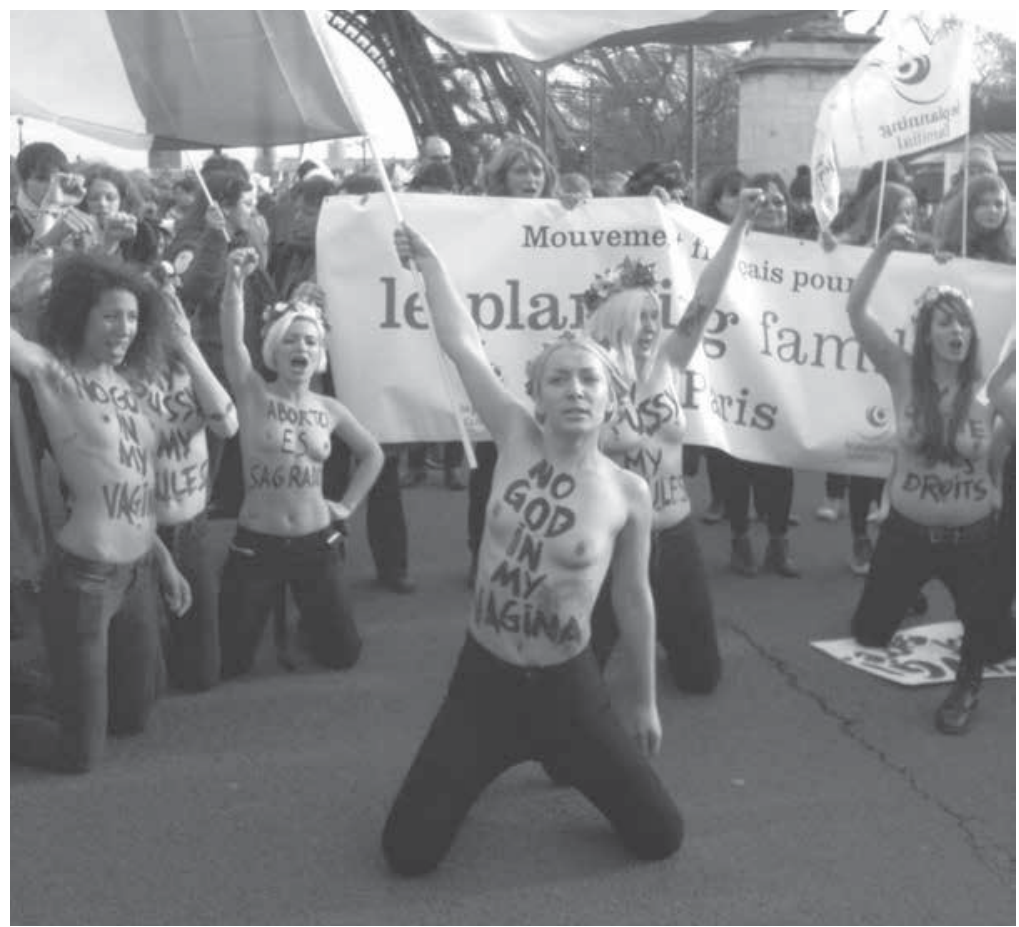

aujourd'hui comme une "nouvelle arme importante dans l'arsenal militant ${ }^{99}$ ». L'usage politique des nouvelles technologies, au même titre que la "spectacularisation" des actions militantes, participe de ce renouvellement des répertoires d'action du féminisme contemporain. En témoigne la mise en scène d'une action symbolique, médiatique et politique, "le train de la liberté ${ }^{100}$ ", lancée à l'initiative de Begoña Piñero, porte-parole de l'association féministe des Asturies, Las Comadres, avec

99. Fabien GRANJON, L'internet militant, Rennes, Apogée, 2001, cité par Pierre MERCKLÉ, Sociologie des réseaux sociaux, Paris, la découverte, 2011, p. 87. Pour plus de détails sur la mobilisation internationale autour de la loi de réforme de l'IVG en Espagne, voir Karine BERGÈs, "Femmes en réseaux et réseaux de femmes : la technologie au service du militantisme », dans Féminismes du xxie siècle, Karine BERGÈs, Florence BINARD, Alexandrine GUYARD-NEDELEC (dir.), Rennes, PUR, collection « Archives du féminisme », 2015.

100. Cette initiative a donné son nom au documentaire, Yo decido. El Tren de la libertad, 2014, [http://vimeo.com/99974636]. 
à son bord des féministes parties du nord de l'Espagne pour rejoindre Madrid, le $1^{\mathrm{er}}$ février, date de la grande journée internationale de mobilisation européenne en soutien à l'IVG et aux femmes espagnoles ${ }^{101}$.

La résistance s'est également organisée sous la tutelle de l'Assemblée féministe de Madrid qui depuis les années 1980 fédère les expériences des collectifs féministes madrilènes ${ }^{102}$. Particulièrement active au cours des derniers mois, elle a mobilisé des collectifs féministes de différentes obédiences - des plus institutionnels aux plus autonomes - à travers la consolidation d'une "Plateforme unitaire avortement ", le défi étant d'organiser la désobéissance civile à travers des modes de protestation visibles dans l'espace public: performances, sitting et escraches. Ce dernier terme, qui n'a pas son équivalent en français, a fait son apparition en Espagne à partir de 2013: il renvoie à un mode de protestation qui s'est généralisé en Argentine en 1995 contre les personnes ayant soutenu ou participé à la dictature militaire de Jorge Rafael Videla (1976-1983). Dans le contexte de la crise espagnole, il prend la forme de "dénonciations citoyennes d'un type de personnes déterminées [personnalités politiques, entités bancaires, etc.] par le biais de manifestations pacifiques devant le domicile ou lieu de travail de celles-ci ${ }^{103}$ ». Les activistes féministes ont repris à leur compte ces modes d'intervention dans l'espace public ${ }^{104}$ et ont organisé, le 16 mai 2013, plusieurs escraches dans vingt-huit villes espagnoles ${ }^{105}$ : initialement promue par la campagne pour le droit à l'avortement libre et rratuit de Catalogne, cette action a trouvé un écho national à travers la Coordination des organisations féministes. Ce jour-là, les militantes

\footnotetext{
101. Le même jour et à la même heure, des manifestations de solidarité se sont déroulées dans de nombreuses villes européennes (en Belgique, Grande-Bretagne, Portugal, France). À Paris, la manifestation a compté plus de 40000 manifestant.e.s.

102. La Asamblea Feminista de Madrid se réunit depuis 1978 au sein de "Barquillo, 44 », lieu de référence du féminisme madrilène depuis la transition démocratique. II a accueilli plus d'une centaine de collectifs et d'associations, devenant ainsi un espace de convergence et de dialogue entre tous les féminismes. En raison des coupes budgétaires, le local a fermé ses portes en octobre 2014 et a été transféré à « Bravo Murillo, 4 ». Cf. « Manifiesto sobre el cierre de Barquillo, 44 », octobre 2014, [http://www.feministas.org/madrid/?p=250], consulté le 18 novembre 2014.

103. Luis RuIz AJA, Florián Manuel PÉREZ, Teresa María Gómez-PAStRANA, El descontento social y la Generación IN, Madrid, Editorial Popular, 2013, p. 30.

104. En Espagne, c'est la "Plateforme des affectés de l'hypothèque» (Plataforma de los Afectados por la Hipoteca) qui a réalisé les premiers escraches pour protester contre les expulsions abusives sous l'effet de la crise économique et de la spéculation financière.

105. Joanna GARCía Grenzer, Pikara Magazine, 24 mai 2013, [http://www.pikaramagazine. com/2013/05/escrache-feminista-hacia-la-desobediencia-civil-ante-la-contrarreforma-de-laley-de-aborto/], consulté le 18 novembre 2014.
} 
s'étaient donné rendez-vous devant les sièges régionaux du Parti populaire et devant le domicile madrilène du ministre de la Justice afin de manifester leur opposition au projet de réforme. "Vos rosaires hors de nos ovaires/Les riches paient, les pauvres meurent/Pour nos droits, pour nos choix", autant de slogans humoristiques, de pancartes et de chansons subversives, qui ne sont pas sans rappeler les modalités d'action des féministes de la deuxième vague, notamment en France, pour défendre le droit à l'avortement dans les années 1970. Malgré le caractère pacifiste des rassemblements, ceux de Madrid, Alicante et Valladolid ont été violemment réprimés par la police ${ }^{106}$ et se sont soldés par plusieurs arrestations assorties d'amendes ${ }^{107}$. Après un bras de fer de plusieurs mois et toute une gestion des crispations dans les rangs du Parti populaire, c'est le chef du gouvernement lui-même qui a annoncé, le 23 septembre 2014, le retrait de l'avant-projet de loi, accélérant ainsi la démission annoncée de son ministre de la Justice ${ }^{108}$. Le manque de consensus au sein même de la droite espagnole, la préservation de ses intérêts politiques et la pression massive des mobilisations nationales et internationales, citoyennes et féministes, ont finalement eu raison d'un projet de loi qui, au bout du compte, menaçait la crédibilité d’un gouvernement déjà très affaibli par la crise économique et la révélation de nombreux scandales de corruption, et qui n'était pas en position de force dans la perspective des différentes échéances électorales de l'année 2015.

\section{$* * *$}

Ces mobilisations massives démontrent le dynamisme du militantisme féministe qui a commencé à se reconfigurer à la fin des

\footnotetext{
106. Les images de la charge de la police contre les manifestant.e.s, devant le domicile d'Alberto Ruiz Gallardón à Madrid, sont disponibles sur le lien suivant, [https ://www.youtube.com/ watch?v=ynDgb7N5D9g], consulté le 10 novembre 2014.

107. Soulignons qu'un avant-projet du ministère de l'Intérieur sur la "nouvelle loi de sécurité citoyenne " soulève depuis plusieurs mois de vives polémiques. II prévoit notamment de renforcer les sanctions contre les escraches, référencés comme des infractions graves et, punis par des amendes entre 30000 et 600000 euros, Diario. es, 14 novembre 2013, [http:// www.publico.es/482327/la-ley-de-seguridad-ciudadana-una-mordaza-para-los-que-protestan], consulté le 18 novembre 2014.

108. Plusieurs figures du Parti populaire ont manifesté publiquement leur opposition au projet de loi : Celia Villalobos (vice-présidente du Congrès et ancienne ministre de la Santé sous le gouvernement de José María Aznar), José Antonio Monago (président de la communauté autonome d'Estrémadure), Alberto Núñez Feijoo (président de la communauté autonome de Galice), Juan Vicente Herrera (président de la communauté autonome de Castille et Léon), Cristina Cifuentes (déléguée du gouvernement à Madrid), Rosa Valdeón (maire de Zamora), Borja Semper (président du PP de Guipuscoa), etc.
} 
années 1990 et, qui a trouvé un terrain d'expression, d’abord dans la " révolution citoyenne " de 2011, puis autour du projet de réforme sur l'avortement. Depuis les luttes féministes pour l'obtention d'une loi sur le divorce et sur l'avortement, au début des années 1980, le pays n'avait pas connu une telle "unité dans l'action ${ }^{109}$ ". L'obstination d'Alberto Ruiz Gallardón dans son entreprise de mise sous tutelle des femmes espagnoles a fait office de catalyseur des forces féministes, qui se sont rassemblées dans un grand mouvement intergénérationnel et contestataire: les manifestations ont offert, tour à tour, l'occasion de marquer une opposition ferme au projet de loi, de dénoncer la dégradation des conditions de vie des familles et des femmes, liée aux coupes budgétaires en matière de santé, d'aides sociales, de gel des salaires ou de s'insurger contre le poids de l'ordre patriarcal, hétérosexiste et capitaliste. On constate que l'Espagne ne fait pas figure de cas isolé car nous assistons, depuis le début des années 2000, au renouveau de la " culture de la contestation ${ }^{110}$ ", qui se traduit, dans une perspective genrée, par une internationalisation des stratégies de l'activisme féministe radical, par la consolidation de réseaux de solidarité féministes nationaux et transnationaux et, par la fondation de nouveaux collectifs qui revendiquent, sur des registres divers, un renouvellement des discours et des modalités d'action féministes. L'histoire du féminisme espagnol est marquée par la consolidation de ses luttes au cours des dernières années du franquisme (tardofranquismo) et, bien que sa fragmentation en courants pluriels ait été une constante, cela ne l'a pas empêché de porter des combats de haut vol visant à l'obtention de nouveaux droits juridiques pour les femmes. L'institutionnalisation du féminisme, sous les gouvernements socialistes, a inscrit les politiques de genre à l'agenda politique mais ce féminisme de service, légitime et nécessaire, a eu pour effet de reléguer le féminisme autonome dans les interstices de la contestation minoritaire. Au tournant des années 1990, sous l'influence des théories post-modernes, post-structuralistes et queer, les féminismes espagnols ont procédé à une réactualisation de leurs théories, postulant pour la "subversion de l'identité " et la performativité des corps ${ }^{111}$. Aussi dès le milieu des années 1990 et, plus encore à partir des années 2000, les activistes se sont montré(e)s perméables à de nouveaux courants remettant en cause la matrice hétérosexuelle,

109. Nous empruntons cette expression à María MARTínEZ GonZÁLEZ, op. cit., 2008.

110. Isabelle SOMMIER, Le renouveau des mouvements contestataires à l'heure de la mondialisation, Paris, Flammarion, 2003, p. 24.

111. Nous reprenons ici le titre de l'ouvrage de référence de Judith BUTLER, op. cit., 1990. 
la catégorisation binaire de genre et le sujet même du féminisme. Les théories Queer, le transféminisme, le postporn, le pornoterrorisme, les mouvements pro-sexe, autant de nouveaux courants qui ont ouvert, nous dit l'activiste Beatriz Gimeno, " un monde de possibilités, nous ont permis de chausser de nouvelles lunettes pour voir la réalité112 ", en rendant visibles d'autres subjectivités, d'autres sujets, de nouvelles inégalités, sous l'effet des politiques néolibérales et de l'imbrication de plusieurs systèmes d'oppression.

Pour conclure, nous ajouterons que cette "marée violette " qui a déferlé ces deux dernières années ne s'est pas tarie, comme en témoigne la déclinaison politique des propositions féministes du 15-M dans la nouvelle formation politique Podemos ${ }^{113}$. Depuis mars 2014, les revendications féministes, au sein de cette nouvelle force montante, sont portées par le cercle Podemos féminismes ${ }^{114}$, un espace de réflexion et de participation citoyenne sur les thématiques en lien avec l'égalité femmes-hommes qui veille à rendre effective, non sans difficultés, la transversalisation au sein des autres cercles thématiques de l'organisation politique ${ }^{115}$. Malgré les critiques formulées par les autres formations politiques à l'égard de ce nouveau parti ${ }^{116}$, malgré les résistances encore perceptibles dans ses rangs à l'égard du féminisme et malgré l'institutionnalisation d'une mobilisation sociale qui pose question, il n'en reste pas moins que cette nouvelle formation politique s'impose comme un laboratoire expérimental des propositions théoriques, trop souvent cantonnées au rang des utopies, une alternative à la représentation politique traditionnelle en mettant au cœur de son programme transformateur la participation citoyenne. "L'un des meilleurs atouts de Podemos est le grand nombre de féministes qu'il compte dans ses rangs ${ }^{117}$ ", assure Beatriz Gimeno, qui milite dans le parti et

112. Beatriz GIMENO, op. cit., 2009.

113. Podemos, dirigé par l'eurodéputé Pablo Iglesias, s'est présenté aux élections européennes de mai 2014 et a obtenu 7,98 \% des voix, ce qui le place au quatrième rang des forces politiques en Espagne.

114. [https://www.facebook.com/pages/Podemos-Feminismos/235288249991431?sk=info], consulté le 24 novembre 2014.

115. Interview Círculo Podemos Feminismos, 8 mars 2014, [http://www.espacioalternativo.org/ spip.php?article29499], consulté le 24 novembre 2014.

116. Les critiques les plus récurrentes sont la proximité idéologique entre Podemos, le populisme, le chavisme et le castrisme ainsi que l'antidémocratisme de l'équipe constituée autour de Pablo Iglesias.

117. Beatriz GIMENO, «Ante las críticas al feminismo de Podemos », blog de Beatriz Gimeno, 17 novembre 2014, [http://beatrizgimeno.es/2014/11/17/ante-las-criticas-al-feminismo-depodemos/\#more-3550], consulté le 24 novembre 2014. 
pour laquelle les mutations qui sont en train de s'opérer sont le fait de " jeunes féministes bien formées, très engagées dans le féminisme, avec les idées claires et un haut degré d'activisme féministe ${ }^{118} »$. Ces nouvelles formes d'engagement s'efforcent de refaçonner l'agir féministe et ouvrent un horizon d'espoir quant à la progressive prise en compte transversale des revendications féministes, non plus traitées à la marge, mais prises comme caisse de résonance des questions du temps présent. Le féminisme hégémonique, qui est aujourd'hui la cible des activistes de la troisième vague, ce féminisme "gris, normatif et puritain ${ }^{119}$ ", de l'aveu même de ses détracteurs/rices, est-il en mesure de répondre aux défis contemporains sans un renouvellement en profondeur de ses théories, de ses modes d'action et de son vivier militant? Parviendra-t-il à se laisser baigner par de nouvelles marées régénératrices, à se laisser secouer par la houle tumultueuse du renouveau, à se laisser porter par les remous des problématiques émergentes? Il semble en tout cas en avoir les capacités structurelles et organisationnelles puisque le féminisme s'est toujours défini comme "une politique de l'action permanente ${ }^{120}$ », un mouvement jalonné de flux et de reflux, d'avancées et de reculs, de conflits et de sororité, qui a reformulé, réinventé, réadapté, repensé inlassablement son corpus théorique et ses pratiques tout au long de sa longue histoire politique et sociale.

\footnotetext{
118. Ibid.

119. Paul B. PrECIADO, « Mujeres en los márgenes », Elpais. com, 13 janvier 2007,

[http://elpais.com/diario/2007/01/13/babelia/1168648750_850215.html], consulté le 18 novembre 2014.

120. Françoise ColuIN et Irène KAUFER, « Post-Scriptum. La Terre promise », op. cit., 2014, p. 32.
} 



\section{DEUXIÈME PARTIE}

\section{REVENDICATIONS IDENTITAIRES \\ ET NOUVEAUX MOUVEMENTS SOCIAUX}





\title{
5 \\ Mouvements de contestation en Catalogne: manifestations et consultation(s) sur l'indépendance
}

\author{
Mercè PUJOL BERCHÉ
}

\begin{abstract}
Malgré le mauvais usage de la justice fait par les autorités du gouvernement espagnol, nous ferons réalité un rêve et ne permettrons pas que l'on nous l'abîme. (Muriel Casals, présidente d'Òmnium Cultural, Gran Teatre del Liceu, Barcelone, 22 décembre 2014)
\end{abstract}

Le 9 novembre 2014, 33 \% des électeurs catalans (un peu plus de deux millions de personnes) se sont rendus aux urnes pour répondre à ces deux questions: "Voulez-vous que la Catalogne soit un État?", et "Voulez-vous que cet État soit indépendant? ». 80,75\% des personnes qui se sont exprimées lors de cette consultation ont répondu "Oui " aux deux questions; $10,07 \%$ « Oui » à l'État, mais " Non » à un État indépendant; et enfin, 4,54 \% "Non " aux deux questions. Cette consultation, voulue par la société civile et organisée par la Generalitat, n'était pas un référendum et n'était pas non plus légale. Elle fait partie d'une "longue histoire ", dont on pourrait situer l'origine en 1714 lorsque la Catalogne, ainsi que les îles Baléares, Valence et l'Aragon ont subi l'abolition des Fors (lois), l'interdiction du catalan et l'instauration des Bourbons en Espagne.

Le renouveau du mouvement indépendantiste catalan doit être analysé dans le contexte des discussions sur la réforme du statut catalan (2004-2006). Il commença à prendre forme avec les consultations populaires initiées en 2009, puis connut un sursaut qualitatif lors de la manifestation massive de juillet 2010 contre la décision du Tribunal constitutionnel sur le caractère anticonstitutionnel des articles les plus emblématiques de ce statut, notamment par rapport à la langue catalane, à la fiscalité et à la reconnaissance de l'identité catalane en 
tant que " nation " politique à part entière. Dans le contexte des crises économique et démocratique, l'indépendantisme catalan s'est cristallisé petit à petit à l'occasion du 11 septembre, le jour de la Diada, la fête nationale catalane, depuis 2011. Une entité culturelle, Òmnium Cultural, et l'Assemblée nationale catalane créée en 2010, deux instances présidées par deux femmes, Muriel Casals et Carme Forcadell respectivement, ont pris en charge l'organisation des mouvements de contestation, en faisant pression sur les politiques et en menant le débat vers la société civile.

Comment a ressurgi la vieille revendication de l'indépendance de la Catalogne? Dans quel contexte social espagnol s'insère-t-elle? Qui organise le mouvement et pourquoi? Ce sont les questions auxquelles le présent chapitre essaie de répondre. Pour ce faire, nous commencerons par un bref rappel historique, afin de donner quelques points de repères permettant de situer la demande contemporaine des Catalans, ce qui nous permettra notamment de retracer la trajectoire du nationalisme catalan depuis la naissance de l'Espagne des autonomies. Puis l'« œuvre collective " qu'a constituée le statut d'autonomie de la Catalogne de 2006 nous servira à "écrire une page de l'histoire ", selon les mots de celui qui fut le président de la Catalogne, Pasqual Maragall. Une histoire du temps présent où la langue catalane ainsi que la "nation catalane " font partie d'un imaginaire collectif qui se sent attaqué et bafoué par le Tribunal constitutionnel et donc par le gouvernement espagnol. L'histoire des relations entre le gouvernement de Madrid et celui de la Generalitat de Catalogne s'est donc ranimée. La voix du peuple s'est organisée et des protestations ont surgi dans une Espagne en crise où les Espagnols sont très remontés contre des politiques menées au détriment des personnes, contre la corruption institutionnelle et l'incapacité des partis à donner des réponses à leurs demandes de démocratie et de mesures sociales. Nous terminerons en rappelant qu'un sondage récent, d'avril 2015, met en évidence que $60 \%$ des Catalans considèrent qu'aucun parti politique ne peut donner une réponse adéquate à leurs problèmes principaux, le chômage et la précarité, donnée qui illustre un important désenchantement démocratique. 


\section{REPÈRES HISTORIQUES : LE NATIONALISME CATALAN EN PERSPECTIVE}

Le débat autour d'un État indépendant pour la Catalogne n'est pas nouveau. En effet, il est le fruit d'une longue histoire qui débute avec les décrets de Nova Planta de Philippe V, avec l'abolition de toutes les institutions catalanes et la mise au ban du catalan. En effet, pendant la période allant de 1707 à 1715, les décrets se traduisirent concrètement par l'abolition des Fors (lois): d'abord en Aragon et à Valence (1707), puis dans les îles Baléares (1715), et enfin en Catalogne (1716). L'espagnol ou castillan sera désormais la seule langue obligatoire de l'administration, de la justice et de l'enseignement.

À partir de la seconde moitié du XIX ${ }^{\mathrm{e}}$ siècle, après une longue période de mise en silence et de relégation de la langue catalane, prend corps une conscience de la langue et de l'identité catalanes. L'avènement des Jocs Florals (littéralement des " Jeux Floraux "), des joutes poétiques en langue catalane, marque une étape importante du renouveau culturel de la Renaixença (" Renaissance "), et réanime la catalanité, sans rejeter l'espagnolité de la Catalogne. Ainsi, lors de l'ouverture des Jocs Florals en 1858, son président, Antoni de Bofarull, prononce quelques mots sur le passé glorieux de la Catalogne, compatible avec l'espagnolité du présent $^{1}$. Le XIX ${ }^{\mathrm{e}}$ siècle verra naître les nationalismes que l'on appelle "périphériques »: basque (ethnique), galicien (plutôt culturel) et catalan (littéraire, culturel et politique) à cause, entre autres, de l'incapacité des gouvernements centraux de mener une politique de progrès social, d'adopter le libéralisme politique et d'affronter sereinement la perte des dernières colonies ${ }^{2}$.

Du point de vue politique, la Lliga Regionalista créée entre 1898 et 1901 sera au pouvoir jusqu'à la dictature de Primo de Rivera (1923) ${ }^{3}$. Son leader, Prat de la Riba, conduira les débats sur la nation et l'État, et publiera La nacionalitat catalana (1906), en établissant la distinction à faire selon lui entre l'État — organisation politique et artificielle - et la nation - entité naturelle avec une histoire et une culture partagées, et

1. Pere ANGUERA, « Nacionalismo e historiografía en Cataluña. Tres propuestas en debate », dans Carlos ForCADELL (dir.), Nacionalismo e historia, Zaragoza, Institución Fernando El Católico \& CSIC, 1998a, p. 73-88.

2. Juan Luis De La Granja, Justo Beramendi et Pere Anguera, La España de los nacionalismos y las autonomías, Madrid, Síntesis, 2001.

3. La Lliga Regionalista fut créée par des groupes politiques catalans dans le but de faire pression sur le gouvernement de Madrid afin de revendiquer les particularités linguistique et culturelle catalanes. Sa presse était La veu de Catalunya (1899-1936). 
dotée d'une langue propre qui a une importance centrale pour la création d'un sentiment national. C'est à partir de là que la nation, la langue et l'identité prendront une forte valeur symbolique: on commence alors à créer une communauté imaginaire basée surtout sur la langue, sur le passé historique ${ }^{4}$ de la Catalogne, ainsi que sur sa littérature ${ }^{5}$.

À propos de l'importance de la langue catalane, signalons quelques faits qui contribuèrent à la construction de cet imaginaire collectif: le Primer Congrés Internacional de la Llengua Catalana a lieu à Barcelone du 13 au 18 octobre 1906 et Joan Bardina demande que cette langue soit la seule enseignée ${ }^{6}$; l'Institut d'Estudis Catalans est créé le 18 juin 1907 par Prat de la Riba, alors président de la province de Barcelone. Puis Pompeu Fabra (1868-1948) élève la langue catalane du statut de langue ancestrale à celui de langue nationale de la Catalogne et des pays catalans, en menant un travail remarquable et de grande profondeur sur le corpus de la langue ${ }^{7}$ (tout ce qui est en rapport avec sa normativité: dictionnaires, grammaires, etc.). La Mancomunitat catalana, créée en 1914, regroupe les quatre institutions provinciales catalanes (Diputacions de Tarragone, de Barcelone, de Lleida et de Gérone), favorise la décentralisation administrative et l'autogouvernance en matière économique, tout en œuvrant considérablement en faveur de la langue, des bibliothèques et de la diffusion de la culture catalane.

Par la suite, pendant les années 1930, comme l'a fait remarquer Riquer, "catalaniser " s'opposera en quelque sorte à " espagnoliser ", dans la mesure où le catalanisme politique émergent entrera de plus en plus en confrontation avec le nationalisme espagnol. Ce sera ensuite grâce à la Seconde République que la Catalogne obtiendra son statut d'autonomie, le 9 septembre $1932^{8}$. C'est là qu'il faut situer le début de l'Espagne des autonomies car pour Manuel Azaña (1880-1940), pré-

\footnotetext{
4. La première histoire écrite de la Catalogne est celle d'Antonio de Capmany, puis celle de Víctor Balaguer en 1860 : Historia de Cataluña y de la Corona de Aragón, cf. Pere ANGUERA 1998b. «El nacionalismo catalán desde sus orígenes a 1930 », dans Jean-Louis GUEREÑA (dir.), Les nationalismes dans I'Espagne contemporaine. Idéologies, mouvements, symboles, Paris, Éditions du temps, 1998, p. 117-146. La première histoire nationale est celle d'Antoni Aulèstia Pijoan, publiée en 1887 : Història de Catalunya.

5. II faut mentionner la publication Lo Verdader Català où l'on proclame que les Catalans sont des Espagnols : "L'Espagne est notre nation, mais la Catalogne est notre Patrie ».

6. Signalons que déjà, lors du congrès de pédagogie de 1888 , on avait sollicité de la reine régente (Marie Christine de Habsbourg-Lorena, épouse d'Alfonse XII), le droit de scolariser les enfants en catalan, au moins chez les tout-petits.

7. Sur l'action pan-catalaniste et le travail de promotion de la langue catalane au début du XXe siècle, voir Isabel GRAÑA I ZAPATA, L'acció pancatalanista i la llengua : nostra parla (1916-1924), Barcelone, Publicacions de l'Abadia de Montserrat, 1995.

8. Référendum du 2 août 1932 avec 75,09\% de « Oui ».
} 
sident de la Seconde République de 1936 à 1939, l’État central était alors devenu capable d'admettre la pluralité territoriale de l'Espagne ${ }^{9}$.

\section{LA CONSTITUTION DE 1978 ET L'ESPAGNE DES AUTONOMIES}

Après la dictature de Franco (1939-1975) et l'approbation de la constitution de 1978, les dix-sept nouvelles " communautés autonomes » et les deux "villes autonomes " (Ceuta et Melilla) rédigeront leurs statuts d'autonomie respectifs à partir de 1979. Ceux de la Catalogne et du Pays Basque furent ainsi votés par référendum le 25 octobre 1979 et celui de la Galice le 21 décembre 1980. D’après certains auteurs, l’Espagne des autonomies présente les caractéristiques d'un «fédéralisme sans État fédéral ${ }^{10}$ " ou d'une "fédéralisation caractérisée par une compétence ethno-territoriale multiple ${ }^{11}$ ». D'autres estiment que la nouvelle structure territoriale de l'État des autonomies a eu cet effet que l'« État devenait ainsi fédéralisable ${ }^{12}$ ».

En effet, l'un des buts de la mise en place des communautés autonomes était d'établir une structure administrative et politique capable de dépasser les grands déséquilibres entre les régions observés et forgés pendant les XVIII ${ }^{\mathrm{e}}$ et XIX ${ }^{\mathrm{e}}$ siècles, que l'industrialisation de seulement quelquesunes d'entre elles (notamment de la Catalogne, du Pays Basque puis de Madrid), avait creusées. Il s'agissait de même de dépasser les blessures collectives du $\mathrm{XX}^{\mathrm{e}}$ siècle, en reconnaissant les particularismes identitaires et en octroyant un statut distinct aux trois "nationalités historiques " dotées d'une langue propre. Or, lorsque l'on rédigea la Constitution de 1978, ce qui a été désigné comme le « café para todos » (" café pour tous »), c’est-à-dire le rejet d'une différence de traitement entre les « nationalités historiques " et les autres communautés autonomes, a eu pour conséquence que l'ensemble des communautés autonomes se sont dotées de

9. Isidre MOLAS, "Los nacionalismos durante la II República. Una perspectiva comparada », dans Justo BERAMENDı et Ramón MÀı (dir), Los nacionalismos en la España de la /l República. Madrid, Siglo XXI, 1991, p. 13-23.

10. Alicia Fernández García et Mathieu Petithomme, "Du nationalisme d'État aux nationalismes espagnols, la réinvention de la "nation" espagnole depuis la transition démocratique ", dans Alicia FERnÁNDEZ GARcía et Mathieu PETITHOMme (dir.), Les nationalismes dans l'Espagne contemporaine (1975-2017). Compétition politique et identités nationales, Paris, Armand Colin, 2012, p. 9.

11. Luís Moreno, La federalización de España. Poder político y territorio, Madrid, Siglo XXI, 2008. 12. Eduardo GARcía DE EnTERRía, Estudios sobre autonomías territoriales, Madrid, S. L. Civitas ediciones, 1985. 
leur propre statut d'autonomie et de leurs symboles. Certaines d'entre elles (non historiques) ont dû, de ce fait, les créer, comme Murcie ou l'Estrémadure (dont l'hymne a été approuvé en 1985).

La réforme des statuts d'autonomie concerna également toutes les communautés autonomes et pas seulement la Catalogne. Les partis de gauche ont donné une nouvelle impulsion à ces débats pendant le premier mandat du socialiste José Luís Rodríguez Zapatero (2004-2008), même si tous les socialistes ne partageaient pas le même avis et si les contextes politique et social étaient très différents de ceux du début des années 1980 lorsque les premiers statuts furent rédigés et votés. Dans ce sens, José Luís Rodríguez Zapatero, président du gouvernement central entre 2004 et 2011 a plaidé lors du débat sur l'état de la nation pour qu'une réforme des statuts puisse avoir lieu. L’un des grands détracteurs d'un tel projet fut Alfonso Guerra ${ }^{13}$, président de la commission constitutionnelle du Congrès des députés entre 2004 et 2011.

Pour donner quelques exemples des moments où les réformes des statuts d'autonomie ont eu lieu, mentionnons: celui de la communauté de Valence a été voté en 2006, en 2007 ont été votés ceux des îles Baléares, de l'Andalousie, de l'Aragon et de la Castille et Léon et en 2011 celui de l'Estrémadure ${ }^{14}$. Les mots de « nation » et de "nationalité » ont à nouveau posé problème, même si, rappelons-le, lors de la déclaration de Barcelone du 16 juillet 1998, les partis CiU (Convergence et Union ${ }^{15}$ ), PNV (Parti nationaliste basque) et BNG (Bloc nationaliste galicien) ont appelé à la reconnaissance du caractère plurinational de l'Espagne et des identités plurielles qu'elle inclut en forgeant une coexistence positive, en reconnaissant l'Espagne comme "nation de nations ». Ces termes ne sont pas exclusifs de la Catalogne, ainsi le statut de l'Andalousie de 2007 utilise-t-il le terme de "nation » pour définir cette communauté autonome: le syntagme de « réalité nationale » est employé pour mettre en évidence sa construction politique ${ }^{16}$. On discute encore et toujours autour de l'État-nation, des

\footnotetext{
13. II avait été vice-président (du 12 décembre 1982 au 12 janvier 1991) des gouvernements de Felipe González et avait reçu, en 2005, le prix de la fondation Abril Martorell pour «sa contribution décisive au "grand pacte" de la rédaction de la constitution de 1978 ", cf. El País, 3 décembre 2005.

14. Les premiers statuts pour ces mêmes communautés autonomes ont été votés comme suit: 1982 : Aragon et Valence; 1983 : Castille et Léon, Estrémadure et lles Baléares.

15. Afin de rendre plus lisible le texte, nous traduisons en français les noms des partis politiques. CiU est une coalition libérale et démocrate-chrétienne.

16. Julio Pérez SerRANo, « Migraciones, identidad cultural y ciudadanía en la construcción de la Comunidad autónoma andaluza (1982-2014) », dans Marie-Claude CHAPUT, Géraldine Galeote, Maria Llombart, Mercè Pujol Berché et Bruno Tur (dir.), Migraciones e identidades en la España plural. Madrid, Biblioteca Nueva, 2015.
} 
nationalités et de l'unité de l'Espagne. Pour l'instant, aucun des gouvernements centraux depuis Leopoldo Calvo-Sotelo jusqu'à Mariano Rajoy n'a accepté de revenir sur les acquis de la transition ${ }^{17}$ (notamment sur le " pacte du silence »), de revoir le modèle de l’État (l’Espagne des autonomies et la monarchie parlementaire), et enfin, de poser clairement et de débattre de la possibilité d'instaurer un véritable État fédéral.

\section{LES STATUTS D’AUTONOMIE DE 1979 ET 2006}

Le statut d'autonomie de la Catalogne fut voté par référendum par le peuple catalan le 25 octobre 1979. Avec une participation de 59,7\%, la consultation donna les résultats suivants: 88,15\% de " oui ", 7,76 \% de " non » et 4,09\% de votes blancs et nuls. Le nouveau statut de 2006 fut voté le 18 juin 2006, avec une participation de seulement 48,85\% des électeurs, et avec les résultats suivants: $73,24 \%$ de " oui », 20,57 \% de " non " et 6,19\% de votes blancs et nuls. Comme tout processus démocratique, le nouveau statut d'autonomie avait d'abord été approuvé par le parlement catalan le 30 septembre 2005, par $89 \%$ des voix (11\% contre $)^{18}$; puis, après de longues discussions et amendements, adopté au Congrès espagnol le 30 mars 2006 avec 189 voix pour, 154 contre et 2 abstentions ${ }^{19}$; et enfin au Sénat, sans modification, le 10 mai 2006 avec 189 voix pour le « oui », 159 pour le " non » et 3 abstentions ${ }^{20}$. Nous y reviendrons.

Lors des élections catalanes de 2003, le CiU obtint le nombre de voix le plus important, mais, même avec les voix du Parti populaire, il ne pouvait pas atteindre la majorité absolue. Ce fut donc la coalition " tripartite ${ }^{21}$ " PSC, ERC et ICV-EUiA qui accéda à la Generalitat, avec comme président, le socialiste Pasqual Maragall ${ }^{22}$. Le 14 décembre 2003,

\footnotetext{
17. Voir Marie-Claude Chaput et Julio PÉREZ SERRANo (dir), La transición española. Nuevos enfoques para un viejo debate, Madrid, Biblioteca Nueva, 2005.

18. Oui : 120 parlementaires : PSC (Parti socialiste de Catalogne), ERC (Gauche Républicaine de Catalogne), ICV-EUiA (Initiative pour la Catalogne-Verts-Gauche unie et alternative) et CiU ; non : 15 parlementaires du PPC (Parti populaire de Catalogne).

19. Les groupes politiques suivant votèrent en faveur du statut d'autonomie : PSOE (Parti socialiste ouvrier espagnol), CiU, PNV, BNG et CC (Coalition Canaries). Les députés du PP et d'ERC (soit 159 représentants) s'y opposèrent. Enfin, deux groupes choisirent l'abstention, EA (Eusko Alkartasuna) et PAR (Parti Aragonais).

20. En faveur: PSOE, CiU, PNV, BNG et CC; Non : PP et 3 abstentions : ERC, EA et PAR.

21. Cette coalition réunit le PSC, ERC, et ICV-EUiA, domina le Parlament et le gouvernement de Catalogne de 2003 à 2006, puis à nouveau de 2006 à 2010.

22. II sera président du 20 décembre 2003 au 28 novembre 2006. C'est aussi grâce à lui que, lorsqu'il était le maire de Barcelone, cette ville a organisé les Jeux olympiques de 1992 qui furent pour cette ville, et pour l'Espagne de 1992 un événement marquant.
} 
le « pacte du Tinell » fut signé, avec pour visée l'autogouvernement, une meilleure qualité démocratique et l'obtention d'un statut plus favorable pour le catalan. Cette coalition de gauche mit fin aux vingt-trois années de gouvernement de Jordi Pujol, du 24 avril 1980 au 16 décembre 2003. La coalition tripartite relança les discussions en vue de la modification du statut d'autonomie de la Catalogne: il en résulta une nouvelle rédaction et une certaine reconnaissance (relative) de la pluralité de l'Espagne. Pour ces trois partis de gauche au pouvoir, il était très important de mener à bien le projet du nouveau statut, car cela impliquait de donner une cohésion interne à leurs actions.

Quant à José Luís Rodríguez Zapatero, il avait promis pendant sa campagne électorale de 2004 de revoir les statuts d'autonomie, de donner son soutien au socialiste Pasqual Maragall, ainsi que d'accepter le statut que les Catalans auraient voté. Dans le contexte politique et institutionnel du gouvernement central, le Parti populaire s'affrontait certes aux socialistes en tant que principal parti de l'opposition. Mais dans le jeu politique de l'alternance (gauche-droite; socialistes-populaires) et du bipartisme, les enjeux des pactes des uns et des autres jouaient un rôle non négligeable, surtout avec les partis "minoritaires " qui servent de charnière lorsque le camp majoritaire ne dispose pas d'une majorité absolue. Le PP était farouchement opposé aux propositions nationalistes tripartites, et encore plus à la demande d'indépendance d'ERC. Rappelons néanmoins que Jordi Pujol ${ }^{23}$ (CiU) avait passé un pacte avec le Parti populaire en 1999 afin que José María Aznar (président entre 1996 et 2004) puisse être investi en tant que président du gouvernement central. Mais à cette époque-là, la CiU n’avait aucune prétention indépendantiste.

Le statut de 2006 fut " une œuvre collective ", comme l'illustrent ces mots écrits par Pasqual Maragall, tirés de l'introduction du texte: "Nous avons démontré une fois encore que la Catalogne est forte lorsque nous les Catalans exprimons librement notre volonté. Nous avons écrit une page de notre histoire ». Malgré le vote du peuple catalan, le Parti populaire présenta un recours d'inconstitutionnalité à l'encontre du nouveau statut à propos de 114 articles et de 12 dispositions ${ }^{24}$.

23. Jordi Pujol avoua le 25 juillet 2014, après des fuites dans la presse qu'il ne pouvait plus cacher, qu'il avait fraudé le fisc au moins pendant 34 ans, concernant la prétendue fortune qu'il avait reçue de son père, qu'il avait transmise à ses sept enfants et gardée en Andorre.

24. Recours du Parti populaire présenté au Tribunal constitutionnel le 31 juillet 2006, admis le 27 septembre 2006 : «Recurso de inconstitucionalidad n 8045-2006 en relación con diversos preceptos de la Ley Orgánica 6/2006, de 19 de julio, de reforma del Estatuto de autonomía de Cataluña », Boletín Oficial del Estado, n²41, 9 octobre 2006, Madrid. 
Le socialiste Enrique Múgica Herzog, défenseur du peuple (du 15 juin 2000 au 30 juin 2010), présenta lui aussi un recours auprès du Tribunal constitutionnel concernant 109 articles et 4 dispositions ${ }^{25}$. Le Tribunal constitutionnel prononça son jugement bien plus tard, le 28 juin 2010, remettant en cause 14 articles seulement, mais les plus emblématiques, à propos de la langue, de la notion de nation et du pacte fiscal, entre autres. C'est cette décision du Tribunal constitutionnel qui déclencha la grande manifestation du 10 juillet 2010 dont le slogan " Nous sommes une nation, nous décidons " (Som una nació, nosaltres decidim), retentit dans les rues de Barcelone ${ }^{26}$. Des manifestations massives se sont répétées chaque année depuis lors à l'occasion de la fête nationale de la Catalogne, la Diada, le 11 septembre.

Rappelons pour terminer que quelques mois après le vote du nouveau statut, des élections régionales anticipées ont dû être organisées pour légitimer à nouveau le gouvernement catalan dans le contexte de l'adoption du statut; des élections qui furent remportée par le PSC. C'est ainsi que José Montilla ${ }^{27}$, qui avait été ministre de l'Industrie, du Tourisme et du Commerce (du 18 avril 2004 au 8 septembre 2006) du premier gouvernement de José Luís Rodríguez Zapatero, fut élu président de la Generalitat, fonction qu'il a occupé du 28 novembre 2006 au 22 décembre 2010. En prévision des élections autonomiques catalanes, José Luís Rodríguez Zapatero avait « demandé à Montilla de quitter le gouvernement pour se consacrer à ces élections qu'il a donc gagnées ».

\section{LA LANGUE CATALANE COMME SYMBOLE D'IDENTITÉ ET DE COHÉSION SOCIALE}

Le nationalisme catalan s'est construit avec presque les mêmes paramètres que les nationalismes d'État: territoire, langue et identité. Il a construit, comme nous l'avons rappelé, un imaginaire collectif autour

\footnotetext{
25. Recours $n^{\circ} 1 / 2006$, présenté le 19 septembre et admis le 10 octobre: "Recursos de inconstitucionalidad n 8675-2006, en relación con diversos preceptos de la Ley Orgánica 6/2006, de 19 de julio, de reforma del Estatuto de autonomía de Cataluña », Boletín Oficial del Estado, n²48, 17/10/2006, Madrid. Voir sur les recours José Carlos HeRRERAS, «Le statut des langues de l'Espagne dans les nouveaux "statuts d'autonomie" », La linguistique, n 44/1, 2008, 7-28.

26. II s'agit de la deuxième manifestation massive après celle de la transition en 1977 avec le slogan « Liberté, amnistie et Statut d'autonomie ».

27. Montilla, né à Iznájar dans la province de Cordoue, a été maire de Cornellà, une ville près de Barcelone, dont la proportion de personnes nées en Andalousie (migration interne des années soixante) était très importante.
} 
de ces trois éléments. La " question de la langue " est devenue un des symboles de l'identité catalane ${ }^{28}$. Rappelons que parmi les compétences des communautés autonomes se trouvent l'éducation et la politique linguistique. Sur ce point, à nouveau, la Catalogne n'est pas différente des autres communautés. Si l'on compare le statut d'autonomie de 1932 avec celui de 1979, il n’y a en effet pas de grande différence, si ce n'est la désignation retenue pour les langues autres que le castillan. En effet, le terme largement débattu de " langue propre " fut accepté et les langues des trois "nationalités historiques ", le catalan, le basque et le galicien, se virent attribuer le statut de langues co-officielles. Si l'on compare maintenant le statut d'autonomie de 1979 avec celui de 2006, on observe un traitement différencié du castillan et du catalan. Dans la constitution de 1978, on privilégie le castillan car il est la seule langue de l'État espagnol, officielle sur l'ensemble du territoire. Le statut catalan de 2006, dans son article 6.1, considère, lui, que la langue catalane est la langue des administrations publiques, la langue véhiculaire et la langue des apprentissages de l'enseignement en Catalogne. L'article 6.2 précise que les citoyens de la Catalogne ont le droit d'employer aussi bien le catalan que le castillan, et l'on ne peut pas les discriminer à cause de la langue.

La politique dite de "normalisation linguistique " de la Generalitat à l'égard de la langue catalane s'est mise en place à partir de 1980 afin de normaliser l'usage de cette langue. L'action de normaliser consiste à mettre en place un ensemble de lois et de textes juridiques permettant d'assurer la stabilité d'une langue. Un bon exemple en est le Québec où l'on parle d'aménagement linguistique. En d'autres termes, il s'agit de réorganiser les fonctions d'une langue minorisée et minorée afin qu'elle puisse être utilisée dans tous les domaines. Les tensions entre l'État central et les communautés autonomes peuvent être mises en évidence au niveau linguistique, comme Ninyoles l'a souligné29. En effet, les différences deviennent politiques et peuvent coïncider avec d'autres lignes de tension. La langue ou la " question de la langue » est ainsi instrumentalisée, notamment par les politiciens lors des élections, comme nous

28. Le lecteur peut consulter Mercè PUJOL BERCHÉ, « Política lingüística : lengua, cultura e identidad. El ejemplo de Cataluña ", Amnis. Revue de civilisation contemporaine Europe/Amériques, [http://amnis.revues.org/2061], mis en ligne le 20 novembre 2013

29. Rafael NINYOLES, "España como país plurilingüe: Líneas de futuro », dans Albert BASTARDAS et Emili BoIx (dir.), ¿Un estado, una lengua? La organización política de la diversidad lingüística, Barcelone, Octaedro, 1994, p. 25-73. 
l'avons mis en évidence dans différents travaux ${ }^{30}$. La politique linguistique concerne aussi la relation entre langue et pouvoir ${ }^{31}$. On voit bien ces tensions: au XIX ${ }^{e}$ siècle avec l'incapacité de l'État à mettre en place un projet national inclusif, puis pendant la rédaction de la constitution avec le « café pour tous " visant à ne pas introduire de traitement différencié parmi les communautés autonomes, en 2006 avec la réforme des statuts d'autonomie et actuellement avec le débat autour de la réforme de la constitution et de la demande d'indépendance de la Catalogne.

Quelques mots sur la politique linguistique de la Generalitat. D’après Isidor Marí, il est possible de distinguer quatre périodes ${ }^{32}$. La première est celle de la "normalisation » (depuis la transition jusqu'à la fin des années 1980), la deuxième est celle de la planification avec le " plan général de normalisation linguistique de 1995 » (depuis la fin des années 1980 jusqu'aux années 1990), la troisième est celle de la mise en place de la " nouvelle loi » de 1998 (fin des années 1990-début 2000), enfin la dernière est celle de la "soutenabilité linguistique ", caractérisée par la gestion de la diversité. Actuellement, la politique linguistique est organisée de manière transversale, en incluant un travail conjoint entre les administrations et les secteurs privés, et la représentation de la langue catalane et de la Catalogne au niveau européen et à l'Unesco. Pendant ces quarante ans de démocratie et de politique linguistique il y a une constante: indépendamment de la couleur politique des partis au pouvoir, à la langue n'a cessé d'être l'un des symboles de l'identité catalane, de même qu'un outil de cohésion sociale et d'inclusion ${ }^{33}$.

30. Sur l'utilisation des langues à des fins politiques pendant les élections voir Mercè PuJoL BERCHÉ, "Une manipulation subtile: Les propositions concernant les langues pendant la campagne électorale espagnole », dans José Carlos DE Hoyos et Marie-Hélène PĖRENNEC (dir), Langue et manipulation, Saint-Étienne, Presses universitaires de Saint-Étienne, 2012, p. 47-60 et Mercè PUJOL BERCHÉ, « La cuestión lingüística en la campaña electoral española de 2008 y su transposición en los periódicos ABC y El País », dans Christian LAGARDE (dir.), Le discours sur les «langues d'Espagne »/El Discurso sobre las « lenguas españolas », (1978-2008), Perpignan, Presses universitaires de Perpignan, 2009, p. 237-254. Sur l'usage que les personnalités politiques font des termes sociolinguistiques, voir Mercè PUJOL BERCHÉ, "Langue, nation et nationalités: Us et abus de notions sociolinguistiques par les politiques", dans Henri BOYER (dir), Colloque International: Pour une épistémologie de la sociolinguistique, Limoges, LambertLucas, 2010, p. 309-318.

31. José Carlos Moreno CABrera, el nacionalismo lingüístico. Una ideología destructiva, Barcelone, Península, 2008.

32. Isidor MARI, « De la normalització a la sostenibilitat: els límits de la planificació de l'estatus », Treballs de Sociolingüística catalana, n²1, 2011, p. 83-94.

33. Impossible de ne pas rappeler que le PP veut des écoles séparées selon la langue, quelque chose qu'il demande sans cesse par exemple aux îles Baléares où il a gouverné pendant des années. 
La Catalogne a toujours été une région d'accueil de migrants, et a toujours veillé à leur insertion: il s'est agi d'abord de migrants originaires de Murcie (au début de l'industrialisation), puis en provenance surtout de l'Andalousie (dans les années 1960), et enfin issus de la nouvelle immigration internationale (depuis les années 1990). Pour illustrer le souci d'inclusion des nouveaux-venus dans la population, mentionnons le Plan pour la langue et la cohésion sociale de 2003-2004, puis le Pacte national pour l'immigration en 2009, où l'un des points reconnus les plus importants est la cohésion sociale et la participation de tous à la société ${ }^{34}$. Sur ces chapitres, les propositions émises par Pasqual Maragall avant qu'il devienne président de la Generalitat en 2003 furent reprises, à savoir que la Catalogne devait travailler pour l'immigration, pour sa place dans l'Union européenne et pour les droits civiques et sociaux de tous. Un travail à l'international que l'on constate aussi au sein du mouvement indépendantiste. Rappelons également que la Generalitat possède des délégations, entre autres, pour la France et la Suisse, dont le siège est à Paris; auprès de l'Union européenne, le siège étant à Bruxelles; et enfin, aux États-Unis, dont les sièges sont à Washington et à New York.

\section{LA PLACE DES CONTESTATIONS : LA VOIX DU PEUPLE}

S’il est vrai que le détonateur des contestations massives a été l'appréciation du Tribunal constitutionnel sur le caractère anticonstitutionnel de plusieurs articles du statut d'autonomie de 2006, il me semble que le "malaise " a commencé à prendre corps lors des discussions à propos dudit statut. Nous avons égrené plus haut quelques éléments des discussions de la classe politique, mais il faut aussi parler des gens. En effet, c'est en 2005 que la plateforme « droit à décider » a vu le jour. Elle a été établie par 700 entités, 49 municipalités et 4000 personnes en réponse à la non-reconnaissance par l'État de la Generalitat comme sujet juridique. En effet, après le vote du statut par le parlement catalan en 2005, ce texte est parti au Congrès et là, comme nous l'avons mentionné plus haut, une multitude de modifications ont été apportées. Pour faire état du mécontentement

34. Nous avons écrit sur l'intégration sociolinguistique des migrants en Catalogne. Voir par exemple Mercè PUJOL BERCHÉ, "Contribution de l'immigration à la richesse linguistique et culturelle de l'Espagne : réflexions autour de l'intégration sociolinguistique », dans Marie-Claude Chaput, María Luisa PeÑAlva et Bruno Tur (dir). Regards, n 14, 2009, p. 253-270 et Mercè PUJOL BERCHÉ, "Immigració i integració sociolingüística a Catalunya », Actes du Colloque international de l'Association rrançaise des catalanistes et de l'université Paris Ouest Nanterre La Défense, Limoges, Lambert-Lucas, 2015. 
populaire, la plateforme a convoqué une manifestation le 18 février 2006, puis une autre en 2007. On passe alors des forces politiques à un mouvement transversal de la société. C'est là, nous semble-t-il, qu'il faut placer le "début du début " de toutes les manifestations qui vont suivre à cause de la décision du Tribunal constitutionnel adoptée en juillet 2010. La société civile va alors s'organiser: les consultations populaires vont commencer, une entité civique et culturelle comme Òmnium Cultural ${ }^{35}$ jouera un rôle important en tant qu'organisatrice du mouvement, l'Assemblée nationale catalane (ANC) sera créée, et la consultation du 9 novembre 2014 aura lieu.

Si tel est le contexte catalan, il ne faut pas oublier qu'il s'insère dans le contexte espagnol de la bulle immobilière de 2008, provoquant la crise économique qui éclate avec force, quoique niée par José Luís Rodríguez Zapatero qui ne prend pas les mesures adéquates. La société civile continue de s'organiser: la "Plateforme des affectés par l'hypothèque " voit le jour en 2009 avec Ada Colau à sa tête, "Jeunesse sans futur " naît en février 2011, le "Mouvement des indignés " en mai de la même année, puis toutes les "marées " et bien sûr le collectif " Démocratie réelle, maintenant!», toujours en 2011. Mariano Rajoy arrivant au pouvoir en décembre 2011 prend une série de mesures d'austérité, comme il l'avait promis pendant sa campagne électorale. Les crises ne font que s'aggraver: crise économique, mais également crise démocratique, crise de l'État-providence et crise de l'État-nation.

Le début du mouvement actuel pour l'indépendance de la Catalogne commence à prendre forme lors de consultations populaires lancées à l'initiative d'une femme, Elisenda Paluzié, à Arenys de Munt, un village situé au nord de Barcelone, le 13 septembre 2009. Lors d'une consultation symbolique, $41 \%$ de la population âgée de plus de seize ans vote sur le futur de la Catalogne. La question posée: "Êtes-vous d'accord pour que la nation catalane devienne un État de droit, indépendant, démocratique et social, intégrée à l'Union européenne? " reçoit 92,2 \% de " oui » et 2,3\% de " non ». Cette consultation a ensuite été reproduite dans 169 communes en 2009, puis d'autres municipalités ont organisé le même scrutin en 2010, puis en 2011 - y compris dans des communes en dehors de la Catalogne comme ce fut le cas d'un village de locuteurs catalans de la Sardaigne. Finalement, le 9 novembre 2014, eut lieu une

35. Òmnium Cultural est une entité catalane crée en 1961 (censurée par Franco entre 1963 et 1967), qui œuvre pour la défense de la langue, la cohésion sociale, la culture, le modèle d'école catalane, de même qu'en faveur de la projection internationale de l'identité catalane. 
grande consultation populaire organisé par la Generalitat dans l'ensemble de la Catalogne ${ }^{36}$, qui eut comme résultat un « oui » sans appel. Nous y reviendrons.

Mais le véritable élément déclencheur fut, comme nous l'avons indiqué, le rejet par le Tribunal constitutionnel de plusieurs articles du nouveau statut d'autonomie voté par le peuple catalan lors du référendum du 18 juin 2006. La réponse à cette décision fut donc la manifestation qui eut lieu le 10 juillet 2010 à Barcelone, et qui fut l'antichambre de celle, encore plus massive, du 11 septembre $2012^{37}$. Sous le slogan " Nous sommes une nation. Nous décidons ", cette manifestation historique fut organisée par Òmnium Cultural. L’Assemblée nationale catalane (ANC) incita aussi les citoyens à se mobiliser dans la rue: deux millions de personnes selon les organisateurs participèrent à ce mouvement social sans précédent ${ }^{38}$. Il s'est agi d'un acte citoyen d'affirmation nationale, réclamant le respect de l'identité catalane et la création d'un nouvel État tourné vers l'Europe, sous les slogans «La Catalogne, un nouvel État européen », « Indépendance » et « L’indépendance, solution pour la Catalogne ".

Pour comprendre cet élan indépendantiste, il faut s'arrêter sur la création de l'ANC le 10 mars 2012, sur la base du travail accompli par les assemblées territoriales ${ }^{39}$. Cette organisation eut pour embryon la Conférence nationale pour un État propre, réunie au palais des congrès de Barcelone le 30 avril 2011 et marquée par l'élection d'un conseil permanent incluant intellectuels, écrivains, artistes et des personnalités de la société civile. L'ANC se considère comme une deuxième chambre du peuple catalan, souveraine et constituée par la société civile ${ }^{40}$. Il s'agit

\footnotetext{
36. La présidence de la Generalitat via le Secrétariat aux Affaires étrangères et à l'Union européenne, a organisé l'inscription au "Registre des Catalanes et Catalans résidant à l'extérieur », et ces Catalans ont pu voter dans différentes capitales du monde.

37. Il est important de mentionner que depuis les manifestations massives de 2003 contre la guerre d'Irak (avec le Parti populaire au pouvoir), on considère ces manifestations comme étant planétaires à cause du nombre de manifestants, du nombre de villes où elles ont eu lieu et du retentissement médiatique qu'elles ont reçu.

38. Les chiffres de manifestants sont toujours sujets à des controverses. La police estima ainsi le nombre de manifestants à 1500 000, et le quotidien El País à 600 000. Mais la plupart des observateurs s'accordèrent pour dire que plus d'un million de personnes participèrent, un chiffre historique, cf. "El independentismo catalán logra una histórica exhibición de fuerza », El País, 11 septembre 2012.

39. II faut, à notre avis, situer l'ANC sur la même ligne que l'assemblée de Catalogne constituée à la fin du franquisme, le 7 novembre 1971, par des syndicats, organisations sociales et secteurs progressistes de l'église. Elle a été dissoute suite à la création de l'assemblée des parlementaires.

40. Pour plus d'informations, voir son site internet, [http://assemblea.cat].
} 
d'un mouvement citoyen (hommes et femmes libres avec des droits) et souverain (autorité suprême). Elle a été présentée à l'université autonome de Barcelone par Mònica Terribas et son père, Jaume Terribas, ainsi que par Joan Manuel Tresserras ${ }^{41}$. Depuis, la relève médiatique a été constante.

Une nouvelle étape commença le 7 mars 2013 lorsque Òmnium Cultural, l'ANC et l'Associació de Municipis per la independència (Association des municipalités pour l'indépendance) avec onze autres organisations souverainistes créèrent le site El clauer, visant à fournir des arguments rassurants et positifs sur les conséquences de l'indépendance et chargé d'expliquer aux citoyens les perspectives possibles à propos des institutions de gouvernement, concernant le statut de la Catalogne dans le monde, les droits et la citoyenneté, la gestion de l'argent public, l'immigration et un ensemble le plus large possible d'enjeux politiques et sociaux $^{42}$. Puis, lors de la Diada suivante, le 11 septembre 2013, la manifestation fut organisée autour de la "Via catalana »: une chaîne humaine de $400 \mathrm{~km}$ traversa symboliquement toute la communauté autonome. Via catalana fait allusion à l'expression «Fer Via ", "Fer la Via ${ }^{43}$ " tirée d'un classique de la littérature catalane du Moyen Âge, Tirant lo Blanc de Joanot Martorell. Il s'agissait de tirer un fil conducteur entre le passé et le présent, de créer et recréer l'imaginaire collectif sous un angle historique et mémoriel. On attendait aussi de cette action très largement médiatisée une visibilité internationale accrue (avec des rassemblements concomitants à Paris, Londres, etc.) de l'idée d’une Catalogne indépendante. Enfin, la manifestation du 11 septembre 2014, dont l'objectif était d'attirer encore plus de monde que les années précédentes, en lien avec les efforts fournis par Muriel Casals et Carme Forcadell, les présidentes respectives d'Òmnium culturel et de l'ANC pour élargir la majorité sociale,

41. Mònica Terribas est une journaliste très connue en Catalogne ; elle fut la directrice générale de la télévision de Catalogne (2008-avril 2012), Professeure à l'université Pompeu Fabra de Barcelone, elle possède un doctorat de l'université de Reading (Écosse), sa thèse ayant pour titre: Television, national identity and the public sphere : a comparative study of Scottish and Catalan discussion programmes. Jaume Terribas a fondé à Montserrat le parti Convergència Democràtica de Catalunya (1974) et Joan Manuel Tresseras fut conseiller pour la culture et la communication de la Generalitat de Catalogne à l'époque de Montilla.

42. [http://www.elclauer.cat], consulté le 14 mars 2014. Les organisations sont: Cercle català de negocis, l'associacionisme cultural català, Sobirania i Justícia, Associació catalana de professionals, Ciemen, Fundació Catalunya Estat, Plataforma per la llengua, Sobirania i Progrès, Collectu Emma, la Fàbrica et Plataforma pro-Seleccions esportives catalanes.

43. Double sens de l'expression. D'une part, le sens réel «fer via » signifie s'unir à la voie et, d'autre part, le sens figuré signifie se presser afin d'atteindre un objectif. On doit à Tirant lo Blanc « fer la via » dans le sens d'aller vers un but. 
fut organisée sous le signe du " V »: V de Victoire, mais aussi V de Vote, en faisant directement allusion au référendum du 9 novembre 2014 sur l'indépendance, « $\mathrm{V}$ de Volonté d'un peuple à décider, $\mathrm{V}$ de Valeurs d'un peuple, $\mathrm{V}$ de Vieilles reVendications qui sont toujours Vives ». La date du 11 septembre 2014 était de surcroît dotée d'une forte composante symbolique, puisque l'on commémorait la défaite de Barcelone " après " la prise de la ville par les partisans de Philippe d'Anjou, lors de la guerre de Succession d'Espagne, le 11 septembre $1714_{\text {_ }}$ c cette guerre qui instaura le pouvoir monarchique des Bourbons.

Toutes ces manifestations, ainsi que d'autres actions collectives locales illustrent le renouveau des mouvements sociaux indépendantistes dans la Catalogne d'aujourd'hui ${ }^{44}$. Il s'agit de mouvements citoyens de masse remettant en cause la légitimité de l'État central, dans une région, la Catalogne, mais avec des répercussions globales profitables à d'autres mouvements indépendantistes comme ceux d'Irlande ou d'Écosse, qui ont eux-mêmes des répercussions sur la construction de l'Union européenne. Comme le signale l'historien Josep Fontana, certains secteurs de la société catalane considèrent que le pacte de 1978-1979 est devenu caduc, et que la Catalogne demeure perçue par le gouvernement central comme une province de la couronne de Castille $^{45}$. À notre avis, c'est à partir de cette intransigeance du gouvernement central, comme du contexte de l'émergence du mouvement des indignés du «11-M » depuis 2011, des « Novísimos » ou de la Spanish Revolution $^{46}$, qu'il faut considérer et analyser la demande d'indépendance des Catalans ${ }^{47}$.

\footnotetext{
44. Le lecteur peut consulter une bibliographie déjà importante sur les mouvements sociaux: Donatella DELLA PORTA et Mario DIANI, Social Mouvements : an introduction, Londres, Blackwell, 2006; Enric PRAT (dir.), Els moviments socials a la Catalunya contemporània, Barcelone, Publicacions i edicions de la Universitat de Barcelona, 2004; Benjamín TEJERINA MONTAÑA, La sociedad imaginada: movimientos sociales y cambio cultural en España. Madrid, Trotta, 2010; Manuel CASTELLS, Redes de indignación y esperanza: Ios movimientos sociales en la era de Internet, Madrid, Alianza editorial, 2012; Josep FonTANA, El futuro es un país extraño: una reflexión sobre la crisis social de comienzos del siglo XXI, Barcelone, Pasado \& Presente, 2013.

45. Josep FonTANA, op. cit., 2013. Voir de même Josep FonTANA, «Espanya i Catalunya: tres-cents anys d'història », Leçon inaugurale du Simposi Espanya contra Catalunya : una mirada histórica, Barcelone, Institut d'Estudis Catalans, mis en ligne le 12 décembre 2013, [http://www. youtube.com/watch?v=3rw-OHM4ysc], consulté le 23 de mars 2014.

46. Francisco Fernández Moreno, Spanish Revolution. Ensayo sobre los lenguajes indignados, Madrid, UnoyCero ediciones, 2013.

47. La composition du Parlement catalan depuis les élections du 10 décembre qui ont porté Artur Mas à la présidence de la Generalitat de Catalogne est la suivante : 62 sièges pour CiU, 28 pour le PSC, 18 pour le PPC, 10 pour ERC, 10 pour ICV-EUiA, 4 pour SI (Solidarité catalane pour l'Indépendance) et 3 pour C's (Citoyens).
} 
En effet, il est essentiel de souligner que ces protestations surgissent en Espagne dans un contexte où les Espagnols (y compris donc les Catalans) sont très mécontents des politiques menées par les différents partis politiques, des sauvetages financiers accordés aux banques au détriment des personnes, des scandales de corruption institutionnelle qui touchent tous les partis politiques y compris la Couronne (la sœur de l'actuel roi Felipe VI, Cristina de Borbón, est toujours inculpée). Les Espagnols se rendent compte que les politiques ne les représentent pas, qu'il y a un abîme de plus en plus profond entre les gens et leurs représentants. La démocratie est en crise. Comme Javier de Lucas le fait remarquer à juste titre, le problème de la société espagnole est non seulement la crise économique (utilisée souvent aussi comme une excuse pour ne pas aborder d'autres sujets probablement plus importants), mais la crise de la démocratie et la méfiance des Espagnols à l'égard des politiques qui n'ont pas su, pu ou voulu s'adapter au nouvel espace social, culturel, politique et économique de la mondialisation ${ }^{48}$. Pour ce professeur de droit constitutionnel, « le modèle de citoyen (consommateur de voix) du Parti populaire c'est la majorité silencieuse ». Face à une politique économique qui favorise les banques et qui paupérise de plus en plus les gens, ces mouvements sociaux demandent des changements profonds. Pour la Catalogne, cela s'exprime dans la manière dont l'ANC pousse, à partir de la base, les politiciens à agir pour qu'ils organisent un référendum: "Regardez le peuple qui est là dehors, lui, il a fait un pas, maintenant c'est au gouvernement de le faire, et qu'il sait que s'il le fait nous serons à son côté. Écoutez la clameur du peuple $^{49}$."

En résumé, les contestations surgissent dans un contexte social de crise: crise économique (chômage, incapacité à créer de l'emploi), crise démocratique (méfiance des gens à l'égard de leurs élus), corruption (institutionnelle), crise de l'État-providence (privatisation de la santé et de l'éducation, âge de la retraite plus tardif), de l'État des autonomies (réforme des statuts, réforme de la constitution). Face à ce marasme, surgit la voix de la citoyenneté qu'incarnent les mouvements sociaux avec leurs revendications, leurs modes de fonctionnement, leurs stratégies d'action allant de l'action collective à la connectivité, dans le contexte plus global de la mondialisation du XxI ${ }^{\mathrm{e}}$ siècle

48. Javier DE LUCAS, "Crisis de la democracia, ciudadanía, desobediencia», conférence plénière prononcée dans le cadre du Congreso Internacional Nuestro Patrimonio Común: Movimientos sociales, université de Cadix, 20 mai 2013.

49. Actes du secrétariat national du 8 septembre 2012. 
avec ses caractéristiques: la rapidité, les nouvelles technologies et les réseaux sociaux.

\section{LE MOUVEMENT VERS L'INDÉPENDANCE ET LA CONSULTATION DU 9 NOVEMBRE 2014}

Les deux collectifs qui ont pris en charge les actions vers l'indépendance sont Òmnium Cultural et l'ANC. Le premier est une entité culturelle qui existe depuis 1961, travaille pour la culture catalane au sens large du terme et, depuis l'automne 2012, se déclare ouvertement pour l'indépendance. La même année, il a reçu la médaille d'honneur du parlement catalan pour l'œuvre réalisée pendant toutes ces années d'existence. L'entité mène différentes actions dans ce sens, dont une intitulée « Un pays normal " pour faire allusion à la nécessité d'être un État différent de celui de l'Espagne. Certaines actions sont en rapport avec la « nation ", même celle de 1981 pendant la transition: « Appel à la solidarité: langue, culture et nations catalanes " (1981), " Freedom for Catalonia " pendant les jeux Olympiques de Barcelone (1992), « Free Catalonia » pendant le Forum des cultures après les jeux (1994), " Dignité nationale » (2007), « Ensemble pour la Catalogne " après les recours déposés auprès du Tribunal constitutionnel (2008), « Nous sommes une nation, nous décidons ", manifestation de juillet (2010), "Construisons tous un nouvel État d'Europe », " Feuille de route » (2012), " La Sant Jordi: rose, livre et "Estelada” sur les balcons » (2013), « Questions d’État: réflexions à propos du pays du futur » (2014).

De son côté, l'ANC soutient un processus qui cherche à mener à l'indépendance à travers l'effort collectif. Ses membres et ses sympathisants veulent faire de la Catalogne un État de droit (par tradition), démocratique (faire face aux élus dont les gens ne sentent pas qu'ils les représentent), social (meilleure répartition des richesses) et inclusif (de tous ceux qui vivent en Catalogne). L'un de ses objectifs a été de faire pression sur les politiciens pour réclamer un référendum sur l'indépendance, une consultation qui a eu lieu le 9 novembre 2014. L’ANC a mené également différentes campagnes: "La marche vers l'indépendance " qui commença à la Seu d'Urgell (au pied des Pyrénées) et se termina à Barcelone; l'« Estelada " (drapeau indépendantiste catalan) organisée par "Bagès independència ". Son caractère non-partisan est l'une de ses caractéristiques, car il s'agit d'une plateforme populaire qui souhaite s’appuyer sur la majorité sociale 
et l'utiliser comme outil pour faire pression. Elle s'autodéfinit aussi comme une organisation inclusive afin que tous les citoyens puissent y adhérer. Ses promoteurs mettent toujours en avant la volonté collective, en soulignant que l'ANC représente une organisation civile, transversale, qui s'est construite depuis le bas vers le haut. Comme dans les mouvements d'assemblée, celle-ci décide les actions que l'organisation doit entreprendre. Ses membres œuvrent à dans ce processus qui demande le droit à décider, dans les urnes, du futur politique de la Catalogne, afin qu'elle puisse avoir son propre État. Si nous nous attardons maintenant sur le discours de l'ANC, on peut observer qu'il se structure autour de trois axes thématiques: la société civile, la démocratie et le mouvement ${ }^{50}$.

Concernant la société civile, l'ANC évoque une "volonté collective, une organisation civile, transversale ", et le fait que "c'est toute la société civile souveraine qui convoque le processus, auquel les politiciens donneront une forme politique, mais depuis la société civile, [et que] nous nous sentons responsables d'animer le débat ». Quant à la démocratie, il s'agit de "faire pression sur les partis pour qu'ils organisent la consultation ", de " porter les urnes dans la rue ", afin de favoriser une "régénération démocratique »: "Nous sommes ici pour faire connaître notre cause, qui est aussi celle de la Catalogne et surtout la cause de la démocratie, celle du peuple, et de la justice. " Enfin, s'agissant du mouvement: " Nous ne bougerons pas d'ici, c'est notre chemin, mettre en marche des actions, suivre le processus d'indépendance afin de sauvegarder notre identité et l'État-providence, nous faisons du chemin vers notre souveraineté. " En phase avec cette dynamique du mouvement, les retours sur avancée sont fréquents: "Nous sommes en train d'initier le chemin de la construction nationale, nous continuerons, nous travaillerons toujours, nous sommes en train de faire une révolution. » Enfin, l'État central, «l'autre », lui, c'est « l'État espagnol qui nous soumet, au gré d'une "situation semicoloniale" ".

La consultation du 9 novembre 2014 sous l'égide de CiU, ERC, ICV et CUP ${ }^{51}$ a posé deux questions: "Voulez-vous que la Catalogne soit un État? ", " Voulez-vous que cet État soit indépendant? ». Le résultat de ce " processus participatif $^{52}$ " avec une participation d'un peu plus de

50. Source: [http://assemblea.cat/?q=node/31], consulté le de 2 mars 2014.

51. Candidature d'Unité populaire-Alternatives de gauche.

52. C'est sous cette désignation qu'il a été nommé par les indépendantistes. 
$33 \%$ des électeurs, a été le suivant: 80,75 \% de " oui " aux deux questions; $10,07 \%$ de " oui " à l'État, mais " non " à un État indépendant, $4,54 \%$ de "non " aux deux questions ${ }^{53}$. Qu'est-ce qu'on peut dire de ces résultats? D'abord, la première constatation importante est que la consultation a eu lieu grâce à la mobilisation des gens — la société civile -, et que l'organisation a été assurée par Òmnium Cultural, l'ANC, ainsi que grâce à la Generalitat elle-même (qui s'est chargée de l'enregistrement des électeurs). Ensuite, il faut noter que les électeurs se sont rendus aux urnes dans la bonne humeur et avec un esprit festif sachant que le moment, malgré le caractère non plébiscitaire de la consultation, était historique. Enfin, bien qu'il n'y ait pas eu d'enjeu politique (car il s'agissait d'une consultation et non d'un référendum organisé de manière légale), une bonne partie des électeurs qui se sont rendus aux urnes ont exprimé le souhait d'une gouvernance agissant dans une Catalogne souveraine. Après cette consultation, le Tribunal supérieur de justice de Catalogne a poursuivi trois personnes: le président de la Generalitat Artur Mas, la vice-présidente Joana Ortega et la conseillère Irene Rigau.

Même s'il s'agissait bien d'un processus entamé par la société civile, il faut également tenir compte de la pression des organisations de la société civile sur les partis, sans oublier les échéances électorales qui, comme dans tout État démocratique, ont lieu de manière périodique et, en ce qui concerne l'Espagne, sont prévues pour décembre 2015. Le "jeu politique" ne fait que commencer, mais ce que l'on peut d'ores et déjà dire, c'est que l'ANC et Òmnium Cultural par le biais de ses deux présidentes, provoquent et stimulent le débat parmi les citoyens, au sein même de chacun des partis politiques et entre les différentes organisations. Voyons donc finalement comment chaque tête de liste se situe par rapport à ces élections.

Les élections municipales du 24 mai 2015, mais surtout les régionales du 27 septembre 2015 ont montré le maintien dans les urnes d'un fort indépendantisme. Quant à la classe politique espagnole, Mariano Rajoy (PP) reste immuable, alors que Pedro Sánchez (PSOE) pencherait plutôt pour essayer d'ouvrir un dialogue vers le fédéralisme. En ce qui concerne la classe politique catalane, Artur Mas (CDC) et Oriol Junqueras (ERC) ont signé, le 30 mars 2015, la "feuille de route » conjointement avec l'ANC, Òmnium Cultural et l'AMI. Miquel

53. [http://premsa.gencat.cat/pres_fsvp/AppJava/notapremsavw/277304/ca/of-2-305-290-catalans-have-taken-part-in-the-9-participative-process.do], consulté le 1er avril 2015. 
Iceta (PSC) demande une nouvelle loi électorale qui prenne plus en compte la proportionnelle et comme le PSOE, un débat sur la réforme de la constitution et le fédéralisme. Pour Alicia Sánchez Camacho (PPC), la feuille de route n'est qu'un "papier mouillé » (" papel mojado "), à savoir que selon elle, "Mas et Junqueras continuent de tromper les Catalans ${ }^{54}$ ». Joan Herrera (ICV) souhaite quant à lui un " pacte pour la démocratie ", sans renoncer à un référendum sur le futur de la Catalogne ${ }^{55}$. Enfin, Albert Rivera (Citoyens), farouche opposant au nationalisme catalan, continue sa croissance dans les intentions de vote au niveau national et pour promouvoir un air de changement (à l'égard du PP et du PSOE), utilise le vocable « mouvement " (très à la mode, il est vrai), en qualifiant sa formation de " mouvement citoyen " ( Movimiento ciudadano »).

\section{LA CATAlogne FACE AU RENOUVEAU INDÉPENDANTISTE}

Òmnium Cultural, l'ANC et l'AMI (Association des municipalités pour l'Indépendance) poursuivent leurs actions, cette fois avec le slogan "Maintenant c'est l'heure", en vue des élections de septembre. Ils organisent un grand meeting au Palais des congrès de Barcelone le 24 avril 2015, et mènent une campagne unitaire pour les élections locales de mai, qu'ils voudraient plébiscitaires, avec le slogan " Revenons aux urnes, revenons dans la rue ". À six mois des élections au parlement de Catalogne, les trois entités ont organisé le 27 mars, plus de cent actions sous le slogan "Là où tout commence ", afin de rendre visible "la force de la société civile ". Si Convergència de Catalunya-Groupement indépendantiste et ERC remportent ces élections, l'ANC interprétera certainement ces résultats en considérant que le peuple a décidé d'entamer le processus vers l'indépendance. Il semble important de souligner deux points majeurs de leur feuille de route: la nécessité d'un État social (santé, éducation et retraites) et la régénération démocratique. On retrouve bien ici les demandes de la société civile quant au renouveau de la démocratie et à la manière de faire face à la crise économique par d'autres biais que les coupes budgétaires («recortes-retallades »).

54. [http://www.ppcatalunya.com/sanchez-camacho-califica-de-papel-mojado-el-preacuerdode-hoja-de-ruta-independentista], consulté le 5 avril 2015.

55. [http://www.iniciativa.cat/icv/news/54829], consulté le 5 avril 2015. 
Les élections régionales de septembre 2015 ont ainsi encore eu lieu sous le signe de l'indépendance, afin de donner une réponse à la société civile, de redonner au peuple la démocratie perdue et de revenir à l'État-providence. Enfin, dans la mesure où le contexte catalan est inséré dans le contexte espagnol, la force du nouveau parti Podemos ${ }^{56}$, qui réclame également une nouvelle démocratie et l'effacement des " castes " peut changer la donne des futures élections législatives. Il en est de même de la crispation d'une partie de la société espagnole, créée par le Parti populaire lorsqu'il nie tout débat, qu'il porte sur la possibilité d'un État fédéral pour l'Espagne, ou sur une plus grande autonomie des communautés "demandeuses " et non de toutes les communautés autonomes à la manière du " café pour tous ". En effet, le processus souverainiste n'est pas envisageable comme un pacte, mais comme un choc à cause d'un manque total de dialogue entre le gouvernement central et le gouvernement de la Generalitat. Ceci par rapport aux politiques, mais qu'en est-il au final en ce qui concerne la société civile?

Le dernier sondage, effectué auprès de deux mille personnes par le $\mathrm{CEO}^{57}$ est riche de renseignements concernant les opinions des citoyens espagnols résidant en Catalogne sur la situation politique, la confiance à l'égard du personnel politique ou de la situation économique. Arrêtons-nous sur quelques données qui vont nous servir à conclure ce chapitre. Près de la moitié des personnes interrogées (49,3 \%) considèrent que la situation politique en Catalogne est mauvaise tandis que plus de $90 \%$ considère que la situation politique en Espagne est très mauvaise $(49,3 \%)$ ou mauvaise $(41,1 \%)$. Plus de la moitié des enquêtés $(60,1 \%)$ considèrent qu'aucun parti politique ne peut donner une réponse adéquate à leurs problèmes, dont les principaux sont le chômage et la précarité (67,4\%). Les résultats en termes de sympathie à l'égard des partis sont les suivants: ERC (11,7\%), CiU (10,6\%), CUP (4,3\%), PSC (3,4\%), C’s (2,8 \%), ICV-EUiA $(2,0 \%)$, PPC (1,3\%). Cette enquête sociologique montre clairement le

56. La progression de Podemos depuis les élections européennes de mai 2014, ainsi que l'apparition de Citoyens (depuis les élections catalanes de 2010, Ciutadans/Ciudadanos, né en 2006, possède 9 sièges), peut remettre en cause le bipartisme, une perspective qui fait peur aux deux partis majoritaires et nationaux, le Parti populaire et le Parti socialiste ouvrier espagnol. Lors des dernières élections anticipées en Andalousie qui ont eu lieu le 22 mars 2015, les deux partis Citoyens et Nous Pouvons ont obtenu des sièges. En effet, la composition actuelle est la suivante: PSOE : 47 sièges, PP : 33, Podemos : 19, Ciudadanos : 9, IU-Verts-Convocation pour l'Andalousie : 5. 57. Centre d'estudis d'Opinió, Baròmetre d'Opinió Política, $1^{\text {a }}$ onada de 2014, n 746, Barcelone, Generalitat de Catalunya, 30 avril 2015. 
désenchantement de la société civile envers les élites politiques, les partis et leurs promesses. Elle illustre bien la grande déception des indépendantistes, mais également du reste de la société catalane, face à l'absence totale de perspective. 



\title{
6 \\ La " transition démocratique " du nationalisme basque radical: de la légitimation de la violence à l'indépendantisme démocratique?
}

\author{
Mathieu PETITHOMME \\ La tolérance est le seul remède contre la diversité des \\ opinions. \\ (Charles Nodier)
}

En décrétant unilatéralement le 20 octobre 2011 « la fin définitive de la lutte armée ", dans le but selon l'organisation de "donner une solution juste et démocratique au conflit politique séculaire ", l'ETA (Euskadi Ta Askatasuna, " Pays basque et liberté ») entérina la "transition démocratique » du nationalisme basque radical, marquée depuis le début des années 2000 par le déclin de la légitimation de la violence, et le choix de plus en plus marqué de ses sympathisants de privilégier la défense d'un indépendantisme démocratique au sein même des institutions. Après avoir causé, directement ou indirectement, la mort d'au moins 843 civils, policiers, militaires ou responsables publics de 1968 à 2010, cette évolution traduisit de fait le déclin de la composante militaire du nationalisme basque radical et son démantèlement progressif par l'État de droit à travers la répression policière ${ }^{1}$. Pour autant, lors de l'Aste Nagusia, la "Grande Semaine " de Bilbao de 2011, lorsque résonnait la chanson "Il n’y a pas de trêve " du groupe de rock navarrais Barrikada au sein de certaines txoznas (paillotes festives), certains criaient encore haut et fort « ETA, ETA, ETA! $»^{2}$.

\footnotetext{
1. En plus des 843 victimes mortelles de l'ETA et de groupes sympathisants, il faut ajouter 2533 personnes blessées (dont 709 souffrent d'une invalidité partielle ou totale permanente) et 80 séquestrées (dont 9 assassinées et 14 libérées suite à des « tirs de châtiment » dans les pieds) pour des durées allant de un jour à 532 jours pour le fonctionnaire de prison José Antonio Ortega Lara.

2. Anecdote racontée par Gaizka FERNÁNDEZ SOLDEVILLA et Raúl LóPEZ LOMO, Sangre, votos, manifestaciones : ETA y el nacionalismo vasco radical 1958-2017, Madrid, Tecnos, 2012, p. 35. Sur le lien entre nationalisme radical et musique alternative, cf. Christian LAHUSEN, « The aesthetic of radicalism: the relationship between punk and the patriotic nationalist movement of the Basque country », Popular Music, nº 12, 1993, p. 263-280.
} 
Ce chapitre a pour objectif de montrer comment, au-delà de l'ETA ${ }^{3}$, de ses nombreuses organisations satellites et des formations politiques et différentes « marques » de la gauche abertzale, le nationalisme basque radical constitue surtout un puissant mouvement social, dont les fondements sociologiques et l'ancrage dans l'espace public permettent d'expliquer la persistance jusqu'à nos jours. Par mouvement social, nous entendons les actions collectives d'une communauté politique qui partage un système de valeurs et un sentiment d'appartenance, tout en se dotant d'une capacité de mobilisation dans l'espace public et en définissant des revendications, des adversaires et un projet politique et social ${ }^{4}$. Même s’il évoque nécessairement le rôle de la lutte armée de l'ETA, le chapitre porte donc avant tout sur la « lutte de masse » du " mouvement basque de libération nationale " (MLNV) à travers le prisme de ses actions collectives. Il s’agira d'étudier l'actualité de cette communauté politique, en la replaçant dans son contexte historique et social, et en partant du point de vue des mobilisations, des manifestations et des mouvements sociaux contemporains qui donnent corps à ses revendications et les légitiment. Par nationalisme basque radical, nous entendons la version la plus intransigeante de l'ultranationalisme basque, qui renvoie à l'extrémisme mais aussi aux racines de l'idéologie nationaliste de Sabino Arana (voir infra), ce courant s'autodésignant comme le représentant légitime de la nation basque entendue au sens large (Euskadi, Pays basque français et Navarre), et revendiquant son droit à l'autodétermination ${ }^{5}$.

Les protestations, les manifestations et les marches constituent en effet des répertoires d'action centraux de l'abertzalisme radical, des formes de "lutte" (borroka, en basque) si importantes pour la

3. Pour les principaux travaux sur l'ETA, se référer à Miren ALCEDo, Militar en ETA. Historias de vida y muerte, San Sebastián, Haranburu, 1996 ; Florencio DoMíNGUEZ, ETA : estrategia organizativa y actuaciones, 1978-1992, Bilbao, Universidad del País Vasco, 1998 ; Carmen GuRRUCHAGA, Los jefes de ETA, Madrid, La Esfera de los libros, 2001 ; Ignacio SÁNCHEZ-CuENCA, ETA contra el Estado. Las estrategias del terrorismo, 2001 ; Fernando REINARES, Patriotas de la muerte. Quiénes han militado en ETA y por qué (2 édition), Madrid, Taurus, 2011 ; Iñigo BULLAIN, Revolucionarismo patriótico. El Movimiento de Liberación Nacional Vasco. Origen, ideología, estrategia y organización, Madrid, Tecnos, 2011. Voir aussi en français Antonio ELORZA et al., ETA une histoire, Paris, Denoël, 2002 et Jacques MASSEY, ETA : histoire secrète d'une guerre de cent ans, Paris, 2010.

4. Sur cette notion, cf. Érik NEVEU, Sociologie des mouvements sociaux, Paris, La Découverte, 2015; Olivier FILLIEULE, Lilian MATHIEU et Cécile PECHU, Dictionnaire des mouvements sociaux, Paris, Presses de Sciences Po, 2009.

5. Le fait que le nationalisme radical se revendique comme le seul représentant légitime de la nation basque constitue une synecdoque (prendre une partie pour le tout) commode, qui exclut une partie des citoyens basques, soit sur des critères d'exclusion notamment linguistiques, soit pour leur « espagnolisme » (leur sentiment d'appartenance à l'Espagne). Sur ce point, cf. Jesús CASQuETE, « La religión de la patria », Claves de Razón Práctica, 2010 b, n²07, p. 30-36. 
diffusion de ses revendications dans l'espace public que ses militants ${ }^{6}$ sont d'ailleurs dénommés les « borrokas ». Des années 1960 jusqu’à nos jours, les nationalistes radicaux ont organisé de nombreuses actions collectives en faveur de l'amnistie de ceux qu'ils considèrent comme des " prisonniers politiques ». Des cérémonies en l'honneur des " gudaris ", un terme initialement utilisé pour désigner les soldats basques et républicains qui luttèrent contre les troupes franquistes lors de la guerre civile, ont été détournées afin de rendre hommage aux " martyrs d'hier et d'aujourd'hui ", en présentant les combattants de l'ETA comme les héritiers historiques des soldats de la guerre civile ${ }^{7}$. Des cérémonies d'accueil triomphantes ont été organisées par les Gestoras pro-amnistia lors des sorties de prison des détenus de l'ETA. Durant les années 1990, la " kale borroka ", la lutte de rue, fut utilisée par des jeunes radicaux du samedi soir qui, combinant kalimotxo, un mélange de vin et de cocacola typique du « botellón » espagnol, passe-montagne, lance-pierre et cocktails molotov, cherchèrent à provoquer des affrontements violents avec les forces de police ${ }^{8}$. Des troubles censés donner corps et représenter le " conflit " basque lors d'actes violents à vocation performative. Les fêtes populaires du Gudari Eguna et de l'Albertia Eguna et des chants tels que l'Agur Jaunak ou la Marche funèbre Guernica ont été aussi récupérés par le nationalisme radical et utilisés pour justifier ses objectifs: l'autodétermination, l'amnistie et l'expulsion des forces armées du Pays basque à travers la lutte armée, les urnes et les manifestations. Ces buts n’ont pratiquement pas changé depuis 1958. Seuls les moyens mis en œuvre ont évolué à travers la fin définitive de la lutte armée depuis octobre 2011.

La « lutte de masse » du nationalisme basque radical peut être appréhendée à travers quatre phases distinctes: la phase de " résistance » au

6. Ce courant s'autodésigne comme « abertzale », à savoir " patriote » et de gauche, en référence à ses liens historiques avec l'extrême gauche, même si le référentiel de gauche est avant tout instrumental et a toujours été secondaire, au contraire de la prédominance de l'ultranationalisme. Sur ce débat cf. Jesús CASQUETE, «Abertzale sí pero, ¿quién dijo de izquierda? », El Viejo Topo, n²68, 2010, p. 15-19.

7. Mathieu Petithomme, "Commémorer les "gudaris" d'hier pour légitimer la violence d'aujourd'hui : une étude iconographique du détournement du Bizkargi et de l'Albertia Eguna au Pays basque », Pôle Sud. Revue de science politique de l'Europe méridionale, n 41, 2015.

8. Le «botellón » est une pratique des jeunes Espagnols, qui consiste à se rassembler dans la rue, les parcs et sur la voie publique pour consommer de l'alcool, fumer et écouter de la musique en minimisant les dépenses, souvent avant des sorties en discothèque. Plus que l'expression d'un simple divertissement, le botellón balise aussi d'une certaine manière un espace de protestation, à travers l'occupation spontanée de lieux publics, et le contournement de l'obligation commerciale de payer l'accès aux boissons alcoolisées au prix fort dans les bars et autres lieux réservés en théorie à cet effet. 
régime franquiste (1958-1977); la monopolisation de l'espace public (1978-1994); le déclin de l'hégémonie mobilisatrice (1995-2011) et l'institutionnalisation du nationalisme radical au sein du jeu démocratique et électoral depuis 2011. En nous appuyant notamment sur des archives de presse et une large littérature scientifique, il s'agira donc de considérer les principales caractéristiques de chacune de ces périodes, en revenant sur les mouvements sociaux qui illustrent le mieux la trajectoire contemporaine de ce courant politique au Pays basque espagnol.

\section{LA « RÉSISTANCE » AU RÉGIME FRANQUISTE ET LA LÉGITIMITÉ ORIGINELLE DU NATIONALISME RADICAL (1958-1977)}

\section{La résistance antifranquiste et le procès de Burgos}

Contrairement aux idées reçues, l'émergence de l'abertzalisme radical est bien antérieure à la fondation de l'ETA en 1958. Elle trouve son origine historique dans une interprétation littérale des positions de Sabino Arana, théoricien du nationalisme basque de la fin du XIX ${ }^{\mathrm{e}}$ siècle, sur les critères linguistiques et ethniques d'exclusion qui caractériseraient selon lui la " race " basque 9 . Un groupe de nationalistes radicaux fut de même formé dès 1906 autour de Santi Meabe et de la publication d'Aberri (patrie) ${ }^{10}$. Toujours autour d'une revue nationaliste, en l'occurrence Jagi-Jagi, le groupe radical du même nom fut formé en 1934 par Elias Gallastegui, en mêlant au nationalisme basque radical une référence anticapitaliste ${ }^{11}$. L'approche idéologique de l'ETA, qui adapta la rhétorique marxiste-léniniste et tiers-mondiste des mouvements de libération nationale des années 1960, ne fut donc pas inédite ${ }^{12}$. Dans les années 1960, l'ETA recevait initialement l'appui d'une partie de l'opinion espagnole, qui considérait l'organisation comme un groupe

\footnotetext{
9. Pour une présentation synthétique de la théorie et de l'apport de Sabino Arana au nationalisme basque, cf. José Luis DE LA GRANJA, El siglo de Euskadi. El nacionalismo vasco en la España del siglo XX, Madrid, Tecnos, 2003, p. 18-20 ; voir aussi du même auteur, «El antimaketismo: La visión de Sabino Arana sobre España y los españoles », Norba, 2006, vol. 19, p. 191-203. 10. Javier CoRCuera ATIENZA, Orígenes, ideología y organización del nacionalismo vasco: 18761904, Madrid, Siglo XXI, 1979, p. 110-115.

11. Sur ce groupe nationaliste radical, antécédent historique de l'ETA, cf. Eduardo RENOBALES, Jagi-Jagi. Historia del independentismo vasco, Bilbao, Ahaztuak, 2010.

12. José Manuel MATA LOPEZ, El nacionalismo vasco radical. Discurso, organización y expresiones, Bilbao, Universidad del País Vasco, 1993, p. 21-39.
} 
d'opposition au franquisme, et ce d'autant plus que le groupe ne fit ses premières victimes frappées à mort qu'en 1968, dix ans après sa fondation. Les premières manifestations de rue lors de l'Aberri Eguna de 1966 symbolisèrent bien ce rôle d'opposition antifranquiste. Le PNV conflua silencieusement à Vitoria et ses membres se dispersèrent avant l'arrivée des forces de police. Les radicaux eux, affrontèrent violemment la police à Irun. Aux nationalistes modérés, la passivité; aux radicaux, l'action et la résistance. Les funérailles de Txabi Etxebarrieta en 1968, le premier " martyr » de l'organisation, furent accompagnées d'incitation à suivre son chemin: ce n'est d'ailleurs pas un hasard si les morts imputables à l'ETA se multiplièrent à partir de cette date. Durant la dictature, le contexte d'absence de liberté d'expression, de réunion et de manifestation, renforcé par l'état d'exception, eut pour conséquence que le nationalisme basque radical fut perçu comme l'avant-garde du mouvement antifranquiste. Cependant, comme l'a bien montré Rafael Durán Muñoz dans sa thèse, ce fut surtout le mouvement ouvrier, à travers des grèves à répétition, qui joua le rôle principal dans la contestation du régime franquiste à la fin des années 1960 et au début des années $1970^{13}$.

$\mathrm{Au}$ Pays basque, le prestige social de l'ETA fut très largement renforcé suite au procès de Burgos du 3 décembre 1970, qui condamna 17 membres de l'organisation à des peines très lourdes, dont six condamnations à mort. Les mobilisations populaires sans précédent au Pays basque et dans l'ensemble de l'Espagne, ainsi que les nombreuses protestations internationales, obligèrent toutefois le régime à transformer les peines de mort en des peines de prison. La médiatisation très forte du procès, les manifestations de rue et les grèves qui se succédèrent pour demander l'amnistie des prisonniers contribuèrent à donner à l'ETA l'image d'une organisation de résistance. L’opération « Ogro » qui réalisa l'assassinat de Luis Carrero Blanco le 20 décembre 1973, accéléra la déliquescence du régime ${ }^{14}$. Lorsque Juan Paredes Manot (Txiki) et Àngel Otaegui, militants de l'ETA-pm, furent mis à mort le 27 septembre 1975 lors des dernières exécutions du régime, le prestige social de l'ETA ne faisait plus aucun doute. Paradoxalement, ces exécutions symbolisèrent la défaite idéologique du franquisme. L’organisation s'empressa

13. Rafael DURÁN MUÑoz, Contención y transgresión. Las movilizaciones sociales y el Estado en las transiciones española y portuguesa, Madrid, Centro de Estudios Políticos y Constitucionales, Estudios Políticos, 2000.

14. Javier TUSELL, Carrero, eminencia gris del régimen de Franco, Madrid, Temas de Hoy, 1993, p. 4-7. 
de faire des condamnés des " martyrs " de la lutte nationaliste basque, célébrant chaque année leur mémoire pour mieux justifier la légitimité de sa cause et la perpétuation de la lutte armée.

En 1974, l'accroissement des attentats aboutit à la scission de l'ETA en deux branches: "l'ETA militaire " (ETA-m) qui privilégia la « lutte armée », et «l'ETA politico-militaire » (ETA-pm) qui adopta la " lutte de masse ». En 1976, lors de sa VII ${ }^{\mathrm{ème}}$ assemblée, l’ETA-pm privilégia la voie politique, ce qui conduira cette branche à intégrer plus tard la coalition nationaliste de gauche Euskadiko Ezkerra ("Gauche d'Euskadi », EE). Dans le mouvement inverse, en 1977, ses commandos spéciaux (bereziak) rejoignirent l'ETA-m. À rebours de la condamnation de la violence du PNV dès 1964, l'ETA-m intensifia celle-ci à partir de 1978, une fois la démocratie réinstaurée, ce qui lui fit perdre progressivement l'appui de l'opinion publique ${ }^{15}$. Le nationalisme radical chercha à disputer au nationalisme modéré du PNV la légitimité de la continuité de la lutte historique du nationalisme basque. Entre démocrates et radicaux, la rupture fut consommée à Saint-Sébastien le 8 septembre 1977: lors d'une manifestation unitaire pour l'amnistie générale, des jeunes proches d'ETA-m s'en prirent au député José Antonio Maturana du PSEPSOE, détruisirent des panneaux et crièrent des slogans tels que « ETA, le peuple est avec toi » ou " Dehors les espagnolistes » (" Espainolistak kanpora »), redéfinissant la ligne de fracture idéologique qui prévalait jusqu'alors entre partisans de la dictature et démocrates, au profit d'une division politique entre Espagnols et Basques (et parmi ces derniers, entre patriotes et traîtres ${ }^{16}$ ).

La transition illustra le rejet par le nationalisme basque radical de la démocratie représentative: il boycotta les élections législatives et autonomiques, et nia toute légitimité à l'État espagnol et au statut d'autonomie de 1979 qui créa la communauté autonome du Pays basque espagnol et la dota d'un parlement. Suite à la mort de Franco en 1975 et à la restauration de la monarchie, le nationalisme modéré du PNV devint majoritaire dans les urnes dès 1977. Il dut faire face aux pressions centrifuges croissantes des radicaux, tant par la lutte armée de l'ETA que dans la rue, puisque ce courant minoritaire de la société basque opposait la légitimité "populaire " des mouvements sociaux proches de sa cause à la légitimité électorale exprimée à travers le vote libre des

\footnotetext{
15. Santiago DE PABLO, Documentos para la historia del nacionalismo vasco, Barcelona, Ariel Practicum, 1998.

16. Gaizka Fernández SOLdEVILLA et Raúl López LoMo, op. cit., 2012, p. 226.
} 
citoyens ${ }^{17}$. Un courant minoritaire issu d'ETA-pm forma le Parti pour la révolution basque (Euskal Iraultzarako Alderdia, EIA) en 1976, puis se regroupa autour d'EE en 1977, adoptant peu à peu un nationalisme plus hétérodoxe et intégrateur ${ }^{18}$. Trois grandes mobilisations durant la transition illustrèrent cependant l'hégémonie du nationalisme radical sur l'expression des revendications identitaires, notamment grâce à sa capacité de mobilisation et aux pressions et intimidations exercées sur ses adversaires: la marche pour la liberté de l'Euskadi durant l'été 1977; l'hommage en l'honneur de la libération du dernier prisonnier de l'ETA, Francisco Aldanondo (Ondarru) le 9 décembre 1977 suite à la loi d'amnistie; et enfin, la " contre-manifestation » convoquée par Herri Batasuna en octobre 1978, en opposition à la manifestation pour la paix organisée par le PNV.

\section{La marche pour la liberté du Pays basque}

Entre le 10 juillet et le 28 août 1977, les Gestoras Pro-Amnistía, convoquèrent une "marche pour la liberté du Pays basque " avec l'objectif d'obtenir une amnistie pour les prisonniers de l'ETA mais aussi, selon le militant Jokin Apalategi, «la reconnaissance de notre identité nationale, un statut d'autonomie qui reconnaîtrait l'autodétermination de l'Euskadi, et la dissolution des corps répressifs ", entendus comme les forces de la Garde civile au Pays basque ${ }^{19}$. Alors que l'ensemble des partis politiques et des organisations syndicales proches $\mathrm{du}$ nationalisme radical et de l'extrême gauche soutinrent l'initiative, les partis de gauche (PSE-PSOE, PCE-EPK), nationalistes basques (PNV, ESEI) et de droite (UCD, AP) intégrés dans le processus de transition et représentés au Congrès des députés depuis les élections de juin 1977, restèrent en marge ${ }^{20}$. Il s'agissait d'organiser une vaste marche autour

17. Sur ce point, voir notamment Fernando MoLINA, «El nacionalismo español y la "guerra del Norte", 1975-1981 », Historia del Presente, n 13, 2009, p. 41-54.

18. Cette évolution politique l'amènera finalement à s'émanciper du nationalisme radical et à intégrer le parti socialiste d'Euskadi, qui deviendra donc le PSE-EE en 1993. Cf. José Luis DE LA GRANJA, "L'évolution des nationalismes hétérodoxes au Pays basque », dans Alicia FERnÁndez GARCía et Mathieu Petithomme (dir.), Les nationalismes dans l'Espagne contemporaine (1975-2017). Compétition politique et identités nationales, Paris, Armand Colin, 2012, p. 196226; Gaizka FERNÁNDEZ SOLDEVILLA, « Agur a las armas. EIA, Euskadiko Ezkerra y la disolución de ETA político-militar (1976-1985)», Sancho el Sabio, n³3, 2010, p. 55-95.

19. Jokin ApAlAtegI (dir.), Marcha de la Libertad, Elkar, Zarauz, 1978.

20. Andrea MICCICHE, "La transizione in Euskadi: un proceso di pacificazione?», Spagna Contemporánea, 2008, n 33, p. 31-42. Le PSE désigne le parti socialiste d'Euskadi, le PCE le parti communiste d'Espagne (et sa branche basque), le PNV le parti nationaliste basque, ESEI l'union des socialistes d'Euskadi (Euskadiko Sozialistak Elkartze Indarra), UCD I'union du centre démocratique et AP l'alliance populaire. 
de quatre colonnes partant de points différents, qui devaient confluer dans la plaine d'Arazuri près de Pampelune. Symbolisant la marche du peuple basque en mouvement, l'événement dura tout l'été, les marcheurs parcourant plus de 1870 kilomètres en Biscaye, à Guipuscoa, en Alava, au Pays basque français et en Navarre, tout en organisant de nombreux meetings, concerts et bals populaires dans les villes et les villages traversés ${ }^{21}$.

La marche devait symboliser le mouvement déterminé du "peuple en marche " vers la liberté, en rupture avec le passé franquiste, en traversant l'ensemble des territoires revendiqués de l' "Euskal Herria ", une terminologie utilisée pour dépasser le cadre de la future communauté autonome du Pays basque espagnol (l'Euskadi), et inclure l'Iparralde, le " Pays Basque nord " réunissant les trois " pays " français du Labourd, de la Basse-Navarre et de la Soule, ainsi que la Navarre. Kepa Aulestia, militant d'ETA-pm puis secrétaire général d'Euskadiko Ezkerra de 1985 à 1990, considéra d'ailleurs que la participation à la marche constituait à certains égards une "profession de foi abertzale $»^{22}$. Des anciens prisonniers de l'ETA condamnés par le conseil de guerre de Burgos, puis remis en liberté et expulsés par le gouvernement d'Adolfo Suárez en mai 1977, tels Mario Onaindia et Eduardo Uriarte (Teo), profitèrent de la marche pour retourner en Espagne dans la clandestinité et furent accueillis en héros à Durango en juillet $1977^{23}$. La plupart d'entre eux intégrèrent pourtant EIA en 1976 puis EE en 1977 (tel le sénateur Juan Mari Bandrés), à savoir la branche " politico-militaire " qui chercha à s'émanciper de l'ETA-m à partir de 1974 en se présentant aux élections et en s'insérant au sein du jeu démocratique. Lors de l'acte final de la marche, le 28 août 1977, l'apparition de Telesforo Monzón, dirigeant indépendantiste, poète et dramaturge basque exilé à SaintJean-de-Luz durant la dictature, fut minutieusement mise en scène aux côtés des principaux dirigeants nationalistes radicaux ${ }^{24}$.

21. Gaizka FERNÁNDEZ SoldeVILLA et Raúl LóPEZ Lomo, op. cit., 2012, p. 212.

22. Kepa AulestiA, HB. Crónica de un delirio, Madrid, Temas de Hoy, 1993, p. 45-50.

23. Gaizka FERNÁNDEZ SOLDEVILLA et Raúl LóPEZ Lomo, op. cit., 2012, p. 212.

24. Né le 1er décembre 1904 à Bergara et décédé le 9 mars 1981 à Bayonne, Telesforo Monzón dirigea le PNV durant la Seconde République puis s'exila à Caracas au Venezuela puis en France durant plus de quarante ans suite à la guerre civile. Figure de référence de l'indépendantisme basque, qu'il prône dans ses poèmes et son œuvre théâtrale en langue basque, il contribua à fonder la coalition Herri Batasuna en 1978, tout en travaillant au développement de la culture basque. Ses références métaphoriques et allégoriques à la lutte et à la liberté du peuple basque ont souvent été utilisées politiquement par les nationalistes radicaux pour justifier leurs propres objectifs. 
Les organisateurs échouèrent toutefois à rallier Pampelune, dont les accès restèrent sous contrôle de la police et où se déroula une contre-manifestation des autonomistes navarrais contre l'abertzalisme, largement rejeté dans une terre historiquement plus conservatrice qui s’opposait à l'intégration du « Vieux Royaume » dans la future communauté autonome basque. Les organisateurs de la marche interdirent les bannières des partis afin de transmettre l'image d'un peuple uni derrière un objectif commun. Mais Florencio Domínguez put noter que les cris et les slogans de soutien à l'ETA-m furent nombreux, la marche ayant même permis à l'organisation de recruter des volontaires ${ }^{25}$. Pour Michel Castells, contrairement à l'image voulue de "neutralité " d'un mouvement directement issu de la société civile, les radicaux utilisèrent la marche pour faire entendre leurs revendications, comme la mise en liberté de Miguel Àngel Apalategi (Apala), accusé de l'assassinat du garde civil Manuel Pérez à Ataun en 1974 et de diriger les commandos bereziak - formés à partir d'ETA-pm en 1977 et qui devaient rejoindre ensuite la branche militaire de l'organisation ${ }^{26}$. Les membres de l'Union des jeunesses maoïstes (UJM) furent aussi sifflés et conspués aux cris de "Komunistak kanpora " ("Dehors les communistes »), sous le prétexte qu'ils utilisaient une marche unitaire pour défendre une propagande minoritaire ${ }^{27}$.

Ainsi, selon Gaizka Fernández Soldevilla et Raúl López Lomo, « il était possible de crier en faveur d'une organisation terroriste, mais pas de montrer le sigle des jeunesses d'un parti politique antifranquiste, mais "espagnoliste"28 ". Le meeting final à Arazuri fut cependant une véritable réussite, à laquelle participèrent plus de cent mille personnes qui supportèrent des contrôles policiers et l'interdiction de l'accès à Pampelune. Cette marche renforça les objectifs politiques maximalistes des nationalistes radicaux, telle l'obtention d'une " amnistie totale ". Cette action collective légitima le discours suivant lequel les conquêtes politiques du " peuple " basque ne pouvaient être obtenues que grâce à la lutte armée et aux manifestations de rue.

25. Florencio DomínguEZ, Dentro de ETA : la vida diaria de los terroristas, Madrid, Santillana, 2002, p. 151.

26. Miguel CASTELLS, Los procesos políticos. De la cárcel a la amnistía, Madrid, Fundamentos, 1977, p. 13; Rogelio ALonso et al., Vidas Rotas. Historia de los hombres, mujeres y niños víctimas de ETA, Madrid, Espasa, 2010, p. 38.

27. Gaizka FERNÁNDEZ SOLDEVILLA et Raúl LóPEZ LoMo, op. cit., 2012, p. 214.

28. Ibid., 2012, p. 215. 


\section{Le tournant de l'amnistie générale}

Comme le suggéra José Luis Unzueta dans son article "Amnistie et retour au départ ", le vote consensuel de la loi d'amnistie générale du 15 octobre 1977 marqua un tournant ${ }^{29}$. Les sociétés basque et espagnole partageaient l'idée que la libération des prisonniers politiques était nécessaire pour la paix au Pays basque et la démocratisation en Espagne. Il fut choisi de privilégier le pardon et la réconciliation au détriment du désir de justice des victimes du terrorisme, puisque même les prisonniers de l'ETA condamnés pour des "délits de sang " furent libérés ${ }^{30}$. Cette loi accrédita ainsi l'idée que les prisonniers de l'ETA pouvaient bénéficier d'un pardon puisque leur lutte s'insérait dans la résistance plus globale au franquisme. En sortant des prisons tous les prisonniers de l'organisation, l'amnistie illustra le caractère "démocratique " du nouveau régime, pardonnant les errements du passé et de la lutte armée dans le contexte de la résistance au franquisme dans le but de parvenir à la paix et à la réconciliation. Mais pour un secteur du nationalisme radical, rien n’avait changé: la lutte, armée si besoin, devait continuer afin de mettre fin à la "répression de l'État espagnol " et au " conflit basque " à travers la mise en place de l'autodétermination. Le propos de l'ancien dirigeant de l'ETA, Kepa Pikabea, aujourd'hui emprisonné pour plus d'une vingtaine d'assassinats et pour l'enlèvement d'Àngel Urteagan en 1985 puis de Julio Iglesias Zamora en 1993, illustre bien le prestige social des militants de l'ETA à cette époque:

Être militant durant la répression franquiste revenait à être doté d’un grand prestige social. Lorsque les amnistiés rentraient dans leur village après la mort de Franco, tout le village sortait pour les recevoir ${ }^{31}$.

Ainsi, lors de la sortie de prison du dernier militant de l'ETA, Francisco Aldanondo (Ondarru) le 9 décembre 1977 à Saint-Sébastien,

\footnotetext{
29. José Luis UNZUETA, «Euskadi : amnistía y vuelta a empezar », dans Santos JULIA, Javier Pradera et Joaquín Prieto (dir.), Memoria de la transición, Madrid, Taurus, 1996, p. 275-283.

30. Paloma AgUiLAR, «La amnesia y la memoria: las movilizaciones por la amnistía en la Transición a la democracia », dans Rafael CRUz et Manuel PéREZ Ledesma (dir.), Cultura y movilización en la España Contemporánea, Madrid, Alianza Editorial, 1997, p. 327-357. Plus globalement, sur la thématique de la mémoire en Espagne, voir l'œuvre magistrale de la même auteure, Políticas de la memoria y memorias de la política. El caso español en perspectiva comparada, Madrid, Alianza Editorial, 2008.

31. Emprisonné en 1994 après son arrestation à Bayonne, Kepa Pikabea devint un dissident de l'ETA après l'assassinat de Miguel Àngel Blanco. II fit son autocritique, considérant que "la stratégie militaire a été inhumaine » et choisit la "voie Nanclares", suivant laquelle il condamna le terrorisme, cf. Monica CeBerIo BELAZA, "Dos condenados "al final del túnel" », El País, 24 octobre 2011. Voir aussi, « De ídolo de ETA a traidor », El Mundo, 27 mars 2014.
} 
une foule de sympathisants proféra des cris en faveur d'une " amnistie totale " et de l'ETA ( ETA, herria Zurekin », "ETA, le peuple est avec toi »), même s'il n'y avait alors plus aucun prisonnier à amnistier et que la lutte armée n'avait plus aucun sens dans le nouveau contexte démocratique ${ }^{32}$.

Durant l'ensemble de la période des sorties de prison des membres de l'ETA amnistiés, l'organisation ne déclara aucune trêve et continua à commettre des attentats: dix victimes moururent en 1977, puis soixantecinq en 1978, soixante-dix-neuf en 1979 et quatre-vingt-quatorze en 1980, qui marquèrent "le zénith des années de plomb ", illustrant justement une escalade de la violence - après - le retour à la démocratie et l'amnistie générale ${ }^{33}$. Après l'amnistie, certains groupes tels que la Comisión Gestora de Guipuscoa décidèrent de s'autodissoudre. Ces collectifs considéraient que leur travail était désormais terminé. Mais d'autres organisations, dans le sillage d'ETA-m, continuèrent à demander une amnistie, anticipant la répression des actions terroristes à venir. Le fait que l'État espagnol n'accepte pas l'autodétermination du Pays basque fut considéré comme un prétexte suffisant pour proclamer le caractère illégitime de ses institutions. Ce casus belli et cette posture de victimisation furent utilisés pour justifier la stratégie « action-répression-action ", visant à utiliser la violence pour susciter en retour une répression policière disproportionnée, et développer ainsi le soutien social au nationalisme radical, tout en obligeant le gouvernement espagnol à accepter ses conditions ${ }^{34}$.

Le fait qu'entre 1978 et 1980 les différents commandos de l'ETA assassinèrent 246 personnes, au moment même où fut approuvée la constitution de 1978, le statut de Guernica de 1979 et furent institués le parlement de Vitoria et le nouveau gouvernement basque, attestèrent de la volonté des radicaux du maintien d'une stratégie violente et antisystème malgré l'avènement de la démocratie. Il apparut alors clairement que l'ETA ne s'opposait pas simplement à Franco et à la dictature, mais aussi et surtout à l'État espagnol. L'institutionnalisation de la démocratie dans le reste de l'Espagne alla ainsi de pair avec l'intensification de la violence politique au Pays Basque.

\footnotetext{
32. Gaizka FernáNDEZ SoldEVILLA et Raúl LóPEZ LoMo, op. cit., 2012, p. 216.

33. José Luis De La Granja, Santiago De PABlo et Coro RuBio PoBES, Breve historia de Euskadi. De los fueros a la autonomía, Barcelona, Editorial Debate, 2011, p. 241.

34. Florencio DomínGUEZ, «El enfrentamiento de ETA con la democracia », dans Antonio ElorzA (dir.), La Historia de ETA, Madrid, Temas de Hoy, 2006, p. 272-435.
} 


\section{VIOLENCE POLITIQUE ET MONOPOLISATION DE L'ESPACE PUBLIC (1978-1994)}

\section{Légitimation de la violence politique et culte des " gudaris "}

Ni les premières élections démocratiques en juin 1977 et l'amnistie générale en octobre de la même année, ni l'approbation de la constitution en 1978 et du statut de Guernica en 1979 ne permirent de contenir l'escalade de la violence. Il est vrai que lors du référendum sur la constitution, une proportion importante de l'électorat basque décida de s'abstenir, illustrant un déficit de légitimité des institutions de l'État central auprès d'un secteur assez large de la société. Malgré l'avènement de la démocratie, le nationalisme radical décida de continuer sa lutte par les armes et les manifestations, jusqu'à la consécration de ses objectifs contenus dans l'" Alternative KAS " ("Koordinadora Abertzale Sozialista ", " Coordination socialiste patriote »), à savoir l'autodétermination pour un Pays basque incluant le " Pays basque nord " (français) et la Navarre, de même que l'expulsion de la police et de l'armée.

La branche basque du parti communiste espagnol (PCE-EPK), peu implanté dans la région, fut la première à adopter une posture de rejet de la violence en convoquant une manifestation sous le slogan " Nous sommes fatigués de la violence et des assassinats " (photo 6.1), qui eut lieu le 28 juin 1978 à Portugalete suite à l'assassinat par ETA-m de José María Portell, journaliste et directeur de l'hebdomadaire Hoja del Lunes de Bilbao ${ }^{35}$. D'autres manifestations convoquées par le parti furent de même organisées en octobre 1978 à Elgoibar et Getxo sous la bannière " Non au terrorisme, Oui à la constitution ", suite aux assassinats de plusieurs gardes civils ${ }^{36}$. Il est intéressant de noter que lors de la première manifestation convoquée par le PNV, la «marche pour un Pays basque libre et en paix » qui réunit entre trente et soixante mille personnes qui défilèrent en silence le 28 octobre 1978 à Bilbao, le mot d'ordre des jetzales n'était pas " contre le terrorisme " ou " contre ETA ", mais " contre la violence " en général. Les dirigeants du PNV comme Xabier Arzalluz, condamnaient les crimes de l'ETA mais attribuaient à l'État espagnol l'origine de la violence politique au Pays basque, ce qui contribua à miner la légitimité du gouvernement auprès d'un secteur non

35. Gaizka FERNÁNDEZ SOLdEVILLA et Raúl López LoMo, op. cit., 2012, p. 219.

36. Rogelio Alonso et al., op. cit., 2010, p. 134. 
négligeable de la société basque. Il est d'ailleurs symptomatique que le PNV s'opposa à la participation de l'UCD d'Adolfo Suárez à la manifestation, suggérant de façon implicite que les responsabilités étaient partagées entre l'ETA et le pouvoir central ${ }^{37}$.

Photo 6.1. Manifestation du PCE-EPK contre la violence, Portugalete, 28 juin 1978

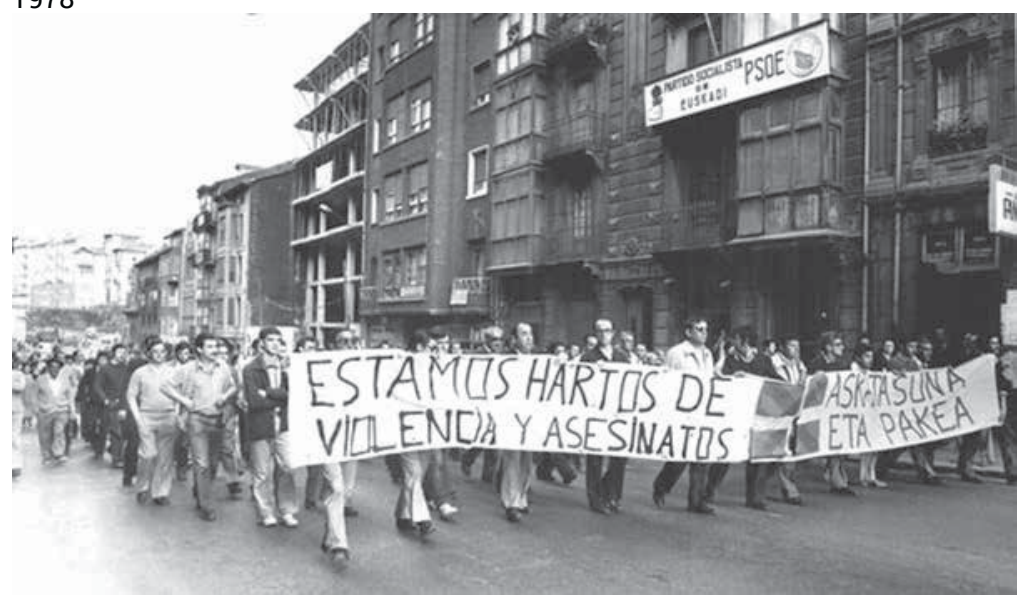

Herri Batasuna, le parti formé en 1978 par les nationalistes radicaux, et les Gestoras Pro Amnistía, interprétèrent cette convocation comme un affront à l'ETA et organisèrent une contre-manifestation le même jour dans le centre historique de Bilbao sous le slogan « Pour les gudaris d'hier et d'aujourd'hui ${ }^{38}$. Ce slogan fut ensuite constamment repris par les radicaux, jusqu'en 2011, lors de leurs meetings et des principales fêtes du calendrier historique du nationalisme basque; les radicaux établirent ainsi à leur profit un parallèle entre les soldats du PNV et de l'ANV qui combattirent en 1937 lors de la guerre civile, et les « martyrs " de l'ETA, en présentant ces derniers comme les continuateurs de la « lutte séculaire » des Basques contre «l'oppression de l'État espagnol». La

37. Le PSE-PSOE, le PCE-EPK, l'organisation révolutionnaire des travailleurs (ORT), le parti du travail d'Espagne (PTE), les syndicats CC. OO et UGT de même que le Conseil général basque, l'organe pré-autonomique créé en janvier 1978, soutinrent la manifestation.

38. La coalition Herri Batasuna fut formée par quatre partis: Herri Alderdi Sozialista Iraultzailea (parti socialiste révolutionnaire populaire, HASI), Langile Abertzaleen Iraultzarako Alderdia (parti révolutionnaire des travailleurs patriotes, LAIA), Euskal Sozialista Biltzarrea (assemblée socialiste basque, ESB) et l'action nationaliste basque (ANV), un parti créé en 1930 sous la Seconde République et qui connut une dérive radicale suite à sa réémergence lors de la transition. Herri Batasuna utilisa notamment sa « légitimité historique » en tant que parti issu de la guerre civile pour obtenir sa légalisation. 
contre-manifestation des radicaux du 28 octobre 1978 débuta d'ailleurs près de la maison de Txabi Etxebarrieta, le membre de l'ETA qui déclencha le premier assassinat (contre le garde civil José Pardines en 1968) et le premier à mourir ensuite dans un affrontement avec la police, tout en se terminant sur le mont Artxanda, lieu de la dernière bataille contre les troupes franquistes en $1937^{39}$. La contre-manifestation, non autorisée, ne réunit que quelques centaines de participants et fut réprimée par la police. Pour les dirigeants de HB Telesforo Monzón et Francisco Letamendia, ce fut là une " preuve » de plus de « l'autoritarisme » du pouvoir central.

Un " calendrier commémoratif " alternatif a peu à peu été institué par les nationalistes radicaux afin d'intégrer la célébration des funérailles de certains "martyrs " historiques de l'ETA. Le Gudari Eguna (" jour du soldat basque "), une fête basque nationaliste traditionnelle célébrant chaque 27 septembre les résistants antifranquistes de la guerre civile, a été détourné par les radicaux pour remémorer les exécutions en 1975 de Txiki et d'Otaegi, membres de l'ETA, par le régime franquiste $^{40}$. Des commémorations sont aussi organisées le 20 novembre et le 21 décembre pour remémorer les assassinats de Santiago Brouard et de Josu Muguruza d'Herri Batasuna par les GAL dans les années 1980, de même que celui de José Miguel Beñaran, membre de l'ETA, en 1978. Les fêtes du Bizkargi Eguna en mai et de l'Albertia Eguna en juillet, ont de même été détournées au profit de la célébration des « martyrs " de l'ETA. À la fin des années 1970 et durant la majeure partie des années 1980, les nationalistes radicaux n'hésitaient pas à légitimer ouvertement la violence, célébrant les membres de l'ETA comme des "résistants » et incitant les jeunes lors des rassemblements de rue à s'engager, si besoin par les armes, pour défendre leur cause.

\section{De l'« Alternative KAS » au monopole de la rue}

Durant l'époque-clé de la transition, la stratégie de l'« Alternative KAS » du MLNV fut définie. Conçue comme une « organisation d'organisations ", l'alternative KAS intégrait ETA-m, permettait à HB de graviter dans son orbite et cherchait à combiner une lutte sur trois fronts: la « lutte armée " de l'ETA-m; la " lutte de masse " à travers les manifestations de rue et la domination de l'espace public; et enfin, la "lutte institutionnelle " à travers la participation d'HB aux élections. Même si les représentants d'HB boycottaient ensuite leurs sièges aux

39. Gaizka FERNÁNDEZ SoldeVILLA et Raúl LóPEZ LOMO, op. cit., 2012, p. 221.

40. Sur le calendrier mémoriel du nationalisme radical, cf. Mathieu Peтітномme, op. cit., 2015. 
institutions nationales et régionales, ils se présentaient aux élections notamment pour barrer la route à d'autres formations indépendantistes telles qu'EE. Les élus d'HB s'impliquaient toutefois au niveau municipal, un échelon plus en accord avec l'idéologie du parti prônant l'auto-affirmation du " peuple " par le bas sous la forme d'un " contrepouvoir local ». HB maintint cependant un lien ambivalent avec la lutte armée. Francisco Letamendia, le député d'HB élu en 1979, expliqua ainsi à l'époque que son parti " assum[ait] toutes les formes de lutte qui conduisent à la libération nationale et sociale de l'Euskadi " ${ }^{41}$. En 1979, ETA-m assassina pourtant soixante-cinq personnes, alors même que ETA-pm et les Commandos autonomes anticapitalistes (CAA) passèrent aussi à l'action, faisant quatorze victimes cette année-là (puis encore quinze l'année suivante), dont les membres de l'UCD basque, José Ignacio Ustarán, Jaime Arrese et Ramón Baglietto.

Le nationalisme basque radical s'organisa en cercles concentriques pour démultiplier son influence sociale: le parti socialiste révolutionnaire du peuple (Herriko Alderdi Sozialista Iraultzailea, HASI) fut formé en 1977 pour représenter la classe ouvrière nationaliste; la solidarité des travailleurs basques (Eusko Langileen Alkartasuna, ELA-STV) et les commissions des ouvriers patriotes (Langile Abertzaleen Batzordeak, LAB), pour impulser le mouvement syndical; les CAA et les commandos bereziak (de 1977 à 1985) de même que ETA-m pour la lutte armée; et enfin, HB comme parti d'« unité populaire " cherchant à offrir un débouché politique à la lutte armée. Le nationalisme radical obtint cent cinquante mille voix, un député et deux sénateurs lors des élections législatives de 1979, puis devint la seconde force politique du Pays basque espagnol derrière le PNV, qui garda le contrôle des trois capitales Vitoria, Bilbao et Saint-Sébastien, mais devant le PSE-PSOE. De la fin des années 1970 jusqu'aux années 1990, les membres de AP et de l'UCD ne bénéficièrent pas de la même liberté d'expression que les autres représentants politiques du Pays basque, devant subir les intimidations et les menaces, en étant présentés comme des "fascistes " liés au franquisme. Mais le nationalisme radical, pour qui les élections étaient avant tout un recours instrumental, demeurait minoritaire dans les urnes, obtenant au mieux entre 20 et $25 \%$ des voix. Il chercha ainsi à compenser cette faiblesse à travers le monopole de la rue, car il constituait de loin le courant politique qui montra la plus forte capacité de mobilisation lors des meetings de campagne et des rassemblements politiques.

$\overline{41 . . ~ « P u n t u a l i z a c i o n e s}$ de Letamendia », El País, 28 octobre 1979. 
Mais les nombreuses manifestations de rue reflétaient plus les préférences politiques d'un groupe organisé que celles du "peuple » basque, au nom duquel les nationalistes radicaux disaient pourtant parler et qu'ils prétendaient incarner. Ils exercèrent en fait un chantage sur les institutions démocratiques, en utilisant la violence pour obliger les gouvernements basque et espagnol à accepter leurs conditions. Cette posture antisystème discréditant le système politique fut bien illustrée par la création de l'" Assemblée nationale du peuple basque " (Euskal Herriko Biltzarre Nazionala) en 1979, une assemblée parallèle qui rassemblait en fait uniquement les membres d'HB, quelques conseillers municipaux d'extrême gauche et des indépendants nationalistes. Pour les nationalistes radicaux, la transition n'avait rien changé car leurs objectifs - «l'amnistie totale », l'autodétermination et l'expulsion des forces de police et de l'armée - n'avaient pas été atteints. La tentative de coup d'État ratée du 23 février 1981 confirma aux yeux de ce secteur social « l'autoritarisme » latent du nouveau régime. Au début des années 1980, les personnes séquestrées par l'ETA furent ainsi maintenues en captivité au nom de la lutte pour la « liberté » du peuple basque, dans ce que l'organisation appelait des " prisons du peuple ». Les sigles de l'ETA et des slogans défendant le groupe armé étaient très clairement mis en avant lors des manifestations de rue. Le monopole de l'espace public du nationalisme radical était d'autant plus prononcé qu'il n'existait pas de véritable confrontation avec d'autres groupes. Cette communauté politique maintenait un quasi-monopole sur l'expression de l'identité territoriale basque. De nombreuses organisations s'institutionnalisèrent autour du MLNV, qui reprit à son compte l'expression des principales revendications sociales du Pays basque en créant des organisations sympathisantes ou en faisant de l'entrisme puis en contrôlant de l'intérieur les mouvements sociaux, ce qui fut particulièrement vrai pour les mouvements ouvriers, féministe, antinucléaire et anti-répression.

La monopolisation de l'espace public par le nationalisme radical fut largement la conséquence des attentats et des assassinats à répétition qui instaurèrent un climat de terreur, condamnant la société civile basque à une "spirale du silence ", et incitant les opposants à ne pas s'engager en politique de peur des représailles ${ }^{42}$. En 1979 par exemple, selon une étude récente des historiens de l'institut Valentín de Foronda

42. Le concept de « spirale du silence » a été proposé par Elisabeth Noelle-Neumann. Pour une discussion de celui-ci dans le contexte espagnol, cf. Alejandro MUÑOZ-ALONSO, « La espiral del silencio en el País Vasco », Cuenta y Razón, n³3, 1988, p. 45-52. 
de l'université du Pays basque, lorsque les victimes étaient des policiers, des manifestations de rejet de la violence furent organisées dans seulement $7 \%$ des assassinats, un taux qui atteignit au contraire $100 \%$ lorsque les victimes étaient des civils ou des membres de l'ETA assassinés par l'extrême droite ${ }^{43}$. Une culture radicale se solidifia, qui célébrait ou au moins justifiait et comprenait l'assassinat des policiers et des militaires, tout en saluant les responsables comme des héros ou des martyrs ${ }^{44}$. Ce contexte d'indifférence à l'égard des victimes de l'ETA et de démobilisation eut pour conséquence que la réponse au terrorisme dans la rue fut pratiquement nulle et se nourrit uniquement d'initiatives institutionnelles comme des minutes de silence. $82 \%$ des assassinats de l'ETA durant les années 1980 n'engendrèrent en fait aucune réponse sociale à travers d'éventuelles manifestations de rejet ${ }^{45}$. À l'inverse, l'ensemble des décès de membres de l'ETA débouchèrent sur des répliques politiques sous la forme de grèves et de manifestations.

Les menaces et les intimidations prirent aussi d'autres formes, notamment à travers l'extorsion et le paiement forcé de "l'impôt révolutionnaire ». Une étude scientifique récente du Centre d'éthique appliquée de l'université de Deusto estime ainsi qu'environ neuf mille personnes ont été victimes d'extorsion de 1993 à 2008 et environ quinze mille depuis les années 1960, principalement des petits commerçants et des professions libérales dans les villes et les villages où la présence des nationalistes radicaux était la plus forte ${ }^{46}$. Les entrepreneurs et les directeurs de grande entreprise pouvaient plus facilement résister en s'appuyant sur des équipes de sécurité. Au contraire, le manque de protection des civils et des petits entrepreneurs victimes, eut pour

43. Contextos históricos del terrorismo y consideración social de las víctimas. 1968-2010, rapport de l'institut Valentín de Foronda, présenté devant la Commission des droits de I'homme du Parlement basque, Victoria, 26 février 2015.

44. Sur cette question du processus de radicalisation, cf. Xavier CRETTIEZ, « High risk activism: comprendre le processus de radicalisation violente », Pôle sud, n³4, 2011 ; Jeff JUSTICE, « Of guns and ballots: Attitudes towards unconventional and destructive political participation among Sinn Fein and Herri Batasuna supporters », Nationalism and Ethnic Politics, $n^{\circ}$ 11, 2005, p. 295-320.

45. "El $82 \%$ de los asesinatos de ETA en los 80 no tuvieron respuesta social », El País, 26 février 2015. La comptabilité de Sokoa, arrêté en France en 1986 à Hendaye, prouva que plus de 7,2 millions d'euros de l'ETA provenaient directement de l'extorsion. À partir de 1993 et face à l'augmentation des arrestations policières, l'extorsion diminua peu à peu, puis reprit après l'assassinat de l'entrepreneur José María Korta, proche du PNV en août 2000, avant de décliner à nouveau suite à la détention en France de Mikel Antza et Soledad Iparraguirre, qui contrôlaient l'appareil d'extorsion. De 2000 à 2004, on estime que l'extorsion représentait 2 millions d'euros par an.

46. Luis AIzPEOLEA, « Los extorsionados por ETA toman la palabra », El País, 1er mars 2015. 
effet qu'ils préféraient souvent payer les demandes de rançon, même si la " collaboration avec le terrorisme " constitue un délit suivant l'article 576 du code pénal espagnol ${ }^{47}$. Le collectif Gesto Por la Paz ("Geste pour la paix ") organisa la première manifestation contre la violence à l'initiative de la société civile le 26 novembre 1985. La violence avait alors déjà fait 465 victimes depuis 1968. Le propos d'Ana Rosa Gómez Moral, membre de Gesto por la Paz, illustre bien le sentiment qui prévalait à l'époque:

Nous avons tardé à réagir parce que nous venions d'une dictature et que de nombreux Basques, de façon erronée, nous justifiions la rébellion de l'ETA contre l'oppression. Nous avons tardé à nous rendre compte que nous étions désormais en démocratie et que le terrorisme n’avait plus de justification possible ${ }^{48}$.

\section{Le déclin de l'hégémonie mobilisatrice (1995-2011)}

À partir du début des années 1990, le soutien social au nationalisme radical déclina. L'attentat à la voiture piégée de l'Hipercor de l'avenue Meridiana à Barcelone le 19 juin 1987, le plus meurtrier de l'ETA, marqua un tournant, tuant vingt et une personnes et en blessant quarantecinq autres, la plupart des civils, dont des femmes et des enfants ${ }^{49}$. Les manifestations de rejet furent sans précédent dans l'ensemble de l'Espagne. Le 21 juin, plusieurs centaines de milliers de Barcelonais se réunirent silencieusement à Sant Andreu, puis occupèrent le paseo de Gràcia le jour suivant lors de la plus grande manifestation depuis 1977 en Catalogne ${ }^{50}$. Cinq minutes de silence furent décrétées dans toutes les institutions espagnoles et catalanes. Dix jours plus tôt, Herri Batasuna, qui critiqua de façon confuse le déroulement de l'attentat sans le condamner, avait obtenu presque quarante mille voix en Catalogne lors des élections européennes ${ }^{51}$. Mais ETA-m continua son escalade de la violence et sa négation de la réalité: le 11 décembre 1987, un attentat du commando Argala contre la caserne de la Garde civile de Saragosse

47. Les seules personnes poursuivies par l'Audience nationale, les sœurs Bruño, furent d'ailleurs ensuite acquittées par le Tribunal suprême en juin 2012 au motif d'une " peur insoutenable ».

48. Ana Rosa Gómez Moral, cité dans Luis AizPeOleA, «Fin del movimiento anti-ETA », 22 février 2015.

49. « Hipercor, el atentado más salvaje », La Vanguardia, 21 juillet 1987.

50. «Barcelona expresó su dolor en silencio », La Vanguardia, 23 juin 1987, p. 24.

51. Lors de ces élections le parti obtint 367000 voix dans l'ensemble de l'Espagne, dont 251000 au Pays basque et en Navarre, faisant élire sa tête de liste Txema Montero au Parlement européen. 
fit onze morts (dont cinq jeunes filles) et quatre-vingt-huit blessés. Le 13 décembre 1987, deux cent cinquante mille personnes défilèrent sous le slogan "Saragosse pour la paix et contre le terrorisme ", dans ce qui restera la plus grande manifestation de l'histoire de la ville ${ }^{52}$. Lorsque l'État fut condamné en 1994 par l'Audience nationale pour « négligence policière ", pour ne pas avoir empêché l'entrée des clients et décidé l'évacuation du magasin suite à trois appels téléphoniques anonymes prévenant de l'attentat, les radicaux y virent la confirmation de leurs arguments et la preuve de « la responsabilité de l'État espagnol dans la violence ${ }^{53}$ ".

\section{La rupture de la spirale du silence: l'émergence de Gesto por la Paz}

Les manifestations de Gesto por la Paz, très peu nombreuses jusqu'alors et principalement silencieuses, prirent une nouvelle ampleur et débouchèrent sur "l'accord pour la normalisation et la pacification de l'Euskadi ", connu comme le pacte d'Ajuria Enea, signé le 12 janvier 1988 par tous les partis démocratiques nationalistes (PNV et EE) et non-nationalistes (PSE-PSOE, CDS, AP) pour le respect de l'État de droit, la coexistence pacifique et contre le terrorisme ${ }^{54}$. Les premiers slogans contre l'ETA apparurent et les mobilisations sociales du collectif jouèrent un rôle déterminant dans la signature du pacte. La première macromobilisation contre l'ETA au Pays basque, «pour la paix maintenant et pour toujours ", eut lieu à Bilbao le 18 mars $1989^{55}$. Avant cette date, les plus grandes mobilisations avaient eu lieu à Bilbao le 2 septembre 1977 pour l'amnistie, puis le 22 octobre 1983 lorsque cent mille personnes protestèrent contre l'assassinat du capitaine Martín Barrios. Cet assassinat avait aussi mis un million et demi de personnes dans la rue le jour précédent à Madrid, du jamais-vu depuis les protestations contre le coup d'État raté du 23 février 1981. La trajectoire de ces mouvements sociaux reflète assez bien l'évolution des attitudes de la société basque à l'égard du terrorisme. Peu à peu, menés par les familles des victimes du terrorisme et des citoyens de plus en plus nombreux

52. «Zaragoza condena el terrorismo y clama por la paz, en la mayor manifestación de toda su historia », La Vanguardia, 14 décembre 1987, p. 5.

53. Anna ARGEMI, «El Estado, condenado por negligencia policial en el atentado de Hipercor», El País, 21 mai 1994.

54. José Luis DE LA GRANJA, El siglo de Euskadi. El nacionalismo vasco en la España del siglo XX, Madrid, Tecnos, 2003, p. 337-340.

55. « La manifestación más concurrida en el País Vasco », El País, 19 mars 1989. 
commencèrent à rompre le monopole de l'espace public et la spirale du silence imposés par le nationalisme radical.

Alors que l'appareil militaire d'ETA-m se retrouva soumis à une pression policière croissante et à des arrestations en chaîne, notamment suite au démantèlement de son groupe dirigeant à Bidart en 1992 puis des commandos Alava, Andalousie et Biscaye en 1996, le déclin du nationalisme radical se fit aussi sentir dans les urnes. Des 172110 voix obtenues par Herri Batasuna lors des élections législatives de 1979, puis 231722 en 1986, il n'en restait plus que 181306 en 1996 (alors même que l'électorat était désormais beaucoup plus important). Entre les européennes de 1987 (360952 voix) et celles de 1994 (180324), ses soutiens électoraux se réduisirent de moitié. La même tendance est observable lors des élections autonomiques et municipales ${ }^{56}$. La séquestration de l'entrepreneur Julio Iglesias Zamora en 1993, puis celles de José María Aldaya, Cosme Delclaux et du gardien de prison José Antonio Ortega Lara, marquèrent un nouveau tournant ${ }^{57}$. Le nationalisme radical chercha à compenser cet ostracisme croissant par un plus grand contrôle social: la déclaration Oldartzen en 1994 acta ainsi le choix d'une stratégie de " socialisation de la souffrance ", à travers l'augmentation des persécutions contre les intellectuels et les opposants non-nationalistes du PP et du PSE-PSOE ${ }^{58}$. Cette période coïncida aussi avec la radicalisation des jeunes activistes violents à travers le développement de la "kale borroka " 59 .

Entre le 5 mai 1995 et le $1^{\text {er }}$ juillet 1997, malgré les intimidations et les menaces, Gesto por la Paz organisa des manifestations hebdomadaires, arborant un emblématique « lacet bleu » pour demander la libération des personnes séquestrées. La manifestation de condamnation de l'enlèvement de Miguel Àngel Blanco en juillet 1997 à Bilbao fut massive. Des contre-manifestations furent cependant organisées par

56. On observe un « pic » lors des années 1986-1987 puis un déclin au début des années 1990. Pour les élections autonomiques, Herri Batasuna obtint 151636 voix (16,5\%) en 1980, puis 199900 voix (17,47\%) en 1986 et 166147 (16\%) en 1994. Lors des élections municipales, le parti évolua de 158000 voix en 1983 (385 conseillers municipaux) à 239010 en 1987 (669 conseillers), puis 199090 en 1991 (701) et 184742 en 1995 (621). Sources : Ministère de l'intérieur et Gouvernement du Pays basque.

57. María Jesús FunEs RIVAS, La salida del silencio. Movilizaciones por la paz en Euskadi 19861998, Madrid, Akal, 1998.

58. "Una estrategia de presión diseñada a raíz de la ponencia "Oldartzen" del 94 », El Diario Vasco, 8 juillet 2007.

59. Hanspeter VAN DER BROEK, "Borroka. The legitimation of street violence in the political discourse of radical basque nationalists », Terrorism and Political Violence, vol. 16, $n^{\circ} 2,2004$, p. $714-736$. 
les radicaux sous le slogan « Euskal Herria Askatu » ("Libérez Euskal Herria »), durant lesquelles de nombreuses insultes étaient proférées contre les citoyens portant le lacet bleu, traités de "fascistes " et de " franquistes ». Mais le discours exaltant le conflit avec "l'Espagne » et « l'État espagnol » était en proie à une crise de légitimité. Suite à l'assassinat de Miguel Àngel Blanco, des mouvements plus activistes firent leur apparition, tels que iBasta Ya! («Ça suffit!»), qui revendiquait clairement l'identité « basco-espagnole " et s'opposait au " nationalisme obligatoire ». $72 \%$ des Basques considéraient d'ailleurs qu'il s’ouvrait une nouvelle étape contre l'ETA ${ }^{60}$.

\section{De la fracture à la dissolution des mouvements antiviolence}

Mais en 1998, la société basque se divisa en deux blocs: les nationalistes modérés et radicaux s'allièrent à travers le pacte de Lizarra pour l'obtention de l'indépendance; à l'inverse, les non-nationalistes convergèrent dans la critique du manque de détermination de ce front souverainiste pour condamner la violence de l'ETA. Les mouvements sociaux antiviolence se scindèrent suivant la même ligne de fracture: Elkarri prétendait obtenir la fin de la violence à travers la condamnation de tous les types de violence et l'exercice du droit à l'autodétermination; d'autres collectifs, dont le plus emblématique fut ¡Basta Ya!, mettaient d'abord en avant le respect de l'unité de l'Espagne et la condamnation de la violence de l'ETA. La posture plus rassembleuse de Gesto por la Paz devint alors dépassée et obsolète face à la radicalisation des deux camps. José María Calleja, l'un des promoteurs de ¡Basta Ya! évoque bien la posture plus militante promue par ce groupe dans le sillage du forum d'Ermua: "Basta Ya chercha à rassembler l'ensemble des Basques qui rejetaient le terrorisme avec l'objectif de mettre fin à la peur et de reprendre la rue aux membres de l'ETA et à leurs sympathisants " ${ }^{61}$. Le groupe organisa d'importantes mobilisations entre 1997 et 2003, à un moment où l'ETA déployait sa stratégie de " socialisation de la souffrance " à travers la répétition d'attaques contre des civils non-nationalistes, notamment des intellectuels, des journalistes et des hommes politiques connus pour leur condamnation de la violence. Deux activistes du mouvement, José Luis López Lacalle et Joseba Pagazaurtundua, furent d’ailleurs assassinés pour prix de leur résistance non-violente.

60. Carlos MARTínez GorRIARÁN, «El discurso del medio. Retóricas comprensivas del terrorismo en el País Vasco », dans Kepa AULESTIA et al., Razones contra la violencia : por la convivencia democrática en el País Vasco, Bilbao, Bakeaz, vol. 1, 1998, p. 103.

61. Cité dans ¡Basta Ya!, Euskadi, del sueño a la vergüenza, Madrid, Ediciones B, 2005, p. 74. 
$\mathrm{Au}$ début des années 2000, la répression s'intensifia contre les groupes politiques et sociaux accusés de servir de "couverture " à l'ETA: les partis Herri Batasuna puis Batasuna et Euskal Herritarrok, les Gestoras Pro Amnistía et les organisations de jeunesse Segi et Ekin furent successivement interdits. De nombreuses " herriko tabernas", ces bars qui rassemblaient les nationalistes radicaux dans le quartier historique de Bilbao et ailleurs au Pays basque, et dont les murs étaient souvent recouverts de portraits des « martyrs " de l'ETA et des prisonniers de l'organisation, furent fermés. Les marches des radicaux furent de plus en plus souvent interdites et les condamnations pour " apologie du terrorisme " se multiplièrent. La mobilisation des mouvements sociaux antiviolence diminua entre 2003 et 2011 parallèlement à la réduction drastique des victimes de l'ETA (douze depuis 2004, la dernière en 2010). L'ensemble de ces évolutions illustrèrent la fatigue de l'opinion publique basque et son désir de fin de la violence et de pacification. Peu à peu, au sein de la communauté nationaliste radicale, certains acteurs commencèrent à prendre conscience que la fin de la violence n'était pas négociable contre des contreparties politiques, et devait être décidée unilatéralement par l'organisation armée.

Dans la veine du cessez-le-feu de 2011, le changement et la pacification sont aujourd'hui très nettement perceptibles au Pays basque, notamment à travers l'autodissolution des mouvements sociaux antiETA. Lokarri, le dernier mouvement social en activité, créé en 2006 dans la continuité de Elkarri né en 1992 avec l'objectif de mettre fin au terrorisme, s'est ainsi dissous en mars 2015. Son coordinateur, Paul Ríos, justifia en effet cette décision par le fait que « la fin de la violence est désormais irréversible ${ }^{62}$. Lokarri a servi de mouvement social médiateur dans le processus de légalisation de la gauche abertzale en février 2011, de même que lors de la déclaration d'Aiete d'octobre 2011 qui mit fin à la lutte armée. Avant lui, en juin 2012, ce fut Gesto por la Paz qui annonça sa dissolution après ¡Basta $\mathrm{Ya}$ ! en 2008, dont les principaux responsables se sont depuis engagés en politique, notamment au sein du parti Union, progrès et démocratie (UPyD). Certaines questions restent cependant en suspens, notamment le désarmement, la réintégration sociale des prisonniers et la coexistence pacifique.

62. «La disolución de Lokarri », El Mundo, 10 mars 2015. 
Photo 6.2. Manifestation de dénonciation de la politique pénitentiaire (2011)

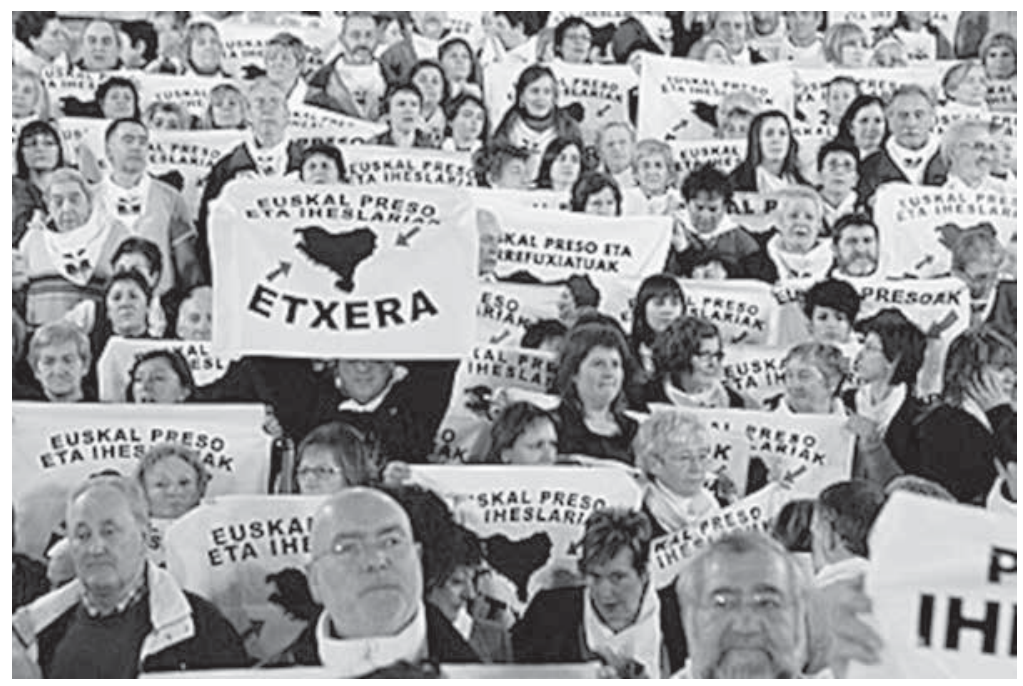

\section{INSTITUTIONNALISATION ET « TRANSITION DÉMOCRATIQUE » DU NATIONALISME BASQUE RADICAL (DEPUIS 2011)}

Depuis le "cessez-le-feu définitif de l'activité armée » de l’ETA le 20 octobre 2011, il est donc possible de dire que l'on assiste à la « transition démocratique " du nationalisme basque radical, caractérisée par un rejet formel de la violence et un début d'autocritique sur les dérives des années de lutte armée ${ }^{63}$. Pendant les années 1980, le nationalisme radical légitimait ouvertement la violence, puis il s'employa à formuler de nombreux euphémismes pour ne pas la condamner durant les années 1990. Ses partisans présentèrent ses postulats comme nonnégociables - l'autodétermination, l'appartenance du Pays basque français, de la Navarre et de l'Euskadi à la même nation, le retrait des forces de police et de l'armée du Pays basque —, leur permettant de justifier, devant la non-réalisation de ces conditions, l'exercice d'une violence présentée comme "défensive " contre une autre violence jugée antérieure de "l’État espagnol » contre le " peuple » basque. La

63. «ETA anuncia el cese definitivo de su actividad armada », Gara, 20 octobre 2011. 
sacralisation de ces postulats hautement contestables créa une "religion politique " légitimant non seulement la désobéissance civile, mais exerçant surtout la violence en niant à l'autre la liberté d'expression que l'on revendiquait pour soi ${ }^{64}$.

La posture antisystème, le populisme - en prétendant constamment agir au nom du " peuple " basque - et la tendance à la victimisation du nationalisme radical n'ont pas fondamentalement changé. Pas plus que le recours très fréquent aux manifestations de rue. Ce courant a fidélisé une base militante déterminée et très impliquée politiquement. Mais il est en passe de s'insérer définitivement au sein du jeu démocratique et c'est tant mieux. Certes, la rhétorique de la "violence de l'État espagnol » est toujours de mise. Mais le choix affirmé de la continuation de la lutte pour l'indépendance par la rue et les urnes en écartant définitivement la violence politique constitue une avancée majeure dans la démocratisation de ce courant politique. Comme nous le verrons ci-dessous en retraçant des événements symptomatiques de l'actualité basque depuis 2011, ce processus en cours est toutefois incomplet et sujet à des tensions importantes au sein même de la communauté nationaliste radicale.

\section{Une rupture avec le passé: fin de la violence, renouveau de l'indépendantisme et pacification}

En octobre 2010, plusieurs anciens responsables de Batasuna, dont son ex-dirigeant Arnaldo Otegi en prison depuis 2009 pour une collaboration présumée avec l'ETA, ont incité l'organisation armée à proclamer un cessez-le-feu unilatéral et inconditionnel de la violence sans exiger de conditions préalables au gouvernement espagnol. La gauche abertzale a donc accueilli comme une "évolution sans précédent " et à la portée " historique ", le communiqué postérieur de l'ETA d'octobre $2011^{65}$. Le nationalisme radical a parallèlement effectué un retour important sur la scène électorale: avec vingt et un représentants sur soixante-quinze (suite à l'obtention de $25 \%$ des voix), Euskal Herria Bildu ("Réunir l'Euskal Herria ", EH Bildu), qui intègre les partis Sortu, Eusko Alkartasuna, Aralar et Alternatiba, constitue désormais la deuxième formation politique derrière le PNV (vingt-sept représentants) au Parlement du Pays basque depuis 2012. Bildu compte aussi onze

64. L'expression de «religion politique » est ici reprise de Jesús CASQUETE, En el nombre de Euskal Herria. La religión política del nacionalismo vasco radical, Madrid, Tecnos, 2009.

65. «Batasuna considera el comunicado de ETA una "decisión sin precedentes" con un alcance "histórico" », El País, 10 janvier 2011. 
représentants (sur cinquante) au Parlement de Navarre et Amairur a envoyé sept parlementaires au Congrès des députés et obtenu quatre sénateurs $^{66}$. Lors des élections municipales de mai 2011, Bildu (sans Aralar) a obtenu 26,3\% des voix (276151) derrière le PNV (30,7\%), même si son vote, plus territorialement concentré dans certaines zones (Guipuscoa notamment), lui a permis d'obtenir 953 conseillers municipaux contre 873 pour le $\mathrm{PNV}^{67}$. La coalition a aussi conquis la ville de Saint-Sébastien, dont Juan Carlos Izagirre est devenu maire. Bildu, une coalition initialement formée le 3 avril 2011, s'est transformée en juin 2012 pour devenir $E H$ Bildu. Il est aussi intéressant de noter que Guipuscoa constitue toujours le " fief " du nationalisme radical (Bildu$E A$ y obtenant $34,6 \%$ des voix et 441 conseillers contre seulement $21 \%$ pour le PNV), alors que la Biscaye est toujours dominée par le PNV (37,4 \% contre $21 \%$ pour Bildu) et que le PP est désormais majoritaire en Alava (25,3\% contre $22,4 \%$ pour le PNV et $20,7 \%$ pour Bildu-EA) ${ }^{68}$.

Dix ans après la condamnation de Batasuna et après avoir présenté huit "marques " électorales distinctes, le " congrès constituant " de Sortu à Pampelune le 23 février 2013, marqua le début d'une nouvelle ère dans le respect de la légalité pour le nationalisme basque radical. Le parti appela à «rompre les chaînes avec la France et l'Espagne et à participer à la vague en faveur de l'indépendance "69. Sortu et $E H$ Bildu cherchent à convaincre le PNV de parvenir à un accord sur «le droit à décider ", tout en appelant la base sociale du PNV à se joindre aux manifestations et au mouvement social indépendantiste ${ }^{70}$. À Irun, le 24 janvier 2015, Sortu proposa la construction d'un État basque indépendant. Le 7 mars suivant, au Bilbao Exhibition Centre de Barakaldo (Biscaye), dix mille militants écoutèrent sa proposition souverainiste surnommée la "voie basque ", présentée face à la "passivité du PNV " et à "l'immobilisme de l'État ». Les dirigeants du parti incitèrent les citoyens basques à une « insubordination démocratique " afin d'avancer

66. Lors des élections européennes de 2014, la coalition a aussi envoyé un représentant, Josu Juaristi, au Parlement de Strasbourg.

67. Notons que ce résultat lui permet d'être loin devant le PSE-EE/PSOE (avec 16,7\% et 177243 voix), et qu'une autre formation indépendantiste, Aralar, a aussi obtenu 2,9\% (avec 30708 voix). Cf. «Elecciones municipales 2011 en Euskadi », Archives des résultats électoraux, Gouvernement basque, département de la sécurité, [http://www.euskadi.net], consulté le 12 mars 2015.

68. Ibid.

69. Mikel OrmaZABAL, « Sortu aguarda su refundación », El País, 22 février 2014.

70. «EH Bildu muestra al PNV su voluntad de acuerdos sobre el derecho a decidir », El País, 4 janvier 2015. 
dans un processus " unilatéral et désobéissant » qui puisse déboucher sur une "constitution de la République basque $»^{71}$. Le parti cherche à amplifier la base sociale de l'indépendantisme en multipliant les organisations politiques, syndicales et culturelles partenaires. Son objectif est de "créer des majorités sociales et politiques pour utiliser les institutions existantes au service de la souveraineté ", puis de redéfinir par le bas les modèles juridico-politiques de l'Euskadi, du Pays basque français et de la Navarre, suivant trois processus distincts, avec des rythmes différents, mais suivant le même objectif de construire un État basque indépendant ${ }^{72}$. Le porte-parole d'EH Bildu, Hasier Arraiz, appelle ainsi à une "rupture démocratique " unilatérale avec l'Espagne et à un " processus constituant en Euskal Herria », puisque selon lui, «l'État espagnol ne reconnaîtra jamais le droit à décider du peuple basque ${ }^{73}$.

Même si le discours a changé et que Sortu rejette désormais clairement la lutte armée dans ses statuts, les anciens membres de Batasuna Rufi Etxebarria, Joseba Permach et Juan José Petrikorena dominent son conseil national, illustrant une certaine continuité des figures dirigeantes. Arnaldo Otegi a joué un rôle central dans l'évolution de la stratégie des indépendantistes, en soutenant depuis sa prison de Logroño la " construction d'une majorité sociale », notamment à travers un " front souverainiste " avec le $\mathrm{PNV}^{74}$. La manifestation commune de la gauche abertzale avec le PNV en janvier 2014 sembla illustrer ce rapprochement. La " lutte idéologique » et la " confrontation démocratique » dans la rue et dans les urnes constituent toujours les piliers de sa stratégie politique. Mais le fait que les militants de Sortu choisirent Otegi pour occuper le poste de secrétaire général, laissé vacant en son absence, illustre bien que pour eux, la "normalisation » du conflit n'aura réellement lieu qu'une fois que les prisonniers de l'ETA seront libérés et que cesseront les emprisonnements de dirigeants abertzales. Devant environ deux mille militants à Irun en janvier 2015, le porte-parole du Conseil National, Pernando Barrena, déclara ainsi que «la politique de répression de l'État espagnol n'est pas encore terminée ", ce qui serait attesté par «ses menaces » et « sa politique pénitentiaire criminelle ».

71. «EH Bildu pide a los vascos que se pongan en pie como en Cataluña », El Paiss, 21 février 2015.

72. "EH Bildu propone un proceso en tres fases hasta una Constitución vasca», El País, 24 janvier 2015.

73. «Arraiz apela a la "ruptura democrática" con España », El País, 25 septembre 2014.

74. Javier DoRIA, «Sortu llama a una alianza soberanista en su constitución », El Mundo, 24 février 2013. 
Sur le plan organisationnel, le nationalisme basque radical a maintenu la tradition de la création d'une multiplicité de groupes politiques s'organisant en cercles concentriques autour d'un noyau central. Cela permet de multiplier les acteurs et les niveaux de discours, tout en développant son impact social: Amairur est présent au Congrès des députés, EH Bildu au sein des institutions basques, et Sortu définit la stratégie d'ensemble. L'utilisation de plusieurs organisations offre la possibilité à Sortu d'adopter une posture moins radicale et plus surplombante, tout en laissant à des organisations proches le soin de prendre des postures plus critiques et anticonventionnelles. Mais la démocratisation interne du parti qui dit opter pour la "démocratie participative " demeure limitée. Certes, plus de six mille personnes ont participé à son congrès constituant, mais seules certaines candidatures furent ouvertes au pluralisme, les militants devant ratifier les candidats uniques proposés pour la direction: Hasier Arraiz fut nommé président, Idoia Aiastui responsable de l'organisation interne, Juan Joxe Petrikorena de la communication, Marisa Alejandro des finances, Maite Ubiria des relations internationales et Arnaldo Otegi fut nommé secrétaire général malgré son incarcération suite à l'affaire Bateragune ${ }^{75}$.

Le responsable de la "lutte idéologique ", Iosu Lizarralde, fut de même imposé d'en haut. Comme pour le conseil national, les militants purent uniquement ratifier en bloc les coordinateurs territoriaux proposés par la direction: Maribi Ugarteburu en Biscaye, Txus Martinez en Alava, Joxean Agirre en Guipuscoa, Juan Kruz Aldasoro en Navarre et Jean-François Lefort pour le Pays basque français. Les bases militantes purent en fait seulement choisir trois porte-parole (Amaia Izko, Xabi Larralde et Pernando Barrena) sur cinq proposés, de même qu'un responsable de la " lutte de masse », en optant pour Marije Fullaondo, et un responsable de la " lutte institutionnelle " (Joseba Permach), parmi trois candidats à chaque fois. Pour la " résolution du conflit ", ils choisirent Rufi Etxeberria (ancien membre de l'ETA-m jusqu'en 1981 puis de HB, EH puis Batasuna) parmi trois candidatures, de même que cinq personnes sur dix proposées par le conseil national pour les représenter à l'international. Suite à un sondage récent annonçant Podemos devant la gauche abertzale, Hasier Arraiz plaida pour une réorganisation au-delà de la coalition de partis et une "nouvelle culture de participation" qui devrait permettre aux militants de "décider

75. "Sortu dejará vacante la secretaria general mientras Arnaldo Otegi siga en prisión », El País, 14 février 2013. 
eux-mêmes $»^{76}$. En plus de sa fragmentation, force est toutefois de constater que le nationalisme basque radical demeure structuré en interne par une certaine verticale du pouvoir, et par une culture du conflit dans sa stratégie de compétition.

\section{Une transition inachevée}

D’autres événements indiquent toutefois que la transition en cours demeure inachevée. Le 23 septembre 2011, le "Collectif des prisonniers et des prisonnières politiques basques " (EPPK) qui regroupe 732 prisonniers de l'ETA, à savoir la quasi-totalité des détenus de l'organisation, émit un communiqué soutenu par $90 \%$ de ses membres, dans lequel il approuvait l'accord de Guernica du 25 septembre 2010 sur la fin de la violence et s'engageait à " avancer dans le processus démocratique ", sans pour autant solliciter clairement la fin des actions de l'ETA, et en plaidant pour un processus de négociation entre l'organisation et le gouvernement ${ }^{77}$. Les détenus considérés comme "dissidents" par l'organisation (la plupart en ont été expulsés), regroupés autour du "Collectif des prisonniers impliqués avec le processus de paix irréversible ", émirent un autre communiqué le même jour appuyant l'accord de Guernica, mais appelant aussi « à la reconnaissance des souffrances infligées aux victimes et à la réconciliation sociale ${ }^{78}$ ". En 2012, seuls une trentaine de prisonniers avaient choisi la voie Nanclares qui facilite les remises de peine pour les prisonniers qui rejettent la violence et assument de façon critique leur passé. Ceci illustre bien le fait que malgré la fin de la violence, la reconnaissance des souffrances infligées aux victimes et la réconciliation demeurent encore des enjeux problématiques.

Le jugement de la Cour européenne des droits de l'homme de juillet 2012, qui donna raison à l'ex-membre de l'ETA Inés del Rio Prada, mit fin à la doctrine Parot, permit la libération de soixante et onze prisonniers de l'ETA et posa encore plus clairement sur l'agenda politique

\footnotetext{
76. Selon l'Euskobarómetro de novembre 2014, à la question «si des élections avaient lieu prochainement pour qui voteriez-vous? », $30,5 \%$ des enquêtés de la communauté autonome d'Euskadi déclarèrent opter pour le PNV, 25,6\% pour Podemos et seulement 19,7\% pour EH Bildu. Cf. "Estimación de voto en el País Vasco », Encuesta electoral Euskobarómetro, novembre 2014.

77. «Los presos de ETA apoyan el acuerdo de Gernika que asume el fin de la violencia », El País, 24 septembre 2011 .

78. "Los presos disidentes de ETA urgen a abordar la reparación de las víctimas », El País, 23 septembre 2011 .
} 
la question de leur réinsertion sociale ${ }^{79}$. Le Forum social créé en février 2013 par Lokarri et dirigé par Paul Ríos, de même que le collectif Bake Bidea dirigé par Peio Dufau, estime que les prisonniers doivent jouer un rôle important dans le nouveau scénario politique, et sont soutenus dans leur démarche par EH Bildu et le $\mathrm{PNV}^{80}$. Le Forum social cherche à obtenir la fin de la politique de dispersion (qui engendre l'incarcération des prisonniers de l'ETA dans différentes prisons d'Espagne et de France) et la libération des prisonniers. Il demande aussi la liberté conditionnelle des prisonniers malades et de ceux âgés de plus de soixante-dix ans. Les prisonniers et leurs associations de défense constituent des groupes de pression centraux dans le processus de pacification. Par exemple, suite à la convocation d'EH Bildu et des syndicats ELA et LAB, plus de dix mille personnes ont manifesté le samedi 17 janvier 2015 dans le centre-ville de Saint-Sébastien pour protester contre l'opération Mate de la Garde civile menée à l'encontre des avocats des prisonniers de l'ETA, suivant le slogan "Droits de l'homme. Solution. Paix " ("Giza Eskubideak. Konponbidea. Bakea »), le même que celui utilisé lors de la manifestation de Bilbao en janvier 2014 à laquelle participa le $\mathrm{PNV}^{81}$. Le 25 février 2015, Iñigo Urkullu est de même devenu le premier lehendakari (président de la communauté autonome) du Pays basque espagnol à recevoir de façon officielle des familles de prisonniers de l'ETA lors d'une réunion avec Maider Alustiza, la porte-parole d'Etxerat, l'association qui les représente ${ }^{82}$.

De plus, le discours de ce courant politique demeure toujours aussi " radical ", flirtant parfois avec " l'apologie du terrorisme ", ce qui crée un climat tendu avec les autres formations politiques et engendre une multiplication des poursuites et des condamnations à répétition de ses dirigeants. En octobre 2013, Hasier Arraiz traita ainsi de "fasciste"

\footnotetext{
79. La "doctrine Parot" correspondait à une jurisprudence du Tribunal suprême qui permettait de maintenir en détention des prisonniers pourtant libérables. Condamnée en juillet 1987, Inés del Rio devait être remise en liberté en 2008 après vingt ans de réclusion. Mais le 2 juillet 2008, l'Audience nationale décida de repousser celle-ci jusqu'au 27 juin 2017, une décision qui fut considérée comme abusive par la Cour européenne en 2012. La Cour considéra que l'Espagne avait violé les articles 5 et 7 de la Convention européenne des droits de l'homme, ce qui fit jurisprudence et engendra la remise en liberté de nombreux prisonniers de l'ETA. Cf. « La Cour de Strasbourg condamne l'Espagne pour la "doctrine Parot" », [EiTb. eu], 10 juillet 2012, consulté le 11 mars 2015.

80. «El Foro Social pide al Parlamento una interlocución con los presos de ETA», El País, 15 mars 2015.

81. Inés CHAVARRI, « Miles de personas defienden en la calle a los abogados de presos de ETA », El País, 17 janvier 2015

82. «Urkullu, el primer lehendakari a recibir presos de ETA », La Vanguardia, 22 février 2015.
} 
Photo 6.3. Manifestation en faveur des prisonniers de l'ETA, Saint-Sébastien (2015)

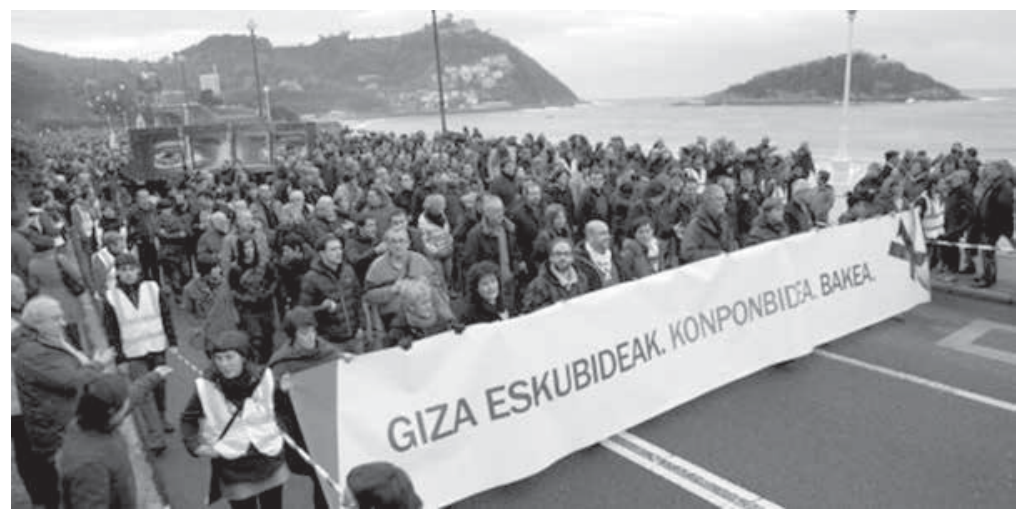

Borja Sémper, le porte-parole du PP au Pays basque. Le 18 décembre 2013, lors d'un hommage aux dirigeants de Herri Batasuna assassinés par les GAL, Santiago Brouard en 1984 et Josu Muguruza en 1989, il déclara que «la seule violence est celle de l'État terroriste, de la Garde civile et des corps répressifs ", revendiquant la trajectoire du parti malgré sa dépendance passée à l'égard de l'organisation armée ${ }^{83}$. Convoqué par le Tribunal suprême de justice du Pays basque pour un délit présumé d'apologie du terrorisme et d'humiliation des victimes suite à une plainte de l'association Dignité et Justice, il déclara avoir défendu la stratégie de la gauche abertzale des trente-cinq dernières années visant à "rompre avec l'Espagne ", et non la " lutte armée de l'ETA ", avant d'être finalement acquitté ${ }^{84}$. Pour lui, sa convocation illustrerait le " manque de liberté d'expression des militants indépendantistes " et leur répression. L’utilisation politique par Sortu de la manifestation conjointe avec le PNV en faveur des droits de l'homme en 2014, qui se termina par des cris en faveur de l'ETA, constitue une autre illustration du chemin qui reste à parcourir. Même si les statuts de Sortu condamnent la violence, les discours des nationalistes radicaux demeurent parfois ambigus, et la condamnation explicite des années de lutte armée de l'ETA demeure encore un tabou pour ce secteur social.

83. «El presidente de Sortu pide a la Guardia Civil que se vaya de Euskadi », El País, 14 janvier 2015.

84. "Arraiz declara que defendió romper con el Estado y no la "lucha armada" de ETA », El País, 2 avril 2014. 
Pour conclure, le nationalisme basque radical est aujourd'hui à un tournant, ce qui donne lieu à de nombreuses divisions en son sein. D’une part, il condamne de plus en plus la lutte armée passée et même la "kale borroka ", certains dirigeants ayant condamné des épisodes récents de violence de rue. Le dirigeant de Sortu, Joseba Permach, a ainsi déclaré son " rejet le plus absolu " de l'attaque contre le quartier général du PP à Barakaldo en novembre 2013, appelant ses sympathisants à défendre les droits des prisonniers de l'ETA « avec des méthodes pacifiques ${ }^{85}$ ". Des dirigeants de Bildu ont de même participé à l'hommage rendu aux parlementaires socialistes Fernando Buesa et Enrique Casas en 2012, témoignant du début d'une reconnaissance des souffrances engendrées par la lutte armée. Le choix d’une ligne dure d’opposition au gouvernement régional dirigé par Urkullu n'est pas partagé par tous, comme l'atteste par exemple la démission de la parlementaire d'EH Bildu Laura Mintegi en septembre 2014, et son remplacement par Iker Casanova, détenu en 2002 et condamné en 2009 par l'Audience nationale comme responsable du mouvement de jeunesse Ekin $^{86}$.

D'autre part, l'autocritique quant à l'usage du terrorisme demeure encore largement taboue, comme en atteste la volonté de mettre « l'ensemble des victimes " affectées par le terrorisme sur le même plan, sous-entendant que les membres de l'ETA tués par les forces de l'ordre doivent tout autant être remémorés que les victimes civiles, policières et militaires de l'organisation ${ }^{87}$. Ainsi, par exemple, Bildu refusa de

85. "Ataque con artefactos incendiarios contra la sede del PP de Barakaldo », $A B C$, 25 novembre 2013.

86.. " Mintegi se va ajena a la oposición dura de Bildu y a su papel diluido », El País, 25 juillet 2014.

87. Au contraire, pour la droite conservatrice, comme en relève le maire de Vitoria Javier Maroto $(P P)$, « seules les victimes de l'ETA méritent une reconnaissance spécifique », considérant qu'il n'y a pas eu de " guerre » entre deux parties au Pays basque, mais plutôt une violence unilatérale de l'ETA. Cf. "Maroto reprocha al gobierne que "mezcle" a todas las víctimas », El Mundo, 9 février 2015. Ce positionnement est défendu avec ardeur par le PP et les associations de victimes du terrorisme. La position la plus partagée au sein de la société basque est cependant de reconnaître qu'il y a eu des victimes des deux côtés, tout en considérant toutefois que les victimes de l'ETA ont été beaucoup plus nombreuses que celles du « terrorisme d'État » des GAL. Pour la plupart des Basques, le «conflit » avec l'État espagnol évoqué par les nationalistes radicaux n'a existé que jusqu'à la fin du franquisme. Le choix du maintien de l'utilisation de la violence par l'ETA malgré l'instauration du cadre démocratique définitivement ancré après 1982, relevant plutôt d'une violence unilatérale. C'est d'ailleurs la conclusion à laquelle parvinrent les historiens Raúl López Romo, Luis Castells, Antonio Ribera et José Antonio Pérez dans un rapport sur la «mémoire historique au Pays basque, 1968-2010 » rendu récemment au gouvernement de Vitoria-Gasteiz. Pour un compte-rendu du rapport, cf. Luis AIzPEOLEA, « No hubo conflicto vasco, sino totalitarismo de ETA », El País, 11 mars 2015. 
participer en 2013 à l'hommage aux victimes soutenu par l'ensemble des partis, célébré à Getxo chaque année depuis 2009 lors du "Jour de la mémoire ». Lors de la commémoration, le maire Imanol Landa, issu du PNV, déclara pourtant dans une volonté de rassemblement que " dans cette ville, nous avons eu des victimes du terrorisme de l'ETA et des GAL. À travers cette minute de silence nous voulons honorer la mémoire de toutes les victimes ${ }^{88}$ ".

Force est toutefois de constater que la démocratisation de ce courant politique est en marche. Notons aussi que, si l'on demande à juste titre aux indépendantistes de condamner le maintien de la lutte armée après la transition, peu nombreux sont ceux qui, parmi les conservateurs, font l'effort d'admettre le terrorisme d'État des GAL et de rendre hommage à ses victimes. Dans les villes moyennes et les villages ruraux du Pays basque, les descendants de victimes de l'ETA côtoient souvent au quotidien d'anciens membres de l'organisation sortis de prison. Ils se haïssent souvent, s'évitent généralement, mais se parlent de plus en plus. Des forums de rencontre et des lieux de parole se créent. La même dynamique est à l'œuvre dans les conseils municipaux où les représentants d'EH Bildu prennent part aux décisions politiques locales. Des confrontations naissent ici ou là. Les indépendantistes n’hésitent pas à hisser des drapeaux basques et à retirer parfois les drapeaux espagnols des frontons des mairies. Ils prennent parfois des décisions ou émettent des communiqués qui illustrent des pratiques de désobéissance civile. Mais ils se plient aussi aux nécessités de la "gestion " municipale et au besoin de satisfaire leurs électeurs, pas toujours indépendantistes. Ceux qui vivent au Pays basque espagnol s'accordent pour dire que les choses ont changé depuis 2011. Le climat est plus serein. La paix se construit jour après jour. Petit à petit, chacun accepte le jeu de la démocratie et de la réconciliation, reconnaissant la nécessité du dialogue et du compromis dans une société basque pluraliste, une caractéristique qui demeure inchangée depuis au moins la fin du XIX ${ }^{e}$ siècle.

88. "La izquierda "abertzale" rechaza la "kale borroka", pero evita recordar a las víctimas ", El País, 29 novembre 2013. Les GAL correspondent aux groupes antiterroristes de libération, groupes d'extrême droite qui assassinèrent des membres de l'ETA lors des années de plomb. 


\title{
7 \\ Le mouvement des indignés: la création du 15-M et sa postérité
}

\author{
Sylvie KOLLER
}

\author{
Ils ne nous représentent pas. \\ Ce n'est pas une crise, c'est une escroquerie. \\ Nous ne sommes pas contre le système, c'est le système \\ qui est contre nous. \\ (Slogans des indignés de Madrid)
}

\begin{abstract}
En mai 2014, l'assemblée de Madrid de ce qui est désormais dénommé le 15-M a célébré le troisième anniversaire de la création du mouvement des indignés ${ }^{1}$. Les formes mêmes de cet anniversaire s'inscrivent dans la continuité de l'élan premier, mais l'événement n'a pas fédéré plus de quelques centaines de personnes et a eu peu de répercussions médiatiques, même dans la presse sympathisante. Est-ce à dire que l'essoufflement du mouvement, annoncé dès juillet 2011, se confirme? La réponse appelle des nuances. Certes, les mobilisations de masse convoquées directement par les différentes ramifications visibles du 15-M (Democracia Real Ya, Juventud sin Futuro, Assemblée de Madrid, assemblées locales) ne se sont pas reproduites après la grande manifestation unitaire du 15 octobre 2011. Mais si le mouvement des indignés ne se pérennise pas dans sa forme initiale, ses nombreuses mutations en gardent l'empreinte originelle. Certains répertoires d'action et formes d'organisation demeurèrent bien présents lors du troisième anniversaire: tenue d'une assemblée ouverte sur la Puerta del Sol, travail échelonné sur plusieurs journées, au sein d'ateliers et de commissions thématiques, dans un espace public représentatif de la
\end{abstract}

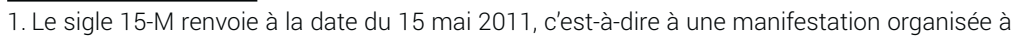
Madrid contre l'ordre économique et politique. Refusant de se disperser, quelques participants à la manifestation passèrent la nuit sur la Puerta del Sol, marquant le début symbolique de l'occupation de la place. Cette date inaugurale est le coup d'envoi du mouvement social des Indignés. II est habituel en Espagne de cristalliser les dates pour évoquer des événements marquants. 
contre-culture: el Campo de la Cebada, dans le Madrid historique. Les indignés ont aussi organisé une célébration alternative de la fête votive de San Isidro, patron de Madrid, et appelé à manifester en direction de la Puerta del Sol. De tous ces événements, le journal de l'assemblée de Madrid s'est fait largement écho².

Les revendications soutenues lors du troisième anniversaire illustrèrent une lutte axée sur deux points centraux: la critique du modèle économique et financier espagnol et le refus du système politique en place, un double fil conducteur présent depuis le début du mouvement. La démocratie participative était encore à l'ordre du jour. Mais par ailleurs, la proclamation d'un esprit de résistance à diverses formes de répression minutieusement recensées, traduisit une forme d'autoglorification compensatrice propre aux groupes militants en perte de vitesse. Le paysage social du mouvement est donc aujourd'hui contrasté: perte d'audience directe, atomisation des groupes, tendance au ressassement de ses revendications et de ses modes d'action, mais aussi persistance d'un idéal incarné dans des espaces de débat public. Il faut ajouter que la perméabilité est grande entre le 15-M et d'autres mouvements sociaux, voire politiques et que les formes d'engagement sont multiples et variables dans le contexte espagnol contemporain, caractérisé par une crise économique et sociale sans précédent. Le 15-M lui-même peut donc paraître en sommeil ou en recul, tandis que les acteurs du mouvement des indignés choisissent en fait de s'investir dans des collectifs citoyens, des plateformes, des comités de quartier et des expériences d'économie alternative.

Comment s'est structuré le mouvement des indignés en Espagne depuis ses origines? Quels autres mouvements sociaux ont émergé dans son sillage? Dans ce chapitre, nous montrerons d'abord que l'influence du mouvement des indignés survit actuellement sous des formes diverses, irriguant le mouvement social depuis 2011, sans qu'il soit possible d'attribuer aux indignés la paternité des protestations syndicales, des manifestations de rue ou de l'émergence de formations politiques. Pour expliquer ce rayonnement diffus, nous nous attacherons aux formes initiales de la mobilisation, dont la portée symbolique a pu éclipser le contenu même des aspirations qu'elle portait. Nous montrerons que la dimension de rassemblement fusionnel n'était pas le seul enjeu, mais que les revendications exprimées dès le début s'articulaient à un diagnostic porté sur l'économie et la politique, à un moment critique

2. «Especial Aniversario 15-M », Madrid 75-M, periódico de Asambleas de Madrid, nº 25, mai 2014. 
de l'histoire de l'Espagne. Puis nous décrirons les actions militantes des acteurs sociaux organisés qui se spécialisent sur certaines revendications, tout en s'inspirant des enseignements du 15-M afin d'entretenir une dynamique de rassemblement. Enfin, nous ouvrirons un questionnement sur la prolongation politique possible du 15-M.

\section{UN ANNIVERSAIRE PEUT EN CACHER UN AUTRE}

Il faut élargir notre champ de vision pour distinguer, au printemps 2014, deux événements qui doivent beaucoup à la brèche des possibles ouverte par les indignés dans le jeu social et politique espagnol depuis 2011. Deux événements préparés par des forces sociales et politiques qui se réclament de l'esprit du 15-M dans la mesure où ils récusent « le système ", mais qui ont aussi des intérêts propres. Ces événements ne devaient rien à l'effet de surprise et à la spontanéité, et tout à la préparation.

Le samedi 22 mars 2014, Madrid a vu converger les «marches de la dignité " parties de différents points de l'Espagne, organisées en huit colonnes, accueillies, hébergées, nourries et fêtées par les Madrilènes qui ont voulu manifester avec les marcheurs. Celles-ci ont été initiées par le Syndicat andalou des travailleurs (SAT) et rejointes par de nombreuses composantes: collectifs, syndicats, assemblées locales. Le triple mot d'ordre des marches était: « Du pain, un toit, du travail. » En contradiction avec l'esprit citoyen et non-partisan d'origine du 15-M, les drapeaux de syndicats et de partis nationalistes et républicains étaient visibles. Non-violente, la manifestation n'a dégénéré en affrontements avec la police que lors de sa dissolution, avec des heurts qui furent suivis d'interpellations. Ce répertoire d'action rappela en fait les marches organisées dans toute l'Espagne par les indignés entre le 19 juin et le 24 juillet 2011, avec des haltes dans les petites villes et une arrivée " triomphale " à Madrid. Ces marches de la dignité représentèrent un effort porté par des militants et de simples citoyens en vue de fédérer les différentes formes de protestation sociale des dernières années contre la politique du gouvernement du Parti populaire, caractérisée par la régression des droits sociaux et l'austérité budgétaire. Bien que l'on soit loin de l'anonymat fusionnel des débuts, ces marches permirent aussi de revivre ce que le 15-M avait de plus convivial: le partage d'espaces publics, le relais entre générations, le bonheur de faire nombre, le soutien des sympathisants. 
Le résultat du vote aux élections européennes du 25 mai constitua l'autre événement du printemps 2014. À la surprise générale, le nouveau parti Podemos, après seulement quatre mois d'existence légale, récolta 1245000 voix et remporta cinq sièges au Parlement européen. La figure médiatique de son leader, Pablo Iglesias, très bon communicant et participant actif de plusieurs tertulias, des débats politiques télévisés hebdomadaires, fut ainsi consacrée. Tandis que le parti fut immédiatement dénigré et calomnié par l'« establishment " politique et les médias de droite, dans la mouvance du 15-M les réactions varièrent de l'indifférence affichée à la réflexion tâtonnante sur l'ouverture d'une " fenêtre d'opportunité " démocratique, en passant par la critique de l'opportunisme des dirigeants de Podemos. De fait, en mai 2014, après déjà plus de six années de crise économique, les circonstances ont changé. La crise sociale persiste, les mobilisations sociales répétées des dernières années n'ont donné que peu de résultats concrets, le pouvoir donne des signes de raidissement et prépare une contre-attaque juridique et judiciaire musclée contre les activistes sociaux. Mais dans le même temps, les signes visibles d'une crise de régime et la désaffiliation politique croissante des Espagnols envers les partis traditionnels illustrent la fragilité du pouvoir. C'est ce moment propice que choisirent les militants de Podemos pour faire lever le grain de la contestation semé par le 15-M.

Du mouvement, ils reprirent un slogan central, Si, Podemos (« Oui, nous pouvons "), lui-même dérivé du célèbre «Yes, we can " popularisé par Barack Obama lors de la présidentielle américaine de 2008. Mais surtout, Podemos a emprunté au 15-M certaines règles de fonctionnement, comme un mode d'affiliation souple (sans cotisation exigée) et des formes de cyberactivisme: délibérations et forums de participation sur internet. De plus, le nouveau parti s'inspire des propositions du mouvement sur le contrôle démocratique: primaires ouvertes pour désigner les candidats aux élections ou à certaines fonctions; possibilité de révoquer les élus; limitation à deux mille euros des indemnités parlementaires. "Le parti, c'est la méthode ", a déclaré Pablo Iglesias. Podemos invite ainsi ses sympathisants à constituer des cercles sur une base locale, professionnelle ou thématique, de façon libre et autonome, ce qui rappelle l'organisation du 15-M. Il est encore trop tôt pour analyser les formes de délégation, de certification et de contrôle dirigeant que le parti va peut-être mettre en place pour limiter l'horizontalité et la démocratie directe et afin de renforcer ses positions dans la concurrence politique. Toujours est-il que suite aux élections européennes de 
mai 2014, un pas majeur fut franchi vers une transformation de l'indignation sociale en un nouveau capital politique.

Revenir à présent sur la façon dont est né le mouvement du 15 mai, sur ses acteurs, sur les formes qu'il a adoptées et sur ses propositions, permet de comprendre l'influence qu'il a exercée en tant que vecteur d'insurrection morale. Peu susceptible de se perpétuer dans son état initial, cette indignation a connu des mutations, tout particulièrement en évoluant vers des formes d'indignation plus sélectives et spécialisées. Elle a servi de carburant à des acteurs sociaux différenciés qui se sont mobilisés pour défendre leurs objectifs propres. Elle a aussi changé de langage en épousant d'autres rhétoriques. Son héritage, cependant, est aujourd'hui bien palpable, et ne se laisse pas facilement enfermer dans des définitions caricaturales (populisme, anti-élitisme, spontanéisme), ni même réduire à des slogans politiques (démocratie directe et participative). À rebours de ces présupposés, il incarne surtout une philosophie de l'engagement social et de l'action politique ${ }^{3}$.

\section{LA TOILE ET LA PLACE}

Si l'explosion du 15-M, incarnée par un mois de campement sur la Puerta del Sol en mai 2011, a pris de court l'opinion publique et les médias, elle n'était pas exactement une mèche qui prend feu par accident. L'étape de gestation du mouvement montre un mélange d'actions dans l'espace public et d'organisation sur la Toile. Sur les réseaux sociaux, on protestait déjà contre la loi Sinde (équivalent de la loi Hadopi). Un groupe de militants s’organisait depuis décembre 2010 sous le nom de Democracia Real Ya, dans le but explicite de catalyser l'énergie des mécontents. Il s'agissait d'une plateforme virtuelle regroupant par adhésion volontaire de petits groupes d'acteurs sociaux sans affiliation partisane, qui s'organisaient sur des points de contestation du système économique et politique. L'interconnaissance et le mode traditionnel de la réunion y jouaient aussi un rôle. Le 7 avril 2011, un autre mouvement alors peu connu, Juventud Sin futuro, appelait à une manifestation de rue dans toute l'Espagne pour dénoncer les conditions de vie de la jeunesse. Sans dépasser un succès d'estime, ces jeunes furent remarqués car leur manifestation prenait la suite d'une mobilisation analogue de la jeunesse au Portugal. Les réseaux créateurs de ces mouvements étaient principalement constitués de personnes de

3. Sylvie KolLER, «Espagne: les mains fragiles des indignés », Études, février 2012, p. 163-173. 
vingt à trente ans, ayant un haut niveau d'études, représentatives de la génération que l'on dit la mieux formée de tous les temps, tout en la qualifiant de "génération perdue ». Un entre-soi solidement tissé et des leaders pour l'heure anonymes ne constituaient pas un levier suffisant. Il fallait y ajouter les circonstances: la proximité des élections municipales et autonomiques du 22 mai, propices à la dénonciation de la crise des institutions démocratiques. Contexte électoral défavorable à une réaction répressive de la part des autorités.

\section{Un campement, des campements}

La forme symbolique adoptée par ce premier cercle de manifestants s'est avérée la plus productive: celle du campement à ciel ouvert, sur une place emblématique de la vie madrilène, où se trouve le siège de la communauté autonome ${ }^{4}$. Délogés une première fois après deux nuits de campement, les manifestants-campeurs ont montré leur aptitude à réoccuper pacifiquement la place en accroissant le nombre de participants. La non-violence trouvait là à s'illustrer avec éclat. La deuxième phase, plus spontanée et véritablement surprenante, a consisté à créer sur la place un espace de confiance rassemblant des campeurs permanents et des visiteurs, des militants expérimentés et des novices en politique, des sympathisants et des curieux.

Que cette phase du campement sur la Puerta del Sol ait pu durer un mois entier, ne se dégradant que vers la fin à cause de la présence de marginaux et d'escarmouches avec la police, fut le principal succès des indignés. Un succès qui reposait sur une philosophie de l'action inventée au fur et à mesure de l'occupation de la place: non-violence affirmée, organisation d'une vie matérielle digne, création d'espaces publics de délibération, prise de décision en assemblées, travail spécialisé en commissions. La création d'une bibliothèque, d'une garderie, de points de secours, la réception et le partage d'aliments, le nettoyage régulier de la place, la mise en place de moyens de communication propres, ont beaucoup contribué à la popularité du 15-M. Il n'est pas excessif de dire que ces expérimentations relevaient de l'autogestion et de la démocratie directe au sein même du mouvement, et qu'elles ont permis de conserver un capital de sympathie et d'attirer de nouveaux participants, au-delà même des frontières espagnoles. Certains détails,

4. Nacima BARON YELLÈS, "Puerta del Sol versus les indignés. Une lecture de la crise espagnole au prisme de l'espace public », Urbanités, n² 2, novembre 2013 [http://www.revue-urbanites.fr/?s=Puerta + del + Sol]. 
comme l'usage d'un langage gestuel dans les assemblées au lieu des traditionnels mégaphones, firent mouche et demeurent dans l'imaginaire de ce mois d'occupation de la place. De même, en choisissant de présenter des porte-paroles tournants aux médias, les indignés ont signifié concrètement leur refus du leadership et de la notoriété médiatique.

Photo 7.1. La Puerta del Sol, le 20 mai 2011

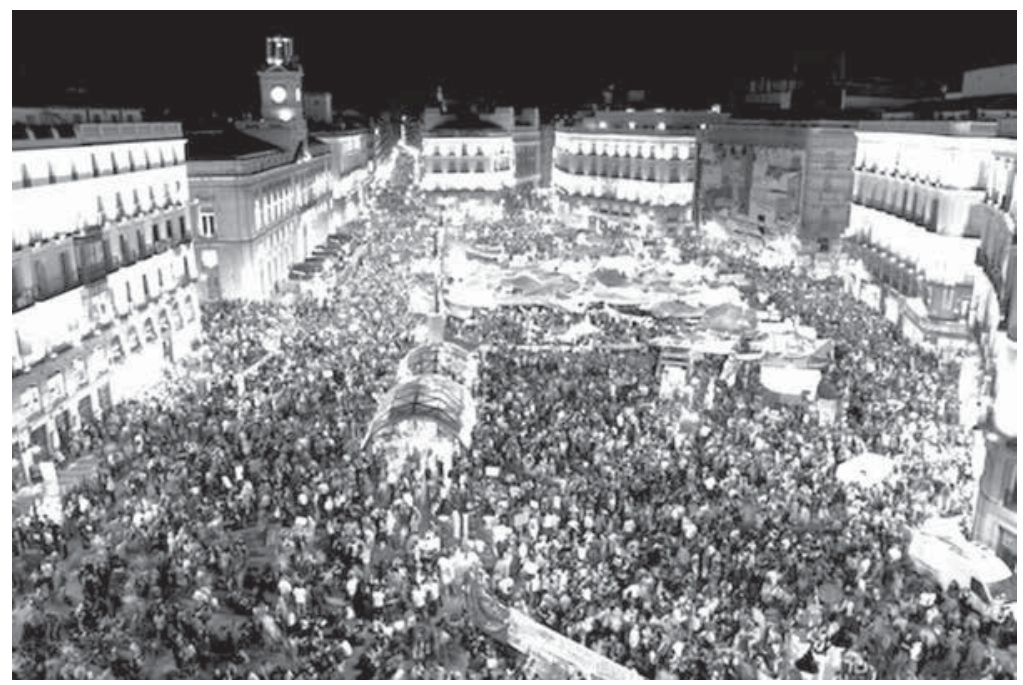

Deux événements ont donné une grande résonance médiatique au mouvement pendant la phase du campement et en ont renforcé la cohésion. Tout d'abord, les indignés ont refusé de se plier aux consignes de l'organisme électoral qui demandait que soit strictement respectée la journée de réflexion la veille du scrutin municipal du 22 mai. Ils ont incarné cette désobéissance civile en restant sur les places du vendredi au samedi. Le grand rassemblement le soir du samedi 21 mai sur la Puerta del Sol, la minute de silence à minuit, les bouches cousues de sparadrap, ont créé une véritable iconographie du 15-M. Une semaine plus tard, les indignés de Barcelone étaient chassés de la Place de Catalogne par la police. Les images de cette éviction par la force firent le tour de l'Espagne et suscitèrent immédiatement des manifestations de solidarité, puis une réoccupation de la Place de Catalogne. Au-delà des péripéties propres aux mouvements de rue, cet événement souligne 
le fait que le 15-M commençait à transcender les clivages nationalistes et territoriaux.

\section{Le socle intergénérationnel du mouvement des indignés}

De même qu'il transcendait les clivages territoriaux, le 15-M dépassait les clivages générationnels. À ce stade, plusieurs générations se trouvèrent rassemblées. Il ne s'agissait pas seulement du soutien des adultes à une génération marquée par la précarité et le chômage, mais d'une inscription dans l'histoire contemporaine des générations. Ces jeunes de vingt à trente ans qui campaient et délibéraient sur la Puerta del Sol étaient les enfants des Espagnols qui s'étaient mobilisés pour instaurer des espaces démocratiques, à la fin du franquisme et pendant la période de la transition démocratique (1975-1982). La crise de la démocratie espagnole décevait les uns et les autres, tandis que le souvenir des luttes passées se trouvait ravivé. La présence d'une "Commission Vétérans " sur la place dès les premiers jours du mouvement préfigura d'ailleurs la constitution d'une branche particulière des aînés du 15-M, celle des Iaioflautas, qui émergea d'abord à Barcelone en octobre 2011 puis essaimera ailleurs en Catalogne et, avec moins de force, dans d'autres villes espagnoles ${ }^{5}$.

L'une des rubriques du manifeste fondateur des Iaioflautas met en évidence un effet générationnel très clair, par la référence explicite aux luttes contre la dictature franquiste ${ }^{6}$. En revendiquant "vérité, justice et réparation " pour les victimes de la guerre civile et du franquisme, ces militants âgés de plus de soixante-dix ans, issus pour la plupart de syndicats et de partis de gauche, mettaient le doigt sur les failles et les oublis du « pacte du silence » de la transition, l'amnistie ayant été accordée aux anciens dignitaires franquistes en échange de leur acceptation de la démocratie. À leur manière, par leurs demandes de réparation et de justice, ils exprimaient une remise en cause de ce pacte de la transition démocratique et du modèle constitutionnel lui-même, que portait désormais le mouvement contestataire. Le mouvement du 15-M, en se saisissant des droits fondamentaux inscrits dans la constitution de 1978, exprima aussi une critique du modèle démocratique incarné par cette constitution.

5. Ce terme retourne un stigmate attaché au mot "Perroflautas», une façon péjorative de désigner les marginaux urbains.

6. laioflautas, «El nostre manifest », 27 octobre 2011, [http://www.iaioflautas.org/el-nostremanifest/\#caste

llano] consulté en août 2014. 


\section{Comment s'organiser? Occupations, assemblées et extension du mouvement}

Une autre dimension de cette philosophie de l'action fut l'essaimage presque immédiat du 15-M dans d'autres villes et sa déconcentration en assemblées de quartiers à partir du 28 mai. Des groupes constitués ont pu continuer à se rassembler après l'étape du campement de la Puerta del Sol et entretenir la flamme pendant tout l'été. Ainsi ont-ils manifesté contre la tenue à Madrid des Journées mondiales de la jeunesse organisées par l'Église catholique, dénonçant l'usage de l'argent public au profit de cet événement. Les formes de participation collective horizontales trouvèrent bien entendu en elles-mêmes leurs limites: épuisement en discussions interminables; empilement des propositions sans hiérarchie; temps passé dans des navettes entre les différentes assemblées; difficulté à prendre des décisions par consensus ou à mettre au point un autre mécanisme de décision juste. Ce bouillonnement confus rappelle ainsi les formes dites horizontales du cyber-activisme: chats, forums, wikis, écriture collective sur des tablettes, etc. Le temps investi dans la définition de règles de délibération et de modes d'organisation a pu sembler stérile pour certains observateurs. Il fut au contraire fondamental comme initiation politique, au sein d'un mouvement qui récusait par principe la démocratie représentative ${ }^{7}$.

La résorption de cette dynamique " assembléiste " et non-violente, propre à rassembler les Espagnols autour du mouvement, au profit de groupes de militants plus spécialisés, porteurs de la culture politique et des pratiques de la gauche radicale, a représenté une mutation et une mutilation $^{8}$. De l'étape fondatrice du premier mois émerge cependant une sorte d' "organigramme idéal " ainsi formalisé de façon simple dans sa version madrilène, sous forme de mode d'emploi:

- l'assemblée symbolisée par le campement de Sol essaime en assemblées de quartier tenues sur des places ou d'autres espaces ouverts;

- chaque assemblée de quartier crée librement en son sein des groupes de travail et de discussion et occupe son propre lieu;

\footnotetext{
7. L'épuisement de telles formes de mobilisation, et leur incapacité à proposer une rénovation du système politique sont pointés comme un échec prévisible par Jean-Jacques KoURLIANSKY, "Espagne, Brésil, des indignations évanescentes », Revue internationale et stratégique, n 93, 2014/1, p. 177-120. Ce chercheur souligne aussi l'absence d'horizons communs aux participants.

8. José-Luis Moreno PestañA, «Vie et mort des assemblées », La vie des Idées, 25 mars 2013 [http://www.laviedesidees.fr/Vie-et-mort-des-assemblees.htm], consulté en août 2014.
} 
— les délibérations de l'assemblée Sol se nourrissent du travail des commissions thématiques (économie, féminisme, grève générale...);

- le mouvement met sur pied des groupes de travail spécialisés (défense légale, communication, préparation d'événements) pour assurer la longévité et la protection du mouvement ${ }^{9}$.

L'articulation territoriale du mouvement, dont le périmètre était laissé à l'initiative des citoyens, se doublait donc d'une spécialisation. L'avantage de cette spécialisation fut de permettre la participation de groupes sociaux très divers, constitués sur la base d'un intérêt commun, que cet intérêt soit le goût pour des formes d'action ou celui des idées. L'inconvénient de ce mode d'organisation fut la prolifération de groupes rassemblés autour de causes très hétéroclites: la défense de la Palestine, la lutte contre les expulsions locatives, la remise en cause de la dette publique, la lutte pour la laïcité, la revendication de la mémoire historique et bien d'autres sujets d'indignation et de mobilisation. Le résultat fut aussi l'inévitable raréfaction d'une ressource capitale: le temps investi. Il va en effet de soi qu'une telle organisation dépend étroitement de la disponibilité d'espaces publics où les militants seront tolérés, mais aussi d'un travail de coordination à plusieurs étages installé sur la longue durée, et de l'utilisation d'outils de communication adaptés. Sur le plan de la coordination, il est permis de considérer que les indignés se sont quelque peu "cassé les dents ». Toutefois, ils se sont montrés prolifiques dans la mise en ligne de documents de référence destinés à leurs sympathisants et dans l'utilisation des réseaux sociaux. La radio locale du mouvement a elle aussi joué un rôle dans la mobilisation, d'autant plus que les médias dits traditionnels suscitent la méfiance des indignés. L’agenda actuel des militants démontre aussi que la tenue d'assemblées dans des lieux publics perdure sur des places, mais aussi dans des parcs ou des lieux déclarés ouverts par occupation spontanée.

Une autre dimension de cette étape initiale est désormais bien ancrée: la publicité des débats, sous forme d'ordre du jour publics et de comptes-rendus de réunions mis en ligne. On peut ainsi suivre dans la durée les hauts et les bas des différentes " marques franchisées " du $15-\mathrm{M}$, les enquêtes qu'elles lancent auprès des assemblées locales ou auprès des personnes inscrites sur leurs réseaux sociaux, tout en lisant les commentaires postés sur leurs sites. L'ensemble de ces documents

9. «Especial Aniversario 15-M », op. cit., mai 2014, p. 22. L'article rappelle la méthode d'organisation instaurée en mai 2011. 
donne corps en quelque sorte aux archives virtuelles du mouvement, certes très éclatées, souvent affectées de discontinuité et truffées de liens hypertexte vers d'autres sites de mouvements sociaux ou d'organisations connexes. Cette façon de procéder est à mettre en relation avec l'impératif de transparence maintes fois affirmé comme horizon démocratique, que l'on tente de s'appliquer à soi-même ${ }^{10}$. Comme l'ont montré par la suite les autres mouvements qui s'ancrèrent aussi symboliquement sur différentes places du monde (Place de la perle à Manama au Bahreïn; Tahrir en Égypte, Syntagma en Grèce, etc.), les outils numériques s'avèrent plus efficaces pour convoquer des manifestations réelles et pour échanger entre sympathisants que pour articuler un discours audible par l'ensemble de la société. La diffusion, l'appropriation et même la transformation des idées et des propositions exprimées par le 15-M dans la phase initiale sur la Toile et sur la Place, est un phénomène difficile à cerner. Quelle que soit l'appréciation que l'on porte sur ces idées, il faut toujours les mettre en rapport avec des formes d'action dans le monde réel.

\section{L'importance de l'expérimentation sociale}

Lorsque fut retombé l'effet euphorisant des rassemblements de foules, les indignés s'intéressèrent à d'autres mouvements sociaux organisés autour d'objectifs concrets. Ils furent ainsi partie prenante de la lutte contre les expulsions locatives, dans un contexte où les banques n'hésitent pas à chasser de leur logement de nombreuses familles frappées par le chômage, qui ne peuvent plus faire face au paiement de leurs emprunts immobiliers. Le 15-M a aussi débouché sur de nombreuses expériences collectives telles que les "banques du temps ", les coopératives de consommation, les jardins communautaires, le troc ou encore l'occupation de locaux collectifs ${ }^{11}$. Cette seconde phase allait de pair avec un certain essoufflement des formes initiales de la mobilisation, devenues plus intermittentes et moins spectaculaires. Un certain esprit demeurait, horizontal et coopératif, tel qu'on l'avait vu à l'œuvre pendant l'étape des campements sur les places. Bien que le mot ne figure pas explicitement à cette époque dans les documents militants, il s'agit d'une forme d'empowerment à l'espagnole, certes non théorisée,

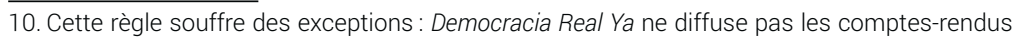
de ses discussions internes à ses membres.

11. Les banques du temps sont des systèmes d'échange locaux, de services et des compétences dans un esprit de coopération. II s'agit d'une forme élaborée de troc de services non marchands, géré par des associations ou des collectivités locales. 
mais visant clairement à l'auto-organisation. Gagner des espaces d'autonomie et s'organiser en dehors des circuits marchands peut donner à des petits groupes de personnes le sentiment de prendre leur vie collective en main, alors que le financement des associations sociales et culturelles se réduit comme peau de chagrin. Il ne s'agit cependant pas de se substituer aux défaillances de l'État-providence, les mêmes individus se trouvant engagés dans ces formes d'organisation autocentrées et dans la défense publique de droits collectifs comme l'accès à la culture $^{12}$. C'est dans cette mutation créative des mobilisations initiales, dont la force intrinsèque demeure comme moteur de la protestation mais surtout de l'engagement, que se joue la postérité du 15-M. En ce sens, le mouvement échappe aux catégorisations traditionnelles, car son indéfinition politique ne l'a pas stérilisé socialement. Elle lui a au contraire permis de durer dans l'imaginaire collectif et de porter des thèmes de mobilisation que le chercheur Jérôme Ferret, témoin et analyste de toute cette période, appelle des " universels dans le concret ", qui associent le registre protestataire aux registres économiques, associatifs et caritatifs ${ }^{13}$.

À Madrid, le 15-M s'est de même doté dès les premiers jours d'un outil culturel et militant qui porte l'emblème du Soleil (Sol) et accompagne ses actions: le chœur et l'orchestre Solfónica ${ }^{14}$. Des musiciens ont d'abord joué le quatrième mouvement de la Neuvième Symphonie de Beethoven sur la place de Neptune. Cette performance s'est répétée lors des grandes manifestations du 19 juin et du 15 octobre 2011. Les musiciens et choristes volontaires se définissent comme "le bras symphonique des marées et manifestations citoyennes ». La Solfónica est constituée d'une base de deux cents musiciens amateurs et professionnels, sans distinction. L'ensemble est à géométrie variable, réunissant vingt à quarante personnes pour certains concerts, parfois davantage pour les grands événements. Il joue aussi bien dans des fêtes de quartier, lors d'événements comme le Forum social mondial qu'à la fin de manifestations de rue dont le concert est le point d’orgue. Chacun peut télécharger les paroles des chansons et les partitions pour se familiariser avec le répertoire et chacun peut faire partie de la Solfónica, quel que soit

12. Cf. Joan SUBIRATS, Otra Sociedad, ¿Otra política? De «no nos representan » a la democracia común, Barcelona, Icaria, 2011, 104 p. Joan Subirats, professeur de sciences politiques, est l'un des porte-parole de la plateforme Guanyem Barcelona.

13. Jérôme FERRET, «Des avenirs minoritaires. Retour sur l'expérience politique des indignés espagnols », Mouvements, nº 75, 2013/3, p. 86-98.

14. Chœur Solfónica, [Solfonica.wordpress.com] consulté en septembre 2014. 
son niveau musical. La moyenne d'âge des choristes est assez élevée, ce qui peut s'expliquer par le répertoire lui-même, peu susceptible d'attirer des jeunes. Ce répertoire reprend de célèbres chansons engagées comme L'Estaca de Luis Llach, Grandola Vila Morena de José Afonso, des versions renouvelées de chants de la guerre d'Espagne, des chants populaires et des pièces de circonstance créées par et pour la Solfónica. Le clou de l'année 2013 fut la mise en scène d'un opéra-bouffe donné plusieurs fois à guichets fermés à la Tabacalera: El crepúsculo del ladrillo, le « crépuscule de la brique » en référence à la bulle immobilière et à la crise du bâtiment, sur un livret de José Manuel Naredo datant des années 1990 et une musique de David Alegre, le directeur du chœur et de l'orchestre. La vie sociale de la Solfónica repose sur ses représentations mais aussi sur les répétitions et sur des ateliers d'initiation aux nouvelles technologies. Cet orchestre et ce chœur sont l'exemple le plus visible de la survie du 15-M à Madrid, à travers la perpétuation d'un collectif de musiciens amateurs et professionnels engagés.

\section{DE L'INSURRECTION MORALE AUX PROPOSITIONS DE CHANGEMENT}

« Ni face A ni face B, on veut changer de disque ». « Nous ne sommes pas contre le système, c'est le système qui est contre nous ". "Ce n'est pas une crise, c'est une escroquerie ». " Haut les mains, c'est un contrat! ». " Rebelles sans toit ». " Mes rêves sont trop grands pour tes urnes ". " Si vous ne nous laissez pas rêver, nous ne vous laisserons pas dormir ». Quelques-uns des slogans de mai 2011 n'étaient pas politiques au sens strict du terme. Leur portée était plus large et plus indéfinie. Par la suite, l'attention médiatique s'est portée sur les protestations anticapitalistes se réclamant des indignés, et sur le slogan du mouvement Occupy Wall Street: "Nous sommes 99 \%, ils sont $1 \%$ ». Mais en Espagne, l’un des slogans les plus repris fut « No nos representan " « Ils ne nous représentent pas »), ce qui mettait davantage l'accent sur le manque de représentativité démocratique du personnel politique que sur le rejet de l'oligarchie financière mondiale. Dignité du peuple, indignité des politiques. Eux et nous, mais quel nous? Voici ce qu'énonçait le début du premier manifeste adopté par consensus pour inaugurer le campement de la Puerta del Sol:

Qui sommes-nous? Des personnes venues ici de notre plein gré, qui ont décidé de nous réunir après la manifestation pour continuer à revendi- 
quer la dignité et la conscience politique et sociale. Nous ne représentons aucun parti, aucune association. Ce qui nous rassemble, c'est l'appel au changement. Nous sommes ici en signe de dignité et de solidarité avec ceux qui ne peuvent pas être ici ${ }^{15}$.

Ainsi s’exprimaient alors les indignés, opposant un " nous » moral à cet " autre ", la classe politique. S'agit-il pour autant d'un certain " populisme »? On peut en douter. Le rejet n’était pas seulement un rejet viscéral de principe. Il prenait clairement pour cible des dysfonctionnements précis de la vie démocratique espagnole, comme on le voit dans le second manifeste adopté par l'assemblée le 20 mai $2011^{16}$. Parmi les seize propositions, figurait en premier point la modification de la loi électorale afin d'instaurer une circonscription unique dans tout le pays, des listes ouvertes et un système proportionnel. Le point 6 demandait de même que la loi électorale obligeât les partis à présenter des listes " propres " où ne figureraient pas de personnes mises en examen ou condamnées pour corruption. Le point 5 proposait " une réforme des conditions de travail de la classe politique » et prévoyait de supprimer les "salaires versés à vie " aux parlementaires, en consonance avec la perception populaire d'un personnel politique formant une caste de privilégiés. Le point 13 portait sur une séparation effective des pouvoirs exécutif, législatif et judiciaire. La moralisation de la vie publique s'exprimait au point 16, par l'exigence de transparence dans les comptes des partis et de leur financement, afin de lutter contre la corruption.

D’autres propositions ont de même été formulées sur la Toile, comme celle d'incarner les votes blancs et nuls par des sièges vides au Parlement. Le 15-M n'est donc pas un mouvement apolitique comme on a pu le dire. Il n’a pas renoncé aux idéaux démocratiques. Il a plutôt tenté d'incarner ces idéaux dans les formes de la démocratie délibérative, alors même que les partis politiques existants ont été récusés comme incapables de faire vivre ces idéaux démocratiques ${ }^{17}$. Nombre d’observateurs se considérant comme qualifiés en tant que spécialistes de sciences politiques ou en tant qu'élus n'ont pas manqué de souligner les impasses de la démocratie directe et participative prônée par le 15-M. Mais la plupart ont reconnu un malaise dans la démocratie

\footnotetext{
15. Traduction de l'auteur, pour cet extrait et tous les extraits suivants.

16. Toma la Plaza, propositions du 20 mai 2011, [http://madrid.tomalaplaza.net/2011/05/20/ propuestas-20-mayo/], consulté en septembre 2014.

17. Eduardo ROMANOS, "Les indignés et la démocratie des mouvements sociaux", La vie des idées, 18 novembre 2011, [http://www.laviedesidees.fr/Les-Indignes-et-la-democratie-des. html?lang=fr].
} 
représentative et un fossé grandissant entre les élus et la population ${ }^{18}$. La faiblesse politique volontaire du 15-M, alors bien incapable d'articuler un programme, a consisté à renvoyer dos à dos tous les partis et à ne donner aucune consigne de vote pour les élections législatives de novembre 2011. Cependant, en tant que telles, les aspirations du mouvement n'ont pas été délégitimées. Elles se retrouvent en 2014 dans le programme des partis qui se réclament de nouveaux modèles, et dans les tentatives d'aggiornamiento de partis de gauche plus classiques.

L'appel au changement s'est également incarné dans des propositions portant sur le respect des droits économiques et sociaux inscrits dans la constitution de 1978: droit au logement, à un système de santé gratuit et universel, protection des conditions de travail par la loi. Fragilisés par la crise économique, ces droits semblaient déjà remis en cause par les mesures prises par le gouvernement de José Luis Zapatero. Après les élections législatives de novembre 2011, les mobilisations incessantes contre les mesures économiques et sociales prises par le gouvernement du Parti populaire ont amplifié l'écho de ces revendications premières. D'une autre nature sont les propositions de réformer l'ordre économique existant, tant sur le plan national que sur le plan international. Le catalogue des propositions adoptées le 20 mai 2011 convergeait avec l'agenda de la gauche radicale et avec les mouvements altermondialistes: implantation de la taxe Tobin, suppression des paradis fiscaux, limitation du pouvoir du FMI et de la Banque centrale européenne.

D'autres propositions ont du sens par rapport à la crise économique espagnole: reprise des entreprises publiques privatisées, nationalisation des banques renflouées par l'État. Les marchés, le secteur bancaire et la troïka (BCE-UE-FMI) ont été voués aux gémonies, au fur et à mesure que les décisions du gouvernement du Parti populaire se faisaient plus durement sentir. Les militants du Forum social mondial de Madrid se sont d'ailleurs intéressés au 15-M. Lors de la cinquième édition du Forum en mai 2012, les assemblées populaires de Madrid et plusieurs commissions de travail du 15-M étaient invitées en tant que telles à participer à des ateliers-débats. Ce rapprochement est à mettre en rapport avec la volonté d'internationaliser la Spanish Revolution à l'automne 2011, sur des bases plus larges que les seules causes de l'indignation en Espagne. La grande manifestation du 15 octobre 2011 se voulait une manifestation mondiale.

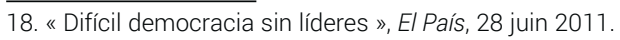


Le mouvement des indignés ne constitue donc pas un mouvement de rupture au sens révolutionnaire du terme. La définition qu'en a donnée Kike Castelló, cofondateur de la plateforme Democracia Real Ya, semble plus pertinente, quoiqu'elle demeure assez vague: celle d'un lobby de citoyens $^{19}$. Le plus intéressant est le fait que bien des Espagnols se reconnaissaient dans ce lobby de citoyens, comme l'attestent les résultats du sondage Metroscopia publiés en juillet 2011: 64 \% des personnes interrogées déclaraient avoir plutôt de la sympathie pour le 15-M; $79 \%$ déclaraient que les motifs de mobilisation du mouvement étaient fondés; $71 \%$ l'identifiaient comme un mouvement pacifique visant à régénérer la démocratie. Quatre propositions avancées par le 15 -M recueillaient entre $86 \%$ et $89 \%$ de réponses favorables: le caractère imprescriptible des délits de corruption, l'interdiction des licenciements collectifs lorsqu'une entreprise réalise des bénéfices, la restitution de l'argent public prêté aux banques et aux caisses d'épargne en difficulté, et la possibilité de solder un prêt hypothécaire en remettant son bien à l'organisme prêteur. Sur le plan politique, $59 \%$ des sondés affirmaient que le 15-M n'avait pas de tendance politique affirmée, ce qui peut être corrélé à la sympathie qu’il suscitait.

\section{LE DUR DÉSIR DE DURER: QUE S'EST-IL PASSÉ DEPUIS LE 15 MAI 2011?}

Établir une filiation entre les formes de mobilisation initiales de 2011 et les formes de mobilisation ultérieures n'est pas une tâche facile. Cette généalogie reste à faire en écrivant une histoire documentée des mouvements sociaux, à partir d'archives et d'entretiens. Concluons à un héritage provisoire, car le dernier mot n'est pas encore dit. Cet héritage se manifeste par la permanence de formes qui relèvent de la philosophie de l'action. Il se lit aussi, plus difficilement, dans l'articulation entre des revendications sociales et des initiatives politiques ${ }^{20}$.

\section{L'appropriation de l'espace public: assemblées, manifestations, marées, marches}

La continuité la plus visible entre ce mois de mai inaugural et la suite des événements est la réappropriation de l'espace public par les

19. «A relaxing cup of democracia », Tinta Libre, nº 16, juillet-août 2016, p. 5.

20. Pour une analyse des suites du mouvement, consulter « Rebelión a bordo », Tinta Libre, $n^{\circ}$ 1, mars 2013, p. 20-21 et le numéro spécial « Rebelión ciudadana contra las élites », Tinta Libre, nº 16, juillet-août 2013. 
Espagnols. Le campement, bête noire des autorités, ressurgit souvent, échouant presque toujours. Mais l'assemblée en plein air demeure. Places, coins de rue, parcs, figurent sur les agendas de réunions. À l'automne 2012, des enseignants et des étudiants protestant contre l'asphyxie budgétaire ont donné des cours dans la rue, ouverts au public. Des lieux de substitution sont recherchés pour une occupation pacifique épisodique ou permanente, permettant d'associer des temps de délibération à la préparation d'actions et d'organiser des manifestations culturelles. À Madrid, l'édifice désaffecté de la Tabacalera, une ancienne manufacture des tabacs, et l'espace appelé Patio Maravillas, une sorte de maison de quartier autogérée, sont représentatifs de tels espaces. Mais il faut sans cesse renégocier leur disponibilité avec les autorités locales ou les propriétaires privés, ce qui les fragilise. En outre, ils sont moins neutres que l'espace public ouvert à tous. La caverne protectrice, l'antre des militants n'est pas la place ouverte aux passants.

\section{Diversification et convergence des manifestations}

La manifestation demeure au centre du répertoire d'action du mouvement, qu'elle réunisse des centaines, des milliers ou des centaines de milliers de personnes. L'idéal-type de la manifestation héritière du 15-M est une manifestation transversale aux différents mouvements sociaux, qui entend porter une protestation globale contre le système politique en place et le modèle économique néolibéral. Les manifestations anniversaires du 15-M et les manifestations convoquées sur des mots d'ordre large de refus des mesures gouvernementales correspondent à cet idéal-type. La démission du gouvernement du Parti populaire a été un mot d'ordre souvent entendu. À partir de l'automne 2012 se sont enchaînées des manifestations qui se situaient sur un axe continu entre les défilés syndicaux et les rassemblements populaires: les "marées". La "marée blanche " aura été une plateforme, un collectif de syndicats, d'associations, d'usagers de santé, de comités de quartier et d'assemblées et de commissions du 15-M. Dans la communauté autonome de Madrid, la marée blanche se mobilisa contre la privatisation annoncée de six hôpitaux et la fermeture de services hospitaliers. L'assemblée du 15-M de Madrid déclare s’y être systématiquement associée. À partir de l'automne 2012, et pendant toute l'année 2013, les mobilisations, les grèves, les rassemblements et les manifestations se sont multipliés. Le blanc, couleur des uniformes de travail, est aussi celui des draps que suspendirent les Madrilènes au balcon en solidarité avec ce mouvement. 
Ce distinctif par couleurs a été utilisé par d’autres mouvements et collectifs à géométrie variable: " marée verte " des travailleurs et usagers de l'Éducation; " marée violette » des mouvements féministes; " marée grenat » des Espagnols ayant émigré pour chercher du travail; " marée jaune " pour défendre les bibliothèques publiques, etc. Même les Iaoflautas se sont rapidement inventé un uniforme, portant des gilets jaune fluo lors de toutes leurs actions publiques. Pendant l'étape de préparation des marches de la dignité de mars 2014, une plateforme numérique intitulée "marée citoyenne" a vu le jour, pour tenter d’organiser la convergence de toutes ces marées sur l'ensemble du territoire $^{21}$. Mais que signifie réellement le fait que plus d'une trentaine d'assemblées du 15-M aient " adhéré » à cette plateforme virtuelle? Une petite centaine de personnes seulement a pris la peine de répondre à une enquête en ligne sur la plateforme à propos de leurs attentes, des priorités à dégager et des raisons de l'essoufflement du mouvement social. Ce qu'il faut retenir de ces tentatives de fédérer des initiatives déjà pluralistes par nature, c'est la nostalgie de l'instant fondateur, du creuset de Sol. Il est permis de se demander si cette aspiration à la fusion des mouvements de protestation et à leur débouché " total " ne vient pas pallier la difficulté à articuler un projet de nature politique. Mais certaines formes de mobilisation sont plus directement politiques car elles s'en prennent aux symboles du pouvoir.

\section{Occupations, obstructions}

Après les élections municipales de mai 2011, des militants se réclamant du 15-M se sont réunis devant les mairies pour perturber l'installation de nouveaux conseils municipaux. D'autres ont cherché à y pénétrer pour dire leur fait aux élus: "Ils ne nous représentent pas ». Suivre les ordres du jour de certaines assemblées du 15-M permet de voir que ces actions ont évolué vers un " contrôle citoyen " plus pacifique des conseils municipaux. Tout simplement, les personnes intéressées utilisent leur droit d'assister au conseil municipal pour connaître ses décisions et délibérations. Ces lieux de la représentation, après avoir été conspués, attirent ainsi une partie des héritiers du 15-M comme autant de lieux d'expérimentation politique. " Prendre d'assaut les institutions ", slogan en soi vide de sens, devient en 2014 un slogan plus ouvert sur un projet politique. En sera-t-il de même du Congrès? Certains groupes militants avaient inauguré cette forme d'action en

21. Appel de la marée citoyenne, [Mareaciudadana. blogspot. fr], consulté en août 2014. 
entourant le parlement de Catalogne le 15 juin 2011 pour empêcher les députés d'y pénétrer, ce qui entraîna la mise en examen et le procès de plusieurs personnes. À partir de septembre 2012, des actions répétées visant à " entourer le Congrès des députés " se sont déroulées à Madrid, vite bloquées par les forces de l'ordre. Ce lieu est devenu un abcès de fixation, à conquérir pour les manifestants qui protestent contre les projets de loi à défendre du gouvernement. Les alentours du Congrès furent maintenus sous haute surveillance et plusieurs affrontements se produisirent à proximité. À défaut de s’y faire représenter, les opposants extra-parlementaires ont perturbé ce symbole de la démocratie parlementaire. À court d'arguments pour la défendre et la rénover, les tenants du pouvoir l'ont protégé manu militari.

D'autres lieux, représentatifs du pouvoir économique et de la faillite des familles et des individus, ont été occupés par de petits groupes constitués dans cet objectif: des banques, notamment les banques renflouées par l'État, dont les pertes ont été socialisées, mais aussi toutes les banques ayant vendu des actifs douteux, et causé la ruine de nombreux petits épargnants, comme celles qui ont participé au scandale des Preferentes. Entrer dans une agence bancaire, s'y maintenir pacifiquement pendant un moment, chanter des slogans et des chansons, filmer l'opération: c'est une forme d'action récurrente que se sont appropriés les Iaioflautas pour dénoncer la spoliation des retraités dont l'épargne s'est volatilisée à cause de pratiques bancaires frauduleuses. Ces actions, comme celles qui ont été inventées par la Plataforma de Afectados por la Hipoteca et son collectif d'action Stop Desahucios ("Stop aux expulsions ») ont frisé l'illégalité tout en se voulant non-violentes. Cette limite entre légalité, illégalité et légitimité est élaborée et justifiée par des personnes appartenant aux mouvements sociaux, par des blogueurs, et plus généralement parlant, par les médias alternatifs, en réponse au pouvoir ou aux médias hostiles à de telles actions. Il s'agit d'opposer la justice sociale incarnée au droit positif. Le slogan du 15-M: " Nous ne sommes pas contre le système: c'est le système qui est contre nous ", a ainsi connu de nombreux avatars, tandis que le mot d'ordre du groupe militant " Désobéissance civile " fait désormais florès dans les documents militants d'autres organisations.

\section{Défense des libertés fondamentales}

Pour bien comprendre la postérité du 15-M et ses mutations, il faut bien avoir à l'esprit la conjoncture politique: en novembre 2011, l'élection d'un gouvernement de droite qui a mené une politique économique 
dure, remit en cause les droits sociaux et opéré des coupes claires dans les budgets publics. Au fur et à mesure que ce gouvernement s'est vu contesté dans la rue, il a contre-attaqué en essayant de décrédibiliser son opposition extra-parlementaire. Il a eu de plus en plus fréquemment recours aux charges policières, aux coups de matraque, aux gaz lacrymogènes, à la vidéosurveillance, aux interpellations et aux inculpations. De ce fait, une nouvelle cause de mobilisation a émergé, celle de la dénonciation des violences policières et de la criminalisation du mouvement social. Les militants se sont organisés pour assurer la défense légale des personnes mises en examen et pour payer collectivement les amendes infligées. Le durcissement annoncé du code pénal et le projet de loi sur la "sécurité des citoyens » ont fait naître le mot d'ordre et la plateforme "Nous ne sommes pas un délit ${ }^{22}$. Les libertés fondamentales sont jugées menacées. Cette escalade n’a pas donné lieu à un changement de tactique de la part des mouvements organisés s'exprimant dans la rue. Le credo non-violent du 15-M n'a pas été altéré. Cependant, lorsque des groupes organisés violents saisissent des occasions d'affrontement délibéré en venant se greffer sur les mouvements pacifiques, comme cela arrive quelquefois, le risque d'amalgame est grand. Le spectre de la mouvance de l'ETA ou celui de mouvements manipulés de l'extérieur par le Venezuela chaviste sont faciles à brandir par la droite conservatrice, comme celui d'une certaine jeunesse violente et incontrôlable. Ainsi, au printemps 2014, alors que la préparation des marches de la dignité et les marches elles-mêmes n'avaient pas fait l'objet d'une couverture importante par les grands médias, ces mêmes médias ont amplement répercuté le dénouement violent de la manifestation organisée en point d'orgue à ces marches.

\section{Le rôle de Juventud Sin futuro}

Tous les motifs de protestation qui ont poussé les jeunes de Juventud Sin Futuro à descendre dans la rue le 7 avril 2011 demeurent. Chômage, précarité, déqualification, faibles revenus, difficultés de logement sont toujours le lot d'une grande partie de la jeunesse espagnole. Un rapport récent du Conseil de la jeunesse d'Espagne, un organisme consultatif créé par les pouvoirs publics, a été mis en valeur par Juventud Sin Futuro $^{23}$. Il dépeint le sort des jeunes de 16 à 29 ans à partir de leur

\footnotetext{
22. "Nous ne sommes pas un délit », [nosomosdelito. net], consulté en septembre 2014. 23. Félix TABERNA et Luis CAMPos, Informe sobre calidad, empleo joven, becarios y prácticas, Consejo de la Juventud de España, 2014, 128p, [http://www.cje.org/descargas/cje5465.pdf].
} 
situation vis-à-vis de l'emploi. Les statistiques mettent l'accent sur des conditions d'emploi dégradées aussi bien du point de vue du statut et du contrat que de la rémunération. Les conclusions sont sans appel: les jeunes sont le groupe d'âge qui a le plus souffert des répercussions de la crise sur l'emploi. Beaucoup d'emplois occupés par les jeunes ont été détruits; les contrats à temps partiel ont augmenté; 4,6\% des jeunes déclarent même travailler sans contrat. L'enquête révèle que sept jeunes sur dix occupant un emploi vivent encore chez leurs parents, et que $54 \%$ d'entre eux déclarent ne pas pouvoir s'émanciper grâce aux revenus de leur travail. Par ailleurs, $35 \%$ d'entre eux répondent qu'ils s'attendent à devoir émigrer pour trouver un emploi ${ }^{24}$.

Les réponses concernant la qualité des emplois occupés par rapport au niveau d'études mettent l'accent sur une insertion très insatisfaisante des jeunes diplômés et sur un véritable gaspillage de ressources humaines et de talents. Le mouvement Juventud Sin Futuro propose des explications à cette situation. Il y voit l'effet des arbitrages effectués en temps de crise, défavorables aux jeunes. Ainsi, les possibilités d'accès aux études universitaires et les conditions d'études se sont-elles dégradées en Espagne, alors qu'une forte proportion de jeunes veut continuer à se former pour améliorer ses chances. Sans surprise, la responsabilité de cet avenir bouché est rejetée sur le gouvernement et sur la classe politique en général, mais aussi sur "les oligarchies économiques et financières ». Le discours est avant tout un discours de dénonciation globalisant, qui néglige les distinctions entre différentes catégories de la jeunesse et les causes structurelles du chômage des jeunes. Mais quelles sont les formes d'action du mouvement?

Le mouvement a pris par surprise les médias qui se sont intéressés à son apparition initiale dans les rues des villes espagnoles le 7 avril 2011. En effet, la jeunesse espagnole était plutôt jugée conformiste, voire résignée, en tout cas acculturée à l'individualisme. Bien vite éclipsé par le 15-M dont il fut l'un des initiateurs, ce mouvement n'a pas disparu pour autant. Il resurgit régulièrement dans l'espace public en lançant des campagnes qui réaffirment le sens de son mot d'ordre: « Sans toit, sans boulot, sans peur ». Celle qui a eu le plus d'impact sur les jeunes et sur l'opinion

24. Sandra Gaviria étudie les politiques de la jeunesse et du logement en Espagne sur le long terme. Elle souligne que la crise a bloqué l'accès à la propriété pour les jeunes Espagnols, modèle le plus acceptable culturellement, alors même que les aides au logement locatif sont insignifiantes. Le retard à l'émancipation, qui d'après elle n'est pas imputable principalement à des facteurs économiques, se trouve de fait aggravé par la dégradation de la situation économique. Cf. Sandra GAVIRIA, « Politique de logement et autonomie résidentielle de la jeunesse en Espagne », Informations sociales, nº 1656 166, 2011/3-4, p. 146-154. 
publique a marqué le deuxième anniversaire du mouvement. Au printemps 2013, Juventud Sin Futuro a appelé les jeunes Espagnols ayant émigré pour trouver un emploi à témoigner en tant qu'exilés, en insistant sur ce terme d'exil. " Nous ne partons pas, ils nous jettent », tel était le slogan de cette campagne. En deux mois, 7000 témoignages ont été recueillis et le site de la campagne a mis en ligne une carte détaillant la présence de ces jeunes exilés dans le monde. Le point d'orgue de la campagne, coordonnée sur les réseaux sociaux, fut un ensemble de manifestations et de rassemblements organisés le 7 avril 2013, non seulement en Espagne mais dans d'autres villes européennes, et même au-delà. La galerie de photos de jeunes arborant des pancartes, postée sur le site de la campagne, illustre bien le refus de considérer l'émigration comme le choix de la mobilité professionnelle, une interprétation avancée à la légère par certains responsables politiques. À l'automne 2014, Juventud Sin Futuro s'associe à une campagne lancée par le Conseil de la jeunesse d'Espagne: " Jeunesse migrante. Regardons du côté de chez nous ». Il s'agit à nouveau de réunir des témoignages de jeunes exilés pour la date du 8 novembre 2014, "jour de la jeunesse européenne». Ce lien noué avec de jeunes compatriotes à l'étranger, comme la reconnaissance d'une communauté de destin avec d'autres mouvements de jeunes précaires au Portugal et en France, constitue peut-être l'embryon de nouvelles formes d'organisation de la jeunesse européenne. L'espace de socialisation perdu ou fermé dans le monde du travail serait en partie compensé par des formes inédites de sociabilité générationnelle protestataire.

La ligne du mouvement n'est pas arrêtée, sauf celle d'une indépendance revendiquée par rapport aux partis de gauche représentés au Parlement. Est-ce à dire que ce mouvement serait l'expression d'un noyau de jeunes militants refusant toute forme d'engagement politique? Les longs entretiens qu'ils donnent à des médias sympathisants tendent à le démentir ${ }^{25}$. Reconnaissant que leurs rangs comptent des militants venus de partis de gauche et de mouvements sociaux « traditionnels ", ils expriment pourtant leur défiance vis-à-vis d'une parole dogmatique et surplombante, des détenteurs de vérité et des avantgardes politiques. L’acquis du 15-M est rappelé: partage entre générations, pluralisme, formes labiles de mobilisation, formes nouvelles de dynamisation collective. La possibilité de construire une alternative à

25. « No nos vamos, nos echan. Entrevista a Juventud Sin Futuro », Relaciones Internacionales, n 24, GERI/Universidad Autónoma de Madrid, octobre 2013-janvier 2014, disponible à l'adresse [http://www. academia. edu/4987169/_NoNosVamosNosEchan_Entrevista_a_ Juventud_Sin_Futuro]. 
partir du bloc des mécontents s'exprime aussi bien plus nettement que la volonté de tourner le dos à la société: Juventud Sin Futuro ne joue pas sur la connotation nihiliste de son nom.

\section{L'avenir politique du 15-M}

Il est indéniable que le succès électoral de Podemos a changé la donne politique en Espagne. Les partis politiques ont été obligés de se repositionner par rapport à ce nouveau venu, qu'ils soient en position dominante ou minoritaire. Par ailleurs, ce succès a agi comme un révulsif sur les personnes et les groupes qui se reconnaissent dans les idéaux du 15-M. Une partie des électeurs de Podemos se sont remobilisés et sont redevenus des militants, faisant de nouveau fructifier leur capital social. Quel était leur horizon à l'été 2014? Ils pouvaient rejoindre les cercles de Podemos et préparer l'Assemblée citoyenne prévue à l'automne, sous l'égide de l'équipe de travail élue par un mécanisme de participation citoyenne (55882 votes exprimés en ligne pour désigner 26 responsables). Ils s'investiraient alors dans la construction d'un nouveau parti politique. Certes, ce parti affichait son intention de faire de la politique " autrement ", mais il se distinguait fortement des idéaux du 15-M sur plusieurs points essentiels: un leadership personnel assumé, celui de Pablo Iglesias, entouré de personnalités déjà présentes lors de la campagne pour les élections européennes; une stratégie médiatique décomplexée; un grand appétit pour les échéances électorales. Du 15-M, Podemos reprend certains idéaux démocratiques (transparence, contrôle des élus, moralisation de la vie politique), mais son langage politique est beaucoup plus musclé. Le document politique soumis à la discussion des sympathisants et ouvert aux amendements (comme le document portant sur l'éthique, et celui portant sur l'organisation) est très corseté par l'esprit de la gauche radicale de rupture, tout en faisant montre d'un opportunisme politique manifeste. Le document se place en surplomb par rapport au 15-M et à la période consécutive:

Le 15-M a donné un coup de vieux aux élites et aux récits officiels, dévoilant l'épuisement de leurs consensus, de leurs certitudes, des cadres servant à distribuer les positions et à expliquer le rôle de chacun dans le contrat social, ou à canaliser les demandes des citoyens. Mais cette accumulation de petites transformations culturelles n'a pas touché tout le pays et n'a pas modifié l'équilibre des forces électorales et institutionnelles ${ }^{26}$.

26. Podemos, « Pre-Borrador político. La crisis del régimen de 1978, Podemos y la posibilidad de cambio político en España », [Podemos. info], 5p., consulté en septembre 2014. 
L'analyse du moment historique est beaucoup plus centrée sur le rapport de forces politiques que sur les aspirations des mouvements sociaux. Le parti se place en "challenger " et en "outsider " placé désormais au centre du jeu. Il entend construire un "appareil discursif, politique et électoral » en élargissant sa base, afin de profiter de la fenêtre d'opportunité que représente la crise du régime hérité de 1978. Il ne s'arrête pas aux élections municipales mais s'inscrit dans le long terme pour construire une autre majorité. Un tel positionnement doit très peu au 15-M. D’ailleurs, le réseau des universitaires engagés de l'université Complutense de Madrid aura joué un rôle plus important dans la gestation du parti que l'expérience du 15-M. La composition de la liste de candidats pour les élections européennes, puis de la liste de l'équipe de travail présente toutefois un mélange de personnalités qualifiées par leur notoriété universitaire et/ou médiatique, de militants de Juventud Sin Futuro et de nouveaux-venus en politique.

\section{L'avènement du " municipalisme "}

Une autre dynamique s'est ouverte à l'été 2014, dont l'étiquetage est le terme de "municipalisme ". Des plateformes citoyennes se sont constituées en vue des élections municipales de mai 2015, pour entrer dans la compétition électorale. Gagnons Barcelone, Madrid, la Corogne, Valladolid, Murcie, etc. Les différents manifestes qui président à ces initiatives sont assez voisins et ressemblent bien davantage aux textes produits par la mouvance du 15-M qu'à ceux de Podemos. Il s'agit d'incarner les idéaux du renouveau démocratique dans l'espace local, en rassemblant des citoyens organisés et d'autres inorganisés pour leur "rendre la ville ». La conversion à la stratégie politique ne s'est pas faite sans mal, comme le montrent les premiers manifestes municipalistes de Madrid qui ont débouché sur la constitution de la plateforme Ganemos Madrid. On y sent une véritable hésitation sur le sens donné à des expressions comme " prendre d'assaut les institutions ", et un mouvement de recul devant la démocratie représentative:

Le défi consiste à reprendre le projet de démocratie territoriale du 15-M, les élections ne représentant qu'une ressource parmi d'autres de ce pouvoir démocratique. En définitive, nous comprenons la politique institutionnelle comme un espace de conflit parmi d'autres et de mise en lumière des tensions qui traversent nos villes ${ }^{27}$.

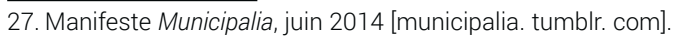


Même après le lancement de la plateforme, alors que le programme de gouvernance municipale est déjà dans une phase avancée d'élaboration, et que les contacts se nouent avec d'autres formations politiques, le groupe de travail intitulé « mouvement municipaliste " reste dans une certaine ambivalence:

Trop souvent, il y a eu confusion entre l'imaginaire de l'assaut institutionnel [...] et la prise pure et simple du pouvoir. Loin de cette image, tout mouvement municipaliste qui entend avoir une présence institutionnelle doit concevoir son rôle de façon inverse. Il faut comprendre le municipalisme comme une façon d'ôter le pouvoir aux institutions et de le rendre aux mouvements ${ }^{28}$.

Une expression se propage dans les entretiens, les déclarations, les textes à propos de ces plateformes. On se réclame de "l'ADN du 15-M ». Que signifie une telle expression? Que les sympathisants et militants se donnent rendez-vous sur les places? Que se reforment des groupes de travail et des commissions chargés de la logistique, de la communication, de la méthodologie? Que les documents de travail et les procès-verbaux de réunions sont disponibles sur la Toile? Que les plateformes se réclament des collectifs, marées, marches, associations locales et « des gens comme toi et moi »? Que l'on retrouve exprimée la même aversion pour les partis politiques dominants, les politiciens véreux, l'autoritarisme? Qu'on y proclame le même amour des biens publics, des biens communs, de l'égalité entre citoyens? Qu'une dynamique d'empowerment désormais explicitement reconnue et revendiquée est à l'œuvre?

Sans doute, mais il y a aussi des groupes de travail " candidatures" et le travail de rapprochement avec les partis d'alternance, y compris Izquierda Unida, est engagé. Les porte-parole de ces plateformes, qui restent autonomes les unes par rapport aux autres, reconnaissent vouloir surfer sur l'effet Podemos et en attirer les militants, car le parti a décidé de ne pas se présenter directement aux élections municipales pour ne pas altérer son capital politique national. C'est dans le discours du rassemblement que se lit le mieux l'héritage du 15-M. La délibération est investie comme forme démocratique nécessairement productive politiquement. Cependant, la construction d'une proposition politique demande d'autres ressources et oblige à choisir ses alliés. Le mot de "marque blanche" utilisé pour définir ces plateformes citoyennes qui refusent le modèle de la coalition multipartite est un élément de

28. Document du groupe de travail « Municipalisme, version 3.0 », [ganemosmadrid. info], consulté en septembre 2014. 
marketing politique. Il désigne aussi le dernier moment où l'illusion d'une limite nette entre " eux et nous " persiste, la blancheur renvoyant à une forme d'innocence. « Tout commence en mystique et finit en politique ", disait Charles Péguy ${ }^{29}$.

29. Charles PÉGuY, Notre jeunesse, Paris, Gallimard, 1910 [1993]. 


\title{
TROISIÈME PARTIE
}

\author{
DE LA CRISE \\ SOCIALE À LA CRISE \\ INSTITUTIONNELLE \\ ET POLITIQUE
}





\title{
8 \\ Le droit au logement et la lutte contre les expulsions: la Plataforma de Afectados por la Hipoteca
}

\author{
Mathieu Petithomme \\ M. Rajoy, il n'est jamais trop tard pour rectifier. \\ N'ayez pas peur des sifflets, n'ayez pas peur de la population. \\ Descendez dans la rue et parlez avec les gens. \\ Faites justice et arrêtez les expulsions. \\ Il y a des vies en jeu qui ne peuvent plus attendre. [...] \\ Nous, les gens, les citoyens d'en bas, nous n'avons pas les \\ mêmes moyens pour faire valoir nos droits. \\ Mais nous avons l'arme la plus puissante de toutes. \\ Contre le jeu sale du système, la force de la raison et du coeur. \\ (Ada Colau et Adrià Alemany ${ }^{1}$ )
}

Carmen Martínez Ayuso est âgée de 85 ans et vit seule dans son appartement avec sa petite retraite de 630 euros par mois, au numéro 10 de la rue Sierra de Palomares dans le quartier populaire de Vallecas à Madrid. Femme de ménage durant toute sa vie, elle a perdu son mari d'un cancer de la gorge il y a sept ans. Mais le 25 novembre 2014, elle a été expulsée de son logement car elle s'était déclarée garante avant la crise du prêt de 40000 euros de son fils unique, qui s'était endetté auprès d'un particulier pour créer un commerce ${ }^{2}$. Ce dernier est depuis au chômage et sans possibilité de rembourser sa dette qui atteint désormais 77000 euros en raison des taux d'intérêt et des frais d'impayés. Le particulier s'est donc retourné contre la garante, sa mère de 85 ans, et suite à l'accord de la justice, la police l'a expulsée de son logement, dont la valeur est estimée à 160000 euros. Grâce à la mobilisation de ses voisins et à l'intervention militante des membres de la Plataforma de Afectados por la Hipoteca (« Plateforme des affectés par l'hypothèque », PAH), elle

1. Ada Colau et Adrià Alemany, jSi se puede!, Barcelona, Ediciones Destino, 2013, p. 5.

2. Luis Javier GonZÁLEZ, « Una anciana de 85 años, desahuciada por avalar un préstamo de su hijo », El País, 21 novembre 2014, p. 12. 
a été relogée depuis lors. De généreux voisins et donateurs ont accepté de l'aider à payer son loyer, les footballeurs du Rayo Vallecano, club local de la Liga, ont apporté une aide financière, et face à l'indignation créée par son expulsion, la mairie de Madrid a décidé de traiter son cas de façon prioritaire pour lui permettre rapidement d'obtenir un logement social. Mais depuis 2008, tous les Espagnols n'ont pas eu cette chance ${ }^{3}$.

Pour s'opposer à ce type de drames individuels et venir en aide aux personnes menacées d'expulsion, le "collectif V " de Vivienda ( logement ») fut créé en mai 2006, puis déboucha sur la formation en février 2009 du mouvement citoyen de la PAH, impulsé par Ada Colau et Adrià Alemany à Barcelone. Depuis lors, ce collectif a créé de nombreuses antennes dans les villes moyennes et les grandes métropoles d'Espagne. Ses militants ont paralysé plus de 1135 expulsions et relogé environ 1180 personnes dans des logements occupés, avant d'obtenir parfois la légalisation de ces occupations en échange du paiement d'un " loyer social » aux banques ${ }^{4}$. La PAH dénonce la loi hypothécaire espagnole, d' "inspiration médiévale " selon certains, qui protège très peu les acheteurs, et milite pour la suppression des clauses abusives dans les contrats de prêts immobiliers ${ }^{5}$. De 2007 à 2014, la PAH a recensé plus de 500000 procédures d'expulsions en Espagne ${ }^{6}$. Dans un pays où le chômage touche presque 6 millions de personnes, 1,7 million de familles survivent avec l'ensemble de leurs membres sans emploi ${ }^{7}$.

Mais il existe pourtant environ 3,5 millions de logements vides sur l'ensemble du territoire. Dans un tel contexte de crise économique et de paupérisation, la PAH lutte pour le droit au logement dans un pays où il n'y a jamais eu autant d'expulsions. Au-delà de ses actions d'interposition pour paralyser les expulsions, la PAH renégocie des centaines de prêts immobiliers frauduleux avec les banques, dépose des plaintes et des recours devant les tribunaux, fait pression sur les pouvoirs publics et milite pour le développement du logement social, très peu étendu en Espagne. Par leurs actions concrètes et profondément ancrées dans leur quartier, les militants de la PAH luttent pour la justice sociale. Comme

3. Ana Pérez BARREDO, «El desahucio de Carmen desata un red de solidaridad dentro y fuera del barrio », El País, 25 novembre 2014, p. 7.

4. Ces chiffres sont fournis par la PAH sur son site internet, cf. [http://afectadosporlahipoteca. com/stop-desalojos], consulté le 10 novembre 2014.

5. Expression employée lors d'un entretien par Jordi, 34 ans, chômeur et militant du collectif de Barcelone, 7 novembre 2014.

6. Entretien avec Ada colau, Regards, 15 avril 2014.

7. Selon les données de la Fondation FoEsSA (liée à l'association chrétienne Caritas), VII Informe sobre exclusión y desarrollo social en España, Madrid, 2014, p. 2. 
l'énonce Alfonso, un militant de Barcelone: «La PAH dénonce les abus et les manipulations des banques et des entités financières. Notre objectif est d'instaurer une "démocratie réelle" par le bas, où le droit au logement, pourtant inscrit dans notre constitution, serait enfin respecté ${ }^{8}$."

Comment la $\mathrm{PAH}$, à travers le mouvement social qui s'est organisé dans son sillage, contribue-t-elle à la défense des citoyens et au progrès social? Ce chapitre se fonde sur une enquête de terrain menée en novembre 2014 au sein des collectifs de la PAH de Barcelone et de l'Hospitalet de Llobregat. En assistant à plusieurs assemblées hebdomadaires, à des actions d'occupation, et en m'entretenant directement avec plus d'une vingtaine de militants, j'ai cherché à appréhender de l'intérieur la structuration, le fonctionnement, les principales revendications, et la sociologie de ces collectifs. Ce chapitre montre comment la $\mathrm{PAH}$, tout en politisant les enjeux du droit au logement et de la responsabilité des banques dans la crise, s'inscrit pleinement dans le mouvement social anti-austérité et a contribué à sensibiliser l'opinion publique et à mettre ces questions sur le devant de la scène politique.

Le chapitre se structure en quatre temps. À travers la trajectoire biographique de Manuel, un membre du collectif du quartier Nou Barris menacé d'expulsion, la première partie exemplifie puis synthétise la spirale de la paupérisation, vécue par de nombreuses familles en Espagne depuis 2008, en insistant sur l'économie politique des prêts bancaires. La deuxième partie s'intéresse plus en détail à la structuration territoriale et au fonctionnement quotidien de la $\mathrm{PAH}$, de même qu'à son insertion dans le mouvement social anti-austérité. La troisième partie présente ses principales revendications, puis la quatrième ses stratégies d'action collective, qui usent habilement du droit et de la force du nombre. Enfin, la conclusion propose une réflexion synthétique sur la contribution du mouvement à la défense des droits des citoyens et au progrès social.

\section{CRISE DU DROIT AU LOGEMENT ET LUTTES COLLECTIVES}

\section{" Dernier toit avant liquidation "}

Mardi 11 novembre 2014 sur l'avenida Rambla à Barcelone, un militant de la PAH brandit une pancarte avec une photographie de son

8. Alfonso, 42 ans, professeur d'espagnol dans le secondaire et militant de la PAH, local du mouvement, Barcelone, 12 novembre 2014. 
appartement et ce slogan: " Dernier toit avant liquidation ». Il s'appelle Manuel Vicentero, Équatorien d'origine. Il a 42 ans, une femme et deux enfants, et vit depuis 2002 à Nou Barris, un quartier populaire périphérique de la ville. Depuis deux mois, il est menacé d'expulsion. Son cas est en appel devant les tribunaux. "Chaque jour, en ouvrant ma boîte aux lettres, j'ai peur pour ma famille ", me dit-il ${ }^{9}$. Maçon depuis son arrivée en Espagne, il travaillait cinq jours par semaine de 8 heures à 18 heures plus une à deux heures de transport aller-retour en moyenne pour 950 euros par mois. En 2004, ses enfants et sa femme, qui a tout de suite trouvé un emploi comme agent d'entretien, ont pu quitter l'Équateur pour le rejoindre. En 2005, ils ont acheté un petit trois pièces de $40 \mathrm{~m}^{2}$, lorsqu'est née Linda, leur fille. En 2007, ils ont été naturalisés espagnols grâce à la loi facilitant l'acquisition de la nationalité pour les ressortissants des pays hispanophones. Puis Jaime est né en 2008. Une trajectoire exemplaire d'intégration. Mais suite à la naissance de leur fils, sa femme n’a pas retrouvé de travail. La récession était passée par là.

Les employeurs ont gelé les embauches. Dans l'entreprise familiale où il travaillait, des dix employés d'avant la crise, il ne restait plus que lui, son patron et son fils. Il a dû accepter une diminution de salaire: 700 euros par mois en travaillant de 8 heures à 14 heures le samedi en plus. Mais l'entreprise a quand même fini par mettre la clé sous la porte en juin 2012. Pendant deux ans, il est resté au chômage. Il touche désormais "la ayuda", l'aide équivalente au RMI français: 450 euros plus 40 euros par enfant, soit 540 euros pour faire vivre une famille de quatre personnes, dont une fille de neuf ans et un fils de six ans. Sa femme ramène jusqu'à 200 euros par mois en s'occupant d'une personne âgée au noir, mais ses revenus ne sont pas fixes. Depuis juillet 2014, il ne peut plus payer les 290 euros mensuels de son prêt immobilier. Il a pourtant tout fait pour: se serrer drastiquement la ceinture; utiliser ses économies patiemment constituées depuis son arrivée en Espagne en 2002; vendre certains meubles. Il a tenté de renégocier son prêt pour allonger sa durée en échange d'une réduction de sa mensualité. Mais sa banque n'a rien voulu savoir et a entamé une action en justice et une procédure d'expulsion contre lui.

Comme Manuel, ils sont plusieurs dizaines à occuper l'agence de Bankia depuis $8 \mathrm{~h} 45$ en cette matinée d'automne. Personnes menacées

9. L'ensemble des informations ci-dessous sont issues de cet entretien avec Manuel Vicentero, 42 ans, Équatorien nationalisé espagnol, membre de la PAH, 11 novembre 2014, Barcelone, puis de l'observation participante de la manifestation de la PAH, le même jour, contre l'agence Bankia. 
d'expulsions, militants ou sympathisants de la PAH, Espagnols pour la plupart, immigrés pour certains, ils cherchent à rencontrer le directeur de l'agence bancaire afin d'ouvrir un processus de négociation pour obtenir l'allongement des dettes des personnes affectées ou le solde de celles-ci en échange du don de leur bien à la banque. Vêtus de teeshirts verts avec le logo du collectif, ils font du bruit avec des casseroles et entonnent des slogans: "Stop aux expulsions! "; "Bankia, voleurs. Rendez-nous notre argent! "; "Cette banque met des gens à la rue »; " Ton taux d'intérêt m'a tué ». Face à l'absence de réponse des dirigeants à leurs nombreuses lettres de demande de dialogue, ils ont choisi de porter atteinte à "l'image de marque " de la banque. D'autres distribuent des tracts et ont monté un stand devant l'agence sur l'une des avenues les plus touristiques de Barcelone. Les passants et les touristes curieux sont de plus en plus nombreux. À 10 heures, pour éviter le scandale, le directeur délégué de l'agence accepte de discuter avec un représentant de la PAH en échange de la fin de l'occupation. La première bataille est gagnée. Mais les négociations, qui durent souvent des semaines, sont loin d'avoir abouti. Après la force dissuasive de l'occupation et de la dénonciation, il faudra faire valoir le poids des arguments.

\section{La spirale de la paupérisation: « de la précarité à l'expulsion, il n'y a qu'un pas »}

Depuis 2008, alors même que l'Espagne est le pays européen où les inégalités sociales ont le plus progressé, plus de cinq cent mille personnes, locataires ou propriétaires, ont été expulsées de leur logement, la plupart du temps sans proposition alternative de relogement par les pouvoirs publics et les mairies ${ }^{10}$. Cinq millions de personnes vivent aujourd'hui en "situation sévère d'exclusion " et 728300 familles ne reçoivent aucun argent ni prestation sociale ${ }^{11}$. Parallèlement, le nombre de millionnaires (465000 en 2014) a augmenté de $24 \%$ en seulement deux ans depuis 2013, et les revenus des $10 \%$ les plus riches n'ont pas changé depuis 2008, alors que ceux des $10 \%$ les plus pauvres ont diminué de $14 \%{ }^{12}$. Dans ce contexte, la loi hypothécaire espagnole, qui date de 1909, est l'une des plus défavorables aux acheteurs en Europe:

10. L'Espagne est ainsi le pays de l'Union européenne où le coefficient de Gini, qui mesure le taux d'inégalités, est le plus fort $(0,34)$, cf. Branko MILANOVIC, Los que tienen y los que no tienen. Una breve y singular historia de la desigualdad global, Madrid, Alianza Editorial, 2012, p. 28.

11. Fondation FoESSA, op. cit., 2014, p. 2.

12. Miguel Ángel GARCíA VEGA, «El negocio está en los extremos », El País, 9 novembre 2014, p. 13. 
inspirée des intérêts de la noblesse et de la bourgeoisie mercantile de la fin du XIX ${ }^{\mathrm{e}}$ siècle, elle entraîne une relation de pouvoir inégalitaire entre les parties au profit des entités financières ${ }^{13}$. Il est ainsi quasiment impossible d'acheter un bien sans signer une hypothèque sur celui-ci. Pour autant, le prêt immobilier repose sur une personne physique et non sur le bien lui-même. Un prêt ne peut pas être soldé en donnant directement le bien à la banque, une revendication activement soutenue par la PAH et l'opinion publique espagnole. Dès qu'un particulier omet de payer une mensualité de son prêt, la banque peut porter plainte et un processus délictueux est automatiquement enclenché, sans évaluation initiale du juge, qui peut entraîner une expulsion à moyen terme. Si trop d'impayés s'accumulent, la banque s'approprie le bien pour $60 \%$ de sa valeur au moment de l'expropriation.

De plus, dans un pays où $80 \%$ de l'épargne des familles est constituée par les biens immobiliers, la valeur de ces actifs a diminué d'environ $30 \%$ depuis $2008^{14}$. Des personnes qui auraient donc pu intégralement rembourser leur banque avant la crise immobilière grâce à la vente de leur appartement, se voient donc non seulement expropriées et expulsées, mais doivent encore s'acquitter du montant de la dette restante si tel est le cas. Les coûts financiers du processus légal d'expulsion et les intérêts des retards de paiement restent aussi à payer par les expulsés. De nombreuses familles se retrouvent ainsi sans appartement et avec une dette qui continue d'augmenter, puisque les intérêts des impayés et des pénalités de retard ne cessent de croître. Les banques peuvent aussi saisir la justice pour obtenir un prélèvement automatique sur les salaires des débiteurs, qui se voient donc contraints à travailler au noir pour continuer à nourrir leurs enfants. Contrairement aux délits de corruption ou de détournement de fonds publics qui sont prescrits après seulement quelques années, permettant souvent aux élites d'échapper à la justice, les dettes des citoyens ordinaires, elles, ne se prescrivent pas $^{15}$. Si les parents, les beaux-parents ou les frères et sœurs se sont portés garants, comme le demandaient souvent les banques avant la crise pour les jeunes travailleurs ou les dossiers " à risque ", ces dernières se

13. Enrique GIL CALVo, Los poderes opacos. Austeridad y resistencia, Madrid, Alianza Editorial, 2013, p. 36. 14. Ramón GARcíA, "Cada español ha perdido 25000 euros de riqueza por la crisis económica », [http://www.invertia.com], 6 juillet 2012.

15. C'est aussi pour ces raisons que certains analystes considèrent qu'une bonne partie des dettes publiques en Europe du Sud sont «illégitimes », puisque des proportions importantes de celles-ci correspondent uniquement à l'augmentation très forte des taux d'intérêt et de la spéculation depuis 2008. Cf. par exemple, Damien MILlET et Éric ToussAINT, La dette ou la vie, Bruxelles, Éditions Aden, 2011. 
tournent aussi vers eux et leur réclament les sommes dues. Enfin, depuis la loi de juin 2013 votée par le PP, les personnes concernées sont fichées $\mathrm{au}$ "registre public des défaillants pour impayés »: elles ne peuvent plus jamais acheter de biens, avoir une ligne téléphonique ou obtenir un crédit, et font face à d'énormes difficultés pour trouver une location, percevoir certaines prestations sociales ou renouveler leur carte bancaire ${ }^{16}$.

Dans ce contexte de chômage de masse et de hausse des inégalités, la PAH se mobilise activement depuis 2009 pour résister aux expulsions, dénoncer la responsabilité de banques aux pratiques commerciales douteuses et maintenir le droit fondamental de tout être humain au logement. " De la précarité à l'expulsion, il n'y a qu'un pas ", me dira un jour Yolanda, une retraitée active au sein du collectif de L'Hospitalet, qui aide les personnes menacées d'expulsion dans leurs recours juridiques ${ }^{17}$. Depuis novembre 2010, lors de la première expulsion entravée avec succès à La Bisbal del Penedès dans la province de Tarragone, plus de 1135 expulsions ont été empêchées par les militants de la PAH. L'« œuvre sociale ", expression qui désigne les occupations en théorie "illégales " de la $\mathrm{PAH}$, a permis de reloger 1180 personnes $^{18}$. Des banques ont aussi été occupées, permettant ultérieurement la renégociation de nombreux prêts de particuliers. L'opinion publique espagnole a été largement sensibilisée par les campagnes de la $\mathrm{PAH}$. Des immeubles délaissés suite à la faillite d'entreprises du bâtiment, devenus les propriétés de banques ou d'assurances, ont été occupés pour reloger des familles. Certains sont même devenus des logements sociaux avec l'accord des banques et suite aux négociations collectives de la $\mathrm{PAH}$, permettant de légaliser les occupations en échange du paiement d'un « loyer social » aux entités financières.

\section{UN MOUVEMENT DÉCENTRALISÉ ET TRANSVERSAL}

\section{Autonomie et coopération des collectifs locaux}

Même si elle est d'abord née en Catalogne, où elle dispose encore $\mathrm{du}$ plus grand nombre de collectifs, la PAH s'est progressivement

16. Boletín Oficial del Estado (BOE), Ley de medidas de flexibilización y fomento del mercado del alquiler de viviendas, Titulo 3, "Creación de un registro público de morosos por impago del alquiler », BOE 4/2013, 4 juin 2013.

17. Entretien avec Yolanda, 62 ans, retraitée, L'Hospitalet de Llobregat, 6 novembre 2014.

18. Sur ce point, cf. Ada ColaU et Adrià ALEMANY, Vidas hipotecadas. De la burbuja inmobiliaria al derecho a la vivienda, Cuadrilátero de libros, Barcelona, 2012, p. 92. 
structurée à travers la création de collectifs locaux dans l'ensemble des capitales de province et la plupart des villes moyennes espagnoles. En 2015, la PAH s'appuie sur un réseau de 223 groupes locaux. Chaque collectif organise sa propre assemblée hebdomadaire, débat et s'organise autour des expulsions et de l'aide juridique à apporter aux personnes affectées au sein de son quartier ou de son territoire. En interne, chaque plateforme s'organise en commissions thématiques, en reprenant globalement la même structure, autour de cinq ou six commissions ${ }^{19}$ : " juridique ", "suivi des cas ", "vidéo ", « communication », " accompagnement" et "actions". Durant la semaine, chaque commission travaille selon son propre agenda, puis les décisions à prendre et les actions à mener sont débattues durant l'assemblée hebdomadaire. Une permanence est assurée chaque soir, de telle sorte que la plateforme joue aussi, en fait, le rôle d'accompagnement et de conseil qui est normalement celui des travailleurs sociaux.

En observant le travail du collectif de Barcelone, j'ai en effet pu constater que le local de la PAH joue bien souvent ce rôle de "centre d'accueil " pour des personnes désespérées, fragiles psychologiquement et en recherche de soutien. Ainsi, Edurne vient chaque soir à la permanence, où elle trouve du réconfort et a l'impression qu'on l'aide concrètement:

Depuis que j'ai reçu un courrier de menace de ma banque, je suis très anxieuse. Je vois seulement mon assistante sociale deux fois par mois. C'est trop long. En venant ici au moins, j'ai l'impression que j'avance, je m'informe de mes droits. On m'aide pour écrire à ma banque et me défendre. C'est concret ${ }^{20}$.

Fernando, un ouvrier équatorien de 51 ans au chômage, rencontré au local de la PAH de L'Hospitalet de Llobregat, ne dit pas autre chose:

Avec le chômage, je me suis isolé. Un compatriote m’a parlé de la plateforme et je suis venu avec lui la première fois. J'avais honte de parler de ma situation. Mais quand j'ai vu que je n'étais pas seul, ça m’a rassuré et aujourd'hui, je vais mieux, même si je suis toujours menacé d'expulsion ${ }^{21}$.

Au-delà de la résistance concrète aux expulsions grâce aux interpositions face aux forces de l'ordre, à l'aide juridique et à la médiatisation

19. Cette information m'a été fournie par Andrés, un étudiant en sociologie de 24 ans, qui se dit « très actif » au sein du collectif de Barcelone, avenida Rambla, 11 novembre 2014.

20. Entretien avec Edurne, sans emploi, 47 ans, local de la PAH, Barcelone, 12 novembre 2014.

21. Entretien avec Fernando, 51 ans, ouvrier au chômage, L'Hospitalet de Llobregat, 6 novembre 2014. 
de leurs actions, les plateformes jouent aussi un rôle social de proximité, en créant des lieux ou les personnes affectées peuvent être écoutées et peuvent échanger sur leurs expériences. Être ancré dans le territoire à travers les collectifs locaux constitue l'élément-clé qui permet de mobiliser suffisamment de personnes lors des actions de manifestation ou de réagir rapidement aux expulsions, qui ont souvent lieu très tôt le matin ou à des heures imprévues, en créant des systèmes collectifs d'alerte et en utilisant habilement les réseaux sociaux. Les assemblées hebdomadaires permettent à l'information de se répandre et favorisent l'implication des gens. Depuis 2011, des stratégies ont d'ailleurs été mises en place afin de faciliter les échanges d'informations entre les collectifs locaux pour aider les nouvelles plateformes à s'organiser ${ }^{22}$. À force de suivre les nombreux cas d'expulsions, les membres de la PAH ont contribué à " la production d'un savoir militant ", fondé sur l'expérience des recours juridiques et les mobilisations sociales passées, qu'il s'agit de transmettre aux nouveaux groupes locaux ${ }^{23}$. Mais l'évolution la plus notable est certainement que, depuis novembre 2012, face à l'augmentation importante du nombre de procédures d'expulsion qui rend plus difficile le suivi cas par cas, les dirigeants de la PAH privilégient de plus en plus des négociations générales avec les banques au nom de l'ensemble des personnes affectées.

\section{Un mouvement social citoyen}

De plus, l'observation participante du quotidien des collectifs locaux permet de souligner que, même si le socle de la PAH est animé par des militants associatifs traditionnels, ses actions s'insèrent dans un mouvement citoyen plus large et transversal. Hormis en ce qui concerne la direction nationale et les quelques professionnels de l'organisation, et au-delà même des bénévoles qui constituent la quasi-totalité des membres, des milliers de citoyens participent en fait de près ou de loin aux activités de la PAH. Lors des actions d'interposition pour éviter les expulsions, lors des occupations des agences bancaires ou des manifestations de rues, de nombreuses personnes se joignent spontanément, de façon temporaire ou récurrente, aux campagnes de la PAH. Lors de ces mobilisations, la frontière entre « l'expert » de l'engagement associatif et «le profane » indigné par les expulsions et l'exclusion sociale tend

22. Ada Colau et Adrià Alemany, op. cit., 2012, p. 53.

23. Yves LOCHARD et Maud SIMONET, « Les experts associatifs, entre savoirs profanes, militants et professionnels », dans Didier DEMAZIĖRE et Charles GADĖA (dir.), Sociologie des groupes professionnels. Acquis récents et nouveaux défis, Paris, La Découverte, 2010, p. 274-284. 
ainsi à disparaitrere ${ }^{24}$. C'est en cela que, couvrant plus qu'une simple organisation associative militante, la PAH dynamise un mouvement social citoyen plus large, entendu comme " un ensemble de réseaux informels d'organisations et d'acteurs isolés, construit sur des valeurs partagées et une solidarité entre leurs membres, qui se mobilisent au sujet d'enjeux conflictuels en ayant recours à différentes formes de protestation ${ }^{25}$ ".

En effet, lors des manifestations de rues de la PAH, à titre individuel ou au nom d'un groupe local, des organisations étudiantes, des mouvements de jeunes comme Juventud Sin Futuro, des militants de partis issus notamment d'Izquierda Unida ou de la formation Candidatura d'Unitat Popular (CUP) en Catalogne, des syndicalistes des Comisiones Obreras (CCOO) ou de l'UGT et des artistes, se joignent aux cortèges par solidarité ${ }^{26}$. Même si les personnes affectées par les expulsions constituent le socle de base des mobilisations, et si le discours de la PAH se situe plus dans la lignée du mouvement des indignés et des références aux catégories politiques de la gauche (égalité, droit au logement, lutte contre le capitalisme financiarisé, les injustices et l'exclusion sociale etc.), la plateforme se revendique comme un mouvement non-partisan et transversal. Ses dirigeants critiquent d'ailleurs tant la politique du PP que celle du PSOE en matière de logement et de régulation des banques. En discutant avec les manifestants à Barcelone le 11 novembre 2014, j'ai pu constater que des électeurs de tous les partis étaient représentés. Mais on trouve surtout de nombreux « abstentionnistes dans le jeu ": des déçus de la politique, qui ne croient plus aux promesses électorales et disent seulement voter de façon sporadique, mais qui demeurent cependant suffisamment indignés et conscients des enjeux pour être prêts à signer un tract ou à participer à une manifestation ${ }^{27}$. Les immigrants, les premiers touchés par la crise, qui sont plus isolés et ne peuvent pas s'appuyer sur leurs réseaux familiaux,

24. Thomas Fromentin et Stéphanie WoJcik, Le profane en politique. Compétences et engagements du citoyen, Paris, L'Harmattan, 2008, p. 7-21.

25. Donatella DelLa PORTA et Mario DiANI, Social Movements : An Introduction, Londres, WileyBlackwell, 2005, p. 12.

26. La candidature d'unité populaire est un mouvement d'assemblée, d'extrême gauche et indépendantiste catalan fondé le 7 mars 1991, successeur du Moviment d'Esquerra Nacionalista ("Mouvement de gauche nationaliste», MEN) qui regroupa en 1987 les mouvements nationalistes et d'extrême gauche de Catalogne fondés dans le sillage de la mort de Franco. La CUP est actuellement dirigée par David Fernández et dispose de trois députés au Parlament de Catalogne. Cf. Ivanna Vallespín, « CUP : independentistas y anticapitalistas », 23 novembre 2012.

27. Anne MUXEL, «La poussée des abstentions. Protestation, malaise, sanction », dans Pascal PERRINEAU et Colette YSMAL (dir.), Le vote de tous les refus. Les élections présidentielle et législative de 2002, Paris, Presses de Sciences Po, 2003, p. 153. 
sont assez représentés, mais les citoyens espagnols dominent, jeunes ou vieux, de classe populaire ou de classe moyenne, en voie de paupérisation et de déclassement. Le caractère interclassiste du mouvement, le fait que près d'une famille sur deux est touchée par le chômage, qui atteignait $24,4 \%$ de la population active en août 2014 , et la peur de nombreux citoyens de subir le même sort que les expulsés, explique le large appui social que la plateforme connaît dans l'opinion.

\section{DES REVENDICATIONS SOCIALES CONCRÈTES}

L'objectif principal de la PAH est de lutter contre les expulsions et d'œuvrer pour le droit au logement en incitant les pouvoirs publics nationaux et locaux à réagir, tout en défendant les milliers de personnes affectées par des prêts immobiliers assortis de clauses douteuses ou dans l'incapacité temporaire ou durable de les payer à cause du chômage. Le collectif dénonce l'inaction des gouvernants face à l'exclusion sociale et résidentielle et les abus des entités financières. Il cherche à replacer l'humain au centre des préoccupations politiques en s’appuyant sur l'indignation citoyenne et en dénonçant les excès du capitalisme financiarisé et de la spéculation immobilière. La PAH a ainsi largement dénoncé les pressions exercées avant la crise par les banques et les groupes financiers sur les gouvernements conservateur et socialiste pour déréguler le marché immobilier, sous le prétexte de flexibiliser le crédit et de faciliter l'accès au logement ${ }^{28}$. Les pratiques des banques sont elles-mêmes mises en cause. Des systèmes d'incitation et de primes récompensaient en effet les commerciaux qui "vendaient " le plus de prêts, incitant les clients à s'endetter parfois très largement au-delà des 33 \% d'endettement maximal normalement requis.

L'abus du langage commercial permettait de largement convaincre, voire même de manipuler les particuliers. Les conseillers s'appuyaient sur un argumentaire bien rodé: « il est bête de payer un loyer, alors que pour le même prix vous pouvez acheter "; " au pire, vous pouvez toujours vendre "; " de toute façon, les prix ne baissent jamais »; « les taux d'intérêt sont à un niveau historiquement très bas "; " c'est vraiment une chance ", etc. ${ }^{29}$. Les banques utilisèrent allègrement leurs " rela-

28. Pour de nombreux exemples, voir le documentaire La ley del Ladrillo ("La loi de la brique »), réalisé par Glòria Matamala en 2007, juste avant l'éclatement de la bulle immobilière, et dont le script a été rédigé par Ada Colau.

29. Ce type d'arguments m'a été transmis par Irene, une avocate trentenaire qui collabore au sein du groupe de travail juridique de L'Hospitalet de Llobregat, le 6 novembre 2014. 
tions de confiance " avec leurs clients pour leur faire signer des clauses abusives comme la " clause sol ", suivant laquelle le particulier s'engage sans le savoir à payer un taux minimum d'intérêt (bien supérieur à celui présenté par le commercial), et qui peut atteindre des sommets en raison des fluctuations d'un taux variable ${ }^{30}$. Les conséquences des impayés n'apparaissaient souvent pas directement sur les contrats, les banques se reposant sur la loi qui leur était favorable. Enfin, de nombreux prêts ont été signés pour des durées allant jusqu'à 30, 35 voire même 40 ans, au mépris complet de l'intérêt économique des particuliers.

Le langage dominant du " tous propriétaires » a monopolisé l'espace public et politique et les banques ont vanté l'accès au crédit "pas cher " à grands coups de publicité mensongère. Durant les années de croissance économique (1993-2008), intériorisant ce discours élitiste auquel elles ont cru avoir un intérêt partagé, les classes populaires et moyennes ont incité leurs enfants à s'endetter et à accéder à la propriété dès qu'ils obtenaient un travail: en 2007, $90 \%$ des familles étaient ainsi propriétaires en Espagne, le taux le plus élevé en Europe, contre seulement $50 \%$ en $1950^{31}$. Mais l'ensemble du château de cartes s'est effondré avec l'éclatement de la bulle de la spéculation immobilière. En 2008, 13 \% de la population active travaillait dans le bâtiment, ce qui représentait $18 \%$ du PIB, voire $30 \%$ si l'on tient compte des fournisseurs et des activités indirectes. Des centaines de milliers d'ouvriers se sont retrouvés au chômage, puis acculés par les banques à payer leur prêt et menacés d'expulsion, dans un pays qui, ironie de l'histoire, n'a jamais connu autant de logements vacants et de chantiers d'immeubles abandonnés. Dans ce contexte, la PAH a mis trois demandes principales sur le devant de la scène depuis 2009: 1) la donation pour paiement rétractif; 2) un moratoire sur les expulsions; 3 ) la location sociale des logements vacants détenus par les entités financières.

\footnotetext{
30. La banque d'Espagne estime qu'un tiers de l'ensemble des contrats de prêt immobilier contient des «clauses sol » abusives, soit environ 3,5 millions de particuliers et d'entreprises. Mais à ce jour, seul $5 \%$ des personnes concernées ont poursuivi leur banque en justice. Le collectif d'avocats Denuncias Colectivas et l'ADICAE, l'association des usagers des banques et des caisses d'épargne, cherchent à favoriser les actions collectives en justice, comme la plainte en cours à Madrid contre Bankia et ses entités financières (Caja Madrid, Bancaja, Caixa Laietana etc.) qui implique 7500 particuliers. Cf. ADICAE, " Más de 7500 preferentistas se suman finalmente a la demanda colectiva de ADICAE contra Bankia », 2 juin 2014.

31. Sur ce point, voir par exemple l'excellente étude de la sociologue Sandra GAVIRIA, Juventud y familia en Francia y en España, Madrid, Centro de Investigaciones Sociológicas, 2007, dans laquelle elle explique bien les différentes trajectoires de vies des jeunes et les discours distincts des parents à l'égard de la location au sein des deux pays.
} 


\section{Instaurer une donation pour paiement}

La « donation pour paiement rétroactif » est l'idée qu'un particulier puisse solder intégralement une dette en donnant son logement à sa banque. Dans la mesure où la dette est liée au prix d'achat du bien, cette proposition fait sens, d'autant plus que de nombreux particuliers ont souvent payé leur dette et ses intérêts durant de nombreuses années mais se font quand même expulser après seulement quelques mois d'impayés. Certes, pour les prêts signés récemment, les banques perdraient leurs intérêts, mais s'agissant des personnes qui ont déjà remboursé plus de $70 \%$ de leur prêt (puisque les intérêts représentent en moyenne au moins $30 \%$ du montant global sur 20 ans), elles seraient gagnantes financièrement. Cette revendication vise à réaffirmer le droit fondamental de chacun à une seconde chance, en permettant à des chômeurs de solder leurs dettes, d'éviter l'expulsion, de pouvoir retrouver un logement en tant que locataires et de se relancer dans la vie.

Une telle mesure permettrait enfin de lutter contre la spéculation: alors qu'elles sont elles-mêmes largement responsables des excès du " crédit facile ", des chantiers à-tout-va aujourd'hui en ruines (aéroports et «nouvelles-villes " fantômes, etc.) et de la bulle immobilière, les banques continuent à s'enrichir en s'adjugeant des biens sur le dos des expulsés pour $60 \%$ de leur valeur de marché (qui a elle-même largement diminué), puis en les revendant en effectuant au passage de juteuses plus-values. Certes, la rétroactivité revendiquée pour les familles déjà affectées et qui ont encore une dette jugée "illégitime " par la PAH peut poser question. Mais le principe du don pour paiement existe et s'applique déjà pour certaines entreprises immobilières en faillite, qui réduisent ou soldent leurs dettes en donnant leurs immeubles inachevés aux banques. La rétroactivité d'une loi est aussi assez rare en droit, mais pas inexistante lorsqu'il existe une volonté politique: la réforme du travail de 2012 a ainsi réduit le nombre de jours par années travaillées lors du calcul des indemnités de licenciement, ce qui limitera les indemnités des chômeurs pour l'ensemble des périodes travaillées après 2012, mais aussi rétroactivement, pour les périodes travaillées avant cette date.

\section{Militer pour un moratoire sur les expulsions}

La PAH milite aussi pour la mise en place d'un moratoire sur les expulsions, au bénéfice notament des familles dont l'ensemble des membres est au chômage et de celles qui s'avèrent en grande précarité 
sociale. Cette revendication est soutenue de longue date par les collectifs de sans-abri et par une association de solidarité chrétienne comme Caritas. Pour les militants de la PAH, il s'agit d'une question d'urgence sociale mais aussi d'un enjeu démocratique, comme le défend Jorge:

Une démocratie qui remet en cause le droit fondamental à avoir un toit n'est pas une démocratie, même si l'on vote tous les quatre ans. La démocratie c'est lorsque l'on prend d'abord en compte l'intérêt général des citoyens et non celui des marchés financiers ${ }^{32}$.

Même si les pouvoirs publics nationaux sont restés inflexibles, tant sous le gouvernement du PSOE que durant celui du PP, les actions des collectifs de la PAH, leur publicité et la mise sur l'agenda public de leurs revendications ont débouché sur des évolutions politiques dans l'espace local. Au niveau municipal, la ville de Sant Adrià del Besòs en Catalogne a approuvé en décembre 2010 à l'unanimité la première motion d'appui à la PAH. Depuis lors, quatre cents municipalités ont adhéré à ses campagnes. À Barcelone, Terrasa, Gérone, Getafe, Logroño et Vigo, des commissions mixtes associant des représentants de la PAH et des municipalités ont été formées afin de trouver des solutions concrètes de relogement ou pour éviter des expulsions. Le gouvernement régional andalou dirigé par la coalition PSOE-IU a de même décidé un moratoire temporaire en 2012. Même si un moratoire national n'a pas été décrété, les mobilisations collectives de la $\mathrm{PAH}$ ont ainsi contribué à politiser localement l'enjeu du logement, et à faire parfois évoluer les politiques des municipalités.

\section{Développer le logement social}

Enfin, la troisième revendication de la PAH est de mettre des logements vacants détenus par les entités financières à la disposition des expulsés, d'abord en les occupant, puis en cherchant à légaliser la situation en négociant avec les banques l'arrêt de la procédure d'expulsion en échange du paiement d'un " loyer social ». Cette campagne, labellisée comme " l'œuvre sociale de la PAH », vise à aider les personnes expulsées, très souvent sans solution de relogement ni aide institutionnelle, en menant des actions de désobéissance civile. Jaime, un travailleur social actif au sein du collectif de L'Hospitalet, défend la légitimité de ces actions pour pallier l'inexistence d'une politique de logement social:

32. Entretien avec Jorge, 37 ans, membre du groupe «communication » de la plateforme de L'Hospitalet de Llobregat, 6 novembre 2014. 
Il est inacceptable que l'Espagne soit le pays européen où il y a le plus d'expulsions, alors que c'est aussi celui où il y a le plus de logements vides. Comme il n'existe pas un parc de logements publics où reloger les gens, il semble légitime de récupérer ces logements vides et de les occuper $^{33}$.

Les militants de la $\mathrm{PAH}$ aident ainsi la famille à rentrer dans l'appartement même d'où elle a été expulsée, même s'il est maintenant légalement propriété de la banque. Si cela n'est pas possible, ils incitent les familles à occuper un appartement vide dans un immeuble racheté par une banque en raison de la faillite d'une entreprise immobilière. Il existe aujourd'hui sept blocs de logements en régime d'« œuvre sociale »: deux à Terrassa et à Sabadell, et un respectivement à Cerdanyola, Ruby et Gérone.

Le fait que l'ensemble de ces occupations aient eu lieu uniquement en Catalogne souligne bien la difficulté du processus et le rôle déterminant de militants de base suffisamment impliqués et politisés pour ne pas être effrayés par les conséquences légales de leurs actions. Mais tant dans le processus individuel que dans le collectif, la PAH cherche à négocier avec les banques pour " légaliser " la situation, à travers la signature d'un contrat et le paiement d'un loyer social par les familles, qui ne peut dépasser $30 \%$ de leurs revenus. En s’appuyant aussi bien sur les actions de désobéissance civile que sont les occupations, que sur des négociations juridiques formalisées, la PAH cherche à répondre à l'inaction des banques et des pouvoirs publics. Ces occupations constituent un instrument de pression politique sur les banques peu scrupuleuses qui ont fourni des prêts immobiliers associés à des projets douteux, tout en spéculant et en achetant des actifs pourtant considérés comme " toxiques " sur les marchés financiers. Le but est aussi de faire pression sur les institutions et les municipalités pour saisir l'opportunité historique de construire un parc de logements sociaux publics quasiment inexistant en Espagne.

Il est intéressant de noter que les revendications centrales de la PAH bénéficient d'un large soutien de l'opinion publique: selon des sondages de Metroscopia publiés par El País en 2012-2013, 86 \% des Espagnols se disaient ainsi favorables à la donation pour paiement, et $94 \%$ à un moratoire sur les expulsions des personnes au chômage ${ }^{34}$. Illustrant bien la forte défiance à l'égard des institutions et du personnel

33. Jaime, travailleur social et militant de la PAH, L'Hospitalet de Llobregat, 6 novembre 2014. 34. Sondage Metroscopia/El País, 4 novembre 2012. 
politique, $81 \%$ des personnes interrogées faisaient confiance à la PAH pour résoudre le problème des expulsions, contre seulement $11 \%$ au gouvernement, $10 \%$ au PSOE et $24 \%$ aux autres partis de l'opposition ${ }^{35}$. Même les électeurs du PP ne sont pas convaincus de la capacité ou de la volonté politique du gouvernement conservateur de trouver des solutions au problème ${ }^{36}$.

\section{DES STRATÉGIES D’ACTION COLLECTIVE DIVERSIFIÉES}

\section{Lutter par le droit: judiciarisation et débat public}

La lutte de la PAH revêt d'abord un aspect légal, en s'appuyant sur ses militants et son expertise de la législation acquise au fur et à mesure du temps, afin de défendre les personnes affectées par les procédures d'expulsion devant les tribunaux. À force de défendre les expulsés ou ceux qui sont menacés de l'être, les militants des collectifs acquièrent une connaissance des procédures juridiques, des recours et des réclamations possibles. Au sein de chaque collectif, les membres de la " commission juridique " s'occupent de ce travail procédurier de veille et de défense juridique: ils rédigent des courriers, contactent et coordonnent leurs activités avec des avocats, préparent les audiences. Ils tentent non seulement d'éviter les expulsions en utilisant toutes les voies de recours et en contestant leur validité, mais ils épluchent aussi les contrats de prêts bancaires des affectés, en cherchant à déceler les clauses ou les pratiques abusives, en écrivant des courriers aux banques pour trouver des solutions à l'amiable, ou en saisissant la justice. Au fil du temps, le travail juridique de la PAH sur ces deux volets, la contestation des expulsions et la renégociation des prêts avec les banques, lui a permis de développer une véritable expertise sur ces questions, ce qui explique que les Espagnols lui fassent plus confiance qu'aux pouvoirs publics pour répondre concrètement à ces problèmes qui touchent l'ensemble de la société. Yolanda m’a expliqué selon elle, les raisons de ce soutien social au travail de lutte juridique et militante de la PAH:

Tu sais, la violence de la prédation des banques n'affecte pas que les expulsés mais l'ensemble des citoyens. C'est un problème qui affecte tout

35. Sondage Metroscopia/El País, 12 juin 2013.

36. Ibid. 
le monde, les jeunes, les vieux, les salariés, les entrepreneurs en crise. Chacun connaît des voisins, des amis, ou a entendu parler d'expulsions à la télévision. Ces situations sont des drames individuels et familiaux et les gens sont touchés par ces expulsions car cela peut arriver à n'importe qui. Avec la crise, beaucoup de gens se sentent vulnérables. Même si tu n’as pas de prêt, tu es affecté par les coupes budgétaires. Les expulsions c'est la goutte d'eau qui déborde du vase ${ }^{37}$.

$\mathrm{Au}$ sein des collectifs, le travail de la " commission juridique " est très respecté et perçu comme celui "des sages et des intellos. Mais des intellos qui nous aident vraiment", pour reprendre l'expression de Trinidad, une affectée de Nou Barris ${ }^{38}$. On y trouve surtout des étudiants en droit, des institutrices et des professeurs, ainsi que des retraités. Ces personnes ont en commun d'être plus diplômées que le reste des militants. On peut d'ailleurs remarquer une tendance à la spécialisation des profils militants. Ceux qui préfèrent l'action directe et sont plus politisés s'engagent plus souvent dans les commissions " vidéo ", " communication" ou " action", au sein desquelles ils discutent des stratégies et des modes d'action pour alerter l'opinion et les pouvoirs publics. Les militants les plus jeunes se retrouvent généralement dans ces commissions, ils incarnent les forces vives des collectifs, sont moins présents quotidiennement dans les locaux, mais à l'avant-garde des interpositions face aux forces de l'ordre.

Les membres des commissions " accompagnement " et "suivi des cas" constituent " les petites mains" des collectifs, ceux qui ont une présence la plus régulière dans les locaux de quartier et qui rassemblent souvent les figures les plus connues. Plus présents au quotidien, ces gens jouent le rôle de personnes dévouées et à l'écoute, les premières à accueillir, à accompagner et à suivre dans le temps les personnes affectées. Ils complètent l'action des travailleurs sociaux, voire même se substituent dans les faits à ces derniers. J'ai pu aussi constater une dimension genrée de l'engagement dans les commissions, les hommes étant plus nombreux dans celles qui sont axées sur les stratégies d'action collective, et les femmes plus représentées dans celles qui sont liées au suivi des personnes. Enfin, les membres de la "commission juridique " ont souvent un statut à part: moins nombreux, leur engagement alterne entre des réunions de groupes, des consultations individualisées

37. Entretien avec Yolanda, op. cit., L'Hospitalet de Llobregat, 6 novembre 2014.

38. Entretien avec Trinidad, 34 ans, Colombienne au chômage, local de la PAH, Barcelone, 11 novembre 2014. 
avec les affectés et du travail de rédaction et de recherche solitaire. Lors des assemblées, là où la parole des membres des commissions de suivi et d'accompagnement est appréciée pour la connaissance des personnes et des trajectoires sociales individuelles dont elle témoigne, celle des membres de la commission juridique constitue la référence quant au suivi des procédures. L'influence de ces derniers est d'autant plus marquée que plus une procédure progresse, plus l'expulsion devient imminente et plus les stratégies de résistance des commissions orientées vers l'action doivent être réactivées.

La PAH cherche aussi à obliger les banques à renégocier les contrats de prêt des personnes affectées, en dénonçant les clauses abusives, le manque d'information sur des taux d'intérêt variables et les nombreuses manipulations ayant amené certains particuliers à s'endetter pour quarante ans sans en mesurer les conséquences. La première négociation collective eut lieu avec la Caixa Catalunya le 5 novembre 2012 à Barcelone: trois cents militants et sympathisants de la PAH occupèrent le quartier général de la banque, situé dans un immeuble moderniste de la via Laietana, près de la cathédrale ${ }^{39}$. Ils sollicitèrent un rendez-vous avec Adolf Todo, le P.-D.G. du groupe, afin de paralyser les expulsions et de renégocier les prêts bancaires. Cette occupation étant filmée et diffusée par eux en direct sur les réseaux sociaux, les internautes furent témoins des bousculades avec les agents de sécurité puis de la tentative de la direction de faire sortir les militants en augmentant très fortement le chauffage. Mais leur obstination aboutit finalement à ce qu'une délégation puisse rencontrer Joan Ràfols, secrétaire du conseil d'administration et Ignasi Fernández, responsable des services juridiques. Le lendemain, par un communiqué public, la Caixa s'engageait à paralyser les expulsions programmées. Suite à cette action, un "représentant de la PAH " fut nommé au sein de chaque collectif de Barcelone et chargé de négocier avec chaque banque concernée au nom de l'ensemble des personnes affectées de son collectif. Si les négociations piétinent, de nouvelles actions sont entreprises. Cette stratégie d'action collective, alternant entre des occupations, des atteintes à l'image de marque des banques et des négociations juridiques, a été depuis étendue à d'autres sociétés bancaires, permettant les signatures de plusieurs dizaines de « donations pour paiement » et de locations sociales.

39. « Movilización de la PAH en contra de la Caixa », El Mundo, 5 novembre 2012. 
La PAH cherche aussi à faire pression sur les institutions politiques nationales et européennes, afin de faire évoluer la loi hypothécaire espagnole. L’utilisation des voies légales passe d'abord par la volonté d'agir sur les parlementaires pour qu'ils relaient ses revendications. En juin 2010, le député Joan Herrera d'Iniciativa per Catalunya-Verds ("Initiative pour la Catalogne-Verts », ICV-IU) proposa au Congrès des députés une motion de soutien à la donation pour paiement, qui fut rejetée par le PSOE, fait qui souligne bien le déphasage d'un parti labellisé " de gauche " mais de plus en plus libéral, avec son électorat populaire et de classe moyenne, qui soutint massivement cette initiative comme le montrent les sondages d'opinion ${ }^{40}$. Opportuniste et voulant donner l'image d'un pouvoir attentif aux préoccupations citoyennes, le gouvernement de José Luis Rodriguez Zapatero ouvrit une commission d'étude sur le logement au Congrès suite à la demande du député Joan Ridao d'Esquerra Republicana de Catalunya ("Gauche républicaine de Catalogne ", ERC), ce qui permit à la PAH de témoigner le 11 juillet $2011^{41}$. Mais cette comparution, en pleines vacances estivales, fut peu reprise par les médias et ne servit à rien puisque le gouvernement du PSOE, devenu extrêmement impopulaire en raison de l'explosion du chômage de 9,3\% lors de sa prise de pouvoir le 9 mars 2008 à 21,8 \% en juillet 2011, mit fin aux travaux de la commission avant même la rédaction de ses conclusions, suite à son choix d'organiser des élections anticipées ${ }^{42}$.

Malgré les difficultés et l'opposition des partis dominants, la PAH continue de dénoncer la responsabilité des banques lors de la crise et à alerter sur la problématique du logement. Ada Colau a ainsi témoigné devant la commission d'économie du Congrès des députés le 5 février 2013, dans le cadre du projet de loi sur les mesures urgentes pour renforcer la protection des endettés hypothécaires. Mais le dédain des conservateurs au pouvoir à l'égard du collectif et l'ordre de passage des intervenants en dit long sur le rapport de force très défavorable: elle ne fut invitée à parler qu'après les représentants des assureurs et Javier Rodriguez Pellitero, porte-parole de l'association espagnole de

40. La seule initiative du gouvernement du PSOE de 2004 à 2008, fut d'augmenter le prix d'évaluation d'un immeuble lors de sa saisie par les entités financières de $50 \%$ à $60 \%$ de sa valeur estimée, cf. Antonio Papell, Zapatero 2004-2008. La legislatura de la crispación, Madrid, Foca Ediciones, 2008, p. 207.

41. «La PAH en el Congreso de los diputados », El País, 11 juillet 2011.

42. Évolution du taux de chômage en Espagne, données Eurostat, Commission Européenne, 2014. 
la banque, le patronat du secteur, qui loua «le comportement exemplaire des banques " et leur "implication sociale " puisqu'elles " font tout ce qu'elles peuvent pour éviter les expulsions ", tout en qualifiant d'« excellente " (" estupenda») la loi hypothécaire espagnole, "l'une des meilleures en Europe » selon lui ${ }^{43}$. Dans une intervention très suivie sur les réseaux sociaux, Ada Colau lui répondit de façon cinglante:

Il n'y a rien de plus cynique que de qualifier cette loi d'“excellente", alors que de nombreuses personnes se suicident à cause d'elle. Je n’ai pas envoyé de chaussure à ce Monsieur par respect, mais je pense que vous êtes un criminel et un menteur. Vous dites que le comportement des banques a été "exemplaire" alors même que les prêts frauduleux, le scandale des "preferentes" et les clauses abusives ont causé la ruine de milliers de personnes ${ }^{44}$.

Mais devant l'inaction du pouvoir politique, la lutte s'est judiciarisée. Le juge Guillem Soler, sympathisant du mouvement, a déposé un recours devant le Tribunal constitutionnel en septembre 2010, au motif que la procédure d'expulsion existante dans la loi espagnole remet en cause les droits de la défense, la tutelle judiciaire ne s'exerçant pas de façon effective, ce qui ne permet pas aux personnes affectées de se défendre correctement. Le juge José Maria Fernández Seijò a aussi effectué une dénonciation de l'Espagne devant la Cour de justice de l'Union européenne au motif que la loi hypothécaire remettrait en cause la norme européenne en matière de droits du consommateur, qui prévoit un minimum de protection et d'information contre les clauses abusives lors de la signature de prêts bancaires: le 14 mars 2013, le tribunal lui a finalement donné raison, enjoignant le pouvoir politique à modifier la loi pour renforcer les droits des particuliers ${ }^{45}$. De 2007 à 2013, les tribunaux espagnols auront donc appliqué une loi qui porte atteinte à certains droits fondamentaux...

Enfin, la PAH a utilisé avec succès l'une des possibilités juridiques permises par la loi espagnole: une initiative législative populaire (ILP) peut en effet être débattue au Congrès des députés suite à une pétition rassemblant les signatures de cinq cent mille citoyens. Même si c'est la majorité parlementaire (et non un éventuel référendum) qui décide ensuite si un débat doit ou non avoir lieu, puis qui vote l'approbation ou

43. «Rodriguez Pellitero defiende los bancos en el Congreso », El País, 5 février 2013.

44. Intervention citée par Ada Colau et Adrià Alemany dans leur ouvrage, op. cit., 2013, p. 26.

45. «El Tribunal de Justicia europeo considera abusiva la ley española sobre desahucios », El País, 14 mars 2013. 
le rejet de l'ILP, cette procédure permet de lancer un vrai débat public autour d'une initiative citoyenne. En octobre 2010, la PAH s'est associée avec les syndicats CC. OO et UGT, la confédération des associations de voisins de Catalogne (CONFAVC), l'observatoire DESC et la Taula del tercer Sector ("Table du troisième secteur "), pour mettre en œuvre une ILP autour de deux revendications, un moratoire sur les expulsions et la donation pour paiement.

Il n'existait alors qu'une douzaine de plateformes de la PAH, la plupart dans la province de Barcelone. Le mouvement des indignés, qui se développa après la grande manifestation du 15 mai 2011, n'était encore qu'embryonnaire. Cette initiative de rassemblement d'organisations syndicales, de collectifs et d'associations de la société civile autour d'un même objectif permit à la PAH de faire connaître son combat. Mais l'implication de nombreux militants dans les manifestations, les occupations et les assemblées de rue des indignés au printemps 2011, à Barcelone, Tarragone, Gérone en Catalogne et dans les autres grandes villes d'Espagne, puis le recentrage du débat public sur les élections législatives anticipées du 20 novembre 2011, retardèrent le processus. Le 23 avril 2012, la première table fut installée dans la rue à Barcelone. Pour Javier, un étudiant en philosophie, membre du collectif de Barcelone depuis trois ans et ayant participé à ce processus: " cette campagne permit de mobiliser les gens contre les expulsions, et de renforcer le soutien populaire à notre cause. L'un amenait des sièges, l'autre les sandwichs, la pétition développa les solidarités ${ }^{46}$ ». Grâce à ce vaste mouvement d'éducation et d'engagement populaire, la pétition fut signée en quelques mois par 1,4 million de citoyens.

\section{Lutter par le nombre: manifestations, occupations et résistances citoyennes}

La PAH cherche également à faire pression sur les municipalités et les pouvoirs publics grâce à des actions collectives de masse: des manifestations de rue, devant le Congrès des députés et les assemblées des communautés autonomes; des occupations de sociétés bancaires et financières et de logements vacants; des actions d'interposition et de résistance aux expulsions face aux forces de l'ordre. Pour l'ensemble de ces actions, le but poursuivi est non seulement d'agir concrètement pour s'opposer ou dénoncer une situation donnée, mais aussi d'attirer l'attention des médias et du public sur la cause du droit au logement

46. Javier, 25 ans, étudiant en philosophie, Barcelone, 11 novembre 2014. 
et les pratiques commerciales frauduleuses des banques. Les logiques médiatiques peuvent en effet "transformer la carrière des mouvements sociaux en contribuant à leur ascension ou en les discréditant ${ }^{47}$ ". Les manifestations de rue de la PAH permettent d'occuper l'espace public et comportent « directement ou indirectement l'expression d'opinions politiques ${ }^{48}$ ".

La campagne Stop Desahucios ("Stop aux expulsions ») est de loin celle qui a obtenu le plus de répercussions médiatiques, à travers des rassemblements de militants de la PAH et de voisins, filmés et diffusés en direct sur les réseaux sociaux, qui ont souvent reporté ou paralysé des expulsions. Lors de ces concentrations, au-delà de l'objectif concret de défense des personnes menacées d'expulsions, «l'expressivité » joue un rôle central: elle permet aux manifestants d'affirmer la visibilité de leur groupe et de leurs demandes sociales ${ }^{49}$. La foule revêt par ellemême un caractère performatif: elle "fait exister " les citoyens d'en bas; elle met en scène la lutte des citoyens ordinaires menacés par la crise et leur position de dominés face aux pouvoirs publics et aux policiers ${ }^{50}$.

Mais la PAH utilise aussi un autre répertoire d'action directement issu du mouvement des indignés: les escraches, qui peuvent être définis comme des manifestations devant une institution publique ou privée ou le domicile d'un particulier, visant à dénoncer par l'intimidation, les cris, les sifflets et les slogans, les agissements considérés comme honteux d'entités publiques ou de personnes privées. Ada Colau et Adrià Alemany rappellent que ces pratiques apparurent en Argentine lors des protestations populaires consécutives à l'adoption de la « loi du point final " le 24 décembre 1986 puis de la « loi du devoir d'obéissance » du 4 juin 1987 sous la présidence de Raúl Alfonsín; ces lois connues comme les " lois de l'impunité » accordaient une prescription et disculpaient les responsables des atrocités de la dictature de Jorge Rafael Videla (1976-1983) ${ }^{51}$. Ce répertoire d'action fut réactivé en Argentine lors des

47. Olivier FILLIEULE (dir.), Sociologie de la protestation, Paris, L'Harmattan, 1993, p. 3.

48. Olivier FIllieule, Stratégies de la rue, Paris, Presses de Sciences Po, 1997, p. 44.

49. Olivier Fillieule et Danielle TARTAKowsky, La manifestation (2e éd.), Paris, Presses de Sciences Po, 2013, p. 16.

50. John LANGShaw Austin, Quand dire, c'est faire, Paris, Le Seuil, 1991.

51. Ada Colau et Adrià Alemany, op. cit., 2013, p. 76. Face à l'indignation populaire persistante, ces lois furent d'ailleurs déclarées nulle part le Congrès national en 2003, puis inconstitutionnelles par la Cour suprême de justice le 14 juin 2005. Sur ces questions, cf. Diana QuATTROCCHI-WoIsSON (dir.), Argentine. Enjeux et racines d'une société en crise, Paris, Tiempo Éditions, 2003. 
manifestations massives du " cacerolazo » du 19 et 20 décembre 2001 contre les banques et le " corralito " décidé par le gouvernement de Fernando de la Rúa; une répression sans précédent entraîna la mort de 28 manifestants $^{52}$. Mais l'étude magistrale de Charles Tilly nous rappelle cependant que ce type de manifestations d'intimidation existe depuis le Moyen Âge ${ }^{53}$.

En Espagne, la PAH a utilisé les sifflets et les casseroles à de nombreuses reprises contre les banques et les responsables publics afin "d'interpeller directement le politique ${ }^{54}$ ». Sa campagne "Cette banque trompe, escroque et met les gens à la rue ", vise à intimider et à rendre directement responsable les banques en occupant, en montrant du doigt, en informant les clients et en attirant l'attention médiatique sur les agences où les personnes affectées par les expulsions possèdent des crédits. Sur La Rambla de Barcelone le 9 juillet 2013, ses militants sifflèrent collectivement, collèrent des autocollants sur l'agence du Banco Popular et crièrent "Cette banque expulse!", "Cette banque nous vole! » en informant les passants. Deux manifestants coiffés de ballons géants en forme de chorizos sur la tête tenaient des pancartes où l'on pouvait lire "Banquiers, chorizos ", un mot assimilé péjorativement à celui de "voleurs » dans la langue de Cervantès. Les quelques passants interrogés jugèrent ces actions " normales " et " nécessaires ", arguant " de la souffrance des gens face à la crise » et de l'indignation face « aux banquiers et aux politiques qui se gavent alors que de nombreuses familles n'ont même pas de quoi manger ${ }^{55}$ ".

Le 12 février 2013, les sifflets et les slogans des manifestants qui encerclaient le Congrès, jouèrent un rôle de pression décisif dans l'acceptation par les députés du débat parlementaire sur l'ILP proposé par la PAH. La partie était pourtant loin d'être gagnée: en janvier 2013, le PP qui disposait d'une majorité absolue au Congrès, n'avait même pas accepté que la proposition fut discutée; il ne se ravisa que face aux

52. Le « corralito » désigne la limitation des retraits bancaires des épargnants à 250 pesos par semaine et l'interdiction d'envoi de fonds à l'extérieur pour tenter de répondre à la fuite des capitaux et à la crise de liquidité. Mais la conversion forcée des comptes en dollar en peso dévalué, fit perdre une grosse partie de leur épargne aux Argentins des classes moyennes et populaires, qui protestèrent par des sifflets, des bruits de casseroles et des manifestations parfois violentes contre les banques et les institutions. Cf. François CHESNAIS et Jean-Philippe DıVÈs, ;Que se vayan todos! Le peuple d'Argentine se soulève, Paris, Éditions Nautilus, 2002.

53. Charles TILLY, La France conteste. De 100 à nos jours, Paris, Fayard, 1986, p. 115-130.

54. Olivier FILliEUle et Danielle TARTAKOWSKY, op. cit., 2013, p. 79.

55. Propos et observations recueillis auprès de passants et de manifestants lors d'un terrain, avenue Rambla, Barcelone, 9 juillet 2013. 
pressions de l'opinion publique (plus d'un million de courriers furent ainsi envoyés aux députés du PP en trois jours). L’attente médiatique était énorme, d'autant plus que l'ILP sur la donation pour paiement et le moratoire sur les expulsions devaient être débattus parallèlement à une autre ILP sur la proclamation de la tauromachie comme « bien d'intérêt culturel ", qui avait recueilli 590000 signatures, et dont on savait qu'elle serait soutenue par le parti au pouvoir ${ }^{56}$. Des membres de la PAH vêtus des tee-shirts verts symbole du collectif crièrent " Si, c'est possible! » et furent expulsés des gradins du Congrès. Puis, lors de la présentation de l'ILP, la députée Uxue Barkos du parti Nafarroa Bai renforça la dramatisation de l'atmosphère en annonçant qu'un couple de retraités de 67 et 68 ans de Calvià, dans la province de Majorque, venaient le jour même de se jeter de leur balcon après avoir reçu leur ordre d'expulsion. Ce jour-là, la pression de la rue et les cris de la foule de Madrid résonnèrent jusque dans l'enceinte du Congrès; on les perçoit sur les reportages diffusés de l'intérieur par les chaînes de télévision. Le principe d'un débat ultérieur sur l'ILP fut finalement approuvé par les députés conservateurs, qui s'empressèrent de jouer la carte de la récupération politique devant les médias, tel le député Teodoro García qui osa déclarer que " la PAH et le PP travaill [ai] ent dans le même sens ", alors même que son parti s'était opposé à toutes les initiatives du collectif depuis 2008. Mais au-delà de l'effet conjoncturel de la pression populaire, l'histoire retiendra surtout que le PP enterra ensuite discrètement l'ILP durant les vacances estivales de 2013.

\section{LA LUTTE NÉCESSAIRE ET LES VICTOIRES CONCRÈTES DU COLLECTIF}

Comment la PAH, à travers le mouvement social qui s'est organisé dans son sillage, contribue-t-elle à la défense des citoyens et au progrès social? Depuis 2008, elle a rempli plusieurs fonctions majeures au sein de la société espagnole. Elle a d'abord joué une fonction sociale cruciale, assimilable à celle des travailleurs sociaux, en créant grâce à ces collectifs locaux des lieux d'écoute, de réconfort et d'entraide, qui ont permis à des milliers de citoyens appauvris par la crise et livrés au désespoir, de retrouver une dignité, de se sentir moins seuls face à la pauvreté et la précarité et de s'appuyer sur les expériences des autres pour défendre leurs droits. Les psychologues sociaux savent combien les événements

56. «El PP dirá no a la dación en pago y sí a los toros », [El diario. es], 7 février 2013. 
dramatiques de la vie comme l'exposition durable à la pauvreté ou une expulsion, peuvent engendrer un "traumatisme psychique ", détruisant les idées reçues de l'individu sur la justice et les droits de l'homme, et entraînant un état de confusion extrême et d'insécurité qui peut l'amener à intérioriser son statut d'infériorité sociale. Par l'apport d'un soutien émotionnel désintéressé aux personnes affectées, la PAH permet de traiter leur "vulnérabilité psychologique ", en répondant à leurs sentiments de honte et d'injustice et à la dégradation morale de leur estime de soi, et en transformant ces sentiments en des propositions constructives et des actes de dénonciation. Au-delà de la lutte pour le droit au logement, comme d'autres associations et collectifs solidaires, la PAH permet aux citoyens en proie au " déclassement » de se reconstruire individuellement, de reprendre confiance en eux-mêmes et en les autres, et de rompre avec la spirale de la "disqualification sociale " et de l'exclusion ${ }^{57}$.

De plus, la PAH a aussi joué les fonctions de mise sur l'agenda politique de certains enjeux sociaux et de reformulation des cadrages dominants de ces enjeux. En interpellant personnellement les députés par lettre avant sa comparution devant la commission d'économie du Congrès du 5 février 2013, en rédigeant des tribunes dans les journaux, en intervenant lors des débats de société sur les chaînes de télévision, en manifestant, en occupant des banques et en s'interposant face aux forces de l'ordre pour paralyser les expulsions, le collectif a joué la fonction de "lanceur d'alerte ", en attirant l'attention des médias et des citoyens sur la problématique du droit au logement et la responsabilité des entités financières dans la crise. En formulant de nouveaux " cadres d'interprétation " des causes et des solutions à donner à ces enjeux, la $\mathrm{PAH}$ a permis de " répandre de nouvelles valeurs opposées à l'idéologie dominante ${ }^{58}$ ». En structurant un "discours d'injustice » sur le caractère moralement inacceptable des expulsions, des fraudes bancaires et de la spéculation immobilière, la PAH a contribué à " donner un sens aux événements, à organiser l'expérience et guider l'action individuelle et collective ${ }^{59}$ ». Son discours alliant dénonciation des causes et des

57. Serge PAUgAm, La disqualification sociale, Paris, Presses universitaires de France, 1991; Camille PeugnY, Le déclassement, Paris, Grasset, 2009.

58. William Gamson parle de «frame transformation » pour caractériser cette requalification du discours dominant. Cf. William GAMSON, Talking Politics, Cambridge, Cambridge University Press, 1992.

59. David SNow et. al., «Frame alignment processes, micromobilization and movement participation », American Sociological Review, vol. 51, n², 1986, p. 464-481. 
responsables de la crise et la proposition de solutions alternatives a permis d' "influencer la réalité perçue et la persuasion des individus ", qui constituent eux-mêmes " des déterminants clés de la participation à un mouvement social ${ }^{60}$ ".

Enfin, à travers ses actions nationales et les luttes localisées de ses collectifs au sein des quartiers et des municipalités, la PAH a joué la fonction d'un groupe de pression en défense de l'intérêt général. Même si ces luttes collectives n'ont pas débouché sur un changement politique majeur face au dédain du PSOE puis du PP, elles ont eu un impact à différents niveaux. D'abord, ses revendications sont désormais très connues et obtiennent le soutien majoritaire de la population, comme le montrent les sondages d'opinion de façon récurrente. Autrement dit, la PAH est en train de marquer des points dans la bataille des idées: ce n'est pas un hasard si la plus puissante fédération du PSOE, celle d'Andalousie, au pouvoir avec IU, a appliqué en 2012 un moratoire sur les expulsions et qu'Izquierda Unida mais surtout la nouvelle formation montante Podemos soutiennent fortement ses revendications. Les municipalités de Madrid, Barcelone, Valence, Cadix et Saragosse, conquises par le parti de Pablo Iglesias lors des municipales de mai 2015, ont ainsi décrété des moratoires sur les expulsions depuis lors. D'autre part, en touchant l'image de marque des banques impliquées dans la spéculation immobilière et les prêts immobiliers frauduleux et en les poursuivant en justice, la PAH a aidé des milliers de petits épargnants à éponger leurs dettes et à les renégocier avec leur banque ${ }^{61}$. Elle a alerté sur l'exclusion sociale croissante et la possibilité d'y remédier concrètement en maniant le droit, la force du nombre et la désobéissance civique. La PAH a contribué à politiser de nouveaux enjeux, jusqu'alors absents du débat politique en Espagne, comme le manque d'un parc public de logements sociaux.

La " loi de seconde chance", décidée par le PP en février 2015 en pleine année électorale afin de donner une image plus « sociale " à son

60. Bert KLANDERMANS, «Mobilization and participation: social psychological expansions of resource mobilization theory », American Sociological Review, vol. 49, n 4, 1984, p. 584.

61. Suite à une plainte en 2011 de plusieurs associations et collectifs dont la PAH et l'ADICAE, l'association des usagers des banques et des caisses d'épargne, le Tribunal Suprême a ainsi condamné les banques BBVA, Cajamar et Nova Galicia en mai 2013, considérant les « clauses sol » comme illégales. Depuis lors, les particuliers gagnent $90 \%$ de leurs procès contre les banques s'ils ont signé un contrat contenant une telle clause. Ces dernières préfèrent donc négocier avec les clients pour perdre moins de temps et d'argent, éviter les atteintes à leur réputation et « l'effet d'appel » des victoires judiciaires. Cf. Iñigo de Barrón, «La banca deja de recurrir las cláusulas suelo de hipotecas y acepta negociar », El País, 16 novembre 2014, p. 27. 
bilan, propose d'appliquer la "donation pour paiement " aux entrepreneurs, et aux familles mais de façon beaucoup plus restrictive ${ }^{62}$. En donnant leurs biens, les particuliers pourront seulement payer $65 \%$ de leurs dettes sur cinq ans et $80 \%$ sur dix ans. La loi facilitera la "renégociation des dettes " entre les banques et les particuliers, actant une procédure que la $\mathrm{PAH}$ a de fait déjà imposée à de nombreuses banques. Certes, une loi bien meilleure aurait pu être votée. La lutte pour le droit au logement ne s'arrête pas là. Mais cette récupération par le pouvoir conservateur, certes pleine d'arrière-pensées électoralistes et dont les effets seront limités, de certaines revendications du mouvement social, montre que les lignes commencent à bouger au sein même de l'idéologie dominante et que les luttes des dernières années n'auront pas été vaines.

62. «El Gobierno habla de dación en pago para emprendedores pero se olvida de las familias », [La Sexta. com], 26 février 2015, consulté le 5 avril. 



\title{
9 \\ La monarchie espagnole entre crises et restaurations (1808-2015)
}

\author{
Benoît PELLISTRANDI \\ En Juan Carlos, nous disons notre gratitude à l'égard \\ d'une génération de citoyens qui a ouvert la voie à la \\ démocratie et à l'entente entre les Espagnols. \\ (Philippe VI, 19 juin 2014)
}

L'abdication du roi Juan Carlos, annoncée le 2 juin 2014, d'abord par le chef du gouvernement Mariano Rajoy puis expliquée par le roi luimême au cours d'une intervention télévisée "institutionnelle ", n'est pas apparue comme un geste volontaire mais bien comme le résultat quasiment obligé d'une détérioration de l'image du roi dans l'opinion publique, détérioration qui entraînait avec elle la remise en cause du système monarchique. Le processus constitutionnel exigeait que fût alors votée une loi organique prenant acte de l'abdication de Juan Carlos; c'est lorsqu'il signerait la loi que son abdication deviendrait effective. L'acte solennel eut lieu le mercredi 18 juin 2014 au Palais Royal à Madrid. Le lendemain, les Cortès procédaient à la proclamation du nouveau roi, Philippe VI.

La séquence politique fut donc extraordinairement rapide: en dixhuit jours, la Couronne avait changé de titulaire et la magistrature suprême de l'État faisait la démonstration qu'elle fonctionnait parfaitement dans le cadre prévu et instauré par la constitution de 1978. Les manifestations de républicains demandant qu'un référendum fût organisé pour décider de la continuité ou non de la forme monarchique de la tête de l'État furent rapidement noyées sous le flot des commentaires, souvent élogieux, qui accompagnèrent la décision de Juan Carlos. Celleci mettant fin à un règne de presque trente-neuf ans, on ne pouvait pas ne pas proposer un bilan. Et à cet égard, l'actif, la transition démocratique, la capacité à accompagner la métamorphose de l'Espagne et à représenter ce pays qui retrouvait la scène internationale, l'emportait 
largement sur le passif constitué par les scandales de corruption qui ont entaché la réputation de la famille royale et le comportement de l'homme privé Juan Carlos.

Aujourd'hui, le nouveau roi Philippe VI jouit d'un crédit considérable: en février 2015, un sondage publié par le quotidien El País lui accordait une cote de popularité de $71 \%$ de satisfaits contre $19 \%$ de mécontents, soit un solde positif de 52 points. À titre de comparaison, les leaders politiques Mariano Rajoy (PP, chef du gouvernement), Pedro Sánchez (PSOE) et Pablo Iglesias (Podemos) ne recueillent, respectivement, que $23 \%$, $31 \%$ et $34 \%$ d'opinions favorables. Dans le contexte de désaffection généralisée qui marque le monde politique, la Couronne, renouvelée en son titulaire, a retrouvé l'appui et la confiance des citoyens ${ }^{1}$. Ce résultat semble effacer en partie la chute vertigineuse de la popularité de Juan Carlos au cours des dernières années. Selon les sondages du quotidien El Mundo élaborés par l'entreprise Sigma Dos: en janvier 2012, 76,4\% des personnes interrogées avaient une très bonne ou une bonne opinion du bilan du règne de Juan Carlos. Un an plus tard, le chiffre tombait à 50,1\% et à 41,3\% en janvier 2014 . La conséquence était que 49,9\% des interrogés contre $43,3 \%$ (et 6,8 \% sans opinion) soutenaient la monarchie comme forme de l'État (contre $53,8 \%$ en janvier 2013). Le seul point positif de ce sondage catastrophique était que 56,6\% des Espagnols estimaient que le prince Philippe serait à même de restaurer le prestige de la monarchie. Bien que très sensibles à la conjoncture immédiate, les sondages révèlent aussi des tendances de fond de l'opinion publique. La popularité actuelle du roi Philippe VI trouve ses fondements dans l'image qu'il s'était construite en tant que prince des Asturies. Fait notable, le samedi 31 janvier 2015, lors du meeting qui concluait la "marche du changement ", le leader de la nouvelle formation radicale de gauche, Pablo Iglesias, n'évoquait pas de changement de régime alors qu'il est ouvertement républicain. Il faut voir là à la fois de la prudence tactique, mais aussi peut-être la relégation, peut-être provisoire, de la question monarchique au second plan de l'agenda politique.

Pour autant, la crise que la monarchie espagnole a traversée de 2012 à 2014 est-elle seulement conjoncturelle ? Faut-il n’y lire que le crépuscule d'un règne qui aurait été trop long? Les erreurs d'appréciation de Juan Carlos seraient-elles les seules raisons de cette crise ou ne faut-il

1. "Encuesta de Metroscopia: el clima político y social en España», El País, dimanche 8 février 2015. 
pas l'inscrire dans un faisceau de crises $^{2}$ ? La monarchie n'aurait-elle pas été pendant trois ans le paratonnerre qui attirait la colère populaire écœurée de découvrir l'ampleur de la corruption de ses élites, tant économiques et financières, que politiques et syndicales? L'ébranlement d'une des clefs de voûte du pacte constitutionnel de 1978 doit être lu dans sa conjoncture courte mais aussi depuis une perspective historique. Si la monarchie en Espagne reste marquée par un héritage historique qui la fragilise, l'action politique de Juan Carlos a permis de nouer un pacte entre elle et la démocratie. La validité de ce pacte suffit-elle à assurer l'avenir de la monarchie ou l'entrée en crise des fondements du consensus démocratique ne peut-elle pas emporter cette réalité politique? Ces questions politiques ne peuvent se comprendre sans une mise en perspective historique. La monarchie espagnole est une institution que l'histoire a fragilisée et la société espagnole en garde la mémoire. Après avoir décrit à grands traits cet héritage, nous montrerons comment grâce au pacte noué avec la démocratie, Juan Carlos, et désormais son successeur Philippe VI, ont fait de la monarchie une institution d'équilibre et d'incarnation. Cette démarche permettra ainsi d'exposer l'une des caractéristiques de la culture politique espagnole dont la juste appréhension est indispensable à la compréhension des enjeux actuels de l'Espagne.

\section{LA MONARCHIE, UN HÉRITAGE FRAGILISÉ PAR L'HISTOIRE}

L'histoire des Bourbons en Espagne est une histoire complexe dans laquelle les scandales, les crises familiales, les abdications, les exils, les restaurations scandent une saga dynastique et politique hautement colorée. Il y eut d'abord la guerre de Succession et la manœuvre politique de Louis XIV, petit-fils de Philippe III (roi d'Espagne de 1598 à 1621) et neveu et gendre de Philippe IV (roi de 1621 à 1665). Bien qu'il ait renoncé à la succession d'Espagne pour sa descendance lors de son mariage avec l'infante Marie-Thérèse, Louis XIV acceptera en 1700 la couronne d'Espagne pour son petit-fils le duc d'Anjou. Entre 1700 et 1714, la lutte entre les partisans de Philippe V et ceux du prétendant Charles de Habsbourg déchira l'Espagne. En Catalogne, notamment, où les Barcelonais qui, en 1640 s'étaient tournés vers Louis XIII

2. Telle est la raison d'un article consacré à la monarchie dans ce livre étudiant la crise démocratique espagnole. 
contre Philippe IV, voient désormais en Charles de Habsbourg le meilleur défenseur des libertés catalanes ${ }^{3}$. Il convient de ne pas tomber dans l'anachronisme et de ne pas relire le XVIII siècle espagnol à la lumière des historiens catalans du $\mathrm{XIX}^{\mathrm{e}}$ siècle. La vision misérabiliste d'une Catalogne opprimée est fausse: Pierre Vilar l'a magistralement démontré dans sa célèbre thèse, La Catalogne dans l'Espagne moderne. Recherches sur les fondements économiques des structures nationales (1962). Retenons cependant l'idée d'une nouvelle étape dans l'histoire nationale marquée, à la fois par l'implantation des Bourbons et par l'abolition des juridictions des différentes couronnes (Aragon, Valence, Catalogne, Baléares) au profit du système judiciaire castillan. D’un côté, un nouvel alignement de Madrid sur la France; de l'autre, l'expérience d'une rationalisation administrative.

L'Espagne du XVIII ${ }^{\mathrm{e}}$ siècle avec ses quatre rois - Philippe V (17001746), Louis I ${ }^{\text {er }}(1724)^{4}$, Ferdinand VI (1746-1759), Charles III (1759-1788) - est une puissance européenne qui compte et qui se modernise. Charles IV (1788-1808) va se trouver confronté à l'épreuve de la Révolution française, ce qui explique ses raidissements intellectuels et idéologiques. Quoiqu'engagé dans les guerres antifrançaises, l'Espagne retrouve très vite son alliance avec la France (traité de San Ildefonso en 1796, qui faisant suite à la paix de Bâle, lie les intérêts espagnols à ceux de la France... et explique l'alliance maritime qui vaudra à l'Espagne la perte de ses navires lors de la bataille de Trafalgar en 1805). La présence de troupes françaises sur son sol dès 1807 - elles se dirigent vers le Portugal — se transformera en occupation militaire en avril 1808 lorsque la crise familiale et politique de la dynastie des Bourbons conduit Napoléon à la déposséder du trône. Charles IV doit, en effet, faire face à l'opposition de son fils Ferdinand, prince des Asturies. Choqué par l'attitude de sa mère, la reine Marie-Louise, protectrice de l'ascension indécente de Manuel Godoy et consterné par la faiblesse de son père Charles IV, Ferdinand est sans aucun doute impliqué dans la préparation du soulèvement d'Aranjuez. Explosion de violence populaire, cette émeute a d'immenses conséquences politiques entre le 17 et le 19 mars 1808: Charles IV abdique et Ferdinand VII est proclamé roi. Deux jours après, le vieux roi reprend sa

\footnotetext{
3. Pour une interprétation globale de ce moment dans l'histoire catalane, voir José Enrique Ruiz-DomĖcEc, Catalunya-España. Encuentros y desencuentros, Barcelone, La Vanguardia 2010 et Henry KAMEN, España y Cataluña, Madrid, La Esfera de los libros, 2014. Pour un point plus détaillé sur la guerre de Succession, voir Joaquim ALBAREDA SALVADÓ, La guerra de Sucesión en España (1700-1714), Barcelone, Crítica, 2011.

4. Philippe V abdiqua en janvier 1724 et son fils Louis lui succéda. II mourut prématurément en août 1724 forçant son père à remonter sur le trône.
} 
décision prétextant qu'elle lui a été arrachée sous la contrainte... Pendant ce temps, Murat est entré dans Madrid. L'empereur français va jouer les médiateurs: convoquant et le père et le fils à Bayonne, il obtient d'eux leur abdication respective! Joseph Bonaparte devient roi d'Espagne.

Les tensions familiales ont pesé plus lourd que l'intérêt national. L'expression peut désormais être utilisée, puisque du 2 mai 1808 avec le soulèvement de Madrid et de la déclaration du maire de Mostoles on peut dater l'avènement de la notion de souveraineté nationale et populaire en Espagne ${ }^{5}$. Désormais, la dynastie a affaire avec un nouvel acteur politique: le peuple, la nation. Les Cortès de Cadix, qui donnent au pays sa première constitution le 19 mars 1812, formalisent cette nouvelle configuration politique. Elle est révolutionnaire. L'Ancien Régime espagnol est mort... Mais paradoxalement, le roi Ferdinand VII représente un élément clef de la mobilisation populaire. C'est au nom de " Ferdinand le Désiré " que luttent des bandes armées qui, grâce à l'aide anglaise supervisée par Wellington, mettent en échec les armées et les généraux napoléoniens. Le 24 mars 1814, Ferdinand VII passe la frontière à Figueras. Il est accueilli triomphalement à Saragosse, puis à Valence. Le 4 mai, avant d'entrer à Madrid, il dénonce la constitution de Cadix, "nulle et non avenue ». L’Ancien Régime vient de renaître... et avec lui l'Inquisition que Napoléon, dans son élan modernisateur, avait supprimée.

De 1814 à 1833, Ferdinand VII gouvernera selon les règles du pouvoir absolutiste. Entre 1820 et 1823, il aura dû composer avec un gouvernement issu d'un pronunciamiento qui avait permis le rétablissement de la constitution de $1812^{6}$. Mais Ferdinand VII est rétabli dans ses prérogatives absolues grâce à l'intervention militaire française des "Cent mille fils de saint Louis ", dont Chateaubriand se vantera dans ses Mémoires d'outre-tombe. La répression qui suivra sera féroce et les historiens ont coutume d'appeler la période 1823-1833 «la décennie odieuse ${ }^{7}$ ». Roi absolu, Ferdinand VII n'en demeure pas moins un roi fragile. À l'étranger, les libéraux en exil noircissent sa réputation. À la cour, il doit affronter les ambitions trop visibles de son frère,

\footnotetext{
5. Miguel ARTOLA, La monarquía de España, Madrid, Alianza Editorial, 1999.

6. II s'agit d'un manifeste politique qui est proclamé par une partie de l'armée qui se soulève au nom des principes exposés. Le pronunciamiento peut aboutir à un changement de gouvernement ou pas. II n'est pas un coup d'État: il est une invitation à changer le gouvernement et sa ligne politique. En vérité, il est la première étape du coup d'État!

7. Benito PĖRES GALDOS (1843-1920) a construit une grande fresque romanesque sur l'histoire contemporaine de l'Espagne rassemblée sous le nom Épisodes nationaux (46 titres !). L'un des romans s'intitule : La terreur de 1824.
} 
don Carlos. En effet, Ferdinand VII n'a pas d'héritier. Sa quatrième épouse, Marie-Christine de Bourbon, épousée en 1829, lui donne deux filles: Isabelle née en 1830 et Louise-Fernande, née en 1832. Le 3 avril 1830, avant la naissance de la princesse, est publiée dans La Gaceta la pragmatique sanction qu'en 1789 le roi Charles IV avait décidée mais pas fait sanctionner et qui abolissait la loi salique introduite en Espagne par le premier des Bourbons, Philippe V. La naissance d'Isabelle en septembre 1830 la convertissait dès lors en princesse héritière: don Carlos était déplacé et relégué. En septembre 1832, Ferdinand VII, victime d'une attaque de goutte, est au plus mal. Le clan des partisans de don Carlos lui arrache l'annulation de la décision de 1830 et le rétablissement de la loi salique. Mais, contre tout pronostic, Ferdinand VII se releva de cette alerte et annula la décision qu'on lui avait arrachée. À sa mort, le 29 septembre 1833, la cour est notoirement divisée entre les " cristinos » - partisans de la régence par la reine Marie-Christine - et les « carlistas» - les appuis de don Carlos.

L'histoire du règne de Ferdinand VII nous révèle la matrice de l'histoire de la dynastie des Bourbons. Elle est faite de divisions familiales qui sont des divisions politiques, d'exils, de revanches, de fragilités, de régences... Entre 1833 et 1839, le pays connaît sa première guerre civile entre carlistes et libéraux. Elle ravage le Nord, notamment le Pays basque et la Navarre. C'est plus qu'une division: on peut presque parler de schisme. Pour sauver le trône de sa fille, Marie-Christine fait alliance avec les libéraux. En 1834, elle octroie une charte (Estatuto Real), puis en 1837 elle accepte une constitution tandis que don Carlos continue de plaider pour l'absolutisme et fait de sa foi catholique sa marque de fabrique. Avec le carlisme naît toute une tradition politique qui irriguera progressivement tout le volet intégriste du catholicisme espagnol. La fracture des droites trouve là une de ses origines. Pour tracer un parallèle avec la France en adoptant la typologie de René Rémond, don Carlos incarne l'ultracisme tandis que Marie-Christine aurait une pratique orléaniste ${ }^{8}$.

La paix de Vergara, en 1839, met fin à la guerre civile. Elle place au premier rang politique le général Espartero qui a mené les troupes isabélines à la victoire. En 1840, il est à l'origine d'un pronunciamiento. Il devient même régent, forçant Marie-Christine à l'exil. La reine ne dispose pas d'une grande force politique. Son comportement personnel - elle s'est remariée en secret à l'un de ses gardes du corps dont elle

8. René RÈMOND, Les droites en France, Paris, Aubier-Montaigne, 1982. 
a huit enfants, tous envoyés en France pour cacher le scandale! - la fragilise. Ses tergiversations - elle n'est libérale que pour sauver son trône -, puis, plus tard, ses malversations financières auront miné le chemin qui devait conduire la jeune Isabelle sur le trône ${ }^{9}$. José Güell avait proposé en 1858 un parallèle entre Isabelle II et la grande Isabelle la catholique. Il s'agissait bien de défendre la figure d'une très jeune femme qui occupait un trône contesté par les carlistes, et d'y voir la promesse d'un grand règne ${ }^{10}$. Cet essai restera infructueux et la réputation d'Isabelle II sera toujours sulfureuse. Cela commença par la question hautement politique de son mariage.

Fruit d'une longue négociation diplomatique dont Guizot a laissé le récit ${ }^{11}$, le mariage d'Isabelle sera espagnol: elle épouse son cousin germain François, fils du fils cadet de Charles IV, un autre François. La sœur cadette de la reine, l'infante Louise-Fernande épouse le duc de Montpensier, un des fils de Louis-Philippe. Le mariage royal, célébré en 1846, fut immédiatement objet de scandale. Non seulement il n'était pas consommé, mais il semble que la jeune reine (elle a entre seize et dix-sept ans) s'attache à d'autres hommes. Il faudra l'intervention du pape Pie IX pour forcer la reine et son époux à vivre ensemble. Si des enfants naquirent de cette union, les appétits sexuels tant d'Isabelle que de François - on le surnommait " Paquita ", diminutif féminin de François! - eurent tôt fait d'alimenter toutes sortes de rumeurs et d'insinuations. La chose ne serait qu'anecdotique si elle n'avait eu des effets politiques. Tout récemment, Isabel Burdiel, à qui l'on doit la meilleure biographie d'Isabelle ${ }^{12}$, a préfacé la réédition d'un ouvrage scandaleux du XIX siècle: Los Borbones en pelota, littéralement Les Bourbons à poil $^{13}$. Les images satiriques du pamphlet sont d'une violence inouïe: on y voit la reine offrant son sexe à ses courtisans dont le pénis est en violente érection. Le confesseur de la reine, le père Claret, sa conseillère spirituelle, Sœur Patrocinio sont tout aussi obsédés sexuels et dénudés... Circulant sous le manteau, ces images ont fait plus qu'abîmer la figure de la reine: elles minaient l'institution monarchique en discréditant la

9. Isabelle est proclamée majeure à ses treize ans en 1843. Mérimée dans sa correspondance insinue que la reine mère, Marie Christine, qu'il appelle "la vieille coquine», avait tenté de vendre des toiles originales du Prado et de les remplacer par des copies... le tout à son profit exclusif!

10. Une deuxième guerre carliste a eu lieu entre 1854 et 1856.

11. François GuIzot, Mémoires pour servir à l'histoire de mon temps, Paris, 1874.

12. Isabel BURDIEL, Isabel II, Madrid, Taurus, 2010.

13. Isabel BURDIEL (dir.), Los Borbones en pelota, Saragosse, Institución Fernando el Católico, 2012. 
dynastie. Mérimée, dès 1853, informe Napoléon III du mépris dont elle fait l'objet ${ }^{14}$.

En 1865, l'émeute dite de la saint-Daniel, née de la décision du gouvernement de suspendre le recteur de l'université de Madrid, plonge en réalité ses racines dans une nouvelle incartade politique et financière de la reine Isabelle. Celle-ci avait décidé de céder une partie de son patrimoine à l'État, afin que celui-ci puisse à son tour le vendre et en tirer des recettes qui réduiraient le déficit. Cependant, $75 \%$ du produit de la vente était affecté à l'État tandis que les $25 \%$ restant alimentaient la caisse personnelle de la monarque. Les affidés virent dans ce geste la répétition du geste généreux d'Isabelle la Catholique vendant ses bijoux pour financer l'expédition de Christophe Colomb. Mais l'opposition libérale et démocrate y vit la spoliation pure et simple d'un patrimoine national. Pour Emilio Castelar, professeur à l'université de Madrid et leader démocrate, la reine volait les Espagnols. L'émeute provoqua neuf morts: le trône en resta tout à fait vacillant. Trois ans plus tard, la "Gloriosa ", (c'est le nom donné à la révolution qui est d'abord une conjuration de toutes les oppositions) met fin au règne d'Isabelle. Elle part en exil en France et connaît dès lors un " triste destin ${ }^{15}$ ». Isabelle a échoué comme reine constitutionnelle et la fragilité morale de ses comportements a convaincu les élites espagnoles de l'abandonner. Incapable de s'en tenir au rôle que lui fixaient les textes constitutionnels (essentiellement celui de 1845 puisque la constitution progressiste de 1856 ne fut pas appliquée), Isabelle a démontré que sa pratique perturbait l'équilibre des pouvoirs. La solution passe donc par son renversement.

Le nouveau pouvoir à Madrid, après que les Cortes constitutionnels ont rédigé un texte (1869), cherche un roi. Parmi les candidats, le duc de Montpensier, beau-frère de la reine déchue qui se vante d'appartenir à la famille d'Orléans: c'est une manière de dire son libéralisme. On sonde un prince Hohenzollern (ce qui provoquera la guerre entre la France et la Prusse). On écarte l'hypothèse d'un roi choisi parmi les prestigieux généraux espagnols. Au final, c'est le fils cadet de VictorEmmanuel II roi de Piémont qui est élu. Amédée de Savoie arrivera à Madrid en décembre 1871 et quittera l'Espagne en février 1873. Son bref règne ne fait que traduire l'instabilité dans laquelle s'enfonce le

\footnotetext{
14. " J'ai dit textuellement à Leurs Majestés que la haine qu'elle inspirait n'était tempérée que par le mépris », Lettre 2082, au général L.A. Callier, 2 janvier 1854, CG, t. VII, p. 244.

15. L'expression est de Perez GaLdos, La de los tristes destinos, Madrid, Pelardo y Peláez, 1907.
} 
pays. Après cette parenthèse italienne de la couronne espagnole, la République est proclamée.

Pendant ce temps, autour d'Antonio Canóvas del Castillo, les partisans d'une restauration de la monarchie et des Bourbons s'activent. Ils obtiennent une renonciation au trône de la reine Isabelle II au profit de son fils aîné, le jeune prince Alphonse, dont l'éducation se poursuit à Paris puis à l'académie militaire britannique de Sandhurst. Publiant un manifeste le $1^{\mathrm{er}}$ décembre $1874^{16}$, le jeune prince s'offre pour une restauration qui reprendrait la forme d'une monarchie constitutionnelle. Pérez Galdos trouvera la formule qui dit la synthèse proposée: il s'agit d'unir dans un même corps l'esprit de Pie IX et celui d'Espartero. Début 1876, Alphonse fait son entrée à Madrid et devient roi sous le nom d'Alphonse XII. Une constitution mettant en place un système bicaméral et faisant du roi l'un des détenteurs de la souveraineté est votée en 1876. Le suffrage est redevenu censitaire. La pensée politique de Cánovas emprunte au libéralisme anglais et au libéralisme doctrinaire ${ }^{17}$. Il rêve d'un système bipartisan: à un grand parti conservateur s'oppose un grand parti libéral, les deux étant unis sur la forme de l'État. Cet idéal est mis en forme à partir de 1876. Il surmontera trois grandes épreuves: la mort prématurée d'Alphonse XII en 1885 et la mise en place d'une régence sous l'autorité de la reine Marie-Christine de Habsbourg, l'instauration du suffrage universel en 1890 par le gouvernement libéral de Mateo Praxedes Sagasta et enfin la grande crise de conscience nationale de 1898 consécutive à la perte des colonies cubaine et philippine, arrachées par les États-Unis au terme de combats rapides et humiliants.

En 1902, le jeune Alphonse est proclamé roi sous le nom d'Alphonse XIII. Il a tout juste seize ans. Né après la mort de son père, il est l'enfant du miracle mais aussi roi dès sa naissance. Dès son plus jeune âge, il recevra les marques d'hommage et de révérence auxquelles son statut lui donne droit. Psychologiquement, cela ne fut pas sans conséquence: le jeune homme n'a jamais fait l'expérience d'une résistance... Entouré d'hommes politiques âgés, il se sent beaucoup plus à l'aise dans une ambiance militaire où ses talents et son énergie se libèrent. Comme roi, il doit faire face au lent dérèglement du système des partis: libéraux et conservateurs continuent d'alterner au pouvoir mais des dissidences purement personnelles compliquent la stabilité des groupes. À Madrid, à Barcelone, le socialisme commence à se manifester électoralement.

16. Ce document est connu sous le nom de Manifeste de Sandhurst.

17. Luis Diez Del Corral, El liberalismo doctrinario, Madrid, 1955. 
En Catalogne et au Pays basque, des mouvements régionalistes, sans remettre en cause leur allégeance à la Couronne, développent de nouvelles perspectives pour l'Espagne.

Le 31 mai 1906, lors du mariage du roi avec la princesse anglaise Victoire-Eugénie de Battenberg, un attentat fait vingt-trois morts sur le passage du convoi nuptial. La chance du roi aurait pu être un signe favorable, mais la poursuite des festivités malgré le drame heurte l'opinion publique. Première grave faute de communication, elle sera suivie d'autres erreurs semblables. Quinze ans plus tard, alors que les troupes espagnoles au Maroc ont subi à Annual un véritable massacre (on parle de dix mille morts), le roi célèbre à Burgos le rapatriement des cendres du Cid campeador! L'écart est décidément trop manifeste entre une élite enfermée dans ses codes et ses symboles et un pays qui ploie sous les épreuves et les revers. La violence politique qui se développe à partir de la grève générale de 1917 accentue cette impression de crise désormais ouverte et non plus larvée. Les contemporains ont conscience de cette crise. Les historiens ont d'ailleurs appelé ce temps " la crise de la Restauration ", sous-entendant l'épuisement de la formule historique de 1876.

On sait comment cela se régla: en septembre 1923, le commandant militaire de Catalogne, le général Miguel Primo de Rivera renverse le gouvernement civil et s'installe à la tête d'un directoire militaire. Alphonse XIII entérine le coup d'État. Primo de Rivera avait promis un gouvernement provisoire de 90 jours: il présidera le gouvernement jusqu'en 1930! La constitution de 1876 est suspendue sans pour autant que soit institutionnalisée la dictature sous la forme d'un régime politique réglé par des lois fondamentales. Alphonse XIII a beau voir en Primo de Rivera "son Mussolini ", l'Espagne n'est pas fasciste ${ }^{18}$. Elle n'est plus libérale. Quand les oppositions surmontant non sans mal leurs divisions se rassemblent - c'est le Pacte de Saint-Sébastien de l'été 1930 -, elles s'accordent sur l'idée que formulera avec audace José Ortega y Gasset: "Delenda est Monarchia ${ }^{19}$ ". Incriminant directement Alphonse XIII, il l'accuse de vouloir faire « comme s'il n'y avait pas eu de dictature ", comme "si rien ne s'était passé " et qu'un retour à la normale était possible.

18. Les deux tantes du roi, les infantes, Eulalie et Paz, disent leur admiration pour Mussolini dans leurs mémoires. Voir María Victoriá LóPEZ-CORDóN, La casa de Borbón, vol. 2: 1808-2000, Madrid, Alianza Editorial, 2000, p. 676.

19. La formule conclut l'article donné par le philosophe le 15 novembre 1930 et passé à la postérité. «Espagnols, écrit Ortega, votre État n'existe pas. Reconstruisez-le! Delenda est Monarchia ». 
Le 12 avril 1931, des élections municipales ont lieu dans toute l'Espagne. Elles sont le prélude à la reprise d'une vie politique selon les règles de la constitution de 1876. L’opposition républicaine l'emporte dans 45 des 50 capitales de province. Et même si ses conseillers tentent de faire croire à Alphonse XIII que le rapport de forces numériques est favorable aux monarchistes (en comptabilisant tous les conseillers municipaux, or près de vingt-deux mille avaient été élus sans compétiteurs aux termes de la loi électorale qui prévoyait l'absence de vote en cas de candidature unique), le roi ne cède pas à la tentation de cette lecture biaisée. Il abdique et le 14 avril 1931 la République est proclamée.

Arrêtons-nous un instant pour faire un bilan de cette monarchie $\mathrm{du} \mathrm{XIX}^{\mathrm{e}}$ et du début du XXe siècle. Ferdinand VII et Alphonse XII sont morts rois d'Espagne. Isabelle II et Alphonse XIII mourront en exil, en 1904 à Paris pour la première, à Rome en 1941 pour le second. Tous auront connu l'exil: Ferdinand VII de 1808 à 1814, Isabelle II de 1868 à 1904, Alphonse XII comme jeune prince de 1868 à 1876, Alphonse XIII de 1931 à 1941. Tous, à l'exception d'Alphonse XII (dont le règne fut bref: une dizaine d'années), ont dû gouverner avec des adversaires politiques. Ils n'y ont jamais vraiment consenti et ont toujours voulu reprendre la main. Ils n’ont pas joué le jeu de la constitution qui leur assignait une fonction précise dans l'État. Leur éducation, le plus souvent négligée, continuait de les convaincre qu'ils incarnaient l'Espagne et que l'État se confondait avec leur volonté.

Ce bilan politique et historique explique la fragilité de la monarchie. Éclaboussée plus qu'il ne faut par des comportements outrageusement scandaleux quand il s'agissait de malversations financières (la reine Marie-Christine de Bourbon, Isabelle II) ou grivoisement comiques (concernant Isabelle II et Alphonse XIII, grand collectionneur de photos érotiques), la monarchie a souffert par et de ses incarnations successives. Le principe qu'incarne l'homme ou la femme qui règne n'a jamais vraiment percé devant des comportements qui trahissaient une trop grande complaisance à l'égard de pulsions privées. On ne compte pas les libelles et les articles qui dénonçaient les Bourbons. Un siècle de critiques, de blagues féroces et de mépris mine le respect, principe essentiel sur lequel reposent le pouvoir royal et sa symbolique.

Il faut avoir présent à l'esprit ces réalités qui sont entrées dans la culture politique espagnole. Elles y sont demeurées et si elles ont, un temps été masquées par la popularité de Juan Carlos, on a pu voir avec quelle intensité elles sont revenues au premier plan lors de la crise de l'institution monarchique ces dernières années. Les images négatives 
que l'on peut avoir des Bourbons ne sont pas que des effets d'opinion: durablement ancrées dans l'esprit public, elles font partie d'une culture de la protestation et à ce titre, elles peuvent être réactivées dès lors que des similitudes entre le présent et le passé semblent apparaître.

\section{LA MONARCHIE ET LE PACTE DÉMOCRATIQUE}

Pour autant, ne voir l'institution monarchique que par le prisme de l'héritage historique négatif ne permet pas de comprendre la place qu'elle a occupée à partir de 1975 quand Juan Carlos, succédant à Franco, devint le "pilote du changement ", pour reprendre l'expression de l'historien Charles Powell ${ }^{20}$. Mais pour que Juan Carlos puisse devenir ce pilote, il avait fallu que l'option monarchiste représente une alternative possible. Reprenons donc rapidement l'histoire des hommes qui font la monarchie pour comprendre l'héritage politique et familial dont Juan Carlos était lesté.

Nous avons laissé Alphonse XIII en exil. Sa famille se déchire: il vit séparé de son épouse la reine Victoire-Eugénie. Son premier fils, Alphonse, prince des Asturies, renonce à ses droits dynastiques le 11 juin 1933 pour pouvoir épouser une Cubaine riche peut-être, mais pas de sang royal. Les temps ne sont pas mûrs pour un mariage morganatique, ou plutôt les mentalités royales ne sont pas prêtes à cela. Don Alphonse meurt dans un accident de voiture, à Miami, en 1938. Le second fils, don Jaime, est contraint de renoncer à ses droits dynastiques: sourd et muet, on estime qu'il est incapable d'être roi ${ }^{21}$. Marié à Emmanuelle de Dampierre, il aura un fils, Alphonse, duc de Cadix et duc d'Anjou qui, en 1972, épousera la petite-fille de Franco ${ }^{22}$. C'est donc au troisième fils, don Juan qu'échoient les droits dynastiques. En 1941, il devient le chef de la famille royale et le prétendant au trône d'Espagne quand son père Alphonse XIII abdique quelques mois avant sa mort en désignant son fils comme son successeur.

Sa vie politique s'organisera désormais autour de sa volonté de restauration des Bourbons. Ce combat est double: pour don Juan, il est un combat dynastique et historique mais aussi un combat politique

20. Charles T. POWELL, El piloto del cambio. El rey, la monarquía y. la transición a la democracia, Barcelone, Editorial Planeta, 1991.

21. Les monarchistes légitimistes français ne reconnaissent pas cette renonciation et tiennent cette branche pour la branche légitime. C'est ainsi que l'actuel duc d'Anjou, Louis est Louis XX pour les légitimistes.

22. Louis d'Anjou est donc l'arrière-petit-fils d'Alphonse XIII et de Franco! 
et il saura faire évoluer le sens de la monarchie pour lui redonner toutes ses chances dans le débat espagnol. Le manifeste de Lausanne de mars 1945 en est la première étape: le comte de Barcelone entend profiter du courant qui emporte tous les régimes totalitaires en Europe et présente la monarchie comme la solution. Ce sera une "monarchie réconciliatrice, juste et tolérante ", encadrée par une constitution qui reconnaîtra « les droits inhérents à la personne humaine et les libertés politiques ", établira une "assemblée législative élue par la nation ", qui reconnaîtra les diversités régionales de l'Espagne et qui approuvera une "large amnistie politique ". Il n'hésite pas à exprimer son opposition frontale aux principes du franquisme ${ }^{23}$.

Comme tout combat politique, il est dépendant des circonstances. En 1947, Franco fait ratifier par référendum la loi de succession qui établit en son premier article que «l'Espagne est un royaume ", en son article 2 que Franco est le chef de l'État et en son article 7 que «Franco peut proposer aux Cortes la personne qui sera appelée à lui succéder comme roi ou régent $»^{24}$. Don Juan proteste contre cet arbitraire qui donnait à Franco toute latitude pour restaurer la monarchie des Bourbons ou au contraire instaurer une nouvelle dynastie. Mais en 1948, il accepte de rencontrer Franco et de lui confier son fils Juan Carlos pour que ce prince espagnol soit éduqué en Espagne. L'épisode est essentiel parce qu'il apparaît, pour l'opposition antifranquiste, plus que comme un compromis, comme une compromission entre don Juan et le dictateur. Après l'avoir publiquement dénoncé, voilà que don Juan se place sous sa férule en lui abandonnant son fils. Pour les franquistes, c'est une véritable "prise de guerre " et Franco jouera le fils contre le père... Quant à Juan Carlos, alors âgé de dix ans (il est né le 5 janvier 1938 à Rome), c'est un arrachement au cadre familial et une plongée dans l'inconnu.

Le jeune prince sera de fait éduqué par Franco dans l'Espagne de Franco. Il y fera une carrière militaire, renouant avec la préparation au trône que l'on avait donnée à Alphonse XII qui lui aussi fut le

23. « Dès que j'ai assumé les devoirs et les droits de la Couronne d'Espagne, j'ai montré mon insatisfaction à l'égard de la politique intérieure et extérieure suivie par le général Franco. [...] Je ne lève aucune étendard de sédition, je n'incite personne à se soulever, mais je veux rappeler à ceux qui soutiennent le régime l'immense responsabilité qu'ils assument en prolongeant ainsi une situation qui est en train de mener le pays vers une irrémédiable catastrophe », Manifeste de Lausanne, 19 mars 1945.

24. Pour une approche détaillée voir Gonzalo REDondo, Política, cultura y sociedad en la España de Franco (1939-1975), t. 1 : La configuración del Estado español, nacional y católico (1939-1947), Pampelune, EUNSA, 1999, p. 787-1056. 
restaurateur des Bourbons. Jusqu'en 1962, la figure de Juan Carlos est discrète. Son mariage avec Sophie de Grèce est un événement de la vie mondaine. L'installation du nouveau couple à Madrid reste discrète. La naissance de leurs trois enfants - Hélène en 1963, Christine en 1965, Philippe en 1968 - reste un événement privé, même si le baptême de Philippe permet à la reine Victoire-Eugénie, la veuve d'Alphonse XIII, de revenir en Espagne pour la première fois depuis 1931. Il faut attendre juillet 1969 pour que Juan Carlos devienne une personnalité politique. Franco le désigne en effet comme son successeur. Cette décision provoque une crise familiale: le comte de Barcelone est furieux de constater que son fils accepte la succession de Franco sans le consulter et en violation flagrante des règles successorales et dynastiques ${ }^{25}$. Juan Carlos prendra d'ailleurs le titre de "prince d'Espagne " et non le titre traditionnel des héritiers de la couronne à savoir " prince des Asturies ". Ce faisant, il cherchait à ménager son père et à ne pas violer protocolairement les règles de la famille royale.

En 1969, Franco est chef de l'État depuis plus de trente ans. Il vieillit et les cercles politiques bruissent des spéculations que génèrent ce que l'on appelle pudiquement " le fait biologique ", c'est-à-dire la mort du vieux général. Juan Carlos est idéalement placé pour recueillir cette succession... si l'ordre franquiste survit à son fondateur. Le prince sera aidé par l'action du directeur général de la Télévision espagnole, un certain Adolfo Suárez ${ }^{26}$. Pendant six ans, le prince s'est donné à connaître et lorsque Franco meurt le 20 novembre 1975, il n'est plus un inconnu. Il demeure cependant une énigme tant il s'est habilement enfermé dans le silence. On sait désormais que cette attitude était le fruit d'une prudence absolue. Juan Carlos sait qu'il possède peu d'atouts: désigné par Franco contre son père, il n’a pas la légitimité monarchique pure; héritier du dictateur, il apparaît comme le continuateur du régime honni par ses adversaires. Enfin, il ne jouit pas de la confiance des cercles franquistes. Le président du conseil Carlos Arias Navarro le méprise ouvertement et Juan Carlos déclarera publiquement lors de son voyage officiel aux États-Unis en mai 1976 que son Premier ministre "est un désastre "! Ce n'est qu'en juillet de la même année que le jeune roi abat sa première carte: il nomme Adolfo Suárez chef du gouvernement. Par un effet d'anachronisme, on est amené à penser

25. Ce point est important : la désignation de Juan Carlos n'est pas le résultat d'un accord au sein de la famille royale comme l'avait été, par exemple, la renonciation au trône d'Isabelle II en faveur de son fils Alphonse XII.

26. Voir Juan Francisco FuENTES, Adolfo Suárez. Una biografía política, Barcelone, Planeta, 2011. 
que la nomination suscita l'approbation générale. Tant s'en faut. Dans la presse, un essayiste, Ricardo de La Cierva, tentera de devenir l'Ortega y Gasset de sa génération en dénonçant « l'erreur Suárez ${ }^{27}$ ». Suárez vient du courant phalangiste du régime: il a été ministre du Mouvement (c'est-à-dire secrétaire général du parti unique). Il n’a que sa jeunesse (il est de 1932) pour lui et son sens de la communication. Tout cela procède bien d'un pari politique fait par Juan Carlos qui a vu dans cet homme la personnalité idoine pour démanteler de l'intérieur le franquisme.

Dès l'automne 1976, la loi de réforme politique est votée par les Cortes franquistes dans un acte d'auto-immolation politique étonnant. Le pari légaliste de Juan Carlos est en route. Des élections générales sont convoquées pour le 15 juin $1977^{28}$. Elles seront des élections pleinement libres et régulières. Le Parti communiste espagnol peut y concourir après avoir été légalisé le samedi saint de cette année 1977. Santiago Carrillo, son leader, donne immédiatement une conférence de presse avec, derrière lui, le drapeau monarchiste et non le drapeau républicain. Le 14 mai 1977, le comte de Barcelone renonce à ses droits dynastiques et reconnaît Juan Carlos, son fils, comme le roi d'Espagne. Il termine son discours en se tournant vers son fils et en disant: " Majesté, pour l'Espagne, tout pour l'Espagne, vive l'Espagne, vive le Roi ». Ainsi, au matin du 16 juin 1977, Juan Carlos peut estimer qu'il a mené la première phase de la transition démocratique sans heurts et qu'il a libéré l'expression démocratique des opinions politiques des Espagnols.

La deuxième phase, d'une certaine façon, ne lui appartient plus. L'assemblée élue est, de fait, une assemblée constitutionnelle. Le texte élaboré par une commission de sept membres sera approuvé par référendum le 6 décembre 1978 par plus de $88 \%$ de oui et une participation de plus de $67 \%$. Dans ce texte, l'alinéa 3 de l'article $1^{\mathrm{er}}$ désigne la forme politique de l'État: une monarchie parlementaire. Le titre II porte sur la Couronne (articles 56 à 65) et établit les fonctions du roi et les règles de son action.

Il y aura une troisième phase qui ne pouvait être prévue. Le 23 février 1981, une tentative de coup d'État a lieu au moment où l'ensemble des forces politiques est rassemblé au Parlement pour la séance d'investiture de Leopoldo Calvo Sotelo, désigné comme président du gouvernement à la suite de la démission d'Adolfo Suárez. Alors que les

27. Ortega y Gasset avait en 1930 dénoncé « l'erreur Berenguer », nom du général nommé à la tête du gouvernement par Alphonse XIII après la démission de Primo de Rivera.

28. À cause du souvenir d'avril 1931, on a choisi d'aller directement aux élections générales et de retarder les élections municipales. De fait, il faudra attendre avril 1979 
institutions politiques sont ainsi prises en otage, seul le roi, entouré de quelques secrétaires d'État, est à même d'assurer le fonctionnement régulier des institutions. Dans la nuit, à 1 h 20 du matin, Juan Carlos, en uniforme de capitaine-général, intervient à la télévision. Son discours est centré sur la défense de la Constitution et il agit comme l'un de ses organes en incarnant la " Couronne ». Il a ordonné aux autorités civiles et militaires de «maintenir l'ordre institutionnel dans la législation en vigueur " et rappelle que " la Couronne ne peut tolérer l'action de personnes qui prétendraient interrompre par la force le processus démocratique que la Constitution votée par le peuple espagnol lors d'un référendum déterminant ". Dans l'émotion du moment, on a trop peu prêté attention au calibrage extrême de ce très bref message d'une minute et demie! Le roi n'a cessé de se placer dans le cadre constitutionnel. Il a sauvé la démocratie et la constitution de 1978 en jouant le rôle que celle-ci lui avait dévolu. Il a agi comme pouvoir constitutionnel démontrant que la Couronne était parfaitement compatible avec la démocratie. Il est le premier roi d'Espagne à faire cette démonstration.

Immédiatement, le sentiment que le roi vient de gagner une partie décisive se répand non seulement parmi les Espagnols mais dans l'opinion publique mondiale. Si certains pouvaient douter de la légitimité $\mathrm{du}$ roi, successeur de Franco, Juan Carlos vient, en agissant constitutionnellement, de gagner sa légitimité historique et politique. Elle sera longtemps la base de l'immense respect qu'il inspirait. Fort de cette transition démocratique réussie, Juan Carlos va devenir l'ambassadeur de la nouvelle Espagne démocratique. La signature de l'adhésion de l'Espagne à la CEE en juin 1985, l'accueil de la conférence pour la paix au Moyen-Orient fin 1991, les Jeux olympiques de Barcelone en 1992 sont autant de moments fastes du règne de Juan Carlos. L'alternance démocratique - de 1982 à 1996 ont gouverné les socialistes de Felipe González, de 1996 à 2004, les conservateurs de José María Aznar, puis de 2004 à 2011 à nouveau les socialistes —, la prospérité du pays et sa modernisation accréditent l'idée d'un succès espagnol. Juan Carlos est célébré comme le promoteur de la période la plus brillante de l'histoire contemporaine de l'Espagne ${ }^{29}$.

Le contraste est saisissant en effet entre ce règne qui voit fonctionner une constitution libérale et démocratique et les expériences antérieures qui avaient vu les rois être en eux-mêmes une partie

29. Voir par exemple, Real Academia de la Historia, 25 años de reinado de S. M. D. Juan Carlos I, Madrid, Espasa Calpe, 2002. 
des obstacles à la démocratisation du pays. Juan Carlos apportait un démenti à l'histoire passée de la dynastie des Bourbons en inscrivant celle-ci dans un système de monarchie parlementaire. Mais à ce premier volet, il en ajoutait un autre: il conjurait l'histoire de l'Espagne avec laquelle se confond celle de sa famille et il en écrivait une autre dont les Espagnols pouvaient être fiers.

\section{UNE MONARCHIE DÉMOCRATIQUE}

Il est temps de conclure car nous avons peut-être là la clef de la crise qui affecta l'institution monarchique dans le courant des années 2000. L'Espagne était devenu un pays normal. Dans l'historiographie, on pouvait mesurer cela dans les ouvrages qui désormais insistaient sur la non-exception espagnole ${ }^{30}$. Un vertige de succès s'empara de la société espagnole: il devait conduire à des excès de toute sorte. Quand la crise économique éclata et révéla brutalement les fragilités du modèle espagnol, l'effet ne fut pas que matériel. Il fut aussi moral. C'est un doute qui, progressivement, gangrena la société. L'effondrement du marché immobilier, l'explosion du chômage, le retour de l'émigration des jeunes pour trouver un emploi: le pays douta de lui-même et du récit que l'on avait donné de sa prospérité. Pire encore: l'ampleur de la corruption des élites se révéla supérieure à ce que les Cassandre avaient pu déjà dénoncer. La révélation des affaires troubles du gendre de Juan Carlos, Iñaki Urdangarin, mari de l'infante Christine, allait lézarder l'image jusque-là épargnée du roi et de sa famille. Urdangarin fut accusé de détournement de fonds publics et sa femme est de fraude fiscale. Mais il y a plus: l'accident du roi au Bostwana, où il était parti en avril 2012 pour un safari, allait mettre sur le devant de la scène sa liaision avec la princesse Corinne zu Sayn-Wittgenstein. Enfin, les problèmes de santé donnaient de Juan Carlos l'image d'un homme fatigué et usé. Très vite, l'opinion devint d'une extrême sévérité. En avril 2012, l'un des journalistes les plus en vue, Iñaki Gabilondo, signait sur El Pais. com un éditorial qui se concluait ainsi: " Majesté, divorcez ou abdiquez. "

Depuis Juan Carlos a abdiqué. La fragilisation de sa position dans l'opinion publique était réelle. Elle posait un problème politique. Pourquoi Juan Carlos a-t-il cependant cédé alors qu'en 2012, lors de ses vœux aux Espagnols, il avait clairement fait savoir que «le service de

30. L'un des premiers titres à représenter ce courant est Juan Pablo Fusı, Jordi PALAFox, España. El desafio de la modernidad, Madrid, Espasa Calpe, 1998. 
l'Espagne était sa passion et sa mission "? La presse avait dès le lendemain titré sur le rejet de l'hypothèse de l'abdication. Les pressions politiques et familiales ont été nombreuses. La bonne image du prince héritier rendait facile la succession. Ensuite, la mort en mars 2014 d'Adolfo Suárez avait d'un coup ramené à la mémoire des citoyens cette page glorieuse du début du règne. Juan Carlos intervint à la télévision pour rendre hommage à son ancien Premier ministre ${ }^{31}$. Ce message est un premier testament politique. Il y revendique " un des épisodes les plus brillants de l'histoire de l'Espagne contemporaine: la Transition qui, portée par le peuple espagnol, fut impulsée par Adolfo et [lui] ». Fort de ce regain de popularité qui est d'abord le fruit d'une nostalgie, Juan Carlos a accepté de se sacrifier pour sauver l'institution monarchique. On peut être sûr que dans ce choix a pesé l'exemple de son père, don Juan, comte de Barcelone. Juan Carlos, lors d'un entretien télévisé réalisé à l'occasion de ses soixante-quinze ans (en janvier 2013), avait rappelé que son père fut son mentor politique et que c'est de lui qu'il avait appris que la monarchie était au service des Espagnols.

La relève désormais est assurée d'une main ferme et rigoureuse. Cette étape est essentielle dans la consolidation du modèle de la monarchie parlementaire et rappelle que la couronne est réglée par la Constitution. Mais si ce pacte de la Couronne avec la démocratie est vivant et solide, l'histoire rappelle que la fragilité d'une monarchie tient moins à ses principes qu'à ses incarnations. C'est tout le défi qui est posé à Philippe VI que de continuer à bénéficier du soutien de l'opinion alors même qu'il est exonéré de toute compétition électorale. L'opinion publique joue dans la confirmation de la monarchie un rôle plus éminent qu'on ne l'a cru. La monarchie espagnole est bien démocratique: c'est, par-delà sa soumission à l'esprit public, sa force.

31. Le roi n'intervient que pour son message de Noël le 24 décembre à 21 heures Par quatre fois, il est intervenu exceptionnellement: dans la nuit du 23 au 24 février 1981 pour empêcher le coup d'État, le 11 mars 2004 au soir des attentats de Madrid qui avaient coûté la vie à 192 personnes, le 23 mars 2014 à l'annonce de la mort d'Adolfo Suárez, le 2 juin 2014 pour expliquer son abdication. 


\title{
10 \\ La crise de la représentation et l'ascension de Podemos: L'émancipation citoyenne « au cœur » de l'échiquier politique?
}

\author{
Mathieu PeTithomme \\ "Les démocraties contemporaines sont issues d'une \\ forme de gouvernement que ses fondateurs opposaient \\ à la démocratie ». \\ (Bernard Manin)
}

\begin{abstract}
Dans son ouvrage classique, Bernard Manin rappelle que l'usage nomme "démocraties représentatives ", par opposition à la démocratie directe, les régimes démocratiques actuels qui trouvent leurs origines dans les trois révolutions modernes (anglaise, américaine et française), alors même que "ces institutions n'ont nullement été perçues, à leurs débuts, comme une variété de la démocratie ou une forme de gouvernement par le peuple ${ }^{1}$ ». De nombreuses démocraties font aujourd'hui face à une " crise de la représentation ", dans le sens où les gouvernants, à l'heure de la mondialisation et de la conditionnalité européenne, tiennent rarement leurs promesses électorales, voire même gouvernent en reniant complètement leurs engagements. Les citoyens ordinaires s'en trouvent d'autant plus frustrés qu'ils ont le sentiment que le principe de l'élection, fondement même de la démocratie, devient alors vide de sens. L'Espagne ne fait pas exception à cette tendance. Elle a vu émerger, en réponse, un mouvement citoyen fondé en janvier 2014, Podemos (" Nous pouvons »), qui a fait une entrée fracassante sur la scène politique lors des élections européennes du 25 mai 2014.

En attirant les voix de plus de 1,2 million d'électeurs, il a obtenu $7,97 \%$ des suffrages exprimés et envoyé cinq eurodéputés au parlement de Strasbourg. Depuis lors, l'« effet » Podemos recompose jour après jour
\end{abstract}

1. Bernard MANIN, Principes du gouvernement représentatif, Paris, Flammarion, [1995] 2012, p. 6. 
le débat politique espagnol et fait pressentir des mutations plus profondes qui pourraient avoir lieu lors des prochaines élections législatives de décembre 2015, sur fond d'une crise économique grave et durable (le taux de chômage est toujours de $23,2 \%$ en avril 2015 et touche 4,5 millions de personnes), de scandales récurrents de corruption (affaire Bárcenas, cas Gürtel pour le PP, scandale des ERE pour le PSOE etc.) et du discrédit de la classe politique. Les sondages d'opinion ne cessent de montrer que "la mayonnaise semble prendre " suivant l'expression d'Iñigo Errejón, secrétaire politique du mouvement, le situant au moins en troisième position. En août 2014, El Mundo plaçait Podemos à 21,2 \% des intentions de vote, sur les talons du PSOE pronostiqué à $22,3 \%$ des suffrages ${ }^{2}$. Le sondage le plus pessimiste pour la nouvelle force politique, celui du journal très conservateur La Razón, le plaçait à $15 \%$ en septembre 2014, soit le double de son résultat des européennes, derrière le PSOE $(23,4 \%)$ et le PP en tête $(33,9 \%)^{3}$. Mais en novembre 2014 , le plus optimiste le plaçait désormais en première position avec $27,7 \%$ des intentions de vote, contre $26,2 \%$ pour le PSOE et $20,7 \%$ pour le $\mathrm{PP}^{4}$.

Même s'il faut prendre ces enquêtes avec précaution en raison de "l'abstention différentielle " des électeurs du PP et des appels certains du PSOE au " vote utile " qui pourront remobiliser leurs sympathisants le moment venu, la percée de Podemos dans l'opinion n'en est pas moins spectaculaire ${ }^{5}$. Ainsi, 60 \% des Espagnols, pour qui le chômage, la corruption et la situation économique constituent les trois enjeux principaux, considèrent "les propositions de Pablo Iglesias comme positives $^{6} »$. Sa montée en puissance s'effectue d'abord au détriment d'Izquierda Unida ("Gauche unie », IU), la coalition dominée par le Parti communiste d'Espagne, représentant traditionnel de la gauche alternative, qui après avoir progressé depuis 2008 en se faisant le porte-parole de l'opposition à l'austérité et obtenu 9,9\% des voix et six eurodéputés en mai 2014, n'attire plus que 3,8\% des intentions de vote.

\footnotetext{
2. Sondage El Mundo/Sigma Dos, 31 août 2014.

3. Sondage La Razón/NC Report, 1er septembre 2014.

4. Sondage El País/Metroscopia, 2 novembre 2014.

5. L'« abstention différentielle» est un phénomène bien connu en sociologie électorale, qui implique que lors des élections « intermédiaires » (régionales, municipales, européennes, etc.) entre deux élections majeures (présidentielles et législatives), les électeurs du parti au pouvoir ont tendance à plus s'abstenir que ceux de l'opposition, qui profitent de ces scrutins pour marquer leur défiance à l'égard du gouvernement. Cf. Raul MAGNI-BERTON, « Pourquoi les partis gouvernementaux perdent-ils dans les élections intermédiaires? Enquête Eurobaromètre 2004 et élections européennes », Revue française de science politique, vol. 58, n 4, 2008, p. 643-656.

6. Barómetro La Sexta, 7 décembre 2014.
} 
Mais Podemos cherche surtout à disputer le statut de principal parti de l'opposition au PSOE: 49 \% des sympathisants socialistes considèrent d'ailleurs que Podemos peut dominer la gauche. Dans un contexte où $92 \%$ des Espagnols pensent que le pays n'est pas sorti de la crise et où $70 \%$ évaluent négativement l'action du gouvernement conservateur de Mariano Rajoy, le mouvement s'est constitué en parti politique lors de son "assemblée citoyenne" de Madrid en octobre 2014, et cherche désormais à occuper " la centralité de l'échiquier politique » en « replaçant l'émancipation citoyenne au cœur du débat " suivant Pablo Iglesias, son dirigeant et habile communicant ${ }^{7}$.

Lors des élections régionales de mars 2015 en Andalousie, Podemos a obtenu 590011 voix, soit $14,8 \%$ des suffrages exprimés, lui permettant d'envoyer quinze députés au parlement régional. Le parti a donc confirmé son statut de troisième force politique, devenant un " outsider " potentiellement déterminant dans la formation d'une majorité. Mais son résultat fut aussi plus faible qu'espéré par sa direction nationale, face au maintien du PSOE (1,4 million de voix, 35,4 \% et 47 sièges) dans l'un des «bastions » historiques du socialisme espagnol. Pour Podemos, ce scrutin illustra toutefois la transformation de l'essai des européennes et la pénétration du parti dans les institutions. Il confirma aussi une évolution locale qui pourrait être prémonitoire de mutations futures plus larges au niveau national, à travers la fragmentation croissante du paysage électoral, de même que le déclin des deux partis dominants traditionnels ${ }^{8}$.

En alliant des critiques radicales à l'égard du "système " et de " la caste PPSOE ", tout en adoptant un " programme économique pour les gens » teinté de références sociales-démocrates et en se disant disposé à des alliances, Podemos cherche à incarner le changement et une alternative de gouvernement en jouant le même rôle que le PSOE durant la transition démocratique 9 . Quels sont les ressorts de cette nouvelle mobilisation politique? En s'appuyant sur une enquête de terrain menée au sein de deux " cercles " du parti en février 2015, au cœur historique de Podemos dans son local du quartier populaire de Lavapiés

\footnotetext{
7. Pablo Manuel Iglesias Turrión est né le 17 octobre 1978 dans le quartier populaire de Vallecas à Madrid. Auteur en 2008 d'une thèse sur l'action collective post-nationale, il est devenu la même année maître de conférences en sciences politiques à l'université Complutense.

8. En effet, le PSOE (35,4\%) et le PP (26,7\%) attirent de moins en moins d'électeurs. À l'inverse, les partis de la "nouvelle politique », Podemos, mais aussi le parti Citoyens représenté en Andalousie par Juan Marin Lozano, qui obtint 369000 voix, 9,2 \% des suffrages exprimés et 9 sièges, firent leur entrée sur la scène politique locale (devant IU-CA, qui obtint 6,89 \% des voix et seulement 5 sièges). 9. Jacobo Rivero, Conversación con Pablo Iglesias. Podemos, de la calle a Bruselas (3e ed.), Madrid, Ediciones Turpial, 2014, p. 12.
} 
et dans le cercle du quartier plus huppé de Salamanca à Madrid, ce chapitre explique les raisons de l'ascension fulgurante du nouveau parti. Il revient d'abord sur le contexte de crise de la représentation en Espagne et sur la structure d'opportunité politique favorable à l'émergence d'une formation qui entend fournir un débouché politique aux mouvements sociaux des indignés. La seconde partie étudie la structuration organisationnelle de Podemos, à partir des militants historiques de Lavapiés et d'Izquierda Anticapitalista ("Gauche anticapitaliste ", IA), en s'appuyant sur une fédération d'assemblées et de collectifs autonomes et en utilisant largement les nouvelles technologies et les réseaux sociaux. La troisième partie revient enfin sur le leadership, le discours politique et la stratégie de compétition de Podemos, avant d'évoquer pour conclure, les effets que son éclosion pourrait potentiellement engendrer sur le système partisan espagnol.

\section{AUSTÉRITÉ ET CORRUPTION: TOILES DE FOND DE LA CRISE DE LA REPRÉSENTATION POLITIQUE}

\section{Le discrédit du " système PPSOE "}

La crise de la représentation entraîne une rupture politique et économique profonde des élites des partis dominants avec les aspirations citoyennes: responsables de la spéculation bancaire et immobilière des années du « boom " (1993-2007), dotés d'appareils corrompus et ayant tour à tour soutenu les politiques d'austérité, le PSOE de 2008 à 2011 puis le PP depuis lors, feraient partie du problème et non de la solution. Il est vrai que l'exaspération des jeunes et des classes populaires est à son comble face à la persistance d'un chômage de masse, à la succession des expulsions locatives, à l'appauvrissement de larges secteurs de la société et à la hausse des inégalités qui fait désormais de l'Espagne le pays le plus inégalitaire d'Europe devant la Grèce. Face à cette dégradation de la situation sociale perçue par tous, puisqu'une famille sur deux a été touchée par le chômage depuis 2008 et que 1,7 million de familles survivent avec l'ensemble de leurs membres sans emploi, le gouvernement et le PP se réjouissent du " retour de la croissance " et de la " sortie de crise ", en déphasage complet avec le ressenti des citoyens ordinaires ${ }^{10}$.

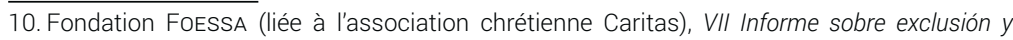
desarrollo social en España, Madrid, 2014, p. 2. Sur l'optimisme macroéconomique du gouvernement, cf. Soraya SÀENZ DE SANTAMARÍA, « La recuperación empieza a llegar a las familias », $A B C, 11$ décembre 2014. 
Éclaboussés par les scandales de fausses factures, de dépenses excessives des députés, de détournement de fonds, d'évasion fiscale et de marchés publics surfacturés par des élites locales à des grandes entreprises du bâtiment, qui sont révélés quotidiennement par la presse, les membres des deux grands partis sont plus que jamais perçus comme une oligarchie, un "cartel » de personnalités qui partagent les mêmes intérêts au maintien du système politique actuel et de ce qu'un nombre croissant de citoyens perçoit comme des " privilèges » indus ${ }^{11}$. Les Espagnols sont frustrés de l'alternance figée au pouvoir, jugée inefficace, entre le PP et le PSOE. Cette structure d'opportunité politique, labellisée par Podemos comme le « PPSOE » (qui rappelle le " UMPS » du FN en France), caractérisée par le discrédit des deux grands partis traditionnels, du bipartisme et du " système " qu'ils ont mis en place lors de la transition, notamment le système électoral, la désignation des candidats par listes fermées, et la politisation de la justice et des grandes entreprises au sein desquelles l'État possède des parts, entre en résonance avec les aspirations des citoyens au changement.

Imprégné de l'intérêt commun des deux groupes dominants, les élites de "l'ancien régime " franquiste qui se recyclèrent dans les rangs de l'Union du centre démocratique (UCD) d'Adolfo Suarez puis du Parti populaire à partir de 1986, et les "nouveaux démocrates " incarnés par le PSOE de Felipe González et d'Alfonso Guerra, le «pacte de la transition " explique le choix en 1978 d'instaurer un système électoral proportionnel en théorie mais majoritaire dans les faits et surtout très inégalitaire, qui favorise structurellement les grands partis au détriment des plus petites formations ${ }^{12}$. Face à ce qui est perçu comme un frein au changement, de nombreux intellectuels et membres de la

11. Sur la théorie de la cartelisation et ses critiques, cf. Peter MAIR, « Changing models of party organization and party democracy: the emergence of the cartel party », Party Politics, vol. 1, $n^{\circ} 1,1995$, p. 5-31; Yohann AuCANTE et Alexandre DÉZE (dir.), Les systèmes de partis dans les démocraties occidentales. Le modèle du parti cartel en question, Paris, Presses de Sciences Po, 2008

12. Pour l'élection des 350 membres du Congrès des députés tous les quatre ans, chacune des 52 circonscriptions (les 50 provinces plus les «villes autonomes » de Ceuta et Melilla) se voit attribuer un nombre de sièges proportionnel à leur population, avec un minimum de deux. La plupart des circonscriptions, rurales et peu peuplées, n'en apportent qu'un nombre très limité : le pourcentage de voix nécessaires pour obtenir un siège est si élevé que les petits partis ne peuvent espérer être représentés que dans les grandes circonscriptions. En 2008, par exemple, le Parti socialiste a obtenu 169 sièges avec 11 millions de voix, alors qu'IU n'a obtenu que deux sièges avec un million de voix. Pour le Parti socialiste, chaque siège au Congrès correspondait à 65470 voix, alors qu'il en fallait 481520 pour qu'lU obtienne un même siège. Sur le pacte de la transition, cf. Álvaro Soтo, Transición y cambio en España 1975-1996, Madrid, Alianza Editorial, 2005, p. 87-95. 
société civile demandent désormais une " seconde transition » à travers une réforme de la constitution et de la loi électorale de 1978, que ni le PP ni le PSOE ne sont prêts à soutenir puisque cela remettrait en cause leur hégémonie ${ }^{13}$. Le "système" semble d'autant plus bloqué qu'une réforme requiert une majorité des trois cinquièmes tant au Congrès des députés qu'au Sénat, disposition qui rend quasiment imprescriptible un accord entre le PP et le $\mathrm{PSOE}^{14}$.

Mais les citoyens ne sont pas dupes. Ils savent aussi que l'indépendance assez partielle de la justice explique que peu de responsables politiques soient condamnés malgré le nombre très élevé de mises en examen: ce sont en effet les partis dominants qui nomment les vingt et un membres du Conseil général du pouvoir judiciaire (CGPJ) et ceux du Tribunal constitutionnel, ce qui explique les interférences constantes de la classe politique dans les affaires judiciaires. Les mairies et les exécutifs des communautés autonomes peuvent aussi nommer un tiers (2087 sur 6000 ) des conseillers généraux des quarante-sept caisses d'épargne nationales, ce qui favorise les échanges de faveur et l'enrichissement illicite des dirigeants, alors même que de nombreuses entités financières expulsent des particuliers de leur logement en se fondant sur une loi hypothécaire très défavorable aux acheteurs. Mais des partis en situation dominante cherchent rarement à transformer un système qui leur a permis de maintenir leur hégémonie.

Bien loin du "populisme ", de la "démagogie » ou d'une posture "d'extrême gauche ", autant de catégories auxquelles ses adversaires veulent réduire le mouvement, c'est l'offre politique renouvelée de Podemos qui séduit les électeurs. Le parti se dirige très clairement aux citoyens d'en bas, aux victimes de la crise et de l'injustice sociale en activant le clivage contre les responsables de la crise politico-économique du pays, le PP, le PSOE, les banques et les puissants qui se sont enrichis depuis 2008 sans répondre au désarroi de la jeunesse et des classes moyennes et populaires. Depuis trente ans, le PSOE s'est appuyé sur un système politique favorisant structurellement le bipartisme: s'étant embourgeoisé, il s'est coupé des classes populaires, s'est converti en un parti « électoral professionnel » sachant mieux faire campagne et user de la communication politique que gouverner pour les générations

13. Sur le débat sur la « seconde transition», cf. notamment Sebastian BALFouR et Alejandro QuiRoga, España reinventada. Nación e identidad desde la Transición, Madrid, Peninsula, 2007, p. $350-364$.

14. Frédéric VERBEKE, «En Espagne, le bipartisme rend les élections moins démocratiques 》, EiTB, 11 septembre 2011. 
futures, tout en devenant très " libéral » sur le plan économique et en perdant de vue tout objectif d'émancipation sociale ${ }^{15}$.

La formule de base qui permet à Podemos de percer dans l'opinion est en fait assez simple mais très puissante. Elle se fonde sur une repolitisation des thèmes traditionnels de la gauche délaissés par le PSOE: demande d'égalité hommes-femmes, dénonciation des salaires indécents des élites politiques et financières, de la hausse des inégalités, du scandale des expulsions, du coût croissant des études ne permettant pas aux classes populaires d'accéder à l'université, de la privatisation des hôpitaux, etc. L'austérité, la corruption politique, la hausse des inégalités et surtout l'incapacité des élites politiques traditionnelles à formuler un discours crédible proposant des solutions alternatives à ces problèmes qui touchent l'ensemble de la société, expliquent la forte réceptivité des citoyens à l'égard du discours de Podemos, qui incarne une nouvelle offre politique et une organisation ex novo, créée de toutes pièces et sans liens symboliques avec le passé, les vieilles idéologies et les anciens appareils partisans.

\section{Transformer l'indignation citoyenne en une nouvelle alternative politique}

Podemos a été officiellement créé le 17 janvier 2014 pour donner un débouché politique aux revendications des « indignés " qui ont occupé la Puerta del Sol à Madrid le 15 mai 2011. Pablo Iglesias, Juan Carlos Monedero et les autres fondateurs du mouvement issus du département de sciences politiques de l'université Complutense, conçoivent leur doctrine politique comme une réponse à l'indignation populaire et au slogan « Ils ne nous représentent pas ${ }^{16}$ ! ». Dans une tribune publiée par El País, Juan Carlos Monedero et Jesús Montero, membre du groupe de travail chargé de l'organisation, établissent avec ironie le constat qui justifie selon eux la création de Podemos:

L'Espagne ressemble aujourd'hui à un reality show où les participants ont laissé leur carte de citoyens à l'entrée de l'enceinte. Un million de jeunes ont choisi l'émigration, presque 400 expulsions quotidiennes, près de 6 millions de chômeurs, un Espagnol sur quatre en risque d'exclusion sociale, des coupes budgétaires dans les secteurs de la santé et de l'éducation, la fermeture de l'université aux secteurs appauvris de la société, et

\footnotetext{
15. Sur la notion de «parti électoral professionnel», cf. Angelo PANEBIANCo, Political parties. Organization and Power, Cambridge, Cambridge University Press, 1988.

16. Pablo IGLESIAS TURRIÓN et Juan Carlos MONEDERo, ¡Que no nos representan!: El debate sobre el sistema electoral español, Madrid, Editorial Popular, 2011.
} 
le président du patronat madrilène qui utilise sa “carte B” de Caja Madrid pour multiplier illégalement ses notes de frais payées par le contribuable, tout en durcissant la loi sur les manifestations et en augmentant les frais de santé à la charge des patients. [...] Le vote pour Podemos est le résultat de l'indignation sociale des places, des revendications des marées et des marches contre "l'État réel de la nation", mais aussi du désir de changement afin de récupérer la démocratie espagnole démoralisée et discréditée. Il faut reconstruire l'espoir perdu en la politique, qui a été trop longtemps abandonné et déléguée aux élites. À travers un processus populaire participatif, Podemos vise à moraliser la vie publique, démocratiser le pouvoir et retrouver le bonheur ${ }^{17}$.

Miguel Urbán, ancienne tête de liste d'Izquierda Anticapitalista lors des élections de 2011, reconnaît lui-même qu'il fallait " rompre avec les partis politiques traditionnels et incarner un discours non pas idéologisant, mais concret, qui parle aux gens ${ }^{18}$ ". Podemos se fonde ainsi sur cette volonté de proposer un débouché politique aux revendications sociales exprimées par les indignés. Le nom du parti, Podemos (" Nous pouvons »), proposé par Miguel Urbán lors du retour d'un diner en voiture dans la banlieue de Rivas avec Pablo Iglesias et l'écrivain Jorge Moruno, entend d'ailleurs aller au-delà du slogan "Sí se puede » ("Si c’est possible ») des manifestations des indignés. Ces origines " mouvementistes » de Podemos, ancré dans les luttes sociales des dernières années, sont bien évoquées par Pablo Ortega, étudiant en communication de vingt-quatre ans, activiste de Juventud Sin Futuro et désormais militant de Podemos:

Podemos est né de la conscience de la fin d'un cycle au sein du mouvement des indignés. Même si nous étions et nous restons profondément défiants à l'égard des partis, le mouvement a connu un reflux depuis un an. Nous avons touché un "plafond de verre". Les assemblées ont débouché sur de nombreuses initiatives locales dans les quartiers: des associations culturelles, artistiques, des collectifs de défense des sans-papiers, des groupes qui se sont organisés contre l'austérité ou la loi contre le droit de manifester. Mais au niveau national, rien n'a changé. Le PP est toujours au pouvoir et la classe politique est toujours corrompue. C'est ce constat qui explique que malgré leur opposition aux partis, les indignés ont massivement investi Podemos qui propose un discours de changement social et redonne du sens à l'action politique ${ }^{19}$.

17. Juan Carlos Monedero et Jesús Montero, «Claro que Podemos », tribune dans le quotidien El País, 17 octobre 2014.

18. Miguel UrBán, cité dans Patricia OrTega Dolz, «Las cuatro esquinas de Podemos », El País, 12 novembre 2014, p. 27.

19. Entretien avec Pablo Ortega, Lavapiés, 27 février 2015. 
Cette volonté d'entrer dans l'arène politique pour répondre aux luttes sociales qui se sont succédé depuis 2008 est évoquée par Juan Carlos Monedero: "Nous avons formé Podemos pour que dans quelques années, si quelqu'un nous demande "Et toi qu'est-ce que tu as fait?", nous puissions lui répondre: "Nous avons fait revenir la politique aux gens, et nous avons rendu possible l'espoir en politique ${ }^{20}$. " Il s'agirait selon Pablo Iglesias, de "transformer la majorité sociale en une nouvelle majorité politique ". Dépasser l'apathie, la résignation passive des citoyens en incitant à l'engagement par une " pédagogie participative " est l'un des objectifs de Podemos.

Le parti contribue à la repolitisation de secteurs de la société qui s'étaient largement éloignés de la politique, notamment les jeunes, les précaires et les abstentionnistes. "Nous naviguons et nous construisons le parti en même temps " déclare Luis Portela, un avocat, lors de l'assemblée du jeudi du quartier huppé de Salamanca, qui réunissait ce jour-là une cinquantaine de personnes ${ }^{21}$. En discutant avec les membres de l'assemblée, je me suis rendu compte que seuls quelques-uns étaient directement issus du mouvement des indignés. La plupart avaient été des "indignés par télévision interposée " comme me dit Clara, une infirmière de quarante ans de l'hôpital $\mathrm{La} \mathrm{Paz}^{22}$. Lors de rencontres hebdomadaires au sein de locaux prêtés ou loués, se forment des groupes de travail et des commissions (" municipale », " extension", " finance ", etc.), formées par des citoyens issus de professions diverses et d'âges très disparates, allant de dix-neuf à soixante-cinq ans en ce qui concerne mon enquête. J'ai rencontré des personnes issues des milieux aisés et des classes moyennes (professeurs d'université, journalistes, avocats, mais aussi des employés de banque et de la communauté de Madrid, un instituteur et quelques commerçants) dans le quartier de Salamanca, et des citoyens plus majoritairement issus des classes moyennes et populaires dans le quartier de Lavapiés (travailleurs sociaux, artistes, étudiants et chômeurs notamment).

Le point commun entre ces individus issus de milieux sociaux très divers est leur volonté de changement et leur indignation face à la corruption politique et la hausse des inégalités. Favorable à la séparation de l'Église et de l'État mais surtout pragmatique, Podemos se réapproprie des pratiques issues de la charité chrétienne: au sein des

20. Juan Carlos Monedero, cité dans « ¿Hacia dónde camina Podemos? », El Mundo, 15 septembre 2014, p. 15.

21. Entretien avec Luis Portela, quartier Salamanca, 26 février 2015.

22. Entretien avec Clara, quartier Salamanca, 26 février 2015. 
cercles de Salamanca et de Lavapiés, chaque assemblée se termine par une "quête " dans des boîtes en plastique surnommées "balais ", en référence au soutien financier au mouvement permettant de «balayer la classe politique " en place. La carte de Madrid du local de Lavapiés, collée au mur derrière un vieux tableau, est une métaphore du débordement: les membres collaient initialement des petites pastilles de couleur pour situer chaque nouveau " cercle ", mais face à la création de nouvelles assemblées chaque semaine partout en Espagne, les militants n'ont plus le temps ni l'espace pour mettre la carte à jour. En s'appuyant sur le socle du mouvement des indignés, Podemos attire des citoyens déçus des partis traditionnels et issus de différents milieux, et cherche désormais à s'adresser à l'ensemble des Espagnols.

\section{LA CRÉATION RAPIDE D'UNE ORGANISATION PARTISANE MODERNE}

\section{Izquierda Anticapitalista et le tissu militant de Lavapiés}

Choisie dès la réunion fondatrice du 17 janvier 2014 tenue au sein du théâtre de Lavapiés, la méthode participative de Podemos s'est diffusée à travers les réseaux sociaux en s'appuyant sur le tissu social construit par les indignés suite au "15-M » de mai 2011. Les membres les plus impliqués de Podemos ont l'impression d'être sans cesse "débordés " par le succès populaire de leur initiative et la création hebdomadaire de nouveaux cercles locaux. Ils disent « travailler contre la montre " pour structurer leur parti dans l'urgence, mais ont en fait peu de prise sur la création, la structuration et les initiatives prises par les cercles locaux: "ce qui séduit les gens, c'est que les bases du parti fonctionnent de façon autogérée " me dit Pablo, un étudiant de $24 \mathrm{ans}^{23}$. Mais au-delà de l'image d'un " parti d'assemblées » décentralisées, qui proposent et qui votent les grandes orientations nationales, Podemos se fonde sur un cercle dirigeant restreint issu de professeurs de la faculté de sciences politiques de l'université Complutense, sur les militants historiques d'Izquierda Anticapitalista et sur le tissu de mouvements sociaux et de collectifs qui ont foisonné au sein du quartier de Lavapiés à Madrid depuis 2008. Pablo Iglesias, Juan Carlos Monedero, Íñigo Errejón, Carolina Bescansa et Luis Alegre sont tous docteurs et

23. Entretien avec Pablo, 24 ans, Lavapiés, 27 février 2015 
professeurs issus du département de sciences politiques et de sociologie de la Complutense. Loin d'être un mouvement "spontané ", Podemos est dominé au contraire par des politologues, sociologues et philosophes spécialistes de la communication politique ${ }^{24}$. Illustrant l'engouement populaire pour la pensée politique de ces "cinq fondateurs", le livre Cours urgent de politique pour les gens honnêtes de Juan Carlos Monedero, authentique best-seller, en est à sa neuvième édition.

Podemos se fonde aussi sur la structure et les six cents militants d'Izquierda Anticapitalista et sa branche catalane Revolta Global (« Révolte globale »), un parti d'extrême gauche fondé en 2008 par l'organisation Espacio Alternativo ("Espace alternatif »), qui regroupait les militants espagnols membres de la Quatrième Internationale qui avaient fait partie de la coalition Izquierda Unida ${ }^{25}$. Certains membres de Podemos ont animé la revue Corriente Alterna d'IA, tels l'eurodéputée Teresa Rodríguez, numéro deux sur la liste de Podemos aux européennes et désormais députée régionale et dirigeante du parti en Andalousie, ou Miguel Urbán, furent membres d'IA jusqu'à sa dissolution récente ${ }^{26}$. Le père d'Íñigo Errejón, José Antonio Errejón Villacieros est un haut fonctionnaire de l'administration espagnole et un militant d'Izquierda Anticapitalista favorable à l'abolition de la monarchie ${ }^{27}$. Dans le projet de "principes éthiques " adopté par $80 \%$ des voix lors du congrès fondateur du 15 novembre 2014, il a été décidé que les membres des autres partis, tout en pouvant militer au sein de Podemos, ne pourraient pas être élus au " conseil citoyen » de la formation, disposition restreignant le "double militantisme " et empêchant une prise de pouvoir éventuelle des militants d'IA, à l'encontre des souhaits de fusion de Pablo Echenique et de Teresa Rodríguez ${ }^{28}$. Face à la perte de pouvoir de ses membres au sein de Podemos, IA a décidé dans un document interne, d'avancer son dernier congrès au 6 au 8 février 2015 pour débattre de sa stratégie, de son adaptation et de son rôle par rapport à

24. Pour justifier leur engagement, Juan Carlos Monedero évoque sur ce point la « responsabilité sociale » des professeurs de science politique de faire surgir une politique utile pour les Espagnols. Cf. Juan Carlos Monedero, Curso urgente de politica para gente decente (9e éd.), Madrid, Seix Barral, 2014, p. 15.

25. «Espacio Alternativo becomes Izquierda Anticapitalista and decides to stand in European elections », International Viewpoint, 24 novembre 2008.

26. Segundo SANZ, «Quién es quién en Izquierda Anticapitalista, el partido que mueve los hilos dentro de Podemos », Vozpópuli, 16 juin 2014.

27. Segundo SANZ, «El padre de Errejón (Podemos) acusa a Cebrián de impulsar una "operación" para salvar la Corona », Vozpópuli, 19 juin 2014.

28. «Pablo Iglesias deja a Izquierda Anticapitalista fuera de Podemos », El Confidencial Digital, 21 octobre 2014. 
Podemos: ce congrès a débouché sur la dissolution d'IA pour permettre à ses membres de pleinement militer et d'accéder à des positions de pouvoir au sein de Podemos $^{29}$. Teresa Rodríguez notamment, qui avait initialement renoncé à faire partie de l'exécutif de Podemos, a joué un rôle central dans la dissolution d'IA, pour pouvoir continuer à influencer Podemos de l'intérieur et permettre à ses militants, qui constituent l'ossature de nombreux groupes locaux de la formation, de se présenter à des responsabilités internes ${ }^{30}$.

Pablo Iglesias, qui porte le même nom que le fondateur historique du PSOE, fils de Luisa Turrión, avocate de Comisiones Obreras et de Javier Iglesias, inspecteur du travail et professeur d'histoire à la retraite, fut lui-même membre de l'Union des jeunesses communistes d'Espagne de quatorze à vingt et un ans (1992-1999), et conseiller d'Izquierda Unida lors des législatives de 2011. Il conseilla ensuite Alternativa Galega de Esquerda (AGE) lors des régionales de 2012 en Galice, permettant à la coalition d'obtenir neuf députés et de devenir la troisième force régionale avec $14 \%$ des voix $^{31}$, devançant le Bloque Nacionalista Galego ("Bloc nationaliste galicien »). Ces élections constituèrent en quelque sorte le "laboratoire électoral " de Podemos $^{32}$. Mais la nouvelle formation entretient aussi des liens personnels et politiques avec Izquierda Unida, un parti avec lequel Podemos est en concurrence directe: Juan Carlos Monedero a par exemple été conseiller de Gaspar Llamazares, le secrétaire général d'IU de 2000 à 2005, et Pablo Iglesias est en couple avec Tania Sánchez Melero, députée du parti à l'assemblée de Madrid.

Enfin, l'émergence de Podemos ne peut être comprise sans tenir compte de son ancrage sociologique au sein du tissu militant du quartier de Lavapiés à Madrid. Le local du parti de Lavapiés, au 21 rue Zurita et à l'angle de la rue Torrecilla de Leal, fut d'ailleurs la librairie-coopérative Marabunta de Miguel Urbán, qu'il transforma en quartier général de la nouvelle organisation. Lavapiés est non seulement le quartier le plus multiculturel de Madrid, peuplé d'Indiens, de Pakistanais,

29. Izquierda Anticapitalista, «El papel y tareas de IA ante la crisis del régimen surgido en 1978. Adecuación organizativa del activismo anticapitalista ante las nuevas responsabilidades », document de travail interne, 24 novembre 2014.

30. Aitor RIVERO, « Izquierda Anticapitalista busca la forma de que sus militantes puedan aspirar a cargos en Podemos », [Eldiario. es], 15 novembre 2014.

31. «Anova e IU se presentarán como Alternativa Galega de Esquerda », El Mundo, 11 septembre 2012.

32. David LomBAo, « Galicia fue el laboratorio electoral de Podemos », [Eldiario. es], 10 octobre 2014. 
d'Équatoriens, de Sénégalais et de nombreux autres peuples du monde, mais aussi le plus politisé: dans la plupart des bars, locaux ou centres sociaux, des réunions sont organisées et des mouvements sociaux emblématiques de l'Espagne d'aujourd'hui comme Juventud Sin Futuro ou Espacio Alternativo s'y sont structurés. Podemos s'est par exemple appuyé sur les sympathisants du Teatro del Barrio, à l'angle de la rue, fondé par l'acteur Alberto San Juán, qui est un projet théâtral coopératif, mettant en scène des pièces et des performances critiques et donnant un espace de libre expression à de nombreux artistes réalistes et à des collectifs politiques qui dénoncent et s'inscrivent pleinement dans la réalité sociale de la crise espagnole. Le noyau fondateur de Podemos se situe donc à la confluence d'intellectuels, de militants de la gauche anticapitaliste et d'activistes du mouvement social des indignés ancrés dans un territoire urbain.

\section{Des assemblées citoyennes au parti politique}

Une anecdote que raconte Miguel Urbán, trente-quatre ans, proche du cercle des fondateurs de Podemos et ami intime de Pablo Iglesias depuis sa jeunesse étudiante, illustre bien l'ascension fulgurante de ce parti de nouvelle génération ${ }^{33}$. Lors de la première réunion publique du mouvement, il raconte comment un quidam lui demanda: "Tu es de Podemos Saragosse?». Miguel pensa alors: "Comment puis-je lui expliquer que Podemos n'existe pas avant que nous réunissions cinquante mille signatures, que nous présentions l'initiative et que les gens choisissent de former un groupe politique? ». Il lui répondit: "Non, je suis de Madrid». Et l'homme lui dit: " Ah, enchanté. Je suis de Podemos Catalogne ». Podemos n'existait pas encore pour Miguel, pourtant responsable de l'organisation et de son extension, mais le mouvement avait déjà une vie locale propre, à la marge de l'équipe nationale dirigeante. Cette petite histoire permet de comprendre comment, avant même de se transformer en parti, Podemos s'est cristallisé en une " méthode participative ", incitant les citoyens à créer eux-mêmes des assemblées et des cercles locaux, au sein desquels ils s'auto-organisent, débattent, réagissent à l'actualité et formulent des initiatives. Comme le déclare Jaime, qui milite en se rendant au sein du local fondateur du parti, dans le quartier populaire de Lavapiés à Madrid:

De nouvelles personnes passent la porte tous les jours. Ils viennent de tous les horizons, mais ce qui attire ces gens, c'est la méthode. Le débat

33. Cette anecdote est citée par Patricia ORTEGA Dolz, op. cit., 12 novembre 2014, p. 27. 
d'idées ouvert, la possibilité de se faire entendre, de dire ce que l'on pense et d'être écouté, de participer. Dans les autres partis, les citoyens doivent écouter les dirigeants, ils n'ont pas de forums pour s'exprimer. Ils ne sont pas vraiment consultés. Ici, ils se sentent valorisés, ils ont le sentiment d'être utiles et d'avoir un réel pouvoir. En renversant la pyramide hiérarchique, les gens se sentent plus concernés et ils s'engagent. C'est la clé du succès de Podemos: remettre l'engagement des citoyens au centre et leur redonner du pouvoir ${ }^{34}$.

Le parti veut montrer qu'il est possible de "diriger en obéissant » suivant l'expression de Juan Carlos Monedero, en se structurant en une fédération d'assemblées autonomes, où les groupes locaux choisissent eux-mêmes leurs représentants. Traditionnellement utilisé par les partis en Espagne, le système de listes fermées favorise la reproduction sociale, l'endogamie et la sélection des candidats sur la base de leur allégeance aux appareils partisans plutôt qu'en fonction de leur implication locale, de leurs soutiens citoyens et de leurs compétences. La présentation systématique par les partis de telles listes, dont les candidatures sont désignées "d'en haut " par les dirigeants, est ainsi directement responsable de la clôture du champ politique. En favorisant la constitution d'assemblées et de plateformes citoyennes pour les élections municipales de 2015, notamment avec la petite formation écologiste Equo ou fondées sur des collectifs citoyens, Podemos cherche à rompre avec ce schéma en privilégiant des listes ouvertes, ce qui suscite un engouement populaire. Cela contredit la thèse d'un déclin de la participation citoyenne: en moins d'un an, environ mille " assemblées citoyennes " ont été constituées sur l'ensemble du territoire, créant de toutes pièces un réseau de 260000 sympathisants ${ }^{35}$. Sergio Pascual, secrétaire de l'organisation, cherche à ce que ces cercles forment et dirigent eux-mêmes " des candidatures d'unité populaire " lors des élections municipales et régionales de 2015, sans utiliser pour autant la " marque » nationale Podemos ${ }^{36}$. Des plateformes telles que Ganemos Madrid ou Ganemos

\footnotetext{
34. Entretien avec Jaime, 29 ans, militant de Madrid, Lavapiés, 25 février 2014.

35. Cherchant à s'appuyer sur une large base sociale, le parti remet en cause la division traditionnelle entre les «militants » (qui paient normalement une cotisation) et les «sympathisants ». II se structure de fait comme un parti d'électeurs où le militantisme est plus fluide. Pour être considéré comme « sympathisant » de Podemos (ce qui implique suivant ses propres critères, faire partie de l'organisation), il suffit de s'affilier à l'un de ses cercles locaux ou d'enregistrer son inscription sur le site internet du parti. Aucune cotisation n'est exigée, mais les dons sont encouragés.

36. Sergio PASCUAL, " Debemos alentar candidaturas de unidad popular en las municipales », El Mundo, 10 décembre 2014.
} 
Barcelona, dirigée par Ada Colau de la PAH, sont ainsi en train de se former dans cet esprit au sein de différentes villes d'Espagne.

Podemos a entamé un processus constituant en septembre 2014, qui déboucha sur une assemblée préparatoire au sein de la Plaza de Toros de Vistalegre les 18 et 19 octobre, et entérina le choix de sa transformation en parti politique. Mille personnes organisées en 164 équipes ont formulé 253 propositions, dont celles qui ont recueilli le plus de voix ont permis de définir les principes de base du parti. Puis, lors de son assemblée constituante du 15 novembre 2014 au théâtre Nuevo Apolo de Madrid, le parti s'est doté d'un " conseil citoyen " composé de 62 membres (sur plus de mille candidats), choisis par l'ensemble des sympathisants s'étant exprimés, plus dix-sept représentants des communautés autonomes et un membre élu par les sympathisants résidant à l'étranger. Pablo Iglesias a été élu secrétaire général en obtenant 90 \% (95000) des 107000 votes électroniques émis, suivant un processus en ligne géré par la compagnie Agora Voting. Le fait que le second meilleur candidat sur les soixante-deux personnes qui se sont présentées au poste de secrétaire général, n’ait obtenu que 900 voix, illustre bien la très forte personnalisation de Podemos autour de Pablo Iglesias. Seuls $41 \%$ des sympathisants du parti (environ 260000) ont cependant voté. Les votants furent les sympathisants inscrits sur le site internet de Podemos, qui purent participer sans avoir besoin de payer une adhésion.

Le " conseil citoyen " du parti se divise en aires de travail (organisation, économie, communication, égalité, réseaux, etc.) et constitue en quelque sorte le parlement de la formation. L'autre organe national est un "conseil de coordination " plus restreint, qui équivaut au " comité de direction" au sein d'autres partis, et qui est composé de dix à quinze personnes élues par le conseil citoyen sur proposition du secrétaire général. À ce jour, en plus des cinq fondateurs, il réunit l'eurodéputée Tania González, l'ancien juge anticorruption Carlos Jiménez Villarejo, l'avocat de la PAH Rafa Mayoral, l'économiste Alberto Montero de l'université de Málaga, l'éditeur Jorge Lago de la maison d'édition Lengua de Trapo et quelques membres de l'équipe technique chargée d'organiser l'assemblée du parti dont Miguel Urbán. Enfin, un " comité de garanties démocratiques " composé de dix personnes, dont Gloria Elizo, responsable de l'équipe juridique de Podemos et de la représentation de la partie civile dans l'affaire Oleguer Pujol, et le professeur de droit pénal Manuel Maroto, a pour rôle d'être le juge de la démocratie interne. Suite à l'approbation des structures centrales 
du parti, des représentants ont été élus au sein de chaque communauté autonome.

Même si Podemos s'appuie sur des procédures visant à créer une " démocratie réelle " sur le plan interne, il serait trompeur de le qualifier de " parti d'assemblée ». Certes, à travers la fédération d'assemblées locales, la consultation par vote des militants sur les grandes orientations du parti et la revendication de "transparence " en publiant ses comptes sur internet, Podemos cherche à mettre en application les principes de la démocratie participative et directe ${ }^{37}$. Mais la ligne politique adoptée lors du congrès fondateur a intronisé un secrétaire général unique et l'ensemble du pouvoir interne a été confié aux groupes des fondateurs ${ }^{38}$. Le parti est certes doté d'un " conseil citoyen ", mais aussi d'un exécutif dirigeant, d'une hiérarchie et d'une discipline commune aux partis traditionnels et à la « loi d'airain de l'oligarchie " définie par Robert Michels ${ }^{39}$. Fédération d'assemblées locales autogérées, dont les décisions sont soumises à l'approbation des bases, Podemos est aussi un parti au leadership très marqué.

La marginalisation des courants internes favorables au maintien d'un mouvement d'assemblées et critiques de la ligne des fondateurs l'illustre bien. Représentant le courant interne "Sumando Podemos " avec les eurodéputées Teresa Rodríguez et Lola Sánchez, les militants Victor García et Beatriz Gimeno et le "cercle des infirmières " de Podemos, l'eurodéputé Pablo Echenique retira sa candidature au secrétariat général après avoir mis en cause la méthode de vote, estimant qu'une compétition interne avec l'équipe de Pablo Iglesias était impossible ${ }^{40}$. Le courant "Construyendo Podemos " dirigé par Clara Marañòn et Carolina Huelmo, qui réunit une dizaine de cercles très actifs (dont ceux de Madrid, Séville, Murcie, Ciudad Real, Alicante et Guipuscoa), fit aussi des déclarations critiques. Élément problématique, les sympathisants devaient soit voter en bloc pour la liste fermée proposée par les fondateurs, soit choisir un à un les soixante-deux candidats au " conseil citoyen ». Dans un tel système, le choix possible des candidats sur une base individuelle ne pouvait être qu'en compétition inégale avec la liste

37. Francesco MANETTO, « Podemos corona a Pablo Iglesias para liderar la pugna al bipartidismo ", El País, 14 novembre 2014, p. 22.

38. Francesco MANETTO, «Iglesias: Las dificultades comienzan ahora », El País, 15 novembre 2014, p. 1.

39. Robert MICHELS, Les partis politiques. Essais sur les tendances oligarchiques des démocraties, Bruxelles, Éditions de l'université de Bruxelles, [1914], 2009.

40. «Las renuncias de Echenique », El Periódico de Catalunya, 24 octobre 2014, p. 5. 
de Pablo Iglesias en raison du déficit de notoriété de la plupart des candidats. Le cercle des infirmières de Podemos, le plus critique, en vint à accuser ouvertement Iglesias de donner corps aux "premiers réflexes de caste" au sein du mouvement, montrant l'évolution rapide de Podemos vers une organisation dotée d'une discipline partisane autour d'une direction verticale et hiérarchisée ${ }^{41}$.

\section{Une révolution " technopolitique "}

Dimanche 19 octobre 2014 dans la soirée. Les 26 membres de l'équipe technique chargés d'organiser l'assemblée constituante de Podemos se connectent tous sur Telegram pour leur « rendez-vous virtuel ». À travers cette application de téléphone portable, ils débattent et votent sur la méthode de choix des documents fondateurs du futur parti. Cet épisode est une bonne illustration du fait que la maîtrise de l'internet et des nouvelles technologiques constitue l'une des pierres angulaires de l'organisation interne de la formation ${ }^{42}$. Dès son lancement le 17 janvier 2014, Twitter a dû suspendre deux fois le compte de Podemos devant l'avalanche de tweets des suiveurs. Depuis les élections européennes, grâce aux financements fournis par le Parlement européen pour l'organisation du travail des eurodéputés, Podemos occupe un local au septième étage d'un immeuble près de la Plaza de España à Madrid, où travaille le groupe spécialisé dans les nouvelles technologies, l'internet, les réseaux sociaux et les applications pour smartphones. Ce groupe se fonde notamment sur des militants de Juventud Sin Futuro, qui ont acquis des compétences en matière de partage numérique des informations dans le cadre du mouvement des indignés et du 15-M. "Réseaux sociaux ", "participation " et " technologies " constituent les trois piliers de l'organisation numérique du parti, qui veut être à la pointe dans ce domaine afin d'impliquer le plus de sympathisants possible et de renouveler les façons de faire de la politique.

Eduardo Rubiño gère le groupe « réseaux sociaux » et coordonne une équipe de quinze à vingt volontaires, qui se relaient quotidiennement

41. Le caractère décentralisé du parti constitue sa plus grande force mais aussi sa plus grande faiblesse : cela permet d'instaurer une démocratie interne participative, mais peut donner une image d'incohérence de son positionnement idéologique. La question de la maîtrise des prises de parole commence à se poser. Preuve en est par exemple, la polémique sur la proposition de Fonsi Loaiza, membre du "cercle des sports », de limiter le salaire maximum des sportifs, une proposition ensuite désavouée par Î́nigo Errejón. Cf. «Podemos no propone futbolistas con estudios o salario máximo », El País, 9 décembre 2014, p. 19.

42. Guiomar DEL SER, « La infraestructura de Podemos vive en internet », El País, 15 novembre 2014. 
de 10 heures à 23 heures et diffusent du contenu sur la Toile. Ce travail d'organisation et de diffusion de contenus numériques porte d'ores et déjà ses fruits. Podemos est la formation politique la plus suivie sur Twitter (428000 suiveurs contre 181000 pour le PSOE et 177000 pour le PP), et domine encore plus ses concurrents sur Facebook (856000 suiveurs contre 77000 pour le PP et 73000 pour le PSOE). La jeunesse de nombreux militants du parti constitue un atout majeur face à ses concurrents pour réinventer des pratiques internes de vote et de partage de l'information. Comme le déclare Fernando, un militant de Lavapiés de trente-trois ans, qui se dit "journaliste précaire » et « hyperconnecté » sur Twitter, Facebook et Instagram:

Nous avons un coup d'avance sur les autres partis. Nous sommes mieux organisés qu'eux sur les réseaux sociaux et internet. Il y a un vrai travail d'organisation. Je pense que cela va payer et faire la différence. On voit d'ailleurs les dirigeants du PP qui commencent à dire qu'ils doivent réagir et être plus actifs. On est en train de créer des brèches dans les partis traditionnels. L'idée est d'attirer les forces vives, de faire travailler les jeunes créateurs, de s'entourer d'ingénieurs et de professionnels de l'internet. Podemos est une sorte de "start-up" politique où se retrouvent ceux qui veulent mettre l'innovation au service du changement politique ${ }^{43}$.

Pablo Iglesias est désormais suivi par 663000 personnes sur Twitter contre 614000 pour Mariano Rajoy, et très loin devant Pedro Sánchez (96000). À cela, il faut ajouter les dizaines de comptes sectoriels et régionaux promus par les cercles et les assemblées territoriales de Podemos, mais aussi ceux animés par les Espagnols à l'étranger. En utilisant l'application Telegram (concurrente russe de WhatsApp), le parti a aussi entrepris de recenser l'ensemble des comptes et des applications sympathisantes afin d'éviter les impostures et d'améliorer la capacité de réaction collective par rapport à l'actualité. Grâce à Telegram, des débats en temps réel pouvant inclure simultanément des représentants de près de 250 cercles distincts ont lieu lors des grandes réunions publiques. La progression des adhésions sur les réseaux sociaux ne cesse de s'amplifier depuis les élections européennes qui ont marqué un point d'inflexion.

Àngel, un étudiant de vingt-cinq ans impliqué au sein du groupe « participation » dirigé par Miguel Ardanuy, m’a expliqué que le parti utilise l'application de vote Appgree, disponible sur les téléphones portables, qui permet de sélectionner à partir de critères sémantiques

43. Entretien avec Fernando, Lavapiés, 25 février 2015. 
et numériques, parmi les centaines d'opinions et de propositions des utilisateurs sur un sujet donné, celles qui présentent les plus forts taux d'interaction, de popularité et de redondance. Pour lui, il s'agit d'un " exemple d'intelligence collective " permettant de travailler en temps réel, et de faire remonter vers la direction du parti les positions les plus appréciées par les sympathisants de base ${ }^{44}$. Cela permet aussi, grâce à la technologie, de tirer profit et de structurer le travail de processus d'assemblées qui ont montré leurs limites organisationnelles suite au 15-M. L'application Appgree a ainsi été utilisée lors de l'assemblée citoyenne d'octobre 2014 pour sélectionner cinquante questions (sur 15000) émanant des cercles de base du parti à travers 260000 votes, qui furent ensuite posées aux porte-parole de chaque aire thématique. Podemos utilise aussi le système de vote créé grâce à l'algorithme des entités indépendantes Open Kratio et Agora Voting, qui existe déjà en Suisse et en Norvège, et qui permet facilement d'organiser des votes en alliant respect de la vie privée, anonymat et garanties de sécurité et de fiabilité.

L'idée de la direction de Podemos est d'instaurer la possibilité de révocation interne des élus de la formation si $25 \%$ des votants en décident ainsi, et de favoriser des débats internes sur les initiatives programmatiques citoyennes qui obtiennent le soutien d'au moins $10 \%$ des votants. Enfin, en utilisant la technologie américaine Reddit, la formation a créé Plaza Podemos, un site internet d'agrégation et d'interaction entre utilisateurs, qui permet de faire vivre ensemble les critiques de certains secteurs, les propositions et les débats. On voit donc bien comment l'essor de Podemos n'est pas le fruit du hasard, et se fonde notamment sur sa rénovation des pratiques politiques au service de la démocratie partisane interne et de la communication politique à l'heure de l'internet et des réseaux sociaux. Les nouvelles technologies sont activement utilisées par Podemos comme des instruments de mobilisation et d'invitation au débat, ce qui permet de relayer plus effectivement les prises de position publiques des porte-parole du parti, et de mener une "campagne 2.0 " plus effective que ses concurrents. Cela rappelle l'innovation technologique utilisée de façon déterminante au service de la campagne présidentielle de Barack Obama en $2008^{45}$.

44. Entretien avec Àngel, siège « numérique » de Podemos, Plaza de España, 24 février 2015. 45. Sur ce point, cf. notamment François HEYNDERICKX, «Obama 2008 : I'inflexion numérique », Hermès, n 59, 2011, p. 135-144; Maria MERCANTI-GUERIN, « Facebook, un nouvel outil de campagne : Analyse des réseaux sociaux et marketing politique ", La Revue des sciences de gestion, $n^{\circ} 242$, 2010, p. 17-28; Patrice FLICHY, «La démocratie 2.0 », Études, n 412, 2010, p. 617-626. 


\section{RENOUVELLEMENT IDÉOLOGIQUE ET STRATÉGIES POLITIQUES}

\section{Un leader médiatique}

Podemos, pour le grand public, c'est avant tout le verbe assez respectueux de ses adversaires et la parole critique étayée d'exemples de Pablo Iglesias. En 2010, ce dernier lança et présenta La Tuerka sur Público TV, une émission de débats politiques, qu'il a créée sur l'internet avec quelques collègues et amis, dont Juan Carlos Monedero, depuis le début des années 2000. Puis, le type de discours que propose désormais Podemos fut testé lors d'une émission hebdomadaire diffusée sur une chaîne télévisée locale du quartier madrilène de Vallecas, d'où est originaire Pablo Iglesias. Devant le succès rencontré par l'initiative, les plateaux télévisés et radios l'invitèrent peu à peu. Ces analyses minutieusement travaillées commencèrent à créer la polémique sur les réseaux sociaux et à faire monter l'audience des chaînes de télévision. En août 2012, il débuta une collaboration plus générale avec cette chaîne, et en novembre 2012, il devint analyste au sein du programme La Sexta Columna de la chaîne Sexta.

Sa première analyse intitulée "Rajoy, an I: La réalité c'était ça ", qui critiquait la première année du gouvernement conservateur, fit le "buzz " sur l'internet et les réseaux sociaux ${ }^{46}$. À partir de janvier 2013, il créa et présenta le programme Fort Apache, réalisé par les productions CMI et émis par la chaîne de télévision publique internationale iranienne Hispan $T V$, destinée au monde hispanique. Le 24 avril 2013, il fut ensuite invité à l'émission très suivie El Gato al Agua sur la chaîne Intereconomía, pour réagir à l'appel du collectif 25-S de tenter d'occuper le Congrès des députés le 25 avril jusqu'à obtenir la démission du gouvernement ${ }^{47}$. Ayant milité au sein du mouvement altermondialiste en 2001, Pablo Iglesias défend la désobéissance civile comme moyen de lutte. Lors de cette intervention, tout en condamnant l'usage de la violence, il justifie les manifestations populaires en cherchant à montrer le manque de légitimité du gouvernement, de ses politiques d'austérité et plus généralement la crise du système politique issu de la constitution de 1978. Ses prises de

46. Pablo IGLESIAS, « Rajoy año I: La realidad era esto », [atresplayer. com], 16 novembre 2012. 47. Miguel HERNÁNDEZ, "El 25S llama a "asediar" el Congreso el 25 de abril y a no abandonar hasta que dimita el Gobierno », La Razón, 31 mars 2013. 
position, très habiles et appuyées de données concrètes, lui ont permis de se faire connaître du grand public et ont suscité un large débat sur internet et dans la presse écrite ${ }^{48}$.

Il est dès lors devenu peu à peu un analyste et un collaborateur habituel invité à différentes "Tertulias políticas ", El Gato al Agua et El Cascabel al Gato (13 TV), La SextaNoche (La Sexta), Las Mañanas de Cuatro (Cuatro) et La noche en 24 horas présenté par Sergio Martin (24 horas $)^{49}$. La principale nouveauté du discours qu'il propose et sa percée à l'écran s'expliquent par le fait que le format télévisuel des "Tertulias", des débats sur l'actualité politique entre supposés "spécialistes ", journalistes et invités, a été largement " vampirisé " par des pseudo-experts au cours des dernières années. Ces « spécialistes du ciel et de la terre ", pour reprendre l'expression d'Iglesias, ont pris l'habitude d'opiner sur tous les sujets et de se dire compétents sur toutes les thématiques, en ressassant les mêmes points de vue et idées reçues. En préparant au contraire très sérieusement en amont ses interventions télévisées, en rédigeant des notes, des argumentaires, et en étayant son propos de nombreux exemples, Pablo Iglesias a soudainement montré le faible niveau intellectuel de nombreux débats, prenant souvent le dessus sur ses interlocuteurs grâce à un vrai travail méthodique d'argumentation et de contre-argumentation.

Ses interventions très critiques, mais intelligentes et très documentées déstabilisent ainsi souvent les autres membres du plateau, en mettant le doigt sur les questions qui fâchent ${ }^{50}$. Avant même la création de Podemos en janvier 2014, elles lui ont permis de fidéliser un public et de diffuser ses prises de position à des heures de grande écoute. Depuis la formation du mouvement, Pablo Iglesias est devenu un vrai phénomène médiatique, invité en 2014 au sein de nombreuses autres émissions comme La Lupa, Via V, Al Rojo vivo, El Objetivo, Viajando con Chester, Un tiempo nuevo et Salvados. L'émergence de Podemos doit ainsi beaucoup au charisme, au travail critique sur le contenu et à la communication politique de Pablo Iglesias. L'essor de la formation est donc intimement lié à la diffusion de nouveaux cadres d'interprétation et d'un discours critique renouvelé au sein même des médias de masse traditionnels.

48. Mario LóPEZ, «Pablo Iglesias y la conquista de la inteligencia », Diario Siglo XXI, 4 juillet 2013.

49. II a aussi participé à l'émission Te vas a enterar en 2013.

50. En octobre 2013, il a d'ailleurs obtenu un prix journalistique octroyé par le département de journalisme de l'université Carlos III de Madrid, puis le prix «Enfocados » de journalisme de I'ONG Coordinadora para el desarrollo, pour sa contribution au changement social. 


\section{Un discours transversal s'adressant à tous}

Une autre clé du succès de Podemos réside dans la volonté de ses dirigeants de se démarquer des étiquettes politiques traditionnelles et du clivage gauche-droite. En refusant d'être "étiqueté » comme un parti "de gauche ", Podemos se place dans une posture visant à articuler un discours transversal s'adressant à tous, une caractéristique des partis "attrape-tout ", plus axés sur la conquête du pouvoir et la volonté de convaincre une majorité des citoyens que sur la défense acharnée d'une idéologie ${ }^{51}$. La présence de l'eurodéputée Maria Matìas du Bloco de Esquerda portugais et d'Alexis Tsipras, dirigeant de Syriza, coalition de gauche radicale grecque, lors de son congrès fondateur, et l'insertion de Podemos dans le groupe de la gauche unitaire européenne au Parlement européen, ne laissent cependant aucun doute sur son affiliation politique ${ }^{52}$. Mais contrairement à Syriza, qui n'a jamais cherché à occulter son idéologie héritée de l'eurocommunisme, Podemos refuse le label " gauche radicale " jugé trop péjoratif, et préfère se présenter comme un " mouvement citoyen » ou " un processus populaire participatif $^{53}$ ». Perçu sans ambiguïté comme « de gauche " par les citoyens, sa posture lui permet de disputer l'espace politique traditionnel du PSOE, tout en étant en phase avec la radicalisation de l'électorat de gauche et en cherchant à attirer un électorat plus vaste: sur une échelle de 0 à 10, les Espagnols situent Podemos à 2,5, soit au cœur de la gauche voire même plus à proximité de la " deuxième gauche ", et mettent le PSOE à 4 , à savoir plus au centre gauche $\mathrm{e}^{54}$. Cela explique l'accent mis par le parti sur la volonté de représenter " les gens » et «le peuple " face à « la caste » des partis traditionnels qui coopèreraient pour maintenir

51. Sur la notion de "parti attrape-tout», cf. l'article classique de Otto KIRCHEIMER, «The transformation of the West European party systems », dans Joseph LAPALOMBARA et Myron WeIner (dir.), Political Parties and Political Development, Princeton, Princeton University Press, 1966, p. 177-200.

52. Francesco MANETTO, «Tsipras arropará a Pablo Iglesias en la clausura de la asamblea de Podemos», El País, 13 novembre 2014, p. 30 ; María Antonia SÀnCHEZ-VALLEJo, "El espejo griego de Syriza », El País, 23 novembre 2014.

53. Les expressions sont ici reprises de Juan Carlos Monedero et Jesús MonTERo, op. cit., 17 octobre 2014. De 3 \% lors des européennes de 2004, Syriza est devenu le premier parti de l'opposition lors des législatives de 2012, envoyant 71 députés (sur 300) au Parlement grec, puis le premier parti grec, le plus voté (26,5\%) lors des européennes de 2014. Pas à pas, Syriza s'est transformé en un parti de gouvernement cherchant à rassurer ses partenaires européens, ce qui a débouché sur sa conquête du pouvoir lors des élections législatives du 25 janvier 2015. Cf. Lamprini RoRı et Elias DINAS, « Les élections législatives grecques de 2012: des élections à haut risque », Pôle sud. Revue de science politique de l'Europe méridionale, n 37, 2012, p. 173-183. 54. Sondage El País/Metroscopia, 2 novembre 2014. 
l'immobilisme du système politique malgré les fortes demandes de changement social ${ }^{55}$.

Dépourvu face à l'ascension fulgurante du parti, le PSOE le qualifia d'abord de " populiste ", mais devant l'inefficacité d'une telle stratégie, il cherche désormais, selon un document interne, à " dévoiler au public le mouvement comme une organisation d'extrême gauche ${ }^{56}$ ". Comme le note Patrick Charaudeau, le " populisme " consiste " à se réclamer du peuple et de ses aspirations profondes " mais " en manipulant la réalité politique et en la dramatisant à l'extrême ${ }^{57}$ ". Néanmoins, Podemos ne manipule pas plus la réalité politique en sa faveur que les autres partis. Il propose un discours simple mais pas simpliste. Pablo Iglesias veut "parler vrai ", en révélant les injustices tout en employant un ton mesuré face à ses adversaires. Derrière chacune de ses interventions publiques et télévisées, il y a un intense travail de préparation, de recherche de données chiffrées, de petites formules et de slogans qui sont repris par les grands médias et qui entrent en écho avec les attentes des citoyens. Ses adversaires sont souvent déstabilisés parce qu'en professionnels confirmés de la politique, ils se sont habitués à la "langue de bois " et à improviser, ce qui n'est pas suffisant face à ses questions très précises. Même s'il propose des solutions de gauche, le discours de Podemos est avant tout concret, et cherche à mettre en avant des problèmes qui concernent "tout le monde ». C'est donc un discours qui s'adresse à la majorité et qui est différent de celui de la gauche traditionnelle, comme l'explique Pablo Iglesias:

J'ai vu que ce discours fonctionnait et qu'il plaisait. Les gens m'arrêtait dans la rue et me disait: « Je sais que tu es de gauche et je ne le suis pas, mais je suis d'accord avec ce que tu dis ${ }^{58}$ ".

Dans son discours d'investiture en tant que nouveau secrétaire général du parti le 15 novembre 2014, Pablo Iglesias a soutenu que «Podemos [n'était pas] une expérimentation politique, mais le résultat de l'échec d'un régime ». Sa formation serait " un balai pour balayer la société de la corruption ». Il a cherché à répondre à la « peur " que ses

55. Pablo Machuca, «Entrevista a Pablo Iglesias: "No es izquierda o derecha, es dictadura o democracia" », El Huffington Post, 26 février 2014.

56. «Documento estratégico », PSOE, 25 novembre 2014, cité dans Anabel DIEZ, «El PSOE tratará de situar a Podemos en la extrema izquierda », El País, 30 novembre 2014, p. 21.

57. Patrick CHARAUDEAU, «Réflexions pour l'analyse du discours populiste », Mots. Les langages du politique, n 97, 2011, p. 101-116.

58. Pablo IGLESIAS, cité dans "¿Hacia dónde camina Podemos?», El Mundo, 15 septembre 2014, p. 15. 
adversaires essaient de répandre à l'égard de sa formation, en disant que « ce qui fait réellement peur aujourd'hui en Espagne est que pendant que le nombre de citoyens riches a augmenté de $24 \%$ l'année dernière, $65 \%$ des personnes en risque de pauvreté ne sortent pas de celleci lorsqu'elles trouvent un travail ${ }^{59} "$. Il s'est principalement focalisé sur la lutte contre la corruption et la nécessité de " changer de régime " pour résoudre le problème au-delà des nombreuses affaires individuelles qui ne seraient que " la pointe de l'iceberg ». Critique des excès du néolibéralisme, le discours politique de Podemos donne une importance centrale aux aspects les plus concrets de la vie des gens: le droit à une alimentation saine et à l'eau pour tous, aux libertés de disposer de son corps et de s'exprimer (contre les réformes du PP anti-avortement et restreignant le droit de manifester), et aux droits fondamentaux de se loger et d'accéder à l'éducation ${ }^{60}$. Comme le collectif de la PAH depuis 2009, Podemos prône l'utilisation des logements vides possédés par les banques et un moratoire sur les expulsions.

En matière économique, la position de Podemos a d'ores et déjà évolué, notamment sur l'euro et la dette publique, en cherchant surtout à rassurer ${ }^{61}$. Les économistes Bibiana Medialdea et les professeurs Alberto Montero et Nacho Álvarez défendent désormais un plan de restructuration partielle et concertée de la dette, notamment pour répondre aux critiques à l'égard de son projet initial lors des européennes, qui défendait le non-paiement des parties "illégitimes » de la dette $^{62}$. Iglesias cherche aussi à rassurer en défendant qu'il ne s’agira de sortir ni de l'euro ni de l’UE. Son « Programme économique pour les gens ", s’inspire des recommandations des économistes Juan Torres et Vicenç Navarro, qui proposent notamment un « plan de développement

59. Pablo IGLESIAS, discours d'investiture, Madrid, 15 novembre 2014.

60. Cherchant à retourner le stigmate des mouvements anti-avortement qui se disent « défenseurs de la vie », Iglesias a par exemple défendu que « défendre la vie, c'est défendre le droit des femmes à décider lorsqu'elles veulent un enfant ». Cf. Discours d'investiture, op. cit., 15 novembre 2014.

61. Critiqué pour les liens supposés du parti avec le Venezuela, dans un entretien au quotidien El País, Íñigo Errejón a bien précisé que Podemos n'a pas l'intention de s'inspirer des politiques menées par Hugo Chávez et Nicolás Maduro, un pays « qui n'est pas un modèle pour l'Espagne » selon lui. Cf. Entretien numérique avec Íñigo Errejón, El País, 13 novembre 2014, p. 15. Cette polémique se fonde notamment sur le fait que Juan Carlos Monedero a été conseiller du gouvernement vénézuélien dirigé par Hugo Chávez entre 2005 et 2010, tant directement avec le président de la république bolivarienne, qu'au sein du ministère de la Planification ou du Centre international Miranda où il fut responsable de formation.

62. L'économiste Carlos Díez, particulièrement critique envers la formation, estime par exemple que «Podemos a choisi un programme utopique, en vendant des promesses aux gens qu'ils ne vont pas pouvoir réaliser ». Selon lui, « ils sont partis vers la Voie lactée et sont toujours sur Mars ». Cf. Carlos DíEZ, « Podemos en el país de Nunca Jamás », El País, 27 novembre 2014, p. 36. 
intégral " pour diversifier l'économie espagnole, trop dépendante des secteurs du bâtiment et du tourisme. Podemos propose de revenir sur la réforme du marché du travail du PP, de diminuer le temps de travail et d'améliorer la protection des salariés. Il veut mettre fin aux coupes budgétaires et favoriser l'investissement public pour créer de l'emploi dans les secteurs de la dépendance, de la recherche et des énergies renouvelables. Le parti prône enfin un «changement du modèle productif » qui soutiendra les PME et facilitera l'accès des entreprises au crédit. En s'entourant d'intellectuels et en leur demandant de proposer des alternatives et des solutions, Podemos cherche à se faire le porteparole de nouvelles idées et donne l'image d'un parti qui pense et qui veut se doter d'un projet positif et progressiste pour le futur. Le parti entreprend en fait le renouvellement du discours de gauche et des pratiques politiques que le PSOE n'a pas su réaliser.

Prenant en compte les critiques à l'égard de la monarchie qui ont poussé Juan Carlos $\mathrm{I}^{\mathrm{er}}$ à abdiquer au nom de sa volonté même de préserver et de renouveler l'institution, Podemos propose un référendum et se dit favorable à l'instauration d'une république. Le 12 juin 2014, Teresa Rodríguez, nouvelle eurodéputée de la formation, participa à une manifestation à Bruxelles d'Espagnols en faveur d'un référendum sur la monarchie. Ayant maintenu un profil bas lors du référendum symbolique sur l'indépendance de la Catalogne le 9 novembre, le parti soutient "le droit à décider " des Catalans lors d'un référendum, "comme les Écossais » selon Íñigo Errejón ${ }^{63}$. Il cherche à replacer la question territoriale dans le cadre de l'essoufflement de la constitution de 1978 et de la nécessité de sa réforme pour évoluer vers un " pays de pays, un pays de nations ". Mais l'ensemble des membres de Podemos ne sont pas sur la même longueur d'onde, comme le prouvent les critiques de l'ex-juge anticorruption Carlos Jiménez Villarejo, qui caractérisa d'« antidémocratique " et d' « illégale " la consultation catalane. La position officielle du parti est cependant de soutenir un référendum, tout en disant « non » à l'indépendance de la Catalogne, mais " oui " au droit à l'autodétermination de la nation catalane dans le cadre d'un État plurinational.

\section{Une stratégie électorale de conquête du pouvoir}

Pablo Iglesias et les dirigeants du parti ne cachent pas leurs ambitions et le répètent à chaque intervention publique: leur but est

63. Elsa GARCíA DE BLAS, «Errejón: "Los catalanes tienen derecho a decidir como los escoceses" », El País, 13 novembre 2014, p. 19. 
d'attirer "la majorité sociale " et d'« occuper la centralité de l'échiquier politique ", des expressions qui ont fait mouche et sont reprises par les journalistes et les médias. Devant sept mille militants lors de l'assemblée de Vistalegre, Pablo Iglesias déclara clairement vouloir conquérir le pouvoir en incarnant l'opposition au PP et l'alternative au PSOE: "Les vraies difficultés commencent maintenant et lorsque nous gagnerons les élections en décembre de l'an prochain, débuteront les difficultés pour de vrai ${ }^{64}$ ». José Pablo Ferrándiz, sociologue et vice-président de l'institut de sondage Metroscopia, analyse ainsi cette stratégie: "Ils savent que c'est là où se trouvent les citoyens. Leur objectif final est d'occuper au sein de la société la position qu'a occupé le PSOE dans les années qui suivirent la transition démocratique $^{65}$ ". La radicalité permet de "faire le buzz ", d'attirer l'attention médiatique, mais n'est pas une fin en soi. Il s'agit avant tout d'un instrument de communication politique au service d'un programme qui apparaîtra « radical » à la droite conservatrice et que le PSOE s'efforce à présenter comme " extrémiste ", mais qui est en fait assez loin d'une idéologie d'extrême gauche traditionnelle, est beaucoup plus modéré et progressiste. Le document fondateur de Podemos, élaboré par Iglesias, Monedero, Íñigo Errejón, Carolina Bescansa et Luis Alegre, reconnaît d'ailleurs un certain mérite à l'étape du socialisme de Felipe González et d'Alfonso Guerra, qui incarnèrent une rupture générationnelle et progressiste avec le passé:

Le parti socialiste a été (suite au rôle initial du PCE et des CC. OO), l'artisan de l'intégration des classes subalternes à l'État en 1978, et par conséquent des conquêtes sociales au sein de celui-ci, avant de devenir une pièce clé de l'incorporation de l'État au pacte social néolibéral. C'est lui qui ferme l'espace politique de la gauche et c'est sa crise qui ouvre les opportunités politiques pour une nouvelle majorité. En récupérant le prestige perdu, en mettant fin aux problèmes internes et en promouvant un nouveau dirigeant doté de peu de liens symboliques avec le passé, il devrait être possible de récupérer une partie de l'espace politique perdu et de renforcer les options d'une force de rupture démocratique, relativement transversale au sein d'un discours d'unité populaire et citoyenne ${ }^{66}$.

\footnotetext{
64. Pablo IGLESIAS, discours de l'assemblée de Vistalegre, 8 octobre 2014.

65. José Pablo FERRÁNDIZ, cité dans «Pablo Iglesias, del ajedrez a la batalla política », El País, 22 septembre 2014, p. 22.

66. Podemos, "Claro que podemos», document fondateur de l'assemblée de Madrid, 15 novembre 2014.
} 
Photo 10.1. La « Marche du changement » de Podemos, Madrid, 31 janvier 2015

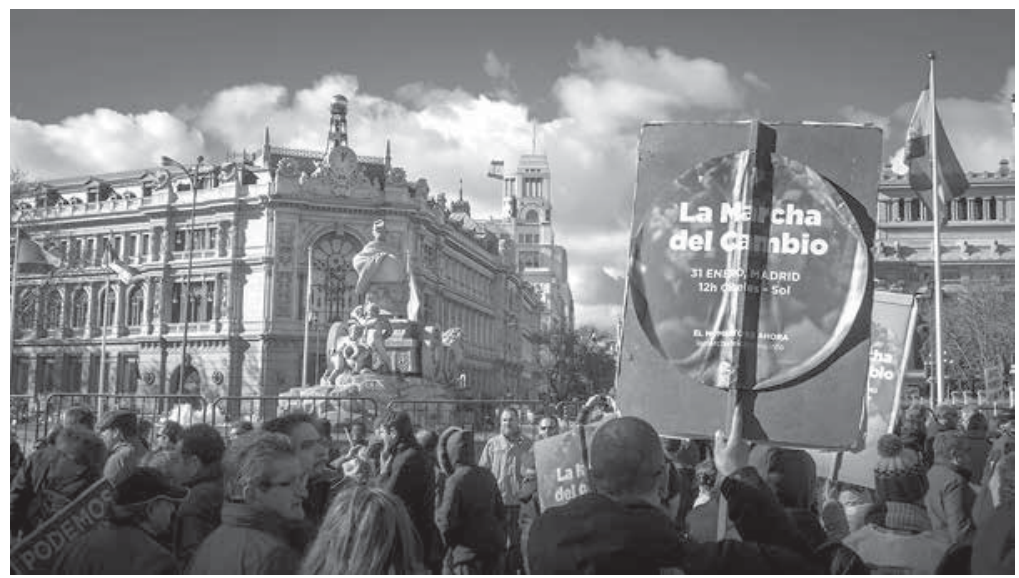

Cette quête du pouvoir à laquelle aspirent les dirigeants de Podemos explique la recherche d'un discours transversal et rassembleur audelà du clivage gauche-droite traditionnel. Contrairement au Front de gauche en France et au Bloco de Esquerda au Portugal, qui s'appuient sur des coalitions de partis et de mouvements dominées en termes organisationnels par les partis communistes français et portugais, Podemos cherche à ne pas apparaître comme un cartel d'organisations et à dépasser les partis traditionnels ${ }^{67}$. Cela différencie le parti du positionnement clairement axé et revendiqué à gauche d'Izquierda Unida qui se divise en deux secteurs face à son ascension. L'ex-coordinateur général d'IU, Cayo Lara, s'oppose à une alliance sans accord sur un programme commun. À Madrid par exemple, le représentant du parti Eddy Sánchez, vainqueur en 2012 avec 51 \% des voix des primaires pour les élections régionales face à Tania Sánchez Melero, dirige le courant majoritaire "Somos IU ", et ne veut pas "perdre son identité dans Ganemos ${ }^{68}$ ". Mais le jeune député Alberto Garzón, actuel coordinateur général du parti et candidat favori à la primaire de la coalition pour les législatives de 2015, pense que « les gens ne comprendraient pas que IU et Podemos ne s'allient pas pour faire face au bipartisme ${ }^{69}$ ".

67. Loïc LE CLERC, « Pourquoi Podemos progresse quand le Front de gauche patine », Marianne, 6 septembre 2014.

68. Gregorio ÀlvAREZ, «IU se divide ante el ascenso de Podemos », El País, 7 novembre 2014. 69. Alberto GARZON, conférence de presse publique, Madrid, 25 octobre 2014. 
Des brèches s’ouvrent aussi au sein du parti socialiste: José Antonio Pérez Tapias, dirigeant du courant " Gauche socialiste " du PSOE qui a obtenu $15 \%$ des voix lors de la primaire de 2013, a qualifié Podemos de " renouveau " pour la vie politique, et invité ses dirigeants à poursuivre leur évolution avec en vue de possibles connexions. Il a assisté à l'assemblée de Podemos du 15 novembre avec le socialiste madrilène Enrique del Olmo, candidat vaincu par Miguel Antonio Carmona lors de la primaire du PSOE pour la mairie de Madrid. La dirigeante du PSOE d'Andalousie, Susana Díaz, s'est aussi déclarée favorable à une alliance avec Podemos si celui-ci s'éloigne de l'anticapitaliste d'IA, mais le nouveau parti semble désormais exclure cette option suite à la victoire électorale du PSOE en Andalousie et à son peu de volonté de négocier sur les politiques qui seront menées par le nouveau gouvernement.

De plus, Podemos n'absorbe pas seulement IU et une bonne partie des électeurs socialistes: son discours attire aussi une frange minoritaire des ouvriers et des électeurs dont l'identification à un parti est la plus faible, et qui ont voté pour le PP ou pour UPyD en 2011 pour sanctionner et "voter contre " le PSOE et sa gestion désastreuse de la crise. Podemos attire ainsi une partie des électeurs du parti de Rosa Díez, qui cherche depuis 2007 à incarner une alternative de centre droit au bipartisme, mais se heurte au système électoral et à la concurrence du PP. Il y a de même fort à croire que les partis nationalistes catalans (CiU et ERC) et basques (PNV et Bildu) se verront affectés par l'essor de Podemos lors des législatives de 2015, d'autant plus lorsque l'on connaît le comportement électoral dual de leurs électeurs, qui ont plus tendance à voter pour des partis " nationaux " lors des législatives que lors des régionales ${ }^{70}$.

Cette stratégie affirmée de conquête du pouvoir au niveau national explique le choix de se focaliser sur l'échéance des législatives de décembre 2015 et de ne pas engager directement Podemos dans les élections municipales et régionales, même si le parti soutient l'auto-organisation de candidatures d'unité populaire et se dit ouvert à des alliances locales à géométrie variable. Pour le moment, au niveau national, la stratégie du parti est de refuser les alliances préélectorales, tout en se disant « ouvert » au dialogue avec les autres formations politiques pour mettre en place une réforme fiscale, la fin des expulsions et la remise

70. Francesc PALLARÈS et Michael KEATING, « Les élections autonomiques et les systèmes partisans régionaux: l'essor d'une compétition électorale multi-niveaux », dans Alicia FERNÁNDEZ GARCIA et Mathieu PETITHOMmE (dir.), Les nationalismes dans l'Espagne contemporaine. Compétition politique et identités nationales, Paris, Armand Colin, 2012, p. 238-263. 
en cause de la réforme du travail votée par le PP. Mais ses dirigeants pensent que « le PSOE devrait adopter un tournant à 180 degrés pour faire partie de la solution et non du problème ", et sont très sceptiques sur la possibilité d'un tel tournant ${ }^{71}$. Podemos se concentre donc sur deux actions: s’organiser et développer ses assemblées citoyennes sur l'ensemble du territoire, et construire un solide discours politique au niveau national qui déterminera son programme électoral, suivant l'objectif affirmé de devenir la première force politique de gauche, voire même d'Espagne ${ }^{72}$.

\section{5, LA FIN DU BIPARTISME IMPARFAIT?}

Au final, comment peut-on expliquer l'essor de Podemos? L'ascension du nouveau parti se fonde sur plusieurs éléments-clés. D’abord, il se structure comme une "méthode participative " plus que comme un parti traditionnel. Il illustre la volonté de construire un parti hétérodoxe moderne, s'appuyant sur les mouvements citoyens et sociaux en attirant les militants associatifs, les abstentionnistes et les citoyens déçus des partis traditionnels, et allie une fédération d'assemblées locales à un exécutif national dominant en s'appuyant sur des procédures numériques de démocratie interne. Ensuite, il formule une proposition politique positive qui redonne de l'espoir aux citoyens et qui n'est pas « antipolitique " ou antisystème, en cherchant à convaincre que chacun peut être acteur de la politique et du changement social. Troisièmement, Podemos repose sur la communication politique médiatisée de son dirigeant Pablo Iglesias, qui lui a ouvert l'espace public de masse, en se fondant sur son expérience des joutes oratoires et politiques au sein de $L a$ Tuerka, la chaîne de débats télévisés en ligne qu'il a créé il y a déjà une dizaine d'années.

Quatrièmement, les réseaux sociaux et la base militante d'Izquierda Anticapitalista ont joué un rôle majeur pour activer des structures de base et diffuser les prises de position du cercle dirigeant à un large public. Enfin, son refus d'être catégorisé comme un parti " de gauche » et sa recherche d'un discours plus transversal s'adressant et cherchant à représenter " le peuple " dans son ensemble, taxé à tort à mon sens de « populiste » par ses adversaires, est néanmoins caractéristique d’un

71. Déclaration publique de Íñigo ERREJòn, Madrid, 12 décembre 2014.

72. Francesco MANETTO, «Podemos aparta de su agenda el debate sobre pactos para las generales », El País, 2 décembre 2014, p. 12. 
parti « attrape-tout " et "électoral-professionnel " clairement axé sur la conquête du pouvoir. L'essor de Podemos se fonde sur sa volonté de dominer le tempo politique en formulant un discours interclassiste qui recentre le débat autour des grandes questions transversales qui concernent la majorité des citoyens (plans de rigueur, corruption, emploi, logement, etc.), obligeant par là même l'ensemble des forces politiques de droite comme de gauche à se justifier ou à se resituer par rapport à ses propositions. L'ascension de Podemos reste à confirmer dans les urnes et dépendra de nombreux facteurs économiques et politiques tant internes qu'européens. Mais les élections municipales et régionales de mai 2015 ont d'ores et déjà illustré une restructuration inédite du système partisan espagnol à travers un déclin du « bipartisme imparfait " incarné par le PP et le PSOE, et au contraire une plus grande fragmentation avec l'essor de nouveaux partis comme Citoyens et Podemos ${ }^{73}$.

Pour terminer, il est possible d'évoquer les scénarios politiques les plus plausibles en vue des législatives de décembre 2015. L’hypothèse stratégique du PP est de se dire que la fragmentation de la gauche lui permettra de maintenir sa position de parti dominant. Il s'agirait alors de gouverner sans majorité absolue, en recherchant soit l'appui de CiU comme en 2000 sous le gouvernement de José María Aznar, soit celui du PSOE, ou celui du nouveau parti de centre droit Citoyens. Un pacte potentiel avec CiU semble toutefois aujourd'hui très improbable, même dans le cas de concessions fiscales, car au vu de la poussée indépendantiste, CiU conditionnerait un tel accord à l'organisation d'un référendum. Par la voix de sa secrétaire générale, Dolores de Cospedal, le PP n'écarte donc plus l'hypothèse d'une "grande coalition " avec le PSOE, même s'il s'agit plus d'une posture de communication qu'une volonté réelle ${ }^{74}$. Pedro Sánchez refuse catégoriquement cette perspective, mais ne s'oppose pas toutefois à la possibilité d'accords ponctuels avec le PP, par exemple sur le débat territorial ou la réforme de la constitution, que le parti propose pour instaurer un État fédéral et répondre aux aspirations autonomistes catalanes ${ }^{75}$. En l'absence de majorité absolue, les dirigeants du PP préféreraient dominer un exécutif certes sans

\footnotetext{
73. Sur cette notion, cf. Gérard GRUNBERG et Florence HAEGEL, La France vers le bipartisme? La présidentialisation du PS et de I'UMP, Paris, Presses de Sciences Po, 2007.

74. Carlos CUÉ, « Dolores de Cospedal no descarta una "gran coalición" si no obtiene la mayoría absoluta », El País, 3 décembre 2014, p. 22 ; voir du même auteur, «El PP flirtea con un posible pacto con el PSOE, que lo niega rotundamente », El País, 2 décembre 2014, p. 18.

75. Francesco MANETTO, "Sánchez no descarta acuerdos parlamentarios con otras fuerzas », El País, 1er décembre 2014, p. 15.
} 
majorité parlementaire, mais pouvant gouverner en minorité si un pacte est passé avec le PSOE pour qu'il s'abstienne. De tels pactes ont de fait déjà eu lieu depuis la transition démocratique ${ }^{76}$. L'argument utilisé par le PP est que s'il maintient sa position de premier parti, il serait " antidémocratique " qu'il ne puisse pas gouverner. Mais l'émergence du parti Citoyens d'Albert Rivera, ancien membre du PP et catalan non nationaliste, complique la tâche du parti conservateur et renforce la concurrence à droite. Suite aux élections andalouses de mars 2015, il apparaît de plus en plus que Citoyens exerce une certaine attraction chez les libéraux et les jeunes conservateurs.

Même s'il s'agit de "politique-fiction", deux autres configurations peuvent émerger. La première, assez improbable à mon sens aujourd'hui, serait celle d'une grande alliance victorieuse des trois composantes de la gauche, le PSOE, Podemos et Izquierda Unida. Si l'on se fonde sur les récentes enquêtes d'opinion sur les intentions de vote respectives du PSOE (20-23\%, de Podemos (20-24\%) et d'IU (5\%), une " grande coalition » de gauche aurait de grande chance de l'emporter. Mais une telle perspective est quasiment impossible pour une raison simple: à cause du mode de scrutin majoritaire à un tour, il faudrait que ces trois forces politiques se mettent d'accord en amont sur un programme politique partagé, mais aussi sur une liste commune de candidats. Cela impliquerait des négociations ardues entre les appareils politiques, mais surtout le retrait de nombreux «barons » locaux du PSOE au profit de candidatures issues de Podemos et d'IU. Ce serait intelligent pour conquérir le pouvoir, mais sonnerait le glas des ambitions de nombreux responsables locaux du PSOE, d'autant plus que ce dernier devrait ensuite trouver des compromis avec deux autres forces politiques pour gouverner, alors même qu'il est profondément empreint d'une culture de parti dominant. Mais le principal obstacle est surtout idéologique: pour le PSOE, s'allier avec Podemos serait s'avouer vaincu avant même d'avoir combattu; pour IU, une alliance avec le PSOE serait contradictoire avec sa forte opposition aux mesures d'austérité prônées par José Luis Rodriguez Zapatero de 2008 à 2011; enfin pour Podemos, une telle alliance serait aussi totalement contradictoire avec son objectif politique de devenir le nouveau parti dominant de la gauche et d'incarner le renouveau en opposition à la « caste PPSOE ".

76. Sur ce point, la secrétaire d'analyse politique et sociale Carolina Bescansa juge « plausible » un pacte post-électoral entre le PP et le PSOE, ce qui serait certainement désastreux pour ce dernier, en actant son déclin, et risquerait d'entraîner sa quasi-disparition comme le PASOK grec. 
Tant Podemos pour confirmer son ancrage électoral, que le PSOE pour ne pas le voir disparaître n'ont donc aucun intérêt stratégique à former une alliance préélectorale. Mais au vu de l'évolution idéologique rapide de Podemos vers la social-démocratie, une convergence post-électorale sous la forme d'un accord de gouvernement peut être possible, comme ce fut le cas dans de nombreuses municipalités. Mais il faudrait pour cela que les deux forces obtiennent suffisamment de soutiens électoraux pour pouvoir constituer une majorité ensemble. Il faudrait aussi que le PSOE préfère s'allier avec Podemos plutôt qu'avec Citoyens, puisqu'un tel pacte est aussi possible.

La seconde configuration serait celle d'une alliance alternative entre IU et Podemos. Après tout, Pablo Iglesias a lui-même collaboré avec IU dans le passé et de nombreux membres du cercle dirigeant du parti sont issus des rangs d'IU. Mais à ce jour, Podemos dépasse quasiment constamment les $20 \%$ d'intentions de vote sans IU, en étant annoncé au mieux comme la première, au pire comme la troisième force politique. L'intérêt d'une telle alliance semble donc limité pour Podemos et ses dirigeants optent plutôt pour préserver leur indépendance et absorber de fait l'électorat d'IU sans avoir besoin d'accords partisans. Il semble clair qu'un affrontement entre le PSOE et Podemos se profile pour le leadership de la gauche. La stratégie du PSOE est de "rappeler aux gens que la majorité des dirigeants de Podemos sont issus de Izquierda Anticapitalista ", en "dévoilant la contradiction entre leurs paroles modérées d'aujourd'hui et leur discours radical de toujours ${ }^{77}$ ". On estime qu'environ un tiers des électeurs de Podemos lors des européennes du 25 mai 2014 ont au moins voté une fois pour le PSOE dans le passé, ce qui témoigne de l'existence d'un électorat « flottant » que les socialistes espèrent récupérer. Mais la tâche semble difficile, puisque cela risque de stigmatiser comme " extrémistes » des électeurs qui ne se ressentent pas comme tels, et d'accroître encore l'attrait de Podemos au moment où il entreprend " un rapide voyage idéologique vers la socialdémocratie $^{78}$ ». Le PSOE reconnaît d'ailleurs lui-même que "les électeurs de Podemos sont majoritairement des personnes progressistes qui expriment leur indignation face au fonctionnement du système et qui ne trouvent pas aujourd'hui au sein du PSOE la réponse adéquate ${ }^{79}$ ". Mais les dirigeants socialistes ne comprennent pas la montée en

77. PSOE, Documento estratégico, novembre 2014.

78. Francesco MANETTO, «Podemos : el rápido viaje ideológico hasta la socialdemocracia », El País, 30 novembre 2014.

79. PSOE, Documento estratégico, novembre 2014. 
puissance du mouvement, empêtrés qu'ils sont dans une vision réductrice du parti comme "une scission de la gauche d'Izquierda Unida", alors que la vraie question est celle de la radicalisation de l'électorat de gauche progressiste face au maintien d'un chômage de masse, à la hausse des inégalités et à la corruption politique ${ }^{80}$. Dans un contexte général de fragmentation et de multiplication des organisations partisanes, le scénario d'une tripartition, voire même d'une quadripartition (Podemos-PSOE-Citoyens-PP) de l'espace politique semble donc le plus probable, avec pour inconnues le poids relatif de chacune de ces quatre composantes principales et leurs stratégies d'alliances respectives.

80. Carlos CARNICERO, «EI PSOE frente a Podemos », El Periódico, 8 novembre 2014. 



\title{
11 \\ Un tournant historique en Espagne? Nouvelles alternatives et renouveau de l'engagement citoyen
}

\author{
Alicia FERNÁNDEZ GARCÍA \\ Le futur a été créé pour être changé » \\ (Paulo Coelho)
}

La séquence historique qui s'est ouverte en 2008 est sans précédent dans l'histoire de l'Espagne contemporaine à plus d'un titre: le pays a connu une récession économique majeure aux effets réels et durables sur la société, la jeunesse, les travailleurs peu qualifiés et les plus vulnérables. La hausse des inégalités, de la précarité et le développement des bas salaires donnent corps à un paysage social plus fragmenté, où les mondes qui séparent classes sociales populaires et aisées tendent à se différencier de plus en plus. Mais loin d'être atone et malgré le découragement, le désespoir et la peur de l'avenir qui touchent de nombreuses familles à travers la dégradation de leurs conditions de vies, la société espagnole s'est remise en mouvement, descendant massivement dans les rues pour exprimer son mécontentement et son indignation à l'égard des élites politiques, des banques et de l'austérité.

Pour clore cet ouvrage collectif, nous dégagerons quelques pistes de réflexion sur les explications de la crise économique, sociale et politique qu'a traversée l'Espagne d'aujourd'hui. Mais loin du pessimisme qui se dégage si l'on s'intéresse à la situation sociale des classes moyennes et populaires, à leurs conditions de vie et de travail, nous tenons à souligner toutefois la vitalité des mouvements sociaux qui ont émergé au cours des dernières années, et leur contribution au changement social et à l'évolution des mentalités. Les crises multiples auxquelles le pays a dû faire face ont au moins eu pour effet positif de contribuer à une 
repolitisation de la société espagnole, en remettant des enjeux sociaux majeurs sur le devant de la scène publique et médiatique. La défense des droits fondamentaux au travail, au logement, à la santé et à l'éducation a engendré un renouveau de l'engagement citoyen. Il semble ainsi désormais que l'Espagne soit à un tournant de son histoire contemporaine, marqué par l'essor de nouvelles demandes citoyennes, qui déboucheront très certainement sur des alternatives et des pratiques politiques et sociales renouvelées.

\section{UNE CRISE AUX ORIGINES ET AUX EFFETS MULTIPLES}

\section{Un « miroir grossissant " des dérives politico-financières}

Dans cet ouvrage collectif, les auteurs ont mis en avant des diagnostics assez proches en ce qui concerne les principales causes du déclenchement de la crise économique. La responsabilité des élites politiques d'abord, largement coupables de l'endettement excessif des communautés autonomes par des investissements publics démesurés qui ont parfois engendré de véritables gouffres financiers. Les gouvernements successifs depuis les années 1990 ont aussi très souvent fermé les yeux sur les pratiques douteuses (emprunts toxiques, clauses abusives de prêt, etc.) des établissements bancaires. Les intérêts de nombreuses élites politiques, membres des conseils d'administration des banques, des caisses d'épargne ou encore des principales multinationales espagnoles, ont évidemment renforcé le manque de contrôle et de transparence, tant dans l'utilisation des deniers publics, que dans les prêts consentis aux particuliers. Les échanges de faveur entre membres de l'élite politico-financière sont aussi directement mis en cause. Les conflits d'intérêts, la surfacturation des marchés publics et le financement illégal des partis politiques, sont autant de pratiques qui ont été mises en lumière et qui ont suscité l'indignation générale des citoyens.

Une deuxième raison qui permet d'expliquer pourquoi l'impact social de la crise a été plus important en Espagne qu'ailleurs en Europe est liée aux limites du modèle économique espagnol et à ses déséquilibres structurels. En effet, les gouvernements successifs du PP et du PSOE ont plébiscité depuis les années 1980 un modèle de croissance économique assez artificiel et peu viable à long terme, fondé principalement sur les secteurs du bâtiment et du tourisme. Les limites de ce 
modèle expliquent l'effondrement de la " bulle immobilière ", l'explosion et le maintien d'un fort taux de chômage, de même que l'aggravation des inégalités. À cet égard, Elìes Furiò Blasco, Mathilde Alonso Pérez et Christel Birabent Camarasa ont bien exposé comment la persistance d'un fort taux de chômage en Espagne « n'est pas uniquement la conséquence de la crise économique ", mais résulte plutôt de facteurs structurels: l'échec scolaire, la proportion importante de travailleurs au faible niveau de qualification, l'importance surdimensionnée du secteur du bâtiment, ou encore la dépendance très forte de l'économie à l'égard de la demande intérieure. Ces déséquilibres, connus de longue date, n'ont pas été corrigés par les différents gouvernements qui ont dirigé le pays au cours des deux dernières décennies. Les élites politiques espagnoles, de gauche comme de droite, se sont accommodées à l'idée que la forte croissance des années d'expansion (1993-2008) serait durable sur ces bases pourtant fragiles.

Le fait que l'Espagne a été plus touchée que d'autres pays européens suite à la grave récession mondiale qui débuta en 2008, s'explique donc par une conjonction de facteurs: les nombreux risques inconsidérés pris par le secteur bancaire; le fort endettement des familles et des entreprises; la sous-qualification de nombreux travailleurs, peu à même de se reconvertir suite à la perte de leur emploi dans les secteurs du bâtiment et de l'hôtellerie/restauration notamment; ou au contraire, la surqualification de nombreux jeunes dans des filières qui ont vu leurs perspectives d'avenir remises en cause par la crise. Parmi les jeunes Espagnols évoqués par Sylvie Koller qui s'organisèrent autour de Juventud Sin Futuro, de Democracia Real Ya et du mouvement des indignés à partir de 2011, on trouve certes de jeunes précaires peu qualifiés, mais aussi et surtout des diplômés universitaires, bien plus qualifiés que leurs parents, mais qui peinent à trouver une place sur un marché du travail peu fluide et dominé par le localisme et le régionalisme. Les perspectives d'embauche de toute une génération se sont progressivement assombries et le règne des enchufes (" pistons ") à travers l'utilisation des réseaux familiaux et amicaux, qui commençait à être remis en cause, a brusquement repris le dessus sur celui du mérite, compliquant l'accès des jeunes au marché du travail et poussant nombre d'entre eux à partir à l'étranger.

L'Espagne a ainsi connu une longue phase de crise sociale pendant au moins cinq ans, si ce n'est plus, depuis 2008. Certains estiment même que la crise est loin d'être terminée, et que malgré la reprise de la croissance économique depuis 2014, ses effets sur la société seront 
beaucoup plus durables. Les politiques d'austérité, la diminution des dépenses publiques et les augmentations d'impôt, de même que "l'objectif prioritaire de diminution du déficit public » comme le soulignent Elìes Furiò Blasco et ses coauteurs, ont largement contribué à renforcer l'impact social de la crise. L'effet collatéral des dernières années est que les choix des gouvernements du PSOE et du PP ont largement été perçus par les citoyens comme faisant partie du problème plus que de la solution, entraînant une crise de légitimité sans précédent de ces partis dominants.

Certes, avec le retour de la croissance, largement dû d'ailleurs à la baisse des taux d'intérêt et à la mise sur le marché de nombreuses liquidités par la Banque centrale européenne, le gouvernement conservateur soutient désormais avec force que les " efforts » des Espagnols et ses choix de politiques publiques commencent à porter leurs fruits. Le fait que le discours des institutions de la Troïka loue la politique du gouvernement espagnol, dont la priorité demeure la réduction des déficits publics, renforce la légitimité de ses choix politiques face à ses adversaires internes. L'entrée dans une phase de précampagne électorale en vue des législatives qui se tiendront à la fin de l'année 2015 laisse augurer que ce discours de la " récupération » constituera l'axe dominant de la campagne du parti conservateur. D’autant plus qu'il doit désormais faire face à l'émergence de nouvelles alternatives politiques. Il est très probable que Mariano Rajoy cherchera donc à agiter le chiffon rouge de « l'instabilité " et à s'octroyer les mérites du retour de la croissance pour tenter de convaincre les électeurs.

Les conservateurs bénéficieront donc peut-être de l'effet des « cycles économiques ", dans le sens où la crise, déjà très longue, ne peut pas durer éternellement. Mais pour les classes moyennes et populaires, ses effets sociaux se font encore largement sentir. L'Espagne d'aujourd'hui est plus inégalitaire que celle de 2008: si certains Espagnols vivent aussi bien en 2015, la plupart vivent moins bien. Une dualité très forte s'est installée sur le marché du travail, avec une minorité de travailleurs bénéficiant de bonnes conditions de travail et de contrats à durée indéterminée, et une majorité devant enchaîner les contrats à durée déterminée et les emplois précaires. Il est de même important de noter que la plupart des emplois créés depuis le renouveau de la croissance économique en 2014 sont des emplois précaires et peu qualifiés. Les employeurs utilisent désormais la réserve de travailleurs pour tirer les conditions de travail et les salaires vers le bas, ce qui touche d'abord les classes populaires et les salariés peu qualifiés. 
Autre conséquence de la crise, le travail au noir a aussi largement refait surface, permettant de limiter l'impact social de la crise en donnant des revenus d'appoint aux familles, mais obligeant aussi de nombreuses personnes à travailler sans cotisations retraites ni protection sociale. Le chômage reste très élevé et touche fortement les jeunes pour qui les perspectives d'avenir ne sont plus les mêmes. Elìes Furiò Blasco et ses coauteurs ont bien mis en avant le fait que la hausse des frais d'inscription à l'université décidée par le gouvernement conservateur illustre "une vision idéologique de l'éducation ", qui risque de priver toute une génération de jeunes issus des classes populaires de l'accès à l'enseignement supérieur, les exposant d'autant plus au chômage sur le long terme et accroissant la fracture entre les classes sociales. La réforme du marché du travail de 2012 facilite les licenciements, même si les études économiques ont montré, selon eux, " qu'il n'existe en fait pas de relation causale directe entre les coûts de licenciement et le taux de chômage moyen ". La diminution de la capacité d'action collective des syndicats risque aussi de modifier durablement "le rapport de force entre les agents sociaux ». Certes, la situation peut évoluer dans les années à venir avec des changements possibles de majorité à l'échelon local ou au niveau national. Mais il sera impossible de compenser les souffrances passées, de rendre leur argent aux épargnants floués et leur appartement aux personnes expulsées durant la crise.

\section{Une crise de légitimité des institutions}

Au-delà de la crise économique et sociale, l'Espagne d'aujourd'hui a aussi connu une crise de légitimité des élites et du système politique issu de la transition et de la constitution de 1978. En étudiant les manifestations républicaines, nous avons montré comment leur renouveau a été intimement lié au contexte des crises multiformes depuis 2008. Cette situation nouvelle s'est traduite par une perte de confiance envers les élites et les principales institutions, ce qui "a amené un nombre croissant de citoyens à réévaluer de façon critique le "pacte" de la transition ", désormais perçu comme le symbole d'une démocratisation inachevée. La récession économique a déclenché une crise du politique, remettant en cause les principaux piliers du compromis de la transition démocratique. Le système électoral majoritaire, la loi sur les partis, le manque de transparence de la vie politique, les échanges de faveurs et la circulation des élites politiques et financières entre les sphères publiques et privées, ou encore le manque d'indépendance de la justice, sont dénoncés par les citoyens comme autant de limites du 
système démocratique actuel. La persistance de certaines pratiques, comme l'ampleur de la corruption politique, tend à donner l'image d'un pays européen en retard, où le clientélisme règne encore en maître. Mais cette image ne constitue qu'un versant de la réalité: la révélation de nombreuses affaires est aussi justement liée à la démocratisation, au travail des juges et aux condamnations de plus en plus récurrentes de pratiques qui passaient inaperçues dans les années 1980 et 1990. D'autre part, les citoyens espagnols du Xxi siècle sont devenus plus exigeants et plus critiques, ce qui débouche sur de nouvelles demandes sociales et sur un contrôle accru des pratiques politiques.

Sur la forme de l'État, la résurgence du républicanisme n'a toutefois pas traduit un mouvement social massif d'opposition, car comme le rappelle Benoît Pellistrandi, la monarchie, certes "marquée par un héritage historique qui la fragilise ", demeure perçue comme "une institution d'équilibre et d'incarnation ». Les manifestations lors de l'abdication de Juan Carlos $\mathrm{I}^{\mathrm{er}}$, marquées par leur caractère spontané et principalement « liées à l'effet de surprise et à l'euphorie du moment ", illustrèrent "la défiance généralisée " et "la volonté de changement des citoyens " plutôt qu'un désir d'en finir avec la monarchie. En étudiant la mémoire historique républicaine, nous avons rappelé le faible soutien au républicanisme en Espagne, délégitimé par les expériences, très courte de la Première République, et plus controversée et traumatique de la Seconde République. Il est vrai que pour certains secteurs, notamment pour les descendants des républicains réprimés, exilés ou victimes de la guerre civile et du franquisme, la transition demeure le symbole d'un "pacte de l'oubli " qui n'a pas permis d'obtenir justice, vérité et réparation pour les crimes commis. De même, dans un contexte marqué par l'austérité et la radicalisation des revendications indépendantistes, la Seconde République, largement idéalisée, demeure un référentiel inconscient pour la gauche, associé au progrès social et à l'autonomie régionale. Mathieu Petithomme et Mercè Pujol s'accordent d'ailleurs à dire que le renouveau de l'indépendantisme tant au Pays basque qu'en Catalogne, est intimement lié à l'attitude dogmatique du gouvernement conservateur, qui refuse d'évoquer une réforme de la structure territoriale de l'État vers plus d'autonomie et de fédéralisme.

Benoît Pellistrandi a d'ailleurs suggéré, à juste titre, que la défiance que les Espagnols ont exprimée à de nombreuses reprises lors des manifestations républicaines, allait plus à l'encontre des responsables politiques et des élites financières que de la monarchie elle-même. Devant la peur de l'inconnu, les Espagnols demeurent majoritairement 
attachés à l'image rassurante de stabilité que transmet la monarchie ${ }^{1}$. La tourmente dans laquelle Juan Carlos $\mathrm{I}^{\mathrm{er}}$ a plongé l'institution monarchique par ses frasques personnelles n'a donc pas débouché sur un mouvement massif favorable à un changement de régime: "à l'heure du bilan, l'actif, la transition démocratique, la capacité à accompagner la métamorphose de l'Espagne et à représenter le pays sur la scène internationale, l'emportait largement sur le passif constitué par les scandales de corruption ». Ce ne fut pas un hasard si les manifestations les plus importantes lors de l'abdication eurent lieu en Catalogne et au Pays basque, où les revendications républicaines se mêlent aux demandes d'indépendance. Mais il est vrai que le clivage à l'égard de la monarchie et de la figure de Juan Carlos $\mathrm{I}^{\mathrm{er}}$ demeure avant tout générationnel. C'est ce défi, susciter l'enthousiasme, ou par défaut, au moins le respect des jeunes, pour qui la monarchie ne va plus forcément de soi, qui est au cœur de la nouvelle mission de Philippe VI, dont l'accession au trône incarne d'une certaine manière en elle-même une forme de renouvellement. En effet, suivant Benoît Pellistrandi, «la fragilité d'une monarchie tient moins à ses principes qu'à ses incarnations ". La résorption de la crise de légitimité de l'institution monarchique dépendra essentiellement de la capacité du nouveau roi à incarner une autorité neutre, exemplaire et rassembleuse.

\section{LA CONTRIBUTION DES MOUVEMENTS SOCIAUX AU CHANGEMENT}

\section{Une diversification des formes de contestation}

En se mobilisant, en manifestant, en signant des pétitions ${ }^{2}$, en cherchant à entourer le Congrès des députés, en utilisant l'humour, la désobéissance civile (des médecins par exemple dans la défense de la santé

\footnotetext{
1. Comme le note Benoît Pellistrandi, malgré que Juan Carlos ler fût « éduqué par Franco dans l'Espagne de Franco », ce qui apparaît pour l'opposition antifranquiste comme « une compromission avec le dictateur », le fait qu'il devint le « pilote du changement démocratique », et qu'il incarne la légitimité et la défense de la Constitution lors du coup d'État raté du 23 février 1981, contribua à asseoir sa légitimité auprès des Espagnols de la génération de la transition. Voir aussi Charles T. PoWELL, El piloto del cambio, op. cit., 1991. Sur l'importance historique du coup d'État de 1981, on peut se référer à l'essai historique primé, sous la forme d'un roman, de Javier CERCAS, Anatomía de un instante, Madrid, Editorial Mondadori, 2009.

2. On peut citer la pétition de l'ILP pour un moratoire sur les expulsions à l'initiative de la PAH, mais aussi suite aux révélations d'El Mundo sur la « comptabilité B » du PP le 31 janvier 2013, la pétition lancée le 1er février sur le site internet change. org, demandant la démission de Mariano Rajoy, qui recueillit un million de signatures en une semaine seulement.
} 
universelle) ou des actions anticonventionnelles, les Espagnols ont fait advenir un renouveau de nombreuses pratiques de contestation. Contrairement aux années 1990 et 2000, les citoyens sont descendus massivement dans les rues depuis 2008 lors d'actions collectives qui resteront dans l'histoire: quatre grèves générales contre l'austérité, le chômage et la précarité ont ainsi été organisées entre 2010 et 2012, $\mathrm{du}$ jamais vu depuis la transition; des dizaines de milliers de jeunes ont protesté puis occupé la Puerta del Sol à Madrid le 11 mai 2011; plus d'un million de Catalans ont manifesté pour l'indépendance le 11 septembre 2012, puis plus de deux millions se sont mobilisés lors de la consultation symbolique sur le futur de la Catalogne le 9 novembre 2014. Les Espagnols ont protesté contre la classe politique, la corruption, l'impunité des élites, le bipartisme, les banques, le néolibéralisme, contre les expulsions, la monarchie, les violences de genre et pour le droit à l'avortement. Des pratiques traditionnelles des mouvements sociaux sont ainsi revenues sur le devant de la scène: défilés massifs de manifestants; signature de pétitions (comme lors de l'initiative législative populaire contre les expulsions à l'initiative de la PAH); sitting de protestation devant des gouvernements de communautés autonomes et le Congrès des députés; ou encore, usages de sifflets et de casseroles par les militants indépendantistes catalans.

Les ressources informationnelles, notamment l'utilisation des réseaux sociaux et de l'internet, se sont imposées comme de nouvelles armes dans l'arsenal militant ${ }^{3}$. Karine Bergès estime en ce sens que « l'usage politique des nouvelles technologies " a participé au "renouvellement des répertoires d'action du féminisme contemporain ". Dans une "démocratie du public " pour reprendre l'expression de Bernard Manin, au sein de laquelle les médias jouent un rôle central, la "spectacularisation des actions militantes » a permis d'attirer l'attention des médias, comme ce fut par exemple le cas pour les initiatives et les "performances " des militantes féministes ${ }^{4}$. Patrick Champagne parle sur ce point de «manifestations de papier ", dans le sens où les mouvements sociaux contemporains se jouent certes sur le terrain à travers la force du nombre de manifestants, mais aussi dans les interprétations que les médias donnent de ces mobilisations ${ }^{5}$. Le rôle des émotions, dans la dramatisation des actions de résistance aux expulsions locatives diffusées à la télévision, a

3. Pierre MERCKLE, Sociologie des réseaux sociaux, Paris, La Découverte, 2011, p. 87.

4. Bernard MANIN, Principes du gouvernement représentatif, Paris, Flammarion, [1995] 2012, p. 6.

5. Patrick Champagne, Faire l'opinion, Paris, Éditions de Minuit, 1990. 
permis à des acteurs faiblement dotés de ressources de toucher l'opinion publique ${ }^{6}$. Olivier Fillieule et Danielle Tartakowsky ont en effet démontré que l'immense majorité des manifestations n'obtient pas de couverture médiatique ( 2 à $5 \%)^{7}$. Les événements routiniers n'intéressent pas les médias, de telle sorte que les mouvements sociaux doivent souvent avoir recours au spectaculaire pour attirer leur attention ${ }^{8}$.

D'autres répertoires d'action, jusqu'alors peu utilisés en Espagne, se sont développés. Mercè Pujol a rappelé comment les indépendantistes catalans ont mis en place une chaîne humaine massive (la Via Catalana) le 11 septembre 2013 ou encore, ont formé un drapeau catalan humain gigantesque dans les rues de Barcelone en 2014. Le phénomène des «marées » (verte, jaune, grenat, violette, etc.) a dévoilé la volonté de confluence de différents mouvements sociaux (étudiants et personnels de l'éducation, de la santé, fonctionnaires des communautés autonomes, féministes etc.), leur appropriation d'un code couleur et le transfert de certaines pratiques entre les groupes mobilisés. De plus, des pratiques artistiques de contestation ont illustré une repolitisation de la culture, du cinéma, le retour du " théâtre social » autour du Teatro del Barrio et d'Alberto San Juan à Madrid, ou encore le renouveau de la veine contestataire du flamenco (Flo 6x8). Les artistes ont souvent joué un rôle direct dans le mouvement social en s'associant à d'autres collectifs. Par exemple, Flo 6x8 et des membres de la PAH se sont associés aux étudiants de l'université Pablo de Olavide en 2013 lors de la venue d'un représentant de la Banque Santander sur le campus, pour contester les profits démesurés de ses actionnaires et ses actions d'expulsion contre certains de ses épargnants. Cette action collective illustra bien la synthèse entre artistes, étudiants, jeunes précaires mobilisés et militants de la PAH pour dénoncer les pratiques d'une entité jugée comme responsable de la bulle immobilière, de la crise économique et de nombreuses expulsions locatives.

Les féministes, comme les indignés et d'autres collectifs, ont de même utilisé les escraches, une pratique ancienne, longtemps tombée en désuétude. Pour Mathieu Petithomme, il s’agit de "manifestations

\footnotetext{
6. Sur les émotions en politique, Christophe TRAINI (dir.), Émotions... mobilisations, Paris, Presses de Sciences-Po, 2009. Voir aussi Dominique WISLER, « La couverture médiatique de l'action protestataire, étude à partir du cas suisse », Revue française de sociologie, n 40, 1999, p. 121-138. 7. Olivier FILLIEUle et Danielle TARTAKowsky, La manifestation, Paris, Presses de Sciences-Po, 2013, p. 145.

8. Érik NeVEU, « Médias, mouvements sociaux, espaces publics », Réseaux, vol. 17, n 98, 1999, p. 17-85.
} 
devant une institution publique ou privée ou le domicile d'un particulier, qui visent à dénoncer par l'intimidation, les cris, les sifflets et les slogans, les agissements considérés comme honteux d'entités publiques ou de personnes privées ". Ces pratiques donnant lieu à des rassemblements populaires et à des intimidations existaient déjà au Moyen Âge sous la forme de ce que l'on appelait alors les " charivaris ». Le retour de ce répertoire d'action n'est pas anodin, dans le sens où il illustre une forme de rage et de colère populaire à l'égard de certaines déviances et de personnes jugées responsables de pratiques délictueuses ou honteuses. Ces réactions populaires peuvent mener à des dérives liées à cette " effervescence collective " évoquée par Gustave le Bon dans $L a$ psychologie des foules ${ }^{9}$. Les intimidations peuvent déboucher sur une violence physique réelle, des menaces que les personnes concernées n’hésitent pas à exagérer pour substituer au débat sur leurs pratiques un autre sur la violence "inacceptable " des manifestants. Elles peuvent conduire à incriminer une personne lors d'un jugement médiatique, sans respecter la présomption d'innocence. Mais les exemples des dernières années montrent que les personnes qui ont subi ces protestations d'indignation avaient souvent des faits lourds à se reprocher. Les escraches ont toujours eu lieu après la révélation par la presse ou les médias de pratiques frauduleuses ou répréhensibles. Le renouveau de ce type d'intimidation révèle donc surtout les frustrations populaires latentes, le retour d'une forme de refoulé, face à des injustices, à l'impunité et à des pratiques jugées non seulement comme honteuses, mais aussi comme intolérables et nocives pour la démocratie.

De plus, les occupations, popularisées dans les années 2000 par le mouvement Okupas, sont devenues plus systématiques. Sylvie Koller a rappelé comment la forme du campement ouvert sur des places et des lieux publics, bien adaptée au tissu urbain, à la localisation et à l'ancrage territorial des luttes, a joué un rôle central dans la médiatisation du mouvement des indignés et la diffusion de ses revendications. Il est d'ailleurs intéressant de noter que l'essor d'une nouvelle formation comme Podemos doit beaucoup à l'adoption d'une structure organisationnelle décentralisée autour de "cercles " et d' "assemblées " locales ancrées dans un territoire et un quartier, qui donnent le sentiment aux citoyens d'agir concrètement dans un espace physique familier. Mathieu Petithomme a expliqué comment les occupations ont été utilisées de façon récurrente par les collectifs de la PAH afin d'occuper des

9. Gustave LE Bon, La Psychologie des foules, Paris, Flammarion, 2003 [1895]. 
sociétés bancaires, de porter atteinte à l'image de marque des banques, et de les forcer à ouvrir une négociation avec les particuliers pour éviter des expulsions et renégocier des prêts bancaires.

La Coordination 25-S a de même appelé à " entourer le Congrès " le 25 septembre 2012, puis à " assiéger le Congrès » le 25 avril 2013, en estimant que les députés ne représentent pas les aspirations du peuple espagnol ${ }^{10}$. Autour de la Coordination 25-S mais aussi d'autres organisations proches des milieux d'extrême gauche et anarchistes, notamment en Catalogne, la violence de rue a fait son retour. Certes, durant les années 1990, elle jouait déjà un rôle central pour certains mouvements sociaux, comme autour de la Kale borroka utilisée politiquement par le nationalisme basque radical pour monopoliser l'espace public et intimider ses adversaires. Mais les affrontements avec la police lors des actions d'interposition des citoyens pour éviter les expulsions, ou l'infiltration de radicaux violents lors des manifestations contre les banques et l'austérité, s'expliquent aussi par l'indignation générale de la société et la radicalisation d'une certaine frange de la jeunesse ${ }^{11}$. Ils traduisent une forte défiance vis-à-vis de la criminalisation et de la pénalisation croissante des mouvements sociaux par la récente loi sur la sécurité intérieure ${ }^{12}$. Le "moment manifestant" selon l'expression de Pierre Favre, a ainsi parfois contribué à délégitimer les pouvoirs publics, suite à l'usage disproportionné de la répression par les forces de l'ordre ${ }^{13}$.

\footnotetext{
10. Luz SÁNCHEZ-MELADO, « Los indignados más furibundos », El País, 25 septembre 2013.

11. Sur ce point, la récente loi sur la sécurité a d'ailleurs été votée par le gouvernement conservateur en réponse aux affrontements et aux arrestations massives qui eurent lieu en septembre 2012. Plutôt que de voir la radicalisation violente d'une partie de la jeunesse comme la conséquence directe de l'inaction des pouvoirs publics à l'égard d'une jeunesse condamnée au chômage de masse (un jeune sur deux est au chômage), le gouvernement a préféré « surveiller et punir » pour reprendre l'expression de Michel Foucault, cf. Surveiller et punir. Naissance de la prison, Paris, Gallimard, 1975.

12. La nouvelle loi introduit un changement de la doctrine de maintien de l'ordre: il s'agira désormais de "prévenir » les troubles à l'ordre public plutôt que de simplement les encadrer, de contrôler les personnes suspectées comme " déviantes », bref pour reprendre l'expression d'Éric Fassin, « d'institutionnaliser la surveillance ». Ceci implique des atteintes croissantes aux libertés individuelles, une pratique plus courante des arrestations de masse et du fichage policier, de même que des actions " préventives ». L'interdiction des manifestations républicaines lors de l'abdication de Juan Carlos ler, symbolisèrent par exemple la primauté des considérations sécuritaires sur la liberté d'expression. Cf. Ėric FASSIN, La force de l'ordre. Une anthropologie de la police des quartiers, Paris, Le Seuil, 2011.

13. Ce fut notamment le cas lors des manifestations étudiantes de 2013 ou de la tentative d'occupation du Congrès des députés: la diffusion de la répression policière à la télévision a développé une certaine solidarité émotionnelle de nombreux Espagnols avec les protestataires. Cf. Pierre FAVRE, «Le moment manifestant », dans Pierre FAVRE (dir.), La manifestation, Paris, Presses de Sciences-Po, 1990, p. 20.
} 


\section{La politisation de nouveaux enjeux}

Les mouvements sociaux espagnols ont également contribué à mettre de nouveaux enjeux au cour de l'agenda politique. L'une des caractéristiques essentielles des manifestations de rue est liée à "la nature politique de la démonstration ": elles "doivent se traduire par ou déboucher sur l'expression de revendications de nature politique ou sociale $^{14}$ ". " L'arène des conflits sociaux " qui se sont exprimés depuis 2008 a donc fonctionné, suivant l'expression d'Érik Neveu, « comme un espace d'appel au double sens d'expression d'une demande de réponse à un problème et, au sens judiciaire, de recours ${ }^{15}$ ". Par leurs slogans, leurs pancartes et leurs chants, transmis sur les réseaux sociaux, de même que filmés puis diffusés par les chaînes de télévision, les Espagnols, qui se sont mobilisés en masse depuis le début de la crise, ont donné une visibilité publique à des injustices et à des problèmes sociaux et politiques, en demandant des réponses et des solutions aux responsables publics.

À travers une forme d' « insurrection morale ", le mouvement des indignés a ainsi contribué à diffuser au sein de la société espagnole la demande d'instauration d'une démocratie plus participative et d'une moralisation de la vie publique. Il a dénoncé les limites de la personnalisation excessive du pouvoir, les comportements répréhensibles, les salaires et les avantages parfois démesurés des élites politiques. Sylvie Koller a bien noté que les principales revendications du mouvement sont de fait soutenues par une large majorité des Espagnols. Il en va ainsi de la volonté d'imposer le "caractère imprescriptible des délits de corruption ", "l'interdiction des licenciements collectifs lorsqu'une entreprise réalise des bénéfices", "la restitution de l'argent public prêté aux banques et aux caisses d'épargne en difficulté ", ou encore d'obtenir "la possibilité de solder un prêt hypothécaire en remettant son bien à l'organisme prêteur ". Cette sympathie montrée par l'ensemble des enquêtes d'opinion, de sept Espagnols sur dix, à l'égard des indignés et de leurs revendications, montre bien le rôle central qu'a joué le mouvement dans la politisation de nouveaux enjeux et la diffusion de leurs propositions de réformes et de changement au sein de la société ${ }^{16}$.

14. Olivier FILlieule et Danielle TARTAKowsky, La manifestation, Paris, Presses de Sciences-Po, 2013, p. 17.

15. Érik NeVEU, Sociologie des mouvements sociaux, Paris, La Découverte, 2000, p. 35.

16. «Siete de cada diez españoles simpatizan con el movimiento 15-M », El Mundo, 20 septembre 2013. 
La question de la corruption politique, qui n'est pas nouvelle en Espagne, tant ces pratiques étaient déjà courantes durant les années 1990, est désormais appréhendée différemment par la société, comme un fléau majeur à traiter. Auparavant, la corruption était perçue comme un phénomène résiduel, comme la résultante des conduites déviantes de certains individus. Elle est désormais associée à un "système " plus général, qui peine à combattre cette tare, ce qui amène à poser la question de réformes profondes, au-delà des cas individuels: nécessité de remédier au manque de transparence dans la gestion des fonds publics, mise en cause du cumul des mandats, de l'opacité du financement des partis, ou encore de l'impunité des élites qui tirent profit d'un système judiciaire qui manque d'indépendance. Même s'il reste encore beaucoup de chemin à parcourir, les partis politiques et leurs acteurs commencent à prendre conscience que la corruption mine leur image, et détourne les électeurs des formations qui n'excluent pas les personnes soupçonnées de corruption ou qui présentent une attitude jugée trop reprochable. Tant à travers l'essor de nouveaux partis qui mettent clairement cet enjeu au centre de leurs préoccupations, que grâce à l'évolution progressive des pratiques des partis traditionnels, il est possible d'espérer que des mesures plus coercitives pour combattre ces dérives et que de nouvelles pratiques seront adoptées au cours de la prochaine décennie.

D'autres enjeux ont aussi ressurgi grâce aux mouvements sociaux: la réforme du système électoral et de la loi sur les partis demandée par les indignés; la réforme de l'État des autonomies voulue par les indépendantistes basques et catalans; la dénonciation de l'austérité par les " marées » citoyennes, ou encore celle de la financiarisation de l'économie et des pratiques frauduleuses des banques par la mobilisation des petits épargnants, notamment autour du scandale des preferentes, ces placements à risque autour d'actifs toxiques vendus sans informations suffisantes qui ont causé la ruine de nombreux particuliers. Mathieu Petithomme a, de même, bien montré combien la PAH a contribué à dénoncer la loi hypothécaire espagnole, les clauses abusives dans les contrats de prêts immobiliers et le scandale des expulsions. Par ses actions d'interposition, ses plaintes et ses recours devant les tribunaux, ce collectif a fait pression sur les pouvoirs publics. Grâce à ses actions, les Espagnols ont pris conscience de la responsabilité des banques dans le déclenchement de la bulle immobilière. Si l'actuel gouvernement conservateur a décidé en mars 2015, avant tout pour des raisons électoralistes, de faire voter une future loi facilitant les renégociations 
entre les particuliers et les banques et instaurant une forme limitée de "donation pour paiement ", c'est parce que l'enjeu du droit au logement politisé par la PAH depuis 2008 fait désormais consensus dans la société. Il s'agit d'un exemple concret d'influence du mouvement social, tant sur des situations locales et personnelles que sur une réforme législative.

Karine Bergès a aussi mis en avant le rôle majeur des femmes dans les mobilisations sociales du temps présent. Elles se sont mobilisées sur les questions de genre, notamment dans le cadre du « mouvement intergénérationnel et contestataire " contre le projet de réforme sur l'avortement de 2011, forçant le gouvernement à faire marche arrière. En première ligne du mouvement des indignés, s'insurgeant " contre le poids de l'ordre patriarcal, hétérosexiste et capitaliste ", elles ont plus généralement dénoncé " la dégradation des conditions de vie des familles et des femmes, liée aux coupes budgétaires en matière de santé, d'aides sociales et de gel des salaires ". Comme le note Karine Bergès, "l'institutionnalisation du féminisme, sous les gouvernances socialistes ", a certes " inscrit les politiques de genre à l'agenda politique ». Cependant, ce " féminisme de service, légitime et nécessaire, a eu pour effet de reléguer le féminisme autonome dans les interstices de la contestation minoritaire ». Depuis 2008, on peut observer une nouvelle phase marquée par un certain renouveau du féminisme contestataire, et par l'insertion croissante des revendications féministes au sein de luttes transversales et à l'avant-garde du mouvement social: Sylvie Koller a évoqué le rôle de la " marée violette " au sein du 15-M; Karine Bergès, celui des "féminismes alternatifs" de la "troisième vague féministe ", mais aussi du cercle féministe au sein de Podemos; Mercè Pujol, l'influence décisive de Muriel Casals et de Carme Forcadell, les présidentes respectives d'Òmnium Cultural et de l'Assemblée nationale catalane, sur le mouvement indépendantiste; Mathieu Petithomme, le charisme d'Ada Colau dans la création de la Plateforme des affectés par l'hypothèque. Cette centralité des femmes dans les luttes, a non seulement permis d'inclure "les sujets des marges " et de politiser les questions sexuelles et du quotidien, mais aussi selon Karine Bergès, de " croiser systématiquement les propositions féministes avec la race, la classe, le genre et la sexualité ». Les enjeux féministes sont devenus plus transversaux, à travers de nombreuses déclinaisons et en pénétrant le corpus des revendications d'autres mouvements.

Enfin, les actions collectives, nombreuses et plurielles qui ont émergé depuis 2008, ont contribué à questionner et à remettre en cause les 
discours dominants, en proposant de nouveaux récits et "cadres d'interprétation " pour expliquer le réel et l'histoire espagnole du temps présent. Les élites politiques, comme l'a bien montré le comportement de José Luís Rodríguez Zapatero, ont d'abord nié l'existence de la crise, pour ensuite minimiser son impact et ses effets. La repolitisation de la société espagnole est en ce sens intimement liée au manque d'empathie et à la déconnexion du réel de la classe politique. Les pensions de retraite généreuses des députés, les " parachutes dorés " des dirigeants de multinationale qui licencient sans état d'âme, les rémunérations démesurées des actionnaires de banques au bord de la faillite sont devenues intolérables pour les citoyens et le symbole même des limites du système politique issu de la transition et de l'ordre économique néolibéral. Face à des acteurs politiques dominants qui partageaient globalement le même discours, la même vénération du libre-échange et le même maniement de la langue de bois pour éviter toute réforme structurelle du système de 1978, du modèle économique espagnol et de leurs pratiques, les citoyens, par leurs mobilisations, ont joué le rôle de " lanceurs d'alerte ", dénonçant les injustices et proposant de nouvelles alternatives. En attirant l'attention sur de nouveaux enjeux, en évoquant des causes, en dénonçant des responsables et en proposant des solutions, les mouvements sociaux ont redonné du sens à l'engagement, rompant avec le cercle vicieux de la lassitude et redonnant de l'espoir aux citoyens. La transformation du slogan "Oui, c'est possible " des indignés, en celui de Podemos "Bien sûr que oui nous pouvons", ou encore l'appellation même du nouveau parti " Citoyens ", symbolisent bien cette volonté de remettre la citoyenneté et son engagement au cœur de l'action politique.

\section{Activisme citoyen et nouvelles pratiques}

Le mouvement des indignés espagnols a eu un retentissement planétaire, illustrant la défiance d'une génération entière à l'égard des élites politiques et du système économique néolibéral. Toutefois, Sylvie Koller a bien montré comment, après quelques mois d'effervescence collective, le mouvement s'est peu à peu estompé face à l'" atomisation des groupes " et à la "tendance au ressassement de ses revendications ». Les dynamiques horizontales, le refus de porte-parole et de dirigeants et le choix de modes de fonctionnement fondés sur l'autogestion, les dynamiques consensuelles et la démocratie directe ont conduit le mouvement à l'« épuisement en discussions interminables " de même qu'à l'« empilement des propositions sans hiérarchie ». Mais au-delà de 
l'image d'une mise en sommeil du 15-M, les acteurs de ce mouvement se sont peu à peu investis " dans des collectifs citoyens, des plateformes, des comités de quartier et des expériences d'économie alternative ", diffusant en fait de nouvelles pratiques citoyennes au sein d'arènes et de lieux publics distincts. Cette " contre-culture » de la protestation a débouché sur des initiatives telles que la création de jardins communautaires, de coopératives de troc, d'électricité, des centres sociaux alternatifs, des occupations d'immeubles abandonnés par des promoteurs immobiliers en faillite, ou encore des villages ruraux autogérés.

En ce sens, l'« esprit citoyen et non-partisan d'origine du 15-M » a eu un impact plus global sur la société espagnole. Il explique par exemple l'essor du "municipalisme", à savoir de nouvelles plateformes citoyennes présentées dans le contexte des élections municipales (Ganemos Barcelona par exemple). Selon Sylvie Koller, en incitant ses sympathisants " à constituer des cercles sur une base locale, professionnelle ou thématique, de façon libre et autonome », Podemos a suscité un large engouement citoyen. Cette dynamique montre l'attachement d'une frange importante des citoyens à l'auto-organisation et à la territorialisation des luttes dans leur quartier et leur municipalité. L'activisme du mouvement des indignés, les nombreux mouvements sociaux qui sont descendus dans la rue depuis 2008, de même que Podemos dans leur sillage par la formulation d'une nouvelle plateforme politique, ont contribué à une repolitisation de la société espagnole par le bas.

Les limites de la dynamique d'assemblée du mouvement des indignés, notamment les difficultés à prendre des décisions par consensus, à hiérarchiser les revendications et à définir une stratégie politique cohérente, ont logiquement débouché sur une volonté de transformer l'indignation sociale et citoyenne en de nouvelles alternatives politiques. Ainsi, selon Sylvie Koller, le nouveau parti Podemos « a emprunté au 15-M certaines règles de fonctionnement, comme un mode d'affiliation souple (sans cotisation exigée et des formes de cyberactivisme: délibérations et forums de participation sur l'internet ". Il s'inspire de même des propositions du mouvement sur la question du contrôle démocratique à travers "des primaires ouvertes pour désigner les candidats aux élections ou à certaines fonctions ", " la possibilité de révoquer les élus ", et " la limitation à 2000 euros des indemnités parlementaires ".

Mais comme l'a souligné Mathieu Petithomme, Podemos est certes " une fédération d'assemblées locales autogérées, dont les décisions sont soumises à l'approbation des bases ", mais aussi "un parti au leadership très marqué ». La centralisation du parti autour d'un noyau 
dirigeant issu des fondateurs, le manque de notoriété de nombreux candidats, qui a débouché sur une compétition assez inégale entre les différentes listes dans l'élection de son "conseil citoyen " et de son secrétaire général, sont autant d'exemples montrant les limites du processus de délégation de pouvoir. À ce jour, le fonctionnement interne de Podemos illustre cependant une tentative de créer une organisation partisane sur des bases nouvelles, alliant une centralisation et une autonomie du cercle dirigeant avec la décentralisation et l'autogestion des assemblées locales. D'une certaine manière, Podemos incarne une forme de " laboratoire politique ", une expérience, à mi-chemin entre la verticale du pouvoir des partis traditionnels hiérarchisés et la mise en œuvre de nouvelles pratiques de démocratie participative directement issues du mouvement des indignés.

De par la nécessité d'adopter une stratégie politique claire pour convaincre les électeurs et parvenir au succès électoral, de nombreux événements de l'actualité incitent à penser que la centralisation des décisions, des prises de parole et de la stratégie nationale du parti tend à se renforcer. Mais ce qui est important est le processus lui-même, et ce que feront les acteurs de cette organisation de cette expérience de « nouvelle politique ». À cet égard, les élections régionales andalouses, qui ont permis au parti d'obtenir quinze représentants au parlement régional, ont illustré tant l'accès à la fonction politique de nouvelles élites, que la défense de leur nouvelle autonomie politique: les conflits entre Teresa Rodriguez, eurodéputée et dirigeante du groupe parlementaire andalou, et la direction nationale sur la stratégie à adopter à l'égard du gouvernement régional du PSOE mettent ainsi à l'épreuve le principe d'autonomie des groupes locaux. L'élection de l'eurodéputé Pablo Echenique au parlement régional d'Aragon, une personnalité assez critique du manque de délégation de pouvoir de la direction, laisse augurer de futures négociations internes entre les acteurs du parti, afin de réellement appliquer les pratiques démocratiques revendiquées par Podemos. Sur ce point, Karine Bergès l'a de même souligné "à travers le grand nombre de féministes qu'il compte dans ses rangs " qui se regroupent dans le cercle Podemos Féminismes, dont une figure emblématique comme Beatriz Gimeno, le nouveau parti s'impose ainsi comme un "laboratoire expérimental " de la mise en œuvre transversale de l'égalité femmes-hommes. Au-delà des déclarations d'intention, ce sera ainsi la pratique politique des acteurs locaux et nationaux de Podemos, qui permettra de dire si de nouvelles pratiques de démocratie interne, participative et d'égalité s'imposeront. 
D’autres tendances récentes, conséquences directes de l'activisme et de l'évolution des préférences des citoyens, indiquent des évolutions. Il en va ainsi pour le système de listes ouvertes, choisi par Podemos pour la désignation de ses candidats locaux, l'utilisation de votes électroniques, ou encore la publication des comptes de ce parti et de ceux d'UPyD sur internet. Une autre tendance intéressante est celle du choix de positionnements transversaux (au moins au niveau du discours), mis en avant par Podemos et le parti Citoyens. Ces deux nouvelles formations, qui incarnent la "nouvelle politique ", refusent d'une certaine manière le clivage gauche-droite et tentent de se démarquer des étiquettes "gauche" et "droite ". Pour beaucoup de gens, ce clivage politique est perçu comme dépassé: un nombre croissant d'entre eux plébiscite le retour à des politiques concrètes, simples, soutenues de façon assez consensuelles, et aux effets immédiats en faveur du plus grand nombre ${ }^{17}$.

Les mouvements sociaux les plus emblématiques des années de crise ont directement contribué à ce changement de paradigme et à ce recentrage sur l'humain. Sylvie Koller a par exemple montré le soutien quasiment consensuel (proche de $90 \%$ ) de l'opinion publique espagnole aux principales revendications des indignés, à savoir « le caractère imprescriptible des délits de corruption, l'interdiction des licenciements collectifs lorsqu'une entreprise réalise des bénéfices, la restitution de l'argent public prêté aux banques et aux caisses d'épargne en difficulté, et la possibilité de solder un prêt hypothécaire en remettant son bien à l'organisme prêteur ". Selon Mathieu Petithomme, il est possible de dire la même chose au sujet du soutien des Espagnols aux demandes de la PAH: ils soutiennent très largement son idée, évoquée précédemment d'instaurer une donation pour paiement, mais aussi sa demande d'un moratoire sur les expulsions, et les idées de développer le logement social et de mieux contrôler les pratiques abusives et frauduleuses des banques.

17. Au niveau local, cette tendance au dépassement du clivage gauche-droite et au recentrage sur des « coalitions de projet » a par exemple débouché sur le soutien inédit d'Izquierda Unida au PP en Estrémadure entre 2011 et 2015 (à travers son abstention pour faciliter le gouvernement du PP avec une majorité simple), une entente qui semblait d'autant plus improbable vu la distance idéologique qui sépare les partis, et le caractère quasiment impossible d'une telle alliance au niveau national. Mais le PP régional, sans majorité absolue, devait absolument trouver un partenaire, et a su convaincre IU en faisant des concessions programmatiques concrètes (maintenir l'impôt sur les successions notamment contrairement à la position du PP national), qui donna à la majorité régionale un programme globalement de droite mais teinté de certaines mesures de gauche. Cf. «Rajoy autoriza a Monago a mantener el impuesto de sucesiones para atraer a IU », [http//www.publico.es], 23 juin 2011, consulté le 8 avril 2015. 
Dans la mesure où les jeunes, les plus touchés par la crise et le chômage, ont été en première ligne des manifestations et des actions collectives, le " cycle protestataire " entamé depuis 2008 a débouché sur de fortes demandes en faveur d'un renouvellement idéologique mais aussi générationnel des organisations politiques ${ }^{18}$. Dans les mouvements protestataires, des confluences entre générations ont été observées par Sylvie Koller à propos du 15-M, par moi-même au sujet du mouvement républicain, ou encore par Karine Bergès dans le croisement de plusieurs générations de militantes féministes. L’activisme des jeunes dans le cadre de Juventud Sin Futuro, Democracia Real Ya, du 15-M, des mouvements étudiants, des mobilisations de la PAH ou des actions collectives lors de l'abdication de Juan Carlos $\mathrm{I}^{\mathrm{er}}$, permet de nuancer la thèse d'un déclin de l'engagement ${ }^{19}$. Les partis traditionnels connaissent un déclin du militantisme, mais une formation comme Podemos plaît aux jeunes et à de nombreux citoyens, et suscite un engouement militant. Certes, le militantisme est aujourd'hui plus diffus, moins stable dans le temps, plus réactif et spontané et intimement lié aux nouveaux moyens de diffusion de l'information que constituent les réseaux sociaux. Militer aujourd'hui ne veut plus vraiment dire la même chose que du temps des partis de masse. Mais l'exemple espagnol montre que lorsque le jeu en vaut la peine, les citoyens s'engagent, se mobilisent dans des collectifs formés sur de nouvelles bases et font valoir leurs droits sociaux et politiques.

À ce jour, hormis le Parti populaire au pouvoir et CiU, l'ensemble des autres partis politiques ont renouvelé leurs dirigeants en faveur de responsables plus jeunes: Alberto Garzòn ( 29 ans) a remplacé Cayo Lara à la tête d'Izquierda Unida; Pedro Sánchez (43 ans) a remporté la primaire socialiste de juillet 2014; Oriol Junqueras (46 ans) est devenu le dirigeant d'ERC et chef de l'opposition en Catalogne; Pablo Iglesias, le nouveau leader de Podemos, est âgé de 37 ans et Albert Rivera, celui de Citoyens, de 36 ans. Même s'il n'existe pas de lien direct entre l'âge et les politiques publiques soutenues, puisque par exemple, une frange importante de la jeunesse présente des attitudes tout à fait conservatrices, parfois même plus que leurs propres parents, force est toutefois de constater que la crise a débouché sur un renouvellement sans précédent des dirigeants politiques nationaux au profit d'une nouvelle

\footnotetext{
18. «Los jóvenes condenan a los partidos clásicos a un futuro precario », El País, 6 avril 2015. 19. Jacques ION, La fin des militants?, Bellecombe-an-Bauges, Éditions de l'Atelier, 1997 ; voir de même Olivier FILLIEULE, Le désengagement militant, Paris, Editions Belin, 2005.
} 
génération de trentenaires et de quadragénaires. Il reste à savoir si ce mouvement, au-delà de son effet cosmétique, se poursuivra au niveau local et dans les structures de base des partis. Mais les évolutions récentes semblent aller dans le bon sens, celui de la volonté de changement et de renouvellement des citoyens, en faisant entrer une nouvelle génération, avec un autre vécu et potentiellement d'autres manières de voir les choses.

\section{NOUVELLES ALTERNATIVES ET RECOMPOSITION DU PAYSAGE POLITIQUE}

\section{Un jeu électoral plus ouvert}

Enfin, les mouvements sociaux qui se sont développés depuis 2008 ont directement contribué à faire émerger de nouvelles alternatives électorales et déboucheront vraisemblablement sur une recomposition du paysage politique, notamment à travers un affaiblissement des partis dominants. Il est possible d'établir un parallèle entre « l'épuisement de la formule historique de 1876 " évoquée par Benoît Pellistrandi, et la crise institutionnelle et démocratique actuelle. En effet, la constitution de l'époque faisait du roi l'un des détenteurs de la souveraineté et avait mis en place un système bicaméral et bipartisan organisé autour de deux partis, l'un conservateur, l'autre libéral, toutefois unis sur la forme de l'État, qui alternaient au pouvoir sans véritable alternative, conduisant peu à peu à un "dérèglement du système des partis " qui se transforma en une sorte de " cartel politique " marqué par l'entente entre les deux partis oligarchiques ${ }^{20}$. Benoît Pellistrandi note d'ailleurs à propos du système politique du début du $\mathrm{Xx}^{\mathrm{e}}$ siècle, que « l'écart " était " décidément trop manifeste entre une élite enfermée dans ses codes et ses symboles et un pays qui ployait sous les épreuves et les revers ». De nombreux points communs peuvent être mis en avant avec cette

\footnotetext{
20. La notion de "parti de cartel » a été proposée en science politique par Peter Mair pour évoquer la tendance des partis dominants dans les démocraties occidentales à dépendre de plus en plus des ressources de l'État (notamment du financement public), et à être de moins en moins ancrés dans la société (à travers un déclin du militantisme). La survie des grands partis serait donc de plus en plus liée à leur capacité à sauvegarder leurs positions de pouvoir au sein du système institutionnel et à maintenir des règles en leur faveur, plutôt que directement liée à leurs soutiens dans la société, qui tendent à décliner. Pour une discussion de cette théorie, voir l'ouvrage de référence en français, Yohann AucANTE et Alexandre DÉZE (dir.), Les systèmes de partis dans les démocraties occidentales. Le modèle du parti cartel en question, Paris, Presses de Sciences Po, 2008.
} 
période que les historiens ont appelée la "crise de la Restauration ". Depuis 2008, la crise économique et sociale a durement touché les Espagnols. La constitution de 1978, la forme de l'État, le système politique et la légitimité des deux principaux partis ont été mis en cause. Les élites, enfermées dans leurs calculs politiciens et personnels et leurs vieux schémas, n'ont pas vu monter la défiance citoyenne et leur volonté de changement.

C'est ce contexte qui explique la sympathie retranscrite par les sondages et exprimée dans les urnes lors des municipales de 2015, à l'égard des nouvelles formations Podemos et Citoyens (devenu le principal parti de l'opposition en Catalogne suite aux régionales du 27 septembre 2015). Mathieu Petithomme a bien illustré les raisons de la percée dans l'opinion du discours du nouveau parti de Pablo Iglesias depuis janvier 2014: un retour aux fondamentaux des "marqueurs" de la gauche (droits des travailleurs, droits à l'éducation, à la santé, au logement, etc.); un travail sur le contenu pour proposer un " contrediscours " opposé au discours conservateur et néolibéral dominant; une mise en application des principes de la démocratie participative qui séduit les citoyens; et une utilisation réfléchie des réseaux sociaux et des outils modernes de la communication politique. De même, Citoyens, fondé le $1^{\text {er }}$ juin 2006 et qui se présente comme « le parti de la citoyenneté ", offre un profil à la fois proche de la droite sur les questions économiques (libéralisme et proximité au monde des affaires) mais proche de la gauche sur les valeurs (droit à l'avortement, mariage homosexuel). Il est centriste sur le soutien au fédéralisme européen. Il prône l'autonomie régionale mais refuse le " nationalisme obligatoire ", adoptant une posture plus conservatrice sur la question identitaire, en décalage avec la majorité des Catalans, mais en phase avec l'électorat du parti conservateur dans le reste de l'Espagne. Initialement localisé en Catalogne, Citoyens s'appuie désormais sur un réseau d'environ 20300 militants, de même que sur 18 députés autonomiques, 116 conseillers municipaux et deux eurodéputés ${ }^{21}$. Comme Podemos, Citoyens cherche à dépasser le clivage gauche-droite, en acceptant seulement le qualificatif de " libéral ». Il occupe l'espace politique du centre laissé vacant par le PP, cause l'hémorragie d'UPyD, et dispute à Podemos le monopole de la « nouvelle politique".

Pour Sylvie Koller, on assiste ainsi aujourd'hui à " une transformation de l'indignation sociale en un nouveau capital politique".

21. «Cidudadanos, un parti centrista y liberal », El Mundo, 12 juin 2014. 
L'application de mesures d'austérité et de coupes budgétaires massives par les gouvernements socialiste et conservateur, sans véritables réformes du système politique et institutionnel ni des pratiques des acteurs politiques, donne l'impression à de nombreux Espagnols que le système ne peut pas être réformé de l'intérieur par les mêmes acteurs qu'hier. $74 \%$ des citoyens considèrent en effet que les mesures du gouvernement conservateur ont engendré plus d'inégalités ${ }^{22}$. Ils sont $81 \%$ à ne pas croire au discours de la "récupération économique ", et $63 \%$ ne mettent pas l'amélioration récenteau crédit du gouvernement. À l'heure du triomphe des réseaux sociaux, les citoyens, mieux informés, ne croient plus aux artifices de la communication politique. C'est cette perception qui explique la crise de légitimité des deux grands partis, le PP et le PSOE, et le désir de voir émerger de nouvelles formations et de nouvelles élites. Il est tout à fait significatif que $77 \%$ des citoyens ne veulent plus que le PP ou le PSOE décident seuls du futur du pays grâce à des majorités absolues ${ }^{23}$. Cela témoigne d'une forte volonté de changement et du désir que l'émergence de nouveaux partis et de leur " capacité de chantage " et " potentiel de coalition » oblige les partis traditionnels à évoluer ${ }^{24}$. Seuls $26 \%$ des citoyens souhaitent une " grande coalition" entre le PP et le PSOE, indication a contrario du soutien possible à un gouvernement qui serait soit de gauche ou de droite, mais s'appuierait surtout sur une coalition entre plusieurs acteurs.

\section{De l'indignation citoyenne au changement politique}

Pour comprendre et anticiper l'Espagne de demain, il faut certes tenir compte du sentiment d'indignation de nombreux citoyens. Mais il est encore trop tôt pour savoir si les Espagnols plébisciteront un changement radical du système à travers l'accession au pouvoir, au niveau régional ou national, de nouveaux partis tels que Citoyens ou Podemos. Il faut aussi tenir compte d'un certain conservatisme qui imprègne

22. Même parmi les sympathisants du parti conservateur, $44 \%$ pensent la même chose. Cf. «Clima político en España », sondage Metroscopia pour El País, 10 avril 2015.

23. «PP y socialistas repuntan ligeramente aunque el $77 \%$ quiere que dejen de ser predominantes », El País, 13 avril 2015.

24. Dans son ouvrage classique sur les systèmes de partis, Giovanni Sartori évoque ces notions de "capacité de chantage » et de "potentiel de coalition » afin de caractériser le rôle important que peuvent jouer des organisations politiques certes mineures, mais qui dans un système fragmenté, ont un rôle central dans la formation des coalitions gouvernementales, ce qui leur permet d'exercer une influence, soit sur la stratégie et le programme des autres partis, soit sur les politiques publiques adoptées par un gouvernement. Cf. Giovanni SARTORI, Partis et systèmes de partis. Un cadre d'analyse, Bruxelles, Éditions de l'université de Bruxelles, 2011 [1976]. 
la société, tant dans les milieux catholiques que parmi les classes moyennes, qui pourrait rendre plus difficile pour Podemos ou Citoyens le fait de devenir de vrai partis de gouvernement et pas seulement des partenaires minoritaires de coalition. Le refus de l'extrémisme et du radicalisme est désormais largement ancré dans une société espagnole pacifique, qui demeure largement influencée par les valeurs démocratiques issues de la transition, du consensus et de la négociation. Sur ce point, c'est donc plutôt la confrontation politicienne stérile et les affrontements partisans sur fond de stratégies électorales lors des alternances entre le PP et le PSOE, cette " lutte politique à l'espagnole " évoquée par Enrique Gil Calvo, qui semble en déphasage avec le désir de compromis des Espagnols et le retour d'une "culture de la négociation ${ }^{25}$ ". Pour beaucoup de citoyens, cette volonté d'entente dans un but commun de modernisation politique et sociale, qui permit les principales réussites de la transition, a progressivement disparu au profit des considérations politiciennes.

Les enquêtes sociologiques ont également bien montré que la société espagnole est de même moins critique à l'égard des étrangers, plus tolérante, ouverte et proeuropéenne que de nombreuses autres sociétés européennes ${ }^{26}$. Aussi évident soit-il, l’un des meilleurs indicateurs demeure toutefois que, contrairement à la Grèce et à l'Italie pour l'Europe du sud, mais aussi à la France, à la Belgique, aux Pays-Bas, au Danemark et à d'autres pays européens, la crise, pourtant plus importante en Espagne qu'ailleurs, n'a pas débouché sur l'émergence d'un parti populiste, xénophobe et antieuropéen. Cette exception espagnole mérite respect, tant elle se situe à contre-courant du repli identitaire et du retour de valeurs réactionnaires qui touche la plupart des pays européens.

Pour l'ensemble de ces raisons, le scénario le plus probable dans les années à venir ne semble donc pas celui d'un renversement complet de l'échiquier politique et institutionnel. Plutôt, à l'image des élections régionales andalouses, il est probable que l'Espagne connaisse une forme de rééquilibrage politique à travers l'entrée de nouveaux acteurs comme Podemos, Citoyens, mais aussi ERC qui pourrait s'imposer en Catalogne, entraînant un affaiblissement des deux partis dominants

25. Enrique GIL CALvo, La lucha politica a la española. Tragicomedia de la crispación, Madrid, Taurus, 2007.

26. Sur ce point, voir les nombreux travaux de Juan DiEZ NicoLAs, par exemple, « Opinión Pública y Políticas de Inmigración », dans Ricard ZAPATA-BARRERo (dir.), Políticas y Gobernabilidad de la Inmigración en España, Ariel, Barcelona, 2009, p. 110-126. 
(PP et PSOE), et une crise ou une quasi-disparition de certaines options (UPyD, Izquierda Unida ou encore le PSC en Catalogne). Le paysage politique, à l'image de la société, deviendra certainement plus fragmenté, avec une forme d'instabilité à court terme, qui obligera à moyen terme les acteurs à coopérer, à trouver de nouvelles alliances et à s'adapter à la nouvelle donne. Il est difficile de prédire les évolutions futures, tant elles seront dépendantes de facteurs internes (taux de chômage, reprise économique etc.) et externes (contexte international, politique monétaire européenne, terrorisme, etc.).

La très forte volatilité électorale observée dans les intentions de vote, qui évoluent chaque mois dans un sens ou dans un autre, montre que "le jeu est désormais plus ouvert ", pour reprendre l'expression $\mathrm{du}$ journaliste Ignacio Urquizu ${ }^{27}$. Face à la concurrence de Podemos, le PSOE va devoir réorienter son discours plus à gauche. De même, face à l'émergence de Citoyens, au positionnement plus libéral et moins traditionnaliste sur les questions de société, le PP va devoir moderniser son discours et son image. L'ordre d'arrivée et la hiérarchisation des forces politiques par les électeurs joueront un rôle central, puisqu'en l'état, le système électoral majoritaire bénéficie au parti qui recueille le plus de votes et dans une moindre mesure à la seconde formation, tout en pénalisant largement les organisations qui terminent troisième ou quatrième. Mais ce qui est clair, c'est que l'Espagne est aujourd'hui « à un tournant ». Certes, pour les sceptiques, la période historique qui s'ouvre incarne peut-être une phase d'incertitude et d'instabilité, mais les optimistes verront dans la redistribution possible des cartes le symbole même de changements démocratiques possibles. Comme le disait Antonio Machado, le chemin se fait en marchant.

27. Ignacio URQUIZU, «Un escenario más abierto », El País, 11 avril 2015. 


\section{Liste des sigles employés}

AGE Alternativa Galega de Esquerda (Alternative galicienne de gauche)

AMI Associació de Municipis per la independència (Association des municipalités pour l'indépendance)

ANC Assemblea Nacional Catalana (Assemblée nationale catalane)

ANV Acción Nacionalista Vasca (Action nationaliste basque)

AP

Alianza Popular (Alliance populaire)

BNG Bloque Nacionalista Gallego (BNG)

CAA Comandos Autónomos Anticapitalistas (Commandos autonomes anticapitalistes)

CC Coalición Canaria (Coalition Canaries)

CCOO Comisiones Obreras (Commissions ouvrières)

CDC Convergència Democrática de Catalunya (Convergence démocratique de Catalogne)

CDS Centro Democrático y Social (Centre démocratique et social)

CEDA Confederación española de las derechas autónomas (Confédération espagnole des droites autonomes)

CGPJ Consejo Superior del Poder Judicial (Conseil supérieur du pouvoir judiciaire)

CGT Confederación General del Trabajo (Confédération générale du Travail)

CIG Confederación Intersindical Galega (Confédération intersyndicale galicienne)

CiU Convergència i Unió (Convergence et union)

CNT Confederación Nacional del Trabajo (Confédération nationale du Travail)

C’s Ciutadans de Catalunya (Citoyens de Catalogne) 
CUP Candidatura d'Unitat Popular (Candidature d'unité populaire)

EA Eusko Alkatasuna (Solidarité Basque)

EE Euskadiko Ezkerra (Gauche du Pays Basque)

EH Euskal Herritarok (Pays Basque Populaire)

EH Bildu Euskal Herria Bildu (Réunir le Pays basque)

EIA Euskal Iraultzarako Alderdia (Parti pour la révolution Basque)

ELA-STV Eusko Langileen Alkartasuna (Solidarité des travailleurs basques)

EPK Euskadiko Partidu Komunista (Parti communiste du Pays Basque)

EPPK Euskal Preso Politikoen Kolektiboa (Collectif des prisonniers et des prisonnières politiques basques)

ERC Esquerra Republicana de Catalunya (Gauche républicaine de Catalogne)

ERE Expediente de Regulación de Empleo (Dossier de régulation de l'emploi)

ESEI Euskadiko Sozialistak Elkartze Indarra (Unification des socialistes du Pays Basque)

ETA Euskadi Ta Askatasuna (Pays Basque et Liberté)

ETAm ETA militar (ETA militaire)

ETApm ETA político-militar (ETA político-militaire)

EUPV Esquerra Unida del País Valencia (Gauche Unie du Pays valencien)

GAL Grupos Antiterroristas de Liberación (Groupes Antiterroristes de Liberation)

HASI Herriko Alderdi Sozializta Iraultzailea (Parti socialiste révolutionnaire du peuple)

HB Herri Batasuna (Unité populaire)

IA Izquierda Anticapitalista (Gauche anticapitaliste)

ICV-EUiA Iniciativa per Catalunya-Esquerra Unida i Alternativa (Unitiative pour la Catalogne-Gauche unie et alternative)

ILP Iniciativa Legislativa Popular (Initiative législative populaire) 
IU

KAS

$\mathrm{LAB}$

LGBT

MLNV

$\mathrm{PAH}$

PCE

PCTV-EHAK Partido Comunista de las Tierras Vascas-Euskal Herrialdeetako Alderdi Komunista (Parti communiste des Terres Basques)

PNV

PP

PSC

PSE-EE

PSOE

TSJ

UCD

UGT

UJM

UPyD

Izquierda Unida (Gauche unie)

Koordinadora Abertzale Sozialista (Coordination patriote socialiste)

Langile Abertzaleen Batzordeak (Commissions d'ouvriers patriotes)

Lesbianas, Gais, Bisexuales y Transexuales (Lesbiennes, gays, bisexuels et transgenres) libération national basque) affectés par l'hypothèque)

Partido Comunista de España (Parti communiste d'Espagne) Partido Nacionalista Vasco (Partinationaliste basque)

Partido Popular (Parti populaire)

Partit dels Socialistes de Catalunya (Parti des socialistes de Catalogne)

Partido Socialista de Euskadi-Euskadiko Ezkerra (Parti socialiste du Pays Basque-Gauche du Pays Basque)

Partido Socialista Obrero Español (Parti socialiste ouvrier espagnol)

Tribunal Superior de Justicia (Tribunal supérieur de Justice) Unión de Centro Democrático (Union du centre démocratique)

Unión General de los Trabajadores (Union générale des travailleurs)

Unión de Juventudes Maoístas (Union des jeunesses maoïstes)

Unidad, Progreso y Democracia (Unité, progrès et démocratie) 


\section{Liste des tableaux, graphiques et schémas}

Graphique 2.1. L'évolution du chômage en Espagne, 1976-2013 (\%) ... 51

Graphique 2.7. L’emploi en Espagne. 58

Graphique 2.8. Chômage de courte et de longue durée en Europe (\%), 2011

Graphique 2.9. Le chômage de longue durée en Espagne,

par âge et par genre (\%), 2010.

Graphique 2.10. Impact de la crise sur le marché du travail

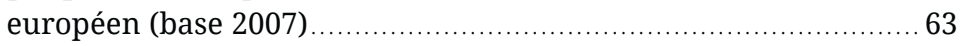

Graphique 2.11. La réforme du travail de 2012 66

Tableau 2.2. Taux de chômage en Espagne par âge et par genre, 2006 et 2012 (\%)

Tableau 2.5. Immigration en Europe (\% de population immigrée par rapport à la population totale)

Tableau 2.6. Force de travail, activité, population active occupée et chômage en Espagne.

Schéma 2.3. Les facteurs de la croissance démographique. 54

Schéma 2.4. Population et offre de travail. 55

Schéma 2.11. Réforme du travail de 2012. 52 


\section{Liste des photographies}

Photo 1.1. "L’homme-avion ", sculpture de Juan Ripollés, aéroport de Castellón de la Plana .

Photo 1.2. Tract de convocation de la grève générale du 29 septembre 2010

Photo 1.3. Action du collectif Flo6x8 ("Flamenco et Activisme "), devant une banque BBVA, Séville, 2011

Photo 3.1. Caricature de la I ${ }^{\text {re }}$ République, revue satirique La Flaca, 3 mars 1873

Photo 3.2. Manifestation républicaine lors de l'abdication de

Juan Carlos I ${ }^{\mathrm{er}}$, Puerta del Sol, Madrid, 2 juin 2014.

Photo 4.1. Pancarte féministe 15-M, Puerta del Sol, Madrid, mai 2011

Photo 4.2. Manifestation contre la loi de réforme de

l'avortement, Madrid, 8 mars 2014.

Photo 4.3. Manifestation en soutien aux femmes espagnoles, Paris, $1^{\mathrm{er}}$ février 2014.

Photo 6.1. Manifestation du PCE-EPK contre la violence,

Portugalete, 28 juin 1978.

Photo 6.2. Manifestation de dénonciation de la politique pénitentiaire (2011.

Photo 6.3. Manifestation en faveur des prisonniers de l'ETA,

Saint-Sébastien (2015) 188

Photo 7.1. La Puerta del Sol, le 20 mai 2011

Photo 10.1. La « Marche du changement » de Podemos, Madrid,

31 janvier 2015 



\section{Table des matières}

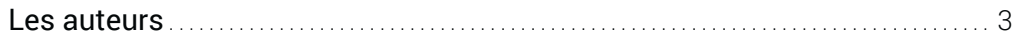

Avant-propos ........................................................ 5

1. La crise démocratique espagnole et le renouveau

de la contestation sociale .......................................... 9

De la récession économique à la crise sociale ......................... 10

L'éclatement de la « bulle immobilière »................................ 10

Une dégradation sans précédent des conditions de vie ................... 15

De la crise économique à la défiance politique ........................... 17

La perception de l'échec du néolibéralisme et des politiques d'austérité. ... 17

L'impact de la corruption sur la crise de la représentation politique ........ 24

Au-delà des affaires, les limites du système institutionnel issu de la

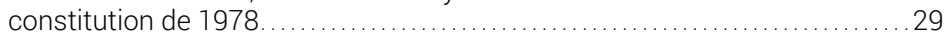

Le renouveau de la contestation dans l'Espagne contemporaine ...........32

Une multiplicité de manifestations anti-austérité ...................... 32

L'émergence du mouvement des indignés ............................... 36

Le développement de nouveaux répertoires d'action ...................... 38

Comprendre la crise démocratique espagnole ...................... 41

Première partie :

De la crise économique au renouveau de la contestation sociale ...... 45

2. Le défı de la montée du chômage et la réforme du marché du travail.... 47

Le problème du chômage en Espagne et ses explications ................. 49

Un enjeu ancien, revenu sur le devant de la scène depuis 2008 ........... 49

Offre et demande de travail.......................................... 53

L'hétérogénéité du marché du travail européen face à la crise ............59

Les points communs de l'Espagne avec le chômage en Europe ............. 59

Le chômage européen. .............................................62

La réforme du marché du travail en Espagne: une politique efficace de lutte contre le chômage ?...............................................64

Politique économique générale et réforme du travail ...................... 64

Le contenu de la réforme du travail................................... 65

La réforme du travail et le problème du chômage: observations finales.... 69

3. Le renouveau du mouvement républicain:

de la nostalgie à la défiance citoyenne ............................ 75

La mémoire historique républicaine en Espagne.......................... 77

La Première République : l'image négative de la « République de 1873 » ...77

La Seconde République : une image très clivée........................ 80 
Républicanisme et victimes de la guerre civile........................ 83

Le mouvement républicain à la confluence des mouvements sociaux .....86

La « Troisième République », un concept rassembleur .................... 86

Les manifestations républicaines lors de l'abdication de Juan Carlos ...... 91

Républicanisme et indépendantisme ............................. 95

La demande d'un référendum dans le contexte de la consultation catalane 95

Au Pays basque : un enjeu mobilisateur pour les indépendantistes .........98

Des mobilisations minoritaires en Galice, symbole d'un régionalisme

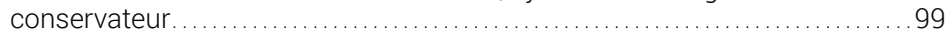

Renouveau et déclin du républicanisme dans l'Espagne d'aujourd'hui . .. 100

4. Les féminismes dans l'Espagne d'aujourd'hui ....................... 103

« Nosotras, las mujeres »: les débats autour de la redéfinition du « sujet du

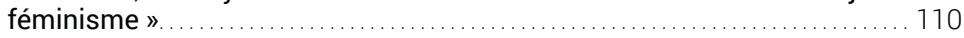

D'une vague à l'autre: l'émergence de nouveaux courants féministes .... 114

« ¡La revolución será feminista o no será ! » . ................................. 119

la « marée violette » au sein du Mouvement des indignés ............... 119

«En nuestros úteros, no se legisla » ..................................... 123

la (re)mobilisation unitaire autour de la question de l'avortement ........ 123

\section{Deuxième partie}

Revendications identitaires et nouveaux mouvements sociaux ....... 133

5. Mouvements de contestation en Catalogne: manifestations et consultation(s) sur l'indépendance ................................. 135

Repères historiques: le nationalisme catalan en perspective ............. 137

La constitution de 1978 et l'Espagne des autonomies.................... 139

Les statuts d'autonomie de 1979 et 2006 ............................... 141

La langue catalane comme symbole d'identité et de cohésion sociale ... 143

La place des contestations: la voix du peuple......................... 146

Le mouvement vers l'indépendance et la consultation du 9 novembre 2014152

La Catalogne face au renouveau indépendantiste ..................... 155

6. La «transition démocratique » du nationalisme basque radical: de la légitimation de la violence à l'indépendantisme démocratique? .... 159

$\mathrm{La}$ « résistance » au régime franquiste et la légitimité originelle du

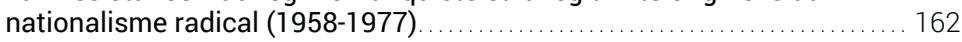

La résistance antifranquiste et le procès de Burgos ................... 162

La marche pour la liberté du Pays basque............................ 165

Le tournant de l'amnistie générale ................................ 168

Violence politique et monopolisation de l'espace public (1978-1994) .... 170

Légitimation de la violence politique et culte des « gudaris » .............. 170

De l'« Alternative KAS » au monopole de la rue .......................... 172

Le déclin de l'hégémonie mobilisatrice (1995-2011) .................... 176

La rupture de la spirale du silence : l'émergence de Gesto por la Paz ..... 177

De la fracture à la dissolution des mouvements antiviolence ............ 179 
Institutionnalisation et « transition démocratique » du nationalisme

basque radical (depuis 2011)

Une rupture avec le passé : fin de la violence, renouveau de

l'indépendantisme et pacification.

Une transition inachevée .......................................... 186

7. Le mouvement des indignés: la création du 15-M et sa postérité ...... 191

Un anniversaire peut en cacher un autre ............................ 193

La Toile et la Place .................................................. 195

Un campement, des campements.................................... 196

Le socle intergénérationnel du mouvement des indignés ................. 198

Comment s'organiser? Occupations, assemblées et extension du

mouvement .................................................... 199

L'importance de l'expérimentation sociale............................... 201

De l'insurrection morale aux propositions de changement .............. 203

Le dur désir de durer: que s'est-il passé depuis le 15 mai 2011 ? ........ 206

L'appropriation de l'espace public : assemblées, manifestations, marées, marches ..................................................... 206

Diversification et convergence des manifestations ...................... 207

Occupations, obstructions........................................ 208

Défense des libertés fondamentales ................................... 209

Le rôle de Juventud Sin futuro ......................................... 210

L'avenir politique du 15-M ............................................ 213

L'avènement du « municipalisme» .................................... 214

\section{Troisième partie:}

De la crise sociale à la crise institutionnelle et politique ........... 217

8. Le droit au logement et la lutte contre les expulsions:

la Plataforma de Afectados por la Hipoteca................................. 219

Crise du droit au logement et luttes collectives ........................ 221

« Dernier toit avant liquidation ».................................... 221

La spirale de la paupérisation : « de la précarité à l'expulsion, il n'y a

qu'un pas »..................................................... 223

Un mouvement décentralisé et transversal .......................... 225

Autonomie et coopération des collectifs locaux........................ 225

Un mouvement social citoyen........................................ 227

Des revendications sociales concrètes .............................. 229

Instaurer une donation pour paiement.............................. 231

Militer pour un moratoire sur les expulsions .......................... 231

Développer le logement social ....................................... 232

Des stratégies d'action collective diversifiées ........................ 234

Lutter par le droit : judiciarisation et débat public....................... 234

Lutter par le nombre : manifestations, occupations et résistances

citoyennes.................................................... 239

La lutte nécessaire et les victoires concrètes du collectif ............... 242 
9. La monarchie espagnole entre crises et restaurations (1808-2015) ... 247

La monarchie, un héritage fragilisé par l'histoire ...................... 249

La monarchie et le pacte démocratique ............................. 258

Une monarchie démocratique ....................................... 263

10. La crise de la représentation et l'ascension de Podemos:

L'émancipation citoyenne « au cœur » de l'échiquier politique? ....... 265

Austérité et corruption: toiles de fond de la crise de la représentation politique

Le discrédit du « système PPSOE »................................. 268

Transformer l'indignation citoyenne en une nouvelle alternative politique. 271

La création rapide d'une organisation partisane moderne .............. 274

Izquierda Anticapitalista et le tissu militant de Lavapiés.................. 274

Des assemblées citoyennes au parti politique........................ 277

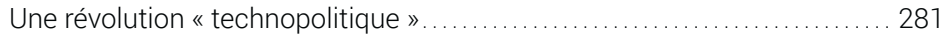

Renouvellement idéologique et stratégies politiques ................... 284

Un leader médiatique.............................................. 284

Un discours transversal s'adressant à tous .......................... 286

Une stratégie électorale de conquête du pouvoir ...................... 289

2015, la fin du bipartisme imparfait ?................................ 293

11. Un tournant historique en Espagne? Nouvelles alternatives et renouveau de l'engagement citoyen ................................ 299

Une crise aux origines et aux effets multiples........................... 300

Un « miroir grossissant » des dérives politico-financières................. 300

Une crise de légitimité des institutions ............................ 303

La contribution des mouvements sociaux au changement .............. 305

Une diversification des formes de contestation ......................... 305

La politisation de nouveaux enjeux ................................. 310

Activisme citoyen et nouvelles pratiques ............................ 313

Nouvelles alternatives et recomposition du paysage politique .......... 318

Un jeu électoral plus ouvert........................................... 318

De l'indignation citoyenne au changement politique ................... 320

Liste des sigles employés ............................................ 323

Liste des tableaux, graphiques et schémas ............................. 326

Liste des photographies ......................................... 327 



\section{Déjà parus aux éditions DEMOPOLIS}

Brossat, Alain

Abécédaire Foucault

Boltanski, Luc

Rendre la réalité inacceptable

Bourdieu, Pierre - Boltanski, Luc

La Production de l'idéologie

dominante

Césaire, Aimé - Malcolm X

Black revolution

Clover, Charles

Surpêche

Da Lage, Olivier (sous la dir. de)

Qatar: les nouveaux maîtres du jeu

Denord, François

Néo-libéralisme, version française

Duclert, Vincent

Occupy Gezi

Durpaire, François -

Richomme, Olivier

L'Amérique de Barack Obama

Obama face à la crise

Gaulard, Mylène

Karl Max à Pékin - Les racines de la crise en Chine capitaliste

Garo, Isabelle

Foucault, Deleuze, Althusser et Marx

Hobsbawm, Éric

Marx et l'histoire

Hroub, Khaled

Le Hamas

Jaurès, Jean

Le socialisme et la Révolution

française

Jennar, Raoul Marc Khieu Samphan

\& les Khmers rouges
Khaldi, Eddy

$A B C$ de la Laïcité

Khaldi, Eddy - Fitoussi, Muriel

Main basse sur l'École publique

La République contre son école

Kalfon, Pierre

Chroniques chiliennes

Kamata, Satoshi,

Toyota : I'usine du désespoir

Mamdani, Mahmoud

La CIA et la fabrique

du terrorisme islamique

Labat, Séverine

Les islamistes tunisiens - entre

l'État et la mosquée

Latour, Bruno - Lippman, Walter

Le public fantôme

Lénine

Petit manuel pour rompre avec le

capitalisme

1914, repenser le nationalisme et la guerre

Marx, Karl

Qu'est-ce que le capitalisme?

Les Crises du capitalisme

Le Capital financier

Mordillat, Gérard -

Prieur, Jérôme

De la crucifixion considérée

comme un accident du travail

Nsar, Vali

Le renouveau chiite

Pivert, Marceau

L'Église et l'École

Prochasson, Christophe

L'Empire des émotions :

les historiens dans la mêlée 
Rebérioux, Madeleine

Vive la République

Rodinson, Maxime

Islam et capitalisme

Sassen, Saskia

Critique de l'État

Saurin, Patrick

Les prêts toxiques : une affaire d'État

Shah, Sonia

Cobayes humains : le grand secret

des essais pharmaceutiques

Uchitelle, Louis

Le salarié jetable

Wallerstein, Immanuel

L'Universalisme européen :

de la colonisation au droit

d'ingérence

Wilkinson, Richard

L'égalité, c'est la santé

\section{Collection « QUAERO »}

Cassin, Barbara et Wosny, Danièle (dir.)

Les intraduisibles du patrimoine en Afrique subsaharienne

Dawod, Hosham (dir.)

La constante "Tribu ", variations

arabo-musulmanes

Ehrenfreund, Christian et Schreiber, Jean-Philippe (dir.)

Les marranismes. De la religiosité cachée à la société ouverte

Emmanuel Ethis,

Le cinéma près de la vie. Prises de vue sociologique sur le spectateur du XXI siècle

Fontaine, Alexandre

Aux heures suisses de l'école répu-

blicaine

Ghasarian, Christian

Rapa. Île du bout du monde, île dans le monde

Hoai Juong Aubert-Nguyen et Michel Magne (dir.)

Le Vietnam, une histoire de transferts culturels

Niveleau, Charles-Édouard (dir.)

Vers une philosophie scientifique - Le programme de Brentano

Émilie Oléron Evans,

Nikolaus Pevsner, arpenteur des arts

Rabault-Feuerhahn, Pascale (dir.)

Théorie intercontinentales -

Voyages du comparatisme

postcolonial 
Achevé d'imprimer en France en 2015 dans les ateliers de Dupli-print à Domont (95) $\mathrm{N}^{\circ}$ d'impression:

Dépôt légal: janvier 2016 


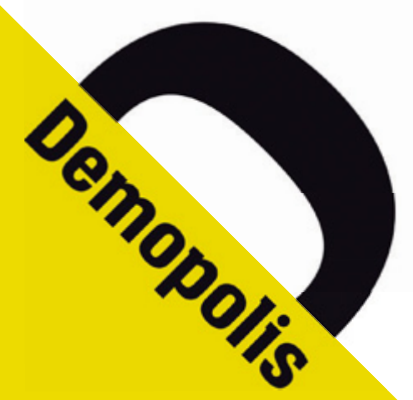

Violence de la crise payée au prix fort par les classes populaires après l'éclatement de la bulle immobilière, plans d'austérité drastiques et chômage avoisinant les $25 \%$, renouveau de l'émigration des jeunes, multiplication des affaires de corruption touchant jusqu'à la famille royale, radicalisation de l'indépendantisme en Catalogne, crise du bipartisme et des partis socialiste et conservateur, les éléments "dramatiques » ne manquent pas dans le tableau de l'Espagne d'aujourd'hui. La crise économique, sociale et politique enclenchée depuis 2008 marquera toute une génération. Mais ce livre montre que cette période troublée a aussi été marquée par le renouveau de la contestation et l'essor de nouveaux mouvements sociaux: luttes contre les expulsions, mouvement des indignés mobilisés à Madrid en 2011, résistances syndicales contre les plans d'austérité, " marées » citoyennes contre les coupes budgétaires dans l'éducation et la santé, mobilisations féministes et républicaines, renouveau des pratiques artistiques critiques. Neuf spécialistes offrent des analyses de l'intérieur de l'actualité sociale et politique espagnole, de l'indignation citoyenne à l'émergence de nouvelles alternatives politiques telles que Podemos et Citoyens.

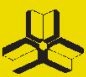

ISBN: 978-2-35457-090-3

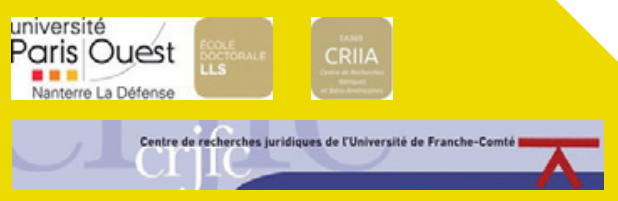

L'ouvrage a été dirigé par Alicia Fernández García, doctorante à l'université de Nanterre et ATER en civilisation espagnole à l'université Paris Est Marne La Vallée; et Mathieu Petithomme, maître de conférences en science politique à l'IUT de Besançon et chercheur au CRJFC de l'université de Besançon.

Illustration (c) AP

$32 €$

www.demopolis.fr

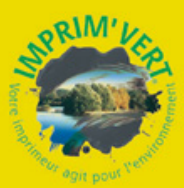

